\title{
Mali: Poverty Reduction Strategy Paper
}

Poverty Reduction Strategy Papers (PRSPs) are prepared by member countries in broad consultation with stakeholders and development partners, including the staffs of the World Bank and the IMF. Updated every three years with annual progress reports, they describe the country's macroeconomic, structural, and social policies in support of growth and poverty reduction, as well as associated external financing needs and major sources of financing. This country document for Mali, dated December 20, 2006, is being made available on the IMF website by agreement with the member country as a service to users of the IMF website.

Copies of this report are available to the public from

International Monetary Fund • Publication Services $70019^{\text {th }}$ Street, N.W. • Washington, D.C. 20431

Telephone: (202) 623-7430 • Telefax: (202) 623-7201

E-mail: publications@imf.org • Internet: http://www.imf.org

Price: $\$ 18.00$ a copy

\section{International Monetary Fund Washington, D.C.}





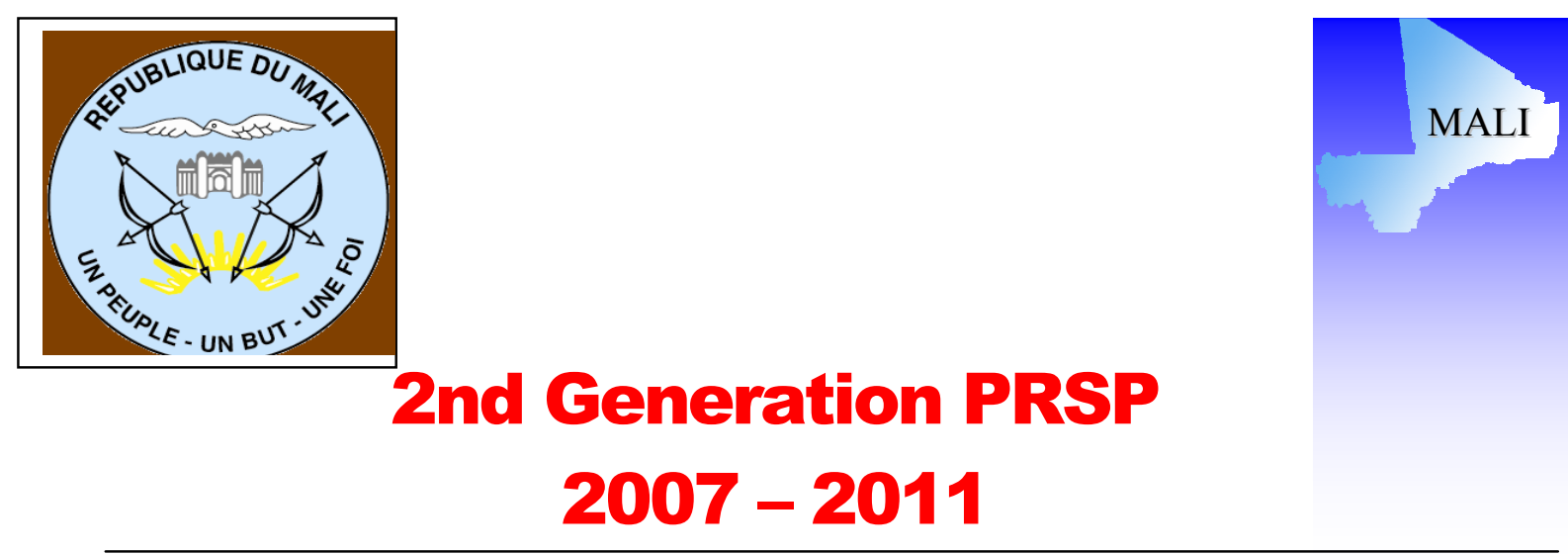

DOCUMENT ADOPTE PAR LE CONSEIL DES MINISTRES LE 20/12/2006

\section{Growth and Poverty Reduction Strategy Paper}

20 December 2006 


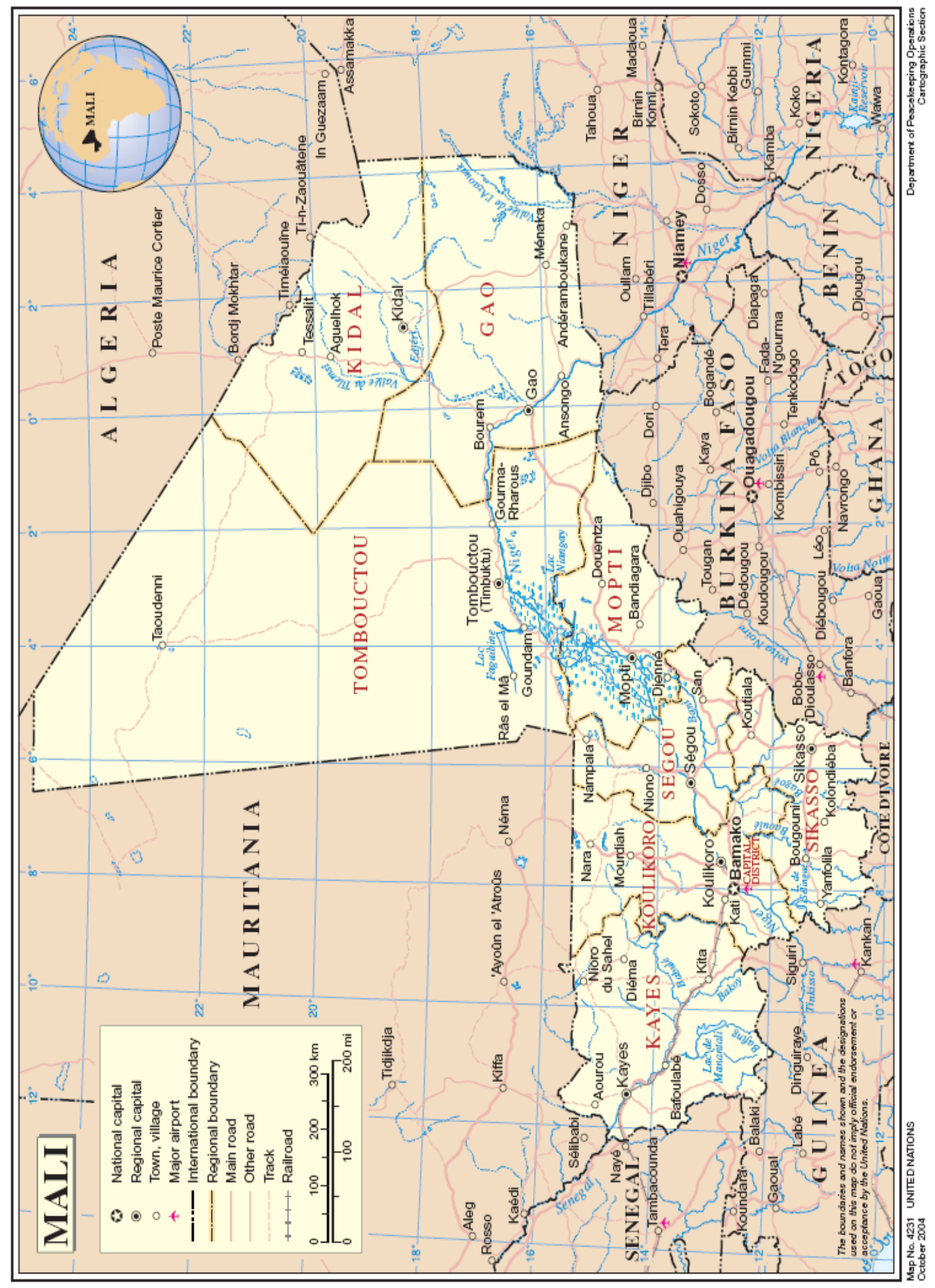




\section{Table of Contents}

$\begin{array}{ll}\text { FOREWORD } & 12\end{array}$

1 EXECUTIVE SUMMARY $\quad 13$

$1.1 \quad$ EVALUATION OF PRSP I 14

1.2 LONG-TERM STRATEGIC VISION

1.3 OVERALL GOALS AND MACRO-ECONOMIC FRAMEWORK

$\begin{array}{lll}1.4 & \text { STRATEIC ORIENTATIONS } & 15\end{array}$

$\begin{array}{lll}1.5 & \text { PRIORITY AREAS OF INTERVENTION } & 16\end{array}$

1.6 IMPLEMENTATION, MONITORING AND EVALUATION 16

1.7 PRESENTATION OF PRSP II 16

$\begin{array}{llr}2 \text { INTRODUCTION } & 17\end{array}$

3 TREND OF POVERTY IN MALI $\quad 18$

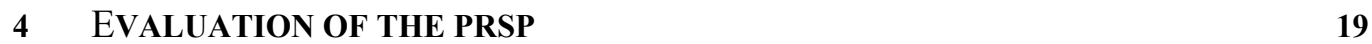

4.1 Evaluation OF THE PRSP PILlars

4.1.1 Macro-economic Framework 19

4.1.2 Institutional Development, Governance and Participation 20

4.1.3 Human Resource Development and Access to Basic Services 21

4.1.4 Development of Basic Infrastructure and Productive Sectors 23

4.2 LINKS BETWEEN THE PRSP AND BUDGET INSTRUMENTS 25

4.3 LINKS BETWEEN THE PRSP AND THE MDGS 25

4.4 Links Between the PRSP AND the National Prospective Study Mali $2025 \quad 26$

4.5 LINKS BETWEEN THE PRSP AND SUPPORT FROM TECHNICAL AND FINANCIAL PARTNERS 26

4.6 LESSONS FROM THE PRSP MONITORING AND EVALUATION

5 GPRSP OBJECIVES AND EXPECTATIONS 27

$\begin{array}{lll}5.1 & \text { OVERALL GOAL } & 27\end{array}$

$\begin{array}{ll}5.2 & \text { SPECIFIC OBJECTIVES }\end{array}$

$\begin{array}{lll}5.3 & \text { EXPECTATIONS } & 27\end{array}$

$\begin{array}{llr}6 & \text { STRATEGIC ORIENTATIONS } & 27\end{array}$

6.1 Productive SECTOR DEVELOPMENT 28

6.2 CONSOlidation OF Public SECTOR REForms 29

6.3 Strengthening Of THE SOCial SeCtOR 31

7 MACRO-ECONOMIC AND BUDGETARY FRAMEWORK 2007 - 2011 33

7.1 ASSUMPTIONS OF FRAMEWORK FORECASTS

7.2 MAIN RESULTS OF THE FRAMEWORK

$\begin{array}{lll}7.3 & \text { PUBLIC FINANCE } & 35\end{array}$

$\begin{array}{lll}7.4 & \text { PUBLIC DEBT } & 38\end{array}$

$\begin{array}{lll}7.5 & \text { BALANCE OF PAYMENTS AND MONETARY SITUATION } & 38\end{array}$

$\begin{array}{lll}7.6 & \text { EXTERNAL AID } & 39\end{array}$

$\begin{array}{lll}7.7 & \text { INCIDENCE ON POVERTY } & 40\end{array}$

8 PRIORITY AREAS OF INTERVENTION

8.1 FoOd SECURITY AND RURAL DEVELOPMENT 41

8.1.1 Food Security 41

8.1.2 Rural Development 41

8.2 DEVELOPMENT OF SME- SMI

8.3 MANAGEMENT OF THE ENVIRONMENT AND NATURAL RESOURCES 43

8.4 CONSOLIDATION OF PUBLIC AdMINISTRATION REFORMS 44

8.4.1 Decentralization and Deconcentration 44

8.4.2 Improvement and Modernization of Public Finance Management 46

8.5 PURSUANCE OF BUSINESS ENVIRONMENT REFORMS 46

8.6 FINANCIAL SECTOR DEVELOPMENT 46

$\begin{array}{lll}8.7 & \text { DEVELOPMENT OF INFRASTRUCTURE } & 47\end{array}$ 
8.8 Promotion of Democratic Governance And Public Freedoms 48

8.9 CAPACITY BUILDING FOR THE CIVIL SOCIETY 49

8.10 STRENTHENING OF REGIONAL AND SUB-REIONAL INTEGRATION INITIATIVES, CONSTANT SUPPORT TO ACHIEVEMENT OF AFRICAN UNITY

8.11 CREATION AND PROMOTION OF SUSTAINABLE JOBS

8.12 DEVElOPMENT OF ACCESS TO BASIC SOCIAL SERVICES

8.12.1 Education $\quad 51$

8.12.2 Health and Social Development 52

8.12.3 Drinking Water and Sanitation 53

8.12.4 Employment and Vocational Training 54

8.12.5 Housing $\quad 54$

8.13 HIV/AIDS CONTROL

8.14 Integration into Multilateral Trade System

9 ACCELERATED GROWTH STRATEGY

9.1 GROWTH-ORIENTED SECTORS

9.1.1 Rural Sector $\quad 57$

9.1.2 Mining 258

9.2 New PossibiLities $\quad 59$

$\begin{array}{lll}9.2 .1 & \text { Industries } & 59\end{array}$

9.2.2 Trade $\quad 59$

9.2.3 Tourism

9.2.4 Fruits, Vegetables, Oilseed Corps and Commodities 60

9.2.5 Handicraft 60

9.2.6 Culture $\quad 61$

9.2.7 Youth and Sports $\quad 62$

9.3 GrowTH-ORIENTED INFRASTRUCTURE $\quad 62$

$\begin{array}{lll}9.3 .1 & \text { Energy } & 63\end{array}$

9.3.2 Transport $\quad 64$

9.3.3 Telecommunications/ICT and Posts 65

9.4 CROSS-CUTTING ISSUES $\quad 65$

$\begin{array}{lll}9.4 .1 & \text { Gender } & 65\end{array}$

9.4.2 Territorial Development $\quad 69$

9.4.3 Population Issues 69

9.4.4 Peace and Security Issues $\quad 70$

10 COORDINATION AND MONITORING-EVALUATION MECHANISMS

10.1 InSTITUTIONAL MONITORING AND EVALUATION MECHANISM

10.2 Strenthening OF THE NATIONAL StATISTICS SYSTEM (SSN) 72

10.3 MONITORING AND EVALUATION INDICATORS

11 IMPLEMENTATION OF THE PARIS DECLARATION 80

12 PRSP II FINANCING PLAN

13 PRSP II LOGICAL FRAMEWORK 184

14 CONCLUSION $\quad 93$ 


\section{List of Tables}

TABle 1: INDICATORS OF MACRO-ECONOMIC PERFormanCE AND DECISION-MAKING CRITERIA ...........34

TABLE 2: CONSOLIDATED BUdGET OF PUBLIC FinANCE AND ITS FINANCING (GFFT) .............................36

TABLE 3: SECTOR BREAKDOWN OF EXPENDITURES 2007-2011 (IN CFAF BILLION) ...............................37

TABLE 4: SECTORAL BREAKDOWN OF EXPENDITURE 2007-2011 IN \% OF TOTAL ...................................37

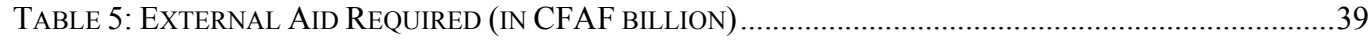

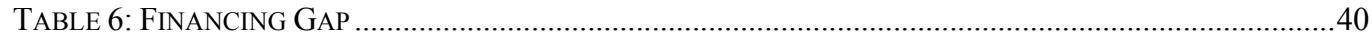

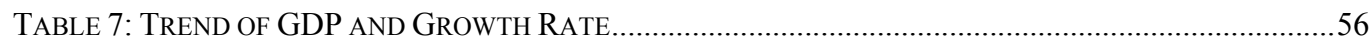

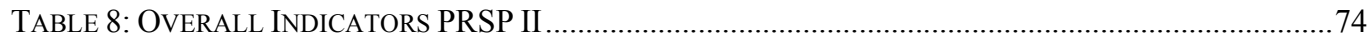

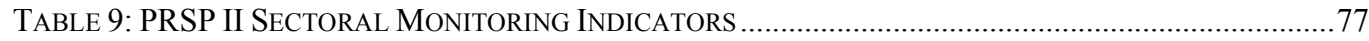

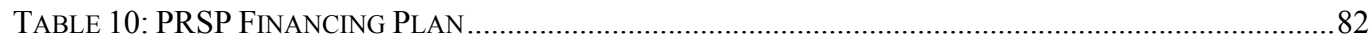

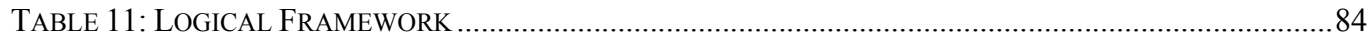

NB. The core document of PRSP II is accompanied by three separate Annexes

Annex I Macro-economic Framework 2007 - 2011

Annex II Medium Term Expenditure Framework 2007 - 2011

Annex III Priority Actions Matrix for 2007 - 2009 


\section{List of Abbreviations and Acronyms}

\begin{tabular}{|c|c|}
\hline ADB & African Development Bank \\
\hline AGETIER & Infrastructure and Rural Utilities Works Implementation Agency \\
\hline AGOA & African Growth Opportunity Act \\
\hline AMADER & Agence Malienne de Développement l'Energie Rurale \\
\hline AMM & Association of Malian Municipalities \\
\hline ANICT & National Local Authorities Investment Agency \\
\hline APCAM & Assemblée Permanente des Chambres d'Agricultures du Mali \\
\hline APCMM & Assemblée Permanente des Chambres de Métiers du Mali \\
\hline ARV & Anti Retro Viral Drugs \\
\hline BCEAO & Central Bank of West African States \\
\hline $\mathrm{BD}$ & Board of Directors \\
\hline BDM & Banque de Développement du Mali (Development Bank of Mali) \\
\hline $\mathrm{BHM}$ & Banque de l'Habitat du Mali (Housing Bank of Mali) \\
\hline BIM & Banque Internationale du Mali (International Bank of Mali) \\
\hline $\mathrm{BIT}$ & International Labour Office \\
\hline BRVM & Regional Stock Exchange \\
\hline CAF & Functional Literacy Centre \\
\hline CAN & African Cup of Nations \\
\hline CAS/SFD & Decentralized Financial Systems Support and Supervision Unit \\
\hline $\mathrm{CCC}$ & Centre de Conseil Communal \\
\hline CCIM & $\begin{array}{l}\text { Chambre de Commerce et d'Industrie du Mali (Chamber of Commerce and } \\
\text { Industry of Mali) }\end{array}$ \\
\hline CDC & Caisse des Dépôts et Consignations \\
\hline
\end{tabular}




\begin{tabular}{|c|c|}
\hline CED & Development Education Centre \\
\hline CEN SAD & Community of Sahel-Saharan States \\
\hline CENTIF & National Financial Information Processing Unit \\
\hline CET & Common External Tariff \\
\hline CFAF & Franc of the African Financial Community \\
\hline CILSS & Permanent Inter-State Committee on Drought Control in the Sahel \\
\hline CLPD & Local Development Planning Committee \\
\hline $\mathrm{CM}$ & Mining Code \\
\hline CMDT & Compagnie Malienne de Développement des Textiles \\
\hline CNPM & Conseil National du Patronat du Mali \\
\hline CNSC & National Civil Society Council \\
\hline CPM & Forecasts and Modelling Committee \\
\hline CPS & Planning and Statistics Unit \\
\hline CRM & Caisse de Retraites du Mali (Pension Fund of Mali) \\
\hline CRPD & Regional Development Planning Committee \\
\hline CSCOM & Community Health Centre \\
\hline DAF & Department of Administration and Financial Affairs \\
\hline DBB & Directorate General of the Budget \\
\hline DGDP & Directorate General for Public Debt \\
\hline DNCC & National Directorate for Trade and Competition \\
\hline DNPD & National Directorate for Development Planning \\
\hline DNSI & National Directorate for Statistics and Information Technology \\
\hline DTC3 & Vaccine against Diphtheria, Tetanus and Whooping Cough \\
\hline EBC & Budget Consumption Survey \\
\hline EBES & Child with Special Education Needs \\
\hline
\end{tabular}




\begin{tabular}{|c|c|}
\hline ECOWAS & Economic Community of West African States \\
\hline EDM & Energie du Mali (Energy Corporation of Mali) \\
\hline EDS & Health Demographic Survey \\
\hline EDSM & Health Demographic Survey in Mali \\
\hline EID & Espace d'Interpellation Démocratique \\
\hline ELIM & Light Integrated Household Survey \\
\hline EMEP & Poverty Evaluation Survey in Mali \\
\hline ENP & National Prospective Study \\
\hline FAO & Food and Agriculture Organization \\
\hline FDE & Economic Development Fund \\
\hline FGHM & Fonds de Garantie Hypothécaire du Mali \\
\hline GAFI & Financial Action Group \\
\hline GDP & Gross Domestic Product \\
\hline GER & Gross Enrolment Rate \\
\hline GFFT & Government Flow of Funds Table \\
\hline GIABA & Inter-Governmental Action Group against Money Laundering in Africa \\
\hline GPRSP & Growth and Poverty Reduction Strategy Paper \\
\hline HCCT & Local Authorities High Council \\
\hline HCNLS & National AIDS Control High Council \\
\hline HIPC & Heavily Indebted Poor Countries \\
\hline HUICOMA & Huilerie Cotonnière du Mali \\
\hline IDA & International Development Agency \\
\hline IDHD & Sustainable Human Development Index \\
\hline IMF & International Monetary Fund \\
\hline INPS & National Social Insurance Institute \\
\hline
\end{tabular}




\begin{tabular}{|c|c|}
\hline IPC & Council Poverty Index \\
\hline LOA & Agriculture Orientation Law \\
\hline LPDSC & Cotton Sector Development Policy Letter \\
\hline LPDSP & Private Sector Development Policy Letter \\
\hline MCA & Millennium Challenge Account \\
\hline MDG & Millennium Development Goals \\
\hline MDRI & Multilateral Debt Relief Initiative \\
\hline MEF & Ministry of the Economy and Finance \\
\hline MFI & Micro Finance Institution \\
\hline MME_DNPD & Modèle Macro-Economique du Mali de la DNPD \\
\hline MPAT & Ministry of Planning and Territorial Development \\
\hline MTBF & Medium Term Budgetary framework \\
\hline MTEF & Medium Term Expenditure Framework \\
\hline NBA & Niger Basin Authority \\
\hline NEPAD & New Partnership for Africa's Development \\
\hline NICT & New Information and Communication Technologies \\
\hline ODHD & Sustainable Human Development Observatory \\
\hline OHADA & Organization for the Harmonization of Business Law in Africa \\
\hline $\mathrm{OMH}$ & Office Malien de l'Habitat (Malian Housing Authority) \\
\hline OMVS & Senegal River Development Organization \\
\hline ONAP & National Petroleum Products Supply Authority \\
\hline PACD & Retailers Development Project \\
\hline PAGAMGFP & $\begin{array}{l}\text { Government Action Plan for the Improvement and Modernization of Public } \\
\text { Finance Management }\end{array}$ \\
\hline PAGIRE & Integrated Water Resources Management Action Plan \\
\hline PASAOP & Agricultural Sector and Farmer Organizations Support Programme \\
\hline
\end{tabular}




\begin{tabular}{|c|c|}
\hline PASC & Growth Sources Support Project \\
\hline PCIME & Integrated Management of Children's Diseases \\
\hline PDI & Institutional Development Programme \\
\hline PDSA & Handicraft Sector Development Programme in Mali \\
\hline PDSF & Financial Systems Development Programme \\
\hline PDSS & Ten-Year Health and Social Development Programme \\
\hline PISE & Education Sector Investment Project \\
\hline PNE & National Employment Policy \\
\hline PNIR & National Rural Infrastructure Programme \\
\hline PNL & National Housing Programme \\
\hline PNP & National Population Policy \\
\hline PNPE & National Environmental Protection Policy \\
\hline PPIP & Priority Population Investment Programme \\
\hline PRODEC & Ten-Year Education Programme \\
\hline PRODEJ & Ten-Year Justice Programme \\
\hline PRODESS & Health and Social Development Programme \\
\hline PROSEPA & Drinking Water and Sanitation Sector Programme \\
\hline PRSP & Poverty Reduction Strategy Paper \\
\hline PTI & Three-Year Investment Programme \\
\hline REM & Pupil Teacher Ratio \\
\hline $\mathrm{SBI}$ & Special Investment Budget \\
\hline SDA & Supply Master Plans (energy wood) \\
\hline SDDR & Rural Development Master Plan \\
\hline SDS & Statistics Master Plan \\
\hline SDU & Town Planning Master Plan \\
\hline
\end{tabular}




\begin{tabular}{|c|c|}
\hline SFD & Decentralized Financial Systems \\
\hline SIG & Geographical Information System \\
\hline SME & Small and Medium Size Enterprises \\
\hline SMI & Small and Medium Size Industries \\
\hline SOTELMA & Société des Télécommunication du Mali \\
\hline SSN & National Statistics System \\
\hline SYSCOA & West African Accounting System \\
\hline TFP & Technical and Financial Partners \\
\hline UGP-Cl & Integrated Framework for Project Management Unit \\
\hline UNDP & United Nations Development Programme \\
\hline VAT & Value Added Tax \\
\hline WAEMU & West African Economic and Monetary Union \\
\hline WFP & World Food Programme \\
\hline WTO & World Trade Organization \\
\hline
\end{tabular}




\title{
FOREWORD
}

The Ministry of the Economy and Finance is pleased to make available to the development stakeholders in Mali (public administration, civil society, private sector, Decentralized Authorities, technical and financial partners, Institutions of the Republic), the final version of the $2^{\text {nd }}$ Generation Poverty Reduction Strategy Paper (PRSP II) adopted by Cabinet Meeting on 20 December 2006. This document, known as Growth and Poverty Reduction Strategy Paper, which will henceforth be the only frame of reference for development policies and strategies in Mali, has been prepared following a broad participatory process at the national, regional and local levels.

The document is the outcome of this long process, which covered nearly one year. It brings together all the sector policies. To a large extent, it draws on lessons learnt from PRSP I 2002-2006 evaluation, the MDGs and the National Prospective Study for Mali 2025 (ENP Mali 2025) conducted from 1997 to 1999 throughout the country and which recorded Malians' perception and vision of their society within a generation.

PRSP II has given an opportunity to review all sectoral, national and thematic policies in light of the main goal of growth and poverty reduction. The reflection helped to underscore, not only the major causes and obstacles to poverty reduction, but also the key economic and social benefits that guarantee strong growth and sustainable development.

Furthermore, I think it is important to point out that the PRSP process is an ongoing process. Consequently, improvements will be made to the document, as relevant information and analyses become available. The aim is that the PRSP should serve as a permanent framework for dialogue between all the stakeholders, and that it should at all times be the best possible response to the problem of poverty reduction.

The process of preparing this document has generated a series of intermediate documents that the Ministry of the Economy and Finance will make available to all users; the documents include ad hoc group reports, as well as PRSP review and workshop reports.

Lastly, I wish to thank all stakeholders for their active involvement in the PRSP preparation process which can still be improved and is open to all because, over and above the production of a reference document, the major challenge remains its implementation and monitoring-evaluation which, if successful, would guarantee achievement of the objectives sought. The success of the PRSP depends on this.

\author{
Abou-Bakar TRAORE \\ Minister of the Economy and Finance
}




\section{EXECUTIVE SUMMARY}

1. The new generation Poverty Reduction Strategy Paper (PRSP), which could be defined as the Growth and Poverty Reduction Strategy Paper, describes the policies and programmes which the country intends to implement at the macro-economic, structural and social levels, so as to promote growth and reduce poverty over the 2007-2011 period. It also presents the financing plan and related external financing requirements for the period.

2. The PRSP also provides the basis for assistance from technical and financial partners, as well as debt relief under the Heavily Indebted Poor Countries (HIPC) Initiative and the Multilateral Debt Reduction Initiative (MDRI), two initiatives from which Mali benefits.

3. The first PRSP for Mali, the final version of which was adopted in May 2002, drew on the Interim PRSP (I-PRSP). It covered the 2002-2006 period. In all, eleven working groups, with representatives from the central administration, the civil society, the private sector and external development partners, played a key role in its preparation. The preparation process also involved regional consultations.

4. As it henceforth provides the single medium-term frame of reference for the development policy of Mali, and the main reference document for all TFPs in their support operations for the country, the PRSP has helped to implement several programmes in each of the proposed priority areas, namely: (i) institutional development and improvement of governance and participation,

(ii) human development and reinforcement of access to social services, and

(iii) development of infrastructures and support to key productive sectors.

5. The reports on PRSP implementation and review conducted in June 2006 underscored the achievements and weaknesses in PRSP preparation and implementation. Justifications for the preparation of a new generation PRSP therefore lie in the weaknesses of PRSP I, in particular: (i) inadequacy of results obtained in relation to the set overall goals, (ii) weak link between the PRSP and the State budget, operational weakness of the institutional monitoring-evaluation mechanism, and weakness of the various working instruments (indicators, statistics).

6. It is within this context that the new generation PRSP, presented in this document, was prepared.

7. The work drew on the results of evaluations of the 2002-2006 PRSP, specific work by the ad hoc working groups, and conclusions of the first PRSP review.

8. Following preparations at end of 2005 , the process was launched in January 2006, and the initial documents were presented in July 2006. Consultations were held with all the stakeholders throughout the preparation process, and a national workshop in September 2006 put together the views of all the stakeholders. This document is the outcome of the consultations.

9. The guiding principles of PRSP II preparation are as follows:

- consolidation of the achievements of PRSP I;

- acceleration of growth by eliminating major constraints;

- implementation of new sources of growth; and

- integration of MDGs. 


\section{Evaluation of PRSP I}

10. The implementation of PRSP I helped to reduce the level of monetary poverty from $68.3 \%$ in 2001 to $59.2 \%$ in 2005 , on the basis of an updated poverty line of CFAF 153,310. The goal of reducing poverty by one-quarter over the 2001-2006 period, and bringing down the level to $47.5 \%$ in 2006 was therefore not achieved. The analysis shows a significant gap between rural areas $(73.0 \%)$ and urban areas $(20.1 \%)$. On the other hand, poverty in urban areas has reduced, with urban poverty incidence dropping from $26.2 \%$ in 2001 to $20.12 \%$ in 2005 , representing a decline of more than 6 points. In rural areas, the incidence of poverty has remained virtually stable, moving from $73.8 \%$ in 2001 to $73.0 \%$ in 2005. Lastly, the other two indicators, depth and severity of poverty, are improving slightly, but insufficiently and less than expected by the first PRSP project.

11. In conclusion, it should be noted that the low level of poverty reduction during PRSP $I$ is due to poor control of population growth, inadequate growth rate of the Malian economy, unequal distribution of the fruits of growth, and limited access to basic services.

\section{Long-term Strategic Vision}

12. Like PRSP I, PRSP II is based on the vision defined in the National Prospective Study Mali 2025. This consensual vision on the country's future by the year 2025 is built around the aspirations of individuals. It expresses what the majority of the Malian population, including the poor, want: "a nation that is united around a diversified and rehabilitated cultural base; a democratic political and institutional organization that guarantees development and social peace; a strong, diversified and open economy; poverty reduction and social progress affecting all the regions and categories of the population".

13. Such a vision is voluntarist. It calls for a proactive attitude, which consists in not being subject to events, but rather acting to cause them. It also entails the mobilization of minds and energies for poverty reduction and sustainable development. It is an extension of international commitments made at various world summits, in particular the Millennium Development Goals for 2015.

\section{Overall Goals and Macro-economic Framework}

\section{Overall Goal}

14. Promote redistributive growth and poverty reduction by boosting productive sectors and consolidating public sector reforms. The main objective of the macro-budgetary framework is to maintain macro-economic and budgetary balances, taking into account the real potential of the Malian economy, as well as the overall and sector goals of the PRSP. Following consideration of several variants based on diverse public investments and tax pressure assumptions, a voluntarist scenario of strong growth was adopted, reflecting the political will to accelerate overall growth driven by rapid private sector development. The average estimated GDP growth rate for the 2007-2011 period will be $+7 \%$. In public finance, efforts will be made towards mobilization of internal resources, with a tax pressure of $17 \%$ as from 2008 , in accordance with Mali's commitments concerning the WAEMU convergence criteria. The Government's budget and financial policy will be supported by activities proposed in the Government's Action Programme for the Improvement and Modernization of Public Finance Management 
(PAGAMGFP). During PRSP II, total revenue and expenditure estimates (including net loans) are consistent with the macro-economic framework and Medium-Term Budgetary framework. The total revenue (excluding grants) would stand at CFAF 884 billion in 2011 as against CFAF 540 billion in 2007. Tax revenue will increase at an average annual rate of $10.3 \%$. Total expenditure and net loans would increase at an average annual rate of $7.1 \%$ to CFAF 1,217 billion in 2011. These estimates include the financing programmes, as well as evaluations of internal and external financing requirements for the period.

\section{Specific Objectives}

- Accelerate growth: $+7 \%$ per year over the $2007-2011$ period.

- Improve the well-being of the Malian populations.

\section{Strategic Orientations}

15. To achieve these objectives, PRSP II proposes three strategic orientations, which reinforce each other to attain the core objective of strong and sustainable growth that would reduce poverty:

- Development of infrastructures and the productive sector;

- Pursuance and consolidation of structural reforms; and

- Strengthening of the social sector.

\section{OS1: Development of infrastructures and productive sectors}

16. This first strategic orientation aims at improving the productive environment to ensure better productivity of factors of production and economic growth.

\section{OS2: Pursuance and consolidation of structural reforms}

17. This second strategic orientation aims at pursuing the implementation of reforms relating to the structure and functioning of the Government and its institutions. To that end, the Government will place the concerns of users at the core of institutional reforms that will be undertaken by the Institutional Development Programme (PDI) to ensure good management of public affairs, peace and social stability. The Programme aims at making profound changes in public management. The reforms, some of which were initiated several years ago, need to be strengthened during PRSP II implementation. In addition to consolidation of the decentralization process, several equally fundamental aspects will be given priority in PRSP II, namely: strengthening of the rule of law and improvement of the judicial system and organization, capacity building for the civil society, and the fight against corruption.

\section{OS3: Strengthening of the Social Sector}

18. This strategic orientation focuses on better delivery of key basic social services, in particular education, health, drinking water and sanitation, and housing. Employment-training and HIVIAIDS control will be priority areas of intervention. 
19. For each of the strategic orientations, emphasis is laid on the need for specific and corrective actions to protect the rights of the poor in decisionmaking and reduce disparities between regions, between councils, between urban and rural areas, and between the sexes.

\section{Priority Areas of Intervention}

20. The three strategic orientations are detailed out in thirteen priority areas, which cover all activities relating to the administration, the civil society, the private sector, and the productive sector: (1) Food security and rural development; (2) development of small and medium size enterprises; (3) protection and sustainable management of natural resources; (4) consolidation of public administration reform; (5) pursuance of reform of the business environment; (6) development of the financial sector; (7) development of infrastructures; (8) promotion of democratic governance and public freedoms; (9) capacity building for the civil society; (10) strengthening of regional and sub-regional integration initiatives; (11) creation and promotion of long-term jobs; (12) development of access to basic services; (13) HIVIAIDS control; and (14) integration into the Multilateral Trade System.

\section{Implementation, Monitoring and Evaluation}

21. It is necessary to clarify and simplify the institutional mechanism. The PRSP institutional mechanisms will comprise: (i) a Policy Committee, (ii) a Mali Development Partners Joint Commission, (iii) a National Steering Committee, and (iv) a PRSP Technical Unit, which will be strengthened. The PRSP process will be conducted and coordinated by the Ministry responsible for the Economy.

22. As regards methods, the PRSP evaluation calls for a review of the number and nature of the proposed indicators by component or thematic area for better legibility and greater relevance.

\section{Presentation of PRSP II}

23. This document presents the results of the work done by the central and deconcentrated administration, in constant collaboration with all partners: civil society, private sector and technical and financial partners. It comprises about ten chapters which cold be divided into five main parts:

- Presentation of the poverty situation in Mali and the results of the first PRSP 2002- 2006;

- Presentation of the key objectives and general framework within which the new PRSP will be implemented: the macro-economic framework and the budgetary framework for 2007 to 2011;

- Presentation of strategies and policies through the strategic orientations, priority areas and details of sector policies;

- Accelerated growth strategy including cross-cutting issues (population, gender, and territorial development); and

- Lastly, presentation of coordination and monitoring-evaluation mechanisms, with monitoring-evaluation indicators, implementation of the Paris Declaration, the Financing Plan, and the Logical Framework of the $2^{\text {nd }}$ Generation PRSP. 


\section{INTRODUCTION}

24. The challenge which Mali has to take up to reduce poverty is first that of creation of wealth through strong and sustained growth. This growth is a prerequisite for the redistribution of wealth for the welfare of the Malian population.

25. Consequently, the $2^{\text {nd }}$ generation PRSP 2007-2011 is known as the "Growth and Poverty Reduction Strategy Paper (GPRSP)" and has two major objectives:

- promote strong annual growth of $7.0 \%$, by generating wealth and creating jobs in growth-oriented sectors of the national economy, such as rural production (agriculture, livestock, fisheries, agro-forestry, fruits and vegetables), the mining and energy sector, and the goods and services sector (trade, tourism, culture and NICT). These growth-oriented sectors require explicit energy strategies that consider all forms of energy (motive force, pumping, new and renewable sources of energy, etc). Real control of population growth and better redistribution of the created wealth will help to reduce inequalities and distortions of access to basic social services, which are the main causes of growing poverty.

- improve the functioning of public services by pursuing, consolidating and deepening reforms initiated at the institutional level (decentralization and deconcentration), democratic governance (democracy, fight against corruption and establishment of the rule of law), the economic level (microfinance and the private sector) and improvement of the social sector (in particular, education, health, drinking water, employment and training, and HIVIAIDS control).

26. During PRSP I, priority was given to allocation of budgetary resources to social sectors, in general. In PRSP II, while continuing with these sectors, emphasis will be laid on the implementation of structural reforms and investments to support growth-oriented sectors, such as rural production, mining, infrastructure and the environment.

27. To ensure sustained growth and sustainable poverty reduction, development should be anchored on the decentralization of government action to the local level and on territorial development which will help to tap the existing economic, human and environmental potential, mitigate constraints and territorial imbalances, and revitalize local economies.

28. Ensuring consistency between national (Government) strategies and local (Local Authorities) priorities and improving production conditions in rural areas should help to create attractive development poles to reduce rural exodus of youths, particularly to urban centres. Poverty reduction also requires real control of population growth and specific attention to the redistribution of wealth by social and spatial category. 


\section{TREND OF POVERTY IN MALI}

29. Previous studies conducted in Mali revealed three forms of poverty:

- Poverty in terms of living conditions or mass poverty, which reflects a situation of lack of food, education, health care and housing.

- Monetary or income poverty, which reflects inadequate resources, leading to insufficient consumption.

- Potentiality poverty, which is defined as the lack of capital (access to land, equipment, loans and employment). This form of poverty is not well evaluated in Mali. However, the Sustainable Human Development and Poverty Reduction Observatory (OOHD) has provided indications on this form of poverty in its Development Report (2003 edition). Furthermore, the Observatory has calculated the Community Poverty Index based on the basic infrastructures of 703 municipal councils.

30. PRSP I was based on the "living conditions" approach, using the Budget Consumption Survey of 1998. On this basis, the 2002 estimate of the incidence of poverty was $64 \%$ of poor people, while the results of the Malian Poverty Evaluation Survey in 2001, based on a monetary approach, indicated $68 \%$ of poor people.

The various PRSP I evaluations show that:

31. implementation of the PRSP helped to reduce the level of poverty from $68.3 \%$ in 2001 (income base) to $59.2 \%$ in 2005 , on the basis of an updated poverty line of CFAF 153,310 . The goal of reducing poverty by one-quarter over the 2001-2006 period and bringing down the level to $47.5 \%$ in 2006 was therefore not achieved. The analysis shows a wide gap between rural areas $(73.04 \%)$ and urban areas $(20.12 \%)$. Furthermore, poverty in urban areas was reduced, since the incidence of poverty in these areas declined from $26.2 \%$ in 2001 to $20.12 \%$ in 2006 , representing a decline of more than 6 points. On the other hand, in rural areas, the incidence of poverty has remained virtually stable, from $73.8 \%$ in 2001 to $73.04 \%$ in 2005 . The preceding analyses therefore show that in Mali poverty is essentially a rural phenomenon;

32. the degree of poverty stood at $24.1 \%$ in 2005 as against $31.4 \%$ in 2001 , which indicates some progress. This shows that the gap between the incomes of the poor and the poverty line is reducing.

33. In the same connection, the severity of poverty has reduced, from $17.6 \%$ in 2001 to $12.6 \%$ in 2005 , representing a decline by 5 points.

34. The Gini index was 0.401 in 2001 . The current available information does not provide a reliable indication of the trend of inequalities since implementation of the PRSP.

35. To make the PRSP process credible, it is necessary to fine-tune the analysis and measurement of poverty so as to better anchor the objectives of the second generation, particularly the trend of inequality and level of access to basic social services. Ongoing surveys (ELIM II, in particular) will help to provide more information on these aspects. 
36. In conclusion, it should be noted that the low level of poverty reduction during the PRSP is due to inadequate growth rate of the Malian economy, and to unequal distribution of the fruits of growth, limited access to basic services, and poor control of population growth.

\section{Evaluation of the PRSP}

37. Adopted on 29 May 2002 following broad consultations with all the stakeholders of the Malian society (Government administration services, the private sector, the civil society, decentralized local authorities and technical and financial partners), the first generation (2002-2006) of the Poverty Reduction Strategy Paper (PRSP) has come to an end. The PRSP evaluation presented below has contributed to better preparation for the second generation known as the "Growth and Poverty Reduction Strategy Paper (GPRSP)", which covers the 2007-2011 period.

\subsection{Evaluation of the PRSP Pillars}

38. The first PRSP review, conducted on 8 and 9 June 2006, helped to assess the trend of the macro-economic situation and sectors in terms of the various PRSP pillars.

39. During the period under review, the Malian economy was hit by exogenous factors: the conflict in Côte d'lvoire, the upsurge in oil prices, the locust invasion and early stoppage of rainfall in 2002 and 2004. Côte d'lvoire, Mali's first trade partner in the sub-region, is the country through which $70 \%$ of trade transits. The conflict forced Mali to go through far-away ports like Lomé or Cotonou to obtain supplies, particularly hydrocarbons. This significantly increased the recurrent costs of transportation of imported goods, and reduced the budget revenue.

\subsubsection{Macro-economic Framework}

40. It was estimated that the Malian economy would record an average annual increase of $6.7 \%$ over the $2002-2005$ period. The increase was expected to reduce the incidence of poverty from $63.8 \%$ in 2001 to $47.5 \%$ in 2006 . The average real GDP growth stood at $5.2 \%$ over the $2002-2005$ period. A breakdown of this indicator shows a growth rate of $4.7 \%$ for the primary sector (as against $7.3 \%$ estimated), $5.3 \%$ for the secondary sector (as against $6.2 \%$ ), and $4.8 \%$ for the tertiary sector (as against $5.9 \%$ ). As a result, the growth objective could not be achieved.

41. Significant progress has been made in the management of public finance and macro-economic planning through: (i) implementation of programme budgets and sectoral MTEFs; (ii) application of expenditure implementation procedures manuals; (iii) interconnection of the computer networks of administrative services responsible for preparation and implementation of the State Budget; (iv) establishment of a new budget nomenclature and strengthening of controls; and (v) setting up of a Forecasts and Modelling Committee (CPM) in 2003.

42. The average inflation rate was $1.9 \%$ over the $2002-2005$ period, thereby remaining below the tolerable level of $3 \%$. 
43. The total external financing of the development programme recorded a significant gap, and stood at $78.4 \%$ (estimates of CFAF 1,043.6 billion). Furthermore, it should be noted that 2002 recorded the highest level of mobilization in comparison to the estimates, as a result of efforts to organize CAN 2002.

44. With respect to public expenditure, stringent management helped to maintain a budget position consistent with the objectives of the IMF staffmonitored programme. Current and capital expenditures were maintained within the limits of the programme. Delays in the disbursements of external aid led to a decline in the implementation volume and rate of the Special Investment Budget (BSI). However, in the past few years, the BSI implementation rate has been improving.

45. Over the PRSP I period, Mali complied with most of the WAEMU convergence criteria, with the exception of the base budget balance and tax ratio.

\subsubsection{Institutional Development, Governance and Participation}

46. With respect to improvement of the performance of public administration, the activities concern in particular, the preparation of the Institutional Development Programme (PDI), and its Operational Plan. As regards strengthening national planning and development management capacities, the services and organs responsible for planning, statistics, macroeconomic forecasts, territorial development and population have been restructured, and development management policies, tools, instruments and methods have been formulated. Furthermore, the strengthening of deconcentration, which should accompany decentralization, is a major State commitment. The financial component of this commitment is being implemented with the Government Action Plan for the Improvement and Modernization of Public Finance Management (PAGAMGFP) through budgetary deconcentration actions, deconcentration of public procurement procedures, and operational establishment of deconcentrated organization charts and organic frameworks.

47. The organization and conduct of democratic elections (presidential, legislative and municipal), within a consensual and peaceful political climate, have helped to consolidate the democratic process. The installation of the "Haut Conseil des Collectivités Territoriales" (HCCT) (Local Authorities High Council), the creation of an Inter-Ministerial Steering Committee for the Transfer of Government Powers and Resources to Local Authorities, and the establishment of a technical and financial support mechanism (CCC and ANICT) for local authorities show that decentralization has become effective. Furthermore, a National Decentralization Policy Framework Paper has been prepared and submitted to the partners. Implementation of the paper will help to consolidate the achievements of this reform.

48. Common understanding of the concept of civil society, the identification of its strengths and weaknesses, mastery of its role and responsibilities within the democratic context of Mali, and establishment of the National Civil Society Council (CNSC) are some of the factors that have helped to strengthen the capacities of this important stakeholder in the Malian society. This importance was demonstrated throughout the PRSP II preparation process by its numerous initiatives, in particular the organization of consultation workshops for the six council of Bamako and eight regions of Mali. 
49. In order to effectively fight against corruption, the Ministry of Justice, through PRODEJ, has taken important measures to strengthen transparency in the processing of court files and reinforce control structures. In 2003, the Government appointed prosecutors to manage economic and financial poles. In 2004, the Office of the Auditor General and judicial police officers was established. Efforts to train and recruit judicial staff, as well as control information systems for human resource management, judicial files and financial resources have helped to strengthen the capacities and credibility of the justice sector. The other control structures, namely the Accounts Section of the Supreme Court and the General Control of Public Services have also been strengthened.

50. The introduction of the culture of peace into teaching programmes, the development of traditional conflict prevention and management mechanisms, the conduct of democratic discussion forums ("Espaces d'Interpellation Démocratiques" (EID) and preservation of the secular nature of the State have helped to establish peace and security.

51. Actions have been taken to restore and rehabilitate historic sites, promote the national heritage, as well as train cultural stakeholders and staff of the Ministry of Culture. Furthermore, as a factor of economic development, the cultural sector has helped to fight against poverty in terms of creating jobs and wealth through the organization of cultural events and activities for the development of industries and cultural undertakings (music, concerts, publishing, plastic arts, and photography).

\subsubsection{Human Resource Development and Access to Basic Services}

52. As regards basic education, significant progress has been made in opening schools. From 2002 to 2005, the mixed Gross Enrolment Rate recorded an increase of $9.66 \%$ (from $64.4 \%$ to $74 \%$ ), and the girls enrolment rate increased by $9.70 \%$ (from $53.7 \%$ to $63.4 \%$ ). The boys literacy rate has remained much higher than that of girls, due to socio-cultural constraints. The Pupil/Teacher Ratio remained constant between 2002 and 2004 (57 pupils/teacher). In 2005, it declined by 3 points, reaching a ratio of 54 pupils to a teacher. This positive development came as a result of huge investments in school infrastructure and significant recruitment of contractual teachers.

53. The achievement of PRSP objectives in health and population has been satisfactory. The extension of DTCP3 vaccination coverage for children below one year old (from 75\% in 2002 to $91 \%$ in 2005) was strong during the period, and the proportion of the population living within $5 \mathrm{~km}$ of a functional health centre increased from $44 \%$ in 2002 to $50 \%$ in 2005 . The key constraints on PRODESS implementation II are, in particular, delays in the operationalization of the Decree on transfer of Government powers and resources to local authorities, inadequate qualified staff and equipment in CSCOMs, as well as lack of a formal framework for the maintenance of equipment and infrastructure.

54. Interventions in the water sector helped to improve drinking water supply. The rate of access to drinking water increased from $57 \%$ in 2002 to $66.1 \%$ in 2005. The major problems encountered consists mainly in the nonfinalization of the Drinking Water Sanitation Sector Programme (PROSEPA), the non-mobilization of adequate financing to support emergency programmes for Bamako and other areas, and the nonestablishment of the Drinking Water and Sanitation Agency. 
55. In order to improve access to housing, the Government adopted a town planning and housing policy, leading to the formulation of a Town Planning Master Plan (SDU) and the National Housing Programme (PNL) as well as the creation of three referral institutions: (i) the "Banque de l'Habitat du Mali" (BHM) specialized in the financing of housing; (ii) the "Office Malien de l'Habitat" (OMH) (Housing Authority of Mali), a financing mechanism for assisting $\mathrm{BHM}$ in its policy to reduce the cost of housing, and (iii) the "Fonds de Garantie Hypothécaire du Mali" (FGHM) (Mortgage Guarantee Fund of Mali) responsible for granting mortgages and refinancing banks and financial institutions that operate in the housing sector.

56 . With respect to the promotion of youth employment, 2000 volunteers have been accepted on internship in public services. However, the primary sector continues to be the greatest provider of jobs with $83.4 \%$ of the working population, and the secondary and tertiary sectors employ $4.1 \%$ and $12.5 \%$ respectively. The employment situation in Mali, particularly youth employment, remains a major cause for concern for the Government. The high population growth (about $2.2 \%$ per year) accelerates the inflow of youths to the labour market, while growing urbanization, fuelled by rural exodus and the return of emigrants, creates a high demand for jobs.

57. As regards social development, significant efforts have been made in the establishment of structures, equipment, as well as laws and regulations for the disabled. Support to old people for access to basic social services (health care, social security) is given through the implementation of a national action plan. Significant initiatives have been taken for underprivileged persons, in particular the financing of income-generating activities, as well as providing medical care and schooling for children in difficult situations. Important reforms have been made in social security and economy. There are currently 75 mutual health insurance societies, 64 of which have been approved. The societies provide coverage for about 160,150 persons (about $1.3 \%$ of the population), all benefits included, with about 144,729 persons for sickness risk (about $1.2 \%$ of the population). As for cooperative societies, about 4,197 cooperative societies are currently registered, and are mainly in the handicraft, multifunctional, agro-pastoral, agricultural, production, consumption, housing, services, promotion of culture, and fisheries sectors.

58. As regards gender, significant efforts still need to be made to ensure the presence of women in policy-making institutions; this area has not recorded any significant development so far.

59. In Mali, the HIVIAIDS prevalence rate remains low (1.7\% in 2001, according to EDSM III). However, HIV-positive cases are increasing, especially among the risk groups. The major causes of the epidemic in Mali are risky sexual behaviour, high migration flows, the extent of poverty, the very high economic and social vulnerability of women, stigmatization and marginalization of affected persons and families, and lastly risky sociocultural practices (levirate).

60. The HIVIAIDS epidemic affects all sectors of the economy negatively through reduction of work time, loss of skilled labour, and increase in direct and indirect costs. The pandemic also has repercussions on social practices, traditions and customs. In order to significantly reduce the 
HIVIAIDS prevalence rate, Mali has undertaken many institutional reforms to intensify the fight against the pandemic. These efforts have resulted in: (i) the creation of an Executive Secretariat responsible for implementing, monitoring and evaluating national policy through multisector coordination; (ii) the adoption of a policy statement; (iii) the creation of a National AIDS Control High Council (HCNLS); (iv) the creation of sector and regional AIDS control committees; (v) modification of the composition of the National AIDS Control High Council (HCNLS) to ensure the participation of all segments of the society and attachment of HCNLS to the Presidency of the Republic of Mali; (vi) the adoption of the National Strategic Framework (CNS) for HIVIAIDS Control; (vii) the commitment to provide free Anti Retrovirals (ARV) to all AIDS patients, and (viii) the enactment of a law on HIVIAIDS on 26 July 2006.

\subsubsection{Development of Basic Infrastructure and Productive Sectors}

61. The results achieved in road infrastructure are significant in terms of construction and maintenance. There were 136 kilometres $(\mathrm{km})$ of rehabilitated tarred roads in 2002, $282 \mathrm{~km}$ in 2003, $160 \mathrm{~km}$ in 2004 and a provisional construction of $103 \mathrm{~km}$ in $2005.246 \mathrm{~km}$ of roads were constructed in 2003, $232 \mathrm{~km}$ in 2004 and $130 \mathrm{~km}$ in 2005. As for modern earth roads, 5,976 km were maintained in 2002, $6012 \mathrm{~km}$ in 2003, 6059 in 2004, and $8880 \mathrm{~km}$ in 2005. The priority actions under PACT concern: (i) organization and competition on the transport market, (ii) sanitation and modernization of the public transport vehicle fleet, (iii) improvement of road safety, (iv) improvement in the collection of road infrastructure charges, and (v) mainstreaming of environmental and social aspects, as well as the problem of HIVIAIDS and transport.

62. As regards airport and railway infrastructures, serious difficulties and shortcomings are still noted. The granting of concession for the railway and "Aéroports du Mali" is under way.

63. With respect to the energy policy, the overall objective was to contribute to the sustainable development of the country by providing services accessible to the greatest number of people at the least cost and by promoting socioeconomic activities. This objective can be achieved only by improving the management and regulation of the energy sector and reinforcing the means of preventing energy shortages. It also requires adequate responses to the energy needs of the other sectors (particularly health and education) and populations in rural and semi-rural areas. The energy policy should meet the needs of the Ten-Year Health and Social Development Programme (PRODESS) with respect to health, of PRODEC with respect to education, or again of the $2^{\text {nd }}$ Rural Development Sector Master Plan.

64. Over the 2002-2005 period, the overall access rate to electricity increased from $12 \%$ to $15.03 \%$, and butane gas consumption increased from 2,740 tonnes in 2002 to 4,084 tonnes in 2005.

65. As regards the primary sector, positive results have been achieved in the implementation of the Government Development Programme for 50,000 hectares, the implementation of the Agricultural Sectors and Farmer Organizations Support Programme (PASAOP), the implementation of the National Rural Infrastructure Programme (PNIR), and the creation and installation of the Rural Infrastructure and Utilities Works Implementation Agency (AGETIER). 
66. The adoption, by Cabinet Meeting, of a National Food Security Strategy in November 2002 and a food security management institutional framework in April 2003, as well as the creation of a Food Security Commission attached to the President of the Republic and responsible for formulating and implementing food security policy show the priority given by the authorities to the issue. After a difficult year in 2004 due to drought and locust invasion, which reduced cereal production to $2,845,000$ tonnes, the said production increased in 2005 to 3,399,000 tonnes, and reached its record level in 2003 $(3,402,000$ tonnes). In 2005 , cereal production recorded a $24 \%$ increase in comparison to the average for the past five years.

67. After increasing between 2002 and $2003(+75 \%)$, the developed areas under total control remained relatively stable at about 5,000 ha per year, representing nearly half of the development target. The overall development programme is 64,279 ha, comprising 50,000 ha under total control and 14,279 ha under partial control. The financing obtained was used in developing $70 \%$ of the areas, or 44,710 ha. On the whole, the completion rate of the proposed actions is $78 \%$.

68. Concerning the secondary sector, the Government in 2004 adopted the industrialization policy to facilitate industrial development. The policy laid emphasis on a strategy based on incentives for investment and development of private enterprise. To that end, a number of priority actions were defined, and their implementation evaluated. The actions included:

- implementation of the Integrated Programme of Mali (PIM phase II) ;

- adoption of the restructuring and upgrading programme for industrial enterprises.

69. Interventions in the mining sector over the 2002-2005 period led to gold production of $63.7 \mathrm{t}$ in 2002, $51.6 \mathrm{t}$ in $2003,44.6 \mathrm{t}$ in 2004 , and $52.1 \mathrm{t}$ in 2005.

70. The initiatives taken to promote trade concerned: (i) support for the promotion of exports of some targeted agricultural products, (ii) support for the restructuring of the sector, (iii) improvement of the business climate, and (iv) involvement of economic operators in decisions concerning them. Sector initiatives launched by four African countries, including Mali, for the attention of WTO were aimed at eliminating all forms of subsidies for cotton and obtaining compensation of victim countries. The formulation and implementation of the Support Project for Retailers (PACD) and of the pilot project of the trade-related technical assistance integrated process helped to support retail operators.

71. Significant developments were made in micro-finance during the period. The number of local structures or service points increased by nearly $10 \%$ from 730 to more than 800 . Furthermore, the number of members and/or beneficiaries of these structures increased from 522,000 to more than 820,000 persons, representing a $57 \%$ increase. One Malian out of every six of the working population benefits from local financial services, and $35 \%$ of the women are members of micro-finance structures. However, despite the favourable trends, financial exclusion remains high $(82 \%$ of the working population do not have access to financial services). Decentralized Financial Systems (DFS) are still concentrated in areas with relatively high economic potential, such as Sikasso, Ségou, Mopti, Kayes and Bamako District, while the less privileged regions of the North (Gao, Timbuktu and Kidal) have 
limited coverage by these services. The DFS distribution by administrative region is as follows: Ségou (27\%), Sikasso (20\%), Bamako District $(18 \%)$, Koulikoro (17\%), Kayes (8\%), Mopti (6\%), Timbuktu (2\%), Gao (1.5\%), and Kidal (0.5\%).

72. In order to ensure better development of the private sector, which is the engine of economic growth, the Government on 12 January 2005 adopted the Private Sector Development Policy Letter (LPDSP) on improving the investment framework and climate, and developing growth-oriented sectors such as mining, handicraft and tourism, and telecommunications. Special emphasis was laid on the development of growth-oriented infrastructures, such as industrial zones and airport facilities, as well as on the development of financial and non-financial services for Small and Medium Size Enterprises. Serious efforts have been made towards capacity building and restructuring in the private sector, with the creation of a database (Websites) on economic and trade issues in the National Employers' Council of Mali (CNPM), the establishment, in partnership with the International Labour Office (ILO), of a programme to support competitiveness and productivity of enterprises, the creation of consular chambers comprising the Chamber of Commerce and Industry of Mali (CCIM), the Permanent Assembly of Chambers of Agriculture of Mali (APCAM), the Permanent Assembly of Chambers of Trades of Mali (APCMM), as well as the creation of an enterprises services development agency and a national sub-contracting and partnership exchange.

73. In order to tap its tourism potential, Mali has developed a cultural policy which aims at structuring the cultural heritage, so as to make it the engine of economic and social development. The Government has also updated some texts relating to the organization of the profession of travel organizers and guides; in addition, it has developed activities for the promotion of tourism. Between 2002 and 2005, Mali recorded an increase of $83 \%$ of its tourism inflow.

\subsection{Links between the PRSP and Budget Instruments}

74. It is accepted by all development stakeholders that the PRSP is the single frame of reference for medium-term development policies and strategies, as well as the main instrument for negotiation with technical and financial partners. However, the various PRSP evaluations show weak links between the PRSP process and short and medium-term budgetary instruments (programme budget, overall MTBF, sector MTEFs). Efforts will be made to ensure greater harmonization between these instruments, and also between the PRSP, the Three-Year Investment Programme (PTI) and its annual tranches (BSI). There is also lack of explicit coherence between the PRSP, the sector/thematic strategies, and the State Budget. Furthermore, there is poor synergy between the PRSP and other sector policy documents as regards identification of actions for the most vulnerable groups of the population.

\subsection{Links between the PRSP and the MDGs}

75. Similarly, the absence of explicit links between the PRSP and the Millennium Development Goals (MDG) weakens the intention of making the PRSP a medium-term action plan to achieve these goals. Consequently, it is 
necessary to closely align the Government's priority actions with the MDGs. The formulation of an MDG-oriented national development strategy should therefore form an integral part of the planning and budgeting process. Such closer links also requires an inventory of previous and existing strategic planning documents, and evaluation of the quality of monitoring and evaluation tools for measuring progress in the achievement of the MDGs.

\subsection{Links between the PRSP and the National Prospective Study Mali 2025}

76. The operationalization of the National Prospective Study (ENP Mali 2025), adopted by the Government in 2000 and aimed at mobilizing all stakeholders around achievement of the development goals, requires that it should be taken into account in the preparation and monitoring of mediumterm development strategic frameworks. ENP Mali 2025 showed that the perception of Malians on poverty issues could be summarized as follows: very low incomes, unfavourable natural conditions, difficulties of access to basic public services, poor management of national resources and corruption, as well as the landlocked position of the country. The study also showed that only sustained investments in agriculture, the creation of new jobs, reinforced solidarity and mutual help, and better management of resources will help to reduce poverty significantly.

77. ENP Mali 2025 also shows that by 2025, Malians will be aspiring for development of the country based on the primary sector, the development of agro-food industries, textiles and mining, the decentralization of public management, internal and external accessibility of country and more balanced development of the territory. These concerns and aspirations should therefore be taken into consideration when preparing and implementing the $2^{\text {nd }}$ generation PRSP.

\subsection{Links between the PRSP and support from Technical and Financial Partners}

78. Predictability of assistance should be a key indicator in the PRSP process. With respect to harmonization of procedures, donors have made efforts to better coordinate joint monitoring and evaluation procedures, as well as strengthen co-financing agreements. Some studies, as well as measures relating to conditionalities, monitoring and evaluation have been conducted jointly, or at least in a coordinated manner. Despite these attempts, harmonization of procedures has not gone a long way since adoption of the PRSP. To ensure alignment of aid and harmonization of practices, a general framework arrangement for budget support and sector agreements were signed in 2006.

\subsection{Lessons from the PRSP Monitoring and Evaluation}

79. Analyses showed: low operationalization of the institutional monitoringevaluation mechanism and the need to strengthen the PRSP Unit and build institutional capacities with respect to the methods, tools, instruments and indicators used. They also showed the poor quality of basic statistics. The PRSP analyses show that the information system used is still incapable of accurately measuring the performance indicators. 


\section{GPRSP OBJECTIVES AND EXPECTATIONS}

\subsection{Overall Goal}

80. Drawing on the achievements and lessons of PRSP I implementation, the $2^{\text {nd }}$ generation, known as the Growth and Poverty Reduction Strategy Paper (GPRSP), has the overall goal of giving impetus to strong and sustained growth (about $7 \%$ per year) and significant poverty reduction. Monetary poverty should also reduce by 5 percentage points over the five-year period. To achieve this level of growth, special attention will be paid to revitalization of the productive sectors and consolidation of the public sector reform process, which will be based on administrative decentralization and promotion of private sector initiatives. Through public sector reform, PRSP II will also consolidate economic and political good governance.

\subsection{Specific Objectives}

81. More specifically, the GPRSP aims at:

- accelerating economic growth, mainly through development of rural and mining production sectors;

- improving the well-being of the Malian populations by pursuing efforts in social sectors, and enhancing them through reforms towards achievement of the Millennium Development Goals (MDG).

\subsection{Expectations}

82. The major expectations, as drawn from the evaluation of PRSP implementation and which can affect the achievement of PRSP II objectives, mainly concern the following points:

- continued stability of the macro-economic environment and consistency between macro-economic and budgetary forecasts, as well as external financing;

- continued peace and security throughout the national territory;

- better adaptation of the strategies, priorities and budget programming of the overall MTBF goal to those of the sectoral MTEFs (particularly in detailed sectoral action and financing plans);

- significant reduction of poverty and hunger, especially in rural areas;

- significant improvement of access by the populations, especially the poorest, to basic social services (in terms of quantity and quality);

- creation of a conducive environment for private sector development and pursuance of structural reforms, such as privatizations (CMDT, SOTELMA) ;

- pursuance and acceleration of Government reform in terms of decentralization, deconcentration and public finance.

\section{Strategic Orientations}

83. In order to achieve the overall goal and specific objectives of PRSP II, three strategic orientation pillars were defined: (i) development of the productive sector, (ii) pursuance and consolidation of structural reforms, and (iii) strengthening of the social sector. These objectives will be divided into areas of intervention that would ensure coherence between the key choices 
in terms of medium-term development objectives and annual and multi-year strategies to be defined and implemented at the sectoral and inter-sectoral levels. Furthermore, achievement of PRSP II objectives requires a stable macro-economic framework, as well as sound and transparent management of public resources, which depends on economic and judicial good governance.

\subsection{Development of the Productive Sector}

84. This pillar comprises the following priority areas of intervention:

- Food security and rural development;

- Development of small and medium size enterprises;

- Protection and sustainable management of the environment and natural resources;

- Development of infrastructure;

- Pursuance of reform of the business environment; and

- Development of the financial sector.

85. The last two areas of intervention form part of the structural reforms to be pursued to enable the private sector to better play its role in boosting growth.

86. The creation of wealth, which will help to reduce the poverty, will come from acceleration of economic growth. In Mali, the bases for such growth are mainly: rural production sub-sectors (agriculture, livestock, fisheries, fruits and vegetables, and agro-forestry), mining, trade, tourism, handicraft and culture. These sub-sectors, which constitute the basic elements of the national economy, should play a more important role in the achievement of food security and contribution to wealth creation. It should be noted that the cross-cutting role of energy in all these rural production sub-sectors is fundamental to ensuring sustainable growth in rural areas. The same applies to telecommunications, as well as information and communication technologies (ICT), which have, in the past two years, played a key role in economic activity at all levels, and boosted GDP growth.

87. Promotion of growth through the productive sector will depend on efforts in structural reforms implementation, especially the quality of the business environment, increased private investment, and success of the ongoing privatizations. The Growth Sources Support Project (PASC) will contribute to it by improving the business climate, supporting the establishment of a new investment promotion agency, and providing assistance for the privatization of SOTELMA. Emphasis on the productive sectors will be reflected by the budget allocations of the proposed PTI.

88. In the past, the privatization of public enterprises encountered difficulties due to weaknesses in the preparation of files, problems in negotiation and looking for partners, and delays in the transfer of assets. A guarantee fund and the National Investment Fund still have to be established to meet the financing needs of the private sector. 
89. Competitiveness of the private sector is hampered by: (i) the high cost of transport and infrastructures (nearly $40 \%$ of the cost of an investment project is used for land development alone), and (ii) logistic constraints due to the fact that trade facilitation is not adapted to transport services. National and regional legal instruments will be applied equitably, in particular Regulation No. 14/2005/CM/UEMOA relating to the size and axle load of transport vehicles. Poor management, lack (very often) of quality policy for manufactured products, ignorance of the markets of developed countries and opportunities offered by multilateral and bilateral agreements, and the production equipment which is often dilapidated and poorly maintained are some of the major obstacles for the private sector. Consolidation of the outputs of the WAEMU Programme for the "Establishment of a Quality Accreditation, Standardization and Promotion System" will help to remedy these weaknesses. The same applies to the enhancement of productive capacities through the development of Securities Chains.

90. The Agricultural Orientation Law (LOA) will serve as basis for the general rural development policy of the country by 2025 . It will be the guiding and single instrument for policies relating to agriculture, livestock, fisheries and forestry. The overall goals mainly concern the country's food self-sufficiency or the country's choice to produce the bulk of its food products on its territory by opting for sustainable methods of production, modernization of family farming, development of agro-industry, environmental protection and natural resource management for sustainable development.

91. The private sector needs financial assistance to be effective, and to fully play its role. All poverty reduction policies should take into account the need to broaden access to financial services so as to eliminate one of the major constraints on the economic and social development of the poorest population, namely financial capital. The PDSF should improve the viability of the financial sector, make it more efficient and competitive so that it can sustain diversified growth of the private sector.

92. Concerning the other sectors (trade, handicraft, tourism and culture), efforts will be made to improve productivity levels by establishing industrial, transport and communication facilities, diversifying them and pursuing the gradual transfer of some functions to the private sector within an enabling environment for investment.

\subsection{Consolidation of Public Sector Reforms}

93. This pillar comprises the following priority areas of intervention:

- Consolidation of public administrative reform;

- Pursuance of reform of the business environment;

- Development of the financial sector;

- Promotion of democratic governance and public freedoms;

- Capacity building for the civil society; and

- Strengthening of regional and sub-regional integration initiatives. 
94. In order to achieve the development goals, the Republic of Mali will pursue the implementation of reforms on the structure and functioning of the Government and its institutions. To that end, the Government will place the concerns of users at the core of institutional reforms that will be conducted by the Institutional Development Programme (PDI). This Programme seeks to carry out profound changes in public management. The reforms, some of which were initiated several years ago, should be reinforced during PRSP II implementation. Concrete results were achieved in terms of institutional change by the end of PRSP I, but major difficulties were noted in the ensuring consistency between the choices for reforms and their implications on the strategies and programmes of productive and social sectors.

95. In PRSP I, "institutional development, improvement of governance and participation" appears as the primary strategic pillar to achieve the poverty reduction objective. This option, which paved the way for profound change in public management, can, in view of the outputs, focus on the following pillars: (i) decentralization and deconcentration of administrative services to bring the administration closer to the people, and therefore make it more efficient; (ii) reform of justice to reinforce the rule of law, (iii) fight against corruption, (iv) improvement and modernization of public finance management, and $(\mathrm{v})$ reform of the financial sector to enhance efficiency in the business environment. In addition to these pillars, mention should also be made of regional and sub-regional integration, which is a choice made by Mali since its independence.

96. In public finance, more particularly, many measures were taken during PRSP I: (i) harmonization of the salary scales of all public service corps, and review of the retirement age, (ii) significant increase of some items contrary to initial trends (particularly, communication and energy expenses) so as to take into account the real level of consumption of public services and avoid outstanding payments prejudicial to SOTELMA and EDM, (iii) internal resources-financed capital expenditure has increased significantly because of the start of projects and programmes totally financed with national resources, and the youth employment and low-cost housing programme. The structure of budget allocations has, however, remained consistent with the guidelines of the Poverty Reduction Strategy Paper, despite coverage of (i) the deficit of the cotton sub-sector, (ii) the payment of extra-budgetary arrears audited with the agreement of development partners, (iii) exceptional subsidy to EDM, and (iv) reimbursement of VAT credits and tax expenditure relating to exemptions for hydrocarbons, particularly for mining companies.

97. In the PRSP II macro-economic framework, the budget policy will continue with adjustment efforts to improve revenue, control public expenditure and search for external financing in accordance with budget support modalities and commitments of the Geneva Round Table of 30-31 March 2004.

98. Budgetary aid is the instrument for financial cooperation between the Government of Mali and TFPs which makes it possible to: (i) better coordinate their activities and gradually substitute the multiple donor procedures with national procedures, and (ii) examine concrete ways of harmonizing programmes and procedures, so as to prepare gradual reorientation of part of international aid in the form of programme aid through the budget. 
99. As regards the mining sector, a single Mining Code will be adopted to control tax assessment and ad valorem tax rate, as well as fine-tune the conditions for paying dividends. Improvement of revenue necessarily requires closer monitoring of the State portfolio, review of existing texts for better definition of land revenues, determination of an ad valorem rate for all mining companies. It also requires effective representation of the Government in the Boards of Directors, and timely communication of the conclusions of these boards.

100. During PRSP II, the salary policy will remain unchanged, and will, through a systematic approach, be integrated into the budget process on the basis of some key indicators (available resources, cost of living, comparisons with the private sector, productivity and priority objectives). The scope of these salary increases should be linked to structural reform efforts. To that end, incentive structures will be established to: (i) promote merit rather than seniority, (ii) streamline bonuses and allowances, (iii) relax salary scales so as to offer appropriate motivation to qualified staff, and (iv) mainstream poverty reduction objectives, such as services in remote areas.

\subsection{Strengthening of the Social Sector}

101. This pillar comprises the following priority areas of intervention:

- creation and promotion of long-term jobs;

- development of access to basic social services; and

- HIVIAIDS control.

102. Economic development requires sustained social development and achievement of the MDGs, which mainly implies continuation of the efforts made during PRSP I in education, health, solidarity, social protection and well-being of the Malian populations. The MDGs cannot be achieved without making a link between the indispensable contribution of energy (lighting, cooking, refrigeration, communication, motive force, pumping) and all rural productive sectors.

103. Creation and access to jobs, especially for the youths, as well as job security are major concerns for all Malian families. Implementation of the National Employment Policy (PNE) will help to solve the problem of unemployment. A long-term solution for this problem requires that training should be tailored to labour market needs.

104. The consolidation of peace and security throughout the country, along with pursuance of dialogue with social partners under the Solidarity Pact for Growth and Development (see Box 1) is a top priority for the Government in its efforts to achieve the objective of decent work in Mali. 
The administrative reform in Mali from 1969 to 1990 was aimed primarily at reducing the recurrent costs of the Administration in the State Budget. This approach, which was praiseworthy in itself, was implemented by reducing the number and size of public services, introducing organizational frameworks, liquidating structurally deficit public enterprises, etc. The main criticism against the reform process in Mali is that it ignores the human aspect. Indeed, the reform never really addressed the issue of motivation for Government employees. Essential notions, such as management of rare skills that remained in the public sector after the voluntary separations, were never clearly addressed.

Indeed, the salaries of Malian government employees (despite efforts made by the Government since 1991) have remained low, and are among the lowest in the sub-region. In addition, with the support of powerful trade unions or under the guise of special factors, some categories of Government employees were granted very attractive salary scales or bonuses and allowances of amounts often above the salaries of their counterparts in other sectors. These iniquities were coupled with widespread demotivation.

The Government of Mali, in the social dialogue precedent to implementation of the National Economic Development Programme, proposed the preparation of a Solidarity Pact for Growth and Development to social partners in its General Policy Statement of 6 May 2000. The Pact, adopted following discussions, is designed as a programme of action and contains the following elements:

1. In order to improve living and working conditions, the Government proposes to develop a single salary scale for all civil servants, except special status for certain corps (Magistrates, Army, and Police) and higher education.

2. Furthermore, in implementing the organizational frameworks, the Government undertakes to: (i) recruit an adequate number of civil servants; (ii) provide training and further training to staff of the administration; and (iii) prepare a career plan for each corps of civil servants.

3. As regards social security, measures will be taken to establish a real social security plan for civil servants, review texts relating to coverage of medical expenses for old people, improvement of the level of pensions, and stabilization of the financial situation of organizations responsible for paying social benefits.

4. To ensure safety for employees at work, the Pact provides a series of measures to protect workers against aggressions by users and risks of occupational accident.

5. The trade unions undertake to take measures to increase the output and quality of service by workers.

All the commitments made in the Pact will be implemented within a multi-year programme according to a schedule, updated each year. These measures are intended to improve the quality of remuneration within a context of sub-regional integration and fight against corruption. 
105. Studies show that limited access to basic public services is one of the main causes of the situation of poverty. Improved access to basic social services (education, health, drinking water, and decent housing) will help to strengthen the social sector. It is also important to note that decentralization and support for institutional devolution to the local level are conditions for achievement of the MDGs. The MDGs should have quantified targets as regards access to energy and telecommunication services (Television, Radio, Telephone, Internet, and Post Office).

106. The fight against HIVIAIDS and the worst forms of child labour, the promotion of gender through greater empowerment of women in public management, and the promotion of solidarity with the underprivileged social groups are conditions for equitable, harmonious and sustainable development.

107. Under PRSP I, several actions were proposed to integrate demographic variables, which would allow for achievement of the objectives of the national population policy, namely issues relating to HIVIAIDS, the needs and rights of youths, the needs and rights of old people, the vulnerable groups of the population, and access to basic services. On the other hand, some issues relating to population trends were not developed. PRSP II provides for better mainstreaming of: (i) control of population growth with advocacy to policy makers and opinion leaders, (ii) the crucial problem of external and internal migratory flows, as well as transfers of funds by Malians from abroad, (iii) gender equity and equality, (iv) the role of communities in PRSP II implementation, ( $v$ ) the issue of inequalities between the regions, (vi) environmental issues, and (vii) the territorial development policy.

108. Since 2006, Mali has a National Programme for combating the worst forms of child labour. The programme, which covers the 2006-2010 period, includes measures to prevent the involvement of children in actions identified as one of the worst forms, as well as measures intended to withdraw, protect and ensure the socio-economic reintegration of children. The programme seeks to establish a link between the strategic orientations of the fight against child labour, PRSP II and the various sector policies, such as those for education, health and justice.

\section{MACROECONOMIC AND BUDgetARY FRAMEWORK 2007 - 2011}

\subsection{Assumptions of Framework Estimates}

109. The main objective of the macro-economic and budgetary framework is to maintain macro-economic and budget balances, taking into account the real potential of the Malian economy, as well as PRSP overall and sector goals.

110. To that end, a voluntarist scenario was selected to guide the preparation of sector policies and implementation of the country's development policies by 2011. This voluntarist scenario (known as PRSP II scenario) makes assumptions of highest growth for growth-oriented sector, namely $7 \%$ per year on average, and enhanced tax system complying with the target of WAEMU tax pressure rate of $17 \%$ at least as from 2008 .

111. The macro-economic framework was prepared by the Forecasts and Modelling Committee (CPM). The modelling and macro-economic framework was based on the Macro-economic Model of Mali (MME) and the 
medium and long-term forecast and simulation model Threshold 21 (T21). Details of the macro-economic framework are presented in ANNEX I.

112. The overall Medium-Term Budgetary framework (MTBF) was based on the results of the macro-economic framework (ref. ANNEX II).

113. The macro-economic and budgetary frameworks take into account the strengths and weaknesses of the first PRSP, and are based on the real productive capacity of the national economy, as well as internal and external potential risks. They also take into account the major international and regional development objectives, in particular, Mali's commitments to the MDGs and WAEMU.

114. The assumptions of the macro-economic framework on the international environment, regarding commodity prices, world inflation, and exchange rates, refer to IMF projections.

115. The analysis between economic growth and poverty using model T21 shows that with the current structure of the Malian economy, an average growth rate of $6.5 \%$ (in terms of GDP at factor costs) in five years would help to reduce the rate of monetary poverty by 6 percentage points by 2011 , representing an annual decline of $1.2 \%$.

\subsection{Main Results of the Framework}

The Table below presents the major results (voluntarist scenario).

Table 1: Indicators of Macro-economic Performance and Decision-making Criteria

\begin{tabular}{|c|c|c|c|c|c|c|c|c|}
\hline & $\begin{array}{l}\text { Average } \\
2002- \\
2005\end{array}$ & 2006 & 2007 & 2008 & 2009 & 2010 & 2011 & $\begin{array}{l}\text { Average } \\
2007-2011\end{array}$ \\
\hline \multicolumn{9}{|l|}{$\begin{array}{l}\text { Resources and Appl. of Funds for Goods \& } \\
\text { services }\end{array}$} \\
\hline GDP at market prices (current CFAF billion) & 2550.3 & 3205.8 & 3419.4 & 3653.0 & 3895.0 & 4196.9 & 4493.8 & 3931.6 \\
\hline GDP at market prices (current $\$$ billion) & 4.5 & 6.1 & 6.7 & 7.0 & 7.7 & 8.3 & 9.0 & 7.8 \\
\hline GDP at market prices (current $€$ billion) & 3.9 & & & & & & & \\
\hline Contribution of informal sector to GDP (in \% GDPf) & $39.9 \%$ & $38.0 \%$ & $38.0 \%$ & $38.0 \%$ & $39.0 \%$ & $39.0 \%$ & $39.0 \%$ & $38.6 \%$ \\
\hline Real growth rate of GDP at market prices & $5.2 . \%$ & $3.6 \%$ & $7.0 \%$ & $6.6 \%$ & $6.5 \%$ & $7.8 \%$ & $7.1 \%$ & $7.0 \%$ \\
\hline Real growth rate of GDP at factor costs & $4.6 \%$ & $4.4 \%$ & $6.5 \%$ & $6.1 \%$ & $6.2 \%$ & $6.7 \%$ & $6.8 \%$ & $6.5 \%$ \\
\hline - Primary sector GDP & $4.7 \%$ & $5.0 \%$ & $5.5 \%$ & $5.6 \%$ & $5.6 \%$ & $5.7 \%$ & $5.9 \%$ & $5.7 \%$ \\
\hline - Secondary sector GDP & $5.3 \%$ & $5.9 \%$ & $7.1 \%$ & $6.0 \%$ & $6.4 \%$ & $6.7 \%$ & $7.0 \%$ & $6.6 \%$ \\
\hline - Tertiary sector GDP & $4.8 \%$ & $2.9 \%$ & $7.2 \%$ & $6.8 \%$ & $6.7 \%$ & $7.7 \%$ & $7.5 \%$ & $7.2 \%$ \\
\hline Total GFCF ( current CFAF billion) & 443.8 & 671.6 & 659.1 & 717.8 & 780.8 & 851.9 & 937.6 & 789.4 \\
\hline -Private GFCF (current CFAF billion) & 255.9 & 351.7 & 376.7 & 400.7 & 425.9 & 454.4 & 505.2 & 432.5 \\
\hline -Public GFCF (current CFAF billion) & 188.0 & 319.9 & 282.5 & 317.2 & 354.9 & 397.6 & 432.4 & 356.9 \\
\hline Gross investment rate (I/GDPm) & $21.4 \%$ & $21.4 \%$ & $19.7 \%$ & $20.1 \%$ & $20.5 \%$ & $20.7 \%$ & $21.2 \%$ & $20.4 \%$ \\
\hline Fixed investment rate (GFCF/GDPm) & $17.6 \%$ & $20.9 \%$ & $19.3 \%$ & $19.7 \%$ & $20.0 \%$ & $20.3 \%$ & $20.9 \%$ & $20.0 \%$ \\
\hline Public GFCF in $\%$ of GDPm & $7.4 \%$ & $10.0 \%$ & $8.3 \%$ & $8.7 \%$ & $9.1 \%$ & $9.5 \%$ & $9.6 \%$ & $9.0 \%$ \\
\hline Private GFCF in $\%$ of GDPm & $10.2 \%$ & $11.0 \%$ & $11.0 \%$ & $11.0 \%$ & $10.9 \%$ & $10.8 \%$ & $11.2 \%$ & $11.0 \%$ \\
\hline Marginal capital coefficient & 14.5 & 2.0 & 3.2 & 2.9 & 3.0 & 2.6 & 2.9 & 2.9 \\
\hline Internal savings rate (in \% of GDPm) & $15.2 \%$ & $15.9 \%$ & $13.9 \%$ & $14.4 \%$ & $15.0 \%$ & $14.5 \%$ & $14.1 \%$ & $14.4 \%$ \\
\hline External savings rate (= balance of BP/GDPm res.) & $6.2 \%$ & $5.5 \%$ & $5.8 \%$ & $5.7 \%$ & $5.4 \%$ & $6.1 \%$ & $7.1 \%$ & $6.0 \%$ \\
\hline Gross national savings rate (in \% of GDPm) & $14.8 \%$ & $17.1 \%$ & $15.1 \%$ & $15.2 \%$ & $15.7 \%$ & $15.3 \%$ & $14.8 \%$ & $15.2 \%$ \\
\hline Consumption rate (in \% of GDPm) & $84.8 \%$ & $84.1 \%$ & $86.1 \%$ & $85.6 \%$ & $85.0 \%$ & $85.5 \%$ & $85.9 \%$ & $85.6 \%$ \\
\hline -Private consumption rate & $73.4 \%$ & $71.2 \%$ & $73.4 \%$ & $73.5 \%$ & $73.0 \%$ & $73.4 \%$ & $73.7 \%$ & $73.4 \%$ \\
\hline -Public consumption rate & $11.4 \%$ & $12.9 \%$ & $12.7 \%$ & $12.1 \%$ & $12.0 \%$ & $12.0 \%$ & $12.2 \%$ & $12.2 \%$ \\
\hline $\begin{array}{l}\text { Per capita Gross National Product in current CFAF } \\
\text { Per capita Gross National Product in constant CFAF }\end{array}$ & 225096 & 269324 & 279650 & 289717 & 300315 & 315076 & 328400 & 302632 \\
\hline (1987) & 112020 & 119061 & 123426 & 127589 & 132145 & 138647 & 144573 & 133276 \\
\hline Per capita real growth rate of Gross National Product & $2.6 \%$ & $2.5 \%$ & $3.7 \%$ & $3.4 \%$ & $3.6 \%$ & $4.9 \%$ & $4.3 \%$ & $4.0 \%$ \\
\hline Per capita Gross National Product in US \$ & 395 & 516 & 548 & 571 & 595 & 627 & 656 & 599 \\
\hline \multicolumn{9}{|l|}{ Balance of Payments } \\
\hline Import rate (in $\%$ of GDPm) current prices & $33.7 \%$ & $32.4 \%$ & $33.6 \%$ & $33.6 \%$ & $33.7 \%$ & $33.5 \%$ & $33.5 \%$ & $33.6 \%$ \\
\hline Export rate (in \% of GDPm) current prices & $27.5 \%$ & $26.9 \%$ & $27.8 \%$ & $28.0 \%$ & $28.2 \%$ & $27.3 \%$ & $26.4 \%$ & $27.5 \%$ \\
\hline Trade deficit (fob) in \% of GDPm & $-0.3 \%$ & $-1.1 \%$ & $-1.1 \%$ & $-1.1 \%$ & $-1.1 \%$ & $-1.7 \%$ & $-2.5 \%$ & $-1.5 \%$ \\
\hline Balance of resources (X-Mcaf) in \% of GDPm & $-6.2 \%$ & $-5.5 \%$ & $-5.8 \%$ & $-5.7 \%$ & $-5.4 \%$ & $-6.1 \%$ & $-7.1 \%$ & $-6.0 \%$ \\
\hline \multirow[t]{2}{*}{ Current account (excl. off. Transf) in \% of GDPm } & $-8.6 \%$ & $-7.4 \%$ & $-7.3 \%$ & $-7.0 \%$ & $-6.7 \%$ & $-7.3 \%$ & $-8.2 \%$ & $-7.3 \%$ \\
\hline & $-6.6 \%$ & $-4.3 \%$ & $-4.6 \%$ & $-4.9 \%$ & $-4.7 \%$ & $-5.4 \%$ & $-6.4 \%$ & $-5.2 \%$ \\
\hline Net reserves in months of import caf & 5.5 & 5.7 & 5.6 & 5.6 & 5.4 & 5.3 & 5.3 & 5.4 \\
\hline Gross reserves in months of imports caf & 8.3 & 7.8 & 7.6 & 7.5 & 7.2 & 6.9 & 6.9 & 7.2 \\
\hline Debt service ratio in $\%$ of exports B \& SNF & $8.1 \%$ & & & & & & & \\
\hline \multicolumn{9}{|l|}{ Public Finance } \\
\hline Tax pressure rate (=Tax revenue/GDPm) & $14.6 \%$ & $14.7 \%$ & $14.9 \%$ & $17.0 \%$ & $17.0 \%$ & $17.0 \%$ & $17.2 \%$ & $16.6 \%$ \\
\hline Tax rate (current revenue, excl. grants, in $\%$ of GDP) & $17.2 \%$ & $16.8 \%$ & $17.0 \%$ & $19.7 \%$ & $19.7 \%$ & $19.7 \%$ & $19.9 \%$ & $19.2 \%$ \\
\hline
\end{tabular}




\begin{tabular}{|c|c|c|c|c|c|c|c|c|}
\hline & $\begin{array}{l}\text { Average } \\
2002- \\
2005\end{array}$ & 2006 & 2007 & 2008 & 2009 & 2010 & 2011 & $\begin{array}{l}\text { Average } \\
2007-2011\end{array}$ \\
\hline Tax rate (current revenue in $\%$ of GDP formal sector) & $47.7 \%$ & $49.0 \%$ & $49.5 \%$ & $57.5 \%$ & $56.3 \%$ & $56.9 \%$ & $57.7 \%$ & $55.6 \%$ \\
\hline Total expenditure and net loans, in $\%$ of GDP & $23.8 \%$ & $27.0 \%$ & $27.3 \%$ & $27.0 \%$ & $26.9 \%$ & $26.9 \%$ & $27.1 \%$ & $27.0 \%$ \\
\hline Balance of current operations (national public & $7.3 \%$ & $40.5 \%$ & $8.1 \%$ & $10.6 \%$ & $10.5 \%$ & $10.6 \%$ & $10.7 \%$ & $10.1 \%$ \\
\hline savings) in \% of GDP & & $3.5 \%$ & $3.6 \%$ & $6.4 \%$ & $6.5 \%$ & $6.5 \%$ & $6.6 \%$ & $5.9 \%$ \\
\hline Balance of current operations (own savings) in $\%$ of & $3.9 \%$ & $4.2 \%$ & $4.0 \%$ & $6.7 \%$ & $6.8 \%$ & $6.8 \%$ & $6.9 \%$ & $6.2 \%$ \\
\hline GDP & & $0.6 \%$ & $0.2 \%$ & $2.9 \%$ & $2.9 \%$ & $3.0 \%$ & $3.1 \%$ & $2.4 \%$ \\
\hline Primary balance (=own public savings excl. interests) & $4.6 \%$ & $-0.6 \%$ & $-1.3 \%$ & $1.3 \%$ & $1.4 \%$ & $1.5 \%$ & $1.6 \%$ & $0.9 \%$ \\
\hline in $\%$ of GDPm & & $-10.2 \%$ & $-10.2 \%$ & $-7.3 \%$ & $-7.2 \%$ & $-7.1 \%$ & $-7.1 \%$ & $-7.8 \%$ \\
\hline Primary budget balance (IMF) in \% of GDP & 1.4 & $27.3 \%$ & $-5.3 \%$ & $-2.8 \%$ & $-2.9 \%$ & $-2.8 \%$ & $-2.9 \%$ & $-3.4 \%$ \\
\hline Primary budget balance (WAEMU) in \% of GDP & $0.2 \%$ & $27.3 \%$ & $-5.3 \%$ & $-2.8 \%$ & $-2.9 \%$ & $-2.8 \%$ & $-2.9 \%$ & $-3.4 \%$ \\
\hline Tot. balance (commit. base) excl. grants in $\%$ of GDP & $-6.7 \%$ & & & & & & & \\
\hline Tot. balance (commit. base) incl. grants in $\%$ of GDP & $-2.6 \%$ & & & & & & & \\
\hline Total balance (cash base) in \% of GDP & $-2.5 \%$ & & & & & & & \\
\hline \multicolumn{9}{|l|}{ Monetary Situation } \\
\hline Treasury debt (growth rate) & $35.8 \%$ & $280.6 \%$ & $-36.1 \%$ & $117.4 \%$ & $62.6 \%$ & $51.6 \%$ & $38.2 \%$ & $46.7 \%$ \\
\hline Economy debt (growth rate) & $11.4 \%$ & $3.2 \%$ & $-3.3 \%$ & $17.2 \%$ & $19.6 \%$ & $20.5 \%$ & $17.6 \%$ & $14.3 \%$ \\
\hline Growth of money supply & $15.2 \%$ & $1.5 \%$ & $5.3 \%$ & $5.4 \%$ & $5.3 \%$ & $6.2 \%$ & $5.6 \%$ & $5.5 \%$ \\
\hline Money circulation velocity (GDP/MS, end of period) & 3.4 & 3.8 & 3.8 & 3.9 & 3.9 & 4.0 & 4.0 & 3.9 \\
\hline Liquidity rate (MS/GDPm) & $29.4 \%$ & $26.6 \%$ & $26.3 \%$ & $25.9 \%$ & $25.6 \%$ & $25.2 \%$ & $24.9 \%$ & $25.6 \%$ \\
\hline \multicolumn{9}{|l|}{ Prices and exchange rate } \\
\hline World inflation (MUV) & $3.5 \%$ & $1.6 \%$ & $1.2 \%$ & $1.2 \%$ & $1.2 \%$ & $1.2 \%$ & $1.2 \%$ & $1.2 \%$ \\
\hline Consumer price index of Bamako households & $1.8 \%$ & $2.4 \%$ & $0.2 \%$ & $0.5 \%$ & $0.3 \%$ & $0.2 \%$ & $0.2 \%$ & $0.3 \%$ \\
\hline GDP deflator (growth rate) & $1.9 \%$ & $6.3 \%$ & $0.2 \%$ & $0.2 \%$ & $0.1 \%$ & $0.0 \%$ & $0.0 \%$ & $0.1 \%$ \\
\hline Terms of trade $(1987=100)$ & 69.2 & 73.8 & 78.2 & 81.7 & 85.3 & 86.6 & 86.7 & 83.7 \\
\hline Exchange rate CFAF/SDR (end of period) & 787.4 & 756.7 & 738.9 & 734.9 & 731.7 & 728.6 & 725.7 & 732.0 \\
\hline Exchange rate CFAF/US\$ (end of period) & 547.0 & 522.3 & 509.9 & 507.2 & 505.0 & 502.9 & 500.8 & 505.2 \\
\hline Exchange rate CFAF/US\$ (mid period) & 582.2 & 522.3 & 509.9 & 507.2 & 505.0 & 502.9 & 500.8 & 505.2 \\
\hline Exchange rate $\mathrm{CFAF} / €$ (mid period) & 656.0 & 656.0 & 656.0 & 656.0 & 656.0 & 656.0 & 656.0 & 656.0 \\
\hline $\begin{array}{l}\text { Real exchange rate index (IP_M/IP_GDP; + } \\
\text { devaluation) }\end{array}$ & 126.7 & 125.9 & 123.5 & 122.9 & 122.7 & 122.5 & 122.4 & 122.8 \\
\hline \multicolumn{9}{|l|}{ External Aid } \\
\hline External aid (gross) in \% of GDP & $9.2 \%$ & $46.5 \%$ & $10.5 \%$ & $10.1 \%$ & $10.0 \%$ & $10.0 \%$ & $10.0 \%$ & $10.1 \%$ \\
\hline External aid (net) in \% of GDP & $7.2 \%$ & $12.7 \%$ & $9.6 \%$ & $9.2 \%$ & $9.0 \%$ & $9.0 \%$ & $9.0 \%$ & $9.2 \%$ \\
\hline External aid (gross) in US\$ million & 407.0 & 2853.8 & 706.7 & 728.6 & 769.3 & 834.0 & 896.6 & 787.0 \\
\hline External aid (net) in US\$ million & 319.3 & 778.9 & 643.2 & 660.5 & 696.0 & 754.2 & 809.9 & 712.8 \\
\hline External aid (gross) in US\$ per capita & 36.0 & 236.8 & 57.1 & 57.3 & 58.9 & 62.2 & 65.0 & 60.1 \\
\hline External aid (net) in US\$ per capita & 28.2 & 64.6 & 52.0 & 52.0 & 53.3 & 56.2 & 58.8 & 54.4 \\
\hline $\begin{array}{l}\text { WAEMU Convergence Criteria } \\
\text { First rank criteria }\end{array}$ & & 2006 & 2007 & 2008 & 2009 & 2010 & 2011 & \\
\hline Base budget balance/GDPm ratio & $0.2 \%$ & $-0.6 \%$ & $-1.3 \%$ & $1.3 \%$ & $1.4 \%$ & $1.5 \%$ & $1.6 \%$ & $0.9 \%$ \\
\hline Inflation rate (IHPC Bamako) & $1.8 \%$ & $2.4 \%$ & $0.2 \%$ & $0.5 \%$ & $0.3 \%$ & $0.2 \%$ & $0.2 \%$ & $0.3 \%$ \\
\hline Outstanding internal and external debt/GDPm ratio & $0.0 \%$ & $0.0 \%$ & $0.0 \%$ & $0.0 \%$ & $0.0 \%$ & $0.0 \%$ & $0.0 \%$ & $0.0 \%$ \\
\hline Incl. outstanding external debt/GDPm & $64.3 \%$ & $23.3 \%$ & $24.9 \%$ & $25.2 \%$ & $23.6 \%$ & $21.1 \%$ & $18.2 \%$ & $22.6 \%$ \\
\hline Variation of internal arrear payments (in CFAF & 0.0 & 0.0 & 0.0 & 0.0 & 0.0 & 0.0 & 0.0 & 0.0 \\
\hline billion) & 0.0 & 0.0 & 0.0 & 0.0 & 0.0 & 0.0 & 0.0 & 0.0 \\
\hline $\begin{array}{l}\text { Variation of external arrear payments (in CFAF } \\
\text { billion) }\end{array}$ & & & & & & & & \\
\hline \multicolumn{9}{|l|}{ Second rank criteria } \\
\hline Wage bill/tax revenue ratio & $30.7 \%$ & $31.7 \%$ & $31.5 \%$ & $28.1 \%$ & $28.2 \%$ & $28.8 \%$ & $28.8 \%$ & $29.1 \%$ \\
\hline Public investments financed with internal & $21.9 \%$ & $25.8 \%$ & $22.5 \%$ & $22.5 \%$ & $22.5 \%$ & $22.5 \%$ & $22.5 \%$ & $22.5 \%$ \\
\hline resources/tax revenue ratio & $-8.6 \%$ & $-7.4 \%$ & $-7.3 \%$ & $-7.0 \%$ & $-6.7 \%$ & $-7.3 \%$ & $-8.2 \%$ & $-7.3 \%$ \\
\hline $\begin{array}{l}\text { Current external deficit excl. public transfers/GDPm } \\
\text { ratio }\end{array}$ & $14.6 \%$ & $14.7 \%$ & $14.9 \%$ & $17.0 \%$ & $17.0 \%$ & $17.0 \%$ & $17.2 \%$ & $16.6 \%$ \\
\hline
\end{tabular}

1) Revenue (excl. grants) less total expenditure (incl. net loans) (excl. capital expenditure with ext. financing and excl. $\mathrm{HIPC}) / \mathrm{GDPm}$

2) Here only BSI investment

Source: DNPD, MME-DNPD model

\subsection{Public Finance}

116. Public finance programming for 2007 corresponds to that of Finance Law 2007. The estimates of the Government Flow of Funds Table (GFFT) for 2008-2011 by the MME model correspond to MTBF projection.

117. The results of the macro-economic framework show significant improvement of tax pressure that ensures achievement of Community standards in public finance, particularly the tax pressure rate of $17 \%$ as from 2008. To comply with this last Community standard and support the assumptions of increased investments, the Government should make more efforts in collecting tax revenues. 
118. With respect to public finance, Government policy would be boosted in the medium term by activities proposed in the Government Action Plan for the Improvement and Modernization of Public Finance Management (PAGAMGFP). This would enhance public finance adjustment efforts through control of expenditure and greater mobilization of internal revenue.

Table 2: Consolidated Budget of Public Finance and its Financing (GFFT)

\begin{tabular}{|c|c|c|c|c|c|c|c|c|}
\hline & $\begin{array}{r}\text { Average } \\
2002- \\
2005\end{array}$ & 2006 & 2007 & 2008 & 2009 & 2010 & 2011 & $\begin{array}{r}\text { Average } \\
2007- \\
2011 \\
\end{array}$ \\
\hline Total revenue and grants & 542.6 & 1740.0 & 749.4 & 881.4 & 935.6 & 1008.0 & 1088.3 & 932.6 \\
\hline Total revenue & 438.5 & 540.0 & 582.4 & 718.6 & 768.6 & 828.5 & 896.3 & 758.9 \\
\hline Budgetary revenue & 398.7 & 497.5 & 535.4 & 663.5 & 708.5 & 765.9 & 829.5 & 700.6 \\
\hline Tax revenue & 373.7 & 469.9 & 509.5 & 621.0 & 662.2 & 713.5 & 773.6 & 655.9 \\
\hline Non-tax revenue & 25.1 & 27.6 & 25.9 & 42.5 & 46.4 & 52.4 & 55.9 & 44.6 \\
\hline Sp. Fd \& suppl. Budgets Revenue & 39.1 & 42.5 & 47.0 & 55.0 & 60.0 & 62.6 & 66.8 & 58.3 \\
\hline Grants & 104.1 & 1200.0 & 167.0 & 162.9 & 167.1 & 179.5 & 191.9 & 173.7 \\
\hline Grants for projects & 67.5 & 81.3 & 93.0 & 102.4 & 110.1 & 119.5 & 129.3 & 110.9 \\
\hline Budgetary grants & 36.6 & 35.8 & 24.8 & 25.0 & 25.2 & 25.3 & 25.5 & 25.2 \\
\hline Sectoral budget support & & 47.2 & 49.2 & 35.5 & 31.8 & 34.7 & 37.1 & 37.7 \\
\hline MDRI debt restructuring & & 1035.7 & 0.0 & 0.0 & 0.0 & 0.0 & 0.0 & 0.0 \\
\hline Expenditure and net loans & 608.5 & 865.6 & 932.3 & 984.5 & 1048.0 & 1127.6 & 1216.7 & 1061.8 \\
\hline Budgetary expenditures & 567.5 & 828.7 & 890.9 & 933.5 & 992.4 & 1069.3 & 1153.9 & 1008.0 \\
\hline Current expenditures & 338.8 & 427.0 & 459.5 & 484.7 & 515.5 & 555.0 & 598.6 & 522.7 \\
\hline Salaries & 114.8 & 149.0 & 160.5 & 174.2 & 186.4 & 205.4 & 222.6 & 189.8 \\
\hline Goods and services & 123.5 & 161.1 & 181.8 & 189.9 & 204.8 & 221.7 & 244.3 & 208.5 \\
\hline Transfers and subsidies & 81.4 & 96.8 & 103.7 & 109.0 & 113.0 & 117.1 & 121.6 & 112.9 \\
\hline Interests due & 19.0 & 20.1 & 13.5 & 11.6 & 11.3 & 10.8 & 10.1 & 11.5 \\
\hline Internal debt & 2.3 & 2.6 & 1.7 & 1.6 & 1.5 & 1.4 & 1.4 & 1.5 \\
\hline External debt & 16.8 & 17.5 & 11.8 & 10.0 & 9.8 & 9.4 & 8.7 & 9.9 \\
\hline Capital expenditure & 228.7 & 401.7 & 431.4 & 448.8 & 476.9 & 514.3 & 555.3 & 485.3 \\
\hline External financing & 146.6 & 280.7 & 295.1 & 303.9 & 322.1 & 351.9 & 382.4 & 331.1 \\
\hline Borrowings & 79.1 & 152.2 & 152.9 & 166.0 & 180.2 & 197.7 & 216.0 & 182.6 \\
\hline Overall grants & 67.5 & 81.3 & 93.0 & 102.4 & 110.1 & 119.5 & 129.3 & 110.9 \\
\hline Sectoral budget support & 0.0 & 47.2 & 49.2 & 35.5 & 31.8 & 34.7 & 37.1 & 37.7 \\
\hline Internal financing 1) & 82.1 & 121.0 & 136.3 & 144.9 & 154.8 & 162.4 & 172.9 & 154.3 \\
\hline Sp. Fd \& Suppl. Budgets Expend. & 39.8 & 42.5 & 47.0 & 55.0 & 60.0 & 62.6 & 66.8 & 58.3 \\
\hline Net loans & 1.2 & -5.6 & -5.6 & -4.0 & -4.4 & -4.3 & -4.0 & -4.5 \\
\hline Primary budget balance (IMF 2) & -23.4 & -44.9 & -54.8 & 37.9 & 42.6 & 52.8 & 62.0 & 28.1 \\
\hline $\begin{array}{l}\text { Overall balance (commits, excl. } \\
\text { grants) }\end{array}$ & -170.0 & -325.6 & 349.9 & -266.0 & -279.5 & -291.1 & -320.4 & -303.0 \\
\hline Overall balance (commitments) & $\begin{array}{c}-165.9 \\
\end{array}$ & 874.4 & $182 . \overline{-}$ & -103.1 & -112.4 & -119.6 & -128.4 & -129.3 \\
\hline Adjustment & 1.8 & 0.0 & 0.0 & 0.0 & 0.0 & 0.0 & 0.0 & 0.0 \\
\hline $\begin{array}{l}\text { Overall balance (cash base } \& \text { excl. } \\
\text { grants) }\end{array}$ & -168.3 & -325.6 & 349.9 & -266.0 & -279.5 & -299.1 & -291.1 & -303.0 \\
\hline Overall balance (cash base) & -64.2 & 874.4 & $\begin{array}{r}- \\
182.9\end{array}$ & -103.1 & -112.4 & -119.6 & -119.6 & -129.3 \\
\hline FINANCING & 64.2 & -874.4 & 182.9 & 103.1 & 112.4 & 119.6 & 119.6 & 129.3 \\
\hline Net external financing & 89.3 & -845.1 & 159.2 & 172.3 & 185.3 & 201.9 & 201.9 & 186.9 \\
\hline Borrowings & 100.6 & 200.7 & 182.9 & 196.0 & 210.2 & 227.7 & 227.7 & 212.6 \\
\hline Projects & 79.1 & 152.2 & 152.9 & 166.0 & 180.2 & 197.7 & 197.7 & 182.6 \\
\hline Budgetary loans & 21.4 & 48.5 & 30.0 & 30.0 & 30.0 & 30.0 & 30.0 & 30.0 \\
\hline Amortization & -39.0 & -1071.7 & -34.2 & -34.4 & -36.1 & -37.9 & -37.9 & -36.8 \\
\hline Debt/HIPC settlement & 27.7 & 25.9 & 10.5 & 10.7 & 11.2 & 12.1 & 12.1 & 11.1 \\
\hline Net internal financing & -25.2 & -43.1 & 23.7 & -69.2 & -72.9 & -82.4 & -82.4 & -57.6 \\
\hline Bank (net) & -3.0 & -34.0 & 36.3 & -76.3 & -88.3 & -118.1 & -118.1 & -75.7 \\
\hline Privatization revenue & 10.3 & 8.1 & 8.1 & 4.0 & 4.0 & 4.0 & 4.0 & 4.8 \\
\hline Other financing & -32.5 & -17.2 & -20.7 & 3.1 & 11.4 & 31.7 & 31.7 & 13.3 \\
\hline Gov't financing gap (+=deficit) & 0.0 & 13.8 & 0.0 & 0.0 & 0.0 & 0.0 & 0.0 & 0.0 \\
\hline
\end{tabular}

1) Banking sector and private sector

2) Revenue (excl. grants) less total expenditure (incl. net loans) (excl. capital expenditure with external financing Source: DNPD, MME-DNPD model 
119. The results of the voluntarist scenario put total revenues (excluding grants) at CFAF 896.3 billion in 2011 as against 540.0 billion in 2006, representing an annual increase rate of $10.7 \%$ (as against $13.0 \%$ in 2002 2005). Tax revenues would increase at an annual average of $10.5 \%$. In view of the average annual tax pressure rate of $14.6 \%$ in $2002-2005$, this indicator would improve significantly; the Community standard would be respected as from 2008 when the tax pressure rate would be $17.0 \%$ and remain at that level until 2011.

120. Effective implementation of the measures contained in PAGAMGFP remains a prerequisite for achievement of this objective.

121. Estimates for total expenditure and net loans are also fully consistent in the macroeconomic framework and the overall MTBF. The macrobudgetary framework provides for an increase in total expenditure and net loans at the average annual rate of $7.0 \%$ to CFAF 1,216.7 billion in 2011.

122. As for the wage bill, it would increase from CFAF 149 billion in 2006 to CFAF 222.6 billion in 2011, representing an average growth rate of $8.4 \%$ as against $12.6 \%$ in $2002-2005$. It would, on average, stand at $29.1 \%$ of tax revenue between 2007 and 2011, as against $30.7 \%$ between 2002 and 2005. Indeed, the WAEMU target of less than $35 \%$ has been amply attained. This also applies to the basic budget balance target, which should be positive. The balance in relation to GDP stands at $0.9 \%$ annual average for $2007-2011$ as against $0.2 \%$ between 2002 and 2005 . The third WAEMU criterion is also observed, namely the ratio of public investments financed with internal resources to GDP, whose minimum threshold is fixed at $20 \%$. The budget estimates give a ratio of $22.6 \%$ on average for the $2007-2001$ period as against $21.9 \%$ in $2002-2005$.

123. The tables below show the sectoral breakdown of budget expenditure in CFAF billion and percentage. It should be noted that this functional breakdown of the DGB and Finance Law is different in certain respects from the GFFT nomenclature; hence the total expenditures (and revenues) are not the same ${ }^{1}$.

Table 3: Sector Breakdown of Expenditures 2007-2011 (in CFAF billion)

\begin{tabular}{|l|l|l|l|l|l|l|}
\hline \multicolumn{1}{|c|}{ SECTORS OF ACTIVITY } & 2006 & 2007 & 2008 & 2009 & 2010 & 2011 \\
\hline $\begin{array}{l}\text { PUBLIC AUTHORITIES AND GENERAL } \\
\text { ADMINISTRATION }\end{array}$ & 115695 & 117318 & 128993 & 133177 & 142494 & 153243 \\
\hline DIPLOMACY AND FOREIGN AFFAIRS & 16714 & 20265 & 20300 & 21778 & 23706 & 25455 \\
\hline $\begin{array}{l}\text { NATIONAL DEFENCE AND INTERNAL } \\
\text { SECURITY }\end{array}$ & 68920 & 75633 & 77290 & 83323 & 93860 & 101587 \\
\hline BASIC EDUCATION & 119322 & 122629 & 135451 & 138575 & 145436 & 159035 \\
\hline $\begin{array}{l}\text { SEC. HIGHER EDUCATION \& SCIENTIFIC } \\
\text { RESEARCH }\end{array}$ & 39169 & 41494 & 44171 & 47763 & 52004 & 56805 \\
\hline CULTURE YOUTH AND SPORTS & 13051 & 13668 & 14780 & 115758 & 17150 & 18126 \\
\hline HEALTH & 72684 & 65307 & 70146 & 72299 & 79797 & 87417 \\
\hline SOCIAL SECTORS & 27849 & 36620 & 38799 & 38976 & 41126 & 43342 \\
\hline EMPLOYMENT & 7636 & 7876 & 7698 & 7045 & 7996 & 8785 \\
\hline AGRICULTURE & 118283 & 131192 & 132908 & 145563 & 158222 & 170297 \\
\hline MINING WATER RESOURCES AND INDUSTRY & 53859 & 68353 & 72882 & 79626 & 85120 & 91030 \\
\hline TOWN PLANNING AND PUBLIC WORKS & 99217 & 115376 & 119051 & 131830 & 140332 & 150908 \\
\hline TRANSPORT & 10570 & 13749 & 14580 & 15969 & 18133 & 19982 \\
\hline COMMUNICATION & 9100 & 10845 & 11945 & 12775 & 13579 & 14487 \\
\hline DOMESTIC DEBT & 1637 & 1748 & 1603 & 1520 & 1446 & 1373 \\
\hline FOREIGN DEBT & 61522 & 34239 & 34410 & 36103 & 37852 & 41513 \\
\hline INTEREST FOREIGN DEBT & 17531 & 11769 & 10042 & 9783 & 9385 & 8671 \\
\hline UNALLOCATED FUNDS & 83002 & 88522 & 79335 & 83189 & 85711 & 89688 \\
\hline & 935759 & 976602 & 1014385 & 1075052 & 1153349 & 1241745 \\
\hline SourCe: DGB & & & & & &
\end{tabular}

\footnotetext{
${ }^{1}$ However, DGB has made reconstitution efforts to present the overall MTBF under the GFFT nomenclature (ref. ANNEX II, Tables 6,7 and 9).
} 
Table 4: Sectoral Breakdown of Expenditure 2007-2011 in \% of Total

\begin{tabular}{|c|c|c|c|c|c|c|}
\hline SECTORS OF ACTIVITY & 2006 & 2007 & 2008 & 2009 & 2010 & 2011 \\
\hline $\begin{array}{l}\text { PUBLIC AUTHORITIES AND GENERAL } \\
\text { ADMINISTRATION }\end{array}$ & 12.4 & 12.0 & 12.7 & 12.4 & 12.4 & 12.3 \\
\hline DIPLOMACY AND FOREIGN AFFAIRS & 1.8 & 2.1 & 2.0 & 2.0 & 2.1 & 2.0 \\
\hline NATIONAL DEFENCE AND INTERNAL SECURITY & 7.4 & 7.7 & 7.6 & 7.8 & 8.1 & 8.2 \\
\hline BASIC EDUCATION & 12.8 & 12.6 & 13.4 & 12.9 & 12.6 & 12.8 \\
\hline $\begin{array}{l}\text { SEC. HIGHER EDUCATION \& SCIENTIFIC } \\
\text { RESEARCH }\end{array}$ & 4.2 & 4.2 & 4.4 & 4.4 & 4.5 & 4.6 \\
\hline CULTURE YOUTH AND SPORTS & 1.4 & 1.4 & 1.5 & 1.5 & 1.5 & 1.5 \\
\hline HEALTH & 7.8 & 6.7 & 6.9 & 6.7 & 6.9 & 7.0 \\
\hline SOCIAL SECTORS & 3.0 & 3.7 & 3.8 & 3.6 & 3.6 & 3.5 \\
\hline EMPLOYMENT & 0.8 & 0.8 & 0.8 & 0.7 & 0.7 & 0.7 \\
\hline AGRICULTURE & 12.6 & 13.4 & 13.1 & 13.5 & 13.7 & 13.7 \\
\hline MINING WATER RESOURCES AND INDUSTRY & 5.8 & 7.0 & 7.2 & 7.4 & 7.4 & 7.3 \\
\hline TOWN PLANNING AND PUBLIC WORKS & 10.6 & 11.8 & 11.7 & 12.3 & 12.2 & 12.2 \\
\hline TRANSPORT & 1.1 & 1.4 & 1.4 & 1.5 & 1.6 & 1.6 \\
\hline COMMUNICATION & 1.0 & 1.1 & 1.2 & 1.2 & 1.2 & 1.2 \\
\hline DOMESTIC DEBT & 0.2 & 0.2 & 0.2 & 0.1 & 0.1 & 0.1 \\
\hline FOREIGN DEBT & 6.6 & 3.5 & 3.4 & 3.4 & 3.3 & 3.3 \\
\hline INTEREST FOREIGN DEBT & 1.9 & 1.2 & 1.0 & 0.9 & 0.8 & 0.7 \\
\hline UNALLOCATED FUNDS & 8.9 & 9.1 & 7.8 & 7.7 & 7.4 & 7.2 \\
\hline TOTAL & 100.00 & 100.00 & 100.00 & 100.00 & 100.00 & 100.00 \\
\hline
\end{tabular}

Source: DGB

\subsection{Public Debt}

124. The Multilateral Debt Relief Initiative (MDRI), which entered into force on 2 January 2006, has a stock estimated at CFAF 64.7 billion under the IMF. Contributions from the World Bank and ADB Group to the same initiative, effective since July 2006, are CFAF 706 billion and about CFAF 265 billion respectively. Indeed, Mali's total multilateral debt has been cancelled; the cancelled debt is estimated at CFAF 1,035.7 billion. The outstanding public debt/ GDP ratio would be $22.6 \%$ on average for the $2007-2011$ period as against $64.3 \%$ in $2002-2005$.

125. Thus the average debt service/exports ratio would stand at $4.4 \%$ between 2007 and 2011, as against $8.1 \%$ between 2002 and 2005 .

126. As for the Treasury, savings from the restructuring of MDRI debt amount to about CFAF 34 billion per year between 2007 and 2011, which is an annual gain of about $3.4 \%$ of budget expenditure (excluding external debt service).

\subsection{Balance of Payments and Monetary Situation}

127. The macro-economic framework provides for an average annual growth rate of $6.6 \%$ for exports and $7.7 \%$ of imports, along with production trends for the major exports (gold and cotton) and their world market prices. Indeed, the average trade deficit would represent $1.5 \%$ of GDP as against $0.3 \%$ over the $2002-2005$ period.

128. The balance of current transactions, excluding public transfers, is expected to be an average of $7.3 \%$ of GDP, as against $8.6 \%$ between 2002 and 2005. This trend would tie in with the improvement in the balance of factor services (decline in payments as interest of debt servicing and repatriations of revenue from investments) and deficit of non-factor services as a result of dynamism of the tourism sector. The balance of current transactions, including grants, would amount to an average of $5.2 \%$ in $2007-$ 2011 as against $6.6 \%$ in $2002-2005$. 
129. Net foreign assets would increase gradually to cover 5.4 months of imports for the net reserve and 7.2 months for the average gross reserve 2007-2011 (as against 5.5 and 8.3 in 2002-2005). They would amount to CFAF 653.5 billion in 2011.

\subsection{External Aid}

130. As regards projections on the volume of external aid, the macroeconomic framework provides for two variants of the voluntarist scenario. The first variant implies that external financing requirements, as expressed in the macro-economic framework, are fully covered. This implies that there is no financing gap. By adopting this optimistic view, the gross external aid requirements (before debt service and HIPC payment) would stand at CFAF 397 billion (US\$ 787 million) per year for the 2007-2011 period. This would correspond to about EURO 606 million per year, as against 355 million in 2002-2005.

131. Since this assumption is considered as too optimistic, an alternative scenario has been created; it is based on the assumption that only $75 \%$ of the foreign financing would be obtained. The table below shows a financing gap of about CFAF 97 billion (US\$ 191 million or EURO 147 million) per year.

Table 5: External Aid Required (in CFAF billion)

\begin{tabular}{|c|c|c|c|c|c|c|c|c|}
\hline & $\begin{array}{l}\text { Average } \\
2002- \\
2005 \\
\end{array}$ & 2006 & 2007 & 2008 & 2009 & 2010 & 2011 & $\begin{array}{l}\text { Average } \\
2007-2011\end{array}$ \\
\hline Total External financial aid required (gross) & 233.0 & 1490.4 & 360.4 & 369.5 & 388.5 & 419.4 & 449.1 & 397.4 \\
\hline $\begin{array}{l}\text { Total grants (BoP, excl. Tech,. Assistance and aid in } \\
\text { kind) }\end{array}$ & 104.7 & 1305.2 & 167.0 & 162.9 & 167.1 & 179.5 & 191.9 & 173.7 \\
\hline Capital grants linked to projects & 68.1 & 186.5 & 93.0 & 102.4 & 110.1 & 119.5 & 129.3 & 110.9 \\
\hline Overall budgetary grants & 36.6 & 35.8 & 24.8 & 25.0 & 25.2 & 25.3 & 25.5 & 25.2 \\
\hline Sectoral budget support & 0.0 & 47.2 & 49.2 & 35.5 & 31.8 & 34.7 & 37.1 & 37.7 \\
\hline MDRI debt restructuring & 0.0 & 1035.7 & 0.0 & 0.0 & 0.0 & 0.0 & 0.0 & 0.0 \\
\hline Total drawings on external loans & 100.6 & 159.3 & 182.9 & 196.2 & 210.2 & 227.7 & 246.0 & 212.6 \\
\hline Budgetary & 21.4 & 48.5 & 30.0 & 30.0 & 30.0 & 30.0 & 30.0 & 30.0 \\
\hline Project loans & 79.1 & 110.8 & 152.9 & 166.2 & 180.2 & 197.7 & 216.0 & 182.6 \\
\hline Reimbursements on public debt & 39.6 & 1071.7 & 34.2 & 34.4 & 36.1 & 37.9 & 41.5 & 36.8 \\
\hline Settlement HIPC debt & 27.7 & 25.9 & 10.5 & 10.7 & 11.2 & 12.1 & 11.1 & 11.1 \\
\hline Total external financial aid (excl. interests) (net) & 165.7 & 392.8 & 315.7 & 324.5 & 341.2 & 369.3 & 396.4 & 349.4 \\
\hline Interests on public external debt & 16.8 & 14.0 & 12.3 & 10.5 & 10.3 & 9.9 & 9.2 & 10.4 \\
\hline Total external financial aid (net) & 182.5 & 406.8 & 328.0 & 335.0 & 351.5 & 379.2 & 405.6 & 259.9 \\
\hline Aid to be sought : financing gap of the budget & 0.0 & 13.8 & 0.0 & 0.0 & 0.0 & 0.0 & 0.0 & 0.0 \\
\hline \multicolumn{9}{|l|}{ External aid (US\$ million) } \\
\hline Total external financial aid required (gross) & 407.0 & 2853.8 & 706.7 & 728.6 & 769.3 & 834.0 & 896.6 & 787.0 \\
\hline $\begin{array}{l}\text { Total grants (BoP, excl. Tech, Assistance and aid in } \\
\text { kind) }\end{array}$ & 184.0 & 2499.1 & 327.5 & 321.1 & 330.8 & 357.1 & 383.3 & 343.9 \\
\hline Capital grants linked to projects & 118.7 & 357.1 & 182.4 & 201.9 & 218.0 & 237.6 & 258.2 & 219.6 \\
\hline Overall budgetary grants & 65.4 & 68.5 & 48.6 & 49.8 & 49.8 & 50.4 & 51.0 & 49.8 \\
\hline Sectoral budget support & 0.0 & 90.4 & 96.5 & 63.0 & 63.0 & 69.0 & 74.1 & 74.5 \\
\hline MDRI debt restructuring & 0.0 & 1983.1 & 0.0 & 0.0 & 0.0 & 0.0 & 0.0 & 0.0 \\
\hline Total drawings on external loans & 174.8 & 305.0 & 358.7 & 416.2 & 416.2 & 452.8 & 491.2 & 421.1 \\
\hline Budgetary & 35.5 & 92.9 & 58.8 & 59.4 & 59.4 & 59.7 & 59.9 & 59.4 \\
\hline Project loans & 139.3 & 212.2 & 299.8 & 356.8 & 356.8 & 393.2 & 431.3 & 361.7 \\
\hline Reimbursements on public debt & 68.7 & 2052.8 & 67.1 & 71.5 & 71.5 & 75.4 & 82.9 & 72.9 \\
\hline Settlement HIPC debt & 48.2 & 49.6 & 20.5 & 22.2 & 22.2 & 24.1 & 22.2 & 22.0 \\
\hline Total external financial aid (excl. interests) (net) & 290.1 & 752.1 & 619.1 & 639.8 & 675.6 & 734.5 & 791.6 & 692.1 \\
\hline Interests on public external debt & 29.2 & 26.8 & 24.1 & 20.7 & 20.4 & 19.7 & 18.4 & 20.7 \\
\hline Total external financial aid (net) & 319.3 & 778.9 & 643.2 & 660.5 & 696.0 & 754.2 & 809.9 & 712.8 \\
\hline Aid to be sought: financing gap of the budget & 0.0 & 26.4 & 0.1 & 0.0 & -0.1 & 0.0 & -0.1 & 0.0 \\
\hline External financial aid (gross) in \% of GDP & $9.2 \%$ & $46.5 \%$ & $10.5 \%$ & $10.1 \%$ & $10.0 \%$ & $10.0 \%$ & $10.0 \%$ & $10.1 \%$ \\
\hline External financial aid (net) in \% of GDP & $7.2 \%$ & $12.7 \%$ & $9.6 \%$ & $9.2 \%$ & $9.0 \%$ & $9.0 \%$ & $9.0 \%$ & $9.2 \%$ \\
\hline External aid (gross) in Euro per capita & 31.5 & 188.5 & 44.4 & 44.3 & 45.4 . & 47.7 & 49.7 & 46.3 \\
\hline External aid (net) in Euro per capita & 22.4 & 49.7 & 38.9 & 38.9 & 39.8 & 42.0 & 43.8 & 40.7 \\
\hline External financial aid (gross) in US\$ per capita & 36.0 & 236.8 & 57.1 & 57.3 & 58.9 & 62.2 & 65.0 & 60.1 \\
\hline External financial aid (net) in US\$ per capita & 28.2 & 64.6 & 52.0 & 52.0 & 53.3 & 56.2 & 58.8 & 54.4 \\
\hline
\end{tabular}

Source: DNPD, MME-DNPD model 
Table 6: Financing Gap

\begin{tabular}{|c|c|c|c|c|c|c|c|c|}
\hline & $\begin{array}{l}\text { Average } \\
2002- \\
2005\end{array}$ & 2006 & 2007 & 2008 & 2009 & 2010 & 2011 & $\begin{array}{l}\text { Average 2007- } \\
2011\end{array}$ \\
\hline Total external financial aid required (gross) & 233.0 & 1490.4 & 272.9 & 279.8 & 294.2 & 317.6 & 339.6 & 300.8 \\
\hline $\begin{array}{l}\text { Total grants (BoP, excl. Tech,. Assistance and aid in } \\
\text { kind) }\end{array}$ & 104.7 & 1305.2 & 125.3 & 122.1 & 125.3 & 134.7 & 144.0 & 130.3 \\
\hline Capital grants linked to projects & 68.1 & 186.5 & 69.8 & 76.8 & 82.6 & 89.6 & 97.0 & 83.1 \\
\hline Overall budgetary grants & 36.6 & 35.8 & 18.6 & 18.7 & 18.9 & 19.0 & 19.2 & 18.9 \\
\hline Sectoral budget support & 0.0 & 47.2 & 36.9 & 26.6 & 23.9 & 26.0 & 27.8 & 28.2 \\
\hline MDRI debt restructuring & 0.0 & 1035.7 & 0.0 & 0.0 & 0.0 & 0.0 & 0.0 & 0.0 \\
\hline Total drawings on external loans & 100.6 & 159.3 & 137.2 & 147.0 & 157.7 & 170.8 & 184.5 & 159.4 \\
\hline Budgetary & 21.4 & 48.5 & 22.5 & 22.5 & 22.5 & 22.5 & 22.5 & 22.5 \\
\hline Project loans & 79.1 & 110.8 & 114.7 & 124.5 & 135.2 & 148.3 & 162.0 & 136.9 \\
\hline Reimbursements on public debt & 39.6 & 1071.7 & 34.2 & 34.4 & 36.1 & 37.9 & 41.5 & 36.8 \\
\hline Settlement HIPC debt & 27.7 & 25.9 & 10.5 & 10.7 & 11.2 & 12.1 & 11.1 & 11.1 \\
\hline Total external financial aid (excl. interests) (net) & 165.7 & 392.8 & 228.2 & 234.7 & 246.8 & 267.5 & 287.0 & 252.9 \\
\hline Interests on public external debt & 16.8 & 14.0 & 12.3 & 10.5 & 10.3 & 9.9 & 9.2 & 10.4 \\
\hline Total external financial aid (net) & 149.0 & 378.8 & 215.9 & 224.2 & 236.5 & 257.6 & 277.8 & 242.4 \\
\hline $\begin{array}{l}\text { Aid to be sought: financing gap of the budget } \\
\text { (CFAF billion) }\end{array}$ & 0.0 & 0.0 & 87.5 & 89.7 & 94.3 & 101.8 & 109.5 & 96.6 \\
\hline $\begin{array}{l}\text { Aid to be sought: financing gap of the budget (US\$ } \\
\text { million) }\end{array}$ & 0.0 & 0.0 & 171.5 & 176.9 & 186.8 & 202.5 & 218.6 & 191.3 \\
\hline $\begin{array}{l}\text { Aid to be sought: financing gap of the budget } \\
\text { (EURO million) }\end{array}$ & 0.0 & 0.0 & 133.4 & 136.8 & 143.8 & 155.2 & 166.9 & 147.2 \\
\hline
\end{tabular}

Source: DNPD, MME-DNPD model

\subsection{Incidence of Poverty}

132. Based on a structural analysis of the Malian economy using the T21 Model, the results of the PRSP II macro-economic framework show that with an average annual GDP economic growth rate at factor cost of $6.5 \%$, the proportion of the population living below the monetary poverty line (CFAF 72,011 at 1987 prices per person and per year) would decline from $56.0 \%$ in 2007 to about $51.2 \%$ in 2011, representing a decline of 5 percentage points in 5 years. This represents an average annual decline of 1.2 point. It should be noted that the monetary poverty rate according to the EMEP was $68.3 \%$ in 2002.

133. This analysis on poverty presupposes an improvement in the distribution of incomes and control of population growth.

134. In view of population growth and taking into account foreign contributions to the national income (current transfers and factor services), the per capita national income would increase on average and in real terms by $4.0 \%$ between 2007 and 2011 as against $2.6 \%$ between 2002 and 2005 , to a level of about CFAF 328,400 at current prices (US\$ 656.) in 2011. 


\section{PRIORITY AREAS OF INTERVENTION}

\subsection{Food Security and Rural Development}

\subsubsection{Food Security}

135. The achievement of food security requires guarantee of supply of foodstuffs to the entire population from domestic production or commercial imports. It is based on a number of key factors such as: (i) availability to facilitate supplies to areas experiencing shortages, (ii) geographic accessibility by opening up production areas, or (iii) stability of production, and (iv) optimum use of foodstuffs in accordance with the millennium goals and the world food summit objectives. It also provides for the inclusion of aspects relating to increase, diversification, and processing of products. Food security will be sought primarily through:

- significant reduction of the impact of major food crises by enhancing and broadening the food crises prevention and management system;

- promotion of sub-sectors relating to agricultural products of plant origin, livestock and animal sub-sectors, fisheries and aquaculture, silviculture, as well as promotion of farm mechanization.

136. As for implementation of the food security strategy, the two programmes below have been prepared in consultation with the technical and financial partners:

- the National Food Security Programme, which aims primarily at enhancing food security in the most vulnerable 166 municipal councils, through small development works, as well as intensification and diversification of production, improvement of the marketing, processing and conservation of products and their better use, and the prevention and management of food crises;

- the Programme to strengthen the National Food Risks Control System, which aims at consolidating and adapting the Cereal Market Restructuring Programme to the new objectives and institutional environment, a successful cooperation experience in the prevention and management of the emergency situations in food security.

\subsubsection{Rural Development}

137. As regards the rural development sectors (agriculture, livestock, fisheries, agro-forestry), the challenges could be summarized as follows:

- reduction of the number of vulnerable municipal councils;

- water availability and control;

- the financing of agriculture ;

- accessibility to factors of production (farm machinery, pest control products, seeds and inputs) ;

- processing, diversification and better marketing of rural produce;

- protection of plants;

- environmental protection and preservation (urban and rural) ; 
- technical supervision and empowerment of rural producers; and

- access to land.

138. The rural development objective is to increase, secure and diversify food production through: (i) development of water control (irrigated agriculture through irrigation schemes, small dams, shallow water, management of pasturelands and water points), along with associated energy services (water drainage, pumping for the irrigation of farm areas, mechanization of agriculture) and (ii) adoption of intensification techniques through:

- facilitation of access to equipment and inputs (mechanization, animal draught, improved seeds, fertilizers, pest control products, animal feed, fodder, as well as agricultural and agro-industrial by-products) ;

- development of access to financing for producers and operators of the subsectors by increasing the availability of financial services (Rural Development Fund, National Agricultural Risks and Disasters Fund, specific lines of credit, guarantee funds, loan refinancing, incentive aid programmes, etc.) and local loan networks;

- opening up of production areas and large rural markets; and

- reinforcement of measures to prevent or control crop pests, major epizootic diseases among cattle, and poultry.

139. Under the MCA, the agricultural planning and farming in the Kouroumari water system of 16000 ha for private farms, and the construction of the Niono-Goma Coura road covering a distance of eightyone (81) kilometers will help to put in place a pilot framework for promoting innovative farming and investment models. This reinforcement of production capacities in the Niger Authority zone, in cooperation with MCC, will help to reduce poverty and improve the living environment of the populations. The objective of this component is to increase the incomes of farmers in Alatona through extension of irrigation schemes, land security, increased farm areas, diversification, intensification, and reduced transport costs.

140. The promotion of rural employment and fight against youth unemployment as defined in the LOA remain a common basic objective for all agricultural and food sector policies and strategies. The objective will be achieved in the agricultural, animal, piscicultural and forestry sub-sectors, which absorb job-seekers, and fruitful points of convergence between them and all categories of job-seekers will be established.

141. The rural development sectors, which are the real engines of economic growth in Mali, should, during the 2007-2011 period, contribute to the achievement of food security and increased incomes for rural producers, and therefore better living conditions for the rural population. To that end, the Government recently adopted an Agricultural Orientation Law (LOA), in addition to the Rural Development Master Plan (SDDR).

142. In addition to these orientation tools, the priority areas selected to ensure that the rural development sector contributes to the achievement of PRSP II objectives, are:

- the development of agricultural, pastoral, piscicultural and forestry production sub-sectors;

- the promotion of appropriate farm mechanization;

- the protection and management of natural resources and wildlife; 
- pursuance of programmes for small schemes, intensification, diversification of production, improvement of marketing and processing, conservation and better use of products, as well as prevention and management of food crises; and

- promotion of rural jobs and fight against youth unemployment.

143. The measures accompanying these priority areas concern: (i) creation of a legal and institutional framework conducive to development of the rural sector, (ii) development of access to the financing of family farm producers and sub-sector operators, (iii) assistance to the sub-sectors through research/dissemination geared towards the demands of producers and the market, and in an environment-friendly manner, and (iv) opening up of production areas and large rural markets.

\subsection{Development of SMEs and SMIs}

144. SME-SMls will be developed by creating and promoting efficient and competitive handicraft and industrial plants for the processing and marketing of agricultural and mining products. The objective of this area of intervention should be to create or increase the value added of these products, which are mainly exported as primary products. The availability of energy is a prerequisite for the competitiveness of SME-SMIs. The development of national markets and the conquest of new markets abroad should be the objectives in this area. This will make it possible to create and promote many stable jobs for youths, and contribute to integrating women more into the national economy. The new basins for creating SME-SMIs are in NICTs, tourism and telephony trades. The preparation of a real Ten-year Private Sector Development Programme and adoption of a SME-SMI Charter in Mali will offer a coherent framework for private sector development, and particularly SME-SMIs.

\subsection{Management of the Environment and Natural Resources}

145. Environmental protection and better management of natural resources require the implementation of decentralized and participatory management of renewable natural resources.

146. This would consist in: (i) creating stations for the purification or depollution of liquid, solid and gaseous waste from industrial and handicraft plants in major towns, (ii) promoting the restoration and reclamation of deteriorated areas and sites, (iii) laying emphasis on the preparation of Natural Resource Management Plans, as well as local agreements for decentralized management, (iv) strengthening the control, monitoring and continued supervision mechanisms for the environment, and (v) capacity building for intervention, analysis, and communication.

147. To achieve sustainable development, the major challenges for Mali as regards the environment are:

- mainstreaming of the environment in all sectoral policies and development planning at all levels (national, regional and local);

- control of desertification and silting of waterways, in particular the Niger river; and

- protection of wildlife and aquatic species. 
148. PRSP II should contribute to achievement of the objective of the National Environmental Protection Policy, which aims at ensuring sustainable economic and social development of the country through food security, as well as the fight against all forms of pollution or nuisance, deterioration of natural resources, and desertification.

149. The strategic pillars of this national policy are: (i) preservation and strengthening of technical and methodological outputs in environmental protection, (ii) promotion of an overall and multisectoral approach to environmental issues, and (iii) promotion, restoration and reclamation of deteriorated areas and sites.

150. The attendant measures proposed for this policy are: (i) strict implementation and close monitoring of legal instruments relating to environmental management, (ii) capacity building for institutions and stakeholders in environmental management, and (iii) information and sensitization.

151. Over the next five years, efforts need to be made to ensure coherent implementation of priority programmes and actions identified through the PNAE, as well as to give the legal framework for managing environmental issues the means to carry out its missions, namely coordination of activities, systematic capacity building for stakeholders in environmental protection, and the fight against desertification and land degradation.

\subsection{Consolidation of Public Administration Reforms}

\subsubsection{Decentralization and Deconcentration}

152. In opting for decentralization, Malians decided to embark on profound reform of public administrations through the establishment of local and regional administrative authorities (decentralized local authorities) and empowering them through elected organs to design and manage the structures, thereby giving them ownership of regional and local development.

153. Although a review of the implementation of the decentralization process since the installation of local authorities in 1999 and 2000 shows some indisputable progress, there are also persistent difficulties. These difficulties are mainly related to: (i) delays in the transfer of ownership of local and regional development to the local authorities; in fact, these delays hamper the transfer of powers, property and resources (human and financial) despite the political will expressed in all the laws and regulations adopted; (ii) difficulties in ensuring consistency between the sectoral strategies at the national level and the choices and priorities of the local and regional authorities; (iii) difficulties of the supervisory authorities, especially at the decentralized level, to appropriately carry out their missions of advisory support services, monitoring and control for the decentralized local authorities; (iv) the low capacity of human resources and low mobilization of human and financial resources at the local level; (v) excessive concentration, at the central level, of human resources and decisions for implementation of public expenditure, (vi) inadequate involvement of the civil society, as custodian of rights and duties towards Local Authorities and representative of local authorities (HCCT, AMM, ACCRM) and as defender and negotiator with the Government on the challenges of decentralization. 
154. Operationalization of decentralization through the installation of elected local administrations thus offer opportunities for deepening the democratic process, strengthening local governance, ensuring better mainstreaming of gender in public management, and in particular, improving coverage of the basic needs of the populations, especially the poorest groups. PRSP II implementation offers the opportunity for focusing on difficulties that hamper the decentralization process, and therefore achievement of its objectives, namely: deepening of the democratization process and boosting of local economies, which form the basis of sustainable economic and human development.

155. The decentralization and deconcentration of public management and greater empowerment of local administrations are conditions to be fulfilled at the strategic level to accelerate achievement of the MDGs. Empowerment of the organs and authorities of the decentralized administrations will create enabling conditions indispensable for the achievement of seven of the eight millennium goals. To that end, emphasis will be laid on:

- consolidation of the achievements of decentralization through effective transfer of ownership of regional and local development to the decentralized local authorities (regions, districts and councils);

- effective deconcentration of the central administrations to make Government interventions more effective and more efficient;

- improvement of the territorialization of sectoral strategies through formulation and effective implementation of the territorial development policy;

- improvement of technical and financial support mechanisms for local authorities, and their sustainability and/or transformation ;

- deconcentration and decentralization of the management of human resources and public expenditure. The challenges remain: (i) local taxes and increased resources for the local authorities, (ii) consolidation of their financial support, and (iii) monitoring/control of financial transfers. Actions towards budget deconcentration, deconcentration of public procurement procedures, and operational establishment of deconcentrated organization charts and organic frameworks will be carried out through the PDI, which centres on six components: (i) reorganization of the central Government, (ii) improvement of the public affairs management process, procedures and methods, (iii) enhancement of deconcentration, (iv) consolidation of decentralization, (v) strengthening and development of human resources, and (vi) communication and relations with users.

156. With decentralization, the Government has decided to share its responsibilities in the design and conduct of territorial development with the decentralized authorities. The Government has therefore decided, through concerted intervention on the territory, to coproduce development, that is define new territorial policies with the local and regional authorities. The deconcentration of management will help to decongest the central structures, and therefore make public decision-making more efficient; it will also give the elected officials of decentralized authorities mandated representatives with recognized responsibilities. Consequently, horizontal consistencies could make up for inadequacies of strictly vertical logical frameworks in public management. 


\subsubsection{Improvement and Modernization of Public Finance Management}

157. In April 2005, the Government adopted a Government Action Plan for the Improvement and Modernization of Public Finance Management (PAGAMGFP). Under this Action Plan, the following activities will be carried out: (i) adaptation and modernization of the General Public Finance Framework, (ii) enhancement of governance and transparency, (iii) enhancement of the efficiency of tax and financial administrations, (iv) improvement of the quality of budget preparation and implementation, (v) inclusion of external financing in national budget procedures, (vi) interconnection of computerized public expenditure management systems, (vii) enhancement of the performance of Departments of Administrative and Financial Affairs (DAF), (viii) increasing the efficiency of public procurements, and (ix) implementation of continuous training for financial employees.

\subsection{Pursuance of Reform of the Business Environment}

158. Severe constraints hamper private sector development in Mali. There is a structural weakness as a result of the exogenous character of growth. An evaluation of the business environment lays emphasis on: (i) constraints relating to corruption (for $48.7 \%$ of the enterprises), (ii) inadequate infrastructure (drainage of wastes, inadequate rail and road transport), (iii) rigidity of the labour market (problematic dismissals, low level of education and vocational training, and absenteeism due to the prevalence of endemic diseases), (iv) inconsistencies in regulations and the judicial system, and (v) limited access to bank financing.

159. Legal uncertainties and difficulties of access to land are also major obstacles. In view of these weaknesses, solutions are required to revitalize investments through: (i) the fight against corruption, (ii) improvement of the regulatory framework, (iii) making the judicial system credible, (iv) reinforcement of infrastructures, ( $v$ ) improvement of the functioning of markets of factors of production, and (vi) significant improvement of bank financing.

160. It is also necessary to underscore the annual meetings of the President of the Republic with the representatives of the private sector. The Presidential Council for Investment has called for: (i) the establishment of an action plan to reduce transaction costs in creating enterprises, (ii) simplification of procedures for awarding licences, (iii) reduction of restrictions on recruitments and dismissals, and (iv) simplification of taxes. By the end of December 2006, a single window will be created for all administrative procedures relating to new investments. Similarly, tripartite Government/Private sector/Banks consultation days are organized each year by the Government to discuss issues relating to bank financing of economic activities.

\subsection{Financial Sector Development}

161. The Government of Mali intends to pursue and consolidate reforms and actions aimed at improving the viability, performance and competitiveness of the financial sector. To that end, periodic meetings have been initiated by the President of the Republic and the Prime Minister with economic operators, bankers and micro-finance stakeholders, leading to the adoption of action plans which will facilitate access by the private sector and populations to financing. 
162. Strengthening of the banking sector and capital markets will require: (i) the development of new financial products, and in particular leasing, (ii) the establishment of an investment fund for financing that could be in the form of lines of credit or budget allocations repayable (or not), (iii) the creation of a risk capital company and/or investment company with equity funds, (iv) the development of mechanisms to facilitate access by SMEs to loans, (v) improvement of banking facilities and modernization of payment instruments, and (vi) supervision and assistance to enterprises for quotation on the Regional Stock Exchange (BVRM).

163. Micro-finance development will be supported by: (i) implementation of the 2005-2008 action plan, (ii) consideration of the operational action plan of the conclusions of the meeting of the Head of State with all the stakeholders of the micro-finance sector in March 2006, and (iii) establishment of a sectoral working group to monitor the implementation of micro-finance aspects.

164. The reform initiatives taken by the Financial Sector Development Programme (PDSF) should be supported by the strengthening of nonbanking financial institutions, namely insurance companies, and restructuring of social security.

\subsection{Development of Infrastructure}

165. The basic infrastructure and utilities are inadequate, dilapidated and in poor state, and constitute obstacles to the economic and social development of Mali.

166. As regards transport, the Government will depend mainly on the following key strategies: (i) introduction of fair competition between the various means of transport, and between the transport enterprises, (ii) extension and better management of the feeder road network, and (iii) restructuring of public enterprises of the transport sector, including the concessioning of "Aeroports de Mali".

167. With respect to communication, the Government will implement the following strategies: (i) finalization of the privatization of SOTELMA before the end of 2007, (ii) development of human resource skills, (iii) promotion of universal access to information and communication through the computerization of public services and decentralized local authorities, as well as modernization and automation of postal services in rural centres, (iv) facilitation of private investment in cyber centres and Multipurpose Community TeleCentres, and (v) exemption of computer equipment from duties and taxes.

168. In the area of energy, the strategies to be implemented will concern: (i) development and supply of profitable sources of energy (hydroelectricity and new and renewable energies), (ii) rehabilitation of the existing infrastructure, (iii) development of a sub-regional cooperation policy, (iv) sensitization of the populations on the use of sources of energy to substitute wood, and (v) exemption of new and renewable energy equipment from duties and taxes.

169. Industrial development aims at facilitating access by investors to developed spaces by providing developed plots, so as to make the sector attractive and promote industrial investments. The key strategy will consist in rehabilitating the existing industrial zone and creating new zones in Bamako and in the regions. As regards Bamako, an economic growth pole will be developed in the Senou airport area. This will consist in improving the passenger airport, rehabilitating the freight terminal, and developing a new 
industrial zone of up to 200 ha. The PASC and Millennium Challenge Account will contribute to the creation of this growth pole in Sénou.

170. The objective of the "Bamako-Sénou Airport" component is to increase the added value of freight and passenger activities. The investment, which aims at developing the airport facilities of Bamako-Sénou airport, will:

- rehabilitate and modernize the airport facilities to bring them to international standards and increase their competitiveness;

- increase the country's export capacity through the new facilities offered to air traffic, particularly the freight traffic;

- increase the capacities of the facilities for better use of its modernization to ensure safe, comfortable and efficient reception of passenger and freight traffic.

Indeed, better infrastructure will reduce the operating costs of aircraft and the airport, and thereby enable it to contribute to boosting activities, such as the export of fruits and vegetables.

\subsection{Promotion of Democratic Governance and Public Freedoms}

171. The establishment of the rule of law and promotion of democratic governance, initiated during PRSP I, will be pursued. To that end, the reform of the justice sector, started since 2000 and supported by several bilateral and multilateral partners, should be pursued.

172. PRODEJ, which is aimed at consolidating the rule of law, guaranteeing social peace and promoting the country's development, has recorded positive results in the following areas: (i) increase in the number and capacity of staff and budget of the justice sector, (ii) creation of an enabling environment for the promotion of human rights and public freedoms, (iii) fight against corruption, and (iv) construction and rehabilitation of infrastructure throughout the country.

173. As regards creation of an enabling environment for the promotion of human rights and the fight against corruption, PRSP II should help to consolidate the outputs of PRODEJ and other public initiatives on the following points: (i) providing courts with adequate staff, infrastructure, logistics and equipment, (ii) continuing to reinforce the capacity of staff, (iii) reorganization of the justice public service to make it more accessible and more efficient, (iv) revision of the rules and regulations governing the legal and judicial professions, and preparation of codes of ethics for the said professions, (v) capacity building for technical services and control structures, (vi) development of the capacities and abilities of the Government and civil society organizations in detecting and preventing corruption, and (vii) enhancement of transparency in the management of public procurements.

174. It will also be necessary to make the texts known and understood by highlighting the rights of women, children and handicapped persons. To that end, a large-scale information and sensitization campaign should be organized to ensure proper implementation of the provisions of human rights. Our codes should also be reviewed and translated into national languages.

175. PRSP II will strive to build a public administration that is republican and credible to all stakeholders of the public space. The capacities of civil society organizations will be strengthened to enable these important stakeholders of public life to play a key role in the debate on the definition and conduct of public policies. Initiatives to maintain and strengthen peace 
and security, which are conditions for tranquility of the populations, should be sustained. The proposed NEPAD peer review exercise and implementation of these conclusions can help to reinforce the credibility of the democratic governance process in Mali.

176. With respect to the fight against corruption and financial delinquency, actions will focus on the relevant international guidelines, namely implementation of the recommendations of the Financial Action Group on the laundering of capital, as well as the Basel Declaration made by the Bank for International Settlements. Mali carries out the activities of the InterGovernmental Action Group against Money Laundering in Africa (GIABA) under ECOWAS, as well as the WAEMU Directive of 19 September 2002 against capital laundering. The Uniform Law on the fight against capital laundering which provides, in particular, for the establishment of a National Financial Information Processing Unit (CENTIF), an administrative service with financial autonomy and responsible for collecting and processing information on the fight against capital laundering, will be created.

\subsection{Capacity Building for the Civil Society}

177. To complement the enhancement of democracy and decentralization, the civil society should be effectively involved in the definition, implementation and monitoring of development policies so as to eventually be a credible partner and real counter-power that can influence actions and decisions in a constructive manner at the national and local levels. The process initiated under the PRSP has, first of all, facilitated involvement of the civil society in defining the pillars and priorities of the strategy.

178. However, in order to consolidate creative and responsible participation of the civil society in the design and implementation of development and poverty reduction policies, the Government, in collaboration with the various components of the society, intends to put in place a vast capacity building programme for the civil society as a key component of PRSP II.

179. Reflection has already been initiated on the programme; its key areas are:

- training of civil society stakeholders to strengthen their technical skills, as well as their material and management capacities;

- greater organization of member institutions to increase their representation;

180. exchange of information and experience between member organizations, with government services and the other development stakeholders;

181. and the establishment of consultation frameworks at the national level with the Government and the strengthening of sectoral frameworks at the local and regional levels with the local authorities;

182. The development of networking at the sub-regional and international levels ;

- The development of efficient systems for information and communication between the local, regional and national levels. 


\subsection{Strengthening of Regional and Sub-regional Integration Initiatives, Constant Support to Achievement of African Unity}

183. Since its independence, Mali has been constantly working for the promotion and establishment of regional and sub-regional integration. Indeed, it is member of about twenty regional integration and cooperation organizations, the most important of which are: ECOWAS, WAEMU, OMVS, CEN-SAD, NBA and LIPTAKO-GOURMA and CILSS.

184. In view of its geographic location and human composition, Mali constantly works for the formation of large regional units. The choice of integration and going beyond the administrative borders has been proclaimed in all Constitutions since independence as follows: "The Republic of Mali can conclude, with any African State, partnership or community agreements comprising partial or total abandonment of sovereignty to achieve African unity".

185. However, this commitment is hampered by some constraints, the most important of which are: (i) the non-preparation of national economic operators for competition that will arise from the integration of markets and liberalization of regional trade, (ii) apprehensions concerning reduction in tax revenue due to complete dismantling of tariff restrictions and the Common External Tariff (CET), (iii) non-compliance of some member States with Community decisions, particularly those relating to the free movement of people and goods and the right of residence and establishment, and (iv) the financial expenses required for compliance with commitments on contributions and other financial payments to inter-Governmental organizations. Despite these difficulties, the major political choice of regional integration is constantly reaffirmed by the creation of a Ministry responsible for African integration.

186. The major conclusions of a study on integration policies show that: (i) information and sensitization on the ideals of African integration should be pursued, (ii) advocacy for the effective implementation of the free movement of people and goods, as well as the right of establishment should be strengthened, (iii) efforts towards the creation of a sub-regional and regional common market should be pursued, (iv) commitment to the harmonization of laws and multilateral surveillance should be maintained, and (v) it is necessary to implement common and joint approaches in strategic sectors such as agriculture, as well as road, air and telecommunications infrastructure, as well as higher education and scientific research.

187. The strengthening of sub-regional and regional integration policies requires the country's continued commitment to WAEMU, ECOWAS and NEPAD. Special attention should be paid to initiatives within the framework of OMVS, whose membership will be extended to the Republic of Guinea, as well as NEPAD in the implementation of the major regional infrastructure programmes.

188. The country should ensure compliance with and implementation of international agreements and better organization of bilateral and multilateral trade agreements (European Union/Africa Caribbean Pacific, and in particular future economic partnership agreements, AGOA, World Trade Organization, FAO, and WFP). 


\subsection{Creation and Promotion of Sustainable Jobs}

189. The priority area of intervention in employment is ensuring that training meets the needs of the labour market, establishing an enabling framework for job creation, and ensuring job security.

190. Job creation will help to: (i) promote local employment through decentralization, (ii) implement labour intensive works through big projects, and (iii) develop SME/SMIs. Special emphasis will be laid on vocational and technical training; the Youth Employment Project (PEJ), which is ongoing, should reinforce apprenticeship and qualifying training, the development of entrepreneurship for youths and access by young business promoters to loans.

\subsection{Development of Access to Basic Social Services}

\subsubsection{Education}

191. The objective of the Ten-year Education Development Programme (PRODEC) by 2015 is that "All Malian children complete quality basic education, and the education sector provides the country with the human resources required for its development".

192. To achieve this objective, the challenges in the sector are: (i) improvement of the quality of education, (ii) increase and improvement of education opportunities, (iii) education should meet the needs of the labour market, and (iv) definition and good management of priority actions for each PISE II component.

193. The strategic pillars for implementation of choices made in the education policy are the four (4) components of PISE II:

- development of quality basic education;

- support to general, technical and vocational secondary education, and vocational training through apprenticeship;

- implementation of a sustainable development policy for higher education and scientific and technological research; and

- establishment of deconcentrated and decentralized management of the education system, which will facilitate the participatory and concerted planning of initiatives in the sector.

194. The attendant measures of the education policy are presented in detail in the Ten-year Education Development Programme. However, the most important measure remains the effective transfer of power and resources as provided for in decentralization.

195. With respect to education, the priority area of intervention is the development of the various cycles of education (basic education, general, technical and vocational secondary education, higher education and scientific and technological research) as well as the establishment of deconcentrated and decentralized management for transparent and participatory planning of the education system.

196. In compliance with the decentralization process, control of the construction of school facilities will be effectively transferred to the local authorities. School furniture, as well as supplies and teaching aids will be provided by the school management committees under the responsibility of the councils. PISE II will support, in particular: (i) the construction and 
equipment of classrooms for primary and secondary education, with delegation of project ownership to the local authorities, (ii) the rehabilitation of about 200 classrooms each year and the fitting up of about 200 classrooms for children who need special education, (iii) construction of latrines in all public and community schools, and (iv) increase in the number of school canteens on the initiative of Local Authorities to improve access to school, especially for girls.

197. The importance of transport facilities in accessibility to basic public services will be taken into account; so also the need for an adequate transport network to establish the Government's presence on the territory and enhance national cohesion and security.

\subsubsection{Health and Social Development}

198. The challenges of PRSP II in the health sector are those defined in the Ten-year Health and Social Development Plan (PDDSS) and the ongoing second Five-year Health and Social Development Programme (PRODESS II). These include: (i) improvement of geographic access to essential health services and availability of qualified human resources, (ii) continued availability of quality drugs, vaccines and consumables at low costs throughout the country, (iii) reduction of health expenses for the poor, particularly for vaccination, prenatal consultation, family planning, the prices of Integrated Management of Children's Diseases (PCIME) services, (iv) reform of hospital and other research institutions, and (v) institutional capacity building of the Ministry of Health and all health structures.

199. Achievement of the objectives of this programme will help to: (i) extend life expectancy, (ii) reduce maternal and infant mortality rate, and (iii) increase prenatal consultations and reduce mortality and morbidity due to priority diseases.

200. The strategies for implementing PDDSS are: (i) geographic access to health services, (ii) improvement of the availability and management of human resources, (iii) improvement of the use, performance and quality of health services, and (iv) protection of household incomes and availability of essential drugs.

201. The attendant measures which should help the health sector to contribute to the achievement of PRSP II expectations are described in detail in the Ten-year Health and Social Development Plan.

202. As regards health and social development, the priority area of focus concerns capacity building for socio-health structures (availability of qualified human resources and essential drugs) and the basis of a systematic response capacity to the energy needs of the said structures (conservation of drugs and vaccines, sterilization of health care equipment, operation of equipment and lighting) and their geographic and financial accessibility through decentralization, in particular.

203. For that, it should be noted that in PRODESS II, the health guidelines concern : (i) the extension of primary health care coverage to the poorest areas (constructions, rehabilitations, revitalization of non-functional Community Health Centres (CSCOM), (ii) the development of partnerships with partners of the private sector, (iii) the development of alternative 
strategies (advanced strategy, mobile teams and community relays, promotion of family practices) in remote and low-populated areas, (iv) multisectoral, decentralized and participatory approaches targeting mainly the poor and marginalized populations, ( $v$ ) strengthening of control of infant and maternal diseases and malaria, (vi) free care for cesarean births, (vii) consideration of unsatisfied needs in family planning, and (viii) free malaria treatment for children.

204. The Social Development Plan adopted by the Government in 2005 was aimed mainly at contributing to the well-being of the populations by reducing the key sources of distress and social instability in order to ensure sustainable human development.

205. The challenges in this sector are many, and lead to the following major problems:

- effective management of persons and social categories in difficult situations. These are mainly old people, handicapped persons, destitute people, women and children in difficult situations, victims of social evils (alcoholism, prostitution, addiction to smoking, HIVIAIDS) and natural and social disasters (floods, drought, fires, epidemics, famine, wars and various social conflicts, forced repatriation) ;

- capacity building for communities to facilitate better access to basic social services and increase the incomes of the poorest populations; and

- gradual extension of social security to the entire population through effective mechanisms.

206. The achievement of PRSP II objectives in this sector should result in:

(i) more solidarity with the most destitute and most underprivileged groups,

(ii) better social security coverage for the entire population, (iii) better access by the most destitute to basic social services and micro-finance, (iv) social mobilization, and $(\mathrm{v})$ promotion of community health.

\subsubsection{Drinking Water and Sanitation}

207. PRSP II objective in the water sector for the 2007-2011 period is to contribute to the development of the country by providing appropriate solutions to problems relating to availability of water and ensuring sustainable management of water resources. This will mainly consist in satisfying the water needs of the populations (quality and quantity), reducing diseasing relating to the consumption of unclean water, and improving the quality of life.

208. With respect to drinking water supply, the access rate should increase in rural areas from $64.4 \%$ in 2005 to $68.4 \%$ in 2007 and $73.2 \%$ in 2011 , and in urban areas from $70.2 \%$ in 2005 to $74.2 \%$ in 2007 and $79.3 \%$ in 2011 . The sanitation coverage rate will increase from $4.4 \%$ in 2004 to $20 \%$ in 2010.

209. To achieve these objectives, which include decentralization and Government disengagement from ownership in favour of the local authorities, the challenges to be met concern pursuance of transfer of powers and resources to the decentralized authorities in water management, as well as improvement of geographic coverage of the national territory in drinking water points. 
210. The proposed accompanying measures are: (i) promotion of techniques for the mobilization of non-sustainable surface water resources in order to meet the needs of social sectors that affect the most underprivileged groups, (ii) effective implementation of the Water Code and related statutory texts, (iii) adoption of measures for monitoring and controlling water resources, (iv) strengthening of the deconcentrated technical services, ( $v$ ) implementation of the sanitation strategy and measures to protect water resources, and (vi) promotion of the private sector.

211. In this regard, the Drinking Water and Sanitation Sector Programme (PROSEPA) has been prepared. The Action Plan for the Integrated Management of Water Resources (PAGIRE) and a National Liquid Waste Drainage Strategy will be adopted in December 2006.

212. With respect to the water sector, the national water policy has the following key objectives: (i) satisfy water needs in terms of quantity and quality for a growing population, as well as those of various sectors of the developing national economy, (ii) contribute to the development of agrosylvo-pastoral activities by protecting them against the vagaries of the weather, so as to actively participate in poverty reduction and food security efforts, (iii) protect people and goods against the aggressive actions of water and protect water resources against the various pollutions, (iv) reduce the burden of the water sector on public finance through sharing of expenses between Government authorities, local authorities and users, and (v) promote regional cooperation for the management of cross-border waters so as to avoid conflicts relating to the use of water resources.

\subsubsection{Employment and Vocational Training}

213. The objective to be achieved through the National Employment Policy (PNE) is to find solutions for job security, reduction of unemployment and under-employment, adaptation of training to the needs of the market, and improvement of employment conditions.

214. To achieve this objective, the strategy to be implemented in PRSP II will consist in creating a legal framework conducive to the promotion of the private sector, and establishing a public service for local authorities.

215. This strategy should be accompanied by measures relating to: (i) pursuance of SME/SMI development, (ii) development of local financing, (iii) reinforcement and improvement of vocational and technical training, (iv) development of private services market to support contractors, and (v) organization of the informal sector.

\subsubsection{Housing}

216. The challenges in this sector are: (i) implementation of the programme for 12000 low-cost housing units as from 2007, (ii) the management of house rents in urban centres, (iii) the rapid and uncontrolled extension of towns, (iv) uncontrolled management of lands, and (v) sanitation of urban centres and control of the quality of buildings.

217. The housing policy to be implemented under PRSP II should contribute to facilitating access to housing for many low-income people, the harmonious development of towns, and improvement of the living environment in urban and rural areas.

218. The major guidelines for housing are: (i) control of the development of towns, (ii) development of the local building industry, (iii) land and real 
estate promotion, (iv) establishment of a housing refinancing institution, and (v) strengthening and improvement of the Government/Local Authorities/Private Sector Partnership Framework.

\section{$8.13 \quad$ HIVIAIDS Control}

219. In July 2006, Mali adopted a National Strategic Framework (CSN) for HIVIAIDS control, which covers the 2006-2010 period. This instrument provides strategic guidelines for HIVIAIDS control in synergy with PRSP II in aspects of sector reforms, as well as development and capacity building mechanisms for local authorities. The new national strategic framework defined three (3) major pillars: (i) promote an environment conducive for ownership, sustainability and good governance of the control efforts, (ii) reduce the risks and vulnerability to the pandemic, and (iii) mitigate the social, economic and cultural impacts of the epidemic, in particular those affecting children and women.

220. The National Strategic Framework defines the key strategic guidelines for HIVIAIDS control for all public, private and civil stakeholders. Through a multisector response framework, coordinated by the National High Council for AIDS Control (HCNLS), Mali ensures massive intensification and extension of programmes and interventions that promote:

- the prevention of HIVIAIDS;

- care and assistance to persons infected or affected by HIVIAIDS; and

- mitigation of the social, economic and cultural impacts of HIVIAIDS.

221. The strategic guidelines pay special attention to socio-cultural and institutional realities so as to foster the defence and protection of human rights and prerogatives of each person. In this respect, it should be noted that:

- the gender aspect is given priority everywhere;

- legislative and statutory reforms, as well as sensitization actions are introduced to protect persons infected or affected by the pandemic against stigmatization and discrimination;

- legislative and statutory reforms, as well as sensitization actions are introduced to fight against harmful physical and psychosocial practices;

- participation and involvement of institutions, persons, structures and organizations that influence HIVIAIDS control are encouraged;

- local authorities are empowered to develop sustainable local response.

\subsection{Integration into the Multilateral Trade System}

222. This consists in implementing the recommendations of the national validation workshop for the diagnostic study on the integration of trade so as to draw utmost benefit from the multilateral trade system and contribute to achievement of the MDGs.

223. It requires greater liberalization of the economy (liberalization of prices and competition) through: (i) the creation of an environment conducive to private sector development, (ii) development of the gold, rice, sugar, meat, hides and skins, fruits and vegetables, shea, Arabic gum and groundnuts sub-sectors, (iii) capacity building for support structures for trade promotion, and (iv) organization of the distribution trade. 


\section{Accelerated Growth Strategy}

224. The implementation of reforms initially proposed in the first generation PRSP (2002-2006) helped to carry out major projects that contributed significantly to improving the living conditions of the populations and reducing poverty in Mali. However, a number of objectives were not achieved, particularly the objective of attaining steady growth of an average annual rate of $6.7 \%$ over the period, so as to reduce poverty substantially. Indeed, between 2002 and 2006, the average annual growth rate was 5.2\%, which was below the set objective. While this level seems to be relatively high on average, significant disparities were observed from one year to another; indeed, the real GDP growth rate was uneven.

Table 7: Trend of GDP and Growth Rate

\begin{tabular}{|l|r|r|r|r|r|}
\cline { 2 - 6 } \multicolumn{1}{c|}{} & \multicolumn{1}{c|}{2002} & 2003 & 2004 & 2005 & \multicolumn{1}{c|}{2006} \\
\hline $\begin{array}{l}\text { GDP (in CFAF } \\
\text { billion }\end{array}$ & 2222.7 & 2453.6 & 2632.1 & 2892.9 & 3205.8 \\
\hline Real Growth rate & 4.4 & 7.7 & 2.8 & 6.1 & 5.0 \\
\hline
\end{tabular}

225. It appears that the annual growth required to generate enough wealth was not achieved. Consequently, it is necessary to reflect on sources of sustained and long-term growth that can improve the country's socioeconomic situation and achieve the Millennium Development Goals (MDG) ${ }^{2}$. To that end, the greatest challenge is to diversify the sources of growth so as to broaden supply capacity. As a result, the country will be able to adapt more easily to climate change and the volatility of world commodity prices.

226. The overall strategy and underlying economic (macro-economic, sectoral, by sub-sector and by product) policies to significantly accelerate economic growth will be based on the idea that the private sector is the main engine of growth.

227. This strategy will be based on: (1) the identification of growth-oriented sectors and sub-sectors; (2) analysis of obstacles to be eliminated in this respect; and (3) proposal of concrete actions (action plans) to accelerate economic growth in Mali.

2 Development goals which the world community intends to achieve by 2015: eradicate extreme poverty and hunger, achieve universal primary education, promote gender equality and empower women, reduce child mortality, improve maternal health, combat HIVIAIDS, malaria and other diseases, ensure environmental sustainability, and develop a global partnership for development. 


\section{Growth-oriented Sectors}

\subsubsection{Rural Sector}

228. Growth will be achieved in the rural sector through maximum development of the agro-ecological potential and agro-pastoral skills of the country, as well as through the creation of an enabling environment for the development of a structured agricultural sector, particularly through revitalization and creation of SME/SMIs. Emphasis will be laid on the development of dry cereals, rice, cotton, fruits and vegetables, and beef.

229. As regards the growth-oriented sectors, the growth of agricultural production will be achieved through: (i) control of water and better management of natural resources (in particular, soils) to minimize vulnerability to the vagaries of the weather; (ii) more availability of energy services for the rural services; (iii) better access to markets; (iv) supply and use of information on markets and technological progress; (v) creation of a coherent and attractive institutional framework to facilitate the professionalization of stakeholders of the sector and coordination of activities in the sub-sector.

230. Cotton will continue to be an important sector during PRSP II. The National Development Strategic Framework for the cotton sector will contribute to increasing the productivity of the sector. The option of privatizing the "Compagnie Malienne de Développement des Textiles (CMDT)" by opening up the capital to national and foreign individuals and controlling production costs are factors that will stimulate growth.

231. The new principles, which will guide the Government-CMDTProducers Memorandum of Understanding, are in particular: (i) producer prices of unginned cotton determined in such manner as to promote sustainable development of the Malian cotton sub-sector, and calculated on the basis of distribution of the gross income of the sub-sector between the producers and CMDT (60\% and $40 \%$ respectively), (ii) the creation of a support fund for flexibility in determining the initial price, and (iii) the establishment of mechanisms to correct fluctuations in the market in favour of CMDT (in a favourable situation) or the producers (in an unfavourable situation).

232. In pursuing the reform of the cotton sector, the revised schedule of the reform process for the sector adopted in November 2005 provides for the option of privatizing CMDT by transfer of shares of CMDT subsidiaries to be created. To that end, the measures adopted will concern, in particular: (i) the definition of organizational and regulatory frameworks within which the stakeholders of the sub-sector will operate, (ii) the establishment of a cotton stock exchange, (iii) the establishment of structures responsible for carrying out statutory functions (classification of unginned cotton and cotton lint, seed policy, cotton research, etc.), (iv) opening of the capital of CMDT subsidiaries to producers, ( $v$ ) completion of the structuring of farmer organizations, and (vi) implementation of a vast and intense producer information and training programme. 
233. Furthermore, a national cotton development strategy paper has been prepared, with the objective of increasing the contribution of the cotton subsector to the county's economic and social development. This objective will be achieved through the following strategic pillars: (i) pursuance of the fight against the practice of subsidies in certain countries (USA, EU), (ii) reinforcement of the competitiveness of the sector, (iii) securing the income generated by the cotton sector against the adverse effects of the volatility of world prices, (iv) the presence of new segments of markets (biological and equitable trade), ( $v$ ) increase in the processing rate of national production, (vi) the development of private sector participation in the cotton sector, and (vii) improvement of concerted management of the cotton sub-sector.

\subsubsection{Mining}

234. The mining sector will also continue to be a driving force in the economy. Gold is the sector in which growth was highest in Mali over the 1994-2005 period, standing at $22 \%$. It is the first export product, and second source of foreign exchange for Mali. The Government's voluntarist policy in this sector has led to substantial investments in infrastructure, cartography, research, exploration, evaluation and exploitation of mining reserves. Similarly, as regards tax incentives, the operators benefit from exemptions from: (i) VAT for three years; (ii) tax on profits for five years; and (iii) custom duties on import of capital goods. Establishment conventions offer the possibility of opening off-shore accounts in which operators can keep part of their resources.

235. Upstream the hydrocarbons sub-sector, special emphasis will be laid on oil research and exploration. Downstream the sub-sector, the challenge consists in reducing the cost of oil supplies and procurement. The strengthening of ONAP will increase storage capacities and improve distribution channels of the products to the populations.

236. The expectations from the mining sector are as follows: (i) increase in State revenue through substantial contribution of mining products to GDP, (ii) job creation, particularly for youths in the production areas, (iii) increase in the incomes of traditional exploiters, and (iv) development of the gold exploitation areas.

237. The challenges to be met by the sector in the medium and long term are: (i) environmental protection, and its restoration in gold exploitation areas, (ii) protection of the populations and animals living in the gold exploitation areas, and protection of the purchasing power of the populations during increases in the cost of living, and (iii) establishment of financing facilities adapted to the activities of the sector.

238. The strategy adopted by the Government is its gradual withdrawal from the sector in favour of private individuals so as to concentrate on its fundamental missions of establishment of basic infrastructure, creation of an environment conducive to investment, as well as promotion, regulation and control of the sector. 
239. To that end, the proposed attendant measures are: (i) capacity building for the stakeholders of the sector, (ii) improvement of the legal, regulatory and institutional framework, (iii) environmental management to minimize the negative impacts on the populations and ecological environment, (iv) support to grassroots communities in the mining zones, and (v) promotion and assistance to small-scale mining and mines handicraft.

\subsection{New Possibilities}

240. There are many sectors with strong potential to accelerate GDP growth, if the necessary attendant measures are taken:

\subsubsection{Industries}

241. In Mali, the industrial sector faces enormous challenges, particularly: (i) the fight against fraud, counterfeiting and unfair competition, (ii) difficulties of emerging industrial enterprises in the processing of local products, (iii) quality control of imported equipment to avoid polluting technologies, and the fight against pollution caused by factories.

242. However, this sector is expected to contribute to the country's economic growth by processing products of the rural sector, such as fruits and vegetables, oilseed crops, cattle and meat, hides and skins, and textile fibres (cotton and others). The development of the industrial sector will create jobs and increase the national value added of the products, which will be exported and will thereby contribute to improving the living conditions of the populations.

243. The attendant measures to be taken in this sector include: (i) creation of an investment promotion fund, (ii) development of viable industrial zones based on an operational industrial development plan, (iii) development of road infrastructure for the distribution of national production, (iv) intensification of the fight against unfair competition and counterfeiting, (v) restructuring and upgrading of industrial enterprises, (vi) promotion of quality and standards, and (vii) development of new industrial centres.

\subsubsection{Trade}

244. As a result of the predominance of trade in the Malian economy, the challenges to trade are many: (i) the fight against fraud so as to clean up the domestic market, (ii) quality assurance for import and export products, (iii) development of the sector by preparing and implementing a national policy harmonized with that of WAEMU, (iv) protection of the purchasing power of consumers in price liberalization, and (v) supervision of informal trade.

245. The objective under PRSP $\|$ is to strengthen the role of trade in economic and social development through better integration of the country into the regional and international market (supply of high quality Malian products on the international market, diversification of markets, compliance with standards, as well as with health and pest control rules, and capacity building for the stakeholders). This will consist in promoting, by a sub-sector approach, products whose increased exports will have a direct impact on the incomes of producers.

\subsubsection{Tourism}

246. Considered as one of the surest sectors in the fight against poverty, because it affects all sectors of the economy, the tourism sector faces 
enormous challenges, in particular: (i) coherence between the actions of the different stakeholders in the sector, including the private sector, (ii) introduction of control of tourism and hotel trades, (iii) development of touristic sites, (iv) creation of trust between private sector professionals and representatives of the public sector, and ( $v$ ) professionalization of employees in the sector.

247. To take up these challenges and make tourism one of the engines of growth, the Government in 2004 adopted a report defining strategic guidelines to promote the development of tourism, which could help to create jobs and increase public revenue (Government and Local Authorities).

248. The strategy in the sector will centre on: (i) strengthening of the institutional mechanism, (ii) diversification of the products offered, and (iii) assistance for better control of the activity by the stakeholders.

249. The attendant measures to support the sector are: (i) strengthening of the institutional mechanism and building the capacities of all the stakeholders, (ii) diversity of supply and development of touristic sites, restaurants and hotels, (iii) better coordination between investment programmes for road and security infrastructure, and organization of tourism events, and (iv) improvement of the quality of tourism products.

\subsubsection{Fruits, Vegetables, Oilseed Crops and Basic Products}

250. The fruits and vegetables sub-sector is promising, and has developed considerably for over ten years. Mali produces several exotic fruits or out-ofseason vegetables (mangoes, green beans, sweet peas) for which there is high demand in Europe. Consequently, important measures will be taken to organize this sub-sector, and facilitate the sale of its products, especially on the foreign market. Indeed, since competition is keen for these products, efforts need to be made to ensure the good quality of fruits and vegetables proposed on the markets, which must meet the commercial and regulatory requirements (international pest control standards, presentation in packing materials, etc).

251. As regards basic products, Mali abounds in products such as Arabic gum, shea, and cashew nut, the development of whose markets will contribute to increasing the incomes of the rural populations.

\subsubsection{Handicraft}

252. The Handicraft Master Plan was prepared in 2003. The handicraft sector, though potentially a great provider of jobs, nevertheless has some weaknesses which impede its development. Even though the tendency is to lay emphasis on art handicraft with the sole objective of promoting exports and supporting tourism, the potential lies more in utilitarian handicraft of products and services for the local market. 
253. To ensure the emergence of a growth-oriented handicraft sector, it is necessary not only that its needs be identified and taken into account, but also that the various stakeholders of the sector (Ministry, apex structures, development partners, etc.) define, in a consensual manner, a long-term strategic vision for handicraft.

254. The Ministry responsible for handicraft will play a uniting role, through the National Handicraft Promotion Centre, so as to make this sector a pole of economic growth and achieve the objectives of growth, poverty reduction and MDGs.

255. To that end, the following strategies are proposed:

- active advocacy to refocus the role of handicraft on achievement of the various sector objectives of growth and poverty reduction;

- availability of information on the evolution of handicraft and actions to improve visibility of contribution by the sector;

- preparation of a sector policy for handicraft development, including a strategic action plan for capacity building and infrastructure ;

- preparation of the Medium-Term Expenditure Framework (MTEF) for Handicraft;

- promotion of the emergence of professional and competitive handicraft industry, by laying emphasis on the interactive role of the industry and its contribution to the achievement of the objectives of other economic sectors;

- promotion of a handcraft industry that produces goods and services, with a strategic development policy adapted to the realities and potential of micro and small enterprises ;

- ensuring the emergence of a professional handicraft industry;

- provide capacity building for stakeholders and infrastructure ;

- collection and consolidation of information on the evolution of the handicraft industry.

256. The attendant measures will include: (i) establishment of a mechanism for controlling, monitoring and evaluating activities, and increased empowerment of professionals of the sector, (ii) establishment of an incentive legislative, regulatory and fiscal framework, (iii) creation of an enabling environment for the financing of investments in the sector, and (iv) mobilization of local initiatives.

\subsubsection{Culture}

257. Culture, a factor of social cohesion, is considered as an approach to poverty reduction. In order to promote the cultural values of our country and create a climate of peace and stability, the Government of Mali adopted the key orientations of the cultural policy, with the following main objectives: (i) promotion and development of a culture rooted in the values of the Malian society and universal civilization, (ii) protection, conservation and development of the national cultural and artistic heritage, and (iii) promotion of culture as a factor of economic development, peace, and stability. 
258. This cultural policy aims at addressing challenges relating to: (i) the restructuring of cultural sites, (ii) respect for and development of our customs and traditions, (iii) building on the positive aspects of cultures, (iv) organization and control of the culture sector, and (v) fight against piracy.

259. Consequently, it is expected that the implementation of this policy under PRSP II will: (i) develop cultural tourism sites, (ii) increase income from cultural activities, (iii) enhance the creativity of artists, and (iv) develop cultural events.

260. The proposed attendant measures are: (i) preservation of historic places and sites, (ii) training of cultural stakeholders and senior staff of the Ministry of Culture, (iii) promotion of cultural enterprises, (iv) protection of creative art, and ( $v$ ) promotion of cultural exchanges.

\subsubsection{Youth and Sports}

261. Mali, like most African countries, has a population which is mostly young, hence the scope of challenges relating to: (i) the creation of jobs for the integration of youths into socio-economic and professional life, (ii) adequate education and development of civic spirit, and (iii) the fight against social evils, such as prostitution, pedophilia, banditry, and in particular the protection of youths against HIVIAIDS.

262. The objectives sought in PRSP II as regards the youths are better integration of youths into social life and development of job-seeking aptitudes.

263. These objectives should contribute to: (i) reduction of youth unemployment rate in urban and rural areas, (ii) settlement of youths, and consequently reducing rural exodus and migrations, (iii) an appeased social climate, and (iv) reduction of distress and frustrations.

264. The strategy, which will help to achieve the objectives, is based on the creation of the legal framework and conditions for the development of youths and, the proposed attendant measures are: (i) socio-educational supervision for youths, (ii) the socio-economic integration of youths, (iii) capacity building for associations in mobilization, citizenship and participation in public life, and (iv) institution building of youth supervision structures.

265. As regards sports, the objectives are to: (i) improve sports results at the national and international level, (ii) develop sports activities by organizing many team sports competitions, (iii) work towards the socioeconomic integration of sports men and women, (iv) promote the development of sports men and women by constructing sports infrastructure, and $(v)$ provide training to youth and sports senior staff.

\subsection{Growth-Oriented Infrastructure}

266. Growth will be boosted through: (i) the development of viable industrial zones; (ii) the availability of water and electricity at better costs, (iii) the construction of transport infrastructure, and (iv) accessibility to more substantial financing. It is therefore necessary to improve the business climate. For industries that process raw materials produced in the country (meat, milk, hides and skins, and fruits and vegetables), the public sector could facilitate a commercial partnership between the large modern private units and the micro and small enterprises in the handicraft and informal sector. 


\subsubsection{Energy}

267. The traditional energy sub-sector is characterized by shortage of domestic fuel made up of firewood and charcoal. The provision of these needs depends, in more than $80 \%$ of the cases, on wood resources and puts great pressure on the forest cover. The preparation of Wood Energy Supply Master Plans (SDA) should help to initiate gradual renewal of the resources, and make it possible to tap the national potential of the agricultural and animal biomass.

268. The major challenges to be addressed by the strategies and policies in the energy sector, which aims at making energy services accessible to the greatest number (population and industrial units) and throughout the country at least cost, are:

- search for an alternative to firewood so as to preserve plant species and stop the abusive felling of trees for wood ;

- introduction of sound management of EDM SA ;

- reduction of water and electricity rates;

- sustainability of public lighting in towns in Mali ; and

- search for financing required for the implementation of priority projects and programmes of the next five years.

269. The intervention proposed by Government in this sector is defined in the Electricity and Drinking Water Sector Policy Letter adopted on 10 November 1999. This letter provides for attendant which centre on:

- strengthening of the institutional and regulatory framework of the energy sector;

- development of domestic energy and rural electrification;

- promotion of alternative sources of energies to traditional fuels;

- constitution of a national buffer stock for hydrocarbons;

- development of the National Interconnected Network;

- development of renewable energies; and

- promotion of the exploration of hydrocarbons, and solid and gaseous fuels.

270. With respect to the management and efficiency of the electrical energy sector, the objective is to improve the productivity of activities of the company "Energie du Mali" (EDM) (Mali Electricity Corporation) in urban areas through a programme to reduce technical and non-technical losses and to reduce electricity rates. It is also recommended that production infrastructure be developed through an appropriate investment programme to increase electricity supply and benefit from economies of scale to reduce electricity costs for the industrial sector. 


\subsubsection{Transport}

271. The central position of Mali in the middle of West Africa subjects this sector to enormous challenges, namely: (i) continued improvement of the efficiency and sustainability of the means and infrastructure of transport (road, railway, air and river), (ii) reduction of transport costs, particularly in rural areas, (iii) improvement in the operation of transport corridors, (iv) implementation of the railway and "Aéroports du Mali" concession, (v) monitoring of compliance with road traffic rules, and (vi) operationalization of the environmental unit for road projects.

272. The transport sector should therefore contribute to the internal and external accessibility of the country through efficient and sustainable management of means of transport, and periodic maintenance of priority highways. Consequently, it is indispensable to prepare a transport infrastructure network development master plan for Mali.

273. The proposed strategy consists in the promotion of private public transport companies. The role of the Government will be limited to formulating the national transport policy and monitoring its implementation.

274. The proposed attendant measures include: (i) capacity building for stakeholders of the transport sector, (ii) cleaning up and modernization of the public transport vehicle fleet, and (iii) strict implementation of the laws in force on transport and safety.

275. The needs identified during the sectoral consultation on the development of transport infrastructure in Mali (2008-2015) comprised 87 priority projects. The key objectives are to: (i) construct the lacking sections of the international corridors, (ii) connect all the chief towns of districts with a tarred or modern earth road, and (iii) connect all the chief towns of councils with an improved feeder road that is motorable throughout the year.

276. Consequently, the action matrix for the integrated trade framework proposes: (i) the reduction, by WAEMU, of the CET for the import of commercial vehicles, (ii) promotion of competition between the various corridors, (iii) at the national level, the adoption of a single tax system for transport companies, (iv) the creation of dry ports; (v) the creation of a national freight exchange, and (vi) reinforcement of the technical regulations of transport vehicles.

277. With respect to air transport, the following measures are proposed: (i) security of air freight according to international standards, (ii) abolition of airport export duties for red meat, fruits and vegetables, (iii) evaluation of the adequacy of the refrigeration logistic chain, and (iv) provision of refrigeration facilities in airports.

278. As for railway transport, measures will be taken to improve Malian warehouses in general, and that of Dakar port in particular, and to ensure compliance with the concession contract clauses for the Dakar-Niger railway. 


\subsubsection{Telecommunications/ICT and Posts}

279. In light of observation of the telecommunications sector since 1999 and implementation of the laws in force, it would be necessary to improve the legal framework so that private investment and use of private sector skills is encouraged, that the competitiveness of SMEs is improved, and that the objectives of social progress are achieved.

280. Detailed studies will be conducted on the postal sector so as to better regulate it and give fresh impetus for growth.

281. Concerning the extension of telecommunications network and ICTs to rural areas, the proposed actions relate to: (i) the formulation of a strategy for access to communication in rural or remote areas; (ii) the formulation of legal/regulatory instruments required for the creation of a universal access fund, for the management and functioning of the fund, and for defining telecommunication services considered as part of service and/or universal access, (iii) an evaluation of the required subsidies, and (iv) the implementation of pilot projects based on the ICT strategy adopted by the Government. The results will help to extend the ICT universal access programme to the national level.

\subsection{Cross-Cutting Issues}

\subsubsection{Gender}

282. The key challenges in the area of gender are:

- the socio-cultural factors, which still weigh on the status of women and reduce their chances of education, thereby limiting their capacities to participate in the socio-economic life of the community;

- gender disparities in education, at all levels of education. These disparities affect the capacities of women, jeopardize their productivity, and limit their access to development opportunities;

- precariousness of the health of women and young girls, leading to a high maternal death rate (582 per 100,000 life births), high fertility (total fertility 6.8) and limited access to modern contraceptive methods (overall contraceptive prevalence rate of $12.7 \%$, and $5 \%$ in rural areas);

- high contribution of women to the household and market economy, and yet low visibility of their work in the economic aggregates and limited access to the benefits of development;

- unequal distribution of roles and responsibilities in the division of labour, unequal access to economic opportunities, which accounts for the low economic power of women and feminization of poverty. Women are underrepresented in the modern private and public sectors. There, they occupy inferior positions and income gaps discriminate against them. Despite the progress made in the micro-finance sector through credit unions, access by women to financial services is still limited, and this hampers real feminine entrepreneurship; 
- different rights and duties for the man and the woman within the family and society despite the notion of equal rights enshrined in the Constitution. This largely accounts for the under-representation and low participation of women in decision-making organs. As a result of poor mainstreaming of gender in the decentralization process, the gender dimension remains very limited in local and council management; and

- limited consideration of gender in the PRSP, which admittedly posed the problem of gender but still shows analysis weaknesses and limits in the capacity to measure the feminization of poverty. The analysis of poverty is based mainly on the poverty of living conditions and does not take into account the impacts which are different for men and women.

283. The recommendations and strategic orientations arising from the analysis of the status of gender, and which should guide GPRSP implementation activities are:

284. Concerning the establishment of a gender strategic framework, proposals are made to:

- provide the country with a gender specific reference framework,

- conduct an institutional review of equity-equality implementation structures,

- $\quad$ put in place a gender information system for the various structures which prepare quantitative data at the national, regional and local levels (DNSI, CPS, PRSP),

- ensure optimum donor interventions by revitalizing the Technical and Financial Partners consultation framework for gender in order to harmonize the interventions (COFED),

- adopt the gender approach as a strategic factor in each development sector and at all levels,

- take measures to ensure recognition of GED Units of the sectoral ministries in the institutional mechanism, and make them operational, and

- review, in terms of gender, the policies and programmes of each sector.

285. Concerning gender and socio-cultural practices, the difficult and slow change will require intense dialogue with the various social groups. To that end, the following actions need to be taken:

- advocacy on gender with policy-makers (Government, National Assembly, Local Authorities) ;

- implementation of a vast information and social mobilization programme on gender issues for the society and opinion leaders ; and

- conduct of supplementary studies to better understand socio-cultural problems and their evolution. 
286. With respect to gender and education, proposals for improving the situation concern:

- capacity building in gender issues for education workers,

- preparation of methodology tools for the planning, budgeting and monitoring-evaluation of gender operations in education sectors,

- increasing the enrolment of girls and reversing the current girls/boys parities,

- abolition of any gender discrimination in school curricula, and assist in the review of school curricula in terms of gender (review the image given of the girl/woman, message on HIVIAIDS).

287. As concerns gender and health, the proposals centre on:

- capacity building in gender issues for health workers,

- preparation of methodology tools for the planning, budgeting and monitoring/evaluation of gender operations in health sectors,

- strengthening information and sensitization programmes on family planning, STI/AIDS, and practices detrimental to women's health for men and women,

- adoption of a population policy consistent with the development projections of the country, and

- greater representation of women in the governing organs of health associations.

288. With respect to gender and the economy, the proposals are:

- improvement of women's economic visibility,

- review of national programmes so as to better integrate the specific needs of women (PCDA, AMADER, PASAOP),

- preparation and implementation of measures to promote equal access by women and men to productive resources, particularly in farming schemes (ORS, ON, ORM PIV), and

- support for the emergence of a female entrepreneurship and the consolidation of income-generating capacities through special measures that foster access by women to loans.

289. As regards gender and the law, the proposals are:

- implementation of international conventions on women's rights, which have already been ratified by Mali,

- finalization of the consultation process and adoption of the new Family Code, and its implementation,

- establishment of a national observatory for women's and girls' rights,

- implementation of a vast programme of information, sensitization and mobilization on women's rights,

- systematic training in gender issues for all staff of the justice sector, and

- legal assistance for all women, and the most underprivileged population. 
290. Concerning gender and participation in governance, women's participation remains low ; consequently, it is important to:

- develop a sensitization programme for the various stakeholders in the society to promote equal exercise of citizenship by men and women,

- provide capacity building for decentralized structures and local authorities for better consideration of the gender dimension, and

- reinforce women's civil society organizations.

291. With respect to gender and decentralization, in order to improve consideration of gender in the decentralization process, it is necessary to:

- encourage women's participation in the preparation of plans, take into account their specific needs as well as their involvement in the implementation of these plans. See to the quality of women's representation in orientation and decision-making organs at the local level,

- see to the integration of the specific needs of grassroots women in service delivery, and include them in the ANICT financing list,

- take into account gender equity in the allocation of resources at the council level,

- improve the capacity of LAs in gender, and provide methodology and tools for mainstreaming gender in local planning,

- create a strong link between vertical programmes and gender horizontal planning at the level of local authorities, and

- monitor and evaluate gender to assess the indicators for results, effects and impacts of the level of poverty reduction in terms of gender at the council level.

292. Lastly, to ensure effective consideration of gender in PRSP II, it is necessary to: (i) strengthen coordination with MPFEF and further involve the civil society, particularly women's associations and organizations, in the formulation process and in poverty and gender monitoring mechanisms, (ii) provide capacity building in gender issues to members of the Poverty Monitoring Unit and develop existing national skills, (iii) adopt the gender approach as a strategic element in each development sector and at all levels, (iv) review national and sectoral development policies and programmes to highlight the needs and potentials of men and women, and to enhance the inclusion of gender in the formulation, monitoring and evaluation of PRSP II, (v) deepen gender-oriented analysis in the preparation of poverty profiles to ensure better knowledge of the real situation of women and vulnerable groups at the national, regional and local levels, (vi) institutionalize a system for targeting/locating the poorest population in separate data (men and women, girls and boys) and (vii) include relevant gender indicators in the poverty monitoring system. 


\subsubsection{Territorial Development}

293. The territorial development policy adopted by the Government has the following objectives:

- balanced distribution of the population and activities throughout the national territory;

- coherence of public and private activities, which contribute to the economic development of the country;

- reduction of inter-regional and intra-regional disparities in development;

- facilitate the emergence of economic regions based on development poles;

- better coordination of the development actions of stakeholders at the different territorial levels;

- promotion of peaceful and traditional land management;

- coherence of national, community and African sectoral policies; and

- strengthening of integration within WAEMU space.

294. This policy will help Mali to cope with major challenges, namely: (i) sustainable development through better territorial balance, (ii) promotion of national solidarity, and (iii) environmental protection.

295. The overall strategy for achieving the objectives of the national territorial development strategy will centre on:

- the establishment of a geographic information system;

- the preparation of development plans for the various territorial levels;

- revision of sector and/or regional and local plans and programmes prior to the adoption of the national territorial development policy;

- training and sensitization of stakeholders of territorial development; and

- establishment of partnership relations with sub-regional organizations/institutions engaged in the promotion of territorial development (WAEMU, CILSS).

296. The proposed attendant measures to support the national territorial development policy concern: (i) improvement of the legal and regulatory framework for territorial development, (ii) ensuring consistency between initiatives from the private sector, local authorities as well as technical and financial partners, and (iii) a good distribution of national resources.

\subsubsection{Population Issues}

297. The incorporation of demographic variables in the preparation of development plans and programmes should be envisaged within the larger perspective of growing appreciation of the significance of mutual relations between the social, the economic and the demographic sectors. Consequently, the challenges at this level centre on the following points:

- advocacy with policy makers for better awareness of interrelations between population and development ;

- social mobilization around PNP objectives;

- capacity building for better visibility of interrelations between population and development ; 
- support to local authorities and sectors for better mainstreaming of population variables in development plans and programmes;

- studies and research on the various aspects of the domain (population);

- harmonization of population concepts; and

- implementation of the PNP coordination and monitoring-valuation mechanism (adopted by the Government).

\subsubsection{Peace and Security Issues}

298. In view of the direct link between peace-security and development, the priority actions of PRSP II concern:

- Incorporation of peace and security aspects in all development projects and programmes and in sector policies;

- preparation of the security sector policy;

- inclusion of the peace and security cross-cutting theme in the various civil society interventions.

299. Seven key priorities should today form the basis of our security policy: (i) give priority to prevention; (ii) lay the bases for a police of proximity; (iii) clarify and coordinate security responsibilities; (iv) adopt a rational use of resources; (v) consolidate and reinforce openness to the outside world; (vi) adopt an appropriate communication strategy; and (vii) include the gender dimension in all security development strategies.

300. The strategic pillars in this area are as follows:

- capacity building for internal security and civil protection forces;

- design of a security coverage mechanism more adapted to the territory;

- improvement of road and river safety;

- reinforcement of the prevention and management of community conflicts;

- reinforcement of the disaster management strategy;

- establishment of good governance of internal security and civil protection;

- strengthening of bilateral and multilateral cooperation.

\section{COORDINATION AND MONITORING-EVALUATION MECHANISMS}

301. Analyses show low operationalization of the monitoring-evaluation institutional mechanism, low capacity of the PRSP Unit, low institutional capacity with respect to methods, tools, instruments and indicators used. Consequently, the information system is still incapable of accurately measuring the performance indicators. The reliability and consistency of the information and statistics obtained from various sources remain a serious problem. The poor quality of basic statistics was also noted. 
302. It has become necessary, at the level of the institutional mechanism, to clarify and simplify the mechanism. As regards the methods, tools, instruments and indicators used, PRSP evaluation requires harmonization with the Three-year Programme and Special Investment Budget, as well as programme budgets. It also requires a review of the number and type of indicators by component or thematic area for better understanding and greater relevance.

\subsection{Institutional Monitoring-Evaluation Mechanism}

303. The PRSP institutional mechanisms comprise: (i) a Policy Committee, (ii) a Mali-Development Partners Joint Committee, (iii) a National Steering Committee, and (iv) a Technical Secretariat. The PRSP process is conducted and coordinated by the Ministry responsible for the Economy.

304. The Policy Committee is the policy and decision-making organ of the PRSP preparation and monitoring process. To that end, it is responsible for: (i) defining policy with respect to the conduct of the process for growth and poverty reduction under the PRSP, (ii) considering issues and proposals submitted by the Technical Secretariat for decision, and (iii) submitting, if necessary, the final documents to the Government for approval.

305. The Policy Committee comprises: (i) the Prime Minister, (ii) the members of Government, (iii) the President of the High Council for Local Authorities, (iv) the President of the National Employers' Council of Mali, (v) the President of the Chamber of Commerce and Industry of Mali, (vi) the President of the Permanent Assembly of the Chambers of Agriculture of Mali, (vi) the President of the National Federation of Craftsmen of Mali, (vii) the President of the National Civil Society Council, (viii) the Federation of NGO Associations, (ix) Secretaries-General of the National Workers' Unions of Mali, and $(x)$ the President of the Association of Municipal Councils of Mali. The Minister responsible for the Economy will provide secretarial services.

306. The Mali-Development Partners Joint Committee is the organ for consultation between the Government and all TFPs in the preparation and monitoring of the Poverty Reduction Strategy Paper. In this capacity, it is responsible for: (i) considering issues and proposals submitted to it by the Steering Committee for opinion, (ii) giving opinions on the said issues and proposals before submission to the Policy Committee, and (iii) monitoring the development of cooperation in key areas for better coordination of aid.

307. The Mali-Development Partners Joint Committee comprises: (i) the Minister responsible for the Economy (Chair), (ii) the Minister responsible for the Plan and Territorial Development, (iii) the Minister responsible for Foreign Affairs and International Cooperation, (iv) the Minister responsible for Territorial Administration and Local Authorities, ( $v)$ the Minister responsible for the Public Service, State Reform and Relations with the Institutions, sectoral Ministers (if necessary), and (vi) the Heads of Aid and Cooperation Agencies, and Ambassadors.

308. A coordination organ has been set up with the Minister of the Economy and Finance, known as the Steering Committee. It is responsible for: (i) promoting synergies between the various stakeholders (Government, civil society, technical and financial partners), (ii) carrying out the technical activities of the PRSP process, (iii) initiating, boosting and coordinating all activities relating to the preparation, monitoring and evaluation of the PRSP, (iv) facilitating consultations between the different parties, ( $v$ ) seeing to the 
technical quality of the documents produced, and (vi) seeing to the publication and dissemination of documents. The Steering Committee is chaired by the Secretary-General of the Ministry responsible for the Economy.

309. The National Technical Committee is organized into working groups on strategic orientation areas of focus: (i) Macro-economic and Financial Framework, (ii) Consolidation of Structural Reforms, (iii) Infrastructure and Development of the Productive Sector, and (iv) Strengthening of the Social Sector.

310. A Regional Committee is set up in each region and in Bamako District to conduct the PRSP process at the regional level. The Regional Committee is chaired by the Governor. It comprises representatives of the regional technical services, the civil society and decentralized authorities. The technical secretarial services are provided by DRPSIAP.

311. A Local Committee is set up in each regional district ("cercle") and each council in Bamako District to conduct the PRSP process at the local level. The Local PRSP Committee is chaired by the Prefect in the regions and by the Council Mayor in Bamako District. It comprises representatives of the district council, technical services, the civil society and mayors of the districts or Bamako District.

312. The Technical Coordination Unit of the Poverty Reduction Strategy Paper (CCSLP) provides technical secretarial services to the institutional mechanisms of the Poverty Reduction Strategy Paper. The Technical Secretariat is responsible for: (i) monitoring the normal conduct of thematic groups within which it plays the role of secretariat and leadership, (ii) preparing a summary of the discussions in thematic groups, (iii) ensuring coherence between the discussions of thematic groups, (iv) preparing the documents to be submitted to the Steering Committee, the National Technical Committee, the Mali-Development Partners Joint Committee or the Policy Committee, and (v) organizing and conducting national and regional seminars/workshops.

\subsection{Strengthening of the National Statistics System (SSN)}

313. The National Statistics System (SSN), comprising, in particular, the National Statistics and Data Processing Directorate and its regional agencies, as well as Planning and Statistics Units (CPS) of the sectoral ministries, is not currently capable of providing the information required for monitoring and evaluating poverty reduction programmes and projects. To remedy this situation, the SSN prepared a Statistics Master Plan 2006-2010 (SDS), including an action plan.

314. The Master Plan (SDS), adopted by the Government in January 2006, makes a diagnosis of the SSN. The diagnosis reveals the major problems encountered by the SSN: (i) existence of serious institutional shortcomings, (ii) lack of a concerted strategy, making coordination difficult, (iii) lack of a real human resources policy, (iv) inadequate utilization of existing data, and (v) inadequate financial resources.

315. In order to guarantee better monitoring and evaluation of MDGs and PRSP II, the SDS proposes solutions centred on the following points: (i) development of statistics production, (ii) development of the utilization of statistics, and (iii) institutional development. 
The main activities selected for the $2007-2001$ period are as follows:

316. Pillar 1: (i) preparation of procedures manuals for the various surveys (consultancy fees, validation workshop, pilot surveys), (ii) application of the methodology in preparing national accounts according to international standards, (iii) application of the methodology in preparing regional accounts, (iv) preparation of nomenclatures, (v) preparation of national accounts in accordance with SCN93, (vi) preparation of regional accounts, (vii) production of business activity indices, (viii) conduct of several nationwide surveys and census (ELIM 2009, RGPH 2008, EMEP 2011, Survey 1-2-3 /Democracy and good governance survey (2007), Basic infrastructure/water point), (ix) implementation of sectoral statistic operations (basic surveys: Informal gold production, Annual EAC, Production of fruits and vegetables, fisheries, private investment, transport, communication, industry, trade, EDS V 2010, Tourism/handicraft, water points), and (x) establishment of information systems in the various CPS.

317. Pillar 2 : (i) analyses and research based on survey and census data (10 studies), (ii) research on modelling of the national economy, (iii) research on modelling of the national economy, (iv) economic and financial studies on sub-sectors (rice, cattle, meat, fisheries, poultry, shea), (v) a study on the use of statistics, (vi) preparation of a dissemination plan for each CPS, (vii) opening of a digital library in each CPS, (viii) opening of a digital library in the DNSI, (ix) creation of a Website for each CPS, (x) preparation and implementation of a plan for communication with the public and private press, (xi) opening of the Malikunnafoni database in DNSI and in DRPSIAPs, and (xii) organization of information and sensitization seminars.

318. Pillar 3 : (i) establishment of an incentive system for staff employed in the national statistics system (special rules and regulations, career plan, allowances, etc.), (ii) organization of further training courses, (iii) granting of scholarships to students admitted to statistics schools, (iv) preparation of a plan for the recruitment of statisticians into the Public Service, (v) organization of seminars for the training of users in statistics methods and language, (vi) creation and establishment of CCSI Permanent Secretariat, (vii) creation of the National Statistics and Data Processing Institute, (viii) construction and equipment of a head office for the National Institute, and (ix) equipment of CPS.

\subsection{Monitoring and Evaluation Indicators}

319. For PRSP II, a limited number of indicators were selected to serve as an instrument panel. These indicators facilitate global monitoring of the progress made. At the sectoral level, a more detailed range of indicators will be monitored. 


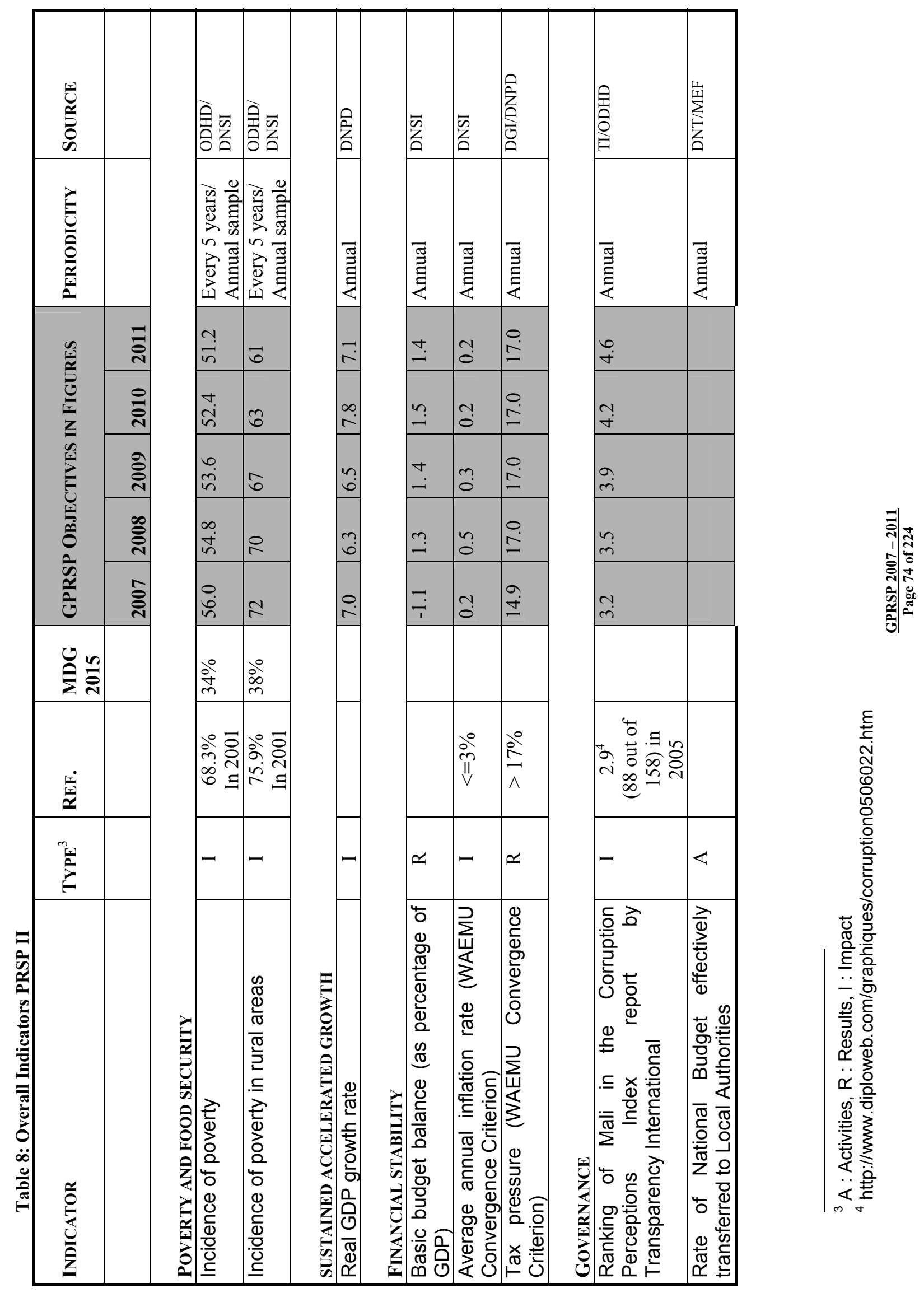




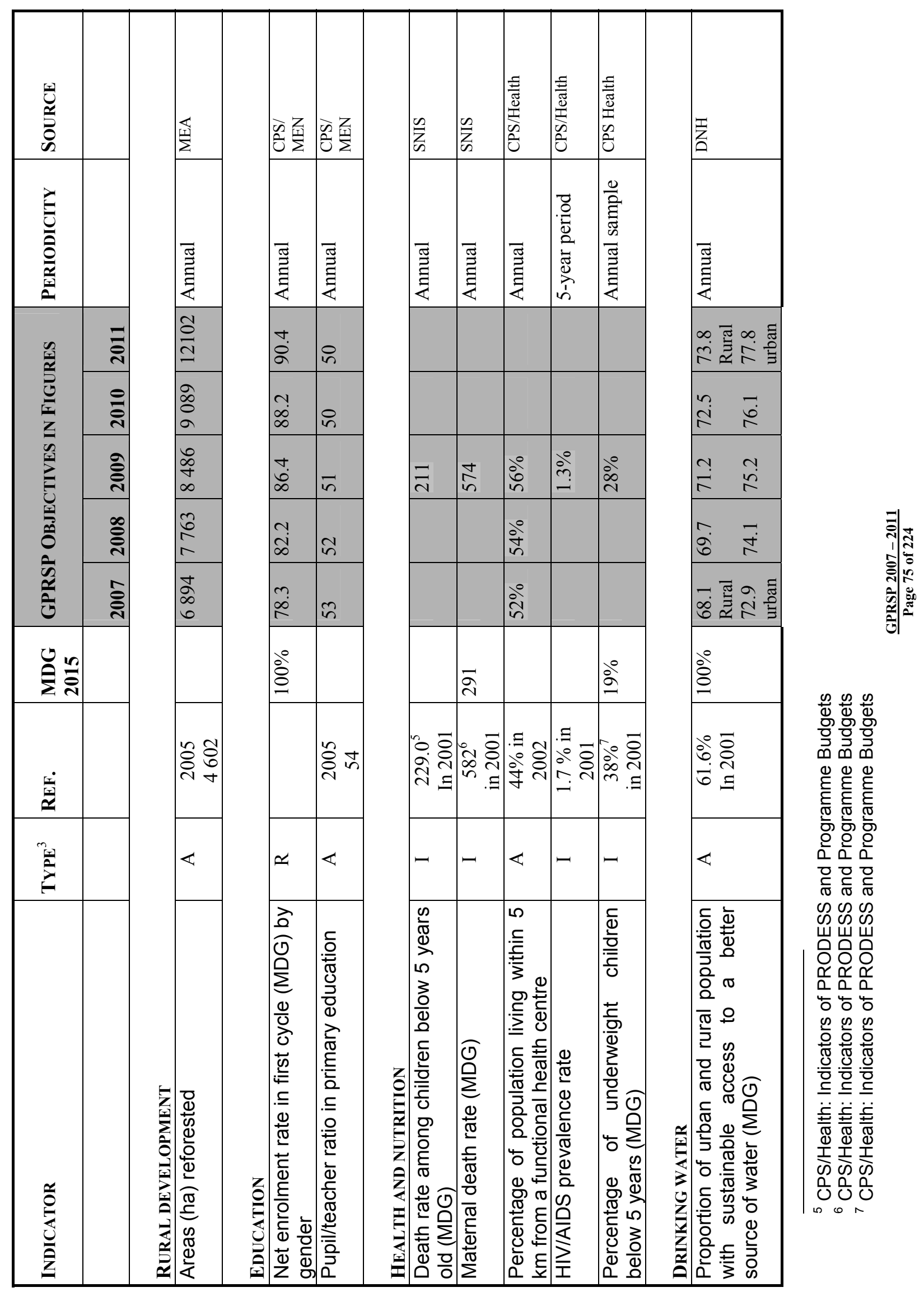



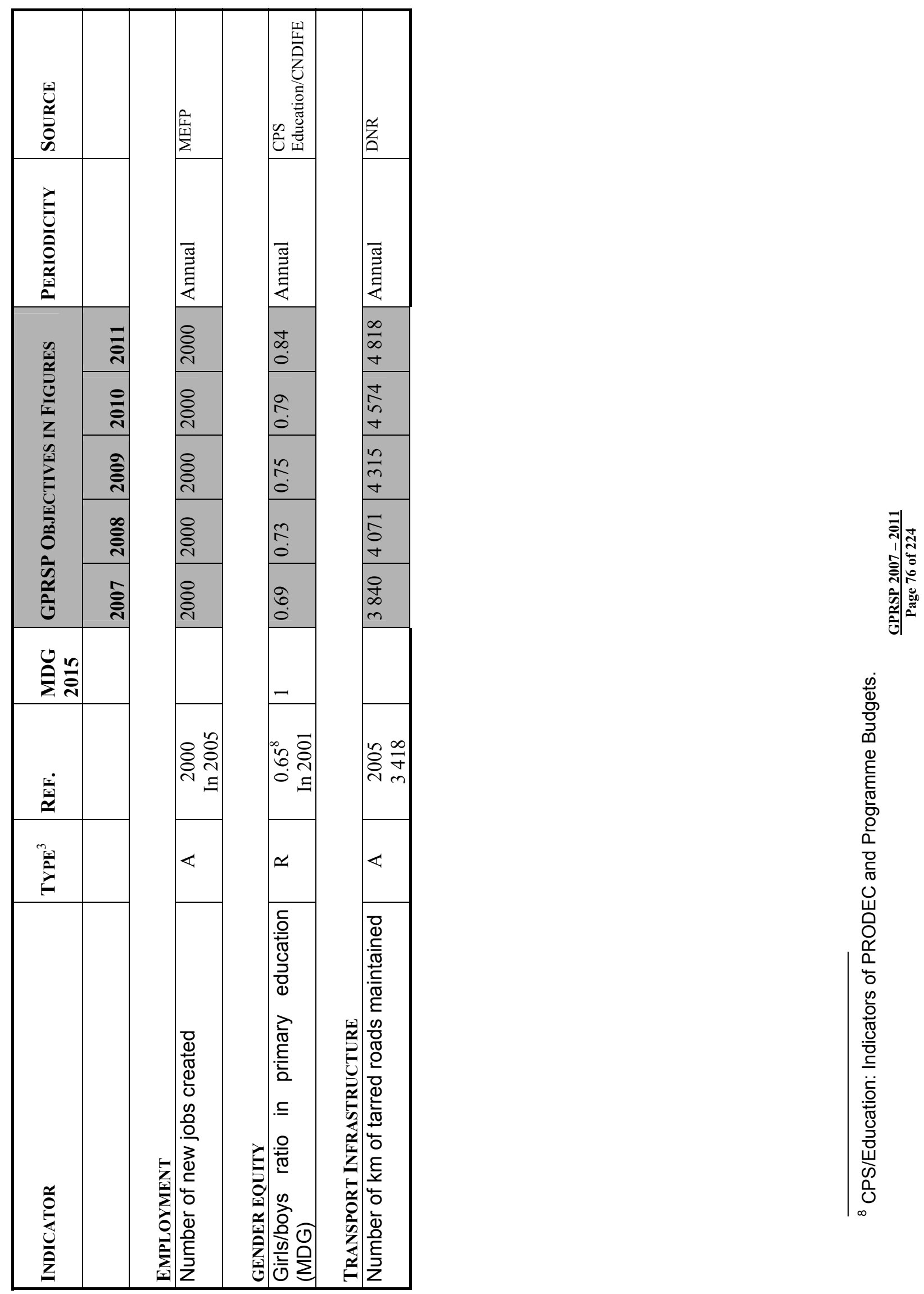


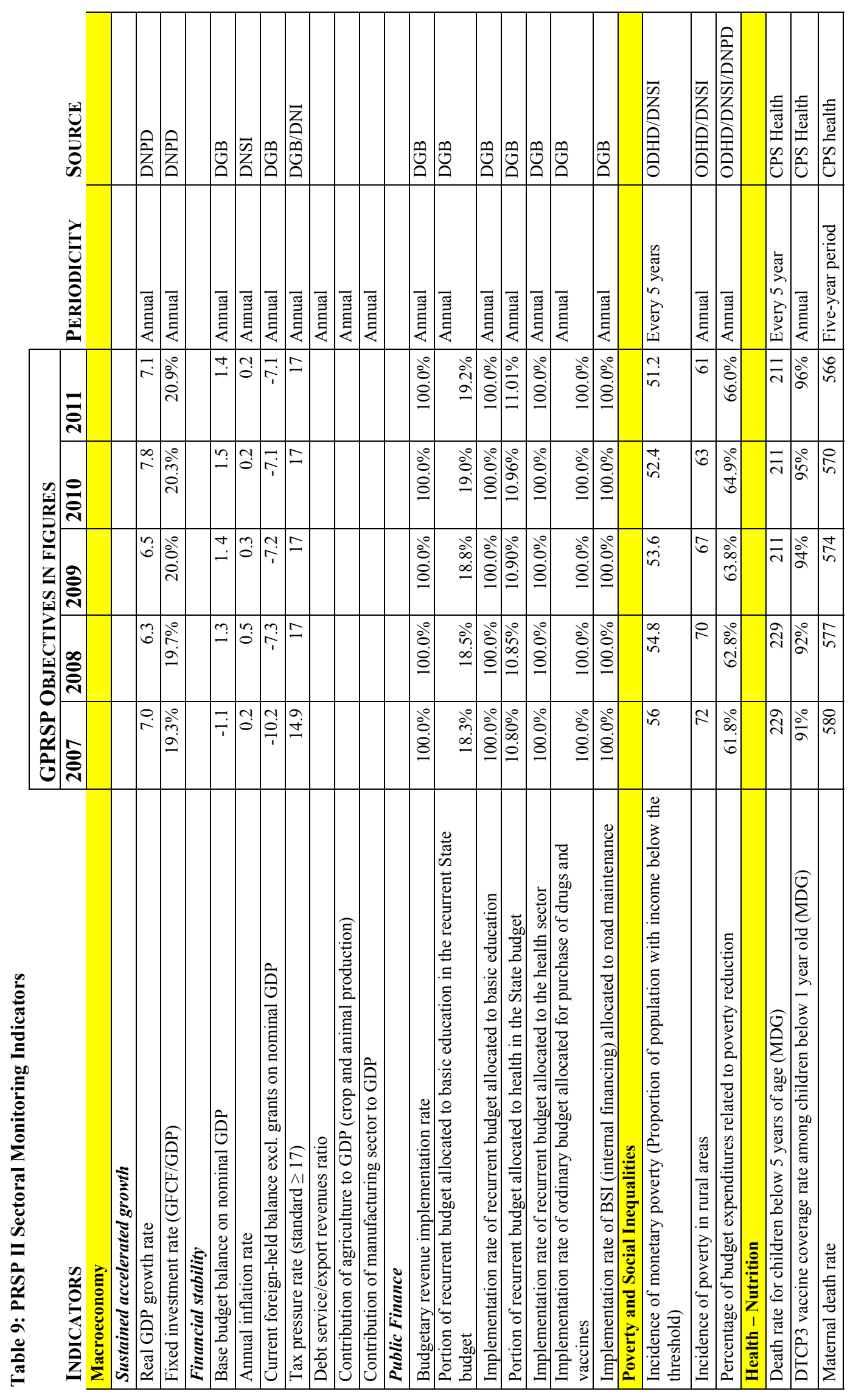

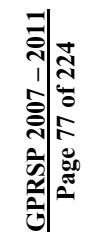




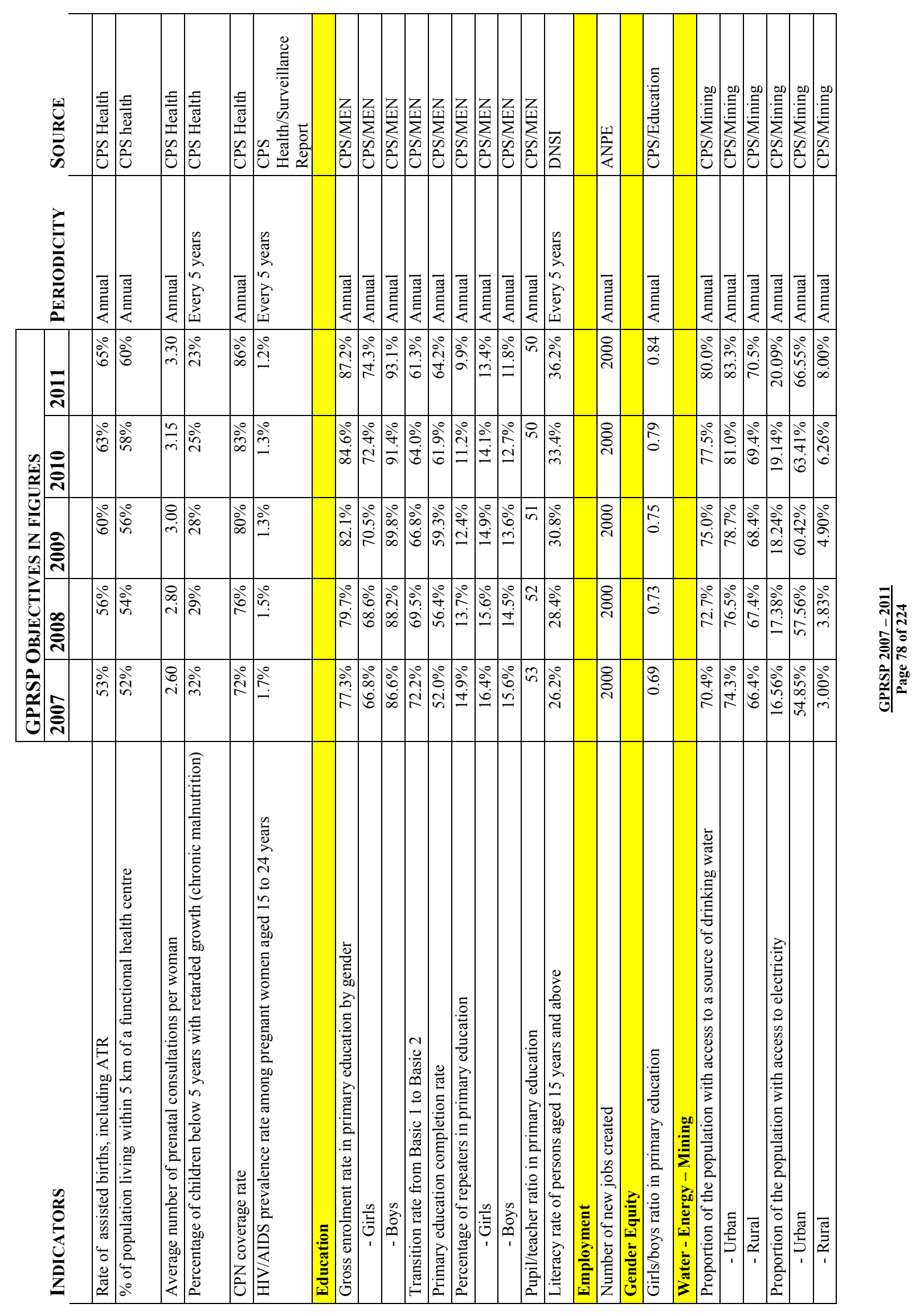




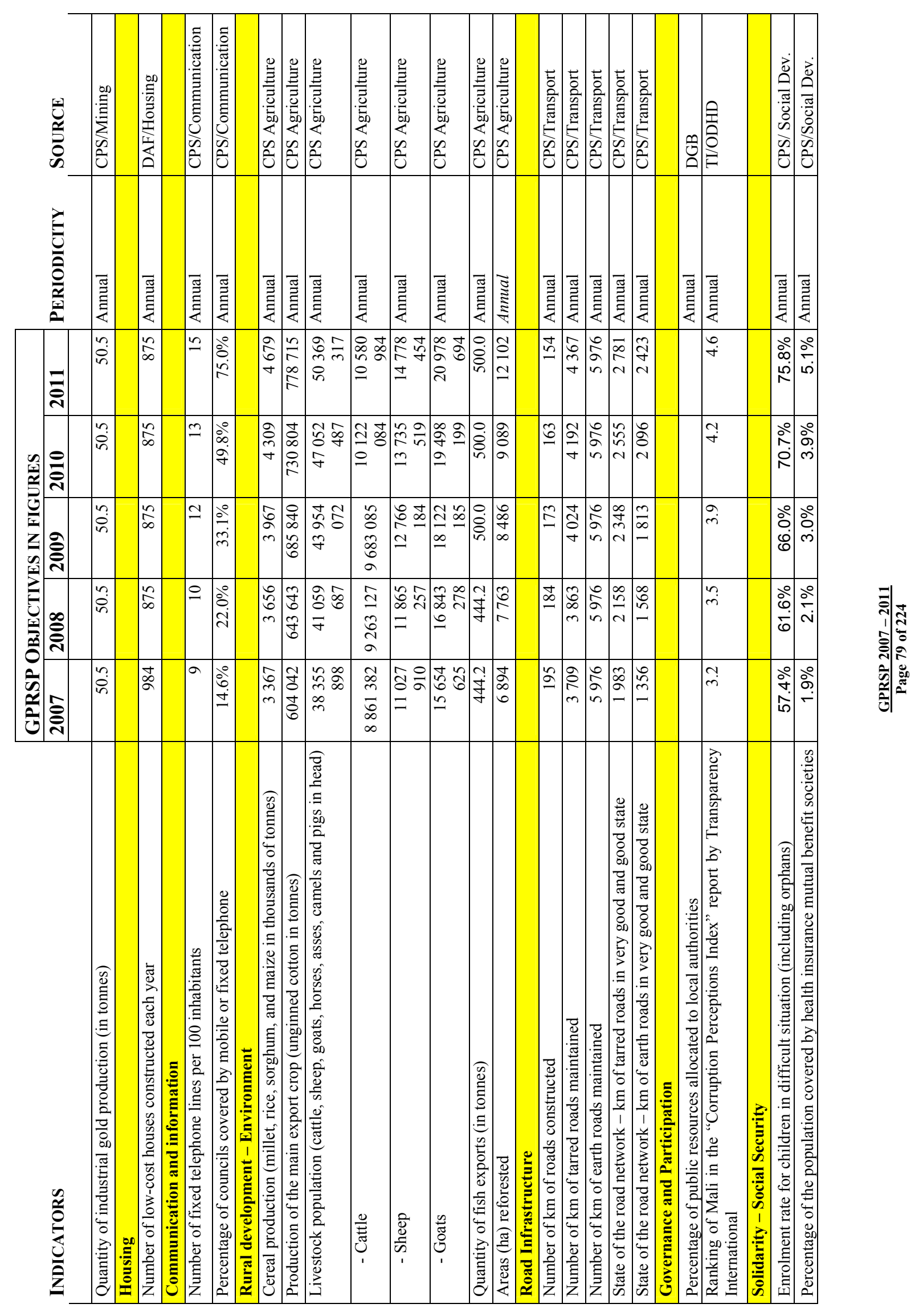




\section{IMPLEMENTATION OF the PARIS DeCLARATION}

320. The Government of Mali has made budget support a choice instrument of its financial cooperation. Accordingly, it has initiated very close dialogue with Technical and Financial Partners (TFP) leading to the signing of Framework Arrangements on general and sectoral budget support. All these activities contribute to the implementation of the Paris Declaration on Aid Effectiveness.

321. To give fresh impetus to the alignment and harmonization process at the national level, it is necessary to immediately assume ownership of the 12 indicators of progress of the Paris Declaration and agree on the monitoring process with the TFPs so as to analyze the progress made. Consequently, the 2008 and 2010 targets should be met. To that end, the preparation of an action plan by the Government of Mali for the implementation of the 12 indicators is a priority.

322. A Joint Government -TFP Secretariat will be established to prepare the action plan for implementing and monitoring the Paris Declaration.

\section{PRSP II FINANCING PLAN}

323. The PRSP implementation strategy is based on a significant increase in domestic financing through greater mobilization of domestic resources (tax pressure rate of at least $17 \%$ in 2008).

\section{Overview of Some Principles}

324. The PRSP is a common framework for all the economic and social development policies, programmes and projects in Mali. Consequently, PRSP financing cannot a priori be distinct from the State budget.

325. For 2007, the modelling work helped to harmonize expenditure projections of the macro-economic framework with those of the budgetary framework. This harmonization was obtained by exogenously basing the forecasts of the macroeconomic framework on those of the budgetary framework by putting in place a conversion scale to make the two expenditure nomenclatures compatible. On the other hand, for 2008-2011, the data are those from the macro-economic framework corresponding to the voluntarist growth scenario adopted for PRSP ( $7 \%$ of average annual growth, and achievement of tax pressure rate of $17 \%$ as from 2008).

326. The PRSP actions matrix developed in recent weeks was based on the programme budgets for the 2007-2009 three-year period (which contain lists of actions, but not costs) and on various sector programmes and projects from the Ministries concerned (which contain information on costs). The information on costs is very heterogeneous for the different projects and sectors of activities, and is not directly comparable. Furthermore, there are areas for which cost estimates in figures for scheduled activities or action programmes are not available.

\section{PRSP Financing Table}

327. The table selected for PRSP financing is identical with the GFFT projections made by DGB for the 2007-2011 period. However, this table may under-estimate the GFFT financing gaps. Indeed, the implicit assumptions underlying the GFFT projections made by the Directorate General of the Budget for 2008-2011 are, a priori, more conservative than those from the implementation of the voluntarist scenario.

328. A more detailed financing plan will be prepared on the basis of the MDGPRSP action plan, and will indicate the financing gap, as well as the financing acquired not only through budget support from TFPs but also through the large 
projects and programmes arising from bilateral and multilateral cooperation (10th EDF, CASRP/BM, IMF, ADB, etc).

\section{Future Activities}

329. PRSP implementation is an ongoing process, involving gradual improvement of methods used in GFFT preparation. Furthermore, some activities to be carried out in the short term and which should be taken into consideration during the next PRSP review in 2007, are as follows:

- improvement of evaluation of the costs of actions proposed in the PRSP, under the normal budget process, since the Directorate General of the Budget alone is authorized and competent to carry out the work;

- prioritization and finalization of proposed actions in close collaboration with the sectoral services concerned;

- joint preparation of costs by the Departments of Financial Affairs of Ministries in MTEFs, and the Directorate General of the Budget;

- identification of net financing gaps at the sectoral level;

- putting together the net financing gaps for the entire Malian economy;

- search for external resources from TFPs to meet financing requirements, at least for activities considered as of priority;

- finalization and consistency between MDG action plan and PRSP II;

- $\quad$ preparation of a financing plan for PRSP II;

- mainstreaming of the results of ongoing surveys in poverty analyses;

- finalization of the institutional mechanism and list of monitoring-evaluation indicators;

- preparation of the PRSP II communication plan; and

- preparation of the PRSP II logical framework. 


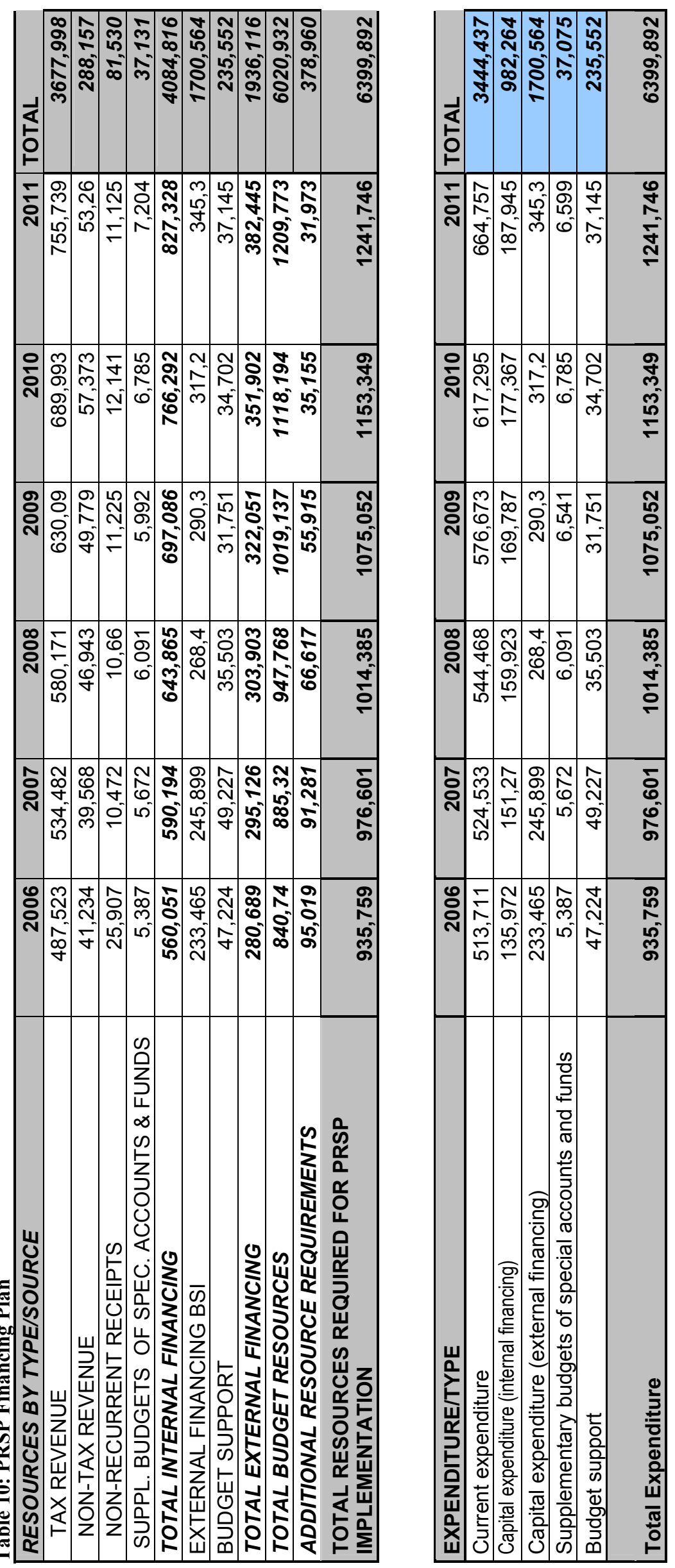

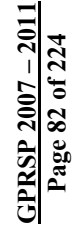




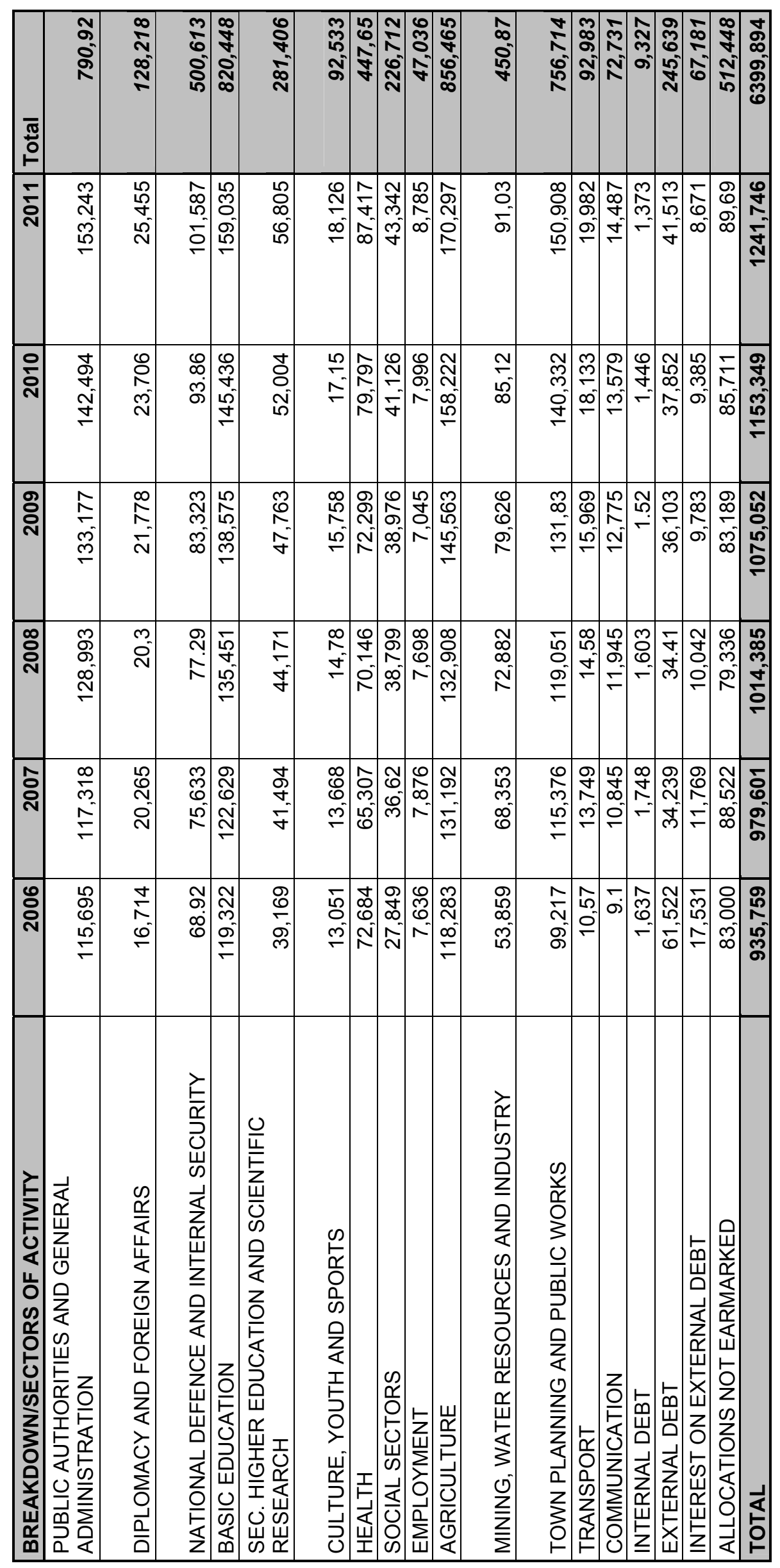

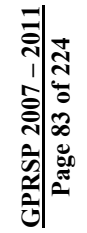




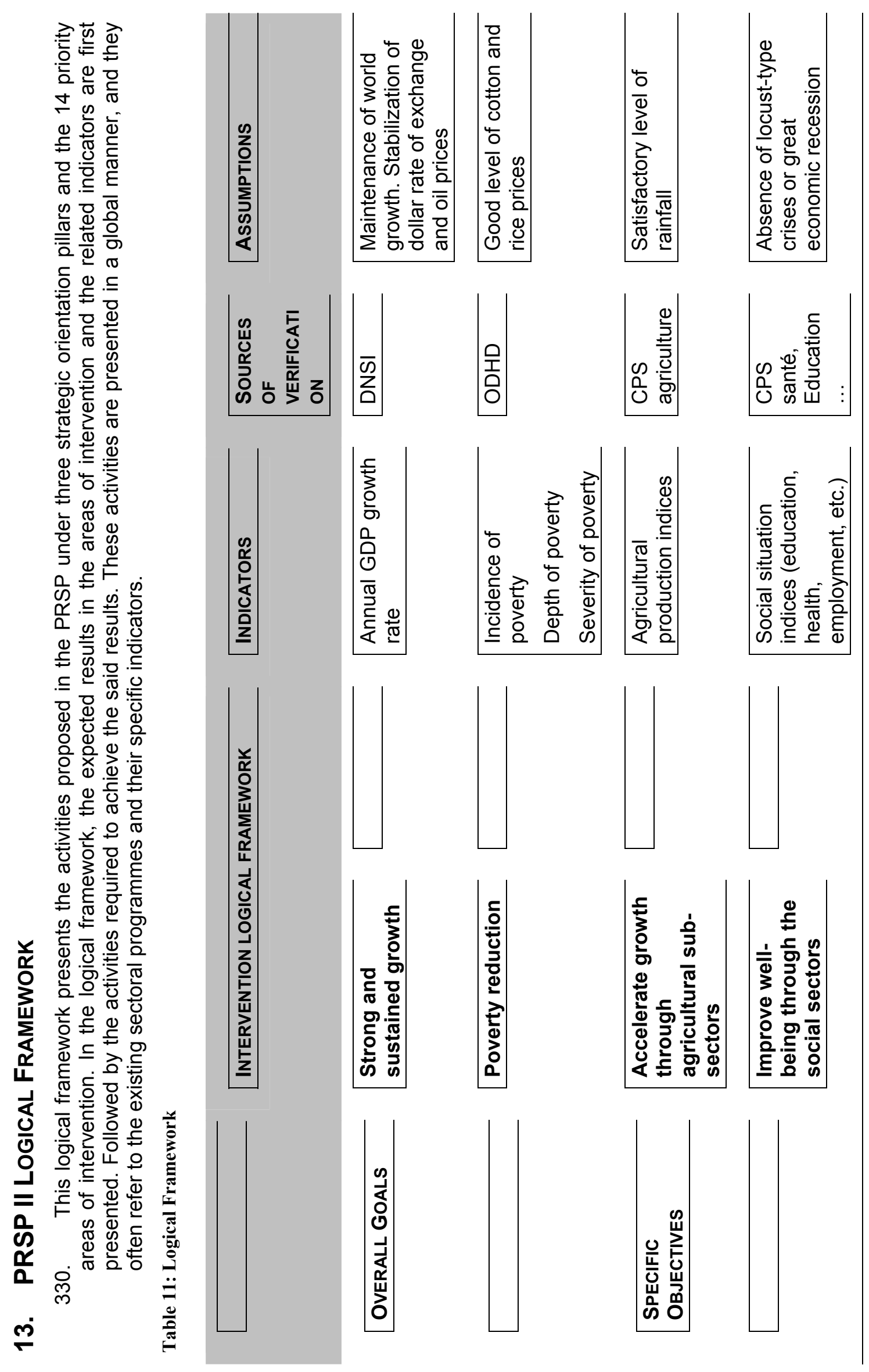

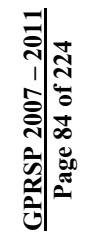



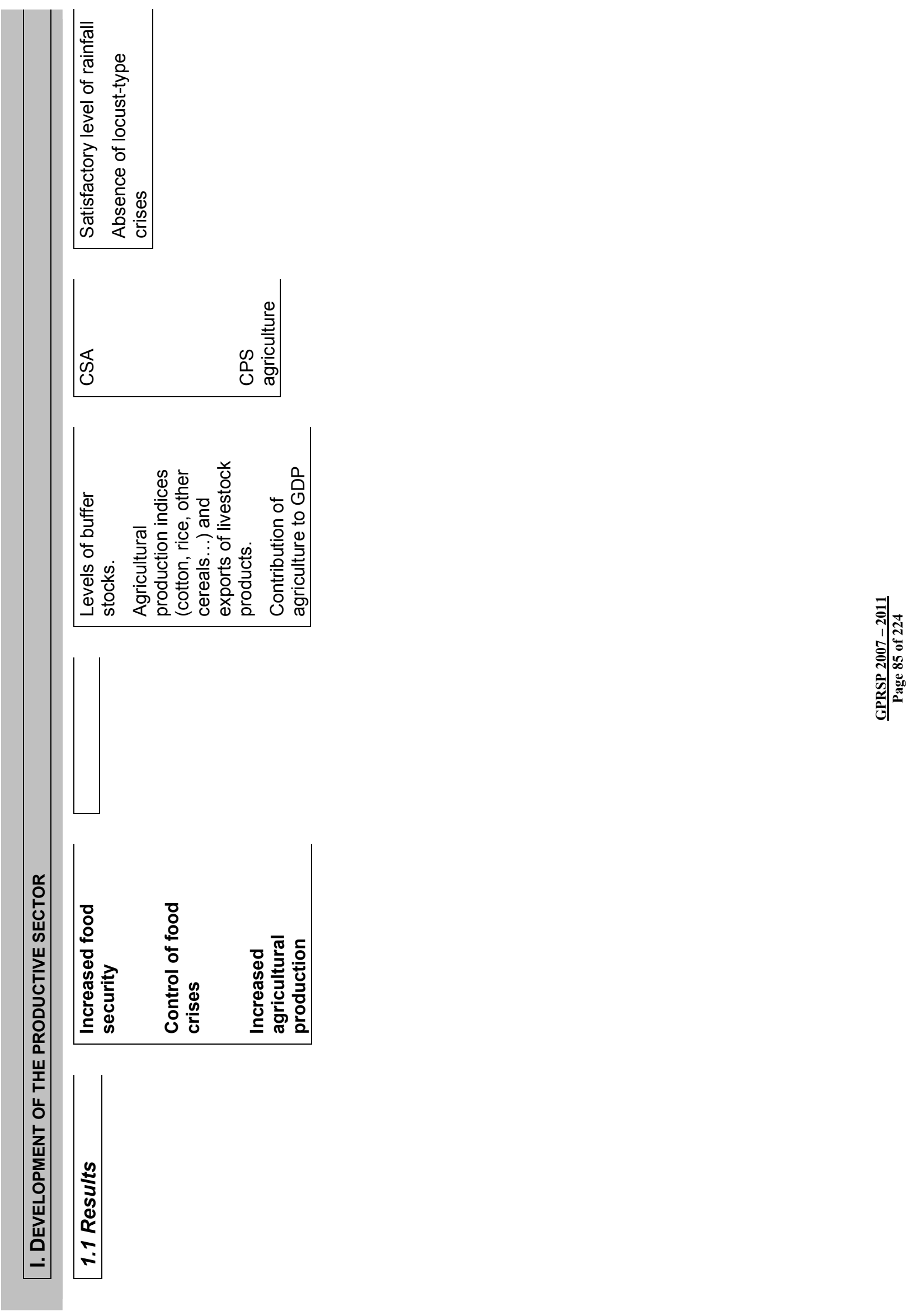


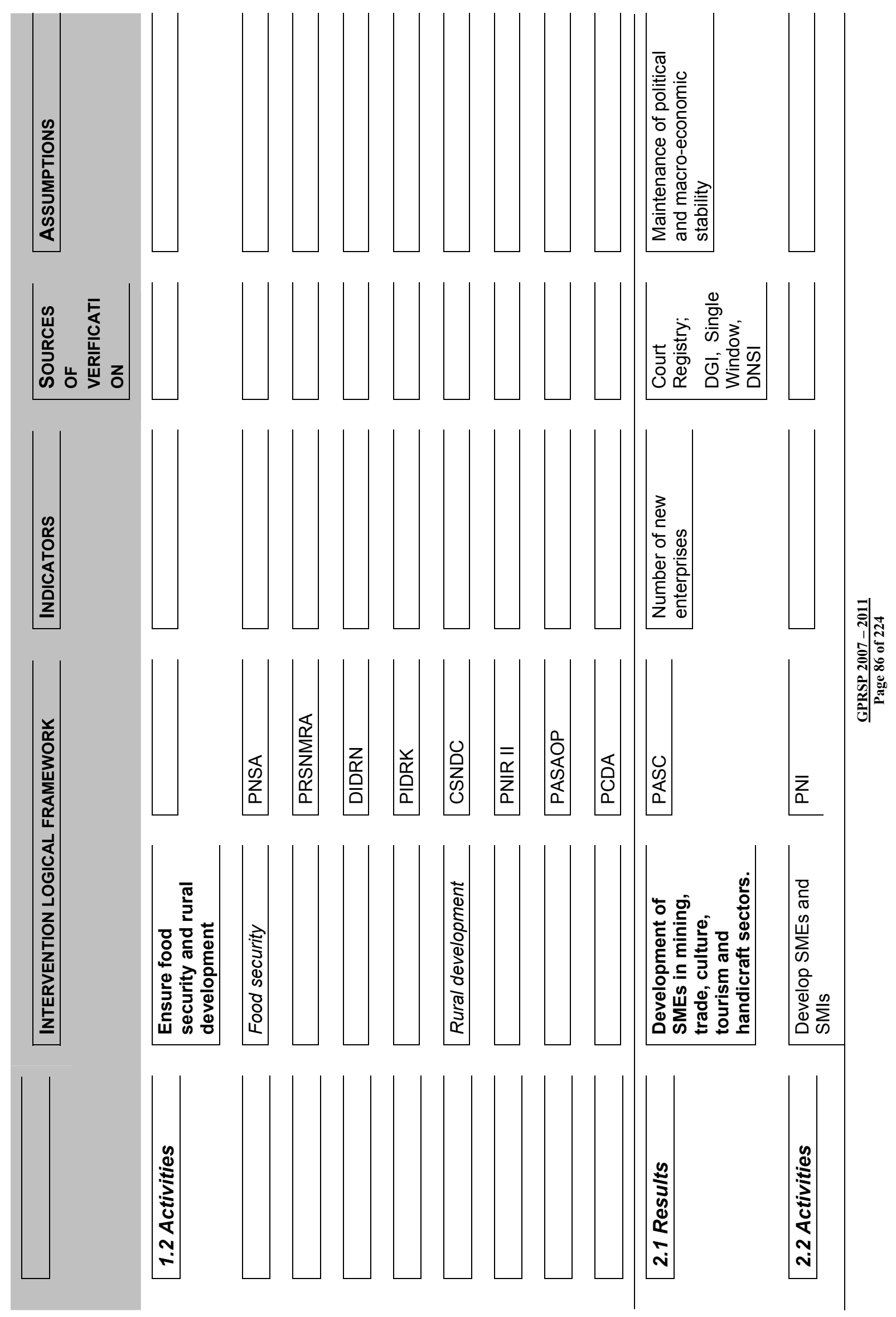




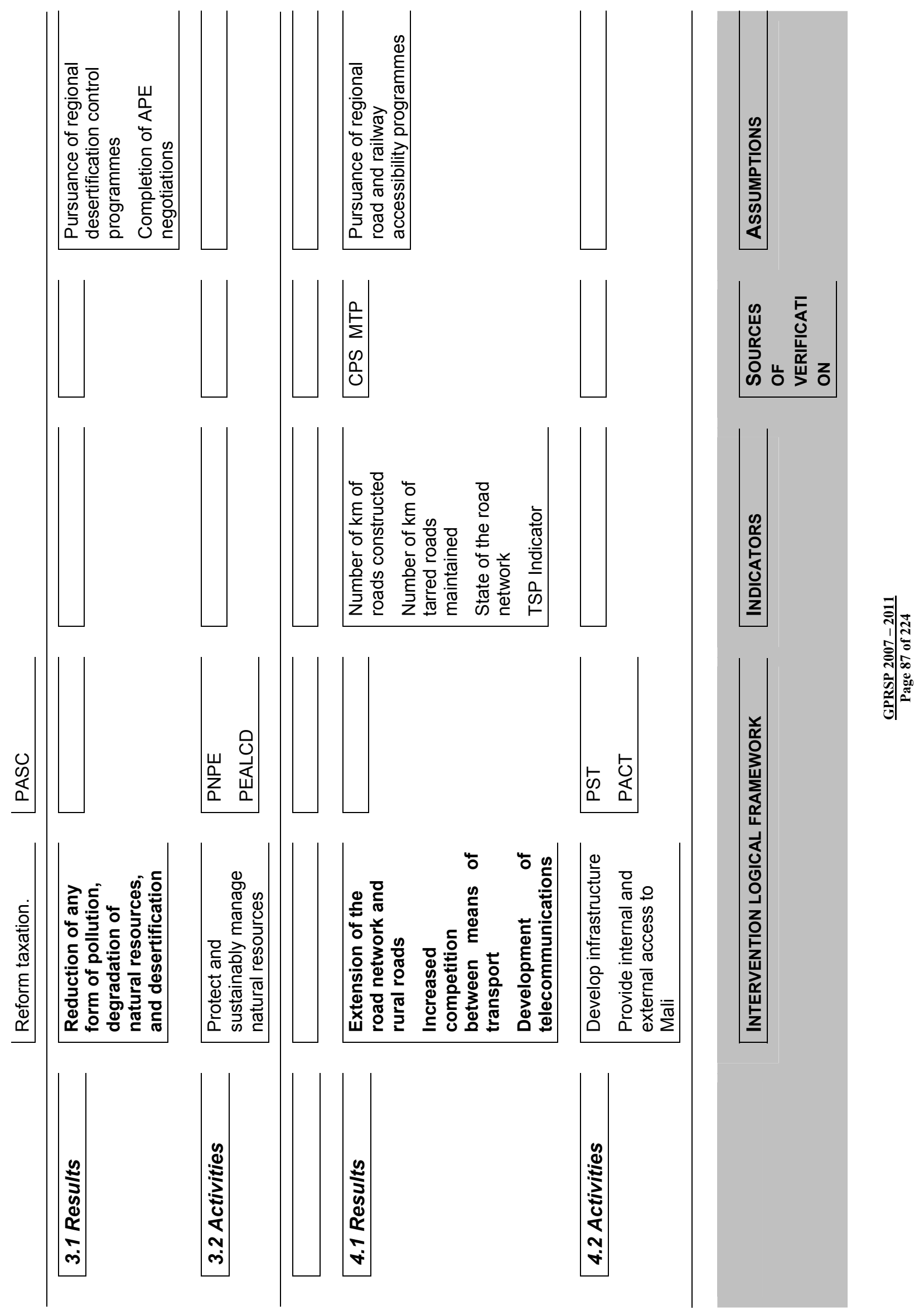




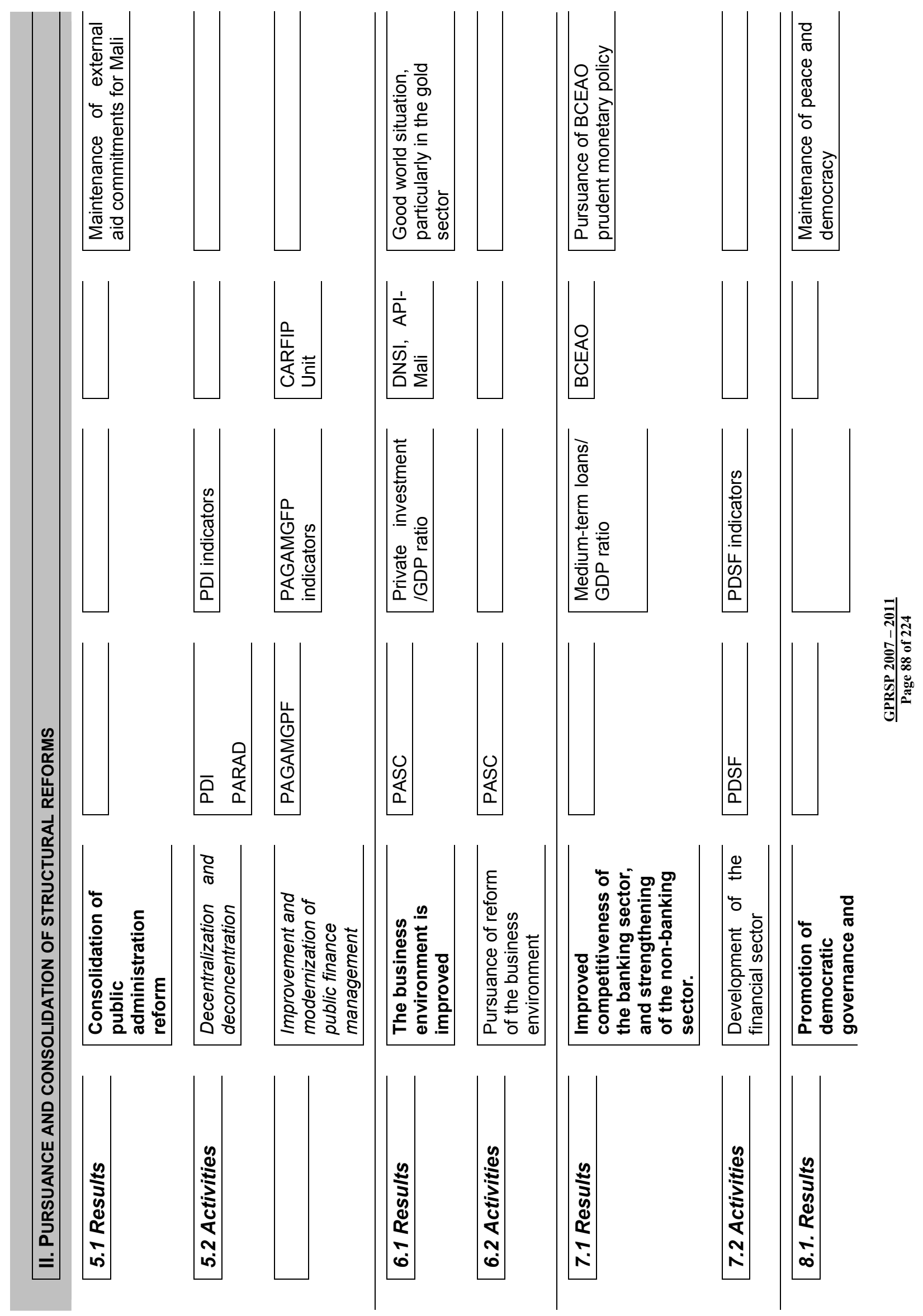



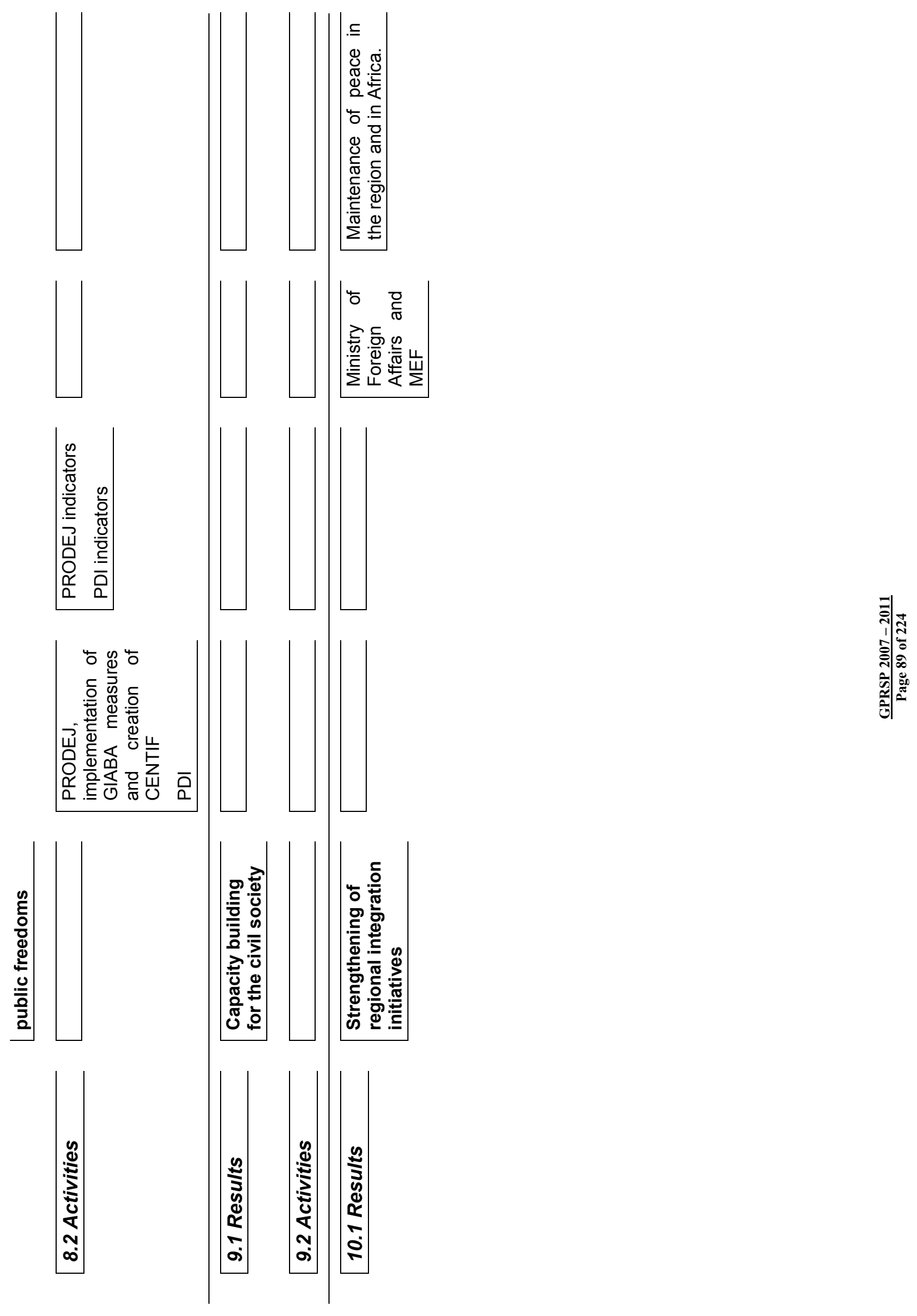


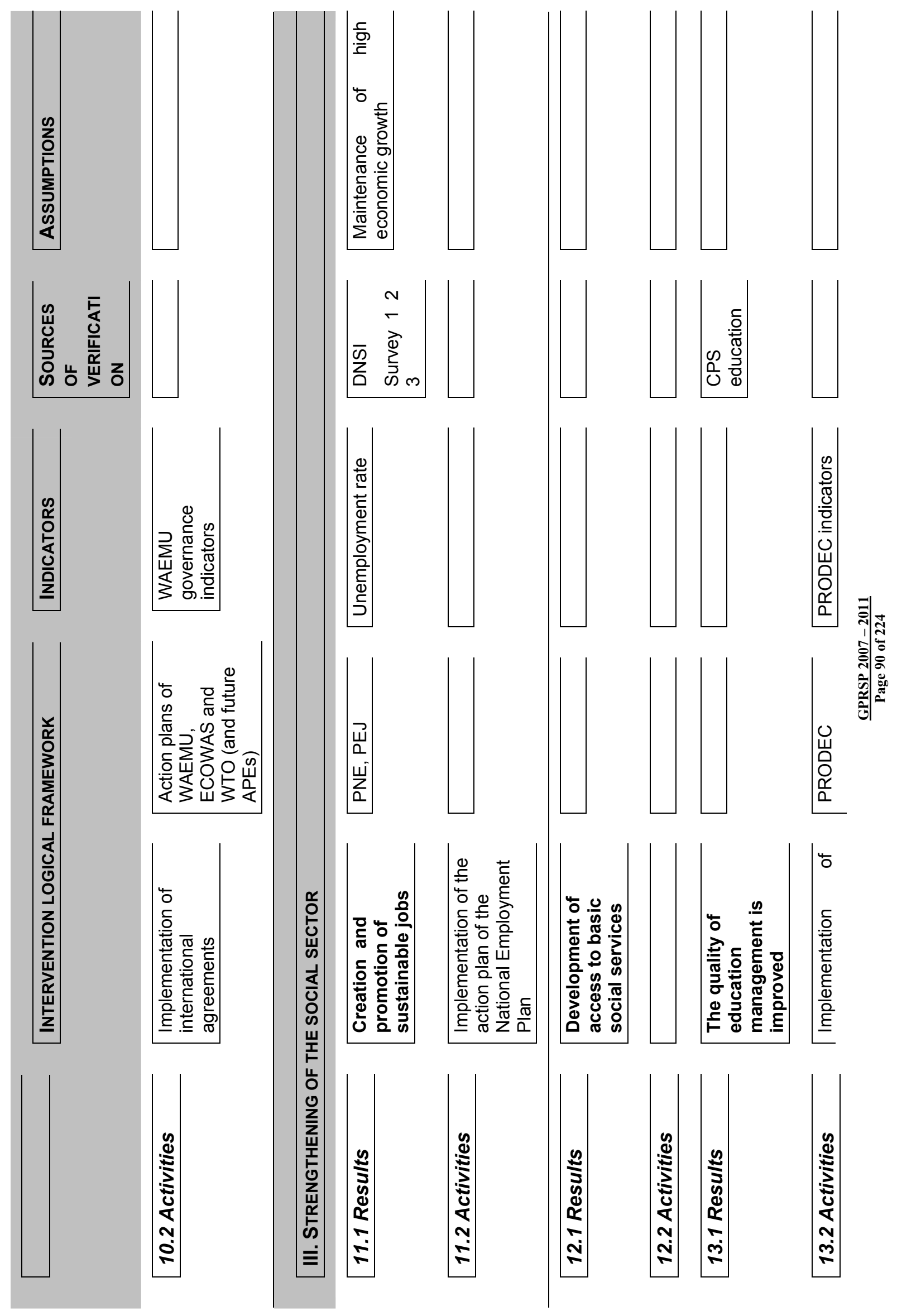



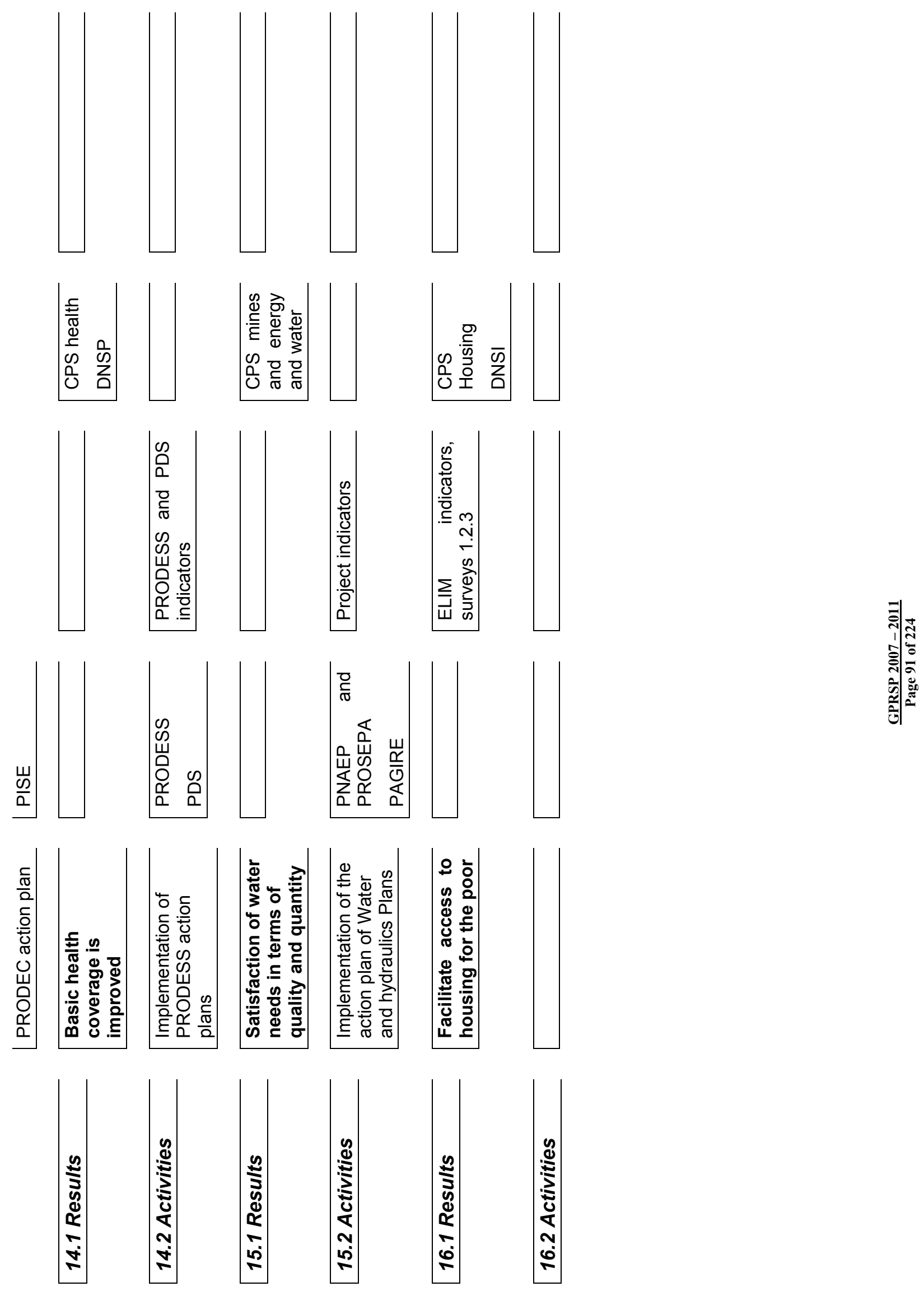

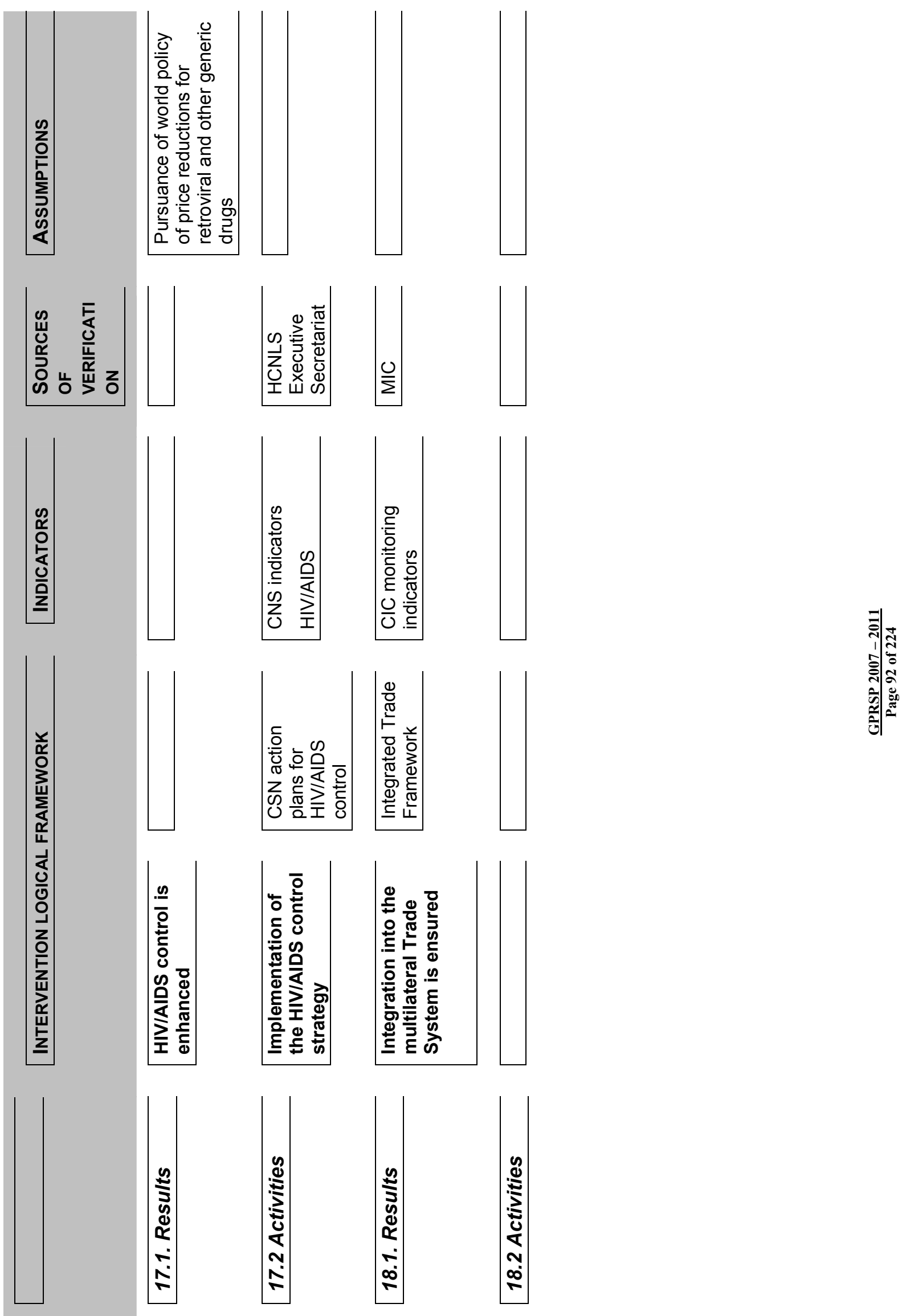


\section{CONCLUSION}

331. This PRSP II document has incorporated the key observations and comments proposed and validated by the participants of the National Workshop on the Preparation and Monitoring-Evaluation of the $2^{\text {nd }}$ generation PRSP $2007-2001$ from 11 to 13 September 2006. Some information is still lacking; it will be included in this report as soon as the respective activities are completed. The information comprises: (i) information on the recent state of poverty as shown by an analysis of the ELIM survey, (ii) selection of key indicators for PRSP monitoring and evaluation, and (iii) presentation of the action plan, which will incorporate actions concerning the Millennium Development Goals (MDG).

332. The $2^{\text {nd }}$ generation PRSP, in its current version, is therefore still evolving, portraying the desire of the authorities to associate all development stakeholders and take into account all the problems of the Malian society. The new generation PRSP is not yet complete and is intangible, but in comparison to PRSP I, it has made significant progress that should be consolidated through implementation and monitoring, which have also made significant progress.

333. The PRSP I implementation period faced constraints due to vagaries of the weather, fluctuation of the prices of major exports (cotton and gold) and imports (increase in the prices of hydrocarbons, building materials), and consequences of conflicts in the sub-region. Ways and means should be found to mitigate the impact of the exogenous factors.

334. Although external constraints have undoubtedly slowed down growth and therefore poverty reduction, endogenous factors remain significant. The growth rate of $6.7 \%$ was not achieved due to inadequacies and delays in the implementation of structural measures. With respect to public finance, the overall goal to curb the deficit of the Government's financial operations is hampered mainly by: (i) the failure to achieve target tax pressure rate (this requires new and bold measures to broaden the tax base, such as taxing the informal sector, land and the agricultural sector), (ii) the difficulty of curbing public expenditure (domestic debt, additional social expenditures), and (iii) delays in the mobilization of external resources. Similarly, severe constraints limit the business environment and slow down growth and poverty reduction. These constraints include corruption, high costs of water, electricity and telephone, as well as deficiencies in transport infrastructure. The enhancement of deconcentration, which should accompany decentralization, has not reached the critical level that shows improvement of living conditions in Local Authorities.

335. The challenges of PRSP II concern acceleration of growth and improvement of economic and political governance, a prerequisite for development.

336. Inadequate mobilization of external financing poses the problem of appropriate solutions for the multiple policies and procedures of the Technical and Financial Partners (TFP). In this connection, it is recommended that the Paris Declaration on Aid Effectiveness should be implemented. In addition to the problem of direct budget support, efforts to effectively implement budget support should be more explicit and pursued.

337. With respect to sectoral measures, PRSP II should lay emphasis on: (i) completion of reform of the cotton sector, (ii) reduction of production cost with, in particular, reform of the water and electricity sector, (ii) extension of the transport and telecommunication infrastructure, and (iv) human, institutional and organizational capacity building. 
338. It is recommended in PRSP II that the relative proportion of tax revenue in the State budget should be increased through: (i) broadening and diversification of taxation basis, (ii) proper identification of taxpayers, (iii) drastic reduction of exemptions, (iv) improvement of the efficiency of collection services with the modernization of tax administration through the use of computers, (v) adaptation of the tax laws reviewing the causes of loss and strengthening the tax system, as well as reorganizing the tax administration. It will also consist in establishing a tax system conducive to better redistribution of incomes and mobilization of savings.

339. To eliminate constraints that undermine the proper implementation of PRSP II and achievement of its objectives, the Government should accelerate the implementation of institutional reforms, particularly the Action Plan for the Improvement and Modernization of Public Finance Management, aimed at obtaining direct budget assistance from the TFPs. It should also determine the main driving force behind accelerated growth, by identifying the growth-oriented sub-sectors and sectors, as well as their diversification, elimination of obstacles, and action plan for accelerating economic growth. It is recommended that efforts be made to build capacities, especially those of DAFs, CPS and Central departments of the Administration, so as to optimize the programming, implementation and monitoring of actions under PRSP II implementation.

340. Furthermore, it is recommended that the institutional monitoring-evaluation mechanism of PRSP I should be clarified and simplified. It is also necessary to harmonize the methods, tools, instruments and indicators with those of PTI/BSI and programme budgets.

341. The PRSP evaluation also calls for a review of the number and type of indicators selected by component or thematic area to ensure better legibility and greater relevance.

342. The uniqueness of PRSP II, the single frame of reference, requires greater ownership by all the stakeholders. It calls for greater integration of all the ongoing major sectoral studies in Mali. The participatory process also calls for the gradual search for regionalization of PRSP II as well as for better determination of the contribution by civil society, NGOs and communities to its implementation.

343. Lastly, the Government gives top priority to two exercises which commit it to the international community: the Ten-Year Action Plan to achieve the MDGs and the preparation of an action plan for the implementation of the Paris Declaration. 


\section{$2^{\text {nd }}$ Generation PRSP 2007 - 2011}

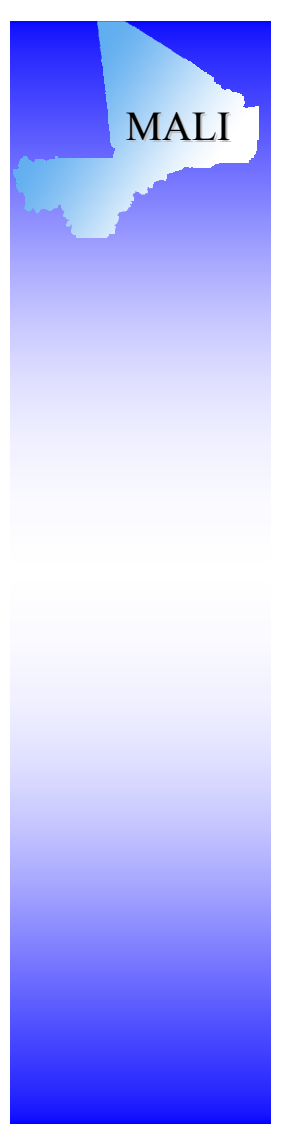

\section{Annex I \\ Macroeconomic Framework \\ 2007 - 2011}

December 20, 2006 


\section{Table of Contents}

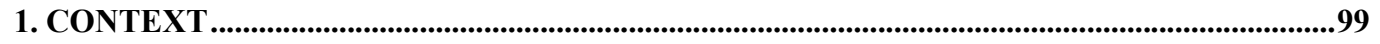

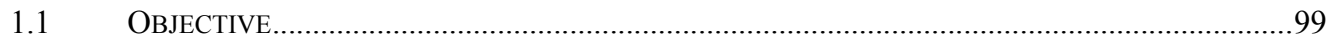

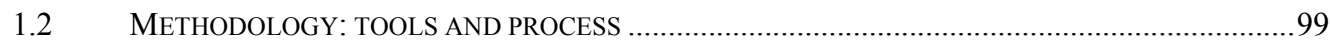

2 PREPARATION OF THE MACROECONOMIC FRAMEWORK......................................101

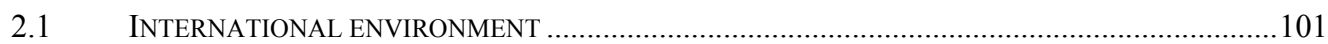

2.2 MALI'S RECENT ECONOMIC SITUATION (ACHIEVEMENTS OF THE 2002-2005 PERIOD)...........102

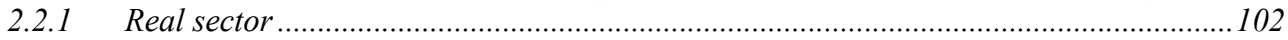

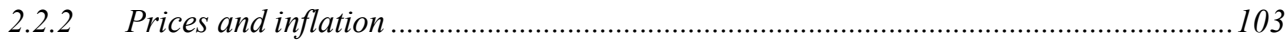

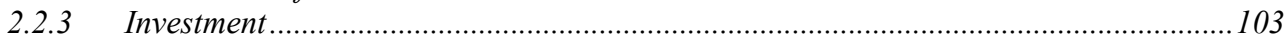

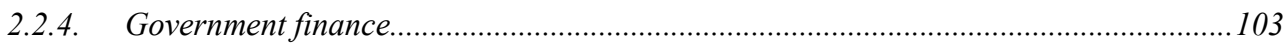

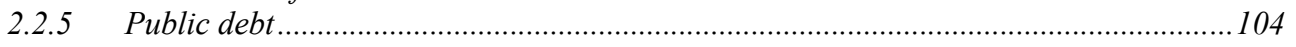

2.2.6 Balance of payments ................................................................................................. 105

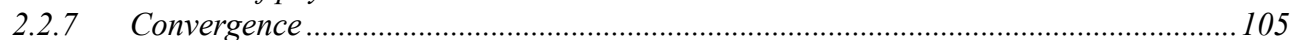

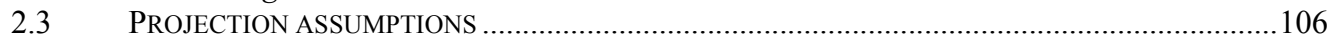

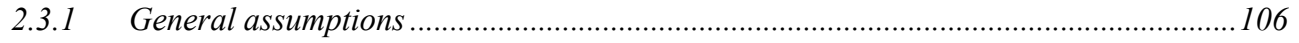

2.3.2 Specific assumptions.................................................................................................... 107

2.4 MAIN RESULTS OF THE MACROECONOMIC FRAMEWORK (AMBITIOUS SCENARIO) ................109

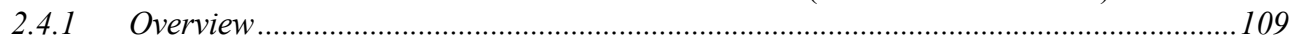

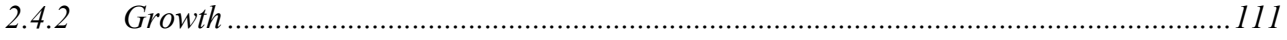

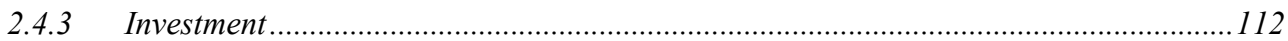

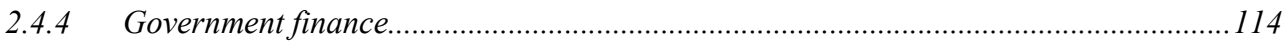

2.4.5 Public debt .............................................................................................................. 115

2.4.6 Balance of payments and monetary survey ......................................................... 115

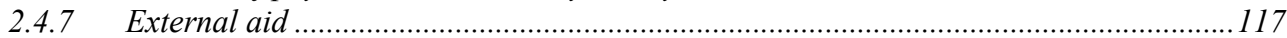

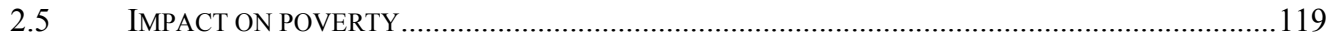

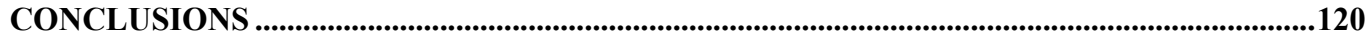

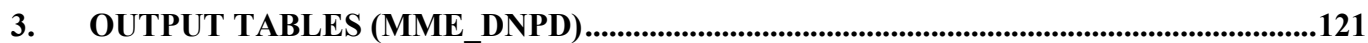

$\begin{array}{lr}\text { TABLE 1: GENERAL ASSUMPTIONS } & 106\end{array}$

TABLE 2: EXTERNAL AID ASSUMPTIONS 108

TABLE 3: MACROECONOMIC PERFORMANCE INDICATORS AND POLICY CRITERIA 110

TABLE 4: SUPPLY AND USE OF GOODS AND NONFACTOR SERVICES IN CFAF BILLION 112

TABLE 5: CONSOLIDATED GOVERNMENT FINANCE BUDGET AND ITS FINANCING (TOFE) (CFAF BILLION CURRENT)

TABLE 6: BALANCE OF PAYMENTS (CFAF BILLION)

TABLE 7: MONETARY SITUATION (CFAF BILLION; END OF PERIOD) 117

TABLE 8: EXTERNAL AID NEEDS (CFAF BILLION) 118

TABLE 9: FINANCING GAP (CFAF BILLION) 118

TABLE 10: PROJECTION ASSUMPTIONS FOR THE BASIC SCENARIO 121

TABLE 11: PROJECTION ASSUMPTIONS FOR THE AMBITIOUS SCENARIO 122

TABLE 12: MACROECONOMIC PERFORMANCE INDICATORS AND POLICY CRITERIA 123

TABLE 13: SUPPLY AND USE OF GOODS AND NONFACTOR SERVICES (CFAF BILLION CONSTANT) 124

TABLE 14: SUPPLY AND USE OF GOODS AND NONFACTOR SERVICES (CFAF BILLION CURRENT) 124

TABLE 15: SAVINGS AND INVESTMENT (CFAF BILLION CURRENT) 125

TABLE 16: CONSOLIDATED GOVERNMENT FINANCE BUDGET AND ITS FINANCING (TOFE) (CFAF BILLION CURRENT) 126

$\begin{array}{lr}\text { TABLE 17: STRUCTURE OF GOVERNMENT EXPENDITURE } & 127\end{array}$

TABLE 18: BALANCE OF PAYMENTS (CFAF BILLION) 128

TABLE 19: MONETARY SURVEY (CFAF BILLION; END OF PERIOD) 129

TABLE 20: PRICE INDICES AND EXCHANGE RATE $(1987=100)$

TABLE 21: PRICE INDICES BY ECONOMIC SECTOR $(1987=100) \quad 130$

TABLE 22: GDP BY SECTOR (CFAF BILLION AT 1987 PRICES) 130

TABLE 23: SECTORAL CONTRIBUTION TO GROWTH (IN PERCENT) 131

TABLE 24: GDP BY SECTOR (CFAF BILLION CURRENT) 132

TABLE 25: EXPORTS OF MERCHANDISE (BILLION OF CFAF CURRENT) 133 
TABLE 26: IMPORTS OF MERCHANDISE (CFAF BILLION PRICES CURRENT)

TABLE 27: EXTERNAL AID

134

TABLE 28: PRIVATE SECTOR DISPOSABLE INCOME (CFAF BILLION CURRENT)

TABLE 29: PUBLIC SECTOR DISPOSABLE INCOME (CFAF BILLION CURRENT)

\section{List of Figures}

FIGURE 1: TRENDS IN REAL GDP GROWTH 102

FIGURE 2: TRENDS IN RATE OF INFLATION (HICP) 103

FIGURE 3: TRENDS IN PUBLIC AND PRIVATE INVESTMENT 103

FIGURE 4: TRENDS IN GOVERNMENT FINANCE INDICATORS (IN BILLIONS OF CFAF AND IN PERCENT) 104

FIGURE 5: TRENDS IN PUBLIC DEBT IN PERCENT OF GDP 105

FIGURE 6: TRENDS IN FOREIGN TRADE INDICATORS (IN CFAF BILLION AND PERCENT) 105

FIGURE 7: TRENDS IN ECONOMIC GROWTH AND MONETARY POVERTY 119 


\section{List of acronyms and abbreviations}

$\begin{array}{ll}\text { ACN } & \text { African Cup of Nations } \\ \text { AMADER } & \text { Malian Agency for the Development of Rural Electricity } \\ \text { BCEAO } & \text { Central Bank of West African States } \\ \text { BSI } & \text { Special Capital Budget } \\ \text { CACEM } & \text { Société d'Exploitation des Phosphates of Tilemsi } \\ \text { CFAF } & \text { African Financial Community franc } \\ \text { CPM } & \text { Forecasting and Modeling Committee } \\ \text { DGB } & \text { National Budget Directorate } \\ \text { DGDP } & \text { National Public Debt Directorate } \\ \text { DNGM } & \text { National Directorate of Geology and Mining } \\ \text { DNPD } & \text { National Planning and Development Directorate } \\ \text { GDP } & \text { Gross Domestic Product (at market prices) } \\ \text { GDPf } & \text { Gross Domestic Product at factor cost } \\ \text { GFCF } & \text { Gross Fixed Capital Formation } \\ \text { HIPC } & \text { Heavily Indebted Poor Countries } \\ \text { IMF } & \text { International Monetary Fund } \\ \text { LOA } & \text { Agricultural Policy Law } \\ \text { MDGs } & \text { Millennium Development Goals } \\ \text { MDRI } & \text { Multilateral Debt Relief Initiative } \\ \text { MEF } & \text { Ministry of Economy and Finance } \\ \text { MME_DNPD } & \text { DNPD Macroeconomic Model for Mali } \\ \text { MPAT } & \text { Ministry of Planning and Land Use Management } \\ \text { MS } & \text { Ministry of Health } \\ \text { MTBF } & \text { Medium Term Budgetary Framework } \\ \text { MTEF } & \text { Medium Term Expenditure Framework } \\ \text { OMVS } & \text { Organization for the Development of the Senegal River } \\ \text { PADEPECHE } & \text { Inland Fisheries Development Support Project } \\ \text { PAGAMGFP } & \text { Government Fiscal Management Improvement and Modernization Action } \\ \text { PRSP } & \text { Program } \\ \text { PST } & \text { Poverty Reduction Strategy Paper } \\ \text { PTF } & \text { Transport Sector Program } \\ \text { PTI } & \text { Technical and financial partners } \\ \text { T21 } & \text { Three-year Investment Program } \\ \text { TOFE } & \text { Threshold 21 Model } \\ \text { WAEMU } & \text { Central Government Consolidated Fiscal Operations } \\ \text { WACEM } & \text { West African Economic and Monetary Union } \\ \text { West African Cement }\end{array}$




\section{CONTEXt}

1. The government of Mali has, since 2002, expressed its firm commitment to making the fight against poverty the main priority of all its development actions. This commitment manifested itself in the preparation, adoption, and implementation of the Poverty Reduction Strategy Paper (PRSP) covering the period 2002-2006.

2. The macroeconomic framework sets forth the broad goals of the government's mediumterm policies and facilitates preparation of optimal sectoral policies consistent with the development goals.

3. Less than one year from the end of the 2002-2006 PRSP, it became apparent that it would be difficult to achieve average economic growth of 6.7 percent over the $2002 / 2006$ period and reduce the incidence of poverty from 63.8 percent to 47.5 percent in 2006, because of a number of shocks that had not been taken into account in the basic assumptions, namely the Ivoirien crisis sparked in 2002, the 2004 locust invasion, the 2005 food crisis, and the upward spiral in oil prices.

4. This macroeconomic framework report forms part of the preparation exercise for the second generation PRSP and is aimed at producing realistic macroeconomic indicators consistent with the true potential of the Malian economy.

5. It presents the context and environment in which the first phase of the PRSP was implemented, and its main achievements, as well as the findings and recommendations of the working group on the PRSP-II macroeconomic framework.

6. For the purpose of conducting multisectoral and pluridisciplinary modeling, harmonizing the national statistics, and performing theoretical and methodological research to manage development in Mali, a Forecasting and Modeling Committee (CPM) was established by Decree 03-366/PM-RM of August 29, 2003 and placed under the responsibility of the Ministry of Planning. The working group on the PRSP-II macroeconomic framework, chaired by the National Planning and Development Directorate, conducted its work under the aegis of this committee.

\subsection{Objective}

7. The overarching policy objective is to maintain macroeconomic stability taking account of the true potential of the Malian economy and the overall and sectoral goals of the PRSP.

8. With this in mind, two scenarios - a basic scenario and an ambitious scenario-were chosen to guide the formulation of sectoral policies and the implementation of national development strategies through 2011.

\subsection{Methodology: tools and process}

9. Macroeconomic planning and modeling is carried out under the responsibility of the National Planning and Development Directorate (DNPD) using various tools. These include the Macroeconomic Model for Mali (MME_DNPD) and the Threshold 21 medium and long-term forecasting and simulation model, T21-Mali (which refers to standing on the threshold of the 21 st century).

10. Work on the framework began in April 2005. A preliminary version was produced and amended on several occasions. 
11. With the official launch of the preparation of the second generation PRSP in February 2006, the CPM focused its work on producing a macroeconomic framework for the PRSPII.

12. To that end, the Technical Secretariat used the two modeling tools to prepare the framework. The tables were produced with the MME_DNDP and the analyses, on poverty in particular, were fine-tuned taking account of the conclusions of the structural analysis of the Malian economy conducted with the T21 in March 2006.

13. The exercise was further intensified with the launch of the PRSP-II ad hoc working groups. The CPM tasked its Technical Secretariat with producing a technical report by May 20, 2006 at the latest. The report was discussed and unanimously adopted by the committee on July 6, 2006. As the budget forecasts for 2006 and 2007 had not yet been revised by the Ministry of Economy and Finance (MEF) and discussed with the IMF, the macroeconomic framework had to be adjusted in September 2006 to ensure its compatibility with the overall Medium Term Budgetary Framework (MTBF).

14. On the basis of assumptions regarding the international environment and promising sectors of the Malian economy, two scenarios, taking account of the country's actual economic potential, were produced. Specifically, these were a basic (trend) scenario that forecasts economic development based on existing policies, and an ambitious scenario (the PRSP-II scenario) that makes assumptions of strong growth in the promising sectors and provides for a broader tax base so as to meet the WAEMU tax ratio target by 2008 and ensure coherence with the overall MTBF in terms of spending. 


\section{Preparation of the Macroeconomic Framework}

15. The macroeconomic framework was prepared taking account of the strengths and weaknesses of the first PRSP, on the one hand, and of the real productive capacity of the national economy and potential domestic and external risks, on the other. The framework also takes account of major international and regional development goals, in particular the MDGs and those of the WAEMU.

\section{$2.1 \quad$ International environment}

16. The international economic environment is characterized by the price instability of Mali's export products, the upward trend in oil prices, and the geopolitical crises in Iraq, Iran, and Côte d'Ivoire, among others.

17. Oil importing countries have been very much affected by the high level of oil prices. Growth has, however, remained sustained as a result of favorable financial market conditions (low interest rates) and controlled inflation.

18. The tense situation in the oil market, the threat of new fuel price hikes, and the possibility of higher interest rates constitute major downside risks to economic expansion.

19. Global GDP grew by 4.8 percent $^{9}$ in 2005 versus 5.3 percent in 2004 , while estimates put growth at 4.9 percent in 2006. Petroleum products price volatility and global current account imbalances were key factors impacting on growth.

20. Thus, Europe continued to record below par growth. In Japan and the Unites States, on the other hand, despite the slowdown in economic activity, performance remained close to the maximum sustainable growth rate.

21. Among the major developing countries, GDP growth continued apace in China and India, which posted figures of 9.0 percent and 7.0 percent, respectively. Growth slowed in Russia, however, following a flattening of production levels in the oil sector.

22. For oil importing developing countries, growth is estimated to have fallen from 6.9 percent to 6.1 percent driven by the combined effect of higher oil prices, domestic capacity constraints and a slowdown in the demand for imports in high-income countries. The fall is even more pronounced in real income terms, dropping from 6.4 percent to 3.7 percent.

23. For oil exporting developing countries, despite the steady increase in oil revenues, reduced capacity to increase production in the oil sector resulted in a decline from 6.6 percent to 5.6 percent.

24. For sub-Saharan Africa, growth firmed up in 2005 mainly as a result of higher commodity prices, greater political stability, favorable climatic conditions, and higher oil and gas production in countries such as Angola, Chad and Equatorial Guinea. Economic activity grew by 5.5 percent in 2005, compared to 4.2 percent in 2004, and is expected to reach 5.8 percent ${ }^{10}$ in 2006.

25. In the WAEMU zone, economic growth is heavily dependent on the vagaries of the climate. With good rainfall levels in 2005, growth accelerated to 4.3 percent in 2005 versus 3.0 percent in 2004. In 2006, growth is projected to be 4.0 percent $^{11}$.

\footnotetext{
${ }^{9}$ IMF, World Economic Outlook, April 2006.

${ }^{10}$ African Economic Outlook, OECD, May 2005.

${ }^{11}$ WAEMU half-yearly progress report on multilateral surveillance, JUNE 2006.
} 
26. As a result of the international economic climate, prices rose in all regions of the world.

- In the Unites States, inflation reached 3.4 percent in 2005 compared to 2.7 percent in 2004.

- In Europe, inflation edged up to 2.2 percent in 2005 from below 2.1 percent in 2004.

- In Asia, even with oil price subsidies, inflation was up in most countries, rising from 4.4 percent in 2004 to 7.2 percent in 2005 .

- In sub-Saharan Africa, the year 2005 saw a rapid rise in inflation. Strong increases in food prices resulting from significant reductions in subsistence crops fed through to double-digit consumer price inflation in Chad, and considerable overruns of government targets in countries such as Niger, Togo, Benin, Burkina Faso, and Mali. The rate of inflation in this region was much higher than in the other regions of the world, at 10.6 percent versus 9.7 percent in 2004 .

- In the WAEMU zone, the average annual inflation rate stood at 4.3 percent in 2005 compared to 0.6 percent in 2004 .

\section{Mali's recent economic situation (achievements of the 2002-2005 period)}

27. In recent years, the economic climate in Mali has been difficult. It has been marked by the Ivoirien crisis (which has been causing economic disruption since September 2002), declining gold production since 2003, the locust invasion of 2004, and poor rainfall in the $2004 / 2005$ crop season, which led to serious food shortages and unprecedented levels of inflation in 2005.

28. Despite the challenging economic climate, in the first four years of implementation of the PRSP, Mali made significant progress on the political, social and economic fronts. Political and social stability and progress in respect for human rights facilitated the implementation of poverty alleviation policies while helping to strengthen the climate of confidence which Mali currently enjoys with the international community.

\subsubsection{Real sector}

29. The Malian economy is heavily influenced by climatic conditions. Economic performance is uneven and growth proceeds by fits and starts. The basic components of the economy are the agriculture-led primary sector, the gold-led secondary sector, and the tertiary sector, which is currently seeing the start of a boom led by the transport, telecommunications, and tourism sectors.

30. Between 2002 and 2005, growth averaged 5.1 percent. Since starting to implement the PRSP, Mali has posted positive growth, with 4.3 percent in 2002, 7.6 percent in 2003, 2.3 percent in 2004, and 6.1 percent in 2005.

\section{Figure 1: Trends in real GDP growth}

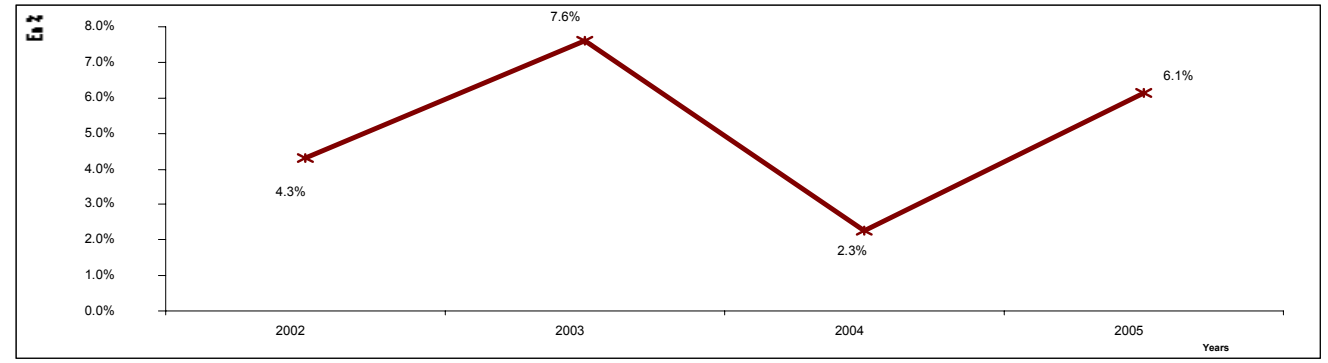

(Source: DNSI/MME_DNPD) 


\subsubsection{Prices and inflation}

31. As a result of vigorous price control efforts, the average inflation rate - measured by the annual change in the Harmonized Index of Consumer Prices (HICP) in Bamako-was 1.8 percent between 2002 and 2005. After reaching 5.1 percent in 2002, negative inflation growth was achieved in 2003 and 2004, with -1.3 percent and -3.1 percent, respectively. Inflation rebounded to 6.4 percent in 2005 , however, as a result of the shortage of food supplies following the poor 2004/2005 crop season.

Figure 2: Trends in rate of inflation (HICP)

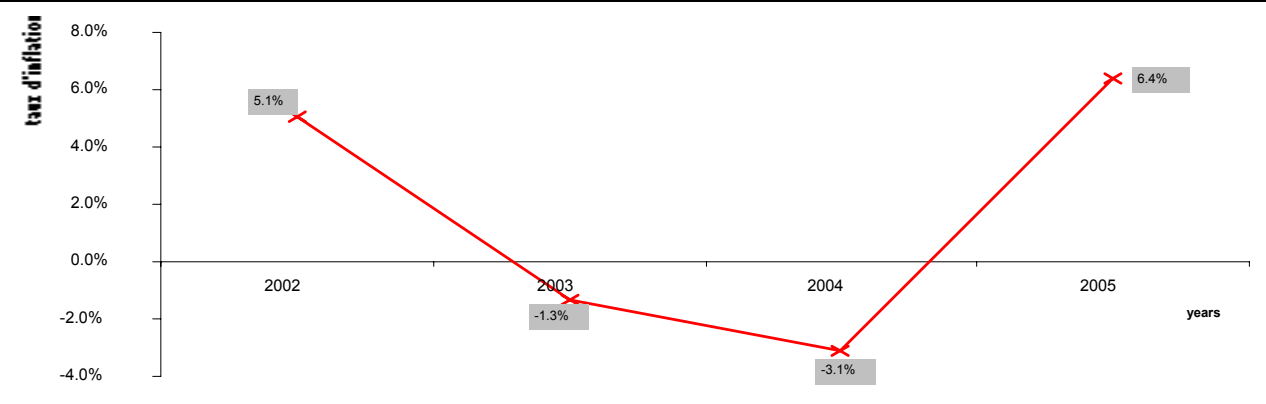

(Source: DNSI/MME_DNPD)

\subsubsection{Investment}

32. The period was marked by huge private and public investment flows. Private investments were channeled essentially into the building of gold mines, the development of mobile telephony and major real estate developments. Average annual net foreign direct investment flows amounted to CFAF 87.9 billion, rising to an exceptional CFAF 168.8 billion in 2002, as a result of the financing of infrastructure development for ACN 2002. Public investment, in turn, focused mainly on infrastructure development for ACN 2002, major road projects, and real estate and irrigated agriculture programs.

33. These public investment efforts were supported by technical and financial partners and saw the gross investment rate increase from 16.0 percent in 2002 to 21.4 percent in 2005 .

Figure 3: Trends in public and private investment

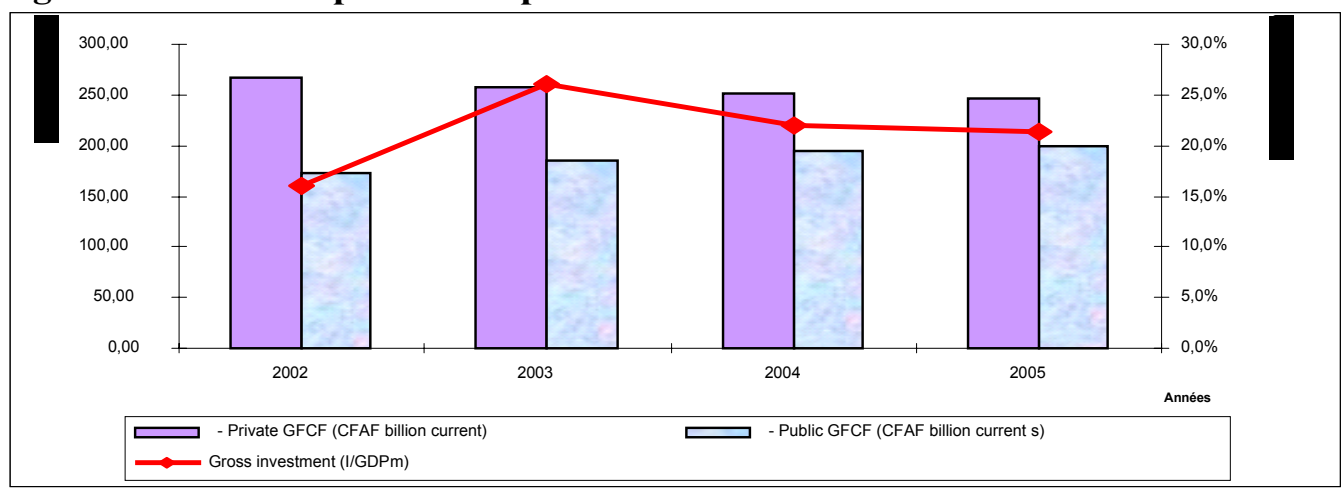

(Source: DNSI/MME_DNPD)

\subsubsection{Government finance}

34. One of the major pillars of the government's economic and financial reform strategy has been ensuring the viability of its financial operations. Official policy in this regard has 
aimed at achieving fiscal consolidation by controlling current expenditures and broadening the tax base.

35. Total revenues and grants in 2003 amounted to CFAF 621.6 billion in 2005 versus CFAF 456.7 billion in 2002, representing average annual growth of 8.0 percent. This performance was driven by tax receipts, which grew 9.9 percent a year on average.

36. Total expenditures and net lending amounted to CFAF 712.7 billion in 2005 versus CFAF 540.5 billion in 2002 , representing an average growth rate of 7.2 percent.

37. The deficit on a payment order basis, excluding grants, went from CFAF 169.6 billion in 2002 to CFAF 206.1 billion in 2005. In relation to GDP, the deficit was 7.6 percent in 2002 and 7.1 percent in 2005 , a 0.5 percentage point improvement. Including grants, the deficit amounted to CFAF 83.8 billion in 2002 and reached CFAF 91.1 billion in 2005, that is, 3.8 percent and 3.1 percent of GDP, respectively.

Figure 4: Trends in government finance indicators (in billions of CFAF and in percent)

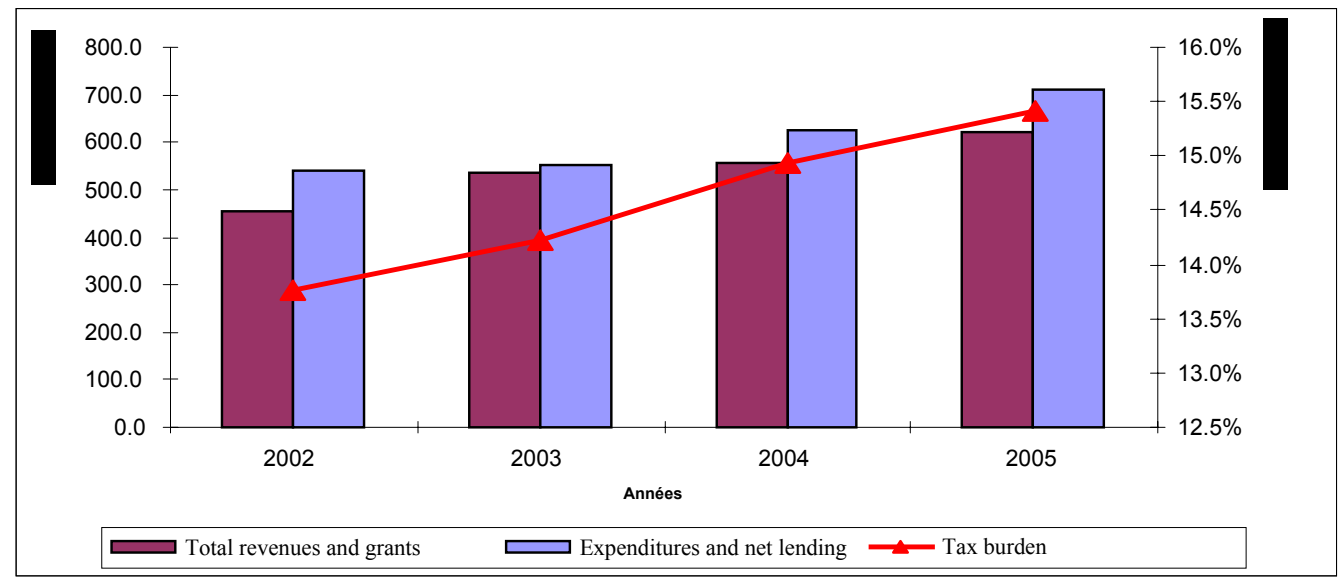

\section{Source: DNTCP-ACCT/MME_DNPD}

\subsubsection{Public debt}

38. In the context of implementing the PRSP, Mali took steps to improve public debt sustainability. Under the combined effect of HIPC debt relief and implementation of economic and financial programs with the IMF, total outstanding debt edged down from CFAF 1,853.2 billion in 2002 to CFAF $1,735.2$ billion in 2005, a decline of 1.6 percent on average. The stock of debt-to-GDP ratio improved from 83.4 percent in 2002 to 60.0 percent in 2005. It should also be noted that Mali is set to benefit from the G8's new Multilateral Debt Relief Initiative announced in 2005 aimed at providing 100 percent debt cancellation for 18 Heavily Indebted Poor Countries. This would mean a fundamental improvement in Mali's debt sustainability indicators in the years ahead. 
Figure 5: Trends in public debt in percent of GDP

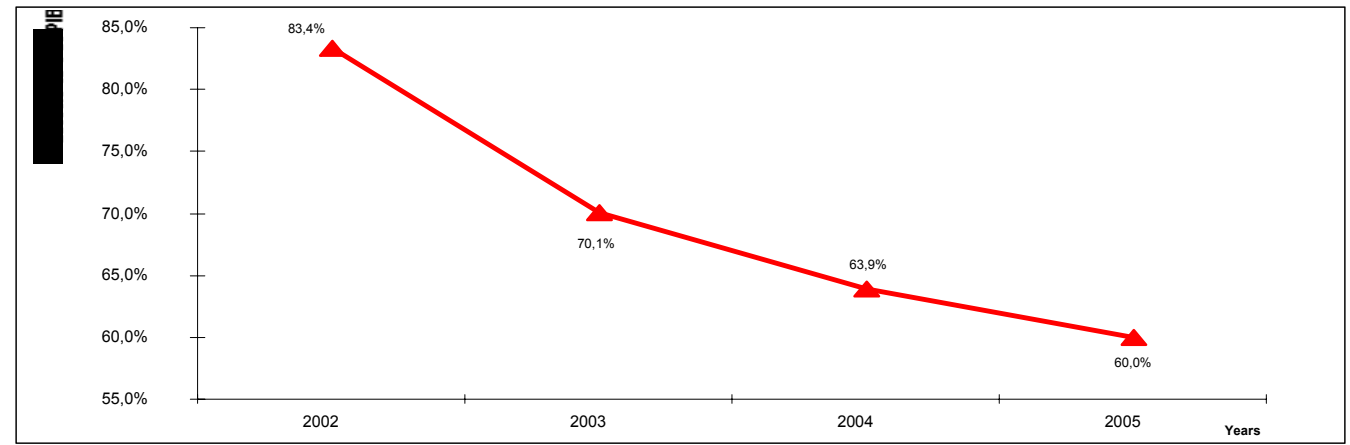

\section{(Source: DGDP/MME_DNPD)}

\subsubsection{Balance of payments}

39. Over the 2002 to 2005 period, Mali's main exports, gold and cotton, which account for over 80 percent of the country's total exports, dipped from CFAF 609.9 billion in 2002 to CFAF 598.9 billion in 2005, a 0.5 percent fall on average between 2002 and 2005.

40. On the subject of imports, petroleum products, chemicals and pharmaceutical products, construction materials, and machines and vehicles accounted for over 70 percent of the total. Imports grew 7.7 percent a year on average, up from CFAF 496.6 billion in 2002 to CFAF 669.0 billion in 2005.

41. The current account deficit, excluding official transfers, rose from CFAF 103.7 billion in 2002 to CFAF 204.1 billion in 2005, representing 8.5 percent of GDP on average over the period under review.

42. In general, Mali's overall balance of payments position improved between 2002 and 2005, with the exception of 2004 when it was negative (CFAF -35.4 billion), averaging 3.2 percent of GDP over the period.

Figure 6: Trends in foreign trade indicators (in CFAF billion and percent)

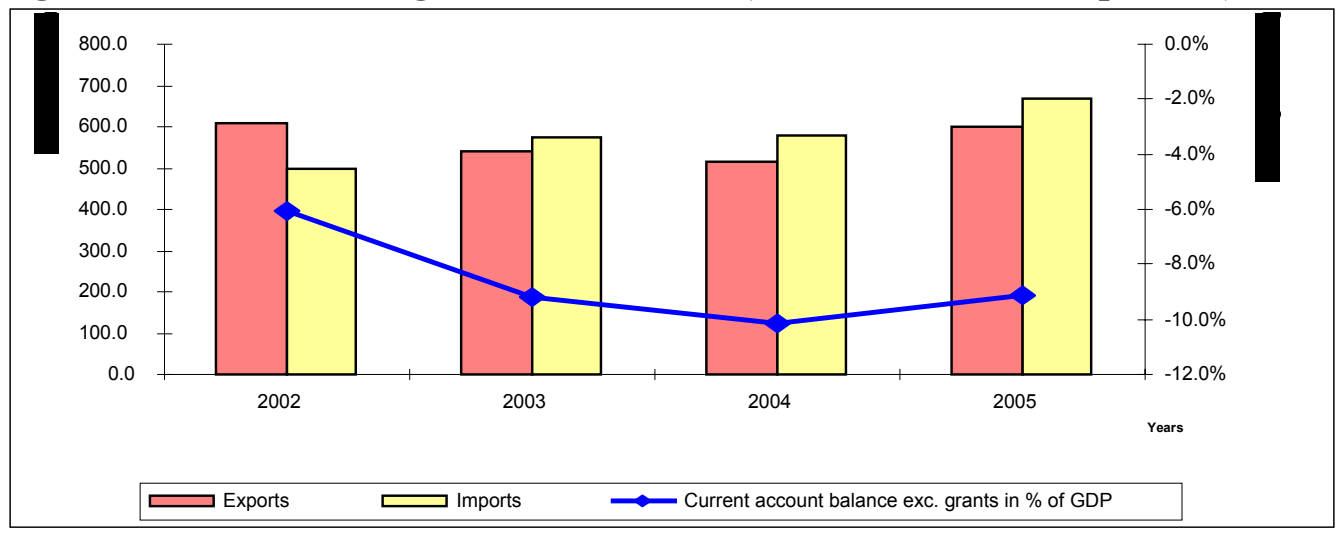

\section{Source: BCEAO/MME_DNPD}

\subsubsection{Convergence}

43. On the whole, Mali complied with all the WAEMU primary convergence criteria between 2002 and 2005. With regard to the secondary criteria, only the tax ratio (14.6 percent on average; target: 17 percent) and the external deficit-to-GDP ratio (8.6 percent on average; target $>5$ percent) were not met between 2002 and 2005 . 
44. In 2005, only one country in the Union, Senegal, complied with the four primary criteria, while, in 2002, two countries, Senegal and Benin satisfied these criteria.

45. This means that the conditions for access to the stability phase as defined in the Pact have not yet been met. Thus, in order to strengthen macroeconomic stability and meet the convergence criteria, a new convergence timeline has been set for December 31, 2008.

46. In the final analysis, despite the challenges of an unfavorable international environment and domestic shocks, Mali achieved economic growth of 5.2 percent on average over the first four years of implementation of the PRSP. This performance is attributable to the government's efforts to rationalize government finance and to the support of technical and financial partners in the area of investment financing. With sustained efforts along these lines, performance could continue to improve. However, there are still potential risks arising from the present upward trend in international oil prices.

\subsection{Projection assumptions}

47. The assumptions of the macroeconomic framework are based on those of the IMF World Economic Outlook and on the promising sectors of the Malian economy over the 20072011 period.

48. A distinction is made between general assumptions, which are the same for the two scenarios (the basic scenario and the ambitious scenario) and specific assumptions, which vary from one scenario to another.

49. The detailed forecast assumptions for the two scenarios can be found in Tables 10 and 11 below.

\subsubsection{General assumptions}

50. For the international environment, the assumptions indicate continuous improvement gold and cotton prices between 2007 and 2011 and a slight decline in oil prices starting in 2008.

51. Indeed, gold prices, which reached 443.5 dollars an ounce in 2005 , are expected to continue their gradual rise up to 775 dollars in 2011.

52. Cotton prices are also expected to continue rising from 55.2 cents/lb in 2005 to 63 cents/lb in 2011.

Table 12: General assumptions

\begin{tabular}{|c|c|c|c|c|c|c|c|c|}
\hline General assumptions & \begin{tabular}{|l|} 
Average \\
$2002-2005$
\end{tabular} & $\begin{array}{r}\text { estim } \\
2006\end{array}$ & $\begin{array}{r}\text { forecast } \\
2007\end{array}$ & $\begin{array}{r}\text { forecast } \\
2008\end{array}$ & $\begin{array}{r}\text { forecast } \\
2009\end{array}$ & $\begin{array}{r}\text { forecast } \\
2010\end{array}$ & $\begin{array}{r}\text { forecast } \\
2011\end{array}$ & $\begin{array}{l}\text { Average } \\
2007-2011\end{array}$ \\
\hline Global inflation rate (measured by the MUV) & $3.5 \%$ & $1.6 \%$ & $1.2 \%$ & $1.2 \%$ & $1.2 \%$ & $1.2 \%$ & $1.2 \%$ & $1.2 \%$ \\
\hline Cotton Prices (Cents/lb) & & 57.0 & 58.5 & 60.5 & 63.0 & 63.0 & 63.0 & 61.6 \\
\hline Gold Prices (\$/ounce) & & 618.0 & 670.0 & 710.0 & 750.0 & 770.0 & 775.0 & 735.0 \\
\hline Oil Prices $(\$ /$ barrel $)$ & & 66.5 & 69.8 & 68.5 & 67.5 & 66.8 & 66.0 & 67.7 \\
\hline Ratio US\$/Euro & 1.14106 & 1.25600 & 1.28635 & 1.29339 & 1.29895 & 1.30446 & 1.30971 & 1.29857 \\
\hline CFAF/US\$ Exchange rate (period average) & 582.2 & 522.3 & 509.9 & 507.2 & 505.0 & 502.9 & 500.8 & 505.2 \\
\hline US\$/CFAF (Change) & $-7.7 \%$ & $-0.8 \%$ & $-2.4 \%$ & $-0.5 \%$ & $-0.4 \%$ & $-0,4 \%$ & $-0.4 \%$ & $-0.8 \%$ \\
\hline CFAF/EURO Exchange rate & 656.0 & 656.0 & 656.0 & 656.0 & 656.0 & 656.0 & 656.0 & 656.0 \\
\hline
\end{tabular}

53. Global inflation, measured by the export price index for manufactured products of the five major industrialized countries (Manufactured Unit Value - MUV), is expected to show annual growth of 1.2 percent between 2007 and 2011 as against an average of 3.5 percent between 2002 and 2005.

54. A regular depreciation of around 0.8 percent a year of the dollar against the CFA franc is forecast over the 2007 to 2011 period. 
55. In terms of net foreign assets, the forecasts include an average annual target of 5.4 months of imports.

\subsubsection{Specific assumptions}

56. The specific assumptions on the national economy are defined for the basic scenario and the optimistic scenario separately (see Section 4.1 below).

57. The main differences between the two scenarios relate to growth in the promising sectors, such as rice, cotton, agrofood, textiles, livestock farming, gold, water/electricity, and private services, as well as to the tax ratio.

\section{Basic scenario assumptions}

58. The average annual growth rate for food crop farming, excluding rice, is projected to be 5.6 percent based on trends of the past six years.

59. For rice, projections put growth at 7.3 percent in 2007 and at 7 percent for the rest of the period.

60. Cotton production, in turn, is expected to remain constant at 2006 levels over the entire period, hence a zero growth projection.

61. Livestock production is expected to grow by 3 percent over the forecast period.

62. Projections for gold production are drawn from the DNGM, with growth of 0.7 percent and -10.5 percent forecast for 2007 and 2008, respectively. For the rest of the period, mining production should grow by 0.7 percent in 2009 , -4.8 percent in 2010 , and -2.7 percent after 2010. This forecast can be explained by the fact that most of the existing mines are ageing and their reserves are low.

63. Electricity and water production is projected to grow at 10.2 percent a year over the whole period. This projection reflects the commitment to boost electricity supplies through ongoing investment in rural electrification.

64. Growth in private services is an endogenous variable of the macroeconomic model (MME). The rate of growth of the related branches follows the pace of development of the so-called "modern" branches of the primary and secondary sectors.

65. The growth of non-market services mirrors the growth, in real terms, of civil service wages paid by the government. Wages are projected by the MEF in the overall MTBF.

66. In sum, real GDP growth at market prices is estimated at 5.0 percent a year on average (5.2 percent for $2002-2005)$.

67. Public investment is projected to grow in line with the Special Capital Budget (BSI) prepared by the MPAT in conjunction with the overall MTBF of the MEF. On that basis, the rate of public investment (in percent of GDP at factor cost, GDPfc) is estimated at 9.9 percent a year on average over the forecast period (versus 7.7 percent for the 2002-2005 period).

68. Private investments are projected on the basis of past trends, namely 10.4 percent of GDPfc in 2002 - 2005, and taking into account the major projects listed in Section 2.4.3 below. The result is an estimated annual average rate of investment of 12.1 percent between 2007 and 2011.

69. Regarding taxation, forecasts of direct and indirect duties and taxes as well as other fiscal revenues are based on individual growth rates resulting from econometric tests of past 
series and independent estimates. Given the annual tax ratio ( $=$ tax revenue in percent of nominal GDP) of 14.6 percent on average between 2002 and 2005, the tax ratio for the basic scenario is set to increase gradually from 15.1 percent in 2007 to 17.0 percent in 2011.

70. Public debt service is expected to drop sharply in the wake of the massive external debt restructuring of mid-2006 to the tune of CFAF 1,035.7 billion. The DGDP's forecasts were adopted.

71. The volume of external financial and budget support was projected essentially on the basis of the Three-year Investment Program (PTI) and other expenditures contained in the national budget within the framework of the overall MTBF. The following ratios of the various forms of aid to total expenditure are the result of that exercise.

Table 13: External aid assumptions

\begin{tabular}{|c|c|c|c|c|c|c|c|c|}
\hline External aid assumptions & $\begin{array}{l}\text { Average } \\
2002-2005\end{array}$ & $\begin{array}{r}\text { estim } \\
2006\end{array}$ & $\begin{array}{r}\text { forecast } \\
2007\end{array}$ & $\begin{array}{r}\text { forecast } \\
2008\end{array}$ & \begin{tabular}{|r|} 
forecast \\
2009
\end{tabular} & \begin{tabular}{|r|} 
forecast \\
2010
\end{tabular} & $\begin{array}{r}\text { forecast } \\
2011\end{array}$ & $\begin{array}{l}\text { Average } \\
2007-2011\end{array}$ \\
\hline Ratio: project-related capital grants/total publ. expenditure & $19.5 \%$ & $41.3 \%$ & $19,6 \%$ & $20.5 \%$ & $20.8 \%$ & $21.1 \%$ & $21.2 \%$ & $20.6 \%$ \\
\hline Ratio: overall budgetary grants/tot. pbl. exp. & $10.6 \%$ & $7.9 \%$ & $5,2 \%$ & $5.0 \%$ & $4.8 \%$ & $4.5 \%$ & $4.2 \%$ & $4.7 \%$ \\
\hline Ratio: sectoral budget support/tot. pbl. exp & $0,0 \%$ & $10.4 \%$ & $10.4 \%$ & $7,1 \%$ & $6.0 \%$ & $6.1 \%$ & $6.1 \%$ & $7.1 \%$ \\
\hline Ratio: external loan drawings (budgetary)/tot. pbl. exp & $6.1 \%$ & $10.7 \%$ & $6.3 \%$ & $6.0 \%$ & $5.7 \%$ & $5.3 \%$ & $4.9 \%$ & $5.6 \%$ \\
\hline Ratio: external loan drawings (projet loans)/tot. pbl. exp & $22.5 \%$ & $24.5 \%$ & $32.2 \%$ & $33.2 \%$ & $34.0 \%$ & $34.9 \%$ & $35.4 \%$ & $34.0 \%$ \\
\hline
\end{tabular}

\section{Ambitious scenario assumptions}

72. As mentioned above, the main differences between the two scenarios relate to the growth assumptions for the promising sectors and taxation.

73. The national program for the supply of farm and irrigation equipment to rural farmers (Programme national pour la fourniture de matériel agricole et d'irrigation au bénéfice des producteurs ruraux) is to be started up and executed under the Team-9 Initiative. A line of credit has been made available to Mali by the Government of India. Two Indian companies have been contracted to supply the following equipment and materials: 395 tractors (50-60 HP) with standard kit and spare parts, 300 disk plows, and a plant for equipment assembly, start-up and training of beneficiaries.

74. Further, the sectoral consultation on rural development and irrigated farming held in Bamako in May 2006 identified financing needs totaling CFAF 364 billion, out of which pledges were made for CFAF 335 billion by the PTF. Implementation of the new agricultural policy law (LOA) is also expected to transform the sector and usher in progress by facilitating the modernization of the agricultural sector and its reorientation towards commercial farming as well as promoting land tenure security and sustainable food sovereignty.

75. Initial implementation of the national policy for the development of livestock farming is due to be launched through projects such as i) the Support Project for Livestock Development in Northeast Mali, ii) the Livestock Development Project in Liptako Gourma, and iii) the Tsetse Fly Eradication Project. Intensive campaigns will be organized from 2006 to 2011 to improve vaccination coverage against major epizootic diseases. The surveillance follow-up and intervention mechanism will provide a watch on avian flu in Mali.

76. In addition, Mali will soon be launching an intensive artificial insemination program aimed at genetic improvement of local breeds, industrial meat production and increased milk production.

77. The national fisheries and fish farming development policy is expected to focus heavily on the promotion of fish farming infrastructure. This strategy will be achieved through the 
implementation of the Central Niger Delta Inland Fisheries Development Support Project (PADEPECHE).

78. All of this augurs well for significant performance improvements in the primary sector and higher levels of exports.

79. The growth rate for food crop farming, excluding rice, has thus been set at 6.0 percent a year starting in 2007, in line with the expected strong increase in yields and land area under maize cultivation.

80. With regard to rice, its growth rate has been projected at 9.9 percent over the period under review, in line with prospects for the intensification of irrigated rice production.

81. Annual cotton production is slated to grow 1.6 percent as of 2007 in the hope that production levels can be maintained at around 600,000 metric tons through to 2011 . Agricultural mechanization and improvements in cotton prices, in line with assumptions, should help make this goal achievable.

82. Livestock production is expected to show growth of 4.6 percent a year over the 2007-2011 period.

83. Forecasts for growth in the mining sector are 3.4 percent in 2007 and 0.0 percent between 2008-2011, which corresponds to annual production of around 60 metric tons of gold. This optimistic assumption reflects the projected entry into production of new mines and the development of gold panning activities.

84. The growth rate for electricity and water production was raised to 12.9 percent a year over the entire period in line with AMADER's program of activities, which was effectively launched in 2005.

85. Given that the building and public works (BTP) sector (including all types of infrastructure) accounts for the lion's share of investment, production in this sector is expected to grow by 8.4 percent a year on average over the period under review as against 5.2 percent between 2002 and 2005 .

86. For the sake of consistency with current and capital expenditure programming in the overall MTBF, the other assumptions on economic growth, investment, and external aid volumes remain virtually the same as in the basic scenario.

87. Regarding taxation, the ambitious scenario deviates from the basic scenario in that it assumes a broader tax base to provide a source of domestic financing for the ambitious PRSP program without having to resort too heavily to bank credit as this could have the effect of crowding out the private sector from bank borrowing to finance private investments. The ambitious scenario provides for achievement of the WAEMU criterion of a tax-to-GDP ratio of 17 percent by 2008 .

88. As a result of these more optimistic assumptions, average annual real GDP growth is projected to be 7.0 percent compared to 5.0 percent in the basic scenario, while the average tax ratio is projected at 16.6 percent for the ambitious scenario and 15.7 percent for the basic scenario over the period $2007-2011$.

\subsection{Main results of the macroeconomic framework (ambitious scenario)}

\subsubsection{Overview}

89. The ambitious scenario formed the policy basis of the PRSP. The table below shows the main results, which are commented on in the subsequent sections. 
Table 14: Macroeconomic performance indicators and policy criteria

\begin{tabular}{|c|c|c|c|c|c|c|c|c|}
\hline & Average & 2006 & 2007 & 2008 & 2009 & 2010 & 2011 & Average \\
\hline Supply and use of goods and services & 2002-2005 & Estim. & Forecast & Forecast & Forecast & Forecast & Forecast & 2007-2011 \\
\hline GDP at market prices (CFAF billion current) & $2,550.3$ & $3,205.8$ & $3,419.4$ & $3,653.0$ & $3,895.0$ & $4,196.9$ & $4,493.8$ & $3,931.6$ \\
\hline GDP at market prices ( $\$$ billion current) & 4.5 & 6.1 & 6.7 & 7.2 & 7.7 & 8.3 & 9.0 & 7.8 \\
\hline GDP at market prices ( $€$ billion current) & 3.9 & 4.9 & 5.2 & 5.6 & 5.9 & 6.4 & 6.9 & 6.0 \\
\hline Formal sector share of GDP (in \% GDPf) & $39.9 \%$ & $38.0 \%$ & $38.0 \%$ & $38.0 \%$ & $39.0 \%$ & $39.0 \%$ & $39.0 \%$ & $38.6 \%$ \\
\hline Real GDP growth at market prices & $5.2 \%$ & $3.6 \%$ & $7.0 \%$ & $6.6 \%$ & $6.5 \%$ & $7.8 \%$ & $7.1 \%$ & $7.0 \%$ \\
\hline Real GDP growth at factor cost & $4.6 \%$ & $4.4 \%$ & $6.5 \%$ & $6.1 \%$ & $6.2 \%$ & $6.7 \%$ & $6.8 \%$ & $6.5 \%$ \\
\hline - Primary sector GDP & $47 \%$ & $5.0 \%$ & $5.5 \%$ & $5.6 \%$ & $5.6 \%$ & $5.7 \%$ & $5.9 \%$ & $5.7 \%$ \\
\hline - Secondary sector GDP & $5.3 \%$ & $5.9 \%$ & $7.1 \%$ & $6.0 \%$ & $6.4 \%$ & $6.7 \%$ & $7.0 \%$ & $6.6 \%$ \\
\hline - Tertiary sector GDP & $4.8 \%$ & $2.9 \%$ & $7.2 \%$ & $6.8 \%$ & $6,7 \%$ & $7.7 \%$ & $7.5 \%$ & $7.2 \%$ \\
\hline Total GFCF (CFAF billion current) & 443.8 & 671.6 & 659.1 & 717.8 & 780.8 & 851.9 & 937.6 & 789.4 \\
\hline - Private GFCF (CFAF billion current) & 255.9 & 351.7 & 376.7 & 400.7 & 425.9 & 454.4 & 505.2 & 432.5 \\
\hline - Public GFCF (CFAF billion current) & 188.0 & 319.9 & 282.5 & 317.2 & 354.9 & 397.6 & 432.4 & 356.9 \\
\hline Gross investment (I/GDPm) & $21.4 \%$ & $21.4 \%$ & $19.7 \%$ & $20.1 \%$ & $20.5 \%$ & $20.7 \%$ & $21.2 \%$ & $20.4 \%$ \\
\hline Fixed investment (CFAF/GDPm) & $17.6 \%$ & $20.9 \%$ & $19.3 \%$ & $19.7 \%$ & $20.0 \%$ & $20.3 \%$ & $20.9 \%$ & $20.0 \%$ \\
\hline - Public GFCF in $\%$ of GDPm & $7.4 \%$ & $10.0 \%$ & $8.3 \%$ & $8.7 \%$ & $9.1 \%$ & $9.5 \%$ & $9.6 \%$ & $9.0 \%$ \\
\hline - Private GFCF in $\%$ of GDPm & $10.2 \%$ & $11.0 \%$ & $11.0 \%$ & $11.0 \%$ & $10.9 \%$ & $10.8 \%$ & $11.2 \%$ & $11.0 \%$ \\
\hline Incremental capital output ratio & 14.5 & 2.0 & 3.2 & 2.9 & 3.0 & 2.6 & 2,9 & 2.9 \\
\hline Domestic saving (in \% of GDPm) & $15.2 \%$ & $15.9 \%$ & $13.9 \%$ & $14.4 \%$ & $15.0 \%$ & $14.5 \%$ & $14.1 \%$ & $14.4 \%$ \\
\hline External saving $(=-$ resource balance BP/GDPm) & $6.2 \%$ & $5.5 \%$ & $5.8 \%$ & $5.7 \%$ & $5.4 \%$ & $6.1 \%$ & $7.1 \%$ & $6.0 \%$ \\
\hline Gross national saving (in \% of GDPm) & $14.8 \%$ & $17.1 \%$ & $15.1 \%$ & $15.2 \%$ & $15.7 \%$ & $15.3 \%$ & $14.8 \%$ & $15.2 \%$ \\
\hline Consumption (in $\%$ of GDPm) & $84.8 \%$ & $84.1 \%$ & $86.1 \%$ & $85.6 \%$ & $85.0 \%$ & $85.5 \%$ & $85.9 \%$ & $85.6 \%$ \\
\hline - Private consumption & $73.4 \%$ & $71.2 \%$ & $73.4 \%$ & $73.5 \%$ & $73.0 \%$ & $73.4 \%$ & $73.7 \%$ & $73.4 \%$ \\
\hline - Public consumption & $11.4 \%$ & $12.9 \%$ & $12.7 \%$ & $12.1 \%$ & $12.0 \%$ & $12.0 \%$ & $12.2 \%$ & $12.2 \%$ \\
\hline Gross national product per capita in CFAF current & 225,096 & 269,324 & 279,650 & 289,717 & 300,315 & 315,076 & 328,400 & 302,632 \\
\hline Gross national product per capita in CFAF constant (1987) & 112,020 & 119,061 & 123,426 & 127,589 & 132,145 & 138,647 & 144,573 & 133,276 \\
\hline Growth rate of real gross national product per capita & $2.6 \%$ & $2.5 \%$ & $3.7 \%$ & $3.4 \%$ & $3.6 \%$ & $4.9 \%$ & $4.3 \%$ & $4.0 \%$ \\
\hline Gross national product per capita in US\$ & 395 & 516 & 548 & 571 & 595 & 627 & 656 & 599 \\
\hline
\end{tabular}

(continued) 


\begin{tabular}{|c|c|c|c|c|c|c|c|c|}
\hline \multirow[t]{2}{*}{ Balance of payments } & \multirow{2}{*}{$\begin{array}{l}\text { Average } \\
2002-2005\end{array}$} & 2006 & 2007 & 2008 & 2009 & 2010 & 2011 & \multirow{2}{*}{$\begin{array}{l}\text { Average } \\
2007-2011\end{array}$} \\
\hline & & Estim. & Forecast & Forecast & Forecast & Forecast & Forecast & \\
\hline Imports (in \% of GDPm), current prices & $33.7 \%$ & $32.4 \%$ & $33.6 \%$ & $33.6 \%$ & $33.7 \%$ & $33.5 \%$ & $33,5 \%$ & $33,6 \%$ \\
\hline Exports (in $\%$ of GDPm), current prices & $27.5 \%$ & $26.9 \%$ & $27.8 \%$ & $28.0 \%$ & $28.2 \%$ & $27.3 \%$ & $26,4 \%$ & $27,5 \%$ \\
\hline Trade deficit (fob) in \% of GDPm & $-0.3 \%$ & $-1.1 \%$ & $-1.1 \%$ & $-1.1 \%$ & $-1.1 \%$ & $-1.7 \%$ & $-2,5 \%$ & $-1,5 \%$ \\
\hline Balance des ressources (X-Mcaf) in \% of GDPm & $-6.2 \%$ & $-5.5 \%$ & $-5.8 \%$ & $-5.7 \%$ & $-5.4 \%$ & $-6.1 \%$ & $-7,1 \%$ & $-6,0 \%$ \\
\hline Current account (excluding off. transf.) in \% of GDPm & $-8.6 \%$ & $-7.4 \%$ & $-7.3 \%$ & $-7.0 \%$ & $-6.7 \%$ & $-7.3 \%$ & $-8,2 \%$ & $-7,3 \%$ \\
\hline Current account (including off. transf.) in $\%$ of GDPm & $-6.6 \%$ & $-4.3 \%$ & $-4.6 \%$ & $-4.9 \%$ & $-4.7 \%$ & $-5.4 \%$ & $-6,4 \%$ & $-5,2 \%$ \\
\hline Net reserves in months of imports c.i.f. & 5.5 & 5.7 & 5.6 & 5.6 & 5.4 & 5.3 & 5,3 & 5,4 \\
\hline Gross reserves in months of imports c.i.f. & 8.3 & 7.8 & 7.6 & 7.5 & 7.2 & 6.9 & 6,9 & 7,2 \\
\hline Debt service ratio in $\%$ of exports B\&SNF & $8.1 \%$ & $125.9 \%$ & $4.9 \%$ & $4.4 \%$ & $4.2 \%$ & $4.2 \%$ & $4,3 \%$ & $4,4 \%$ \\
\hline \multirow[t]{2}{*}{ Public finance } & Average & 2006 & 2007 & 2008 & 2009 & 2010 & 2011 & Average \\
\hline & $2002-2005$ & Estim. & Forecast & Forecast & Forecast & Forecast & Forecast & $2007-2011$ \\
\hline Tax ratio (= tax revenue/GDPm) & $14.6 \%$ & $14.7 \%$ & $14.9 \%$ & $17.0 \%$ & $17.0 \%$ & $17.0 \%$ & $17,2 \%$ & $16,6 \%$ \\
\hline Tax level (recurrent revenue, exc. grants, in \% of GDP) & $17.2 \%$ & $16.8 \%$ & $17.0 \%$ & $19.7 \%$ & $19.7 \%$ & $19.7 \%$ & $19,9 \%$ & $19,2 \%$ \\
\hline Tax level (recurrent revenue in $\%$ of GDP formal sector) & $47.7 \%$ & $49.0 \%$ & $49.5 \%$ & $57.5 \%$ & $56.3 \%$ & $56.9 \%$ & $57,7 \%$ & $55,6 \%$ \\
\hline Total expenditures and net lending, in $\%$ of GDP & $23.8 \%$ & $27.0 \%$ & $27.3 \%$ & $27.0 \%$ & $26.9 \%$ & $26.9 \%$ & $27,1 \%$ & $27,0 \%$ \\
\hline Current account balance (nat. publ. savings) in \% of GDP & $7.3 \%$ & $40.5 \%$ & $8.1 \%$ & $10.6 \%$ & $10.5 \%$ & $10.6 \%$ & $10,7 \%$ & $10,1 \%$ \\
\hline Current account balance (own savings) in \% of GDP & $3.9 \%$ & $3.5 \%$ & $3.6 \%$ & $6.4 \%$ & $6.5 \%$ & $6.5 \%$ & $6,6 \%$ & $5,9 \%$ \\
\hline Primary balance (=own publ.savings exc. interest) in $\%$ of GDPm & $4,6 \%$ & $4,2 \%$ & $4.0 \%$ & $6.7 \%$ & $6.8 \%$ & $6.8 \%$ & $6,9 \%$ & $6,2 \%$ \\
\hline Primary balance (IMF), in \% of GDP & $1.4 \%$ & $0.6 \%$ & $0.2 \%$ & $2.9 \%$ & $2.9 \%$ & $3.0 \%$ & $3,1 \%$ & $2,4 \%$ \\
\hline Primary balance (WAEMU), in \% of GDP & $0.2 \%$ & $-0.6 \%$ & $-1.3 \%$ & $1.3 \%$ & $1.4 \%$ & $1.5 \%$ & $1,6 \%$ & $0,9 \%$ \\
\hline Overall balance (commitment basis), exc. grants, $\%$ of GDP & $-6.7 \%$ & $-10.2 \%$ & $-10.2 \%$ & $-7.3 \%$ & $-7.2 \%$ & $-7.1 \%$ & $-7,1 \%$ & $-7,8 \%$ \\
\hline Overall balance (commitment basis), inc. grants, $\%$ of GDP & $-2.6 \%$ & $27.3 \%$ & $-5.3 \%$ & $-2.8 \%$ & $-2.9 \%$ & $-2.8 \%$ & $-2,9 \%$ & $-3,4 \%$ \\
\hline Overall balance (cash basis), in \% of GDP & $-2.5 \%$ & $27.3 \%$ & $-5.3 \%$ & $-2.8 \%$ & $-2.9 \%$ & $-2.8 \%$ & $-2,9 \%$ & $-3,4 \%$ \\
\hline Monetary survey & Average & 2006 & 2007 & 2008 & 2009 & 2010 & 2011 & Average \\
\hline & $2002-2005$ & Estim. & Forecast & Forecast & Forecast & Forecast & Forecast & $2007-2011$ \\
\hline Claims on the Treasury (growth rate) & $35.8 \%$ & $280.6 \%$ & $-36.1 \%$ & $117.4 \%$ & $62.6 \%$ & $51.6 \%$ & $38,2 \%$ & $46,7 \%$ \\
\hline Claims on the economy (growth rate) & $11.4 \%$ & $3.2 \%$ & $-3.3 \%$ & $17.2 \%$ & $19.6 \%$ & $20.5 \%$ & $17,6 \%$ & $14,3 \%$ \\
\hline Increase in the money supply (M2) & $15.2 \%$ & $1.5 \%$ & $5.3 \%$ & $5.4 \%$ & $5.3 \%$ & $6.2 \%$ & $5,6 \%$ & $5,5 \%$ \\
\hline Velocity of circulation (GDP/M2, end of period) & 3.4 & 3.8 & 3.8 & 3.9 & 3.9 & 4.0 & 4,0 & 3,9 \\
\hline Liquidity ratio (M2/GDPm) & $29.4 \%$ & $26.6 \%$ & $26.3 \%$ & $25.9 \%$ & $25.6 \%$ & $25.2 \%$ & $24,9 \%$ & $25,6 \%$ \\
\hline Prices and exchange rates & Average & 2006 & 2007 & 2008 & 2009 & 2010 & 2011 & Average \\
\hline & $2002-2005$ & Estim. & Forecast & Forecas & Forecast & Forecast & Forecast & $2007-2011$ \\
\hline Global inflation (MUV) & $3.5 \%$ & $1.6 \%$ & $1.2 \%$ & $1.2 \%$ & $1.2 \%$ & $1.2 \%$ & $1.2 \%$ & $1.2 \%$ \\
\hline Increase in CPI-Bamako households & $1.8 \%$ & $2.4 \%$ & $0.2 \%$ & $0.5 \%$ & $0.3 \%$ & $0.2 \%$ & $0.2 \%$ & $0.3 \%$ \\
\hline GDP deflator (growth rate) & $1.9 \%$ & $6.3 \%$ & $0,2 \%$ & $0.2 \%$ & $0.1 \%$ & $0.0 \%$ & $0.0 \%$ & $0.1 \%$ \\
\hline Terms of trade $(1987=100)$ & 69.2 & 73.8 & 78.2 & 81.7 & 85.3 & 86.6 & 86.7 & 83.7 \\
\hline CFAF/SDR exchange rate (end of period) & 787.4 & 756.7 & 738.9 & 734.9 & 731.7 & 728.6 & 725.7 & 732.0 \\
\hline CFAF/US\$ exchange rate (end of period) & 547.0 & 522.3 & 509.9 & 507.2 & 505.0 & 502.9 & 500.8 & 505.2 \\
\hline CFAF/US\$ exchange rate. (period average) & 582.2 & 522.3 & 509.9 & 507.2 & 505.0 & 502.9 & 500.8 & 505.2 \\
\hline CFAF/€ exchange rate (period average) & 656.0 & 656.0 & 656.0 & 656.0 & 656.0 & 656.0 & 656.0 & 656.0 \\
\hline Real exchange rate index (IP_M/IP_GDP; + devaluation) & 126.7 & 125.9 & 123.5 & 122.9 & 122.7 & 122.5 & 122.4 & 122.8 \\
\hline External aid & Average & 2006 & 2007 & 2008 & 2009 & 2010 & 2011 & Average \\
\hline & $2002-2005$ & Estim. & Forecast & Forecast & Forecast & Forecast & Forecast & $2007-2011$ \\
\hline External aid (gross) in \% of GDP & $9.2 \%$ & $46.5 \%$ & $10.5 \%$ & $10.1 \%$ & $10.0 \%$ & $10.0 \%$ & $10.0 \%$ & $10.1 \%$ \\
\hline External aid (net) in \% of GDP & $7.2 \%$ & $12.7 \%$ & $9.6 \%$ & $9.2 \%$ & $9.0 \%$ & $9.0 \%$ & $9.0 \%$ & $9.2 \%$ \\
\hline External aid (gross) in US\$ million. & 407.0 & $2,853.8$ & 706.7 & 728.6 & 769.3 & 834.0 & 896.6 & 787.0 \\
\hline External aid (net) in US\$ million & 319.3 & 778.9 & 643.2 & 660.5 & 696.0 & 754.2 & 809.9 & 712.8 \\
\hline External aid (gross) US\$ per capita & 36.0 & 236.8 & 57.1 & 57.3 & 58.9 & 62.2 & 65.0 & 60.1 \\
\hline External aid (net) US\$ per capita & 28.2 & 64.6 & 52.0 & 52.0 & 53.3 & 56.2 & 58.8 & 54.4 \\
\hline WAEMU convergence criteria & Average & 2006 & 2007 & 2008 & 2009 & 2010 & 2011 & Average \\
\hline Primary criteria: & $2002-2005$ & Estim. & Forecast & Forecast & Forecast & Forecast & Forecast & $2007-2011$ \\
\hline Ratio: basic fiscal balance/GDPm 1/ & $0.2 \%$ & $-0.6 \%$ & $-1.3 \%$ & $1.3 \%$ & $1.4 \%$ & $1.5 \%$ & $1.6 \%$ & $0.9 \%$ \\
\hline Inflation (HICP Bamako) & $1.8 \%$ & $2.4 \%$ & $0.2 \%$ & $0.5 \%$ & $0.3 \%$ & $0.2 \%$ & $0.2 \%$ & $0.3 \%$ \\
\hline Ratio: outstanding domestic and external debt/GDPm & $0.0 \%$ & $0.0 \%$ & $0.0 \%$ & $0.0 \%$ & $0.0 \%$ & $0.0 \%$ & $0.0 \%$ & $0.0 \%$ \\
\hline of which: outstanding external debt/GDP m & $64.3 \%$ & $23.3 \%$ & $24.9 \%$ & $25.2 \%$ & $23.6 \%$ & $21.1 \%$ & $18.2 \%$ & $22.6 \%$ \\
\hline Change in domestic payments arrears (in CFAF billion) $\quad<=0$ & 0.0 & 0.0 & 0.0 & 0.0 & 0.0 & 0.0 & 0.0 & 0,0 \\
\hline Change in external payments arrears (in CFAF billion) & 0.0 & 0.0 & 0.0 & 0.0 & 0.0 & 0.0 & 0.0 & 0,0 \\
\hline Secondary criteria: & & & & & & & & \\
\hline Ratio: wage bill to tax revenue & $30.7 \%$ & $31.7 \%$ & $31.5 \%$ & $28.1 \%$ & $28.2 \%$ & $28.8 \%$ & $28.8 \%$ & $29.1 \%$ \\
\hline Ratio: public invest. financed by domestic res. from tax. rev. $2 />=20 \%$ & $21.9 \%$ & $25.8 \%$ & $22.5 \%$ & $22.5 \%$ & $22.5 \%$ & $22.5 \%$ & $22.5 \%$ & $22.5 \%$ \\
\hline Ratio: ext. curr. account deficit exc. public transfers/PIB m $\quad<=5 \%$ & $-8.6 \%$ & $-7.4 \%$ & $-7.3 \%$ & $-7.0 \%$ & $-6.7 \%$ & $-7.3 \%$ & $-8.2 \%$ & $-7.3 \%$ \\
\hline Tax ratio $(=$ Tax revenue/GDP $\mathrm{m}) \quad>=17 \%$ & $14.6 \%$ & $14.7 \%$ & $14.9 \%$ & $17.0 \%$ & $17.0 \%$ & $17.0 \%$ & $17.2 \%$ & $16.6 \%$ \\
\hline
\end{tabular}

\subsubsection{Growth}

90. Based on the assumptions of the ambitious scenario, growth of GDP at factor cost is expected to average 6.5 percent over the 2007-2011 period and 7.0 percent at market prices (the latter includes a strong increase in indirect taxes in line with the aim of achieving compliance with the WAEMU tax ratio criterion by 2008).

91. Over the whole 2007-2011 period, growth in the primary sector (5.7 percent on average as against 4.7 percent between 2002 and 2005) is projected to be driven by food crop framing 
(rice, maize, etc.) and industrial farming excluding cotton (groundnuts, wheat, etc.), reflecting the spinoff effects of the implementation of major agricultural development projects.

92. In the secondary sector, average growth is forecast to be 6.6 percent versus 5.3 percent in the first four years of implementation of the PRSP. The main drivers are set to be the agrofood, water and electricity, and BTP sectors as well as the textile industry to a lesser extent. These performance projections take account of planned investment in rural electrification and the cement and sugar industries. Furthermore, the stated commitment to step up cotton processing activities should also give the textile industries a boost, despite the quite limited increase in cotton production.

93. As for the tertiary sector, average growth is expected to reach 7.2 percent, up from 4.8 percent between 2002 and 2005, driven essentially by the transport and telecommunications industries as well as by trade, buoyed by stronger performance in the primary and secondary sectors. In addition, public services (non-market) consisting mainly of civil service wages, are poised for strong growth consistent with the overall MTBF.

94. Taking account of population growth and external contributions to national income (current transfers and factor services), average real per capita national income is expected to grow by 4.0 percent between 2007 and 2011, as against 2.6 percent between 2002 and 2005, to around CFAF 328,400 current (US\$656) in 2011.

Table 15: Supply and use of goods and nonfactor services in CFAF billion

\begin{tabular}{|c|c|c|c|c|c|c|c|c|}
\hline & Average & 2006 & 2007 & 2008 & 2009 & 2010 & 2011 & Average \\
\hline & $2002-2005$ & Estim. & Prév. & Prév. & Prév. & Prév. & Prév. & $2007-2011$ \\
\hline GDP at market prices & $2,550.3$ & $3,205.8$ & $3,419.4$ & $3,653.0$ & $3,895.0$ & $4,196.9$ & $4,493.8$ & $3,931.6$ \\
\hline Annual change & $7.0 \%$ & $10.8 \%$ & $6.7 \%$ & $6.8 \%$ & $6.6 \%$ & $7.7 \%$ & $7.1 \%$ & $7.0 \%$ \\
\hline Imports of nf goods and services & 858.0 & $1,040.2$ & $1,149.0$ & $1,228.6$ & $1,311.6$ & $1,405.4$ & $1,506.8$ & $1,320.3$ \\
\hline Annual change & $3.3 \%$ & $9.2 \%$ & $10.5 \%$ & $6.9 \%$ & $6.8 \%$ & $7.2 \%$ & $7.2 \%$ & $7.7 \%$ \\
\hline Total resources & $3,408.3$ & $4,246.0$ & $4,568.5$ & $4,881.6$ & $5,206.6$ & $5,602.3$ & $6,000.6$ & $5,251.9$ \\
\hline Exports of nf goods and services & 695.5 & 862.6 & 949.8 & $1,021.1$ & $1,100.1$ & $1,147.7$ & $1,186.7$ & $1,081.1$ \\
\hline Annual change & $4.2 \%$ & $16.4 \%$ & $10.1 \%$ & $7.5 \%$ & $7.7 \%$ & $4.3 \%$ & $3.4 \%$ & $6.6 \%$ \\
\hline Gross investment & 548.5 & 687.4 & 675.2 & 734.0 & 796.9 & 868.0 & 953.7 & 805.6 \\
\hline Gross fixed capital formation & 443.8 & 671.6 & 659.1 & 717.8 & 780.8 & 851.9 & 937.6 & 789.4 \\
\hline Annual change & $1.5 \%$ & $50.3 \%$ & $-1.9 \%$ & $8.9 \%$ & $8.8 \%$ & $9.1 \%$ & $10.1 \%$ & $7.0 \%$ \\
\hline Change in stocks & 104.6 & 15.8 & 16.1 & 16.1 & 16.1 & 16.1 & 16.1 & 16.1 \\
\hline Final consumption & $2,164.2$ & $2,696.1$ & $2,943.5$ & $3,126.5$ & $3,309.6$ & $3,586.5$ & $3,860.2$ & $3,365.3$ \\
\hline Annual change & $7.4 \%$ & $8.5 \%$ & $9.2 \%$ & $6.2 \%$ & $5.9 \%$ & $8.4 \%$ & $7.6 \%$ & $7.4 \%$ \\
\hline Public consumption & 291.2 & 415.1 & 433.6 & 442.0 & 465.7 & 504.8 & 547.4 & 478.7 \\
\hline Annual change & $10.8 \%$ & $22.3 \%$ & $4.5 \%$ & $1.9 \%$ & $5.4 \%$ & $8.4 \%$ & $8.4 \%$ & $5.7 \%$ \\
\hline Household consumption & $1,873.0$ & $2,281.0$ & $2,509.9$ & $2,684.6$ & $2,843.9$ & $3,081.7$ & $3,312.9$ & $2,886.6$ \\
\hline Annual change & $6.9 \%$ & $6.4 \%$ & $10.0 \%$ & $7.0 \%$ & $5.9 \%$ & $8.4 \%$ & $7.5 \%$ & $7.8 \%$ \\
\hline
\end{tabular}

\subsubsection{Investment}

95. The fixed investment rate (GFCF/GDP) is expected to improve gradually over the 20072011 period, edging up to 20.0 percent on average, from the 17.6 percent recorded between 2002 and 2005. This increase is attributable to an improvement in the average annual rate of public investment, which is projected to be 9.0 percent versus 7.4 percent in 2002-2005. Private investment, in turn, should reach 11.0 percent in 2007-2011, up from 10.2 percent in 2002-2005.

96. Public investment levels will be supported by a number of major initiatives under the following project and program areas:

- The Kayes-Bafoulabé road, 2006-2010, for an amount of CFAF 17.8 billion;

- The Kita-Saraya road, 2007-2011, for an amount of CFAF 52 billion;

- Transport corridor improvements, 2005-2008, for an amount of CFAF 31.9 billion; 
- The Gao-Ansongo-Labezenga road, 2005-2008, for an amount of CFAF 38 billion;

- Kayes airport expansion for an amount of CFAF 6.6 billion;

- The Niono-Tonka road;

- The Transport Sector Program PST-2, 2008-2013;

- The accelerated economic growth program, 2004-2013, for a cost of CFAF 62.7 billion;

- The investment and rural development program for the northern regions (2006-2012) for CFAF 17.8 billion

- The Liptako-Gourma livestock development project (2005-2011) for CFAF 6.6 billion;

- The Mopti region development support program (2003-2010) for a cost of CFAF 14 billion;

- The agricultural competitiveness and diversification program, 2006-2011, estimated at CFAF 23.8 billion;

- The Baguineda rehabilitation project phase-II, 2007-2012, the cost of which has been estimated at CFAF 11.0 billion;

- The central delta inland fisheries development support project, 2005-2010, for an estimated CFAF 14.5 billion;

- The food security program for an amount of CFAF 113 billion;

- The artificial rain program for a cost of around CFAF 5 billion over the next five years;

- The rural communities support program (2006-2012) for an amount of CFAF 33.0 billion;

- The growth support project (2006-2011) for an amount of CFAF 35.7 billion;

- The Taoussa development project (2009-2013) for CFAF 104 billion;

- Construction of the Kenie hydroelectric power plant for an amount of CFAF 75 billion;

- Oil prospecting;

- Construction of the Felou hydroelectric power plant (see OMVS);

- The investment program of Mali's electric utility, EDM.

97. Over the 2007-2011 period, private investments will flow mainly to the mining, textiles (cotton processing), agro-industry, and infrastructure development sectors. Thus, the main private efforts will focus on:

- Cement works: West Africa Cement (WACEM) plans to invest CFAF 55 billion in Diamou;

- Sugar industry: the Markala and Sukala-III factories will be financed by the Americans and Chinese, respectively. The financing cost of Sukala-III has been estimated at 103.8 million dollars; 
- Fertilizer manufacturing: by the Tilemsi phosphate rock mining company, La Société d'Exploitation des Phosphates (CACEM), with Chinese, Canadian and British financing;

- Spinning: a spinning project (COPEMA) is to be implemented with Portuguese support at an estimated cost of around CFAF 7 billion;

- Irrigated agriculture programs: planned under the Millennium Challenge Account, for WAEMU (5,000 ha), and CENSAD (100,000 ha), to be handled by the Niger Office.

\subsubsection{Government finance}

98. In respect of government finance, the government's medium-term policy will be guided by the activities contained in its fiscal management improvement and modernization action program, PAGAMGFP. This will take the form of greater fiscal consolidation efforts through tighter spending controls and higher domestic revenue mobilization.

Table 16: Consolidated government finance budget and its financing (TOFE) (CFAF billion current)

\begin{tabular}{|c|c|c|c|c|c|c|c|c|}
\hline & & 2006 & 2007 & 2008 & 2009 & 2010 & 2011 & Average \\
\hline & $2002-2005$ & & CSLP & CSLP & CSLP & CSLP & CSLP & $2007-2011$ \\
\hline Total revenue and grants & 542.6 & $1,740.0$ & 749.4 & 881.4 & 935.6 & $\mathbf{1 , 0 0 8 . 0}$ & $\mathbf{1 , 0 8 8 . 3}$ & 932.6 \\
\hline Total revenue & 438.5 & 540.0 & 582.4 & 718.6 & 768.6 & 828.5 & 896.3 & 758.9 \\
\hline Budgetary revenue & 398.7 & 497.5 & 535.4 & 663.5 & 708.5 & 765.9 & 829.5 & 700.6 \\
\hline Tax revenue & 373.7 & 469.9 & 509.5 & 621.0 & 662.2 & 713.5 & 773.6 & 655.9 \\
\hline Nontax revenue & 25.1 & 27.6 & 25.9 & 42.5 & 46.4 & 52.4 & 55.9 & 44.6 \\
\hline Special funds and annexed budgets & 39.8 & 42.5 & 47.0 & 55.0 & 60.0 & 62.6 & 66.8 & 58.3 \\
\hline Grants & 104.1 & $1,200.0$ & 167.0 & 162.9 & 167.1 & 179.5 & 191.9 & 173.7 \\
\hline Project grants & 67.5 & 81.3 & 93.0 & 102.4 & 110.1 & 119.5 & 129.3 & 110.9 \\
\hline Budgetary grants & 36.6 & 35.8 & 24.8 & 25.0 & 25.2 & 25.3 & 25.5 & 25.2 \\
\hline Sectoral budget support & & 47.2 & 49.2 & 35.5 & 31.8 & 34.7 & 37.1 & 37.7 \\
\hline MDRI debt relief & & $1,035.7$ & 0.0 & 0.0 & 0.0 & 0.0 & 0.0 & 0.0 \\
\hline Total expenditure and net lending & 608.5 & 865.6 & 932.3 & 984.5 & $1,048.0$ & $1,127.6$ & $1,216.7$ & $1,061.8$ \\
\hline Budgetary expenditure & 567.5 & 828.7 & 890.9 & 933.5 & 992.4 & $1,069.3$ & $1,153.9$ & $1,008.0$ \\
\hline Current expenditure & \begin{tabular}{l|l}
338.8 & \\
\end{tabular} & 427.0 & 459.5 & 484.7 & 515.5 & 555.0 & 598.6 & 522.7 \\
\hline Wages and salaries & 114.8 & 149.0 & 160.5 & 174.2 & 186.4 & 205.4 & 222.6 & 189.8 \\
\hline Goods and services & 123.5 & 161.1 & 181.8 & 189.9 & 204.8 & 221.7 & 244.3 & 208.5 \\
\hline Transfers and subsidies & 81.4 & 96.8 & 103.7 & 109.0 & 113.0 & 117.1 & 121.6 & 112.9 \\
\hline Interest payable & 19.0 & 20.1 & 13.5 & 11.6 & 11.3 & 10.8 & 10.1 & 11.5 \\
\hline Domestic debt & 2.3 & 2.6 & 1.7 & 1.6 & 1.5 & 1.4 & 1.4 & 1.5 \\
\hline External debt & 16.8 & 17.5 & 11.8 & 10.0 & 9.8 & 9.4 & 8.7 & 9.9 \\
\hline Capital expenditure & 228.7 & 401.7 & 431.4 & 448.8 & 476.9 & 514.3 & 555.3 & 485.3 \\
\hline External financing & 146.6 & 280.7 & 295.1 & 303.9 & 322.1 & 351.9 & 382.4 & 331.1 \\
\hline Loans & 79.1 & 152.2 & 152.9 & 166.0 & 180.2 & 197.7 & 216.0 & 182.6 \\
\hline Total grants & 67.5 & 81.3 & 93.0 & 102.4 & 110.1 & 119.5 & 129.3 & 110.9 \\
\hline Sectoral budget support & 0.0 & 47.2 & 49.2 & 35.5 & 31.8 & 34.7 & 37.1 & 37.7 \\
\hline Domestic financing 1) & 82.1 & 121.0 & 136.3 & 144.9 & 154.8 & 162.4 & 172.9 & 154.3 \\
\hline Special funds and specific budgets & 39.8 & 42.5 & 47.0 & 55.0 & 60.0 & 62.6 & 66.8 & 58.3 \\
\hline Net lending & 1.2 & -5.6 & -5.6 & -4.0 & -4.4 & -4.3 & -4.0 & -4.5 \\
\hline Primary balance (IMF) 2) & -23.4 & -44.9 & -54.8 & 37.9 & 42.6 & 52.8 & 62.0 & 28.1 \\
\hline Overall balance (payment order basis, excluding grants) & -170.0 & -325.6 & -349.9 & -266.0 & -279.5 & -299.1 & -320.4 & -303.0 \\
\hline Overall balance (payment order basis) & -65.9 & 874.4 & -182.9 & -103.1 & -112.4 & -119.6 & -128.4 & -129.3 \\
\hline Adjustment & 1.8 & 0.0 & 0.0 & 0.0 & 0.0 & 0.0 & 0.0 & 0.0 \\
\hline Overall balance (cash basis \& excluding grants) & -168.3 & -325.6 & -349.9 & -266.0 & -279.5 & -299.1 & -320.4 & -303.0 \\
\hline Overall balance (cash basis) & -64.2 & 874.4 & -182.9 & -103.1 & -112.4 & -119.6 & -128.4 & -129.3 \\
\hline FINANCING & 64.2 & -874.4 & 182.9 & 103.1 & 112.4 & 119.6 & 128.4 & 129.3 \\
\hline Net external financing & 89.3 & -845.1 & 159.2 & 172.3 & 185.3 & 201.9 & 215.6 & 186.9 \\
\hline Loans & 100.6 & 200.7 & 182.9 & 196.0 & 210.2 & 227.7 & 246.0 & 212.6 \\
\hline Projects & 79.1 & 152.2 & 152.9 & 166.0 & 180.2 & 197.7 & 216.0 & 182.6 \\
\hline Budgetary lending & 21.4 & 48.5 & 30.0 & 30.0 & 30.0 & 30.0 & 30.0 & 30.0 \\
\hline Amortization (-) & -39.0 & $-1,071.7$ & -34.2 & -34.4 & -36.1 & -37.9 & -41.5 & -36.8 \\
\hline HIPC debt relief & 27.7 & 25.9 & 10.5 & 10.7 & 11.2 & 12.1 & 11.1 & 11.1 \\
\hline Net domestic financing & -25.2 & -43.1 & 23.7 & -69.2 & -72.9 & -82.4 & -87.2 & -57.6 \\
\hline Bank (net) & -3.0 & -34.0 & 36.3 & -76.3 & -88.3 & -118.1 & -132.2 & -75.7 \\
\hline Privatization receipts & 10.3 & 8.1 & 8.1 & 4.0 & 4.0 & 4.0 & 4.0 & 4.8 \\
\hline Other financing & -32.5 & -17.2 & -20.7 & 3.1 & 11.4 & 31.7 & 41.0 & 13.3 \\
\hline Government financing gap $(+=$ shortfall $)$ & 0.0 & 13.8 & 0.0 & 0.0 & $\mathbf{0 . 0}$ & 0.0 & $\mathbf{0 . 0}$ & 0.0 \\
\hline
\end{tabular}

1) Banking and private sector

2) Revenue (excluding grants) less total expenditure (including net lending) (excluding

externally financed capital expenditure)

Source: DNPD, MME-DNPD model 
99. The results of the ambitious scenario (see Annex II for details on public finance forecasts) put total income, excluding grants, at CFAF 896.3 billion in 2011 versus CFAF 540.0 in 2006, that is, an average annual progression of 10.7 percent, compared to 13.0 percent in 2002-2005. Tax revenue is projected to grow by an annual average of 10.5 percent. As the tax ratio in 2002-2005 stood at 14.6 percent a year on average, this indicator is poised to grow considerably, with compliance with the community standard of 17.0 percent expected to be met in 2008 and maintained through to 2011.

100. Effective implementation of the measures contained in the PAGAMGFP is a necessary pre-condition for achieving this objective.

101. The forecasts for total expenditure and net lending are fully in line with the macroeconomic framework and the overall MTBF. The macro-fiscal framework provides for a 7.0 percent average annual increase in total expenditure and net lending to CFAF 1,216.7 billion in 2011 .

102. For its part, the wage bill is set to increase from CFAF 149 billion in 2006 to CFAF 222.6 billion in 2011, up by 8.4 percent on average as against 12.6 percent in 20022005. This represents an average of 29.1 percent of tax revenue between 2007 and 2011 , down from 30.7 percent between 2002 and 2005, thus complying with the WAEMU criterion of less than 35 percent. The latter is also true for the basic fiscal balance criterion, which should be positive. In relation to GDP, the average annual ratio is 0.9 percent in the 2007-2011 period versus 0.2 percent in 2002-2005. The third WAEMU criterion is also expected to be met, namely that the ratio of public investment financed from domestic resources must be at least 20 percent of GDP. The budget forecasts project a ratio of 22.6 percent on average for the period 2007-2001 compared to 21.9 percent in 2002-2005

\subsubsection{Public debt}

103. The IMF Multilateral Debt Relief Initiative (MDRI), which entered into force on January 2, 2006, covers an estimated debt stock of CFAF 64.7 billion. The World Bank and AfDB group contributions to the Initiative, with effect from July 2006, total around CFAF 706 billion and CFAF 265 billion, respectively. Mali has, therefore, benefited from 100 percent cancellation of its estimated CFAF 1,035.7 billion multilateral debt, bringing its stock of public debt-to-GDP ratio down to 22.6 percent on average for the period 20072001 from 64.3 percent in 2002-2005.

104. The debt service to exports ratio will, thus, drop to 4.3 percent on average in 20072011 from 8.1 percent in 2002-2005.

105. For the Treasury, MDRI debt relief represents savings of around CFAF 34 billion a year between 2007 and 2011, that is, a gain of around 3.4 percent of annual budgetary expenditure, excluding external debt service.

\subsubsection{Balance of payments and monetary survey}

106. The macroeconomic framework provides for average annual growth of 6.6 percent in exports and 7.7 percent in imports, in line with production trends and international market prices for Mali's main export products, gold and cotton. In that context, the average trade deficit is expected to widen to 1.5 percent of GDP from 0.3 percent over the 2002-2005 period.

107. The current account balance, excluding official transfers, is projected to be 7.3 percent of GDP on average versus 8.6 percent between 2002 and 2005. This development is 
attributable to the improvement in the trade balance and in the deficit in respect of nonfactor services, spurred by the booming tourism sector. The current account balance, including grants, is, thus, forecast to be 5.2 percent on average in 2007-2011, as against 6.6 percent in 2002-2005.

108. In terms of net foreign assets, from 5.5 months and 8.3 months, respectively in 20022005, over the 2007-2011 period, net reserves have been estimated at 5.4 months, and gross reserves at 7.2 months, of import coverage on average, with total net foreign assets amounting to CFAF 653.5 billion in 2011 .

Table 17: Balance of payments (CFAF billion)

\begin{tabular}{|c|c|c|c|c|c|c|c|c|}
\hline & Average & 2006 & 2007 & 2008 & 2009 & 2010 & 2011 & Average \\
\hline & $2002-2005$ & Estim. & Prév. & Prév. & Prév. & Prév. & Prév. & $2007-2011$ \\
\hline Balance commerciale (marchand. fob) & -13.4 & -33.9 & -36.4 & -41.1 & -42.8 & -70.8 & -111.0 & -60.4 \\
\hline Exportations (fob) & 566.0 & 714.4 & 772.2 & 823.5 & 880.1 & 918.1 & 949.4 & 868.6 \\
\hline Coton fibre & 151.2 & 154.5 & 154.3 & 161.3 & 170.0 & 172.0 & 174.1 & 166.3 \\
\hline Or & 347.4 & 487.9 & 534.3 & 563.1 & 592.3 & 605.5 & 607.0 & 580.5 \\
\hline Elevage & 24.4 & 22.7 & 24.2 & 26.2 & 28.4 & 30.7 & 33.3 & 28.5 \\
\hline Autres & 43.0 & 49.3 & 59.4 & 72.9 & 89.5 & 109.9 & 134.9 & 93.3 \\
\hline Importations (fob) & -579.3 & -748.3 & -808.5 & -864.5 & -922.9 & -988.9 & $-1,060.3$ & -929.1 \\
\hline Services non-facteurs (net) & -149.1 & -143.7 & -162.9 & -166.4 & -168.6 & -186.9 & -209.2 & -178.8 \\
\hline Crédit & 129.6 & 148.2 & 177.6 & 197.6 & 220.0 & 229.5 & 237.3 & 212.4 \\
\hline Débit & -278.6 & -291.9 & -340.5 & -364.1 & -388.7 & -416.5 & -446.5 & -391.2 \\
\hline Services facteurs (net) & -118.4 & -111.2 & -99.3 & -98.0 & -98.5 & -98.8 & -98.8 & -98.7 \\
\hline Rémunérations des salaries & 3.3 & 4.0 & 4.0 & 4.0 & 4.0 & 4.0 & 4.1 & 4.0 \\
\hline Revenus des investissements & -121.8 & -115.2 & -103.2 & -102.0 & -102.5 & -102.8 & -102.8 & -102.7 \\
\hline - Intérêts sur la dette publique & -16.8 & -14.0 & -12.3 & -10.5 & -10.3 & -9.9 & -9.2 & -10.4 \\
\hline - Autres revenus des investissements & -105.0 & -92.0 & -90.9 & -91.5 & -92.2 & -92.9 & -93.6 & -92.2 \\
\hline Transferts courants & 110.5 & 151.0 & 141.2 & 128.1 & 125.1 & 128.7 & 131.9 & 131.0 \\
\hline Transferts du secteur privé (net) & 58.1 & 50.0 & 49.4 & 49.7 & 50.1 & 50.5 & 50.9 & 50.1 \\
\hline Transferts officiels & 52.4 & 101.0 & 91.8 & 78.4 & 75.0 & 78.2 & 81.0 & 80.9 \\
\hline Balance des ressources $(\mathrm{X}-\mathrm{M})$ & -162.4 & -177.6 & -199.2 & -207.5 & -211.5 & -257.7 & -320.1 & -239.2 \\
\hline Solde des transactions courantes (hors transferts officiels) & -222.8 & -238.8 & -249.1 & -255.8 & -259.8 & -306.0 & -368.0 & -287.8 \\
\hline Solde des transactions courantes (y.c. transferts officiels) & -170.3 & -137.8 & -157.3 & -177.4 & -184.9 & -227.8 & -287.0 & -206.9 \\
\hline Compte de capital et financier & 188.2 & 187.2 & 173.6 & 202.6 & 192.5 & 246.2 & 313.1 & 225.6 \\
\hline Compte de capital & 74.5 & 191.5 & 95.5 & 105.1 & 113.1 & 122.7 & 132.8 & 113.8 \\
\hline Compte financier & 113.6 & -4.3 & 78.2 & 97.5 & 79.4 & 123.5 & 180.4 & 111.8 \\
\hline Financier (net) & 52.7 & -127.6 & -70.5 & -64.1 & -94.7 & -66.3 & -24.1 & -63.9 \\
\hline Officiel (net) & 61.0 & 123.3 & 148.7 & 161.6 & 174.1 & 189,8 & 204.5 & 175.7 \\
\hline Tirages & 100.6 & 159.3 & 182.9 & 196.0 & 210.2 & 227.7 & 246.0 & 212.6 \\
\hline Budgétaires & 21.4 & 48.5 & 30.0 & 30.0 & 30.0 & 30.0 & 30.0 & 30.0 \\
\hline Prêts-projets & 79.1 & 110.8 & 152.9 & 166.0 & 180.2 & 197.7 & 216.0 & 182.6 \\
\hline Restructuration dette IADM & 0.0 & 1035.7 & 0.0 & 0.0 & 0.0 & 0.0 & 0.0 & 0.0 \\
\hline Remboursements dus sur dette publique & -39.6 & -1071.7 & -34.2 & -34.4 & -36.1 & -37.9 & -41.5 & -36.8 \\
\hline Erreurs et omissions & 5.6 & 0.0 & 0.0 & 0.0 & 0.0 & 0.0 & 0.0 & 0.0 \\
\hline Balance globale & 23.5 & \begin{tabular}{l|}
49.4 \\
\end{tabular} & \begin{tabular}{|l|}
16.3 \\
\end{tabular} & 25.2 & \begin{tabular}{l|l}
7.6 \\
\end{tabular} & \begin{tabular}{ll|}
18.5 \\
\end{tabular} & 26.1 & $\begin{array}{l}18.7 \\
\end{array}$ \\
\hline Financing & -23.5 & -49.4 & -16.3 & -25.2 & -7.6 & -18.5 & -26.1 & -18.7 \\
\hline Avoirs extérieurs nets (- $=$ augmentation) & -51.2 & -75.3 & -26.8 & -35.9 & -18.8 & -30.6 & -37.2 & -29.9 \\
\hline PPTE assistance & 27.7 & 25.9 & 10.5 & 10.7 & 11.2 & 12.1 & 11.1 & 11.1 \\
\hline Financing gap & 0.0 & 0.0 & 0,0 & 0.0 & 0.0 & 0.0 & 0.0 & 0.0 \\
\hline
\end{tabular}

109. Money supply (M2) is projected in relation to trends in real GDP (7.0 percent) and inflation ( 0.1 percent) which will make it possible to maintain a liquidity ratio (M2/GDP) of 25.6 percent on average.

110. In addition, credit to the economy is forecast at CFAF 1,022 billion in 2011, amply covering all the private sector's financing needs.

111. The government should see its net position improve from CFAF -64.1 billion in 2007 to around CFAF -475 billion in 2011, bolstered in large measure by the broader tax base. 
Table 18: Monetary situation (CFAF billion; end of period)

\begin{tabular}{|c|c|c|c|c|c|c|c|c|}
\hline Fin d'année & Average & 2006 & 2007 & 2008 & 2009 & 2010 & 2011 & Average \\
\hline & 2002-2005 & Estim. & Prév. & Prév. & Prév. & Prév. & Prév. & $2007-2011$ \\
\hline Avoirs extérieurs bruts & 556.4 & 693.8 & 718.3 & 755.4 & 775.7 & 807.8 & 846.5 & 780.7 \\
\hline Engagements extérieurs & 186.0 & 189.6 & 187.3 & 188.6 & 190.0 & 191.5 & 193.0 & 190.1 \\
\hline Avoirs extérieurs nets & 370.4 & 504.2 & 530.9 & 566.8 & 585.6 & 616.3 & 653.5 & 590.6 \\
\hline BCEAO & 330.1 & 468.1 & 477.8 & 510.1 & 527.1 & 554.7 & 588.2 & $\overline{531.6}$ \\
\hline Banques commerciales & 40.3 & 36.1 & 53.1 & 56.7 & 58.6 & 61.6 & 65.4 & 59.1 \\
\hline Avoirs intérieurs nets & 434.3 & 432.0 & 450.5 & 463.5 & 494.5 & 525.1 & 547.3 & 496.2 \\
\hline Créances sur l'Etat, nettes & -47.1 & -100.4 & -64.1 & -139.4 & -226.7 & -343.8 & -475.0 & -249.8 \\
\hline Créances sur l'économie & 481.5 & 532.4 & 514.6 & 602.9 & 721.2 & 868.9 & $1,022.2$ & 746.0 \\
\hline Ressources = emplois & 804.5 & 936.2 & 981.4 & $1,030.3$ & $1,080.1$ & $1,141.4$ & $1,200.8$ & $1,086.8$ \\
\hline Masse Monétaire (M2) & 749.1 & 852.6 & 897.7 & 946.4 & 996.2 & $1,057.5$ & $1,116.9$ & $1,003.0$ \\
\hline Circulation fiduciaire & 296.5 & 347.5 & 362.7 & 379.1 & 395.7 & 415.9 & 435.3 & 397.7 \\
\hline Dépôts à vue et à terme & 452.6 & 505.2 & 530.7 & 553.6 & 576.7 & 605.0 & 632.0 & 579.6 \\
\hline Autres postes, nets & 55.5 & 83.5 & 83.7 & 83.9 & 83.9 & 83.9 & 83.9 & 83.9 \\
\hline Ressources = emplois & 804.5 & 936.2 & 981.4 & $1,030.3$ & $1,080.1$ & $1,141.4$ & $1,200.8$ & $1,086.8$ \\
\hline \multicolumn{9}{|l|}{ Pour mémoire: } \\
\hline Produit intérieur brut aux prix du marché & $2,550.3$ & $3,205.8$ & $3,419.4$ & $3,653.0$ & $3,895.0$ & $4,196.9$ & $4,493.8$ & $3,931.6$ \\
\hline Taux de liquidité (M2/PIBm) & $29.4 \%$ & $26.6 \%$ & $26.3 \%$ & $25.9 \%$ & $25.6 \%$ & $25.2 \%$ & $24.9 \%$ & $25.6 \%$ \\
\hline Vitesse de circulation (PIBm/M2) & 3.4 & 3.8 & 3.8 & 3.9 & 3.9 & 4.0 & 4.0 & 3.9 \\
\hline
\end{tabular}

\subsubsection{External aid}

112. With regard to projections of external aid volumes, the macroeconomic framework provides for two variants of the ambitious scenario. The following table shows the forecasts (based on the balance of payments) assuming full coverage of the external financing needs as expressed in the macroeconomic framework and, thus, a financing gap of zero. In adopting this optimistic view, gross external aid needs (before debt servicing and HIPC debt relief) would amount to CFAF 397 billion (US\$787 million) a year for the 2007-2011 period, which corresponds to around EUR 606 million a year versus 355 million in 2002-2005. 
Table 19: External aid needs (CFAF billion)

\begin{tabular}{|c|c|c|c|c|c|c|c|c|}
\hline & \multirow{2}{*}{$\begin{array}{c}\text { Average } \\
2002-2005\end{array}$} & 2006 & 2007 & 2008 & 2009 & 2010 & 2011 & \multirow{2}{*}{$\begin{array}{l}\text { Average } \\
2007-2011\end{array}$} \\
\hline & & Estim. & Prév. & Prév. & Prév. & Prév. & Prév. & \\
\hline Total Aide extérieure financière requise (brut) & 233.0 & $1,490.4$ & 360.4 & 369.5 & 388.5 & 419.4 & 449.1 & 397.4 \\
\hline Total des Dons (BdP, hors Ass.technique et aide en nature) & 104.7 & $1,305.2$ & 167.0 & 162.9 & 167.1 & 179.5 & 191.9 & 173.7 \\
\hline Dons en capital liés aux projets & 68.1 & 186.5 & 93.0 & 102.4 & 110.1 & 119.5 & 129.3 & 110.9 \\
\hline Dons budgétaires globaux & 36.6 & 35.8 & 24.8 & 25.0 & 25.2 & 25.3 & 25.5 & 25.2 \\
\hline Appui budgétaire sectoriel & 0.0 & 47.2 & 49.2 & 35.5 & 31.8 & 34.7 & 37.1 & 37.7 \\
\hline Restructuration dette IADM & 0.0 & $1,035.7$ & 0.0 & 0.0 & 0.0 & 0.0 & 0.0 & 0.0 \\
\hline Total des tirages sur emprunts extérieurs & 100.6 & 159.3 & 182.9 & 196.0 & 210.2 & 227.7 & 246.0 & 212.6 \\
\hline Budgétaires & 21.4 & 48.5 & 30.0 & 30.0 & 30.0 & 30.0 & 30.0 & 30.0 \\
\hline Prêts-projets & 79.1 & 110.8 & 152.9 & 166.0 & 180.2 & 197.7 & 216.0 & 182.6 \\
\hline Remboursements dus sur dette publique & 39.6 & $1,071.7$ & 34.2 & 34.4 & 36.1 & 37.9 & 41.5 & 36.8 \\
\hline Régulation dette/PPTE & 27.7 & 25.9 & 10.5 & 10.7 & 11.2 & 12.1 & 11.1 & 11.1 \\
\hline Total Aide extérieure financière (hors intérêts) (net) & 165.7 & 392.8 & 315.7 & 324.5 & 341.2 & 369.3 & 396.4 & 349.4 \\
\hline Intérêts sur la dette extérieure publique & 16.8 & 14.0 & 12.3 & 10.5 & 10.3 & 9.9 & 9.2 & 10.4 \\
\hline Total Aide extérieure financière (net) & 182.5 & 406.8 & 328.0 & 335.0 & 351.5 & 379.2 & 405.6 & 359.9 \\
\hline Aide à rechercher: gap de financement du Budget & 0.0 & 13.8 & 0.0 & 0.0 & 0.0 & 0.0 & 0.0 & 0.0 \\
\hline & Average & & & & & & & Average \\
\hline Aide extérieure (millions \$ E.U.) & $2002-2005$ & 2006 & 2007 & 2008 & 2009 & 2010 & 2011 & $2007-2011$ \\
\hline Total Aide extérieure financière requise (brut) & 407.0 & $2,853.8$ & 706.7 & 728.6 & 769.3 & 834,0 & 896,6 & 787,0 \\
\hline Total des Dons (BdP, hors Ass.technique et aide en nature) & 184.0 & $2,499.1$ & 327.5 & 321.1 & 330.8 & 357,1 & 383,3 & 343,9 \\
\hline Dons en capital liés aux projets & 118.7 & 357.1 & 182.4 & 201.9 & 218,0 & 237,6 & 258,2 & 219,6 \\
\hline Dons budgétaires globaux & 65.4 & 68.5 & 48.6 & 49.2 & 49,8 & 50,4 & 51,0 & 49,8 \\
\hline Appui budgétaire sectoriel & 0.0 & 90.4 & 96.5 & 70.0 & 63,0 & 69,0 & 74,1 & 74,5 \\
\hline Restructuration dette IADM & 0.0 & $1,983.1$ & 0.0 & 0.0 & 0,0 & 0,0 & 0,0 & 0,0 \\
\hline Total des tirages sur emprunts extérieurs & 174.8 & 305.0 & 358.7 & 386.5 & 416,2 & 452,8 & 491,2 & 421,1 \\
\hline Budgétaires & 35.5 & 92.9 & 58.8 & 59.2 & 59,4 & 59,7 & 59,9 & 59,4 \\
\hline Prêts-projets & 139.3 & 212.2 & 299.8 & 327.3 & 356,8 & 393,2 & 431,3 & 361,7 \\
\hline Remboursements dus sur dette publique & 68.7 & 2052.0 & 67.1 & 67.8 & 71,5 & 75,4 & 82,9 & 72,9 \\
\hline Régulation dette/PPTE & 48.2 & 49.6 & 20.5 & 21.0 & 22,2 & 24,1 & 22,2 & 22,0 \\
\hline Total Aide extérieure financière (hors intérêts) (net) & 290.1 & 752.1 & 619.1 & 639.8 & 675,6 & 734,5 & 791,6 & 692,1 \\
\hline Intérêts sur la dette extérieure publique & 29.2 & 26.8 & 24.1 & 20.7 & 20,4 & 19,7 & 18,4 & 20,7 \\
\hline Total Aide extérieure financière (net) & 319.3 & 778.9 & 643.2 & 660.5 & 696,0 & $\mathbf{7 5 4 , 2}$ & 809,9 & 712,8 \\
\hline Aide à rechercher: gap de financement du Budget & 0.0 & 26.4 & 0.1 & 0.0 & $-0,1$ & $\mathbf{0 , 0}$ & $-0,1$ & $\mathbf{0 , 0}$ \\
\hline Aide extérieure financière (brut) en \% du PIB & $9.2 \%$ & $46.5 \%$ & $10.5 \%$ & $10.1 \%$ & $10,0 \%$ & $10,0 \%$ & $10,0 \%$ & $10,1 \%$ \\
\hline Aide extérieure financière (net) en \% du PIB & $7.2 \%$ & $12.7 \%$ & $9.6 \%$ & $9.2 \%$ & $9,0 \%$ & $9,0 \%$ & $9,0 \%$ & $9,2 \%$ \\
\hline Aide extérieure (brut) Euro par tête de la population & 31.5 & 188.5 & 44.4 & 44.3 & 45,4 & 47,7 & 49,7 & 46,3 \\
\hline Aide extérieure (net) Euro par tête de la population & 22.4 & 49.7 & 38.9 & 38.9 & 39,8 & 42,0 & 43,8 & 40,7 \\
\hline Aide extérieure financ. (brut) \$ E.U. par tête de la population & 36.0 & 236.8 & 57.1 & 57.3 & 58,9 & 62,2 & 65,0 & 60,1 \\
\hline Aide extérieure financ. (net) \$ E.U. par tête de la population & 28.2 & 64.6 & 52.0 & 52.0 & 53,3 & 56,2 & 58,8 & 54,4 \\
\hline
\end{tabular}

113. In the event that this assumption might be considered too optimistic, an alternative scenario has been established based on the assumption that only 75 percent of the external financing needs would be met. The table below, thus, shows a financing gap of around CFAF 97 billion (U\$191 million or EUR 147 million) a year.

114. To this gap should be added a domestic financing gap of around CFAF 27 billion a year should the assumptions of the basic scenario be realized, which would mean, inter alia, achieving a 17 percent tax ratio by 2011 only.

Table 20: Financing gap (CFAF billion)

\begin{tabular}{|c|c|c|c|c|c|c|c|c|}
\hline Aide extérieure (mrd. FCFA) & Moyenne & & & & & & & Moyenne \\
\hline Scénario alternatif & $2002-2005$ & 2006 & 2007 & 2008 & 2009 & 2010 & 2011 & $2007-2011$ \\
\hline Total Aide extérieure financière requise (brut) en mrd. FCFA & 233,0 & $1.494,8$ & 272,9 & 279,8 & 294,2 & 317,6 & 339,6 & 300,8 \\
\hline Total des Dons (BdP, hors Ass.technique et aide en nature) & 104,7 & $1.309,6$ & 125,3 & 122,1 & 125,3 & 134,7 & 144,0 & 130,3 \\
\hline Dons en capital liés aux projets & 68,1 & 186,5 & 69,8 & 76,8 & 82,6 & 89,6 & 97,0 & 83,1 \\
\hline Dons budgétaires globaux & 36,6 & 35,8 & 18,6 & 18,7 & 18,9 & 19,0 & 19,2 & 18,9 \\
\hline Appui budgétaire sectoriel & 0,0 & 47,2 & 36,9 & 26,6 & 23,9 & 26,0 & 27,8 & 28,2 \\
\hline Restructuration dette IADM & 0,0 & 1040,1 & 0,0 & 0,0 & 0,0 & 0,0 & 0,0 & 0,0 \\
\hline Total des tirages sur emprunts extérieurs & 100,6 & 159,3 & 137,2 & 147,0 & 157,7 & 170,8 & 184,5 & 159,4 \\
\hline Budgétaires & 21,4 & 48,5 & 22,5 & 22,5 & 22,5 & 22,5 & 22,5 & 22,5 \\
\hline Prêts-projets & 79,1 & 110,8 & 114,7 & 124,5 & 135,2 & 148,3 & 162,0 & 136,9 \\
\hline Remboursements dus sur dette publique & 39,6 & 1076,1 & 34,2 & 34,4 & 36,1 & 37,9 & 41,5 & 36,8 \\
\hline Régulation dette/PPTE & 27,7 & 25,9 & 10,5 & 10,7 & 11,2 & 12,1 & 11,1 & 11,1 \\
\hline Total Aide extérieure financière (hors intérêts) (net) en mrd. FCFA & 165,7 & 392,8 & 228,2 & 234,7 & 246,8 & $\mathbf{2 6 7 , 5}$ & 287,0 & 252,9 \\
\hline Intérêts sur la dette extérieure publique & 16,8 & 14,0 & 12,3 & 10,5 & 10,3 & 9,9 & 9,2 & 10,4 \\
\hline Total Aide extérieure financière (net) en mrd. FCFA & 149,0 & 378,8 & 215,9 & 224,2 & $\mathbf{2 3 6 , 5}$ & 257,6 & 277,8 & 242,4 \\
\hline Aide à rechercher: gap de financement du Budget (mrd. FCFA) & 0,0 & 13,8 & $\mathbf{8 7 , 5}$ & $\mathbf{8 9 , 7}$ & 94,3 & 101,8 & $\mathbf{1 0 9 , 5}$ & 96,6 \\
\hline Aide à rechercher: gap de financement du Budget (millions \$ E.U.) & 0,0 & 26,4 & 171,5 & 176,9 & $\mathbf{1 8 6 , 8}$ & 202,5 & 218,6 & 191,3 \\
\hline Aide à rechercher: gap de financement du Budget (millions EURO) & 0,0 & 21,0 & 133,4 & 136,8 & 143,8 & 155,2 & 166,9 & 147,2 \\
\hline
\end{tabular}




\section{$2.5 \quad$ Impact on poverty}

115. Based on a structural analysis of the Malian economy using the T21 model, the findings of the PRSP-II macroeconomic framework indicate that with average annual GDP growth at factor cost of 6.5 percent, the percentage of the population living below the monetary poverty line (CFAF 72,011 at 1987 prices per capita and per year) ${ }^{12}$ would fall from 56.0 percent in 2007 to around 51.2 percent in 2011 , that is a reduction of 5 percentage points in five years. This represents an average annual decline of 1.2 points. It should be noted that, according to the Malian poverty assessment survey (EMEP), the monetary poverty rate stood at 68.3 percent $^{13}$ in 2002.

116. This poverty analysis supposes an improvement in income distribution and the control of population growth.

Figure 7: Trends in economic growth and monetary poverty

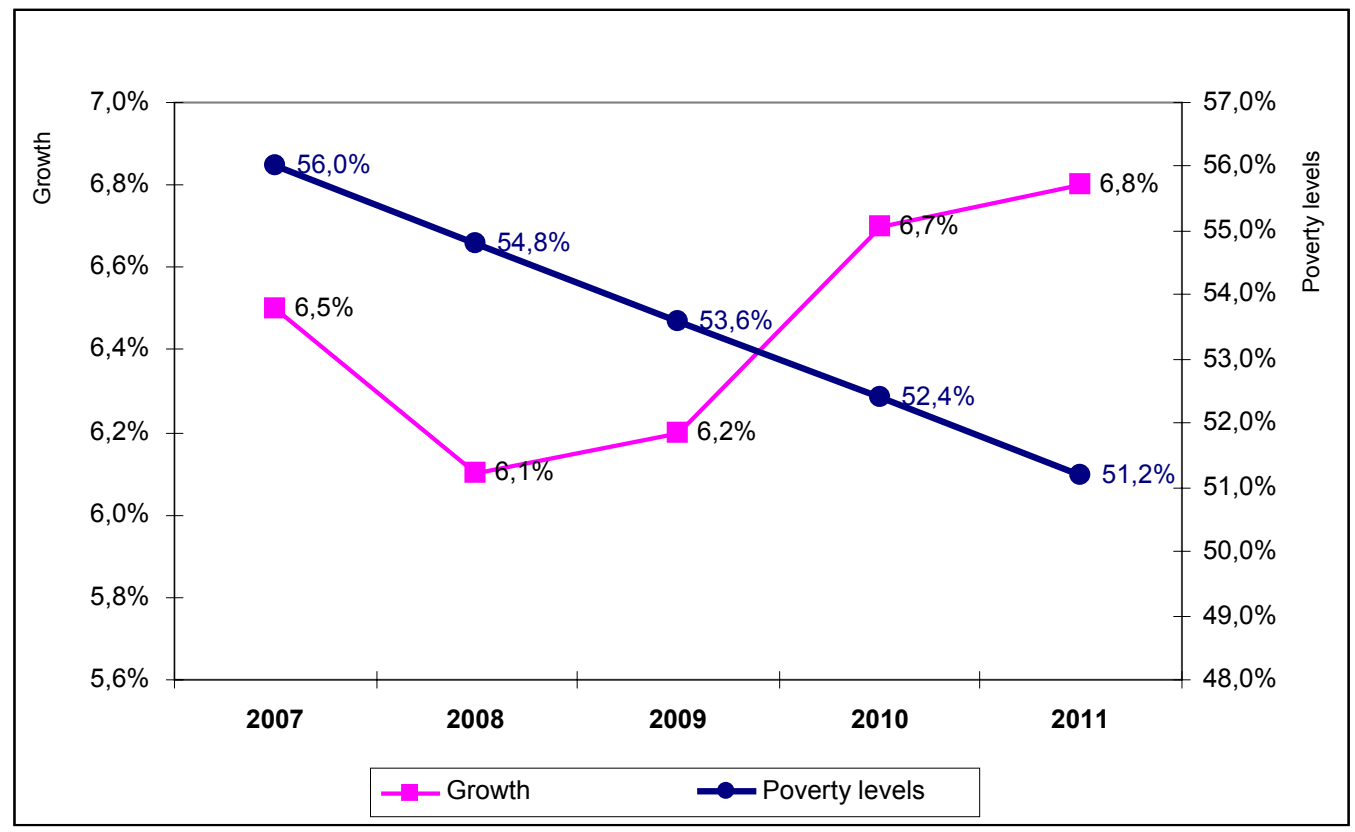

Source: T21/MME_DNPD

\footnotetext{
122005 ODHD Report, Dynamique de l'Analyse de la pauvreté de 1993 à 2003, July 2005.

${ }^{13}$ EMEP 2001, summary report, annex 3, November 2003.
} 


\section{CONCLUSIONS}

117. The macroeconomic framework of the PRSP was produced at a time when the department in charge of planning and development was updating its working tools, particularly those used for macroeconomic modeling and forecasting. The Forecasting and Modeling Committee was set up for that purpose and the planning exercise was entrusted to it.

118. Assumptions regarding the international environment contained in the framework, related to commodity prices, global inflation and exchange rates, were based on IMF projections.

119. In addition, specific assumptions were made for the promising sectors of the national economy, in particular, rice, cotton, agrofood, textiles, livestock farming, gold, water and electricity, BTP, and taxation.

120. On the basis of these assumptions, two scenarios, taking account of the country's actual economic potential, were produced. A basic (trend) scenario that forecasts economic development based on existing policies and an ambitious scenario (called the PRSP-II scenario) that makes assumptions of strong growth in the promising sectors of the economy and of major efforts to strengthen government revenues.

121. Projections were made over the 2007-2011 period. The results of the exercise show the economy growing by 5 percent on average over the period, a tax ratio of 15.7 percent on average and a financing gap of CFAF 27 billion a year (4.4 percent of fiscal revenue) for the basic scenario. Regarding the ambitious scenario, these indicators project economic growth of 7.0 percent and a tax ratio of 17 percent as of 2008. The annual financing gap would be around US\$191 million if only 75 percent of external aid needs were to be met.

122. The results of the ambitious exercise show a marked improvement in the tax ratio, bringing Mali into compliance with community criteria for government finance, in particular the 17 percent tax ratio, from 2008. In order to achieve the latter minimum community objective and fulfill the assumptions of increased investment, the government will need to make even greater efforts to strengthen tax revenue collection.

123. Analysis of the relationship between economic growth and poverty using the T21 model shows that with the current structure of the Malian economy, average GDP growth of 6.5 percent at factor cost over five years will contribute to lowering the monetary poverty rate by 5 percentage points by 2011, that is, an annual reduction of 1.2 percent. 


\section{OUtPut TABLES (MME_DNPD)}

Table 10: Projection assumptions for the basic scenario

\begin{tabular}{|c|c|c|c|c|c|c|c|c|}
\hline Hypothèses générales & \begin{tabular}{|l|} 
Average \\
$2002-2005$
\end{tabular} & \begin{tabular}{r|} 
estim \\
2006
\end{tabular} & $\begin{array}{l}\text { prév } \\
2007\end{array}$ & $\begin{array}{l}\text { prév } \\
2008\end{array}$ & $\begin{array}{l}\text { prév } \\
2009\end{array}$ & $\begin{array}{l}\text { prév } \\
2010\end{array}$ & \begin{tabular}{l|} 
prév \\
2011
\end{tabular} & \begin{tabular}{|l|} 
Average \\
2007-2011
\end{tabular} \\
\hline Taux d'inflation mondiale (mesuré par le MUV) & $3,5 \%$ & $1,6 \%$ & $1,2 \%$ & $1,2 \%$ & $1,2 \%$ & $1,2 \%$ & $1,2 \%$ & $1,2 \%$ \\
\hline Prix Coton $($ Cents/lb) & 0,0 & 57,0 & 58,5 & 60,5 & 63,0 & 63,0 & 63,0 & 61,6 \\
\hline Prix Or $(\$ /$ once $)$ & 0,0 & 618,0 & 670,0 & 710,0 & 750,0 & 770,0 & 775,0 & 735,0 \\
\hline Prix Petrole (\$/baril) & 0,0 & 66,5 & 69,8 & 68,5 & 67,5 & 66,8 & 66,0 & 67,7 \\
\hline Ratio US \$ / Euro & 1,14106 & 1,25600 & 1,28635 & 1,29339 & 1,29895 & 1,30446 & 1,30971 & 1,29857 \\
\hline Tx de change FCFA/US \$ (moyenne de période) & 582,2 & 522,3 & 509,9 & 507,2 & 505,0 & 502,9 & 500,8 & 505,2 \\
\hline US \$/FCFA (Variation) & $-7,7 \%$ & $-0,8 \%$ & $-2,4 \%$ & $-0,5 \%$ & $-0,4 \%$ & $-0,4 \%$ & $-0,4 \%$ & $-0,8 \%$ \\
\hline Tx de change FCFA/EURO & 656,0 & 656,0 & 656,0 & 656,0 & 656,0 & 656,0 & 656,0 & 656,0 \\
\hline \multirow{2}{*}{ Hypothèses secteur réel } & Average & estim & prév & prév & prév & prév & prév & Average \\
\hline & $2002-2005$ & 2006 & 2007 & 2008 & 2009 & 2010 & 2011 & $2007-2011$ \\
\hline TC réel PIB Agriculture vivrière & $8,7 \%$ & $8,3 \%$ & $3,8 \%$ & $6,0 \%$ & $6,0 \%$ & $6,0 \%$ & $6,0 \%$ & $5,6 \%$ \\
\hline TC réel PIB branche consolidé du riz & $2,7 \%$ & $7,3 \%$ & $7,3 \%$ & $7,0 \%$ & $7,0 \%$ & $7,0 \%$ & $7,0 \%$ & $7,1 \%$ \\
\hline $\mathrm{TC}$ réel PIB Agriculture industrielle hors coton & $14,3 \%$ & $2,1 \%$ & $6,3 \%$ & $6,3 \%$ & $6,3 \%$ & $6,3 \%$ & $6,3 \%$ & $6,3 \%$ \\
\hline $\mathrm{TC}$ réel PIB branche consolidé coton & $1,1 \%$ & $-0,4 \%$ & $0,0 \%$ & $0,0 \%$ & $0,0 \%$ & $0,0 \%$ & $0,0 \%$ & $0,0 \%$ \\
\hline $\mathrm{TC}$ réel PIB Elevage & $4,1 \%$ & $2,5 \%$ & $3,0 \%$ & $3,0 \%$ & $3,0 \%$ & $3,0 \%$ & $3,0 \%$ & $3,0 \%$ \\
\hline TC réel PIB Pêche & $2,2 \%$ & $3,8 \%$ & $4,5 \%$ & $4,5 \%$ & $4,5 \%$ & $4,5 \%$ & $4,5 \%$ & $4,5 \%$ \\
\hline TC réel PIB Produits de la forêt & $2,9 \%$ & $3,8 \%$ & $4,2 \%$ & $4,2 \%$ & $4,2 \%$ & $4,2 \%$ & $4,2 \%$ & $4,2 \%$ \\
\hline TC réel PIB Produits de l'extration & $2,0 \%$ & $10,6 \%$ & $0,7 \%$ & $-10,5 \%$ & $0,7 \%$ & $-4,8 \%$ & $-2,7 \%$ & $-3,3 \%$ \\
\hline TC réel PIB Agroalimentaires & $9,4 \%$ & $0,6 \%$ & $8,0 \%$ & $8,0 \%$ & $8,0 \%$ & $8,0 \%$ & $8,0 \%$ & $8,0 \%$ \\
\hline TC réel PIB Industries textiles & $9,5 \%$ & $0,2 \%$ & $2,0 \%$ & $2,0 \%$ & $2,0 \%$ & $2,0 \%$ & $2,0 \%$ & $2,0 \%$ \\
\hline TC réel PIB Autres branches manufacturières & $9,5 \%$ & $0,2 \%$ & $9,7 \%$ & $9,7 \%$ & $9,7 \%$ & $9,7 \%$ & $9,7 \%$ & $9,7 \%$ \\
\hline TC réel PIB Electricité eau & $12,0 \%$ & $8,3 \%$ & $10,2 \%$ & $10,2 \%$ & $10,2 \%$ & $10,2 \%$ & $10,2 \%$ & $10,2 \%$ \\
\hline TC réel PIB Batiments, Travaux publics & $5,2 \%$ & $5,7 \%$ & $7,5 \%$ & $5,8 \%$ & $7,9 \%$ & $7,5 \%$ & $8,9 \%$ & $7,5 \%$ \\
\hline FBCF publique en $\%$ du PIB coût d.fact. (prix const.) & $7,7 \%$ & $8,0 \%$ & $9,0 \%$ & $9,5 \%$ & $10,0 \%$ & $10,5 \%$ & $10,7 \%$ & $9,9 \%$ \\
\hline FBCF privée en $\%$ du PIB coût d.fact. (prix const.) & $10,4 \%$ & $10,0 \%$ & $12,0 \%$ & $12,0 \%$ & $12,0 \%$ & $12,0 \%$ & $12,5 \%$ & $12,1 \%$ \\
\hline \multirow[t]{2}{*}{ Hypothèses Finances Publiques } & Average & estim & prév & prév & prév & prév & prév & Average \\
\hline & 2002-2005 & 2006 & 2007 & 2008 & 2009 & 2010 & 2011 & $2007-2011$ \\
\hline Ratio TVA intérieure / PIB Sect. moderne & $5,9 \%$ & $7,6 \%$ & $8,0 \%$ & $8,0 \%$ & $8,5 \%$ & $9,5 \%$ & $10,3 \%$ & $8,9 \%$ \\
\hline Ratio Autres droits et taxes / PIB Sect. moderne & $7,0 \%$ & $8,1 \%$ & $8,0 \%$ & $8,2 \%$ & $8,4 \%$ & $8,8 \%$ & $9,2 \%$ & $8,5 \%$ \\
\hline Mesures supplémentaires (mrd. FCFA) & 0,0 & 0,0 & 0,0 & 70,0 & 56,8 & 15,0 & 0,0 & 28,4 \\
\hline Recettes non fiscales par rapport au PIB Sect.mod. & $2,9 \%$ & $2,5 \%$ & $3,0 \%$ & $3,2 \%$ & $3,4 \%$ & $3,6 \%$ & $3,8 \%$ & $3,4 \%$ \\
\hline Recettes fonds spéc. et budgets annexes /PIB Sect. mod. & $4,3 \%$ & $3,9 \%$ & $4,0 \%$ & $4,2 \%$ & $4,4 \%$ & $4,5 \%$ & $4,6 \%$ & $4,3 \%$ \\
\hline Ratio Salaires/Recettes totales & $26,1 \%$ & $27,6 \%$ & $27,6 \%$ & $27,7 \%$ & $27,4 \%$ & $28,1 \%$ & $28,4 \%$ & $27,8 \%$ \\
\hline Ratio Matériel/Recettes totales & $9,4 \%$ & $10,7 \%$ & $11,2 \%$ & $11,9 \%$ & $11,9 \%$ & $12,3 \%$ & $12,8 \%$ & $12,0 \%$ \\
\hline Ratio Communication - énergie/Recettes tot. & $5,4 \%$ & $6,0 \%$ & $5,5 \%$ & $5,8 \%$ & $5,9 \%$ & $6,1 \%$ & $6,3 \%$ & $5,9 \%$ \\
\hline Ratio Déplacem., entret. et carburants/Rec. tot. & $5,3 \%$ & $5,5 \%$ & $5,8 \%$ & $5,8 \%$ & $5,7 \%$ & $5,7 \%$ & $5,7 \%$ & $5,7 \%$ \\
\hline Ratio Bourses/Recettes totales & $1,3 \%$ & $1,0 \%$ & $1,0 \%$ & $0,9 \%$ & $0,8 \%$ & $0,8 \%$ & $0,7 \%$ & $0,8 \%$ \\
\hline Ratio Autres transferts et subventions/Rec.tot. & $9,0 \%$ & $10,8 \%$ & $11,4 \%$ & $11,2 \%$ & $10,9 \%$ & $10,7 \%$ & $10,6 \%$ & $11,0 \%$ \\
\hline Intérêts sur dette extérieure & 16,8 & 17,5 & 11,8 & 10,0 & 9,8 & 9,4 & 8,7 & 9,9 \\
\hline Remboursements sur dette extérieure & 39,0 & 1076,1 & 34,2 & 34,4 & 36,1 & 37,9 & 41,5 & 36,8 \\
\hline \multirow[t]{2}{*}{ Hypothèses secteur extérieur } & Average & estim & prév & prév & prév & prév & prév & Average \\
\hline & 2002-2005 & 2006 & 2007 & 2008 & 2009 & 2010 & 2011 & $2007-2011$ \\
\hline TC Importations des textiles (aux prix constants) & $-12,8 \%$ & $11,4 \%$ & $2,2 \%$ & $2,2 \%$ & $2,2 \%$ & $2,2 \%$ & $2,2 \%$ & $2,2 \%$ \\
\hline TC Autres Importations (aux prix constants) & $2,5 \%$ & $0,2 \%$ & $0,5 \%$ & $0,5 \%$ & $0,5 \%$ & $0,5 \%$ & $0,5 \%$ & $0,5 \%$ \\
\hline TC réel Exportation Coton fibre & $19,8 \%$ & $-5,3 \%$ & $-0,4 \%$ & $0,0 \%$ & $0,0 \%$ & $0,0 \%$ & $0,0 \%$ & $-0,1 \%$ \\
\hline TC réel Exportation Elevage & $-14,8 \%$ & $-14,6 \%$ & $6,7 \%$ & $6,7 \%$ & $6,7 \%$ & $6,7 \%$ & $6,7 \%$ & $6,7 \%$ \\
\hline TC réel Exportations Or & $4,8 \%$ & $8,1 \%$ & $0,7 \%$ & $-10,5 \%$ & $0,7 \%$ & $-4,8 \%$ & $-2,7 \%$ & $-3,3 \%$ \\
\hline TC réel Autres exportations & $-1,8 \%$ & $-7,4 \%$ & $20,5 \%$ & $21,0 \%$ & $21,0 \%$ & $21,0 \%$ & $21,0 \%$ & $20,9 \%$ \\
\hline Ratio Export. Services non-facteurs/Exportations & $23,0 \%$ & $20,7 \%$ & $23,0 \%$ & $24,0 \%$ & $25,0 \%$ & $25,0 \%$ & $25,0 \%$ & $24,4 \%$ \\
\hline Réserves de dev. nettes en mois d'importation caf & 5,5 & 5,8 & 5,7 & 5,7 & 5,6 & 5,5 & 5,4 & 5,6 \\
\hline Réserves de dev. brutes en mois d'importation caf & 8,3 & 8,0 & 7,8 & 7,7 & 7,5 & 7,3 & 7,1 & 7,5 \\
\hline \multirow[t]{2}{*}{ Hypothèses aide extérieure } & Average & estim & prév & prév & prév & prév & prév & Average \\
\hline & $2002-2005$ & 2006 & 2007 & 2008 & 2009 & 2010 & 2011 & $2007-2011$ \\
\hline Ratio Dons en capital liés aux projets / Dépenses publ. totales & $19,5 \%$ & $41,3 \%$ & $19,6 \%$ & $20,6 \%$ & $20,9 \%$ & $21,1 \%$ & $21,2 \%$ & $20,7 \%$ \\
\hline Ratio Dons budgétaires globaux / Dép.pbl.tot. & $10,6 \%$ & $7,9 \%$ & $5,2 \%$ & $5,0 \%$ & $4,8 \%$ & $4,5 \%$ & $4,2 \%$ & $4,7 \%$ \\
\hline Ratio Appui budgétaire sectoriel / Dép.pbl.tot. & $0,0 \%$ & $10,4 \%$ & $10,4 \%$ & $7,1 \%$ & $6,0 \%$ & $6,1 \%$ & $6,1 \%$ & $7,2 \%$ \\
\hline Ratio Tirages emprunts extérieur (budgétaire) / Dép.pbl.tot. & $6,1 \%$ & $10,7 \%$ & $6,3 \%$ & $6,0 \%$ & $5,7 \%$ & $5,3 \%$ & $4,9 \%$ & $5,7 \%$ \\
\hline Ratio Tirages emprunts extérieurs (prêts projets) / Dép.pbl.tot. & $22,5 \%$ & $24,5 \%$ & $32,2 \%$ & $33,4 \%$ & $34,2 \%$ & $34,9 \%$ & $35,5 \%$ & $34,0 \%$ \\
\hline
\end{tabular}

Ratio Tirages emprunts extérieurs (prêts projets) / Dép pl tot. 
Table 11: Projection assumptions for the ambitious scenario

\begin{tabular}{|c|c|c|c|c|c|c|c|c|}
\hline Hypothèses générales & $\begin{array}{c}\text { Average } \\
2002-2005\end{array}$ & $\begin{array}{r}\text { estim } \\
2006\end{array}$ & \begin{tabular}{l|} 
prév \\
2007
\end{tabular} & $\begin{array}{l}\text { prév } \\
2008\end{array}$ & $\begin{array}{l}\text { prév } \\
2009\end{array}$ & \begin{tabular}{l|} 
prév \\
2010
\end{tabular} & $\begin{array}{l}\text { prév } \\
2011\end{array}$ & \begin{tabular}{|l|} 
Average \\
$2007-2011$
\end{tabular} \\
\hline Taux d'inflation mondiale (mesuré par le MUV) & $3,5 \%$ & $1,6 \%$ & $1,2 \%$ & $1,2 \%$ & $1,2 \%$ & $1,2 \%$ & $1,2 \%$ & $1,2 \%$ \\
\hline Prix Coton (Cents/lb) & & 57,0 & 58,5 & 60,5 & 63,0 & 63,0 & 63,0 & 61,6 \\
\hline Prix Or (\$/once) & & 618,0 & 670,0 & 710,0 & 750,0 & 770,0 & 775,0 & 735,0 \\
\hline Prix Petrole (\$/baril) & & 66,5 & 69,8 & 68,5 & 67,5 & 66,8 & 66,0 & 67,7 \\
\hline Ratio US \$ / Euro & 1,14106 & 1,25600 & 1,28635 & 1,29339 & 1,29895 & 1,30446 & 1,30971 & 1,29857 \\
\hline Tx de change FCFA/US \$ (moyenne de période) & 582,2 & 522,3 & 509,9 & 507,2 & 505,0 & 502,9 & 500,8 & 505,2 \\
\hline US \$/FCFA (Variation) & $-7,7 \%$ & $-0,8 \%$ & $-2,4 \%$ & $-0,5 \%$ & $-0,4 \%$ & $-0,4 \%$ & $-0,4 \%$ & $-0,8 \%$ \\
\hline Tx de change FCFA/EURO & 656,0 & 656,0 & 656,0 & 656,0 & 656,0 & 656,0 & 656,0 & 656,0 \\
\hline \multirow[t]{2}{*}{ Hypothèses secteur réel } & Average & estim & prév & prév & prév & prév & prév & Average \\
\hline & 2002-2005 & 2006 & 2007 & 2008 & 2009 & 2010 & 2011 & 2007-2011 \\
\hline TC réel PIB Agriculture vivrière & $8,7 \%$ & $8,3 \%$ & $6,0 \%$ & $6,0 \%$ & $6,0 \%$ & $6,0 \%$ & $6,5 \%$ & $6,1 \%$ \\
\hline TC réel PIB branche consolidé du riz & $2,7 \%$ & $7,3 \%$ & $9,9 \%$ & $9,9 \%$ & $9,9 \%$ & $9,9 \%$ & $9,9 \%$ & $9,9 \%$ \\
\hline TC réel PIB Agriculture industrielle hors coton & $14,3 \%$ & $2,1 \%$ & $6,3 \%$ & $6,3 \%$ & $6,3 \%$ & $6,3 \%$ & $6,3 \%$ & $6,3 \%$ \\
\hline TC réel PIB branche consolidé coton & $1,1 \%$ & $-0,4 \%$ & $1,6 \%$ & $1,6 \%$ & $1,6 \%$ & $1,6 \%$ & $1,6 \%$ & $1,6 \%$ \\
\hline TC réel PIB Elevage & $4,1 \%$ & $2,5 \%$ & $4,6 \%$ & $4,6 \%$ & $4,6 \%$ & $4,6 \%$ & $4,6 \%$ & $4,6 \%$ \\
\hline TC réel PIB Pêche & $2,2 \%$ & $3,8 \%$ & $4,5 \%$ & $4,5 \%$ & $4,5 \%$ & $4,5 \%$ & $4,5 \%$ & $4,5 \%$ \\
\hline TC réel PIB Produits de la forêt & $2,9 \%$ & $3,8 \%$ & $4,2 \%$ & $4,2 \%$ & $4,2 \%$ & $4,2 \%$ & $4,2 \%$ & $4,2 \%$ \\
\hline TC réel PIB Produits de l'extration & $2,0 \%$ & $10,6 \%$ & $3,4 \%$ & $0,0 \%$ & $0,0 \%$ & $0,0 \%$ & $0,0 \%$ & $0,7 \%$ \\
\hline TC réel PIB Agroalimentaires & $9,4 \%$ & $0,6 \%$ & $11,2 \%$ & $11,2 \%$ & $11,2 \%$ & $11,2 \%$ & $11,2 \%$ & $11,2 \%$ \\
\hline TC réel PIB Industries textiles & $9,5 \%$ & $0,2 \%$ & $6,8 \%$ & $6,8 \%$ & $6,8 \%$ & $6,8 \%$ & $6,8 \%$ & $6,8 \%$ \\
\hline TC réel PIB Autres branches manufacturières & $9,5 \%$ & $0,2 \%$ & $9,7 \%$ & $9,7 \%$ & $9,7 \%$ & $9,7 \%$ & $9,7 \%$ & $9,7 \%$ \\
\hline TC réel PIB Electricité eau & $12,0 \%$ & $8,3 \%$ & $12,9 \%$ & $12,9 \%$ & $12,9 \%$ & $12,9 \%$ & $12,9 \%$ & $12,9 \%$ \\
\hline TC réel PIB Batiments, Travaux publics & $5,2 \%$ & $5,7 \%$ & $7,5 \%$ & $7,7 \%$ & $8,5 \%$ & $8,7 \%$ & $9,4 \%$ & $8,4 \%$ \\
\hline FBCF publique en $\%$ du PIB coût d.fact. (prix const.) & $7,7 \%$ & $8,0 \%$ & $9,0 \%$ & $9,5 \%$ & $10,0 \%$ & $10,5 \%$ & $10,7 \%$ & $9,9 \%$ \\
\hline FBCF privée en \% du PIB coût d.fact. (prix const.) & $10,4 \%$ & $10,0 \%$ & $12,0 \%$ & $12,0 \%$ & $12,0 \%$ & $12,0 \%$ & $12,5 \%$ & $12,1 \%$ \\
\hline \multirow[t]{2}{*}{ Hypothèses Finances Publiques } & Average & estim & prév & prév & prév & prév & prév & Average \\
\hline & $2002-2005$ & 2006 & 2007 & 2008 & 2009 & 2010 & 2011 & $2007-2011$ \\
\hline Ratio TVA intérieure / PIB Sect. moderne & $5,9 \%$ & $7,6 \%$ & $8,0 \%$ & $8,0 \%$ & $8,3 \%$ & $11,0 \%$ & $11,5 \%$ & $9,4 \%$ \\
\hline Ratio Autres droits et taxes / PIB Sect. moderne & $7,0 \%$ & $8,1 \%$ & $8,0 \%$ & $8,1 \%$ & $8,4 \%$ & $8,9 \%$ & $9,2 \%$ & $8,5 \%$ \\
\hline Mesures supplémentaires (mrd. FCFA) & 0,0 & 0,0 & 0,0 & 60,4 & 48,2 & 6,6 & 0,0 & 23,0 \\
\hline Recettes non fiscales par rapport au PIB Sect.mod. & $2,9 \%$ & $2,5 \%$ & $3,0 \%$ & $3,4 \%$ & $3,4 \%$ & $3,6 \%$ & $3,6 \%$ & $3,4 \%$ \\
\hline Recettes fonds spéc. et budgets annexes /PIB Sect. mod. & $4,3 \%$ & $3,9 \%$ & $4,0 \%$ & $4,4 \%$ & $4,4 \%$ & $4,3 \%$ & $4,3 \%$ & $4,3 \%$ \\
\hline Ratio Salaires/Recettes totales & $26,1 \%$ & $27,6 \%$ & $27,6 \%$ & $24,2 \%$ & $24,3 \%$ & $24,8 \%$ & $24,8 \%$ & $25,1 \%$ \\
\hline Ratio Matériel/Recettes totales & $9,4 \%$ & $10,7 \%$ & $11,1 \%$ & $10,4 \%$ & $10,6 \%$ & $10,9 \%$ & $11,2 \%$ & $10,8 \%$ \\
\hline Ratio Communication - énergie/Recettes tot. & $5,4 \%$ & $6,0 \%$ & $5,5 \%$ & $5,1 \%$ & $5,3 \%$ & $5,3 \%$ & $5,5 \%$ & $5,3 \%$ \\
\hline Ratio Déplacem., entret. et carburants/Rec. tot. & $5,3 \%$ & $5,5 \%$ & $5,8 \%$ & $5,1 \%$ & $5,0 \%$ & $5,0 \%$ & $5,0 \%$ & $5,2 \%$ \\
\hline Ratio Bourses/Recettes totales & $1,3 \%$ & $1,0 \%$ & $1,0 \%$ & $0,8 \%$ & $0,7 \%$ & $0,7 \%$ & $0,6 \%$ & $0,8 \%$ \\
\hline Ratio Autres transferts et subventions/Rec.tot. & $9,0 \%$ & $10,8 \%$ & $11,3 \%$ & $9,8 \%$ & $9,7 \%$ & $9,5 \%$ & $9,3 \%$ & $9,9 \%$ \\
\hline Intérêts sur dette extérieure & 16,8 & 17,5 & 11,8 & 10,0 & 9,8 & 9,4 & 8,7 & 9,9 \\
\hline Remboursements sur dette extérieure & 39,0 & 1071,7 & 34,2 & 34,4 & 36,1 & 37,9 & 41,5 & 36,8 \\
\hline \multirow{2}{*}{ Hypothèses secteur extérieur } & Average & estim & prév & prév & prév & prév & prév & Average \\
\hline & $2002-2005$ & 2006 & 2007 & 2008 & 2009 & 2010 & 2011 & $2007-2011$ \\
\hline TC Importations des textiles (aux prix constants) & $-12,8 \%$ & $11,4 \%$ & $2,2 \%$ & $2,2 \%$ & $2,2 \%$ & $2,2 \%$ & $2,2 \%$ & $2,2 \%$ \\
\hline TC Autres Importations (aux prix constants) & $2,5 \%$ & $0,2 \%$ & $0,5 \%$ & $0,5 \%$ & $0,5 \%$ & $0,5 \%$ & $0,5 \%$ & $0,5 \%$ \\
\hline TC réel Exportation Coton fibre & $19,8 \%$ & $-5,3 \%$ & $-0,4 \%$ & $1,6 \%$ & $1,6 \%$ & $1,6 \%$ & $1,6 \%$ & $1,2 \%$ \\
\hline TC réel Exportation Elevage & $-14,8 \%$ & $-14,6 \%$ & $6,7 \%$ & $6,7 \%$ & $6,7 \%$ & $6,7 \%$ & $6,7 \%$ & $6,7 \%$ \\
\hline TC réel Exportations Or & $4,8 \%$ & $8,1 \%$ & $3,4 \%$ & $0,0 \%$ & $0,0 \%$ & $0,0 \%$ & $0,0 \%$ & $0,7 \%$ \\
\hline TC réel Autres exportations & $-1,8 \%$ & $-7,4 \%$ & $20,5 \%$ & $21,0 \%$ & $21,0 \%$ & $21,0 \%$ & $21,0 \%$ & $20,9 \%$ \\
\hline Ratio Export. Services non-facteurs/Exportations & $23,0 \%$ & $20,7 \%$ & $23,0 \%$ & $24,0 \%$ & $25,0 \%$ & $25,0 \%$ & $25,0 \%$ & $24,4 \%$ \\
\hline Réserves de dev. nettes en mois d'importation caf & 5,5 & 5,7 & 5,6 & 5,6 & 5,4 & 5,3 & 5,3 & 5,4 \\
\hline Réserves de dev. brutes en mois d'importation caf & 8,3 & 7,8 & 7,6 & 7,5 & 7,2 & 6,9 & 6,9 & 7,2 \\
\hline \multirow[t]{2}{*}{ Hypothèses aide extérieure } & Average & estim & prév & prév & prév & prév & prév & Average \\
\hline & $2002-2005$ & 2006 & 2007 & 2008 & 2009 & 2010 & 2011 & $2007-2011$ \\
\hline Ratio Dons en capital liés aux projets / Dépenses publ. totales & $19,5 \%$ & $41,3 \%$ & $19,6 \%$ & $20,5 \%$ & $20,8 \%$ & $21,1 \%$ & $21,2 \%$ & $20,6 \%$ \\
\hline Ratio Dons budgétaires globaux / Dép.pbl.tot. & $10,6 \%$ & $7,9 \%$ & $5,2 \%$ & $5,0 \%$ & $4,8 \%$ & $4,5 \%$ & $4,2 \%$ & $4,7 \%$ \\
\hline Ratio Appui budgétaire sectoriel / Dép.pbl.tot. & $0,0 \%$ & $10,4 \%$ & $10,3 \%$ & $7,1 \%$ & $6,0 \%$ & $6,1 \%$ & $6,1 \%$ & $7,1 \%$ \\
\hline Ratio Tirages emprunts extérieur (budgétaire) / Dép.pbl.tot. & $6,1 \%$ & $10,7 \%$ & $6,3 \%$ & $6,0 \%$ & $5,7 \%$ & $5,3 \%$ & $4,9 \%$ & $5,6 \%$ \\
\hline Ratio Tirages emprunts extérieurs (prêts projets) / Dép.pbl.tot. & $22,5 \%$ & $24,5 \%$ & $32,2 \%$ & $33,2 \%$ & $34,0 \%$ & $34,9 \%$ & $35,4 \%$ & $34,0 \%$ \\
\hline
\end{tabular}

Source: DNPD, modèle MME-DNPD 
Table 12: Macroeconomic performance indicators and policy criteria

\begin{tabular}{|c|c|c|c|c|c|c|c|c|}
\hline & Average & 2006 & 2007 & 2008 & 2009 & 2010 & 2011 & Average \\
\hline Ressources et emplois des biens \& services & $2002-2005$ & Estim. & Prév. & Prév. & Prév. & Prév. & Prév. & $2007-2011$ \\
\hline PIB aux prix du marché (mrd. FCFA courants) & 2550,3 & 3205,8 & 3419,4 & 3653,0 & 3895,0 & 4196,9 & 4493,8 & 3931,6 \\
\hline PIB aux prix du marché (mrd. \$ courants) & 4,5 & 6,1 & 6,7 & 7,2 & 7,7 & 8,3 & 9,0 & 7,8 \\
\hline PIB aux prix du marché (mrd. $€$ courants) & 3,9 & 4,9 & 5,2 & 5,6 & 5,9 & 6,4 & 6,9 & 6,0 \\
\hline Part du PIB du secteur formel (en \% PIBf) & $39,9 \%$ & $38,0 \%$ & $38,0 \%$ & $38,0 \%$ & $39,0 \%$ & $39,0 \%$ & $39,0 \%$ & $38,6 \%$ \\
\hline Taux de croissance réelle du PIB aux prix du marché & $5,2 \%$ & $3,6 \%$ & $7,0 \%$ & $6,6 \%$ & $6,5 \%$ & $7,8 \%$ & $7,1 \%$ & $7,0 \%$ \\
\hline Taux de croissance réelle du PIB au coût des facteurs & $4,6 \%$ & $4,4 \%$ & $6,5 \%$ & $6,1 \%$ & $6,2 \%$ & $6,7 \%$ & $6,8 \%$ & $6,5 \%$ \\
\hline - PIB secteur primaire & $4,7 \%$ & $5,0 \%$ & $5,5 \%$ & $5,6 \%$ & $5,6 \%$ & $5,7 \%$ & $5,9 \%$ & $5,7 \%$ \\
\hline - PIB secteur secondaire & $5,3 \%$ & $5,9 \%$ & $7,1 \%$ & $6,0 \%$ & $6,4 \%$ & $6,7 \%$ & $7,0 \%$ & $6,6 \%$ \\
\hline - PIB secteur tertiaire & $4,8 \%$ & $2,9 \%$ & $7,2 \%$ & $6,8 \%$ & $6,7 \%$ & $7,7 \%$ & $7,5 \%$ & $7,2 \%$ \\
\hline FBCF total (mrd. FCFA courants) & 443,8 & 671,6 & 659,1 & 717,8 & 780,8 & 851,9 & 937,6 & 789,4 \\
\hline - FBCF privée (mrd. FCFA courants) & 255,9 & 351,7 & 376,7 & 400,7 & 425,9 & 454,4 & 505,2 & 432,5 \\
\hline - FBCF publique (mrd. FCFA courants) & 188,0 & 319,9 & 282,5 & 317,2 & 354,9 & 397,6 & 432,4 & 356,9 \\
\hline Taux d'investisssements bruts (I/PIBm) & $21,4 \%$ & $21,4 \%$ & $19,7 \%$ & $20,1 \%$ & $20,5 \%$ & $20,7 \%$ & $21,2 \%$ & $20,4 \%$ \\
\hline Taux d'investissement fixe (FBCF/PIBm) & $17,6 \%$ & $20,9 \%$ & $19,3 \%$ & $19,7 \%$ & $20,0 \%$ & $20,3 \%$ & $20,9 \%$ & $20,0 \%$ \\
\hline - FBCF publique en $\%$ du PIBm & $7,4 \%$ & $10,0 \%$ & $8,3 \%$ & $8,7 \%$ & $9,1 \%$ & $9,5 \%$ & $9,6 \%$ & $9,0 \%$ \\
\hline - FBCF privée en $\%$ du PIBm & $10,2 \%$ & $11,0 \%$ & $11,0 \%$ & $11,0 \%$ & $10,9 \%$ & $10,8 \%$ & $11,2 \%$ & $11,0 \%$ \\
\hline Coefficient marginal de capital & 14,5 & 2,0 & 3,2 & 2,9 & 3,0 & 2,6 & 2,9 & 2,9 \\
\hline Taux d'épargne intérieure (en \% PIBm) & $15,2 \%$ & $15,9 \%$ & $13,9 \%$ & $14,4 \%$ & $15,0 \%$ & $14,5 \%$ & $14,1 \%$ & $14,4 \%$ \\
\hline Taux d'épargne extérieure (= - balance des ressources BP/PIBm) & $6,2 \%$ & $5,5 \%$ & $5,8 \%$ & $5,7 \%$ & $5,4 \%$ & $6,1 \%$ & $7,1 \%$ & $6,0 \%$ \\
\hline Taux d'épargne nationale brute (en \% PIBm) & $14,8 \%$ & $17,1 \%$ & $15,1 \%$ & $15,2 \%$ & $15,7 \%$ & $15,3 \%$ & $14,8 \%$ & $15,2 \%$ \\
\hline Taux de consommation (en \% PIBm) & $84,8 \%$ & $84,1 \%$ & $86,1 \%$ & $85,6 \%$ & $85,0 \%$ & $85,5 \%$ & $85,9 \%$ & $85,6 \%$ \\
\hline - Taux de consomma & $73,4 \%$ & $71,2 \%$ & $73,4 \%$ & $73,5 \%$ & $73,0 \%$ & $73,4 \%$ & $73,7 \%$ & $73,4 \%$ \\
\hline - Taux de consom & $11,4 \%$ & $12,9 \%$ & $12,7 \%$ & $12,1 \%$ & $12,0 \%$ & $12,0 \%$ & $12,2 \%$ & $12,2 \%$ \\
\hline Produit national brut par tête en FCFA courants & 225096 & 269324 & 279650 & 289717 & 300315 & 315076 & 328400 & 302632 \\
\hline Produit national brut & 112020 & 119061 & 123426 & 127589 & 132145 & 138647 & 144573 & 133276 \\
\hline Taux de $\mathrm{c}$ & $2,6 \%$ & $2,5 \%$ & $3,7 \%$ & $3,4 \%$ & $3,6 \%$ & $4,9 \%$ & $4,3 \%$ & $4,0 \%$ \\
\hline Produit national brut par tête en \$ E.U. & 395 & 516 & 548 & 571 & 595 & 627 & 656 & 599 \\
\hline \multirow[t]{2}{*}{ Balance des paiements } & \multirow{2}{*}{$\begin{array}{l}\text { Average } \\
2002-2005\end{array}$} & 2006 & 2007 & 2008 & 2009 & 2010 & 2011 & \multirow{2}{*}{\begin{tabular}{|l}
$\begin{array}{l}\text { Average } \\
2007-2011\end{array}$ \\
\end{tabular}} \\
\hline & & Estim. & Prév. & Prév. & Prév. & Prév. & Prév. & \\
\hline Taux d'importation (en \% du PIBm), prix cour. & $33,7 \%$ & $32,4 \%$ & $33,6 \%$ & $33,6 \%$ & $33,7 \%$ & $33,5 \%$ & $33,5 \%$ & $33,6 \%$ \\
\hline en $\%$ du PIBm), prix cour. & $27,5 \%$ & $26,9 \%$ & $27,8 \%$ & $28,0 \%$ & $28,2 \%$ & $27,3 \%$ & $26,4 \%$ & $27,5 \%$ \\
\hline Déficit commercial (fob) en \% du PIBm & $-0,3 \%$ & $-1,1 \%$ & $-1,1 \%$ & $-1,1 \%$ & $-1,1 \%$ & $-1,7 \%$ & $-2,5 \%$ & $-1,5 \%$ \\
\hline Balance des ressources (X-Mcaf) en \% du PIBm & $-6,2 \%$ & $-5,5 \%$ & $-5,8 \%$ & $-5,7 \%$ & $-5,4 \%$ & $-6,1 \%$ & $-7,1 \%$ & $-6,0 \%$ \\
\hline Compte courant (hors transf. off.) en \% du PIBm & $-8,6 \%$ & $-7,4 \%$ & $-7,3 \%$ & $-7,0 \%$ & $-6,7 \%$ & $-7,3 \%$ & $-8,2 \%$ & $-7,3 \%$ \\
\hline Compte courant (y compris transf. off.) en $\%$ du PIBm & $-6,6 \%$ & $-4,3 \%$ & $-4,6 \%$ & $-4,9 \%$ & $-4,7 \%$ & $-5,4 \%$ & $-6,4 \%$ & $-5,2 \%$ \\
\hline Réserves nettes en mois d'importations caf & 5,5 & 5,7 & 5,6 & 5,6 & 5,4 & 5,3 & 5,3 & 5,4 \\
\hline Réserve & 8,3 & 7,8 & 7,6 & 7,5 & 7,2 & 6,9 & 6,9 & 7,2 \\
\hline Ratio du service de la dette en $\%$ des exportations B\&SNF & $8,1 \%$ & $125,9 \%$ & $4,9 \%$ & $4,4 \%$ & $4,2 \%$ & $4,2 \%$ & $4,3 \%$ & $4,4 \%$ \\
\hline \multirow[t]{2}{*}{ Finances publiques } & \multirow{2}{*}{\begin{tabular}{|c|} 
Average \\
$2002-2005$ \\
\end{tabular}} & 2006 & 2007 & 2008 & 2009 & 2010 & 2011 & \multirow{2}{*}{\begin{tabular}{|l} 
Average \\
$2007-2011$ \\
\end{tabular}} \\
\hline & & Estim. & Prév. & Prév. & Prév. & Prév. & Prév. & \\
\hline Recettes fiscales / PIB m) & $14,6 \%$ & $14,7 \%$ & $14,9 \%$ & $17,0 \%$ & $17,0 \%$ & $17,0 \%$ & $17,2 \%$ & $16,6 \%$ \\
\hline courantes, hors dons, en \% du PIB) & $17,2 \%$ & $16,8 \%$ & $17,0 \%$ & $19,7 \%$ & $19,7 \%$ & $19,7 \%$ & $19,9 \%$ & $19,2 \%$ \\
\hline antes en \% du PIB sect.formel) & $47,7 \%$ & $49,0 \%$ & $49,5 \%$ & $57,5 \%$ & $56,3 \%$ & $56,9 \%$ & $57,7 \%$ & $55,6 \%$ \\
\hline Total des dépenses et prêts nets, en \% du PIB & $23,8 \%$ & $27,0 \%$ & $27,3 \%$ & $27,0 \%$ & $26,9 \%$ & $26,9 \%$ & $27,1 \%$ & $27,0 \%$ \\
\hline Solde opérations courantes (épargne publ. nat.) en $\%$ du PIB & $7,3 \%$ & $40,5 \%$ & $8,1 \%$ & $10,6 \%$ & $10,5 \%$ & $10,6 \%$ & $10,7 \%$ & $10,1 \%$ \\
\hline épargne propre) en \% du PIB & $3,9 \%$ & $3,5 \%$ & $3,6 \%$ & $6,4 \%$ & $6,5 \%$ & $6,5 \%$ & $6,6 \%$ & $5,9 \%$ \\
\hline abl. propre hors intérêts) en \% du PIBm & $4,6 \%$ & $4,2 \%$ & $4,0 \%$ & $6,7 \%$ & $6,8 \%$ & $6,8 \%$ & $6,9 \%$ & $6,2 \%$ \\
\hline PIB & $1,4 \%$ & $0,6 \%$ & $0,2 \%$ & $2,9 \%$ & $2,9 \%$ & $3,0 \%$ & $3,1 \%$ & $2,4 \%$ \\
\hline$\%$ du PIB & $0,2 \%$ & $-0,6 \%$ & $-1,3 \%$ & $1,3 \%$ & $1,4 \%$ & $1,5 \%$ & $1,6 \%$ & $0,9 \%$ \\
\hline Solde global (base engagements), hors dons, en \% du PIB & $-6,7 \%$ & $-10,2 \%$ & $-10,2 \%$ & $-7,3 \%$ & $-7,2 \%$ & $-7,1 \%$ & $-7,1 \%$ & $-7,8 \%$ \\
\hline ments), dons compris, en \% du PIB & $-2,6 \%$ & $27,3 \%$ & $-5,3 \%$ & $-2,8 \%$ & $-2,9 \%$ & $-2,8 \%$ & $-2,9 \%$ & $-3,4 \%$ \\
\hline Solde global (base caisse), en \% du PIB & $-2,5 \%$ & $27,3 \%$ & $-5,3 \%$ & $-2,8 \%$ & $-2,9 \%$ & $-2,8 \%$ & $-2,9 \%$ & $-3,4 \%$ \\
\hline \multirow[t]{2}{*}{ Situation monétaire } & \multirow{2}{*}{$\begin{array}{c}\text { Average } \\
2002-2005\end{array}$} & 2006 & 2007 & 2008 & 2009 & 2010 & 2011 & \multirow{2}{*}{$\begin{array}{l}\text { Average } \\
2007-2011\end{array}$} \\
\hline & & Estim. & Prév. & Prév. & Prév. & Prév. & Prév. & \\
\hline Créances sur le trésor (taux de croissance) & $35,8 \%$ & $280,6 \%$ & $-36,1 \%$ & $117,4 \%$ & $62,6 \%$ & $51,6 \%$ & $38,2 \%$ & $46,7 \%$ \\
\hline Créances sur l'économie (taux de croissance) & $11,4 \%$ & $3,2 \%$ & $-3,3 \%$ & $17,2 \%$ & $19,6 \%$ & $20,5 \%$ & $17,6 \%$ & $14,3 \%$ \\
\hline Croissance de la masse monétaire (M2) & $15,2 \%$ & $1,5 \%$ & $5,3 \%$ & $5,4 \%$ & $5,3 \%$ & $6,2 \%$ & $5,6 \%$ & $5,5 \%$ \\
\hline Vitesse de circulation de la monnaie (PIB/M2, fin de période) & 3,4 & 3,8 & 3,8 & 3,9 & 3,9 & 4,0 & 4,0 & 3,9 \\
\hline Taux de liquidité (M2/PIBm) & $29,4 \%$ & $26,6 \%$ & $26,3 \%$ & $25,9 \%$ & $25,6 \%$ & $25,2 \%$ & $24,9 \%$ & $25,6 \%$ \\
\hline Prix et taux de change & Average & 2006 & 2007 & 2008 & 2009 & 2010 & 2011 & Average \\
\hline & $2002-2005$ & Estim. & Prév. & Prév. & Prév. & Prév. & Prév. & $2007-2011$ \\
\hline Inflation mondiale (MUV) & $3,5 \%$ & $1,6 \%$ & $1,2 \%$ & $1,2 \%$ & $1,2 \%$ & $1,2 \%$ & $1,2 \%$ & $1,2 \%$ \\
\hline TC Indice des prix à la consommation des ménages de Bamako & $1,8 \%$ & $2,4 \%$ & $0,2 \%$ & $0,5 \%$ & $0,3 \%$ & $0,2 \%$ & $0,2 \%$ & $0,3 \%$ \\
\hline Déflateur du PIB (taux de croissance) & $1,9 \%$ & $6,3 \%$ & $0,2 \%$ & $0,2 \%$ & $0,1 \%$ & $0,0 \%$ & $0,0 \%$ & $0,1 \%$ \\
\hline Termes de l'échange $(1987=100)$ & 69,2 & 73,8 & 78,2 & 81,7 & 85,3 & 86,6 & 86,7 & 83,7 \\
\hline Taux de change FCFA/DTS (fin de période) & 787,4 & 756,7 & 738,9 & 734,9 & 731,7 & 728,6 & 725,7 & 732,0 \\
\hline Taux de change FCFA/\$ E.U. (fin de période) & 547,0 & 522,3 & 509,9 & 507,2 & 505,0 & 502,9 & 500,8 & 505,2 \\
\hline Taux de change FCFA/\$ E.U. (moyenne de période) & 582,2 & 522,3 & 509,9 & 507,2 & 505,0 & 502,9 & 500,8 & 505,2 \\
\hline Taux de change FCFA/ $€$ (moyenne de période) & 656,0 & 656,0 & 656,0 & 656,0 & 656,0 & 656,0 & 656,0 & 656,0 \\
\hline Indice du taux de change réel (IP_M/IP_PIB; + dévalua & 126,7 & 125,9 & 123,5 & 122,9 & 122,7 & 122,5 & 122,4 & 122,8 \\
\hline
\end{tabular}




\begin{tabular}{|c|c|c|c|c|c|c|c|c|}
\hline \multirow[t]{2}{*}{ Aide extérieure } & \multirow{2}{*}{$\begin{array}{l}\text { Average } \\
2002-2005\end{array}$} & 2006 & 2007 & 2008 & 2009 & 2010 & 2011 & \multirow{2}{*}{$\begin{array}{l}\text { Average } \\
2007-2011\end{array}$} \\
\hline & & Estim. & Prév. & Prév. & Prév. & Prév. & Prév. & \\
\hline Aide extérieure (brut) en $\%$ du PIB & $9,2 \%$ & $46,5 \%$ & $10,5 \%$ & $10,1 \%$ & $10,0 \%$ & $10,0 \%$ & $10,0 \%$ & $10,1 \%$ \\
\hline Aide extérieure (net) en \% du PIB & $7,2 \%$ & $12,7 \%$ & $9,6 \%$ & $9,2 \%$ & $9,0 \%$ & $9,0 \%$ & $9,0 \%$ & $9,2 \%$ \\
\hline Aide extérieure (brut) en mio. \$ E.U. & 407,0 & 2853,8 & 706,7 & 728,6 & 769,3 & 834,0 & 896,6 & 787,0 \\
\hline Aide extérieure (net) en mio. \$ E.U. & 319,3 & 778,9 & 643,2 & 660,5 & 696,0 & 754,2 & 809,9 & 712,8 \\
\hline Aide extérieure (brut) \$ E.U. par tête de la population & 36,0 & 236,8 & 57,1 & 57,3 & 58,9 & 62,2 & 65,0 & 60,1 \\
\hline Aide extérieure (net) \$ E.U. par tête de la population & 28,2 & 64,6 & 52,0 & 52,0 & 53,3 & 56,2 & 58,8 & 54,4 \\
\hline \multirow{2}{*}{$\begin{array}{l}\text { Critères de convergence UEMOA } \\
\text { Critères de premier rang: }\end{array}$} & \multirow{2}{*}{$\begin{array}{c}\text { Average } \\
\text { anto2-2005 }\end{array}$} & 2006 & 2007 & 2008 & 2009 & 2010 & 2011 & \multirow{2}{*}{$\begin{array}{l}\text { Average } \\
2007-2011\end{array}$} \\
\hline & & Estim. & Prév. & Prév. & Prév. & Prév. & Prév. & \\
\hline Ratio du solde budgétaire de base / PIB $\mathrm{m} 1 /$ & $0,2 \%$ & $-0,6 \%$ & $-1,3 \%$ & $1,3 \%$ & $1,4 \%$ & $1,5 \%$ & $1,6 \%$ & $0,9 \%$ \\
\hline Taux d'inflation (IHPC Bamako) $\quad<=3 \%$ & $1,8 \%$ & $2,4 \%$ & $0,2 \%$ & $0,5 \%$ & $0,3 \%$ & $0,2 \%$ & $0,2 \%$ & $0,3 \%$ \\
\hline Ratio de l'encours de la dette intérieure et extérieure / PIB $\mathrm{m}<=70 \%$ & $0,0 \%$ & $0,0 \%$ & $0,0 \%$ & $0,0 \%$ & $0,0 \%$ & $0,0 \%$ & $0,0 \%$ & $0,0 \%$ \\
\hline dont: encours dette extérieure / PIB m & $64,3 \%$ & $23,3 \%$ & $24,9 \%$ & $25,2 \%$ & $23,6 \%$ & $21,1 \%$ & $18,2 \%$ & $22,6 \%$ \\
\hline Variation des Arriérés de paiement intérieurs (en mrd. FCFA) $\quad<=0$ & 0,0 & 0,0 & 0,0 & 0,0 & 0,0 & 0,0 & 0,0 & 0,0 \\
\hline Variation des Arriérés de paiement extérieurs (en mrd. FCFA) $\quad<=0$ & 0,0 & 0,0 & 0,0 & 0,0 & 0,0 & 0,0 & 0,0 & 0,0 \\
\hline \multicolumn{9}{|l|}{ Critères de second rang: } \\
\hline $\begin{array}{ll}\text { Ratio de la masse salariale sur les recettes fiscales } & <=35 \%\end{array}$ & $30,7 \%$ & $31,7 \%$ & $31,5 \%$ & $28,1 \%$ & $28,2 \%$ & $28,8 \%$ & $28,8 \%$ & $29,1 \%$ \\
\hline Ratio invest. publics financés sur ress. internes sur rec. fisc. $2 / 20 \%$ & $21,9 \%$ & $25,8 \%$ & $22,5 \%$ & $22,5 \%$ & $22,5 \%$ & $22,5 \%$ & $22,5 \%$ & $22,5 \%$ \\
\hline Ratio déficit extérieur courant hors transferts publics / PIB $m<=5 \%$ & $-8,6 \%$ & $-7,4 \%$ & $-7,3 \%$ & $-7,0 \%$ & $-6,7 \%$ & $-7,3 \%$ & $-8,2 \%$ & $-7,3 \%$ \\
\hline Taux de pression fiscale (= Recettes fiscales / PIB m) $\quad=17 \%$ & $14,6 \%$ & $14,7 \%$ & $14,9 \%$ & $17,0 \%$ & $17,0 \%$ & $17,0 \%$ & $17,2 \%$ & $16,6 \%$ \\
\hline
\end{tabular}

1) Recettes (hors dons) moins total des dépenses (y c. prêts nets) (hors dépenses en capital à financem. ext. et hors PPTE) / PIBm

2/ ici seulement invest. BSI

Source: DNPD, modèle MME-DNPD

Table 13: Supply and use of goods and nonfactor services (CFAF billion constant)

\begin{tabular}{|c|c|c|c|c|c|c|c|c|}
\hline & \multirow{2}{*}{$\begin{array}{c}\text { Average } \\
2002-2005\end{array}$} & 2006 & 2007 & 2008 & 2009 & 2010 & 2011 & \multirow{2}{*}{$\begin{array}{l}\text { Average } \\
2007-2011\end{array}$} \\
\hline & & Estim. & Prév. & Prév. & Prév. & Prév. & Prév. & \\
\hline PIB aux prix du marché & 1263,3 & 1410,4 & 1509,2 & 1608,7 & 1713,9 & 1846,8 & 1978,3 & 1731,4 \\
\hline Variation annuelle & $5,2 \%$ & $3,6 \%$ & $7,0 \%$ & $6,6 \%$ & $6,5 \%$ & $7,8 \%$ & $7,1 \%$ & $7,0 \%$ \\
\hline Importations de biens et snf & 337,0 & 365,3 & 410,8 & 440,2 & 470,5 & 504,8 & 541,7 & 473,6 \\
\hline Variation annuelle & $-0,2 \%$ & $5,9 \%$ & $12,5 \%$ & $7,2 \%$ & $6,9 \%$ & $7,3 \%$ & $7,3 \%$ & $8,2 \%$ \\
\hline Total des ressources & 1600,3 & 1775,7 & 1920,0 & 2048,9 & 2184,4 & 2351,6 & 2520,1 & 2205,0 \\
\hline Exportations de biens et snf & 396,0 & 410,3 & 434,3 & 447,6 & 462,7 & 476,2 & 492,1 & 462,6 \\
\hline Variation annuelle & $3,6 \%$ & $0,4 \%$ & $5,8 \%$ & $3,1 \%$ & $3,4 \%$ & $2,9 \%$ & $3,3 \%$ & $3,7 \%$ \\
\hline Investissements bruts & 256,8 & 238,8 & 293,8 & 318,6 & 345,7 & 376,6 & 413,9 & 349,7 \\
\hline Formation brute de capital fixe & 207,1 & 231,2 & 286,8 & 311,6 & 338,7 & 369,6 & 406,9 & 342,7 \\
\hline Variation annuelle & $5,4 \%$ & $1,2 \%$ & $24,0 \%$ & $8,7 \%$ & $8,7 \%$ & $9,1 \%$ & $10,1 \%$ & $12,1 \%$ \\
\hline Variation des stocks & 49,7 & 7,6 & 7,0 & 7,0 & 7,0 & 7,0 & 7,0 & 7,0 \\
\hline Consommation finale & 947,5 & 1126,6 & 1191,9 & 1282,7 & 1376,0 & 1498,8 & 1614,1 & 1392,7 \\
\hline Variation annuelle & $3,5 \%$ & $14,3 \%$ & $5,8 \%$ & $7,6 \%$ & $7,3 \%$ & $8,9 \%$ & $7,7 \%$ & $7,5 \%$ \\
\hline Consommation publique & 127,3 & 173,5 & 175,6 & 181,3 & 193,6 & 211,0 & 228,9 & 198,1 \\
\hline Variation annuelle & $6,9 \%$ & $28,8 \%$ & $1,2 \%$ & $3,3 \%$ & $6,8 \%$ & $9,0 \%$ & $8,5 \%$ & $5,7 \%$ \\
\hline Consommation des ménages & 820,2 & 953,1 & 1016,3 & 1101,4 & 1182,4 & 1287,8 & 1385,2 & 1194,6 \\
\hline Variation annuelle & $3,1 \%$ & $12,0 \%$ & $6,6 \%$ & $8,4 \%$ & $7,4 \%$ & $8,9 \%$ & $7,6 \%$ & $7,8 \%$ \\
\hline Produit national brut ("revenu disponible brut") & 1263,5 & 1434,8 & 1527,7 & 1622,0 & 1725,6 & 1860,0 & 1992,9 & 1745,6 \\
\hline Produit national net ("revenu disponible net") & 1219,0 & 1375,4 & 1469,5 & 1558,8 & 1656,9 & 1785,0 & 1910,3 & 1676,1 \\
\hline Produit national brut par tête, en FCFA const. & 112020 & 119061 & 123426 & 127589 & 132145 & 138647 & 144573 & 133276 \\
\hline \multicolumn{9}{|l|}{ en \% du PIBm } \\
\hline Importations de biens et snf & $26,7 \%$ & $25,9 \%$ & $27,2 \%$ & $27,4 \%$ & $27,5 \%$ & $27,3 \%$ & $27,4 \%$ & $27,3 \%$ \\
\hline Exportations de biens et snf & $31,5 \%$ & $29,1 \%$ & $28,8 \%$ & $27,8 \%$ & $27,0 \%$ & $25,8 \%$ & $24,9 \%$ & $26,9 \%$ \\
\hline Balance des ressources (X-Mcaf) & $4,8 \%$ & $3,2 \%$ & $1,6 \%$ & $0,5 \%$ & $-0,5 \%$ & $-1,5 \%$ & $-2,5 \%$ & $-0,5 \%$ \\
\hline Investissements bruts & $20,1 \%$ & $16,9 \%$ & $19,5 \%$ & $19,8 \%$ & $20,2 \%$ & $20,4 \%$ & $20,9 \%$ & $20,2 \%$ \\
\hline Consommation finale & $75,1 \%$ & $79,9 \%$ & $79,0 \%$ & $79,7 \%$ & $80,3 \%$ & $81,2 \%$ & $81,6 \%$ & $80,3 \%$ \\
\hline Consommation finale par tête (FCFA, const.) & 84066 & 93484 & 96297 & 100900 & 105373 & 111723 & 117093 & 106277 \\
\hline & 200,7 & 226,2 & 226,6 & 227,1 & 227,3 & 227,3 & 227,2 & 227,1 \\
\hline Variation annuelle du Déflateur $\mathrm{d}$ & $1,9 \%$ & $6,3 \%$ & $0,2 \%$ & $0,2 \%$ & $0,1 \%$ & $0,0 \%$ & $0,0 \%$ & $0,1 \%$ \\
\hline
\end{tabular}

urce: DNPD, modèle MME-DNPD

Table 14: Supply and use of goods and nonfactor services (CFAF billion current)

\begin{tabular}{|c|c|c|c|c|c|c|c|c|}
\hline & Average & 2006 & 2007 & 2008 & 2009 & 2010 & 2011 & Average \\
\hline & $2002-2005$ & Estim. & Prév. & Prév. & Prév. & Prév. & Prév. & 2007-2011 \\
\hline PIB au prix du marché & 2550,3 & 3205,8 & 3419,4 & 3653,0 & 3895,0 & 4196,9 & 4493,8 & 3931,6 \\
\hline Variation annuelle & $7,0 \%$ & $10,8 \%$ & $6,7 \%$ & $6,8 \%$ & $6,6 \%$ & $7,7 \%$ & $7,1 \%$ & $7,0 \%$ \\
\hline Importations de biens et snf & 858,0 & 1040,2 & 1149,0 & 1228,6 & 1311,6 & 1405,4 & 1506,8 & 1320,3 \\
\hline Variation annuelle & $3,3 \%$ & $9,2 \%$ & $10,5 \%$ & $6,9 \%$ & $6,8 \%$ & $7,2 \%$ & $7,2 \%$ & $7,7 \%$ \\
\hline Total des ressources & 3408,3 & 4246,0 & 4568,5 & 4881,6 & 5206,6 & 5602,3 & 6000,6 & 5251,9 \\
\hline Exportations de biens et snf & 695,5 & 862,6 & 949,8 & 1021,1 & 1100,1 & 1147,7 & 1186,7 & 1081,1 \\
\hline Variation annuelle & $4,2 \%$ & $16,4 \%$ & $10,1 \%$ & $7,5 \%$ & $7,7 \%$ & $4,3 \%$ & $3,4 \%$ & $6,6 \%$ \\
\hline Investissements bruts & 548,5 & 687,4 & 675,2 & 734,0 & 796,9 & 868,0 & 953,7 & 805,6 \\
\hline Formation brute de capital fixe & 443,8 & 671,6 & 659,1 & 717,8 & 780,8 & 851,9 & 937,6 & 789,4 \\
\hline Variation annuelle & $1,5 \%$ & $50,3 \%$ & $-1,9 \%$ & $8,9 \%$ & $8,8 \%$ & $9,1 \%$ & $10,1 \%$ & $7,0 \%$ \\
\hline Variation des stocks & 104,6 & 15,8 & 16,1 & 16,1 & 16,1 & 16,1 & 16,1 & 16,1 \\
\hline Consommation finale & 2164,2 & 2696,1 & 2943,5 & 3126,5 & 3309,6 & 3586,5 & 3860,2 & 3365,3 \\
\hline Variation annuelle & $7,4 \%$ & $8,5 \%$ & $9,2 \%$ & $6,2 \%$ & $5,9 \%$ & $8,4 \%$ & $7,6 \%$ & $7,4 \%$ \\
\hline Consommation publique & 291,2 & 415,1 & 433,6 & 442,0 & 465,7 & 504,8 & 547,4 & 478,7 \\
\hline Variation annuelle & $10,8 \%$ & $22,3 \%$ & $4,5 \%$ & $1,9 \%$ & $5,4 \%$ & $8,4 \%$ & $8,4 \%$ & $5,7 \%$ \\
\hline Consommation des ménages & 1873,0 & 2281,0 & 2509,9 & 2684,6 & 2843,9 & 3081,7 & 3312,9 & 2886,6 \\
\hline Variation annuelle & $6,9 \%$ & $6,4 \%$ & $10,0 \%$ & $7,0 \%$ & $5,9 \%$ & $8,4 \%$ & $7,5 \%$ & $7,8 \%$ \\
\hline
\end{tabular}


Table 15: Savings and investment (CFAF billion current)

\begin{tabular}{|c|c|c|c|c|c|c|c|c|}
\hline & \multirow{2}{*}{$\begin{array}{l}\text { Average } \\
2002-2005\end{array}$} & 2006 & 2007 & 2008 & 2009 & 2010 & 2011 & \multirow{2}{*}{$\begin{array}{c}\text { Average } \\
2007-2011 \\
\end{array}$} \\
\hline & & Estim. & Prév. & Prév. & Prév. & Prév. & Prév. & \\
\hline INVESTISSEMENTS bruts & 548,5 & 687,4 & 675,2 & 734,0 & 796,9 & 868,0 & 953,7 & 805,6 \\
\hline Formation brute de capital fixe & 443,8 & 671,6 & 659,1 & 717,8 & 780,8 & 851,9 & 937,6 & 789,4 \\
\hline publique 1) & 188,0 & 319,9 & 282,5 & 317,2 & 354,9 & 397,6 & 432,4 & 356,9 \\
\hline privée & 255,9 & 351,7 & 376,7 & 400,7 & 425,9 & 454,4 & 505,2 & 432,5 \\
\hline Variation des stocks & 104,6 & 15,8 & 16,1 & 16,1 & 16,1 & 16,1 & 16,1 & 16,1 \\
\hline Total emplois (invest.) & 548,5 & 687,4 & 675,2 & 734,0 & 796,9 & 868,0 & 953,7 & 805,6 \\
\hline EPARGNE INTERIEURE BRUTE & 386,1 & 509,7 & 476,0 & 526,5 & 585,5 & 610,3 & 633,6 & 566,4 \\
\hline Epargne publique & 59,9 & 70,5 & 75,9 & 178,8 & 193,0 & 210,9 & 230,9 & 177,9 \\
\hline Epargne privée & 326,2 & 439,2 & 400,1 & 347,6 & 392,4 & 399,5 & 402,6 & 388,4 \\
\hline EPARGNE EXTERIEURE ( $=$ - balance des ressources BP) & 162,4 & 177,6 & 199,2 & 207,5 & 211,5 & 257,7 & 320,1 & 239,2 \\
\hline Total ressources (= Epargne intérieure et extérieure) & 548,5 & 687,4 & 675,2 & $\mathbf{7 3 4 , 0}$ & 796,9 & 868,0 & 953,7 & 805,6 \\
\hline \multicolumn{9}{|l|}{ Pour mémoire: } \\
\hline Service facteurs (nets) & $-118,4$ & $-111,2$ & $-99,3$ & $-98,0$ & $-98,5$ & $-98,8$ & $-98,8$ & $-98,7$ \\
\hline Epargne nationale brute & 378,1 & 549,5 & 517,9 & 556,5 & 612,1 & 640,3 & 666,6 & 598,7 \\
\hline publique & 96,5 & 153,5 & 149,9 & 239,3 & 250,0 & 270,9 & 293,6 & 240,7 \\
\hline privée & 281,6 & 396,0 & 368,0 & 317,2 & 362,1 & 369,4 & 373,1 & 357,9 \\
\hline Taux d'investissement, y compris var. stocks (Inv/PIB) & $21,4 \%$ & $21,4 \%$ & $19,7 \%$ & $20,1 \%$ & $20,5 \%$ & $20,7 \%$ & $21,2 \%$ & $20,4 \%$ \\
\hline Taux d'épargne intérieure (Ep/PIB) & $15,2 \%$ & $15,9 \%$ & $13,9 \%$ & $14,4 \%$ & $15,0 \%$ & $14,5 \%$ & $14,1 \%$ & $14,4 \%$ \\
\hline Taux d'épargne extérieure 2) & $6,2 \%$ & $5,5 \%$ & $5,8 \%$ & $5,7 \%$ & $5,4 \%$ & $6,1 \%$ & $7,1 \%$ & $6,0 \%$ \\
\hline Taux d'épargne nationale (Ep nat/PIB) & $14,8 \%$ & $17,1 \%$ & $15,1 \%$ & $15,2 \%$ & $15,7 \%$ & $15,3 \%$ & $14,8 \%$ & $15,2 \%$ \\
\hline Taux d'épargne nationale publique & $3,7 \%$ & $4,8 \%$ & $4,4 \%$ & $6,6 \%$ & $6,4 \%$ & $6,5 \%$ & $6,5 \%$ & $6,1 \%$ \\
\hline Taux d'épargne nationale privée & $11,1 \%$ & $12,4 \%$ & $10,8 \%$ & $8,7 \%$ & $9,3 \%$ & $8,8 \%$ & $8,3 \%$ & $9,2 \%$ \\
\hline Epargne intér. en \% des investissem. & $72,3 \%$ & $74,2 \%$ & $70,5 \%$ & $71,7 \%$ & $73,5 \%$ & $70,3 \%$ & $66,4 \%$ & $70,5 \%$ \\
\hline Epargne extér. en \% des investissem. & $27,7 \%$ & $25,8 \%$ & $29,5 \%$ & $28,3 \%$ & $26,5 \%$ & $29,7 \%$ & $33,6 \%$ & $29,5 \%$ \\
\hline
\end{tabular}

es ressources / PIB

Source: DNPD, modèle MME-DNPD 
Table 16: Consolidated government finance budget and its financing (TOFE) (CFAF billion current)

\begin{tabular}{|c|c|c|c|c|c|c|c|c|}
\hline & \multirow{2}{*}{$\begin{array}{l}\text { Average } \\
2002-2005\end{array}$} & \multirow[t]{2}{*}{2006} & \multirow{2}{*}{\begin{tabular}{|c|}
$\mathbf{2 0 0 7}$ \\
CSLP
\end{tabular}} & \multirow{2}{*}{\begin{tabular}{c|}
$\mathbf{2 0 0 8}$ \\
CSLP
\end{tabular}} & \multirow{2}{*}{\begin{tabular}{|c|}
$\mathbf{2 0 0 9}$ \\
CSLP
\end{tabular}} & \multirow{2}{*}{\begin{tabular}{|c|}
$\mathbf{2 0 1 0}$ \\
CSLP
\end{tabular}} & \multirow{2}{*}{\begin{tabular}{|c|}
2011 \\
CSLP
\end{tabular}} & \multirow{2}{*}{$\begin{array}{l}\text { Average } \\
2007-2011\end{array}$} \\
\hline & & & & & & & & \\
\hline Total des recettes et dons & 542,6 & 1740,0 & 749,4 & 881,4 & 935,6 & 1008,0 & 1088,3 & 932,6 \\
\hline Recettes totales & 438,5 & 540,0 & 582,4 & 718,6 & 768,6 & 828,5 & 896,3 & 758,9 \\
\hline Recettes budgétaires & 398,7 & 497,5 & 535,4 & 663,5 & 708,5 & 765,9 & 829,5 & 700,6 \\
\hline Recettes fiscales & 373,7 & 469,9 & 509,5 & 621,0 & 662,2 & 713,5 & 773,6 & 655,9 \\
\hline Impôts directs & 72,4 & 89,9 & 106,2 & 112,3 & 122,5 & 131,1 & 141,3 & 122,7 \\
\hline Impôts indirects & 301,3 & 380,0 & 403,3 & 448,4 & 491,5 & 575,8 & 632,3 & 510,3 \\
\hline TVA & 156,2 & 216,2 & 240,0 & 256,2 & 280,0 & 341,1 & 375,4 & 298,5 \\
\hline TVA intérieure & 54,9 & 84,0 & 93,0 & 100,1 & 113,3 & 160,1 & 178,7 & 129,0 \\
\hline TVA sur importations & 101,3 & 132,2 & 147,0 & 156,2 & 166,7 & 181,0 & 196,7 & 169,5 \\
\hline Taxe intérieure sur produits pétroliers & 31,1 & 25,0 & 27,0 & 28,7 & 30,5 & 33,0 & 35,7 & 31,0 \\
\hline Taxe sur les importations & 61,5 & 71,9 & 75,0 & 79,2 & 84,5 & 91,8 & 99,7 & 86,0 \\
\hline Autres droits et taxes & 64,2 & 88,9 & 87,3 & 101,3 & 114,6 & 129,6 & 142,9 & 115,1 \\
\hline Remboursement de taxes exonérées & $-11,3$ & $-15,0$ & $-16,0$ & $-17,0$ & $-18,1$ & $-19,7$ & $-21,4$ & $-18,5$ \\
\hline Mesures supplémentaires & 0,0 & 0,0 & 0,0 & 60,4 & 48,2 & 6,6 & 0,0 & 23,0 \\
\hline Recettes non fiscales & 25,1 & 27,6 & 25,9 & 42,5 & 46,4 & 52,4 & 55,9 & 44,6 \\
\hline Recettes fonds spéc. et budgets annexes & 39,8 & 42,5 & 47,0 & 55,0 & 60,0 & 62,6 & 66,8 & 58,3 \\
\hline Dons & 104,1 & 1200,0 & 167,0 & 162,9 & 167,1 & 179,5 & 191,9 & 173,7 \\
\hline Dons pour projets & 67,5 & 81,3 & 93,0 & 102,4 & 110,1 & 119,5 & 129,3 & 110,9 \\
\hline Dons budgétaires & 36,6 & 35,8 & 24,8 & 25,0 & 25,2 & 25,3 & 25,5 & 25,2 \\
\hline Appui budgétaire sectoriel & & 47,2 & 49,2 & 35,5 & 31,8 & 34,7 & 37,1 & 37,7 \\
\hline Restructuration dette IADM & & 1035,7 & 0,0 & 0,0 & 0,0 & 0,0 & 0,0 & 0,0 \\
\hline Dépenses et prêts nets & 608,5 & 865,6 & 932,3 & 984,5 & 1048,0 & 1127,6 & 1216,7 & 1061,8 \\
\hline Dépenses budgétaires & 567,5 & 828,7 & 890,9 & 933,5 & 992,4 & 1069,3 & 1153,9 & 1008,0 \\
\hline Dépenses courantes & 338,8 & 427,0 & 459,5 & 484,7 & 515,5 & 555,0 & 598,6 & 522,7 \\
\hline Salaires & 114,8 & 149,0 & 160,5 & 174,2 & 186,4 & 205,4 & 222,6 & 189,8 \\
\hline Fonctionnaires & 105,5 & 129,9 & 138,9 & 150,1 & 159,8 & 176,3 & 191,1 & 163,2 \\
\hline Contractuels (HIPC) & 9,4 & 19,1 & 21,6 & 24,1 & 26,6 & 29,1 & 31,5 & 26,6 \\
\hline Biens et services & 123,5 & 161,1 & 181,8 & 189,9 & 204,8 & 221,7 & 244,3 & 208,5 \\
\hline Matériel & 41,5 & 57,9 & 64,9 & 74,5 & 81,3 & 89,9 & 100,1 & 82,1 \\
\hline Communication - énergie & 23,9 & 32,6 & 32,1 & 36,3 & 40,4 & 44,3 & 49,1 & 40,4 \\
\hline Déplacements, entretien et carburants & 23,1 & 29,9 & 33,7 & 36,6 & 38,7 & 41,6 & 45,1 & 39,1 \\
\hline Elections & 4,4 & 3,0 & 15,0 & 4,0 & 2,0 & 2,0 & 2,0 & 5,0 \\
\hline Autres dépenses sur biens et services & 30,7 & 37,7 & 36,1 & 38,5 & 42,4 & 43,9 & 48,0 & 41,8 \\
\hline Transferts et subventions & 81,4 & 96,8 & 103,7 & 109,0 & 113,0 & 117,1 & 121,6 & 112,9 \\
\hline Bourses & 5,6 & 5,6 & 5,6 & 5,6 & 5,6 & 5,6 & 5,6 & 5,6 \\
\hline Filet social & 9,8 & 10,0 & 10,0 & 10,0 & 10,0 & 10,0 & 10,0 & 10,0 \\
\hline Subvention eau-énergie & 1,8 & 0,0 & 0,0 & 0,0 & 0,0 & 0,0 & 0,0 & 0,0 \\
\hline Subvention secteur coton & 6,8 & 0,0 & 0,0 & 0,0 & 0,0 & 0,0 & 0,0 & 0,0 \\
\hline Subvention CRM & 13,0 & 18,0 & 21,0 & 18,0 & 18,0 & 18,0 & 18,0 & 18,6 \\
\hline Plans sociaux & 5,1 & 5,0 & 1,0 & 5,0 & 5,0 & 5,0 & 5,0 & 4,2 \\
\hline Dépenses PAGE & 0,0 & 0,0 & 0,0 & 0,0 & 0,0 & 0,0 & 0,0 & 0,0 \\
\hline Autres transferts et subventions & 39,4 & 58,2 & 66,1 & 70,4 & 74,4 & 78,5 & 83,0 & 74,5 \\
\hline Intérêts dus & 19,0 & 20,1 & 13,5 & 11,6 & 11,3 & 10,8 & 10,1 & 11,5 \\
\hline Dette intérieure & 2,3 & 2,6 & 1,7 & 1,6 & 1,5 & 1,4 & 1,4 & 1,5 \\
\hline FMI & 0,5 & 0,5 & 0,0 & 0,0 & 0,0 & 0,0 & 0,0 & 0,0 \\
\hline BCEAO (avance stat. et BDM) & 0,6 & 0,5 & 0,0 & 0,0 & 0,0 & 0,0 & 0,0 & 0,0 \\
\hline Autres intérieurs & 1,2 & 1,6 & 1,7 & 1,6 & 1,5 & 1,4 & 1,4 & 1,5 \\
\hline Dette extérieure & 16,8 & 17,5 & 11,8 & 10,0 & 9,8 & 9,4 & 8,7 & 9,9 \\
\hline Dépenses en capital & 228,7 & 401,7 & \begin{tabular}{l|l|l}
431,4 \\
\end{tabular} & 448,8 & 476,9 & 514,3 & \begin{tabular}{l|l}
555,3 \\
\end{tabular} & 485,3 \\
\hline Financement extérieur & 146,6 & 280,7 & 295,1 & 303,9 & 322,1 & 351,9 & 382,4 & 331,1 \\
\hline Emprunts & 79,1 & 152,2 & 152,9 & 166,0 & 180,2 & 197,7 & 216,0 & 182,6 \\
\hline Dons globaux & 67,5 & 81,3 & 93,0 & 102,4 & 110,1 & 119,5 & 129,3 & 110,9 \\
\hline Appui budgétaire sectoriel & 0,0 & 47,2 & 49,2 & 35,5 & 31,8 & 34,7 & 37,1 & 37,7 \\
\hline Financement intérieur 1) & 82,1 & 121,0 & 136,3 & 144,9 & 154,8 & 162,4 & 172,9 & 154,3 \\
\hline Dépenses fds.spéc. et budgets annexes & 39,8 & 42,5 & 47,0 & 55,0 & 60,0 & 62,6 & 66,8 & 58,3 \\
\hline Autres (extrabudgétaires et reconstruction) & 0,0 & 0,0 & 0,0 & 0,0 & 0,0 & 0,0 & 0,0 & 0,0 \\
\hline Prêts nets & 1,2 & $-5,6$ & $-5,6$ & $-4,0$ & $-4,4$ & $-4,3$ & $-4,0$ & $-4,5$ \\
\hline Solde budgétaire primaire (FMI) 2) & $-23,4$ & $-44,9$ & $-54,8$ & 37,9 & 42,6 & 52,8 & 62,0 & 28,1 \\
\hline Solde global (engagements, hors dons) & $-170,0$ & $-325,6$ & $-349,9$ & $-266,0$ & $-279,5$ & $-299,1$ & $-320,4$ & $-303,0$ \\
\hline Solde global (engagements) & $-65,9$ & 874,4 & $-182,9$ & $-103,1$ & $-112,4$ & $-119,6$ & $-128,4$ & $-129,3$ \\
\hline Ajustement & 1,8 & 0,0 & 0,0 & 0,0 & 0,0 & 0,0 & 0,0 & 0,0 \\
\hline Solde global (base caisse \& hors dons) & $-168,3$ & $-325,6$ & $-349,9$ & $-266,0$ & $-279,5$ & $-299,1$ & $-320,4$ & $-303,0$ \\
\hline Solde global (base caisse) & $-64,2$ & 874,4 & $-182,9$ & $-103,1$ & $-112,4$ & $-119,6$ & $-128,4$ & $-129,3$ \\
\hline
\end{tabular}




\begin{tabular}{|c|c|c|c|c|c|c|c|c|}
\hline FINANCEMENT & 64,2 & $-874,4$ & 182,9 & 103,1 & 112,4 & 119,6 & 128,4 & 129,3 \\
\hline \begin{tabular}{|c|} 
Financement extérieur net \\
\end{tabular} & 89,3 & $-845,1$ & 159,2 & 172,3 & 185,3 & 201,9 & 215,6 & 186,9 \\
\hline Emprunts & 100,6 & 200,7 & 182,9 & 196,0 & 210,2 & 227,7 & 246,0 & 212,6 \\
\hline PASEP & 0,0 & 0,0 & 0,0 & 0,0 & 0,0 & 0,0 & 0,0 & 0,0 \\
\hline BDM & 0,0 & 0,0 & 0,0 & 0,0 & 0,0 & 0,0 & 0,0 & 0,0 \\
\hline Projets & 79,1 & 152,2 & 152,9 & 166,0 & 180,2 & 197,7 & 216,0 & 182,6 \\
\hline Prêts budgétaires & 21,4 & 48,5 & 30,0 & 30,0 & 30,0 & 30,0 & 30,0 & 30,0 \\
\hline Amortissement (-) & $-39,0$ & $-1071,7$ & $-34,2$ & $-34,4$ & $-36,1$ & $-37,9$ & $-41,5$ & $-36,8$ \\
\hline Régulation dette/PPTE & 27,7 & 25,9 & 10,5 & 10,7 & 11,2 & 12,1 & 11,1 & 11,1 \\
\hline Financement intérieur net & $-25,2$ & $-43,1$ & 23,7 & $-69,2$ & $-72,9$ & $-82,4$ & $-87,2$ & $-57,6$ \\
\hline bancaire (net) & $-3,0$ & $-34,0$ & 36,3 & $-76,3$ & $-88,3$ & $-118,1$ & $-132,2$ & $-75,7$ \\
\hline Position nette du Gouvernement & $-2,1$ & $-33,4$ & 36,3 & $-75,3$ & $-87,3$ & $-117,1$ & $-131,2$ & $-74,9$ \\
\hline Avance statutaire & $-1,6$ & $-2,1$ & $-2,1$ & $-2,1$ & $-2,1$ & $-2,1$ & $-2,1$ & $-2,1$ \\
\hline Tirages nets & $-11,1$ & $-9,0$ & 2,0 & 2,0 & 2,0 & 2,0 & 2,0 & 2,0 \\
\hline FMI rachats & 15,8 & 11,1 & 0,0 & 0,0 & 0,0 & 0,0 & 0,0 & 0,0 \\
\hline FMI achats & 4,7 & 2,1 & 2,0 & 2,0 & 2,0 & 2,0 & 2,0 & 2,0 \\
\hline Autres postes (nets) & 12,6 & $-20,3$ & 36,4 & $-75,2$ & $-87,2$ & $-117,0$ & $-131,1$ & $-74,8$ \\
\hline Concours cons./Titrisation & $-2,0$ & $-2,0$ & 0,0 & 0,0 & 0,0 & 0,0 & 0,0 & 0,0 \\
\hline Autres financements monétaires & $-0,9$ & $-0,6$ & 0,0 & $-1,0$ & $-1,0$ & $-1,0$ & $-1,0$ & $-0,8$ \\
\hline Avance CMDT & 0,0 & 0,0 & 0,0 & 0,0 & 0,0 & 0,0 & 0,0 & 0,0 \\
\hline Recetttes de privatisation & 10,3 & 8,1 & 8,1 & 4,0 & 4,0 & 4,0 & 4,0 & 4,8 \\
\hline Autres financements & $-32,5$ & $-17,2$ & $-20,7$ & 3,1 & 11,4 & 31,7 & 41,0 & 13,3 \\
\hline Gap de financement Etat (+= déficit) & $\mathbf{0 , 0}$ & 13,8 & $\mathbf{0 , 0}$ & $\mathbf{0 , 0}$ & $\mathbf{0 , 0}$ & $\mathbf{0 , 0}$ & $\mathbf{0 , 0}$ & $\mathbf{0 , 0}$ \\
\hline \multicolumn{9}{|l|}{ Pour mémoire: } \\
\hline PIB aux prix du marché (milliards FCFA, prix courants) & 2550,3 & 3205,8 & 3419,4 & 3653,0 & 3895,0 & 4196,9 & 4493,8 & 3931,6 \\
\hline Solde primaire en \% du PIB & $1,4 \%$ & $0,6 \%$ & $0,2 \%$ & $2,9 \%$ & $2,9 \%$ & $3,0 \%$ & $3,1 \%$ & $2,4 \%$ \\
\hline Déficit (engagements, hors dons) en \% PIB & $-6,7 \%$ & $-10,2 \%$ & $-10,2 \%$ & $-7,3 \%$ & $-7,2 \%$ & $-7,1 \%$ & $-7,1 \%$ & $-7,8 \%$ \\
\hline Déficit (caisse) en \% PIB & $-2,5 \%$ & $27,3 \%$ & $-5,3 \%$ & $-2,8 \%$ & $-2,9 \%$ & $-2,8 \%$ & $-2,9 \%$ & $-3,4 \%$ \\
\hline Solde opérations courantes hors dons en \% PIB & $3,9 \%$ & $3,5 \%$ & $3,6 \%$ & $6,4 \%$ & $6,5 \%$ & $6,5 \%$ & $6,6 \%$ & $5,9 \%$ \\
\hline
\end{tabular}

1) secteur bancaire et secteur privé

2) Recettes (hors dons) moins total des dépenses (y c. prêts nets) (hors dépenses

en capital à financement extérieur)

Source: DNPD, modèle MME-DNPD

\section{Table 17: Structure of government expenditure}

\begin{tabular}{|c|c|c|c|c|c|c|c|c|}
\hline Structure des dépenses (\% des dépenses totales) & Average & 2006 & 2007 & 2008 & 2009 & 2010 & 2011 & Average \\
\hline & $2002-2005$ & & & & & & & 2007-2011 \\
\hline Dépenses courantes & $55,9 \%$ & $49,3 \%$ & $49,3 \%$ & $49,2 \%$ & $49,2 \%$ & $49,2 \%$ & $49,2 \%$ & $49,2 \%$ \\
\hline Dépenses en capital & $37,6 \%$ & $46,4 \%$ & $46,3 \%$ & $45,6 \%$ & $45,5 \%$ & $45,6 \%$ & $45,6 \%$ & $45,7 \%$ \\
\hline Autres dépenses et prêts nets & $6,6 \%$ & $4,3 \%$ & $4,4 \%$ & $5,2 \%$ & $5,3 \%$ & $5,2 \%$ & $5,2 \%$ & $5,1 \%$ \\
\hline Ajustements & $0,4 \%$ & $0,0 \%$ & $0,0 \%$ & $0,0 \%$ & $0,0 \%$ & $0,0 \%$ & $0,0 \%$ & $0,0 \%$ \\
\hline Total des dépenses & $100,4 \%$ & $100,0 \%$ & $100,0 \%$ & $100,0 \%$ & $100,0 \%$ & $100,0 \%$ & $100,0 \%$ & $100,0 \%$ \\
\hline \multicolumn{9}{|l|}{ Structure de financement (\% des dépenses totales) } \\
\hline Recettes budgétaires, etc. & $72,1 \%$ & $62,4 \%$ & $62,5 \%$ & $73,0 \%$ & $73,3 \%$ & $73,5 \%$ & $73,7 \%$ & $71,2 \%$ \\
\hline Dons & $17,2 \%$ & $138,6 \%$ & $17,9 \%$ & $16,5 \%$ & $15,9 \%$ & $15,9 \%$ & $15,8 \%$ & $16,4 \%$ \\
\hline Financement extérieur (tirages sur emprunts nets) (hors PPTE) & $10,2 \%$ & $-100,6 \%$ & $15,9 \%$ & $16,4 \%$ & $16,6 \%$ & $16,8 \%$ & $16,8 \%$ & $16,5 \%$ \\
\hline Régulation de la dette/PPTE & $4,6 \%$ & $3,0 \%$ & $1,1 \%$ & $1,1 \%$ & $1,1 \%$ & $1,1 \%$ & $0,9 \%$ & $1,1 \%$ \\
\hline Financement intérieur & $-4,5 \%$ & $-5,0 \%$ & $2,5 \%$ & $-7,0 \%$ & $-7,0 \%$ & $-7,3 \%$ & $-7,2 \%$ & $-5,2 \%$ \\
\hline Ajustements & $0,4 \%$ & $0,0 \%$ & $0,0 \%$ & $0,0 \%$ & $0,0 \%$ & $0,0 \%$ & $0,0 \%$ & $0,0 \%$ \\
\hline Financement extér. exceptionn. à rechercher (gap) & $0,0 \%$ & $1,6 \%$ & $0,0 \%$ & $0,0 \%$ & $0,0 \%$ & $0,0 \%$ & $0,0 \%$ & $0,0 \%$ \\
\hline Total des dépenses & $100,0 \%$ & $100,0 \%$ & $100,0 \%$ & $100,0 \%$ & $100,0 \%$ & $100,0 \%$ & $100,0 \%$ & $100,0 \%$ \\
\hline Total financement intérieur des dépenses & $67,6 \%$ & $\mathbf{5 7 , 4 \%}$ & $65,0 \%$ & $66,0 \%$ & $66,4 \%$ & $66,2 \%$ & $66,5 \%$ & $66,0 \%$ \\
\hline Total financement extérieur des dépenses & $32,0 \%$ & $42,6 \%$ & $35,0 \%$ & $34,0 \%$ & $33,6 \%$ & $33,8 \%$ & $33,5 \%$ & $34,0 \%$ \\
\hline \multicolumn{9}{|l|}{ Structure des dépenses (\% du PIBm) } \\
\hline Dépenses courantes & $13,3 \%$ & $13,3 \%$ & $13,4 \%$ & $13,3 \%$ & $13,2 \%$ & $13,2 \%$ & $13,3 \%$ & $13,3 \%$ \\
\hline Dépenses en capital & $9,0 \%$ & $12,5 \%$ & $12,6 \%$ & $12,3 \%$ & $12,2 \%$ & $12,3 \%$ & $12,4 \%$ & $12,4 \%$ \\
\hline Autres dépenses et prêts nets & $1,6 \%$ & $1,2 \%$ & $1,2 \%$ & $1,4 \%$ & $1,4 \%$ & $1,4 \%$ & $1,4 \%$ & $1,4 \%$ \\
\hline Ajustements & $0,1 \%$ & $0,0 \%$ & $0,0 \%$ & $0,0 \%$ & $0,0 \%$ & $0,0 \%$ & $0,0 \%$ & $0,0 \%$ \\
\hline Total des dépenses & $23,9 \%$ & $27,0 \%$ & $27,3 \%$ & $27,0 \%$ & $26,9 \%$ & $26,9 \%$ & $27,1 \%$ & $27,0 \%$ \\
\hline \multicolumn{9}{|l|}{ Structure de financement (\% du PIBm) } \\
\hline Recettes budgétaires, etc. & $17,2 \%$ & $16,8 \%$ & $17,0 \%$ & $19,7 \%$ & $19,7 \%$ & $19,7 \%$ & $19,9 \%$ & $19,2 \%$ \\
\hline Dons & $4,1 \%$ & $37,4 \%$ & $4,9 \%$ & $4,5 \%$ & $4,3 \%$ & $4,3 \%$ & $4,3 \%$ & $4,4 \%$ \\
\hline Financement extérieur (tirages sur emprunts nets) (hors PPTE) & $2,4 \%$ & $-27,2 \%$ & $4,3 \%$ & $4,4 \%$ & $4,5 \%$ & $4,5 \%$ & $4,6 \%$ & $4,5 \%$ \\
\hline Régulation de la dette/PPTE & $1,1 \%$ & $0,8 \%$ & $0,3 \%$ & $0,3 \%$ & $0,3 \%$ & $0,3 \%$ & $0,2 \%$ & $0,3 \%$ \\
\hline Financement intérieur & $-1,0 \%$ & $-1,3 \%$ & $0,7 \%$ & $-1,9 \%$ & $-1,9 \%$ & $-2,0 \%$ & $-1,9 \%$ & $-1,4 \%$ \\
\hline Ajustements & $0,1 \%$ & $0,0 \%$ & $0,0 \%$ & $0,0 \%$ & $0,0 \%$ & $0,0 \%$ & $0,0 \%$ & $0,0 \%$ \\
\hline Financement extér. exceptionn. à rechercher (gap) & $0,0 \%$ & $0,4 \%$ & $0,0 \%$ & $0,0 \%$ & $0,0 \%$ & $0,0 \%$ & $0,0 \%$ & $0,0 \%$ \\
\hline Total des dépenses & $23,8 \%$ & $27,0 \%$ & $27,3 \%$ & $27,0 \%$ & $26,9 \%$ & $26,9 \%$ & $27,1 \%$ & $27,0 \%$ \\
\hline Total financement intérieur des dépenses (\% du PIBm) & $16,1 \%$ & $15,5 \%$ & $17,7 \%$ & $17,8 \%$ & $17,9 \%$ & $17,8 \%$ & $18,0 \%$ & $17,8 \%$ \\
\hline Total financement extérieur des dépenses (\% du PIBm) & $7,6 \%$ & $11,5 \%$ & $9,5 \%$ & $9,2 \%$ & $9,0 \%$ & $9,1 \%$ & $9,1 \%$ & $9,2 \%$ \\
\hline
\end{tabular}


Table 18: Balance of payments (CFAF billion)

\begin{tabular}{|c|c|c|c|c|c|c|c|c|}
\hline & \multirow{2}{*}{$\begin{array}{c}\text { Average } \\
2002-2005\end{array}$} & 2006 & 2007 & 2008 & 2009 & 2010 & 2011 & \multirow{2}{*}{$\begin{array}{l}\text { Average } \\
2007-2011\end{array}$} \\
\hline & & Estim. & Prév. & Prév. & Prév. & Prév. & Prév. & \\
\hline Balance commerciale (marchand. fob) & $-13,4$ & $-33,9$ & $-36,4$ & $-41,1$ & $-42,8$ & $-70,8$ & $-111,0$ & $-60,4$ \\
\hline Exportations (fob) & 566,0 & 714,4 & 772,2 & 823,5 & 880,1 & 918,1 & 949,4 & 868,6 \\
\hline Coton fibre & 151,2 & 154,5 & 154,3 & 161,3 & 170,0 & 172,0 & 174,1 & 166,3 \\
\hline Or & 347,4 & 487,9 & 534,3 & 563,1 & 592,3 & 605,5 & 607,0 & 580,5 \\
\hline Elevage & 24,4 & 22,7 & 24,2 & 26,2 & 28,4 & 30,7 & 33,3 & 28,5 \\
\hline Autres & 43,0 & 49,3 & 59,4 & 72,9 & 89,5 & 109,9 & 134,9 & 93,3 \\
\hline Importations (fob) & $-579,3$ & $-748,3$ & $-808,5$ & $-864,5$ & $-922,9$ & $-988,9$ & $-1060,3$ & $-929,1$ \\
\hline Services non-facteurs (net) & $-149,1$ & $-143,7$ & $-162,9$ & $-166,4$ & $-168,6$ & $-186,9$ & $-209,2$ & $-178,8$ \\
\hline Crédit & 129,6 & 148,2 & 177,6 & 197,6 & 220,0 & 229,5 & 237,3 & 212,4 \\
\hline Débit & $-278,6$ & $-291,9$ & $-340,5$ & $-364,1$ & $-388,7$ & $-416,5$ & $-446,5$ & $-391,2$ \\
\hline dont: fret et assurance (net) & $-159,9$ & $-176,5$ & $-255,5$ & $-273,2$ & $-291,6$ & $-312,5$ & $-335,1$ & $-293,6$ \\
\hline Services facteurs (net) & $-118,4$ & $-111,2$ & $-99,3$ & $-98,0$ & $-98,5$ & $-98,8$ & $-98,8$ & $-98,7$ \\
\hline Rémunérations des salaries & 3,3 & 4,0 & 4,0 & 4,0 & 4,0 & 4,0 & 4,1 & 4,0 \\
\hline Revenus des investissements & $-121,8$ & $-115,2$ & $-103,2$ & $-102,0$ & $-102,5$ & $-102,8$ & $-102,8$ & $-102,7$ \\
\hline - Intérêts sur la dette publique & $-16,8$ & $-14,0$ & $-12,3$ & $-10,5$ & $-10,3$ & $-9,9$ & $-9,2$ & $-10,4$ \\
\hline - Autres revenus des investissements & $-105,0$ & $-92,0$ & $-90,9$ & $-91,5$ & $-92,2$ & $-92,9$ & $-93,6$ & $-92,2$ \\
\hline Transferts courants & 110,5 & 151,0 & 141,2 & 128,1 & 125,1 & $\mathbf{1 2 8 , 7}$ & 131,9 & 131,0 \\
\hline Transferts du secteur privé (net) & 58,1 & 50,0 & 49,4 & 49,7 & 50,1 & 50,5 & 50,9 & 50,1 \\
\hline Transferts officiels & 52,4 & 101,0 & 91,8 & 78,4 & 75,0 & 78,2 & 81,0 & 80,9 \\
\hline - Dons budgétaires & 36,6 & 35,8 & 24,8 & 25,0 & 25,2 & 25,3 & 25,5 & 25,2 \\
\hline - Appui budgétaire sectoriel & 0,0 & 47,2 & 49,2 & 35,5 & 31,8 & 34,7 & 37,1 & 37,7 \\
\hline - Autres transferts officiels & 15,8 & 18,0 & 17,8 & 17,9 & 18,0 & 18,2 & 18,3 & 18,0 \\
\hline Balance des ressources $(\mathrm{X}-\mathrm{M})$ & $-162,4$ & $-177,6$ & $-199,2$ & $-207,5$ & $-211,5$ & $-257,7$ & $-320,1$ & $-239,2$ \\
\hline Solde des transactions courantes (hors transferts officiels) & $-222,8$ & $-238,8$ & $-249,1$ & $-255,8$ & $-259,8$ & $-306,0$ & $-368,0$ & $-287,8$ \\
\hline Solde des transactions courantes (y.c. transferts officiels) & $-170,3$ & $-137,8$ & $-157,3$ & $-177,4$ & $-184,9$ & $-227,8$ & $-287,0$ & $-206,9$ \\
\hline Compte de capital et financier & 188,2 & 187,2 & 173,6 & 202,6 & 192,5 & 246,2 & 313,1 & 225,6 \\
\hline Compte de capital & 74,5 & 191,5 & 95,5 & 105,1 & 113,1 & 122,7 & 132,8 & 113,8 \\
\hline dont: dons projets & 68,1 & 186,5 & 93,0 & 102,4 & 110,1 & 119,5 & 129,3 & 110,9 \\
\hline Compte financier & 113,6 & $-4,3$ & 78,2 & 97,5 & 79,4 & 123,5 & 180,4 & 111,8 \\
\hline Financier (net) & 52,7 & $-127,6$ & $-70,5$ & $-64,1$ & $-94,7$ & $-66,3$ & $-24,1$ & $-63,9$ \\
\hline Investissement direct (net) & 88,0 & 47,9 & 47,3 & 47,6 & 48,0 & 48,4 & 48,8 & 48,0 \\
\hline Investissement portfolio privé (net) & 13,3 & 6,5 & 6,4 & 6,5 & 6,5 & 6,6 & 6,6 & 6,5 \\
\hline Autres flux financiers privés & $-48,6$ & $-182,0$ & $-124,3$ & $-118,2$ & $-149,2$ & $-121,2$ & $-79,5$ & $-118,5$ \\
\hline Officiel (net) & 61,0 & 123,3 & 148,7 & 161,6 & 174,1 & 189,8 & 204,5 & 175,7 \\
\hline Tirages & 100,6 & 159,3 & 182,9 & 196,0 & 210,2 & 227,7 & 246,0 & 212,6 \\
\hline Budgétaires & 21,4 & 48,5 & 30,0 & 30,0 & 30,0 & 30,0 & 30,0 & 30,0 \\
\hline Prêts-projets & 79,1 & 110,8 & 152,9 & 166,0 & 180,2 & 197,7 & 216,0 & 182,6 \\
\hline Restructuration dette IADM & 0,0 & 1035,7 & 0,0 & 0,0 & 0,0 & 0,0 & 0,0 & 0,0 \\
\hline Remboursements dus sur dette publique & $-39,6$ & $-1071,7$ & $-34,2$ & $-34,4$ & $-36,1$ & $-37,9$ & $-41,5$ & $-36,8$ \\
\hline Erreurs et omissions & 5,6 & 0,0 & 0,0 & 0,0 & 0,0 & 0,0 & 0,0 & 0,0 \\
\hline Balance globale & 23,5 & 49,4 & 16,3 & 25,2 & 7,6 & $\mathbf{1 8 , 5}$ & 26,1 & 18,7 \\
\hline Financement & $-23,5$ & $-49,4$ & $-16,3$ & $-25,2$ & $-7,6$ & $-18,5$ & $-26,1$ & $-18,7$ \\
\hline Avoirs extérieurs nets (- $=$ augmentation) & $-51,2$ & $-75,3$ & $-26,8$ & $-35,9$ & $-18,8$ & $-30,6$ & $-37,2$ & $-29,9$ \\
\hline dont: FMI (net) & $-12,4$ & $-9,0$ & 2,0 & 2,0 & 2,0 & 2,0 & 2,0 & 2,0 \\
\hline Achats & 4,0 & 2,1 & 2,0 & 2,0 & 2,0 & 2,0 & 2,0 & 2,0 \\
\hline Rachats & 16,4 & 11,1 & 0,0 & 0,0 & 0,0 & 0,0 & 0,0 & 0,0 \\
\hline PPTE assistance & 27,7 & 25,9 & 10,5 & 10,7 & 11,2 & 12,1 & 11,1 & 11,1 \\
\hline Gap de financement & $\mathbf{0 , 0}$ & $\mathbf{0 , 0}$ & $\mathbf{0 , 0}$ & $\mathbf{0 , 0}$ & $\mathbf{0 , 0}$ & $\mathbf{0 , 0}$ & $\mathbf{0 , 0}$ & $\mathbf{0 , 0}$ \\
\hline & & & & & & & & \\
\hline pour mémoire: & & & & & & & & \\
\hline Produit intérieur brut aux prix du marché (mrd. Fbu) & 2550,3 & 3205,8 & 3419,4 & 3653,0 & 3895,0 & 4196,9 & 4493,8 & 3931,6 \\
\hline Balance commerciale/PIB & $-0,3 \%$ & $-1,1 \%$ & $-1,1 \%$ & $-1,1 \%$ & $-1,1 \%$ & $-1,7 \%$ & $-2,5 \%$ & $-1,5 \%$ \\
\hline Compte courant (hors dons)/PIB & $-8,6 \%$ & $-7,4 \%$ & $-7,3 \%$ & $-7,0 \%$ & $-6,7 \%$ & $-7,3 \%$ & $-8,2 \%$ & $-7,3 \%$ \\
\hline Compte courant (dons inclus)/PIB & $-6,6 \%$ & $-4,3 \%$ & $-4,6 \%$ & $-4,9 \%$ & $-4,7 \%$ & $-5,4 \%$ & $-6,4 \%$ & $-5,2 \%$ \\
\hline Réserves brutes (en mio. \$ E.U.) & 1029,5 & 1328,4 & 1408,6 & 1489,4 & 1536,0 & 1606,4 & 1690,2 & 1546,1 \\
\hline Réserves brutes/mois d'importation & 8,3 & 7,8 & 7,6 & 7,5 & 7,2 & 6,9 & 6,9 & 7,2 \\
\hline Service de la dette/exportations bsnf & $8,1 \%$ & $125,9 \%$ & $4,9 \%$ & $4,4 \%$ & $4,2 \%$ & $4,2 \%$ & $4,3 \%$ & $4,4 \%$ \\
\hline FCFA/US \$ & 582,2 & 522,3 & 509,9 & 507,2 & 505,0 & 502,9 & 500,8 & 505,2 \\
\hline
\end{tabular}

Source: DNPD, modèle MME-DNPD 
Table 19: Monetary survey (CFAF billion; end of period)

\begin{tabular}{|c|c|c|c|c|c|c|c|c|}
\hline Fin d'année & Average & 2006 & 2007 & 2008 & 2009 & 2010 & 2011 & $\overline{\text { Average }}$ \\
\hline & $2002-2005$ & Estim. & Prév. & Prév. & Prév. & Prév. & Prév. & $2007-2011$ \\
\hline Avoirs extérieurs bruts & 556,4 & 693,8 & 718,3 & \begin{tabular}{|c|}
755,4 \\
\end{tabular} & 775,7 & 807,8 & 846,5 & 780,7 \\
\hline Engagements extérieurs & 186,0 & 189,6 & 187,3 & 188,6 & 190,0 & 191,5 & 193,0 & 190,1 \\
\hline Avoirs extérieurs nets & 370,4 & 504,2 & 530,9 & 566,8 & 585,6 & 616,3 & 653,5 & 590,6 \\
\hline BCEAO & 330,1 & 468,1 & 477,8 & 510,1 & 527,1 & 554,7 & $\begin{array}{l}588,2 \\
\end{array}$ & 531,6 \\
\hline Banques commerciales & 40,3 & 36,1 & 53,1 & 56,7 & 58,6 & 61,6 & 65,4 & 59,1 \\
\hline Avoirs intérieurs nets & 434,3 & 432,0 & 450,5 & 463,5 & 494,5 & 525,1 & 547,3 & 496,2 \\
\hline Créances sur l'Etat, nettes & $-47,1$ & $-100,4$ & $-64,1$ & $-139,4$ & $-226,7$ & $-343,8$ & $-475,0$ & $-249,8$ \\
\hline Créances sur l'économie & 481,5 & 532,4 & 514,6 & 602,9 & 721,2 & 868,9 & $1.022,2$ & 746,0 \\
\hline Ressources = emplois & 804,5 & 936,2 & 981,4 & $1.030,3$ & $1.080,1$ & $1.141,4$ & $1.200,8$ & $1.086,8$ \\
\hline Masse Monétaire (M2) & 749,1 & 852,6 & 897,7 & 946,4 & 996,2 & $1.057,5$ & $1.116,9$ & $1.003,0$ \\
\hline Circulation fiduciaire & 296,5 & 347,5 & 362,7 & 379,1 & 395,7 & 415,9 & 435,3 & 397,7 \\
\hline Dépôts à vue et à terme & 452,6 & 505,2 & 535,0 & 567,3 & 600,5 & 641,6 & 681,6 & 605,2 \\
\hline Autres postes, nets & 55,5 & 83,5 & 83,7 & 83,9 & 83,9 & 83,9 & 83,9 & 83,9 \\
\hline Ressources = emplois & 804,5 & 936,2 & 981,4 & $1.030,3$ & $1.080,1$ & $1.141,4$ & $1.200,8$ & $1.086,8$ \\
\hline Taux annuels de croissance: & & & & & & & & \\
\hline Avoirs extérieurs bruts & $11,2 \%$ & $14,6 \%$ & $3,5 \%$ & $5,2 \%$ & $2,7 \%$ & $4,1 \%$ & $4,8 \%$ & $4,1 \%$ \\
\hline Engagements extérieurs & $-3,8 \%$ & $7,5 \%$ & $-1,2 \%$ & $0,6 \%$ & $0,8 \%$ & $0,8 \%$ & $0,8 \%$ & $0,4 \%$ \\
\hline Avoirs extérieurs nets & $23,2 \%$ & $17,6 \%$ & $5,3 \%$ & $6,8 \%$ & $3,3 \%$ & $5,2 \%$ & $6,0 \%$ & $5,3 \%$ \\
\hline BCEAO & $43,0 \%$ & $17,0 \%$ & $2,1 \%$ & $6,8 \%$ & $3,3 \%$ & $5,2 \%$ & $6,0 \%$ & $4,7 \%$ \\
\hline Banques commerciales & $-18,8 \%$ & $24,6 \%$ & $47,1 \%$ & $6,8 \%$ & $3,3 \%$ & $5,2 \%$ & $6,0 \%$ & $13,7 \%$ \\
\hline Avoirs intérieurs nets & $11,4 \%$ & $-11,8 \%$ & $4,3 \%$ & $2,9 \%$ & $6,7 \%$ & $6,2 \%$ & $4,2 \%$ & $4,9 \%$ \\
\hline Créances sur l'Etat, nettes & $35,8 \%$ & $280,6 \%$ & $-36,1 \%$ & $117,4 \%$ & $62,6 \%$ & $51,6 \%$ & $38,2 \%$ & $46,7 \%$ \\
\hline Créances sur l'économie & $11,4 \%$ & $3,2 \%$ & $-3,3 \%$ & $17,2 \%$ & $19,6 \%$ & $20,5 \%$ & $17,6 \%$ & $14,3 \%$ \\
\hline Ressources $=$ emplois & $15,9 \%$ & $1,9 \%$ & $4,8 \%$ & $5,0 \%$ & $4,8 \%$ & $5,7 \%$ & $5,2 \%$ & $5,1 \%$ \\
\hline Masse Monétaire (M2) & $15,2 \%$ & $1,5 \%$ & $5,3 \%$ & $5,4 \%$ & $5,3 \%$ & $6,2 \%$ & $5,6 \%$ & $5,5 \%$ \\
\hline Circulation fiduciaire & $19,6 \%$ & $0,7 \%$ & $4,4 \%$ & $4,5 \%$ & $4,4 \%$ & $5,1 \%$ & $4,7 \%$ & $4,6 \%$ \\
\hline Dépôts à vue et à terme & $13,0 \%$ & $2,0 \%$ & $5,9 \%$ & $6,0 \%$ & $5,9 \%$ & $6,8 \%$ & $6,2 \%$ & $6,2 \%$ \\
\hline Autres postes, nets & $27,3 \%$ & $6,9 \%$ & $0,2 \%$ & $0,2 \%$ & $0,1 \%$ & $0,0 \%$ & $0,0 \%$ & $0,1 \%$ \\
\hline Pour mémoire: & & & & & & & & \\
\hline Produit intérieur brut aux prix du marché & $2.550,3$ & $3.205,8$ & $3.419,4$ & $3.653,0$ & $3.895,0$ & $4.196,9$ & $4.493,8$ & $3.931,6$ \\
\hline Taux de liquidité (M2/PIBm) & $29,4 \%$ & $26,6 \%$ & $26,3 \%$ & $25,9 \%$ & $25,6 \%$ & $25,2 \%$ & $24,9 \%$ & $25,6 \%$ \\
\hline Vitesse de circulation (PIBm/M2) & 3,4 & 3,8 & 3,8 & 3,9 & 3,9 & 4,0 & 4,0 & 3,9 \\
\hline
\end{tabular}

Table 20: Price indices and exchange rate $(1987=100)$

\begin{tabular}{|c|c|c|c|c|c|c|c|c|}
\hline & \multirow{2}{*}{$\begin{array}{l}\text { Average } \\
2002-2005\end{array}$} & \multirow{2}{*}{$\begin{array}{l}\mathbf{2 0 0 6} \\
\text { Estim. }\end{array}$} & \multirow{2}{*}{$\frac{2007}{\text { Prév. }}$} & \multirow{2}{*}{$\begin{array}{l}2008 \\
\text { Prév. }\end{array}$} & \multirow{2}{*}{$\begin{array}{l}2009 \\
\text { Prév. }\end{array}$} & \multirow{2}{*}{$\frac{2010}{\text { Prév. }}$} & \multirow{2}{*}{$\begin{array}{l}2011 \\
\text { Prév. }\end{array}$} & \multirow{2}{*}{$\begin{array}{c}\text { Average } \\
2007-2011\end{array}$} \\
\hline & & & & & & & & \\
\hline Indice des prix au PIB & 200,7 & 226,2 & 226,6 & 227,1 & 227,3 & 227,3 & 227,2 & 227,1 \\
\hline Indice des prix à l'importation & 254,3 & 284,8 & 279,7 & 279,1 & 278,8 & 278,4 & 278,1 & 278,8 \\
\hline Indices des prix pour le total des ressources & 212,5 & 239,1 & 237,9 & 238,3 & 238,4 & 238,2 & 238,1 & 238,2 \\
\hline Indice des prix à la consommation totale & 227,9 & 239,3 & 247,0 & 243,7 & 240,5 & 239,3 & 239,2 & 241,9 \\
\hline Indice des prix à l'investissement & 220,6 & 229,5 & 229,8 & 230,3 & 230,5 & 230,5 & 230,4 & 230,3 \\
\hline Indice des prix à l'exportation & 175,6 & 210,2 & 218,7 & 228,1 & 237,8 & 241,0 & 241,2 & 233,4 \\
\hline Indice des termes de l'échange & 69,2 & 73,8 & 78,2 & 81,7 & 85,3 & 86,6 & 86,7 & 83,7 \\
\hline \multicolumn{9}{|l|}{ Taux de croissance des indices en \% } \\
\hline Indice des prix au PIB & $1,9 \%$ & $6,3 \%$ & $0,2 \%$ & $0,2 \%$ & $0,1 \%$ & $0,0 \%$ & $0,0 \%$ & $0,1 \%$ \\
\hline Indice des prix à l'importation & $3,4 \%$ & $3,1 \%$ & $-1,8 \%$ & $-0,2 \%$ & $-0,1 \%$ & $-0,1 \%$ & $-0,1 \%$ & $-0,5 \%$ \\
\hline Indices des prix pour le total des ressources & $1,9 \%$ & $6,1 \%$ & $-0,5 \%$ & $0,1 \%$ & $0,0 \%$ & $0,0 \%$ & $-0,1 \%$ & $-0,1 \%$ \\
\hline Indice des prix à la consommation totale & $3,8 \%$ & $-5,0 \%$ & $3,2 \%$ & $-1,3 \%$ & $-1,3 \%$ & $-0,5 \%$ & $-0,1 \%$ & $0,0 \%$ \\
\hline Indice des prix à l'investissement & $-1,1 \%$ & $6,3 \%$ & $0,2 \%$ & $0,2 \%$ & $0,1 \%$ & $0,0 \%$ & $0,0 \%$ & $0,1 \%$ \\
\hline Indice des prix à l'exportation & $0,6 \%$ & $15,9 \%$ & $4,0 \%$ & $4,3 \%$ & $4,2 \%$ & $1,4 \%$ & $0,1 \%$ & $2,8 \%$ \\
\hline Indice des termes de l'échange & $-2,7 \%$ & $12,5 \%$ & $5,9 \%$ & $4,5 \%$ & $4,3 \%$ & $1,5 \%$ & $0,2 \%$ & $3,3 \%$ \\
\hline \multicolumn{9}{|l|}{ Taux de change et inflation mondiale } \\
\hline Indice du Manufacturing Unit Value (OCDE) & 112,2 & 124,3 & 125,7 & 127,3 & 128,8 & 130,3 & 131,9 & 128,8 \\
\hline Indice de l'inflation mondiale pour le Mali & 215,9 & 209,5 & 207,0 & 208,3 & 209,9 & 211,5 & 213,2 & 210,0 \\
\hline Tx de change FCFA / DTS (moyenne de période) & 785,5 & 755,0 & 737,1 & 733,1 & 730,0 & 726,9 & 724,0 & 730,2 \\
\hline Tx de change FCFA/USD (moyenne de période) & 582,2 & 522,3 & 509,9 & 507,2 & 505,0 & 502,9 & 500,8 & 505,2 \\
\hline Tx de change FCFA/€ (moyenne de période) & 656,0 & 656,0 & 656,0 & 656,0 & 656,0 & 656,0 & 656,0 & 656,0 \\
\hline Indice du taux de change réel (IP_M/IP_PIB; + dévaluation) & 126,7 & 125,9 & 123,5 & 122,9 & 122,7 & 122,5 & 122,4 & 122,8 \\
\hline \multicolumn{9}{|l|}{ Taux de croissance en $\%$} \\
\hline Indice du Manufacturing Unit Value (OCDE) & $3,5 \%$ & $1,6 \%$ & $1,2 \%$ & $1,2 \%$ & $1,2 \%$ & $1,2 \%$ & $1,2 \%$ & $1,2 \%$ \\
\hline Indice de l'inflation mondiale pour le Mali & $-4,7 \%$ & $0,8 \%$ & $-1,2 \%$ & $0,6 \%$ & $0,8 \%$ & $0,8 \%$ & $0,8 \%$ & $0,4 \%$ \\
\hline Tx de change FCFA / DTS (moyenne de période) & $-4,9 \%$ & $-0,8 \%$ & $-2,4 \%$ & $-0,5 \%$ & $-0,4 \%$ & $-0,4 \%$ & $-0,4 \%$ & $-0,8 \%$ \\
\hline Tx de change FCFA/USD (moyenne de période) & $-7,7 \%$ & $-0,8 \%$ & $-2,4 \%$ & $-0,5 \%$ & $-0,4 \%$ & $-0,4 \%$ & $-0,4 \%$ & $-0,8 \%$ \\
\hline Tx de change FCFA/Euro (moyenne de période) & $-2,9 \%$ & $0,0 \%$ & $0,0 \%$ & $0,0 \%$ & $0,0 \%$ & $0,0 \%$ & $0,0 \%$ & $0,0 \%$ \\
\hline Indice du taux de change réel & $1,6 \%$ & $-3,0 \%$ & $-1,9 \%$ & $-0,4 \%$ & $-0,2 \%$ & $-0,1 \%$ & $-0,1 \%$ & $-0,6 \%$ \\
\hline
\end{tabular}


Table 21: Price indices by economic sector $(1987=100)$

\begin{tabular}{|c|c|c|c|c|c|c|c|c|}
\hline & Average & 2006 & 2007 & 2008 & 2009 & 2010 & 2011 & Average \\
\hline & $2002-2005$ & Estim. & Prév. & Prév. & Prév. & Prév. & Prév. & 2007-2011 \\
\hline SECTEUR PRIMAIRE & 198,2 & 224,0 & 225,8 & 226,7 & 227,1 & 227,1 & 227,1 & 226,8 \\
\hline Agriculture vivrière hors riz & 195,9 & 242,3 & 244,3 & 245,3 & 245,7 & 245,7 & 245,7 & 245,3 \\
\hline Branche consolidé du riz & 152,8 & 176,4 & 177,8 & 178,5 & 178,8 & 178,9 & 178,8 & 178,6 \\
\hline Agriculture industrielle hors coton & 255,2 & 276,6 & 278,9 & 279,9 & 280,4 & 280,5 & 280,4 & 280,0 \\
\hline Branche consolidé coton & 238,1 & 253,7 & 255,8 & 256,8 & 257,2 & 257,3 & 257,2 & 256,9 \\
\hline Elevage & 187,3 & 198,6 & 200,3 & 201,0 & 201,4 & 201,4 & 201,4 & 201,1 \\
\hline Pêche & 179,2 & 190,6 & 192,2 & 192,9 & 193,2 & 193,3 & 193,3 & 193,0 \\
\hline Sylviculture & 241,4 & 256,9 & 259,1 & 260,1 & 260,5 & 260,6 & 260,5 & 260,1 \\
\hline SECTEUR SECONDAIRE & 203,9 & 255,5 & 215,9 & 216,2 & 216,4 & 216,5 & 216,5 & 216,3 \\
\hline Produits de l'extraction & 184,5 & 223,1 & 188,5 & 188,8 & 188,9 & 189,0 & 189,0 & 188,8 \\
\hline Industries manufacturières & 218,4 & 297,2 & 251,2 & 251,5 & 251,7 & 251,9 & 251,9 & 251,6 \\
\hline Agroalimentaires & 187,5 & 255,1 & 215,6 & 215,9 & 216,1 & 216,2 & 216,2 & 216,0 \\
\hline Industries textiles & 299,2 & 407,2 & 344,1 & 344,6 & 344,9 & 345,0 & 345,1 & 344,7 \\
\hline Autres branches manufact. & 167,1 & 227,3 & 192,1 & 192,4 & 192,5 & 192,6 & 192,6 & 192,5 \\
\hline Electricité eau & 172,7 & 201,9 & 170,6 & 170,8 & 171,0 & 171,1 & 171,1 & 170,9 \\
\hline Bâtiment, Travaux publics & 226,1 & 256,1 & 216,4 & 216,7 & 216,9 & 217,0 & 217,0 & 216,8 \\
\hline SECTEUR TERTIAIRE & 201,1 & 209,8 & 215,9 & 216,2 & 216,4 & 216,5 & 216,5 & 216,3 \\
\hline Commerce & 186,6 & 194,9 & 200,6 & 200,9 & 201,1 & 201,2 & 201,2 & 201,0 \\
\hline Transport et télécommunication & 174,4 & 178,0 & 183,2 & 183,5 & 183,6 & 183,7 & 183,7 & 183,5 \\
\hline Autr. services march. non financiers & 189,4 & 193,8 & 199,5 & 199,8 & 199,9 & 200,0 & 200,1 & 199,9 \\
\hline Services financiers & 188,5 & 192,6 & 198,2 & 198,5 & 198,7 & 198,7 & 198,8 & 198,6 \\
\hline Services non marchands & 246,9 & 264,3 & 272,0 & 272,4 & 272,7 & 272,8 & 272,8 & 272,5 \\
\hline Total branche fictive & 188,5 & 192,6 & 198,2 & 198,5 & 198,7 & 198,7 & 198,8 & 198,6 \\
\hline PIB AU COUT DES FACTEURS & 200,7 & 226,2 & 226,6 & 227,1 & 227,3 & 227,3 & 227,2 & 227,1 \\
\hline
\end{tabular}

Table 22: GDP by sector (CFAF billion at 1987 prices)

\begin{tabular}{|c|c|c|c|c|c|c|c|c|}
\hline & Average & 2006 & 2007 & 2008 & 2009 & 2010 & 2011 & Average \\
\hline & $2002-2005$ & Estim. & Prév. & Prév. & Prév. & Prév. & Prév. & $2007-2011$ \\
\hline Secteur primaire & 431,4 & 485,1 & 512,0 & 540,6 & 571,0 & 603,3 & 638,8 & 573,1 \\
\hline Agriculture vivrière hors riz & 149,4 & 175,5 & 186,1 & 197,2 & 209,1 & 221,6 & 236,0 & 210,0 \\
\hline Branche consolidé du riz & 50,0 & 58,5 & 64,3 & 70,7 & 77,7 & 85,4 & 93,9 & 78,4 \\
\hline Agriculture industrielle hors coton & 11,3 & 15,4 & 16,4 & 17,4 & 18,5 & 19,7 & 20,9 & 18,6 \\
\hline Branche consolidé coton & 35,3 & 34,6 & 35,2 & 35,8 & 36,4 & 37,0 & 37,6 & 36,4 \\
\hline Elevage & 123,8 & 134,2 & 140,4 & 146,8 & 153,5 & 160,6 & 167,9 & 153,8 \\
\hline Pêche & 11,4 & 12,3 & 12,9 & 13,4 & 14,1 & 14,7 & 15,4 & 14,1 \\
\hline Sylviculture & 50,2 & 54,5 & 56,8 & 59,2 & 61,7 & 64,3 & 67,1 & 61,8 \\
\hline Secteur secondaire & 278,5 & 309,7 & 331,7 & 351,6 & 374,1 & 399,0 & 427,1 & 376,7 \\
\hline Produits de l'extraction & 106,5 & 116,5 & 120,6 & 120,6 & 120,6 & 120,6 & 120,6 & 120,6 \\
\hline Industries manufacturières & 94,4 & 101,8 & 111,3 & 121,7 & 133,1 & 145,7 & 159,5 & 134,3 \\
\hline Agroalimentaires & 35,2 & 38,0 & 42,3 & 47,0 & 52,3 & 58,2 & 64,7 & 52,9 \\
\hline Industries textiles & 31,3 & 33,7 & 36,0 & 38,4 & 41,1 & 43,9 & 46,9 & 41,3 \\
\hline Autres branches manufact. & 27,9 & 30,1 & 33,0 & 36,2 & 39,8 & 43,6 & 47,9 & 40,1 \\
\hline Electricité eau & 24,5 & 30,7 & 34,7 & 39,2 & 44,2 & 50,0 & 56,4 & 44,9 \\
\hline Bâtiment, Travaux publics & 53,2 & 60,7 & 65,2 & 70,2 & 76,2 & 82,8 & 90,6 & 77,0 \\
\hline Secteur tertiaire & 435,9 & 487,0 & 522,0 & 557,3 & 594,4 & 640,1 & 688,0 & 600,4 \\
\hline Commerce & 166,9 & 183,6 & 196,5 & 208,8 & 222,5 & 237,6 & 254,5 & 224,0 \\
\hline Transport et télécommunication & 65,0 & 81,0 & 86,8 & 92,2 & 98,2 & 104,9 & 112,4 & 98,9 \\
\hline Autr. services march. non financiers & 86,7 & 94,2 & 100,9 & 107,1 & 114,2 & 122,0 & 130,6 & 115,0 \\
\hline Services financiers & 9,8 & 10,9 & 11,7 & 12,4 & 13,2 & 14,1 & 15,1 & 13,3 \\
\hline Services non marchands & 114,2 & 124,8 & 134,2 & 145,3 & 155,4 & 171,2 & 185,7 & 158,4 \\
\hline Production imputée de services bancaires (marges d'intérêt) & $-6,7$ & $-7,5$ & $-8,0$ & $-8,5$ & $-9,1$ & $-9,7$ & $-10,4$ & $-9,2$ \\
\hline PIB au coût des facteurs & 1145,8 & 1281,7 & 1365,7 & 1449,5 & 1539,5 & 1642,5 & 1753,8 & 1550,2 \\
\hline Taxes indirectes (moins subventions) & 117,5 & 128,7 & 143,5 & 159,2 & 174,4 & 204,3 & 224,5 & 181,2 \\
\hline PIB aux prix du marché & 1263,3 & 1410,4 & 1509,2 & 1608,7 & 1713,9 & 1846,8 & 1978,3 & 1731,4 \\
\hline PIB du secteur formel au coût des facteurs & 395,6 & 487,1 & 519,0 & 550,8 & 600,4 & 640,6 & 684,0 & 599,0 \\
\hline
\end{tabular}




\begin{tabular}{|c|c|c|c|c|c|c|c|c|}
\hline Taux annuel de croissance & Average & 2006 & 2007 & 2008 & 2009 & 2010 & 2011 & Average \\
\hline & $2002-2005$ & Estim. & Prév. & Prév. & Prév. & Prév. & Prév. & $2007-2011$ \\
\hline Secteur primaire & $4,7 \%$ & $5,0 \%$ & $5,5 \%$ & $5,6 \%$ & $5,6 \%$ & $5,7 \%$ & $5,9 \%$ & $\mathbf{5 , 7 \%}$ \\
\hline Agriculture vivrière hors riz & $8,7 \%$ & $8,3 \%$ & $6,0 \%$ & $6,0 \%$ & $6,0 \%$ & $6,0 \%$ & $6,5 \%$ & $6,1 \%$ \\
\hline Branche consolidé du riz & $2,7 \%$ & $7,3 \%$ & $9,9 \%$ & $9,9 \%$ & $9,9 \%$ & $9,9 \%$ & $9,9 \%$ & $9,9 \%$ \\
\hline Agriculture industrielle hors coton & $14,3 \%$ & $2,1 \%$ & $6,3 \%$ & $6,3 \%$ & $6,3 \%$ & $6,3 \%$ & $6,3 \%$ & $6,3 \%$ \\
\hline Branche consolidé coton & $1,1 \%$ & $-0,4 \%$ & $1,6 \%$ & $1,6 \%$ & $1,6 \%$ & $1,6 \%$ & $1,6 \%$ & $1,6 \%$ \\
\hline Elevage & $4,1 \%$ & $2,5 \%$ & $4,6 \%$ & $4,6 \%$ & $4,6 \%$ & $4,6 \%$ & $4,6 \%$ & $4,6 \%$ \\
\hline Pêche & $2,2 \%$ & $3,8 \%$ & $4,5 \%$ & $4,5 \%$ & $4,5 \%$ & $4,5 \%$ & $4,5 \%$ & $4,5 \%$ \\
\hline Sylviculture & $2,9 \%$ & $3,8 \%$ & $4,2 \%$ & $4,2 \%$ & $4,2 \%$ & $4,2 \%$ & $4,2 \%$ & $4,2 \%$ \\
\hline Secteur secondaire & $5,3 \%$ & $5,9 \%$ & $7,1 \%$ & $6,0 \%$ & $6,4 \%$ & $6,7 \%$ & $\mathbf{7 , 0} \%$ & $6,6 \%$ \\
\hline \begin{tabular}{|l|} 
Produits de l'extraction \\
\end{tabular} & $2,0 \%$ & $10,6 \%$ & $3,4 \%$ & $0,0 \%$ & $0,0 \%$ & $0,0 \%$ & $0,0 \%$ & $0,7 \%$ \\
\hline Industries manufacturières & $9,5 \%$ & $0,3 \%$ & $9,3 \%$ & $9,4 \%$ & $9,4 \%$ & $9,4 \%$ & $9,5 \%$ & $9,4 \%$ \\
\hline Agroalimentaires & $9,4 \%$ & $0,6 \%$ & $11,2 \%$ & $11,2 \%$ & $11,2 \%$ & $11,2 \%$ & $11,2 \%$ & $11,2 \%$ \\
\hline Industries textiles & $9,5 \%$ & $0,2 \%$ & $6,8 \%$ & $6,8 \%$ & $6,8 \%$ & $6,8 \%$ & $6,8 \%$ & $6,8 \%$ \\
\hline Autres branches manufact. & $9,5 \%$ & $0,2 \%$ & $9,7 \%$ & $9,7 \%$ & $9,7 \%$ & $9,7 \%$ & $9,7 \%$ & $9,7 \%$ \\
\hline Electricité eau & $12,0 \%$ & $8,3 \%$ & $12,9 \%$ & $12,9 \%$ & $12,9 \%$ & $12,9 \%$ & $12,9 \%$ & $12,9 \%$ \\
\hline Bâtiment, Travaux publics & $5,2 \%$ & $5,7 \%$ & $7,5 \%$ & $7,7 \%$ & $8,5 \%$ & $8,7 \%$ & $9,4 \%$ & $8,4 \%$ \\
\hline Secteur tertiaire & $4,8 \%$ & $2,9 \%$ & $7,2 \%$ & $6,8 \%$ & $6,7 \%$ & $7,7 \%$ & $7,5 \%$ & $7,2 \%$ \\
\hline Commerce & $3,8 \%$ & $3,6 \%$ & $7,1 \%$ & $6,2 \%$ & $6,6 \%$ & $6,8 \%$ & $7,1 \%$ & $6,8 \%$ \\
\hline Transport et télécommunication & $9,3 \%$ & $3,4 \%$ & $7,1 \%$ & $6,2 \%$ & $6,6 \%$ & $6,8 \%$ & $7,1 \%$ & $6,8 \%$ \\
\hline Autr. services march. non financiers & $3,9 \%$ & $3,8 \%$ & $7,1 \%$ & $6,2 \%$ & $6,6 \%$ & $6,8 \%$ & $7,1 \%$ & $6,8 \%$ \\
\hline Services financiers & $4,5 \%$ & $4,1 \%$ & $7,1 \%$ & $6,2 \%$ & $6,6 \%$ & $6,8 \%$ & $7,1 \%$ & $6,8 \%$ \\
\hline Services non marchands & $4,7 \%$ & $0,9 \%$ & $7,5 \%$ & $8,3 \%$ & $6,9 \%$ & $10,2 \%$ & $8,4 \%$ & $8,3 \%$ \\
\hline Production imputée de services bancaires (marges d'intérêt) & $5,1 \%$ & $4,3 \%$ & $7,1 \%$ & $6,2 \%$ & $6,6 \%$ & $6,8 \%$ & $7,1 \%$ & $6,8 \%$ \\
\hline PIB au coût des facteurs & $4,6 \%$ & $\mathbf{4 , 4 \%}$ & $6,5 \%$ & $6,1 \%$ & $6,2 \%$ & $6,7 \%$ & $6,8 \%$ & $6,5 \%$ \\
\hline Taxes indirectes (moins subventions) & $12,1 \%$ & $-4,2 \%$ & $11,5 \%$ & $10,9 \%$ & $9,5 \%$ & $17,2 \%$ & $9,9 \%$ & $11,8 \%$ \\
\hline PIB aux prix du marché & $5,2 \%$ & $3,6 \%$ & $7,0 \%$ & $6,6 \%$ & $6,5 \%$ & $7,8 \%$ & $7,1 \%$ & $7,0 \%$ \\
\hline
\end{tabular}

Source: DNPD, modèle MME-DNPD

Table 23: Sectoral contribution to growth (in percent)

\begin{tabular}{|c|c|c|c|c|c|c|c|c|}
\hline & Average & 2006 & 2007 & 2008 & 2009 & 2010 & 2011 & Average \\
\hline & $2002-2005$ & Estim. & Prév. & Prév. & Prév. & Prév. & Prév. & $2007-2011$ \\
\hline Secteur primaire & $1,6 \%$ & $1,9 \%$ & $2,1 \%$ & $2,1 \%$ & $2,1 \%$ & $2,1 \%$ & $2,2 \%$ & $2,1 \%$ \\
\hline Agriculture vivrière hors riz & $1,0 \%$ & $1,1 \%$ & $0,8 \%$ & $0,8 \%$ & $0,8 \%$ & $0,8 \%$ & $0,9 \%$ & $0,8 \%$ \\
\hline Branche consolidé du riz & $0,0 \%$ & $0,3 \%$ & $0,5 \%$ & $0,5 \%$ & $0,5 \%$ & $0,5 \%$ & $0,5 \%$ & $0,5 \%$ \\
\hline Agriculture industrielle hors coton & $0,1 \%$ & $0,0 \%$ & $0,1 \%$ & $0,1 \%$ & $0,1 \%$ & $0,1 \%$ & $0,1 \%$ & $0,1 \%$ \\
\hline Branche consolidé coton & $0,0 \%$ & $0,0 \%$ & $0,0 \%$ & $0,0 \%$ & $0,0 \%$ & $0,0 \%$ & $0,0 \%$ & $0,0 \%$ \\
\hline Elevage & $0,4 \%$ & $0,3 \%$ & $0,5 \%$ & $0,5 \%$ & $0,5 \%$ & $0,5 \%$ & $0,4 \%$ & $0,5 \%$ \\
\hline Pêche & $0,0 \%$ & $0,0 \%$ & $0,0 \%$ & $0,0 \%$ & $0,0 \%$ & $0,0 \%$ & $0,0 \%$ & $0,0 \%$ \\
\hline Sylviculture & $0,1 \%$ & $0,2 \%$ & $0,2 \%$ & $0,2 \%$ & $0,2 \%$ & $0,2 \%$ & $0,2 \%$ & $0,2 \%$ \\
\hline Secteur secondaire & $1,2 \%$ & $1,4 \%$ & $1,7 \%$ & $1,5 \%$ & $1,6 \%$ & $1,6 \%$ & $1,7 \%$ & $1,6 \%$ \\
\hline Produits de l'extraction & $0,0 \%$ & $0,9 \%$ & $0,3 \%$ & $0,0 \%$ & $0,0 \%$ & $0,0 \%$ & $0,0 \%$ & $0,1 \%$ \\
\hline Industries manufacturières & $0,7 \%$ & $0,0 \%$ & $0,7 \%$ & $0,8 \%$ & $0,8 \%$ & $0,8 \%$ & $0,8 \%$ & $0,8 \%$ \\
\hline Agroalimentaires & $0,2 \%$ & $0,0 \%$ & $0,3 \%$ & $0,3 \%$ & $0,4 \%$ & $0,4 \%$ & $0,4 \%$ & $0,4 \%$ \\
\hline Industries textiles & $0,2 \%$ & $0,0 \%$ & $0,2 \%$ & $0,2 \%$ & $0,2 \%$ & $0,2 \%$ & $0,2 \%$ & $0,2 \%$ \\
\hline Autres branches manufact. & $0,2 \%$ & $0,0 \%$ & $0,2 \%$ & $0,2 \%$ & $0,2 \%$ & $0,3 \%$ & $0,3 \%$ & $0,2 \%$ \\
\hline Electricité eau & $0,2 \%$ & $0,2 \%$ & $0,3 \%$ & $0,3 \%$ & $0,3 \%$ & $0,4 \%$ & $0,4 \%$ & $0,4 \%$ \\
\hline Bâtiment, Travaux publics & $0,2 \%$ & $0,3 \%$ & $0,4 \%$ & $0,4 \%$ & $0,4 \%$ & $0,4 \%$ & $0,5 \%$ & $0,4 \%$ \\
\hline Secteur tertiaire & $1,8 \%$ & $1,1 \%$ & $2,7 \%$ & $2,6 \%$ & $2,6 \%$ & $3,0 \%$ & $2,9 \%$ & $2,8 \%$ \\
\hline Commerce & $0,5 \%$ & $0,5 \%$ & $1,0 \%$ & $0,9 \%$ & $0,9 \%$ & $1,0 \%$ & $1,0 \%$ & $1,0 \%$ \\
\hline Transport et télécommunication & $0,5 \%$ & $0,2 \%$ & $0,4 \%$ & $0,4 \%$ & $0,4 \%$ & $0,4 \%$ & $0,5 \%$ & $0,4 \%$ \\
\hline Autr. services march. non financiers & $0,3 \%$ & $0,3 \%$ & $0,5 \%$ & $0,5 \%$ & $0,5 \%$ & $0,5 \%$ & $0,5 \%$ & $0,5 \%$ \\
\hline Services financiers & $0,0 \%$ & $0,0 \%$ & $0,1 \%$ & $0,1 \%$ & $0,1 \%$ & $0,1 \%$ & $0,1 \%$ & $0,1 \%$ \\
\hline Services non marchands & $0,5 \%$ & $0,1 \%$ & $0,7 \%$ & $0,8 \%$ & $0,7 \%$ & $1,0 \%$ & $0,9 \%$ & $0,8 \%$ \\
\hline Production imputée de services bancaires (marges d'intérêt) & $0,0 \%$ & $0,0 \%$ & $0,0 \%$ & $0,0 \%$ & $0,0 \%$ & $0,0 \%$ & $0,0 \%$ & $0,0 \%$ \\
\hline PIB au coût des facteurs & $4,6 \%$ & $4,4 \%$ & $6,5 \%$ & $6,1 \%$ & $6,2 \%$ & $6,7 \%$ & $6,8 \%$ & $6,5 \%$ \\
\hline PIB du secteur formel au coût des facteurs & $1,3 \%$ & $6,2 \%$ & $2,5 \%$ & $2,3 \%$ & $3,4 \%$ & $2,6 \%$ & $2,6 \%$ & $2,7 \%$ \\
\hline
\end{tabular}

PIB du secteur formel au coût des facteu 
Table 24: GDP by sector (CFAF billion current)

\begin{tabular}{|c|c|c|c|c|c|c|c|c|}
\hline & Average & 2006 & 2007 & 2008 & 2009 & 2010 & 2011 & Average \\
\hline & $2002-2005$ & Estim. & Prév. & Prév. & Prév. & Prév. & Prév. & $2007-2011$ \\
\hline Secteur primaire & 859,2 & 1086,4 & 1251,1 & 1325,9 & 1402,7 & 1482,6 & 1569,5 & 1406,3 \\
\hline Agriculture vivrière hors riz & 298,3 & 427,4 & 454,7 & 483,8 & 513,6 & 544,6 & 579,9 & 515,3 \\
\hline Branche consolidé du riz & 76,1 & 104,6 & 157,1 & 173,3 & 190,9 & 209,9 & 230,7 & 192,4 \\
\hline Agriculture industrielle hors coton & 29,2 & 45,0 & 40,0 & 42,7 & 45,5 & 48,4 & 51,4 & 45,6 \\
\hline Branche consolidé coton & 79,0 & 65,2 & 86,1 & 87,8 & 89,4 & 90,9 & 92,3 & 89,3 \\
\hline Elevage & 234,0 & 278,2 & 343,0 & 360,1 & 377,2 & 394,6 & 412,6 & 377,5 \\
\hline Pêche & 20,5 & 23,8 & 31,4 & 33,0 & 34,5 & 36,1 & 37,7 & 34,6 \\
\hline Sylviculture & 122,1 & 142,2 & 138,8 & 145,3 & 151,6 & 158,1 & 164,8 & 151,7 \\
\hline Secteur secondaire & 568,6 & 791,3 & 716,2 & 760,4 & 809,7 & 864,0 & 924,8 & 815,0 \\
\hline \begin{tabular}{|l|} 
Produits de l'extraction \\
\end{tabular} & 201,6 & 254,0 & 260,3 & 260,7 & 260,9 & 261,0 & 261,0 & 260,8 \\
\hline Industries manufacturièrs & 207,7 & 363,4 & 240,2 & 263,2 & 288,1 & 315,5 & 345,4 & 290,5 \\
\hline Agroalimentaires & 66,6 & 116,5 & 91,3 & 101,7 & 113,2 & 126,0 & 140,2 & 114,5 \\
\hline Industries textiles & 94,2 & 164,8 & 77,7 & 83,1 & 88,9 & 95,0 & 101,5 & 89,3 \\
\hline Autres branches manufact. & 47,0 & 82,2 & 71,3 & 78,3 & 86,0 & 94,5 & 103,7 & 86,8 \\
\hline Electricité eau & 42,4 & 55,4 & 74,9 & 84,7 & 95,7 & 108,2 & 122,2 & 97,1 \\
\hline Bâtiment, Travaux publics & 116,9 & 118,4 & 140,8 & 151,9 & 164,9 & 179,3 & 196,2 & 166,6 \\
\hline Secteur tertiaire & 876,7 & 1021,8 & 1127,0 & 1205,1 & 1286,4 & 1386,0 & 1489,6 & 1298,8 \\
\hline Commerce & 312,8 & 354,8 & 424,3 & 451,4 & 481,5 & 514,5 & 551,2 & 484,6 \\
\hline Transport et télécommunication & 114,2 & 164,8 & 187,3 & 199,3 & 212,6 & 227,1 & 243,3 & 213,9 \\
\hline Autr. services march. non financiers & 165,3 & 186,2 & 217,8 & 231,7 & 247,1 & 264,1 & 282,9 & 248,7 \\
\hline Services financiers & 18,7 & 21,7 & 25,2 & 26,8 & 28,6 & 30,6 & 32,8 & 28,8 \\
\hline Services non marchands & 278,4 & 309,3 & 289,8 & 314,3 & 336,3 & 370,8 & 402,0 & 342,6 \\
\hline Production imputée de services bancaires (marges d'intérêt) & $-12,8$ & $-14,9$ & $-17,4$ & $-18,5$ & $-19,7$ & $-21,1$ & $-22,6$ & $-19,8$ \\
\hline PIB au coût des facteurs & 2304,5 & 2899,4 & 3094,2 & 3291,5 & 3498,7 & 3732,6 & 3983,9 & 3520,2 \\
\hline Taxes indirectes (moins subventions) & 245,8 & 306,4 & 325,2 & 361,5 & 396,3 & 464,3 & 509,9 & 411,5 \\
\hline PIB aux prix du marché & 2550,3 & 3205,8 & 3419,4 & 3653,0 & 3895,0 & 4196,9 & 4493,8 & 3931,6 \\
\hline \multirow[t]{2}{*}{ Taux annuel de croissance } & Average & 2006 & 2007 & 2008 & 2009 & 2010 & 2011 & Average \\
\hline & $2002-2005$ & Estim. & Prév. & Prév. & Prév. & Prév. & Prév. & $2007-2011$ \\
\hline Secteur primaire & $7,9 \%$ & $8,1 \%$ & $15,2 \%$ & $6,0 \%$ & $5,8 \%$ & $5,7 \%$ & $5,9 \%$ & $7,7 \%$ \\
\hline Agriculture vivrière hors riz & $14,7 \%$ & $9,4 \%$ & $6,4 \%$ & $6,4 \%$ & $6,2 \%$ & $6,0 \%$ & $6,5 \%$ & $6,3 \%$ \\
\hline Branche consolidé du riz & $5,1 \%$ & $14,5 \%$ & $50,2 \%$ & $10,4 \%$ & $10,1 \%$ & $10,0 \%$ & $9,9 \%$ & $18,1 \%$ \\
\hline Agriculture industrielle hors coton & $18,9 \%$ & $10,2 \%$ & $-11,0 \%$ & $6,7 \%$ & $6,5 \%$ & $6,4 \%$ & $6,3 \%$ & $3,0 \%$ \\
\hline Branche consolidé coton & $-1,4 \%$ & $-0,4 \%$ & $31,9 \%$ & $2,0 \%$ & $1,8 \%$ & $1,7 \%$ & $1,6 \%$ & $7,8 \%$ \\
\hline Elevage & $7,5 \%$ & $6,8 \%$ & $23,3 \%$ & $5,0 \%$ & $4,7 \%$ & $4,6 \%$ & $4,6 \%$ & $8,4 \%$ \\
\hline Pêche & $7,1 \%$ & $5,9 \%$ & $32,0 \%$ & $4,9 \%$ & $4,7 \%$ & $4,6 \%$ & $4,5 \%$ & $10,1 \%$ \\
\hline Sylviculture & $7,8 \%$ & $5,9 \%$ & $-2,4 \%$ & $4,6 \%$ & $4,4 \%$ & $4,3 \%$ & $4,2 \%$ & $3,0 \%$ \\
\hline Secteur secondaire & $8,8 \%$ & $22,5 \%$ & $-9,5 \%$ & $6,2 \%$ & $6,5 \%$ & $6,7 \%$ & $7,0 \%$ & $3,4 \%$ \\
\hline \begin{tabular}{|l|} 
Produits de l'extraction \\
\end{tabular} & $4,6 \%$ & $13,9 \%$ & $2,5 \%$ & $0,2 \%$ & $0,1 \%$ & $0,0 \%$ & $0,0 \%$ & $0,6 \%$ \\
\hline Industries manufacturièrs & $22,3 \%$ & $41,0 \%$ & $-33,9 \%$ & $9,5 \%$ & $9,5 \%$ & $9,5 \%$ & $9,5 \%$ & $0,8 \%$ \\
\hline Agroalimentaires & $14,5 \%$ & $41,0 \%$ & $-21,6 \%$ & $11,4 \%$ & $11,3 \%$ & $11,3 \%$ & $11,2 \%$ & $4,7 \%$ \\
\hline Industries textiles & $44,7 \%$ & $41,0 \%$ & $-52,9 \%$ & $7,0 \%$ & $6,9 \%$ & $6,9 \%$ & $6,8 \%$ & $-5,0 \%$ \\
\hline Autres branches manufact. & $13,1 \%$ & $41,0 \%$ & $-13,3 \%$ & $9,9 \%$ & $9,8 \%$ & $9,8 \%$ & $9,7 \%$ & $5,2 \%$ \\
\hline Electricité eau & $13,6 \%$ & $10,5 \%$ & $35,1 \%$ & $13,1 \%$ & $13,0 \%$ & $13,0 \%$ & $12,9 \%$ & $17,4 \%$ \\
\hline Bâtiment, Travaux publics & $1,0 \%$ & $2,8 \%$ & $18,9 \%$ & $7,9 \%$ & $8,6 \%$ & $8,7 \%$ & $9,4 \%$ & $10,7 \%$ \\
\hline Secteur tertiaire & $5,4 \%$ & $6,4 \%$ & $10,3 \%$ & $6,9 \%$ & $6,7 \%$ & $7,7 \%$ & $7,5 \%$ & $7,8 \%$ \\
\hline Commerce & $3,3 \%$ & $4,7 \%$ & $19,6 \%$ & $6,4 \%$ & $6,7 \%$ & $6,9 \%$ & $7,1 \%$ & $9,3 \%$ \\
\hline Transport et télécommunication & $11,1 \%$ & $17,9 \%$ & $13,7 \%$ & $6,4 \%$ & $6,7 \%$ & $6,9 \%$ & $7,1 \%$ & $8,1 \%$ \\
\hline Autr. services march. non financiers & $4,3 \%$ & $6,0 \%$ & $17,0 \%$ & $6,4 \%$ & $6,7 \%$ & $6,9 \%$ & $7,1 \%$ & $8,8 \%$ \\
\hline Services financiers & $5,9 \%$ & $6,2 \%$ & $16,5 \%$ & $6,4 \%$ & $6,7 \%$ & $6,9 \%$ & $7,1 \%$ & $8,7 \%$ \\
\hline Services non marchands & $6,6 \%$ & $3,1 \%$ & $-6,3 \%$ & $8,5 \%$ & $7,0 \%$ & $10,2 \%$ & $8,4 \%$ & $5,6 \%$ \\
\hline Production imputée de services bancaires (marges d'intérêt) & $6,4 \%$ & $6,4 \%$ & $16,5 \%$ & $6,4 \%$ & $6,7 \%$ & $6,9 \%$ & $7,1 \%$ & $8,7 \%$ \\
\hline PIB au coût des facteurs & $6,6 \%$ & $11,0 \%$ & $6,7 \%$ & $6,4 \%$ & $6,3 \%$ & $6,7 \%$ & $6,7 \%$ & $6,6 \%$ \\
\hline Taxes indirectes (moins subventions) & $11,3 \%$ & $9,2 \%$ & $6,1 \%$ & $11,2 \%$ & $9,6 \%$ & $17,2 \%$ & $9,8 \%$ & $10,8 \%$ \\
\hline PIB aux prix du marché & $7,0 \%$ & $10,8 \%$ & $6,7 \%$ & $6,8 \%$ & $6,6 \%$ & $7,7 \%$ & $7,1 \%$ & $7,0 \%$ \\
\hline
\end{tabular}


Table 25: Exports of merchandise (billion of CFAF current)

\begin{tabular}{|c|c|c|c|c|c|c|c|c|}
\hline & \multirow{2}{*}{$\begin{array}{l}\text { Average } \\
2002-2005\end{array}$} & \multirow{2}{*}{$\begin{array}{l}\mathbf{2 0 0 6} \\
\text { Estim. }\end{array}$} & \multirow{2}{*}{\begin{tabular}{r|}
2007 \\
Prév.
\end{tabular}} & \multirow{2}{*}{$\begin{array}{c}2008 \\
\text { Prév. }\end{array}$} & \multirow{2}{*}{\begin{tabular}{r|}
2009 \\
Prév.
\end{tabular}} & \multirow{2}{*}{\begin{tabular}{r|}
2010 \\
Prév.
\end{tabular}} & \multirow{2}{*}{$\begin{array}{l}2011 \\
\text { Prév. }\end{array}$} & \multirow{2}{*}{$\begin{array}{l}\text { Average } \\
2007-2011\end{array}$} \\
\hline & & & & & & & & \\
\hline Cotton fibre & 151,2 & 154,5 & 154,3 & 161,3 & 170,0 & 172,0 & 174,1 & 166,3 \\
\hline Elevage & 24,4 & 22,7 & 24,2 & 26,2 & 28,4 & 30,7 & 33,3 & 28,5 \\
\hline Or & 347,4 & 487,9 & 534,3 & 563,1 & 592,3 & 605,5 & 607,0 & 580,5 \\
\hline Autres exportations & 43,0 & 49,3 & 59,4 & 72,9 & 89,5 & 109,9 & 134,9 & 93,3 \\
\hline Exportations de marchandises aux prix courants & 566,0 & 714,4 & 772,2 & 823,5 & 880,1 & 918,1 & 949,4 & 868,6 \\
\hline \multicolumn{9}{|c|}{ Exportations de marchandises (mrd. FCFA aux prix de 1987) } \\
\hline Cotton fibre & 86,1 & 73,5 & 73,2 & 74,4 & 75,6 & 76,9 & 78,1 & 75,7 \\
\hline Elevage & 13,9 & 10,8 & 11,5 & 12,3 & 13,1 & 14,0 & 14,9 & 13,2 \\
\hline Or & 197,8 & 232,1 & 240,1 & 240,1 & 240,1 & 240,1 & 240,1 & 240,1 \\
\hline Autres exportations & 24,5 & 23,4 & 28,2 & 34,2 & 41,3 & 50,0 & 60,5 & 42,9 \\
\hline Exportations de marchandises aux prix constants & 322,3 & 339,8 & 353,0 & 361,0 & 370,2 & 381,0 & 393,7 & 371,8 \\
\hline Services non-facteurs crédit (mrd. FCFA constants) & 73,7 & 70,5 & 81,2 & 86,6 & 92,5 & 95,2 & 98,4 & 90,8 \\
\hline Services non-facteurs crédit (mrd. FCFA courants) & 129,6 & 148,2 & 177,6 & 197,6 & 220,0 & 229,5 & 237,3 & 212,4 \\
\hline Exportations totales (mrd. FCFA constants) & 396,0 & 410,3 & 434,3 & 447,6 & 462,7 & 476,2 & 492,1 & 462,6 \\
\hline Exportations totales (mrd. FCFA courants) & 695,5 & 862,6 & 949,8 & 1021,1 & 1100,1 & 1147,7 & 1186,7 & 1081,1 \\
\hline TC Exportations march. (prix constants) (\%) & $3,2 \%$ & $2,9 \%$ & $3,9 \%$ & $2,2 \%$ & $2,6 \%$ & $2,9 \%$ & $3,3 \%$ & $3,0 \%$ \\
\hline TC Exportations march. (prix courants) (\%) & $3,7 \%$ & $19,3 \%$ & $8,1 \%$ & $6,6 \%$ & $6,9 \%$ & $4,3 \%$ & $3,4 \%$ & $5,9 \%$ \\
\hline TC Exportations totales (FCFA constants) & $3,6 \%$ & $0,4 \%$ & $5,8 \%$ & $3,1 \%$ & $3,4 \%$ & $2,9 \%$ & $3,3 \%$ & $3,7 \%$ \\
\hline TC Exportations totales (FCFA courants) & $4,2 \%$ & $16,4 \%$ & $10,1 \%$ & $7,5 \%$ & $7,7 \%$ & $4,3 \%$ & $3,4 \%$ & $6,6 \%$ \\
\hline L'indice des prix à l'exportation & 175,6 & 210,2 & 218,7 & 228,1 & 237,8 & 241,0 & 241,2 & 233,4 \\
\hline
\end{tabular}

Table 26: Imports of merchandise (CFAF billion prices current)

\begin{tabular}{|c|c|c|c|c|c|c|c|c|}
\hline & \multirow{2}{*}{\begin{tabular}{|l} 
Average \\
$2002-2005$
\end{tabular}} & \multirow{2}{*}{\begin{tabular}{|l|}
$\mathbf{2 0 0 6}$ \\
Estim.
\end{tabular}} & \multirow{2}{*}{\begin{tabular}{|r|}
2007 \\
Prév.
\end{tabular}} & \multirow{2}{*}{\begin{tabular}{|c|}
2008 \\
Prév.
\end{tabular}} & \multirow{2}{*}{\begin{tabular}{|c|}
2009 \\
Prév.
\end{tabular}} & \multirow{2}{*}{\begin{tabular}{|l|}
2010 \\
Prév.
\end{tabular}} & \multirow{2}{*}{\begin{tabular}{|l}
2011 \\
Prév.
\end{tabular}} & \multirow{2}{*}{$\begin{array}{l}\text { Average } \\
2007-2011\end{array}$} \\
\hline & & & & & & & & \\
\hline Biens alimentaires (prix courants) & 85,4 & 111,7 & 118,0 & 124,2 & 130,5 & 137,5 & 144,9 & 131,0 \\
\hline Machines et véhicules (prix courants) & 124,6 & 102,7 & 111,9 & 121,2 & 131,1 & 142,5 & 155,0 & 132,3 \\
\hline Produits pétroliers (prix courants) & 121,5 & 228,1 & 248,2 & 265,3 & 282,6 & 301,8 & 322,4 & 284,0 \\
\hline Matériaux de construction (prix courants) & 75,8 & 94,2 & 105,0 & 114,8 & 125,2 & 137,0 & 150,1 & 126,4 \\
\hline Produits chimiques (prix courants) & 104,7 & 139,9 & 154,4 & 167,7 & 181,7 & 197,7 & 215,1 & 183,3 \\
\hline Textiles et cuir (prix courants) & 12,4 & 11,2 & 11,3 & 11,5 & 11,7 & 12,0 & 12,2 & 11,8 \\
\hline Autres (prix courants) & 54,9 & 60,6 & 59,8 & 60,0 & 60,2 & 60,4 & 60,7 & 60,2 \\
\hline Total importations marchandises FOB (prix courants) & 579,3 & 748,3 & 808,5 & 864,5 & 922,9 & $\mathbf{9 8 8 , 9}$ & 1060,3 & $\overline{929,1}$ \\
\hline \multicolumn{9}{|c|}{ Importations de marchandises (mrd. FCFA prix de 1987) } \\
\hline Biens alimentaires (prix constants) & 33,3 & 39,2 & 42,2 & 44,5 & 46,8 & 49,4 & 52,1 & 47,0 \\
\hline Machines et véhicules (prix constants) & 49,4 & 36,1 & 40,0 & 43,4 & 47,0 & 51,2 & 55,7 & 47,5 \\
\hline Produits pétroliers (prix constants) & 47,3 & 80,1 & 88,7 & 95,0 & 101,4 & 108,4 & 115,9 & 101,9 \\
\hline Matériaux de construction (prix constants) & 29,7 & 33,1 & 37,5 & 41,1 & 44,9 & 49,2 & 54,0 & 45,3 \\
\hline Produits chimiques (prix constants) & 41,0 & 49,1 & 55,2 & 60,1 & 65,2 & 71,0 & 77,3 & 65,8 \\
\hline Textiles et cuir (prix constants) & 4,9 & 3,9 & 4,0 & 4,1 & 4,2 & 4,3 & 4,4 & 4,2 \\
\hline Autres (prix constants) & 21,6 & 21,3 & 21,4 & 21,5 & 21,6 & 21,7 & 21,8 & 21,6 \\
\hline Total importations marchandises FOB (prix de 1987) & 227,2 & 262,8 & 289,0 & 309,7 & 331,1 & 355,2 & 381,2 & 333,3 \\
\hline Indice des prix à l'importation & 254,3 & 284,8 & 279,7 & 279,1 & 278,8 & 278,4 & 278,1 & 278,8 \\
\hline
\end{tabular}

prix à l'importation

Source: DNPD, modèle MME-DNPD 
Table 27: External aid

\begin{tabular}{|c|c|c|c|c|c|c|c|c|}
\hline & Moyenne & 2006 & 2007 & 2008 & 2009 & 2010 & 2011 & Moyenne \\
\hline en milliards de FCFA & $2002-2005$ & Estim. & Prév. & Prév. & Prév. & Prév. & Prév. & $2007-2011$ \\
\hline Total Aide extérieure financière requise (brut) & 233,0 & $1.490,4$ & 360,4 & 369,5 & 388,5 & 419,4 & 449,1 & 397,4 \\
\hline Total des Dons (BdP, hors Ass.technique et aide en nature) & 104,7 & $1.305,2$ & 167,0 & 162,9 & 167,1 & 179,5 & 191,9 & 173,7 \\
\hline Dons en capital liés aux projets & 68,1 & 186,5 & 93,0 & 102,4 & 110,1 & 119,5 & 129,3 & 110,9 \\
\hline Dons budgétaires globaux & 36,6 & 35,8 & 24,8 & 25,0 & 25,2 & 25,3 & 25,5 & 25,2 \\
\hline Appui budgétaire sectoriel & 0,0 & 47,2 & 49,2 & 35,5 & 31,8 & 34,7 & 37,1 & 37,7 \\
\hline Restructuration dette IADM & 0,0 & $1.035,7$ & 0,0 & 0,0 & 0,0 & 0,0 & 0,0 & 0,0 \\
\hline Total des tirages sur emprunts extérieurs & 100,6 & 159,3 & 182,9 & 196,0 & 210,2 & 227,7 & 246,0 & 212,6 \\
\hline Budgétaires & 21,4 & 48,5 & 30,0 & 30,0 & 30,0 & 30,0 & 30,0 & 30,0 \\
\hline Prêts-projets & 79,1 & 110,8 & 152,9 & 166,0 & 180,2 & 197,7 & 216,0 & 182,6 \\
\hline Remboursements dus sur dette publique & 39,6 & 1071,7 & 34,2 & 34,4 & 36,1 & 37,9 & 41,5 & 36,8 \\
\hline Régulation dette/PPTE & 27,7 & 25,9 & 10,5 & 10,7 & 11,2 & 12,1 & 11,1 & 11,1 \\
\hline Total Aide extérieure financière (hors intérêts) (net) & 165,7 & 392,8 & 315,7 & 324,5 & 341,2 & 369,3 & 396,4 & $\mathbf{3 4 9 , 4}$ \\
\hline Intérêts sur la dette extérieure publique & 16,8 & 14,0 & 12,3 & 10,5 & 10,3 & 9,9 & 9,2 & 10,4 \\
\hline Total Aide extérieure financière (net) & 182,5 & 406,8 & 328,0 & 335,0 & 351,5 & 379,2 & 405,6 & 359,9 \\
\hline \multirow[t]{2}{*}{ Aide à rechercher: gap de financement du Budget } & $\mathbf{0 , 0}$ & 13,8 & $\mathbf{0 , 0}$ & $\mathbf{0 , 0}$ & $\mathbf{0 , 0}$ & $\mathbf{0 , 0}$ & $\mathbf{0 , 0}$ & $\mathbf{0 , 0}$ \\
\hline & Moyenne & & & & & & & Moyenne \\
\hline Aide extérieure (millions \$ E.U.) & $2002-2005$ & 2006 & 2007 & 2008 & 2009 & 2010 & 2011 & $2007-2011$ \\
\hline Total Aide extérieure financière requise (brut) & 407,0 & 2853,8 & 706,7 & 728,6 & 769,3 & 834,0 & 896,6 & $\mathbf{7 8 7 , 0}$ \\
\hline Total des Dons (BdP, hors Ass.technique et aide en nature) & 184,0 & 2499,1 & 327,5 & 321,1 & 330,8 & 357,1 & 383,3 & 343,9 \\
\hline Dons en capital liés aux projets & 118,7 & 357,1 & 182,4 & 201,9 & 218,0 & 237,6 & 258,2 & 219,6 \\
\hline Dons budgétaires globaux & 65,4 & 68,5 & 48,6 & 49,2 & 49,8 & 50,4 & 51,0 & 49,8 \\
\hline Appui budgétaire sectoriel & 0,0 & 90,4 & 96,5 & 70,0 & 63,0 & 69,0 & 74,1 & 74,5 \\
\hline Restructuration dette IADM & 0,0 & 1983,1 & 0,0 & 0,0 & 0,0 & 0,0 & 0,0 & 0,0 \\
\hline Total des tirages sur emprunts extérieurs & 174,8 & 305,0 & 358,7 & 386,5 & 416,2 & 452,8 & 491,2 & 421,1 \\
\hline Budgétaires & 35,5 & 92,9 & 58,8 & 59,2 & 59,4 & 59,7 & 59,9 & 59,4 \\
\hline Prêts-projets & 139,3 & 212,2 & 299,8 & 327,3 & 356,8 & 393,2 & 431,3 & 361,7 \\
\hline Remboursements dus sur dette publique & 68,7 & 2052,0 & 67,1 & 67,8 & 71,5 & 75,4 & 82,9 & 72,9 \\
\hline Régulation dette/PPTE & 48,2 & 49,6 & 20,5 & 21,0 & 22,2 & 24,1 & 22,2 & 22,0 \\
\hline Total Aide extérieure financière (hors intérêts) (net) & 290,1 & 752,1 & 619,1 & 639,8 & 675,6 & 734,5 & 791,6 & 692,1 \\
\hline Intérêts sur la dette extérieure publique & 29,2 & 26,8 & 24,1 & 20,7 & 20,4 & 19,7 & 18,4 & 20,7 \\
\hline Total Aide extérieure financière (net) & 319,3 & $\mathbf{7 7 8 , 9}$ & 643,2 & 660,5 & 696,0 & $\mathbf{7 5 4 , 2}$ & 809,9 & 712,8 \\
\hline \multirow[t]{2}{*}{ Aide à rechercher: gap de financement du Budget } & $\mathbf{0 , 0}$ & 26,4 & $\mathbf{0 , 1}$ & $\mathbf{0 , 0}$ & $-0,1$ & $\mathbf{0 , 0}$ & $-0,1$ & $\mathbf{0 , 0}$ \\
\hline & Moyenne & & & & & & & Moyenne \\
\hline Aide extérieure (millions EURO) & $2002-2005$ & 2006 & 2007 & 2008 & 2009 & 2010 & 2011 & 2007-2011 \\
\hline Total Aide extérieure financière requise (brut) & 355,2 & 2272,1 & 549,4 & 563,3 & 592,2 & 639,4 & 684,6 & 605,8 \\
\hline Total des Dons (BdP, hors Ass.technique et aide en nature) & 159,7 & 1989,8 & 254,6 & 248,3 & 254,7 & 273,7 & 292,6 & 264,8 \\
\hline Dons en capital liés aux projets & 103,8 & 284,3 & 141,8 & 156,1 & 167,8 & 182,2 & 197,1 & 169,0 \\
\hline Dons budgétaires globaux & 55,8 & 54,6 & 37,8 & 38,1 & 38,3 & 38,6 & 38,9 & 38,4 \\
\hline Appui budgétaire sectoriel & 0,0 & 72,0 & 75,0 & 54,1 & 48,5 & 52,9 & 56,6 & 57,4 \\
\hline Restructuration dette IADM & 0,0 & 1578,9 & 0,0 & 0,0 & 0,0 & 0,0 & 0,0 & 0,0 \\
\hline Total des tirages sur emprunts extérieurs & 153,3 & 242,9 & 278,8 & 298,8 & 320,4 & 347,1 & 375,0 & 324,0 \\
\hline Budgétaires & 32,7 & 73,9 & 45,7 & 45,7 & 45,7 & 45,7 & 45,7 & 45,7 \\
\hline Prêts-projets & 120,6 & 168,9 & 233,1 & 253,1 & 274,7 & 301,4 & 329,3 & 278,3 \\
\hline Remboursements dus sur dette publique & 60,3 & 1633,8 & 52,1 & 52,4 & 55,0 & 57,8 & 63,3 & 56,1 \\
\hline Régulation dette/PPTE & 42,3 & 39,5 & 16,0 & 16,3 & 17,1 & 18,5 & 17,0 & 17,0 \\
\hline Total Aide extérieure financière (hors intérêts) (net) & 252,6 & 598,8 & 481,3 & 494,6 & 520,1 & 563,1 & 604,4 & 532,7 \\
\hline Intérêts sur la dette extérieure publique & 25,5 & 21,3 & 18,8 & 16,0 & 15,7 & 15,1 & 14,0 & 15,9 \\
\hline Total Aide extérieure financière (net) & 278,2 & 620,2 & 500,0 & \begin{tabular}{ll|}
510,6 \\
\end{tabular} & 535,8 & 578,2 & 618,4 & 548,6 \\
\hline Aide à rechercher: gap de financement du Budget & $\mathbf{0 , 0}$ & 21,0 & $\mathbf{0 , 0}$ & $\mathbf{0 , 0}$ & $-0,1$ & $\mathbf{0 , 0}$ & $\mathbf{0 , 0}$ & $\mathbf{0 , 0}$ \\
\hline Aide extérieure financière (brut) en \% du PIB & $9,2 \%$ & $46,5 \%$ & $10,5 \%$ & $10,1 \%$ & $10,0 \%$ & $10,0 \%$ & $10,0 \%$ & $10,1 \%$ \\
\hline Aide extérieure financière (net) en \% du PIB & $7,2 \%$ & $12,7 \%$ & $9,6 \%$ & $\mathbf{9 , 2} \%$ & $\mathbf{9 , 0} \%$ & $9,0 \%$ & $\mathbf{9 , 0 \%}$ & $\mathbf{9 , 2} \%$ \\
\hline Aide extérieure (brut) Euro par tête de la population & 31,5 & 190,3 & 45,0 & 45,1 & $\mathbf{4 6 , 4}$ & 48,9 & 51,2 & 47,3 \\
\hline Aide extérieure (net) Euro par tête de la population & 22,4 & $\mathbf{5 0 , 2}$ & 39,4 & 39,6 & 40,7 & 43,1 & 45,2 & 41,6 \\
\hline Aide extérieure financ. (brut) \$ E.U. par tête de la populatio & 36,0 & 239,1 & 57,9 & 58,4 & 60,2 & 63,8 & 67,1 & 61,5 \\
\hline Aide extérieure financ. (net) \$ E.U. par tête de la population & 28,3 & 65,3 & 52,7 & 52,9 & 54,5 & 57,7 & 60,6 & $\mathbf{5 5 , 7}$ \\
\hline
\end{tabular}

Table 28: Private sector disposable income (CFAF billion current)

\begin{tabular}{|l|r|r|r|r|r|r|r|r|}
\hline & Average & $\mathbf{2 0 0 6}$ & $\mathbf{2 0 0 7}$ & $\mathbf{2 0 0 8}$ & $\mathbf{2 0 0 9}$ & $\mathbf{2 0 1 0}$ & $\mathbf{2 0 1 1}$ & Average \\
\cline { 4 - 7 } & $\mathbf{2 0 0 2 - 2 0 0 5}$ & Estim. & Prév. & Prév. & Prév. & Prév. & Prév. & $2007-2011$ \\
\hline Produit intérieur brut aux prix du marché & $\mathbf{2 . 5 5 0 , 3}$ & $\mathbf{3 . 2 0 5 , 8}$ & $\mathbf{3 . 4 1 9 , 4}$ & $\mathbf{3 . 6 5 3 , 0}$ & $\mathbf{3 . 8 9 5 , 0}$ & $\mathbf{4 . 1 9 6 , 9}$ & $\mathbf{4 . 4 9 3 , 8}$ & $\mathbf{3 . 9 3 1 , 6}$ \\
\hline moins Recettes totales de l'Etat & $-438,5$ & $-540,0$ & $-582,4$ & $-718,6$ & $-768,6$ & $-828,5$ & $-896,3$ & $-758,9$ \\
Transferts et subventions de l'Etat & 81,4 & 96,8 & 103,7 & 109,0 & 113,0 & 117,1 & 121,6 & 112,9 \\
Intérêts BCEAO (avance stat. et BDM) & 0,6 & 0,5 & 0,0 & 0,0 & 0,0 & 0,0 & 0,0 & 0,0 \\
Intérêts sur dette publique intérieure (autres) & 1,2 & 1,6 & 1,7 & 1,6 & 1,5 & 1,4 & 1,4 & 1,5 \\
\hline Total Transferts du secteur privé à l'Etat & $\mathbf{3 5 5 , 2}$ & $\mathbf{- 4 4 1 , 1}$ & $\mathbf{- 4 7 7 , 0}$ & $\mathbf{- 6 0 8 , 0}$ & $\mathbf{- 6 5 4 , 1}$ & $\mathbf{- 7 1 0 , 0}$ & $\mathbf{- 7 7 3 , 3}$ & $\mathbf{- 6 4 4 , 5}$ \\
\hline Transferts extérieurs privés nets & 58,1 & 50,0 & 49,4 & 49,7 & 50,1 & 50,5 & 50,9 & 50,1 \\
Revenu services facteurs du secteur privé & $-101,7$ & $-97,2$ & $-87,0$ & $-87,5$ & $-88,2$ & $-88,9$ & $-89,6$ & $-88,2$ \\
\hline Total du revenu extérieur du secteur privén & $\mathbf{- 4 3 , 6}$ & $\mathbf{- 4 7 , 2}$ & $\mathbf{- 3 7 , 5}$ & $\mathbf{- 3 7 , 8}$ & $\mathbf{- 3 8 , 1}$ & $\mathbf{- 3 8 , 4}$ & $\mathbf{- 3 8 , 7}$ & $\mathbf{- 3 8 , 1}$ \\
\hline Total revenu disponible du secteur privé & $\mathbf{2 . 1 5 1 , 5}$ & $\mathbf{2 . 7 1 7 , 5}$ & $\mathbf{2 . 9 0 4 , 9}$ & $\mathbf{3 . 0 0 7 , 2}$ & $\mathbf{3 . 2 0 2 , 9}$ & $\mathbf{3 . 4 4 8 , 5}$ & $\mathbf{3 . 6 8 1 , 8}$ & $\mathbf{3 . 2 4 9 , 1}$ \\
\hline Consommation privée & $1.869,9$ & $2.321,5$ & $2.536,9$ & $2.690,0$ & $2.840,8$ & $3.079,2$ & $3.308,7$ & $2.891,1$ \\
\hline Epargne privée nationale & 281,6 & 396,0 & 368,0 & 317,2 & 362,1 & 369,4 & 373,1 & 357,9 \\
\hline Source: DNPD, modèle MME-DNPD & & & & & & &
\end{tabular}


Table 29: Public sector disposable income (CFAF billion current)

\begin{tabular}{|c|c|c|c|c|c|c|c|c|}
\hline & Average & 2006 & 2007 & 2008 & 2009 & 2010 & 2011 & Average \\
\hline \multirow[b]{2}{*}{ Total des recettes fiscales, non-fisc. et autres } & $2002-2005$ & Estim. & Prév. & Prév. & Prév. & Prév. & Prév. & $2007-2011$ \\
\hline & 438,5 & 540,0 & 582,4 & 718,6 & 768,6 & 828,5 & 896,3 & $\mathbf{7 5 8 , 9}$ \\
\hline Transferts extérieurs officiels & 52,4 & 101,0 & 91,8 & 78,4 & 75,0 & 78,2 & 81,0 & 80,9 \\
\hline Appui budgétaire sectoriel & 0,0 & 47,2 & 49,2 & 35,5 & 31,8 & 34,7 & 37,1 & 37,7 \\
\hline Dons budgétaires (Budget) & 36,6 & 35,8 & 24,8 & 25,0 & 25,2 & 25,3 & 25,5 & 25,2 \\
\hline Autres transferts officiels nets & 15,8 & 18,0 & 17,8 & 17,9 & 18,0 & 18,2 & 18,3 & 18,0 \\
\hline moins Total intérêts dûs sur la dette publique & $-18,6$ & $-16,1$ & $-14,0$ & $-12,1$ & $-11,8$ & $-11,3$ & $-10,6$ & $-12,0$ \\
\hline moins Intérêts BCEAO (avance stat. et BDM) & $-0,6$ & $-0,5$ & 0,0 & 0,0 & 0,0 & 0,0 & 0,0 & 0,0 \\
\hline moins Intérêts sur dette publique intérieure (autres) & $-1,2$ & $-1,6$ & $-1,7$ & $-1,6$ & $-1,5$ & $-1,4$ & $-1,4$ & $-1,5$ \\
\hline moins Intérêts sur dette publique extérieure & $-16,8$ & $-14,0$ & $-12,3$ & $-10,5$ & $-10,3$ & $-9,9$ & $-9,2$ & $-10,4$ \\
\hline Transferts extérieurs officiels nets & 52,4 & 101,0 & 91,8 & 78,4 & 75,0 & $\overline{78,2}$ & 81,0 & 80,9 \\
\hline moins Transferts et subventions de l'Etat au sect. privé & $-81,4$ & $-96,8$ & $-103,7$ & $-109,0$ & $-113,0$ & $-117,1$ & $-121,6$ & $-112,9$ \\
\hline Total revenu disponible du secteur public & 390,9 & 528,1 & 556,5 & 675,8 & 718,8 & 778,3 & 845,1 & 714,9 \\
\hline Consommation publique & 294,3 & 374,6 & 406,6 & 436,5 & 468,8 & 507,4 & 551,5 & 474,2 \\
\hline Epargne publique nationale & 96,5 & 153,5 & 149,9 & 239,3 & 250,0 & 270,9 & 293,6 & 240,7 \\
\hline \multicolumn{9}{|l|}{ Pour mémoire: } \\
\hline PNB ("revenu disponible brut"), prix cour. & $2.542,4$ & $3.245,6$ & $3.461,4$ & $3.683,1$ & $3.921,6$ & $4.226,8$ & $4.526,9$ & $3.964,0$ \\
\hline Amortissements (sur stock de capital total), p.cour. & 89,1 & 134,3 & 131,8 & 143,6 & 156,2 & 170,4 & 187,5 & 157,9 \\
\hline PNN ("revenu disponible net"), prix cour. & $2.453,2$ & $3.111,3$ & $3.329,5$ & $3.539,5$ & $3.765,5$ & $4.056,4$ & $4.339,4$ & $3.806,1$ \\
\hline Revenu disponible brut du secteur privé en $\%$ & $84,7 \%$ & $83,7 \%$ & $83,9 \%$ & $81,7 \%$ & $81,7 \%$ & $81,6 \%$ & $81,3 \%$ & $82,0 \%$ \\
\hline Revenu disponible brut du secteur public en $\%$ & $15,3 \%$ & $16,3 \%$ & $16,1 \%$ & $18,3 \%$ & $18,3 \%$ & $18,4 \%$ & $18,7 \%$ & $18,0 \%$ \\
\hline PNB ("revenu disponible brut"), prix const. & $1.263,5$ & $1.434,8$ & $1.527,7$ & $1.622,0$ & $1.725,6$ & $1.860,0$ & $1.992,9$ & $1.745,6$ \\
\hline PNN ("revenu disponible net"), prix const. & $1.219,0$ & $1.375,4$ & $1.469,5$ & $1.558,8$ & $1.656,9$ & $1.785,0$ & $1.910,3$ & $1.676,1$ \\
\hline PNB ("revenu disp. brut") par tête, en FCFA cour. & 225.403 & 271.899 & 283.555 & 294.994 & 307.057 & 323.478 & 338.567 & 309.530 \\
\hline TC nominal du PNB ("revenu disp. brut") par tête & $4,7 \%$ & $9,5 \%$ & $4,3 \%$ & $4,0 \%$ & $4,1 \%$ & $5,3 \%$ & $4,7 \%$ & $4,5 \%$ \\
\hline PNB ("revenu disp. brut") par tête, en FCFA const. & 112.165 & 120.199 & 125.150 & 129.913 & 135.112 & 142.344 & 149.048 & 136.313 \\
\hline TC réel du PNB ("revenu disp. brut") par tête & $2,7 \%$ & $3,0 \%$ & $4,1 \%$ & $3,8 \%$ & $4,0 \%$ & $5,4 \%$ & $4,7 \%$ & $4,4 \%$ \\
\hline
\end{tabular}

Source: DNPD, modèle MME-DNPD 


\section{$\mathbf{2}^{\text {nd }}$ Generation PRSP $2007-2011$}

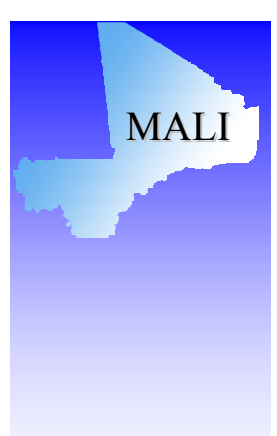

\section{Annex II \\ Overall Medium Term \\ Budgetary Framework \\ (MTBF) \\ 2007 - 2011}

20 December 2006 


\section{Table of Contents}

1 PUBLIC FINANCE AND BUDGET MANAGEMENT REFORMS

$2 \quad$ TREND OF STATE BUDGET $2002-2006 \quad 8$

3 MACRO-BUDGETARY FRAMEWORK 2007-2011 13

3.1 BUdGETARY RESOURCES 2007-2011

3.2 BUDGETARY EXPENDITURES 2007-2011

3.3 BUDGETARY RESOURCES AND APPLICATION OF FUNDS 2007-2011

4 BUDGETARY ALLOCATIONS BY TYPE OF EXPENDITURE 2007-2011

5 SECTORAL BUDGETARY ALLOCATIONS 2007-2011

$\begin{array}{lll}5.1 & \text { OVERVIEW } & 29\end{array}$

$\begin{array}{lll}5.2 & \text { EDUCATION } & 31\end{array}$

5.2.1 Basic Education Component 31

5.2.2 General Secondary Education (ESG), Technical and Vocational Education (ETP), and Apprenticeship

Component

5.2.3 Higher Education and Research Component $\quad 35$

$\begin{array}{lr}\text { 5.2.4 General Administration Component } & 35\end{array}$

5.3 HEALTH

5.3.1 Sub-Component 1: Geographic accessibility to health services in health districts: 37

5.3.2 Sub-Component: Availability, Quality and Management of Human Resources 37

5.3.3 Sub-Component 3: Availability of Drugs, Vaccines and Medical Consumables 37

5.3.4 Sub-Component 4: Improvement of quality of health services, increase in demand and control of diseases 37

5.3.5 Sub-Component 5: Financial accessibility and support to demand and participation 38

5.3.6 Sub-component 6: Reform of hospital and other research institutions 38

5.3.7 Sub-Component 7: Institutional capacity building and decentralization 38

5.4 OTHER SOCIAL SECTORS 38

5.4.1 Sub-Component 1: Strengthening of Solidarity and Fight against Exclusion 39

5.4.2 Sub-component 2: Poverty Reduction 39

5.4.3 Sub-Component 3: Reinforcement of Social Security 39

5.4.4 Sub-Component 4: Institution Building 39

5.4.5 Sub-Component 5: Human Resource Development 40

5.5 CONDITIONS FOR BUdGET SUPPORT (SOCIAL SECTOR) 40

5.6 CULTURE, YOUTH AND SPORTS 44

5.6.1 Pillar I: Socio-education supervision of youths:

5.6.2 Pillar II: Youths and Social Vulnerability: 44

5.6.3 Pillar III: Youths and Socio-economic Integration:

5.6.4 Pillar IV: Capacity building for youth associations in mobilization, citizenship and participation in public life

5.6.5 Pillar V: Institution Building

5.7 RURAL DEVELOPMENT AND ENVIRONMENT

5.8 TRANSPORT

5.8.1 Pillar 1: Internal accessibility of Mali-Rural Transport (roads - river ways) 46

5.8.2 Pillar 2: Internal Accessibility of Mali - urban and interurban transport (Roads, Rail, Air) 47

5.8.3 Pillar 3: External Accessibility of Mali (Roads-Rail-Air) 47

5.8.4 Pillar 4: Maintain and preserve infrastructure and equipment of the rural network (roads - river ways) 48

5.8.5 Pillar 5: Maintain and preserve infrastructures and equipment of the urban network 49

5.8.6 Pillar 6: Maintain and preserve infrastructures and equipment of the interurban network 49

5.8.7 Pillar 7: Capacity building for the institution and human resources 49

5.8.8 Pillar 8: Improve levels of services, safety and security of transport and performance of BET/PME 50

5.9 TOWN PLANNING AND PUBLIC WORKS

$\begin{array}{lll}5.10 & \text { COMMUNICATION } & 51\end{array}$

5.11 ARMED FORCES AND SECURITY

$\begin{array}{lll}\text { 5.11.1 Armed Forces } & 51\end{array}$

5.11.2 Internal Security and Civil Protection 51

5.12 DEBT - PRINCIPAL AND INTEREST

5.13 MINING - WATER RESOURCES AND INDUSTRY

$\begin{array}{llr}5.13 .1 \quad M i n i n g & 52\end{array}$

$\begin{array}{ll}5.13 .2 & 52\end{array}$ 
$\begin{array}{lll}\text { 5.13.3 Water } & 53\end{array}$

5.14 PUBLIC AUTHORITIES AND ADMINISTRATION

5.15 DIPLOMACY AND FOREIGN AFFAIRS

6 ANNEXES

6.1 ANNEX 1: Presentation OF THE OPERATIONALIZATION AND INTERNALIZATION LOGICAL FramEWORK OF THE MTBF PROCESS

6.2 AnNex 2: Some Projects illustrating EXtension of Projects/Programmes 59

6.3 ANNEX 3: CONTRIBUtion OF MALIAN Mining COMPANIES TO BUdGETARY REVENUE 2002-2006 60

\section{Table of Tables}

TABLE 1: GOVERNMENT FlOW OF FundS TABLE (GFFT) 2002-2006 IN CFAF BILLION 9

TABLE 2: MACRO-BUDGETARY PERFORMANCE 2002-2006 10

TABLE 3: COMPARISON OF BUDGETARY ALLOCATIONS (INCLUDING EXTERNAL FINANCING) AND BREAKDOWN OF BUDGETARY EXPENDITURES IN THE PRSP: 2002-2006

TABLE 4: COMPARISON OF EXTERNAL FINANCING OF FINANCE LAW AND PRSP (2002 - 2005) IN CFAF BILLION

TABLE 5: TOTAL REVENUE 2006-2011 (DGB PRESENTATION) (IN CFAF BILLION) 14

TABLE 6: BUDGETARY REVENUE BY DEPARTMENT 2006-2011 (IN CFAF BILLION) 14

TABLE 7: TOTAL REVENUE 2006-2011 IN CFAF BILLION

TABLE 8: TOTAL EXPENDitURE 2006-2011 (DGB PRESENTATION) IN CFAF BILLION 16

TABLE 9: TRANSITION FROM DGB PRESENTATION (FINANCE LAW) TO GFFT 17

TABLE 10: BUdGETARY EXPENDITURE 2006-2011 (GFFT PRESENTATION) 18

TABLE 11 : BREAKDOWN OF BUdGet SuPPORT BY PROGRAMME IN CFAF 18

TABLE 12: BudgetARY RESOURCES AND APPLICATION OF FUNDS (GFFT) OF PRSP 2006-2011 IN CFAF BILLION 19

TABLE 13: EXPECTED MACRO-BUdGETARY PERFORMANCE 2006-2011 20

TABLE 14: Budget BREAKDOWN By TyPe (DGB PRESENTATION) (IN CFAF BILLION) 2006 - 2011

TABLE 15: TREND OF TRANSFER EXPENDITURES 2006-2011 (IN CFAF BILLION) 24

TABLE 16: TREND OF HIPC EXPENDITURES 2006-2011 (IN CFAF BILLION) 25

TABLE 17: SECTORAL BREAKDOWN OF PROJECTS AND PROGRAMMES 26

TABle 18: AVERAge Project ANd Programmes Duration 26

TABle 19: Some Projects AND PRogrammes following EXTENSIONS OF COMPLETION DATES (IN CFAF MILliON) 26

TABLE 20: BREAKDOWN OF BSI (EXTERNAL FINANCING) BY AREA OF INTERVENTION 2006-2008 28

TABLE 21: SECTORAL BREAKDOWN OF EXPENDITURES (DGB PRESENTATION) 2006-2011 IN CFAF BILLION 29

TABLE 22: SECTORAL BREAKDOWN OF EXPENDITURES 2006-2011 IN \% OF GDP 29

TABLE 23: SECTORAL BREAKDOWN OF EXPENDITURES 2006-2011 IN \% OF TOTAL 30

TABLE 24: OVERALL RATIOS BY SECTOR 2006-2011 30

TABLE 25: RECURRENT COST RATIOS BY SECTOR 2006-2011 30

TABLE 26: TREND OF EDUCATION EXPENDITURE 2006-2011 (IN CFAF BILLION) 31

TABLE 27: TREND OF HEALTH EXPENDITURES (IN CFAF BILLION) 36

TABLE 28: COMMON CONDITIONS FRAMEWORK (EDUCATION) 41

TABLE 29: COMMON CONDITIONS FRAMEWORK (HEALTH AND SOCIAL) 42

TABle 30: TREND of Budgetary EXPENDiture On DeCENTRALIZATION (IN CFAF THOUSAND) 55

TABLE 31: BUdGET TIMETABLE

TABle 32: Some Projects illustrating EXTEnsions of Projects/Programmes 59

TABLE 33: SHARE OF MINING COMPANIES IN REVENUE OF DIRECTORATE GENERAL OF TAXES FROM 1 JANUARY 2002 TO 31 MARCH 2006 (IN CFAF BILLION) $\quad 61$

Table 34: Situation of Gold Production, Payment of Dividends AND Ad Valorem Tax to DNDC 62

TABLE 35: CONTRIBUTION OF THE MINING SECTOR TO THE REVENUE OF DNDC FROM 1 JANUARY 2002 TO 31 MARCH 2006 (IN CFAF BILLION)

TABLE 36: EXEMPTIONS GRANTED TO MINING COMPANIES FROM 2002 TO 2005 (IN CFAF BILLION) 63

TABLE 37: CONTRIBUTION OF MINING SECTOR TO STATE BUDGETARY REVENUE FROM 1 JANUARY 2002 TO 31 MARCH 2006 (IN CFAF BILLION) 


\section{ACRONYMS}

\begin{tabular}{|c|c|}
\hline $\mathrm{AE}$ & Académie d’Enseignement (Education Academy) \\
\hline AGEROUTE & Agence d'Exécution des Travaux Routiers (Road Works Agency) \\
\hline ANICT & Agence Nationale d'Investissement des Collectives Territoriales \\
\hline APC & Skills Approach \\
\hline AR & Road Authority \\
\hline ARV & Anti-retrovirals \\
\hline BCEAO & Central Bank of West African States \\
\hline BRVM & Regional Stock Exchange \\
\hline CAD/DE & Decentralization/Education Decentralization Support Unit \\
\hline CAF & Functional Literacy Centre \\
\hline CAFÉ & Women's Apprenticeship Training Centre \\
\hline CAP & Certificat d'Aptitude Professionnelle (Vocational School Certificate) \\
\hline CAP & Centre d'Animation Pédagogique (Teachers' Training Centre) \\
\hline CDI & Documentation and Information Centre \\
\hline CED & Development Education Centre \\
\hline CFAF & Franc of the African Financial Community \\
\hline CNPAM & Conseil National des Personnes Agées du Mali \\
\hline COMANAV & Compagnie Malienne de Navigation \\
\hline CPS & Planning and Statistics Unit \\
\hline CSAR & Revitalized District Health Centre \\
\hline CSC & District Health Centre \\
\hline CSCOM & Community Health Centre \\
\hline CSREF & Referral Health Centre \\
\hline DEF & Diplôme d'Études Fondamentales (Primary School Certificate) \\
\hline DGABE & Directorate General of Administration of State Property \\
\hline DGB & Directorate General of the Budget \\
\hline DGD & Directorate General of Customs \\
\hline DGDP & Directorate General of Public Debt \\
\hline DGI & Directorate General of Taxes \\
\hline DGMP & Directorate General of Public Procurements \\
\hline DNDC & National Directorate of Lands and Survey \\
\hline DNGM & National Directorate of Geology and Mines \\
\hline DNM & National Directorate of Mines \\
\hline DNPD & National Directorate of Planning and Development \\
\hline DNR & National Highways Directorate \\
\hline DNSI & National Directorate of Statistics and Data Processing \\
\hline DNTCP & National Directorate of the Treasury and Public Accounting \\
\hline DTCP & Diphtheria Tetanus Whooping Cough Polio \\
\hline EAC & Enquête Agricole et de Conjoncture \\
\hline EBES & Children with Special Education Needs \\
\hline ECOWAS & Economic Community of West African States \\
\hline EDSM & Enquête Démographique et de Santé/Mali \\
\hline EMEP & Enquête Malienne d'Évaluation de la Pauvreté \\
\hline $\mathrm{EPH}$ & Public Hospital Institution \\
\hline FAFPA & Fonds d'Appui à la Formation Professionnelle et à l'Apprentissage \\
\hline FAM & Medical Assistance Fund \\
\hline GD & Generic Drugs \\
\hline GDP & Gross Domestic Product \\
\hline GFCF & Gross Fixed Capital Formation \\
\hline GFFT & Government Flow of Funds Table \\
\hline HIPC & Heavily Indebted Poor Countries \\
\hline I/BIC & Corporate Tax \\
\hline IAS & Social Affairs Inspection \\
\hline $\mathrm{ICO}$ & Islamic Conference Organization \\
\hline IGM & Institut Géographique du Mali (Geograp \\
\hline
\end{tabular}




$\begin{array}{ll}\text { IMF } & \text { International Monetary Fund } \\ \text { INFET } & \text { National Equipment and Transport Training Institute } \\ \text { IRVM } & \text { Securities Income Tax } \\ \text { LA } & \text { Local Authority } \\ \text { LSI } & \text { Light and Sound Indicators } \\ \text { MDRI } & \text { Multilateral Debt Relief Initiative } \\ \text { MDSSPA } & \text { Ministry of Social Development, Solidarity and Old Persons } \\ \text { MEF } & \text { Ministry of the Economy and Finance } \\ \text { MEFP } & \text { Ministry of Employment and Vocational Training } \\ \text { MEN } & \text { Ministry of National Education } \\ \text { MME_DNPD } & \text { Macro-Economic Model of Mali by DNPD } \\ \text { MPAT } & \text { Ministry of the Plan and Territorial Development } \\ \text { MS } & \text { Ministry of Health } \\ \text { MTBF } & \text { Medium Term Budgetary Framework } \\ \text { MTEF } & \text { Medium Term Expenditure Framework } \\ \text { PAGAMGFP } & \text { Government Action Plan for the Improvement and Modernization of } \\ & \text { Public Finance Management } \\ \text { PARAD } & \text { Administrative Reform and Decentralization Support Programme } \\ \text { PASAOP } & \text { Agricultural Services and Farmer Organizations Support Programme } \\ \text { PDDSS } & \text { Ten-year Socio-Health Development Plan } \\ \text { PDI } & \text { Institutional Development Programme } \\ \text { PDS } & \text { Health Development Project } \\ \text { PISE } & \text { Education Sector Investment Programme } \\ \text { PMA } & \text { Minimum Activities Package } \\ \text { PNG } & \text { Government Net Position } \\ \text { PNIR } & \text { National Rural Infrastructure Programme } \\ \text { PRODEC } & \text { Ten-year Education Development Programme } \\ \text { PRODEJ } & \text { Ten-year Justice Development Programme } \\ \text { PRODESS } & \text { Social and Health Development Programme } \\ \text { PRSP } & \text { Poverty Reduction Strategy Paper } \\ \text { RNDB } & \text { Gross National Disposable Income } \\ \text { SiSo } & \text { Social Information System } \\ \text { SPB } & \text { Special Capital Budget } \\ \text { VAT } & \text { Value Added Tax } \\ \text { WAEMU } & \text { West African Economic and Monetary Union } \\ & \end{array}$




\section{Public Finance and Budget Management Reforms}

1. During PRSP I, significant progress was made in public finance management, as well as macro-economic and macro-budget planning through: (i) implementation of Programme Budgets (MTEF); (ii) implementation of expenditure procedures manuals; (iii) interconnection of computer networks of administrative services responsible for implementing the State Budget; (iv) introduction of a new budget nomenclature and reinforcement of controls; (v) establishment of a macro-economic and macro-budget model, as well as the creation of a Forecasts and Modelling Committee in 2003.

2. With respect to public expenditure, stringent management helped to maintain the budget position in line with the objectives of the IMF programme. Recurrent and capital expenditure was maintained within the limits of the programme. Delays in disbursements of external aid led to a decline in the volume and rate of implementation of the Special Investment Budget (BSI).

3. Throughout PRSP I, Mali complied with most of the WAEMU convergence criteria (base budget balance excl. HIPC, public investment rate, inflation rate, wage bill in percentage of budgetary revenue). However, this could not significantly reduce the level of poverty mainly because of the inadequate level of growth. Non-compliance with the tax pressure rate criterion show that considerable efforts still have to be made in the mobilization of internal budgetary resources.

4. In April 2005, the Government adopted a Government Action Plan for the Improvement and Modernization of Public Finance Management (PAGAMGFP). In this connection, actions will be undertaken to: (i) adapt and modernize the General Public Finance Framework, (ii) enhance governance and transparency, (iii) increase the efficiency of tax and financial administrations, (iv) increase the quality of budget preparation and implementation, (v) include external financing in national budget procedures, (vi) interconnect computerized public expenditure management systems, (vii) improve the performance of Departments of Administrative and Financial Affairs (DAF), (viii) enhance the efficiency of public procurements, and (ix) provide continuous training to financial employees.

5. Sustainable improvement of the Government's financial situation will remain a key component of budget management. The objective is to contain the overall deficit of the Government's financial operations to a sustainable level, while taking charge of pressing needs in priority sectors, as well as to create a "budget space" for achieving poverty reduction objectives.

6. The budget policy will continue to be marked by adjustment efforts to: (i) improve revenue, (ii) control public expenditure, and (iii) search for external financing in accordance with budget support conditions and the conclusions of the Geneva Round Table in March 2004.

7. Budget support is the instrument for financial cooperation between the Government of Mali and the Technical and Financial Partners, which makes it possible to: (i) better coordinate their activities, (ii) gradually replace the multiplicity of donor procedures with national procedures, and (iii) consider concrete means of harmonizing programmes and procedures, so as to prepare a gradual reorientation of part of international aid in the form of programme aid transiting through the budget.

8. This Medium Term Budgetary Framework contributes to the improvement of budget management by providing a document that gives a vision of the trend of medium-term revenue and expenditure so as to: (i) strengthen the results-based management mechanisms, (ii) seek greater efficiency in expenditure, and (iii) have a support tool for 
decision-making and negotiation with development partners in the search for financing for development programmes.

9. The Medium Term Budgetary Framework is the principal means of operationalizing the PRSP document. This framework determines budgetary aggregates in line with the macroeconomic framework and strategies and guidelines defined in the PRSP. The MTBF presents the macro-economic framework on the basis of which the budget programming of revenue and expenditure is conducted. It determines the overall sector allocations, as well as the policies of strategies and actions envisaged in the various sectors.

10. Estimates of total expenditure and net loans are fully consistent in the macro-economic framework and overall MTBF. The macro-budgetary framework provides for an increase in total expenditure and net loans at an average annual rate of $7.1 \%$ to CFAF $1,216.7$ billion in 2011. Budgetary expenditure will represent an average of $28.1 \%$ of GDP, as against $27.5 \%$ of GDP over the 2002-2005 period. These indicators reflect a prudent budget policy, based on the mobilization of national resources. Emphasis will be laid on the search for greater efficiency in expenditure, which could be achieved through deconcentration of budgetary allocations at the operational level so as to further increase the impact of Government interventions on the living conditions of the populations.

11. The results of the MME_DNPD voluntarist scenario show total revenue (excluding grants) of CFAF 896.3 billion in 2011, as against CFAF 540.0 in 2006, representing an average annual increase rate of $10.7 \%$ (as against $13.0 \%$ in 2002-2005). Tax revenue would increase at an average annual rate of $10.5 \%$. Consequently, the tax pressure rate would improve rapidly, and stand at 17\% as from 2008 (an average of 16.6\% between 2007 and 2011), as against an average of 14.6\% between 2002 and 2005. The Community standard would therefore be respected as from 2008. The base macro-economic scenario stems from the more modest assumption that the tax pressure rate would increase gradually to $17 \%$ in 2011 .

12. As for the wage bill, it would increase from CFAF 149 billion in 2006 to CFAF 222.6 billion in 2011, representing an average increase rate of $8.4 \%$ as against $12.6 \%$ in 2002 2005. It would account for an average of $29.2 \%$ of tax revenue between 2007 and 2011, as against $30.7 \%$ between 2002 and 2005. Consequently, the WAEMU target of less than $35 \%$ would be amply achieved. This also applies to the base budget balance target, which should be positive. The ratio of this balance to GDP stands at an average annual rate of $0.9 \%$ in $2007-2011$ as against $0.2 \%$ between 2002 and 2005 . The third WAEMU criterion is also observed, namely the ratio of public investments financed by internal resources to GDP, which is fixed at a minimum of $20 \%$. Budget estimates show an average ratio of $22.5 \%$ over the $2007-2001$ period, as against $21.9 \%$ in $2002-2005$. 


\section{TRend of State Budget 2002 - 2006}

13. The budget policy over the 2002-2006 period was aimed at containing budget deficit and making significant public investments, to ensure recovery of economic activities and improvement of the living conditions of the population.

14. The period was marked by a low taxing rate by assessment services; the tax pressure rate was $13.8 \%$ in 2002 and $14.7 \%$ in 2006 . The total revenue and grants increased from CFAF 456.7 billion in 2002 to CFAF 1,740 billion in 2006 because of the restructuring of the MDRI debt $(1,035.7)$, while the total expenditure and net loans increased from CFAF 541 billion in 2002 to CFAF 865.6 billion in 2006. This expenditure trend is due to poverty reduction expenditure and exceptional expenditures.

15. Public finance adjustment efforts increased the primary budget balance deficit from CFAF 29.8 billion in 2002 to CFAF 44.9 billion in 2006. As for the overall balance commitment base, it has continued to record a deficit from CFAF 84.3 billion in 2002 to CFAF 874.4 billion in 2006.

16. Budget allocations in the Finance Law increased from CFAF 679.3 billion to CFAF 935.8 billion in 2006, representing an average increase of $8.3 \%$ over the $2002-2006$ period. The implementation level of budget allocations rose from CFAF 591.6 billion in 2002 to CFAF 774.1 billion in 2005, representing an average increase of $9.5 \%$.

17. The external financing of the Finance Law increased from CFAF 208.3 billion in 2002 to CFAF 231.6 billion in 2006, representing an average increase of 3.6\%. Its implementation level rose from CFAF 140.7 billion in 2002 to CFAF 179.8 billion in 2005, representing an average increase of $9.2 \%$.

18. Between 2000 and 2005, Mali obtained a total HIPC debt relief of CFAF 141.97 billion, comprising CFAF 29.05 billion for the IMF, CFAF 48.57 billion for IDA, CFAF 16.66 billion for the Paris Club, and CFAF 26.83 billion for ADB/ADF. 
Table 21: Government Flow of Funds Table (GFFT) 2002-2006 in CFAF billion

\begin{tabular}{|c|c|c|c|c|c|}
\hline & 2002 & 2003 & 2004 & 2005 & 2006 \\
\hline Total revenue and grants & 456.7 & 534.0 & 557.9 & 621.6 & $1,740.0$ \\
\hline Total revenue & 370.9 & 421.7 & 454.6 & 506.6 & 540.0 \\
\hline Budgetary revenue & 337.2 & 384.3 & 412.0 & 461.3 & 497.5 \\
\hline Tax revenue & 306.0 & 349.1 & 393.3 & 446.2 & 469.9 \\
\hline Additional measures & 0.0 & 0.0 & 0.0 & 0.0 & \\
\hline Non-tax revenue & 31.2 & 35.2 & 18.7 & 15.1 & \\
\hline Sp. Fd \& suppl. Budgets Revenue & 33.7 & 37.4 & 42.6 & 45.3 & 42.5 \\
\hline Grants & 85.8 & 112.3 & 103.3 & 115.0 & $1,200.0$ \\
\hline Grants for projects & 69.2 & 60.7 & 70.0 & 70.0 & 81.3 \\
\hline Budgetary grants & 16.6 & 51.6 & 33.3 & 45.0 & 35.8 \\
\hline Sectoral budget support & 0.0 & 0.0 & 0.0 & 0.0 & 47.2 \\
\hline MDRI debt restructuring & 0.0 & 0.0 & 0.0 & 0.0 & $1,035.7$ \\
\hline Expenditure and net loans & 541.0 & 552.0 & 626.1 & 714.9 & 865.6 \\
\hline Budgetary expenditures & 512.2 & 518.5 & 592.5 & 646.9 & 828.7 \\
\hline Current expenditures & 309.2 & 316.9 & 350.3 & 378.8 & 427.0 \\
\hline Salaries & 93.5 & 106.2 & 121.7 & 137.8 & 149.0 \\
\hline Goods and services & 109.0 & 107.7 & 136.5 & 140.9 & 161.1 \\
\hline Transfers and subsidies & 87.8 & 83.8 & 74.5 & 79.6 & 96.8 \\
\hline Interests due & 18.9 & 19.2 & 17.6 & 20.5 & 20.1 \\
\hline Internal debt & 2.1 & 3.3 & 1.5 & 2.3 & 2.6 \\
\hline External debt & 16.8 & 15.9 & 16.1 & 18.2 & 17.5 \\
\hline Capital expenditure & 203.0 & 201.6 & 242.2 & 268.1 & 401.7 \\
\hline External financing & 140.3 & 123.3 & 152.8 & 170.0 & 280.7 \\
\hline Borrowings & 71.1 & 62.6 & 82.8 & 100.0 & 152.2 \\
\hline Overall grants & 69.2 & 60.7 & 70.0 & 70.0 & 81.3 \\
\hline Sectoral budget support & 0.0 & 0.0 & 0.0 & 0.0 & 47.2 \\
\hline Internal financing 1) & 62.7 & 78.3 & 89.4 & 98.1 & 121.0 \\
\hline Sp. Fd \& Suppl. Budgets Expend. & 33.7 & 37.4 & 42.6 & 45.3 & 42.5 \\
\hline Net loans & -4.9 & -3.9 & -9.0 & 22.7 & -5.6 \\
\hline Primary budget balance (IMF 2) & -29.8 & -7.0 & -18.7 & -38.3 & -44.9 \\
\hline Overall balance (commits, excl. grants) & -170.1 & -130.3 & -171.5 & -208.3 & -325.6 \\
\hline Overall balance (commitments) & -84.3 & -18.0 & -68.2 & -93.3 & 874.4 \\
\hline Adjustment & -1.5 & 11.0 & 7.9 & -10.3 & 0.0 \\
\hline Overall balance (cash base \& excl. grants) & -171.6 & -119.3 & -163.6 & -218.6 & -325.6 \\
\hline Overall balance (cash base) & -85.8 & -7.0 & -60.3 & -103.6 & 874.4 \\
\hline FINANCING & 85.8 & 7.0 & 60.3 & 103.6 & 874.4 \\
\hline Net external financing & 88.5 & 90.8 & 74.5 & 103.4 & -845.1 \\
\hline Borrowings & 102.6 & 97.5 & 82.8 & 119.36 & 200.7 \\
\hline Projects & 71.1 & 62.6 & 82.8 & 100.30 & 152.2 \\
\hline Budgetary loans & 31.5 & 34.9 & 0.0 & 19.3 & $-1,071.7$ \\
\hline Amortization & -41.6 & -36.8 & -37.0 & -40.5 & 25.9 \\
\hline Debt/HIPC settlement & 27.5 & 30.1 & 28.7 & 24.6 & \\
\hline Net internal financing & -2.7 & -83.8 & -14.2 & 0.1 & -43.1 \\
\hline Bank (net) & -9.9 & -49.6 & 14.4 & 33.1 & -34.0 \\
\hline Privatization revenue & 29.4 & 1.0 & 1.2 & 9.7 & 8.1 \\
\hline Other financing & -22.2 & -35.2 & -29.8 & -42.7 & -7.2 \\
\hline Gov't financing gap (+=deficit) & 0.0 & 0.0 & 0.0 & 0.0 & 13.8 \\
\hline
\end{tabular}

2) Banking sector and private sector

3) Revenue (excl. grants) less total expenditure (incl. net loans) (excl. capital expenditure with external financing) Source: DGD/DNPD 
Table 22: Macro-budgetary Performance 2002-2006

\begin{tabular}{|c|c|c|c|c|c|}
\hline & 2002 & 2003 & 2004 & 2005 & 2006 \\
\hline Resources and Appl. of Funds for Goods \& services & Réal. & Réal. & Réal. & Prov. & Estim. \\
\hline GDP at market prices (current CFAF billion) & $2,222.7$ & $2,453.6$ & $2,632.1$ & $2,892.9$ & $3,205.8$ \\
\hline Real growth rate of GDP at market prices & $4.4 \%$ & $7.7 \%$ & $2.8 \%$ & $6.1 \%$ & $3.6 \%$ \\
\hline Fixed investment rate GFCF/GDPm) & $19.8 \%$ & $18.0 \%$ & $17.0 \%$ & $15.4 \%$ & $20.9 \%$ \\
\hline -Public GFCF in \% of GDPm & $7.8 \%$ & $7.5 \%$ & $7.4 \%$ & $6.9 \%$ & $10.0 \%$ \\
\hline -Private GFCF in $\%$ of GDPm & $12.0 \%$ & $10.5 \%$ & $9.6 \%$ & $8.5 \%$ & $11.0 \%$ \\
\hline Consumption rate (in $\%$ of GDPm) & $85.7 \%$ & $81.5 \%$ & $86.2 \%$ & $85.9 \%$ & $84.1 \%$ \\
\hline -Private consumption rate & $75.2 \%$ & $70.0 \%$ & $74.4 \%$ & $74.1 \%$ & $71.2 \%$ \\
\hline -Public consumption rate & $10.5 \%$ & $11.5 \%$ & $11.8 \%$ & $11.7 \%$ & $12.9 \%$ \\
\hline Per capita Gross National Product in current CFAF & 199,502 & 223,302 & 230,402 & 247,176 & 269,324 \\
\hline Per capita real growth rate of Gross National Product & $0.1 \%$ & $8.6 \%$ & $-1.7 \%$ & $3.4 \%$ & $2.5 \%$ \\
\hline Public Finances & 2002 & 2003 & 2004 & 2005 & 2006 \\
\hline Tax pressure rate (=Tax revenue/GDPm) & $13.8 \%$ & $14.2 \%$ & $14.9 \%$ & $15.4 \%$ & $14.7 \%$ \\
\hline Tax rate (current revenue, excl. grants, in \% of GDP) & $16.7 \%$ & $17.2 \%$ & $17.3 \%$ & $17.5 \%$ & $16.8 \%$ \\
\hline Tax rate (current revenue in \% of GDP formal sector) & $45.0 \%$ & $52.6 \%$ & $46.1 \%$ & $47.3 \%$ & $49.0 \%$ \\
\hline Total expenditure and net loans, in \% of GDP & $24.3 \%$ & $22.5 \%$ & $23.8 \%$ & $24.7 \%$ & $27.0 \%$ \\
\hline Balance of current operations (national public savings) in $\%$ of GDP & $5.9 \%$ & $8.2 \%$ & $7.3 \%$ & $7.8 \%$ & $40.5 \%$ \\
\hline Balance of current operations (own savings) in $\%$ of GDP & $2.8 \%$ & $4.3 \%$ & $4.0 \%$ & $4.4 \%$ & $3.5 \%$ \\
\hline Primary budget balance (IMF) in \% of GDP & $1.0 \%$ & $2.0 \%$ & $1.6 \%$ & $1.0 \%$ & $0.6 \%$ \\
\hline Primary budget balance (WAEMU) in $\%$ of GDP & $-0.1 \%$ & $0.9 \%$ & $0.4 \%$ & $-0.5 \%$ & $-0.6 \%$ \\
\hline Total balance (commitment base) excl. grants in $\%$ of GDP & $-7.7 \%$ & $-5.3 \%$ & $-6.5 \%$ & $-7.2 \%$ & $-10.2 \%$ \\
\hline Total balance (cash base) in \% of GDP & $-3.9 \%$ & $-0.3 \%$ & $-2.3 \%$ & $-3.6 \%$ & $27.3 \%$ \\
\hline External Aid & 2002 & 2003 & 2004 & 2005 & 2006 \\
\hline External aid (gross) in \% of GDP & $9.7 \%$ & $9.8 \%$ & $8.2 \%$ & $9.0 \%$ & $46.5 \%$ \\
\hline External aid (gross) in US\$ million & 310.8 & 413.8 & 407.1 & 496.5 & 2853.8 \\
\hline WAEMU Convergence Criteria & 2002 & 2003 & 2004 & 2005 & 2006 \\
\hline \multicolumn{6}{|l|}{ First rank criteria } \\
\hline Base budget balance/GDPm ratio $>=0$ & $-0.1 \%$ & $0.9 \%$ & $0.4 \%$ & $-0.5 \%$ & $-0.6 \%$ \\
\hline Inflation rate (IHPC Bamako) $<=3 \%$ & $5.1 \%$ & $-1.3 \%$ & $-3.1 \%$ & $6.4 \%$ & $2.4 \%$ \\
\hline Outstanding internal and external debt/GDPm ratio $<=70 \%$ & $0.0 \%$ & $0.0 \%$ & $0.0 \%$ & $0.0 \%$ & $0.0 \%$ \\
\hline Incl. outstanding external debt/GDPm & $74.2 \%$ & $59.0 \%$ & $63.9 \%$ & $60.0 \%$ & $23.3 \%$ \\
\hline Variation of internal arrear payments (in CFAF billion) $<=0$ & 0.0 & 0.0 & 0.0 & 0.0 & 0.0 \\
\hline Variation of external arrear payments (in CFAF billion) $<=0$ & 0.0 & 0.0 & 0.0 & 0.0 & 0.0 \\
\hline Second rank criteria & 0.0 & 0.0 & 0.0 & 0.0 & \\
\hline Wage bill/tax revenue ratio $<=35$ & $30.6 \%$ & $30.4 \%$ & $30.9 \%$ & $30.9 \%$ & $31.7 \%$ \\
\hline Public investments financed with internal resources/tax revenue ratio $>=20 \%$ & $20.5 \%$ & $22.4 \%$ & $22.7 \%$ & $22.0 \%$ & $25.8 \%$ \\
\hline Current external deficit excl. public transfers/GDPm ratio $<=5 \%$ & $-6.1 \%$ & $-9.2 \%$ & $-10.2 \%$ & $-9.1 \%$ & $-7.4 \%$ \\
\hline Tax pressure rate $(=$ Tax revenue $/ \mathrm{GDPm})>=17 \%$ & $13.8 \%$ & $14.2 \%$ & $14.9 \%$ & $15.4 \%$ & $14.7 \%$ \\
\hline
\end{tabular}

1) Revenue (excl. grants) less total expenditure (incl. net loans) (excl. capital expenditure with external financing and excl. HIPC) /GDPm

2) Here only BSI investment.

Source: DNPD/DGB 


\begin{tabular}{|c|c|c|c|c|c|c|c|c|c|c|c|c|c|c|c|c|c|c|}
\hline 0 & త్ర & 10 & 0 & 0 & & 0 & lo & 100 & & 010 & & 0 & 0 & 100 & 00 & 10 & & 0 \\
\hline $\begin{array}{l}\text { مे } \\
\stackrel{6}{\prime} \\
=\end{array}$ & 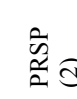 & & $\mid \begin{array}{l}\vec{\partial} \\
\vec{\partial} \\
\dot{0}\end{array}$ & בี & & 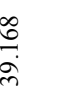 & $\begin{array}{l}\vec{n} \\
\hat{\sigma} \\
\ddot{\sim}\end{array}$ & 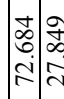 & & 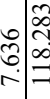 & & $\begin{array}{l}\text { हे } \\
\infty \\
\text { nं }\end{array}$ & 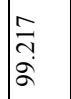 & {$\left[\begin{array}{l}n \\
0 \\
0 \\
0\end{array}\right.$} & :a & $\partial_{2}^{2}$ & & $\begin{array}{l}\hat{h} \\
\hat{n} \\
\text { నू }\end{array}$ \\
\hline $\begin{array}{l}0 \\
\hat{o} \\
\Leftrightarrow \\
=\end{array}$ & 质 & 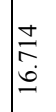 & 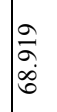 & 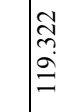 & & $\begin{array}{l}\infty \\
\stackrel{0}{0} \\
\stackrel{0}{0}\end{array}$ & 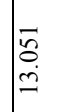 & 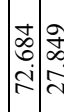 & & 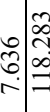 & & $\begin{array}{l}\text { ळे } \\
\text { ळై }\end{array}$ & 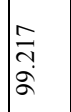 & $\hat{n}$ & $\sigma: \overrightarrow{\hat{b}}$ & 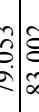 & & 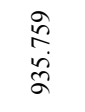 \\
\hline $\begin{array}{l}\infty \\
\stackrel{\infty}{\circ} \\
\stackrel{+}{+}\end{array}$ & 苂 & 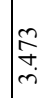 & $\mid \begin{array}{c}\hat{\alpha} \\
\infty \\
\infty \\
0 \\
i\end{array}$ & $\begin{array}{l}\bar{n} \\
\frac{\infty}{1}\end{array}$ & & 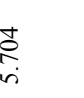 & $\frac{8}{1}$ & $\left.\mid \begin{array}{c}\infty \\
\infty \\
\infty \\
\hdashline\end{array}\right]$, & 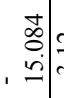 & $\begin{array}{c}\because \\
\stackrel{7}{i}\end{array}$ & & $\begin{array}{l}\hat{0} \\
\infty \\
\infty \\
0 \\
0\end{array}$ & $\begin{array}{l}\vec{\nabla} \\
i \\
i\end{array}$ & 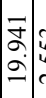 & 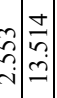 & 8 & & $\begin{array}{l}\underset{\tilde{q}}{\mathrm{i}} \\
\underset{\mathrm{d}}{\mathrm{j}}\end{array}$ \\
\hline $\begin{array}{l}\infty \\
\stackrel{0}{0} \\
\infty \\
\infty\end{array}$ & 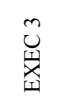 & 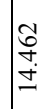 & 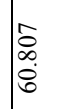 & $\frac{\bar{F}}{\infty}$ & & $\frac{n}{m}$ & \begin{tabular}{l}
$\infty$ \\
\hdashline \\
$\varrho$
\end{tabular} & 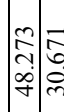 & & 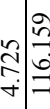 & & $\begin{array}{l}\overrightarrow{5} \\
\infty \\
\text { ते }\end{array}$ & $\begin{array}{l}\not 2 \\
\partial^{2} \\
\ddot{\infty}\end{array}$ & $\mid$\begin{tabular}{l|l}
$\infty$ \\
0 \\
0 \\
0 \\
0 \\
0
\end{tabular} & $\begin{array}{l}\text { çר } \\
\end{array}$ & $\begin{array}{l}\bar{\alpha} \\
\vdots \\
\alpha \\
\alpha \\
\alpha\end{array}$ & & $\underset{\stackrel{I}{\vec{I}}}{\vec{I}}$ \\
\hline 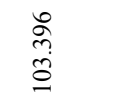 & $\begin{array}{l}\tilde{\tilde{\Xi}} \\
\widetilde{\Xi}\end{array}$ & 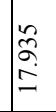 & $\frac{\hat{a}}{\vec{n}}$ & $\begin{array}{l}\hat{\mathrm{g}} \\
\mathrm{i} \\
\mathrm{i}\end{array}$ & & مे & त̂. & 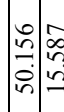 & & 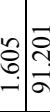 & & 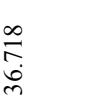 & $\begin{array}{l}\infty \\
\\
\infty \\
\infty\end{array}$ & 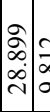 & 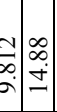 & $\begin{array}{l}\infty \\
\tilde{E} \\
\vdots \\
\vdots\end{array}$ & & 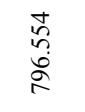 \\
\hline $\begin{array}{l}\infty \\
\stackrel{0}{0} \\
\stackrel{0}{0} \\
\alpha\end{array}$ & 导 & \begin{tabular}{l}
$\infty$ \\
$\infty$ \\
$\infty$ \\
$\stackrel{\infty}{ \pm}$ \\
\hdashline
\end{tabular} & $\begin{array}{l}\overrightarrow{\hat{\jmath}} \\
\overrightarrow{6}\end{array}$ & 离 & & $\begin{array}{l}\text { ôे } \\
\text { ले } \\
\text { m. }\end{array}$ & 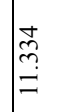 & 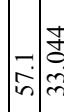 & & 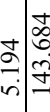 & & $\begin{array}{l}\vec{\partial} \\
\vec{\sigma}\end{array}$ & $\begin{array}{l}\tilde{\omega} \\
\tilde{D}^{-} \\
\end{array}$ & 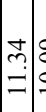 & 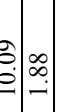 & & & $\begin{array}{l}\overrightarrow{6} \\
\stackrel{0}{0} \\
\infty\end{array}$ \\
\hline 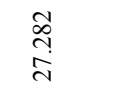 & $\hat{\mathrm{J}} \widehat{\mathrm{d}}$ & $\begin{array}{l}\overrightarrow{\widehat{N}} \\
\text { rn}\end{array}$ & 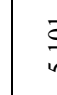 & & $\begin{array}{l}\hat{\jmath} \\
\\
\text { ते }\end{array}$ & $\vec{\sigma}$ & 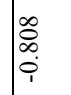 & & خ & בֶ: & & $\begin{array}{l}\hat{a} \\
\dot{b}\end{array}$ & 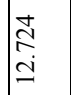 & $\stackrel{m}{\Rightarrow}$ & 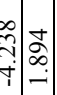 & 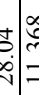 & & 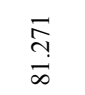 \\
\hline $\begin{array}{l}n \\
\hat{o} \\
\hat{\sigma}\end{array}$ & 畺 & 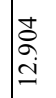 & 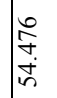 & $\begin{array}{l}\vec{\sigma} \\
\dot{\infty}\end{array}$ & & 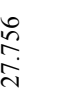 & 角 & 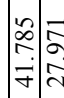 & & $\vec{m} \mid \vec{m}$ & & $\begin{array}{l}\frac{\infty}{\vec{m}} \\
\stackrel{\infty}{\circ}\end{array}$ & $\begin{array}{l}\hat{0} \\
\dot{b} \\
\hat{\sigma}\end{array}$ & 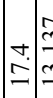 & 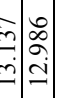 & & & $\begin{array}{l}\bar{a} \\
\overline{\hat{\sigma}}\end{array}$ \\
\hline $\begin{array}{l}\vec{m} \\
\stackrel{m}{a}\end{array}$ & $\stackrel{\tilde{\tilde{\varkappa}}}{\widetilde{\alpha}}$ & 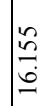 & $\begin{array}{l}\mathfrak{n} \\
\hat{m} \\
\dot{q} \\
\sigma\end{array}$ & 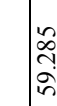 & & $\begin{array}{l}\stackrel{2}{E} \\
\dot{m}\end{array}$ & $\begin{array}{l}\hat{f} \\
\mathbf{b} \\
\infty\end{array}$ & \begin{tabular}{|l|l}
$\infty$ & $\hat{0}$ \\
0 & 0 \\
$\dot{b}$ & 0 \\
0 & 0
\end{tabular} & & 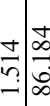 & & 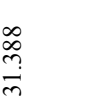 & 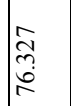 & $\left|\begin{array}{c}m \\
\infty \\
\dot{\sim} \\
\dot{\sim}\end{array}\right|$ & 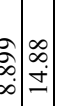 & & & $\begin{array}{l}\text { ஸ̆ } \\
\text { مे }\end{array}$ \\
\hline 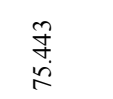 & $\begin{array}{l}\Theta \\
\text { 在 }\end{array}$ & 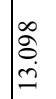 & 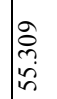 & $\begin{array}{l}\hat{\tilde{b}} \\
\vdots \\
\infty\end{array}$ & & 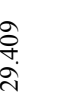 & 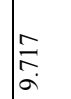 & 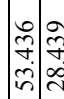 & & 党 & & 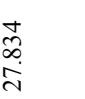 & 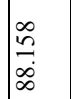 & 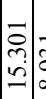 & 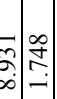 & a & & $\underset{\substack{\infty \\
\stackrel{\infty}{\infty}}}{\stackrel{\infty}{\infty}}$ \\
\hline $\begin{array}{l}\stackrel{0}{\circ} \\
\infty \\
\stackrel{9}{9}\end{array}$ & 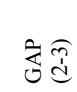 & 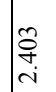 & 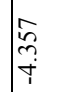 & 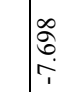 & & 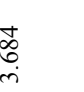 & $\vec{f}$ & 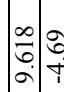 & : & 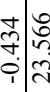 & & $\underset{\substack{\hat{\infty} \\
\text { in } \\
\text { in }}}{ }$ & 志 & {$\left[\begin{array}{c}0 \\
\infty \\
\infty \\
\infty\end{array}\right]=$} & 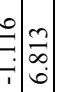 & & 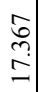 & $\begin{array}{l}\hat{\mathbf{D}} \\
\infty \\
\infty \\
\infty\end{array}$ \\
\hline $\begin{array}{l}\tilde{D} \\
\infty \\
\dot{b}\end{array}$ & 恖 & $\underset{\overrightarrow{0}}{\vec{I}}$ & 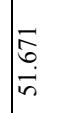 & तु & & 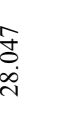 & & 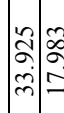 & & 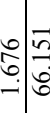 & & $\begin{array}{l}\text { के̀ } \\
\text { ஸें }\end{array}$ & $\begin{array}{l}0 \\
0 \\
\infty \\
2 \\
i\end{array}$ & 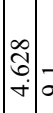 & 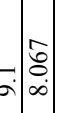 & 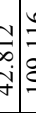 & & 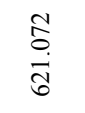 \\
\hline$\ddot{\infty}$ & 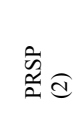 & 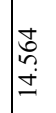 & 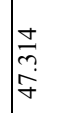 & $\begin{array}{l}\tilde{D} \\
\text { in } \\
\stackrel{8}{n}\end{array}$ & & $\stackrel{\vec{n}}{\stackrel{m}{m}}$ & •. & 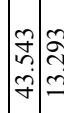 & & $\stackrel{\frac{1}{2}}{\stackrel{7}{2}}$ & & $\begin{array}{l}\overrightarrow{\tilde{n}} \\
\text { స్ }\end{array}$ & $\begin{array}{l}\tilde{O} \\
\tilde{n} \\
\check{n} \\
\end{array}$ & 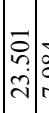 & 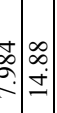 & $\frac{9}{7}$ & & $\begin{array}{l}\text { ô } \\
0 \\
0 \\
8 \\
0\end{array}$ \\
\hline 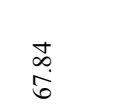 & $\underset{\Xi}{\Theta}$ & 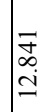 & 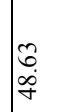 & 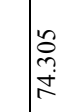 & & 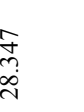 & 童 & 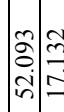 & & 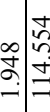 & & 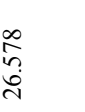 & $\begin{array}{c}1 \\
\\
\stackrel{\infty}{\infty}\end{array}$ & 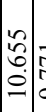 & & $\AA$ & & $\begin{array}{l}\tilde{n} \\
n \\
\stackrel{n}{n}\end{array}$ \\
\hline $\begin{array}{l}\hat{a} \\
\text { ồ } \\
\text { ते }\end{array}$ & 청 & 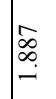 & 光 & $\stackrel{m}{\dddot{m}}$ & & ह̂. & 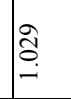 & 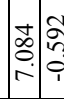 & 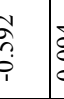 & 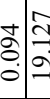 & & 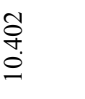 & 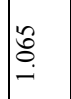 & 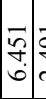 & 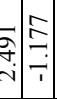 & 8 & & $\frac{\text { Jै }}{\text { aे }}$ \\
\hline $\begin{array}{l}\stackrel{0}{\leftrightarrow} \\
\stackrel{\sim}{n}\end{array}$ & 兽 & 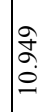 & 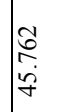 & $\begin{array}{l}\bar{Z} \\
\text { in }\end{array}$ & & $\begin{array}{l}\vec{b} \\
\text { d. } \\
\text { i. }\end{array}$ & 勇 & 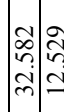 & & : & & 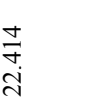 & $\begin{array}{l}\hat{1} \\
\infty \\
\dot{b} \\
\dot{b}\end{array}$ & 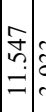 & 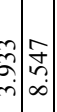 & $\delta$ & & 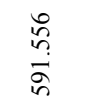 \\
\hline 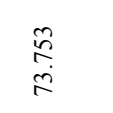 & 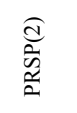 & 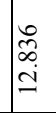 & 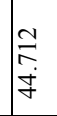 & 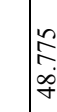 & & $\begin{array}{l}\stackrel{\infty}{\hat{i}} \\
\stackrel{\text { ते }}{2}\end{array}$ & ف. & 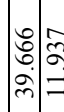 & & 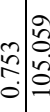 & & $\begin{array}{l}\underset{\infty}{\infty} \\
\underset{j}{j} \\
\tilde{m}\end{array}$ & $\begin{array}{l}\text { चे } \\
\text { هे }\end{array}$ & $\mid$\begin{tabular}{l}
$\infty$ \\
$\infty$ \\
$\vdots$ \\
\hdashline \\
\hdashline
\end{tabular} & 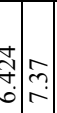 & & & 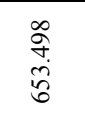 \\
\hline $\begin{array}{c}\text { ते } \\
\text { }\end{array}$ & 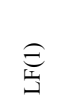 & $\stackrel{\infty}{\stackrel{\infty}{2}}$ & 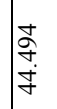 & 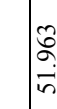 & $\S$ & $\begin{array}{l}\hat{\text { ôे }} \\
\text { i. }\end{array}$ & فَ & 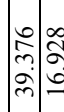 & ל. & 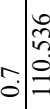 & & 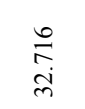 & $\begin{array}{l}\vec{F} \\
m \\
0 \\
0\end{array}$ & ذ: & 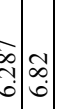 & - & & $\begin{array}{l}\vec{m} \\
\hat{0} \\
\hat{\sigma}\end{array}$ \\
\hline 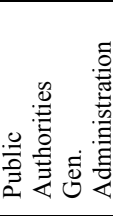 & & 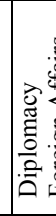 & & & & 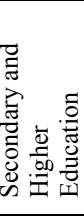 & $\begin{array}{ll}0 \\
\bar{z}\end{array}$ & 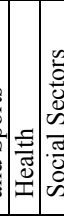 & & 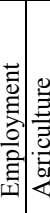 & & 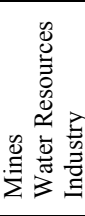 & 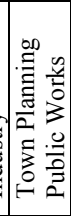 & 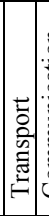 & 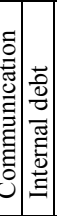 & & & 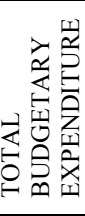 \\
\hline
\end{tabular}




\begin{tabular}{|c|c|c|c|c|c|c|c|c|c|c|c|c|c|c|c|}
\hline 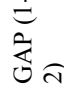 & $\hat{\infty}$ & 0 & i & 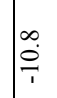 & $\partial$ & $\overbrace{0}^{+}$ & ì & ì & 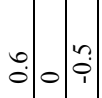 & 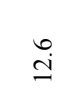 & อี. & • & 00 & $p \mid 4$ & i. \\
\hline 恖 & 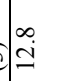 & 0 & $\overrightarrow{0}$ & $\begin{array}{l}\infty \\
\stackrel{\infty}{\dot{\omega}}\end{array}$ & 0 & $\overrightarrow{0}$ & & 5 & - $\overrightarrow{\text { in }}$ & $\stackrel{t}{\mathfrak{g}}$ & & 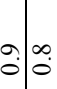 & & 0 & $\begin{array}{l}\infty \\
\stackrel{0}{0} \\
\underline{\Xi}\end{array}$ \\
\hline 蒿 & $\frac{n}{n}$ & 0 & 0 & 6 & $\dot{q}$ & 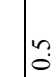 & & . & o in. & $\stackrel{\infty}{\sim}$ & तi & i. & 10 & $g \mid$ & 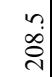 \\
\hline 牙 & 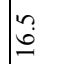 & 0 & o: & $\overrightarrow{0}$ & 0 & o & & $\vec{i}$ & $0 \begin{array}{c}\hat{\infty} \\
0\end{array}$ & f & مُ & N & 10 & 0 & $\stackrel{0}{\vec{\pi}}$ \\
\hline $\begin{array}{l}\dot{d} \\
\stackrel{\vec{d}}{0} \widehat{m}\end{array}$ & $\simeq$ & 0 & lo & 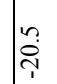 & f & $\stackrel{+}{0}$ & & 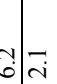 & $0 \cong$ & $\stackrel{\infty}{\underline{\varphi}}$ & $\stackrel{\infty}{\infty}: \overrightarrow{0}$ & فे & 10 & 9 & $\hat{\mathrm{J}}$ \\
\hline 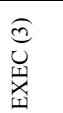 & 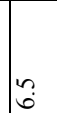 & 0 & 0 & के & 0 & 0 & & 我| & ○ & 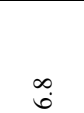 & & ? & 10 & olo & I \\
\hline 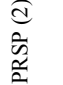 & $\frac{n}{4}$ & 0 & 0 & tु. & F & $t_{0}^{+}$ & $\infty$ & . & $\mid \begin{array}{l}0 \\
\dot{b} \\
i\end{array}$ & तें & $\vec{i}=$ & $\therefore$ : & 10 & 3 & $\stackrel{\circ}{\stackrel{d}{d}}$ \\
\hline$\underset{\text { 岃 }}{\Xi}$ & $\underline{\mathrm{I}}$ & 0 & 0 & $\mid \begin{array}{l}\infty \\
\dot{N} \\
0\end{array}$ & $=$ & F. & & $\stackrel{\infty}{\circ} \cdot \stackrel{\leftrightarrow}{\sigma}$ & $\left|\begin{array}{c}m \\
0 \\
0 \\
\infty\end{array}\right|$ & $\bar{g}$ & î่อ & - $\vec{m}$ & & 0 & $\begin{array}{l}\text { ֶี. } \\
\text { ปี }\end{array}$ \\
\hline 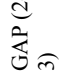 & I & 0 & 0 & $\vec{\varphi}$ & $\underset{\sim}{\infty}$ & $\because$ & & $=$ & $\mid$ & 0 & & 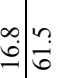 & & 0 & dे \\
\hline $\begin{array}{l}\hat{0} \\
\text { 蓄 }\end{array}$ & $\stackrel{\sim}{ \pm}$ & 0 & lo & $\stackrel{\text { İ }}{\text { İ }}$ & $=$ & lo & & $\sigma=$ & ○ & $\stackrel{N}{\Omega}$ & $\vec{s}$ & ב. & 10 & b & $\stackrel{\vec{J}}{\vec{\Xi}}$ \\
\hline $\begin{array}{l}\text { a } \\
\text { ă } \\
\approx \\
\approx\end{array}$ & $\frac{n}{i}$ & 0 & lo & कु. & $\dot{q}$ & 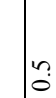 & $\propto$ & ف & o in. & $\stackrel{\sim}{\Omega}$ & $\vec{i}$ & $=$ & & .0 & $\stackrel{2}{\stackrel{d}{d}}$ \\
\hline$\underset{\square}{\varrho}$ & તુ & 0 & 0 & नें & $=$ & $\left.\right|_{0} ^{+}$ & & है: & 0 & $\begin{array}{l}\infty \\
\stackrel{\infty}{\rightarrow}\end{array}$ & $\stackrel{m}{i n} \underset{q}{q}$ & 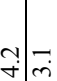 & 100 & lo & $\begin{array}{l}\dot{0} \\
\stackrel{\infty}{\sim}\end{array}$ \\
\hline ્ㅗㅇ & $\infty$ & 0 & 10 & $\infty$ & $\stackrel{\sim}{\sim}$ & : & 6 & $0 \stackrel{\infty}{i}$ & $\overrightarrow{0}:$ & $\stackrel{\infty}{a}$ & $a F$ & $\vec{\forall})$ & 00 & o & త్రి \\
\hline 䓢望 & 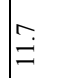 & 0 & 10 & $\stackrel{\sim}{\varrho}$ & t. & $\overrightarrow{0}$ & & $\vec{a} \mid \stackrel{i}{\pi}$ & o $\begin{array}{l}n \\
0 \\
m\end{array}$ & $\overrightarrow{=}$ & & 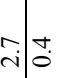 & & 10 & \\
\hline 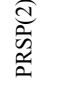 & $\frac{n}{n}$ & 0 & 0 & tr. & $\dot{\gamma}$ & 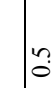 & $\vec{\infty}$ & : & $\begin{array}{l}7 \\
0 \\
0\end{array}\left|\begin{array}{ll}n \\
n \\
n\end{array}\right|$ & ڤें & $\vec{i} \mid \infty$ & i. & 10 & $\mid \begin{array}{l}0 \\
0\end{array}$ & ठें \\
\hline 胥 & $\frac{n}{n}$ & 0 & 0 & $\stackrel{+}{\varrho}$ & {$\left[\begin{array}{l}\infty \\
0 \\
0\end{array}\right.$} & $\because$ & $\infty$ & . & 0 में & ठें & $\vec{i}$ & 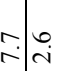 & & 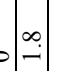 & $\begin{array}{l}\text { on } \\
\stackrel{\sim}{0}\end{array}$ \\
\hline & 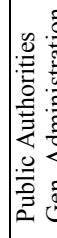 & 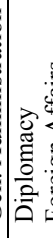 & $\begin{array}{ll}0 \\
0 \\
0 \\
0\end{array}$ & 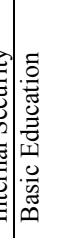 & 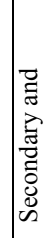 & 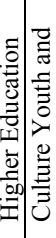 & 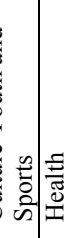 & 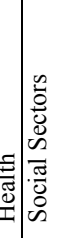 & 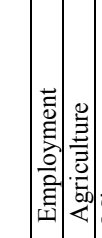 & 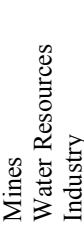 & 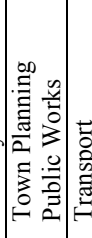 & ڤ. & \begin{tabular}{|l|l|} 
\\
$\mid$
\end{tabular} & 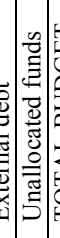 & 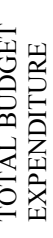 \\
\hline
\end{tabular}




\section{MACRO-BUDGETARY FRAMEWORK 2007-2011}

19. The economic situation of Mali in recent years has been marked by the Ivorian crisis which started in 2002, the decline in gold production in 2003, the desert locust invasion in 2004, and the low rainfall during the 2004/2005 season. However, the expected average growth rate would be $7 \%$ over the $2007-2011$ period, as against $5.2 \%$ between 2002 and 2005.

20. Budget programming is based on determining the State revenue, calculating allocations taking into account the objectives of the budget policy, and determining the budget deficit in line with the macro-economic framework.

\subsection{Budgetary Resources 2007-2011}

21. The resources of the 2007 State Budget amount to CFAF 885.3 billion. In 2008, 2009, 2010 and 2011, the resources should increase to CFAF 947.8 billion, CFAF 1,019.7 billion, CFAF 1,118.2 billion and CFAF 1,209.8 respectively, representing an increase rate of $7.1 \%$ in $2007,7.6 \%$ in $2008,9.7 \%$ in 2009 and $8.2 \%$ in 2010 respectively.

22. To achieve the above resource estimates, the tax assessment and collection services will continue to optimize the current collection systems, while developing new initiatives.

23. As regards internal taxation, the strengthening of fiscal control and operations to broaden the taxation base initiated five years ago will be maintained and implemented as effectively as possible through new measures. These measures will result in:

- broadening the tax base: the strategy will centre on mobilizing the overall potential of the national economy;

- proper identification and information of taxpayers, that will help to limit tax evasions;

- improvement of the efficiency of collection services: modernization of the taxation administration, adaptation of the tax laws to the taxable event, and reinforcement of the system of tax deducted at source;

- reorganization of the tax administration;

- intensification of the fight against fraud;

- closer monitoring of the mining sector;

- conduct of periodic controls to ensure strict application of penalties;

- improvement of collection of parol tenancy taxes;

- positive impacts of some ongoing reforms of the General Tax Code (introduction of the Simplified Tax System);

- better management of the petroleum products taxation mechanism;

- control of customs exemptions;

- improvement of implementation of the Imports Verification Programme (PVI);

- capacity building for tax assessment and collection services;

- improvement in the processing of tax declarations for products of WAEMU origin;

- compliance with goods collection provisions. 
Table 25: Total Revenue 2006-2011 (DGB Presentation) (in CFAF billion)

\begin{tabular}{|c|c|c|c|c|c|c|}
\hline & 2006 & 2007 & 2008 & 2009 & 2010 & 2011 \\
\hline TAX REVENUE & 487.523 & 534.482 & 580.171 & 630.090 & 689.993 & 755.739 \\
\hline NON-TAX REVENUE & 41.234 & 39.568 & 46.943 & 49.779 & 57.373 & 53.260 \\
\hline EXCEPTIONAL REVENUE & 25.907 & 10.472 & 10.660 & 11.225 & 12.141 & 11.125 \\
\hline SPECIAL INVESTMENT BUDGET & 233.465 & 245.899 & 268.400 & 290.300 & 317.200 & 345.300 \\
\hline BUDGET SUPPORT & 47.224 & 49.227 & 35.503 & 31.751 & 34.702 & 37.145 \\
\hline SUPPL. BUDGETS SP. ACCOUNTS AND FUNDS & 5.387 & 5.672 & 6.091 & 6.541 & 6.785 & 7.204 \\
\hline TOTAL & 840.740 & 885.320 & 947.768 & $1,019.685$ & $1,118.195$ & $1,209.772$ \\
\hline
\end{tabular}

Source: DGB, DNDC, DNTCP, DNPD, DGABE, DGD, DGI and DGDP

Chart 8: Trend of Tax and Non-tax Revenue 2006-2011 (in CFAF billion)

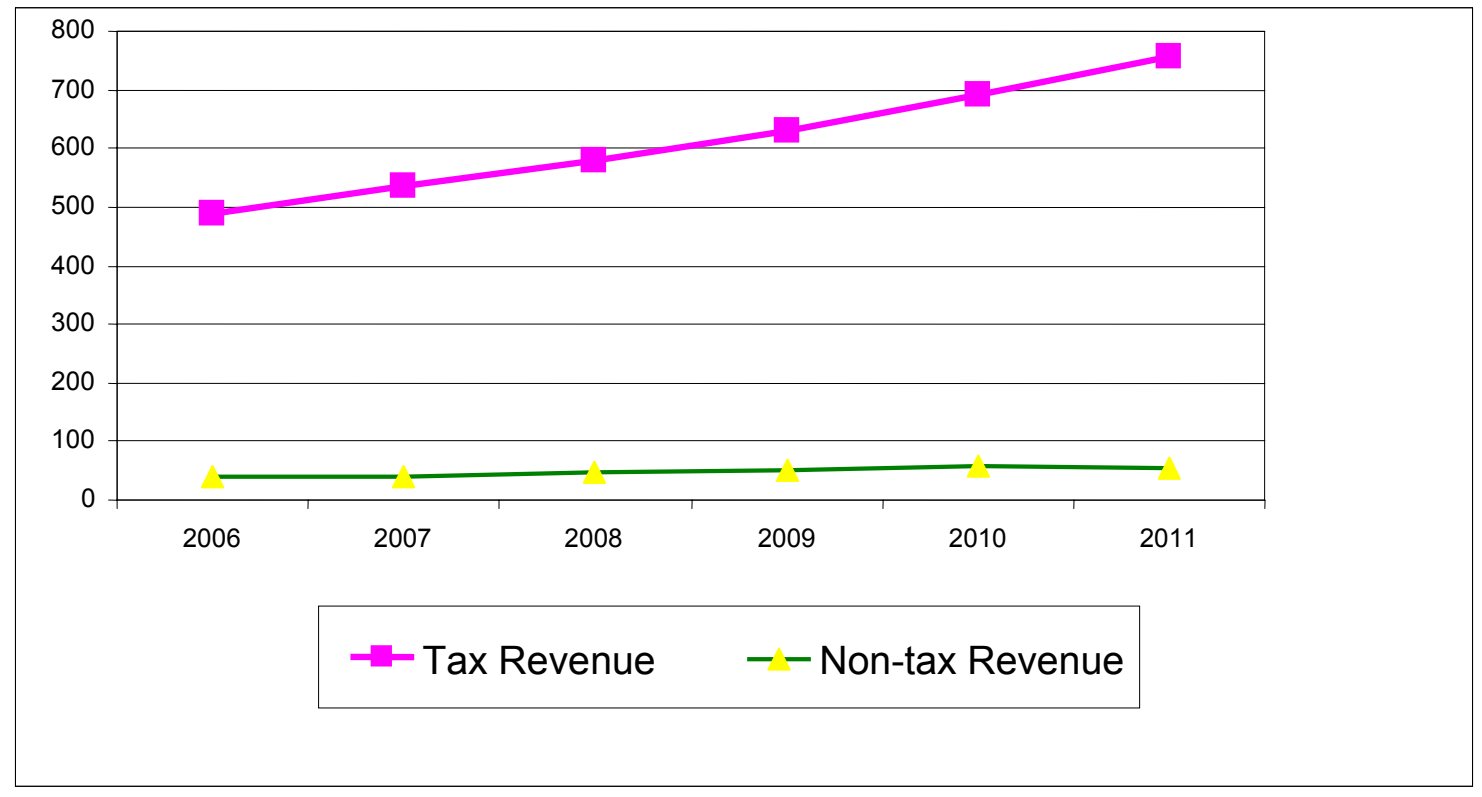

Tax revenue will increase over the 2007-2011 period as indicated in Chart 1, while non-tax revenue will remain stable linearly over the same period. The budgetary revenue, by collection service, is as follows for the period:

Table 26: Budgetary Revenue by Department 2006-2011 (in CFAF billion)

\begin{tabular}{|c|c|c|c|c|c|c|}
\hline SERVICES & 2006 & 2007 & 2008 & 2009 & 2010 & 2011 \\
\hline Directorate General of Customs & 244.100 & 265.628 & 293.900 & 317.500 & 348.400 & 382.300 \\
\hline Directorate General of Taxes & 215.133 & 237.647 & 254.896 & 280.386 & 308.424 & 339.267 \\
\hline National Directorate of the Treasury and Public Accounting & 19.878 & 18.609 & 21.915 & 23.011 & 24.162 & 25.369 \\
\hline Directorate General of State property Management 3/ & 8.070 & 8.070 & 3.000 & 3.000 & 8.000 & 1.000 \\
\hline Directorate General of Lands and Survey & 36.000 & 38.520 & 49.405 & 51.555 & 54.122 & 57.021 \\
\hline Directorate General of Public Debt 2/ & 5.576 & 5.576 & 3.998 & 4.417 & 4.258 & 4.042 \\
\hline TOTAL Budgetary Revenue (according to DGB) & 528.757 & 574.050 & 627.114 & 679.869 & 747.366 & 808.999 \\
\hline TOTAL Budgetary Revenue (according to GFFT) 3/ & 493.111 & 535.404 & 595.917 & 648.337 & 711.278 & 780.249 \\
\hline
\end{tabular}

Source: DNDC, DGD, DGI, DNTCP, DGDP, DGABE 
Chart 9: Trend of budgetary revenue by Department 2006-2011 (in CFAF billion)

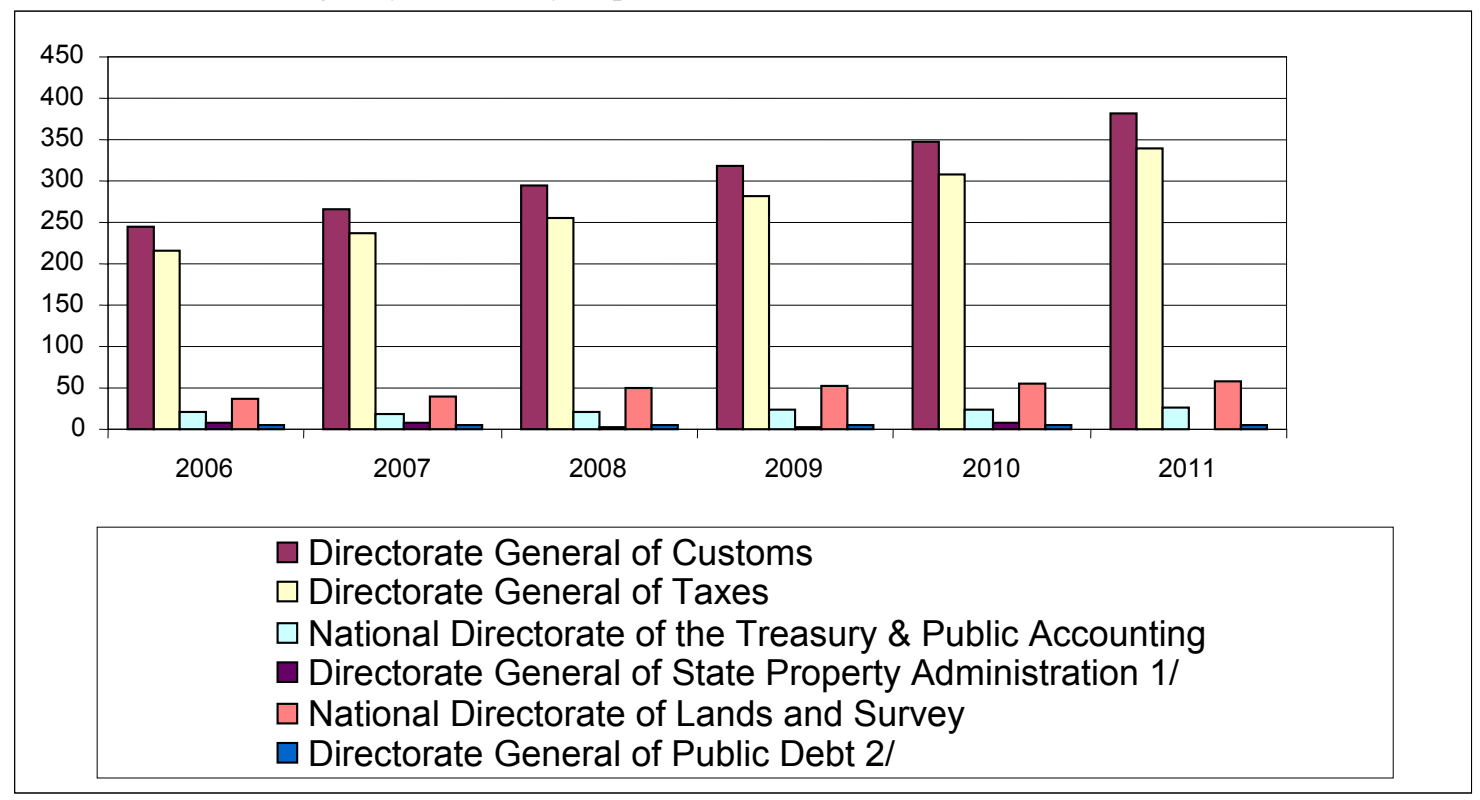

Table 27: Total Revenue 2006-2011 in CFAF billion

\begin{tabular}{|c|c|c|c|c|c|c|c|}
\hline & 2006 & 2007 & 2008 & 2009 & 2010 & 2011 & $\begin{array}{l}\text { Average } \\
2007-2011\end{array}$ \\
\hline Total revenue and grants & 1740.0 & 749.4 & 881.4 & 935.6 & 1008.0 & 1088.3 & 932.6 \\
\hline Budgetary revenue & 497.5 & 535.4 & 663.5 & 708.5 & 465.9 & 829.5 & 700.6 \\
\hline Tax revenue & 469.9 & 509.5 & 621.0 & 662.2 & 713.5 & 773.6 & 655.9 \\
\hline Direct taxes & 89.9 & 106.2 & 112.3 & 122.5 & 131.1 & 141.3 & 122.7 \\
\hline Internal VAT & 84.0 & 93.0 & 100.1 & 113.3 & 160.1 & 178.7 & 129.0 \\
\hline VAT on imports & 132.2 & 147.0 & 156.2 & 166.7 & 181.0 & 196.7 & 169.5 \\
\hline Internal tax on oil products & 25.0 & 27.0 & 28.7 & 30.5 & 33.0 & 35.7 & 31.0 \\
\hline Tax on imports & 71.9 & 75.0 & 79.2 & 84.5 & 91.8 & 99.7 & 86.0 \\
\hline Other duties and taxes & 88.9 & 87.3 & 101.3 & 114.6 & 129.6 & 142.9 & 115.1 \\
\hline Grants & 1200.0 & 167.0 & 162.9 & 167.1 & 179.5 & 191.9 & 173.7 \\
\hline Grants for projects & 81.3 & 93.0 & 102.4 & 110.1 & 119.5 & 129.3 & 110.9 \\
\hline Budget grants & 35.8 & 24.8 & 25.0 & 25.2 & 25.3 & 25.5 & 25.2 \\
\hline Sectoral budget support & 47.2 & 49.2 & 35.5 & 31.8 & 34.7 & 37.1 & 37.7 \\
\hline MDRI debt restructuring & 1035.7 & 0.0 & 0.0 & 0.0 & 0.0 & 0.0 & 0.0 \\
\hline
\end{tabular}

\section{Source: DGB, DNPD}

\subsection{Budgetary Expenditures 2007-2011}

25. Budgetary expenditure projections are based on past trends and adjustments to the impacts of national economic policies. Expenditure projections for the special investment budget are based on the Three-year Investment Programme and the macro-economic framework. Total expenditures will be maintained at an average of $28.1 \%$ of GDP between 2007 and 2011, as against $27.5 \%$ over the $2002-2005$ period.

Total budgetary expenditures amount to CFAF 976.6 billion in 2007, and will stand at CFAF $1,241.7$ billion in 2011 , representing an increase rate of $3.9 \%$ in $2007,6.0 \%$ in $2008,7.3 \%$ in 2009 and $7.7 \%$ in 2010 respectively. This trend is due to the decline in foreign debt.

Recurrent expenditures amount to CFAF 524.5 billion in 2007, and will stand at CFAF 664.8 billion in 2011 , representing an increase rate of $3.8 \%$ in $2007,5.9 \%$ in $2008,7.0 \%$ in 
2009 , and $7.7 \%$ in 2010 respectively. This trend is due to the recurrent expenditures in Government services.

26. Capital expenditures from internal financing (including HIPC resources) amount to CFAF 151.3 billion in 2007, and will stand at CFAF 187.9 billion in 2011, representing an increase rate of $5.7 \%$ in $2007,6.2 \%$ in $2008,4.5 \%$ in 2009 and $6.0 \%$ in 2010 respectively. Capital expenditures comprise counterpart funds from the special investment budget, the internal special investment budget and investment expenditures of the ordinary budget.

27. Capital expenditures from internal financing stand at CFAF 245.9 billion in 2007, and will amount to CFAF 345.3 billion in 2011, representing an increase rate of $9.2 \%$ in 2007 , $8.2 \%$ in $2008,9.3 \%$ in 2009 and $8.9 \%$ in 2010 respectively.

28. Budget support amounts to CFAF 49.2 billion in 2007, and will stand at CFAF 37.1 billion in 2011. The amounts come from support (2006-2008) and a slight annual increase.

29. Budget support is an instrument of financial cooperation between the Government of Mali and the Technical and Financial Partners aimed at: (i) better coordinating their activities and gradually replacing the multiple donor procedures with national procedures, and (ii) examining concrete means of harmonizing programmes and procedures, so as to prepare a gradual reorientation of part of international aid to programme aid transiting through the budget.

30. It should be noted that the presentation of expenditures in the Finance Law does not fully correspond with that the GFFT. It is therefore necessary to revise the figures to ensure consistency with the IMF methodology, particularly as concerns the subsequent calculation of performance ratios (budget balance, tax rate, etc.). Table 9 presents the conversion of Budget expenditures to GFFT expenditures. Table 10, which is more detailed, therefore corresponds to Table 8 . As indicated above, the expenditure projections made by DGB fully correspond to those of DNPD's voluntarist scenario. It should be noted only that DNPD's GFFT contains higher figures as regards receipts and expenditures of the Special Fund and supplementary budgets because many elements are not recorded in the DGB but are recorded in the Treasury.

Table 28: Total Expenditure 2006-2011 (DGB Presentation) in CFAF billion

\begin{tabular}{|c|c|c|c|c|c|c|}
\hline & 2006 & 2007 & 2008 & 2009 & 2010 & 2011 \\
\hline Current expenditure & 513.711 & 524.533 & 544.468 & 576.673 & 617.295 & 664.757 \\
\hline Capital expenditure (internal financing) & 135.972 & 151.270 & 159.923 & 169.787 & 177.367 & 187.945 \\
\hline Capital expenditure (external financing) & 233.465 & 245.899 & 245.899 & 290.300 & 317.200 & 345.300 \\
\hline Suppl. budgets special accounts and funds & 5.387 & 5.672 & 6.091 & 6.541 & 6.785 & 6.599 \\
\hline Support budget & 47.224 & 49.227 & 35.503 & 31.751 & 34.702 & 37.145 \\
\hline Total Expenditure & 935.759 & 976.602 & $1,014.385$ & $1,075.052$ & $1,153.349$ & $1,241.745$ \\
\hline
\end{tabular}

Source: DGB, DNDP 
Chart 10: Evolution of Budgetary Expenditures 2006-2011 (in CFAF billion)

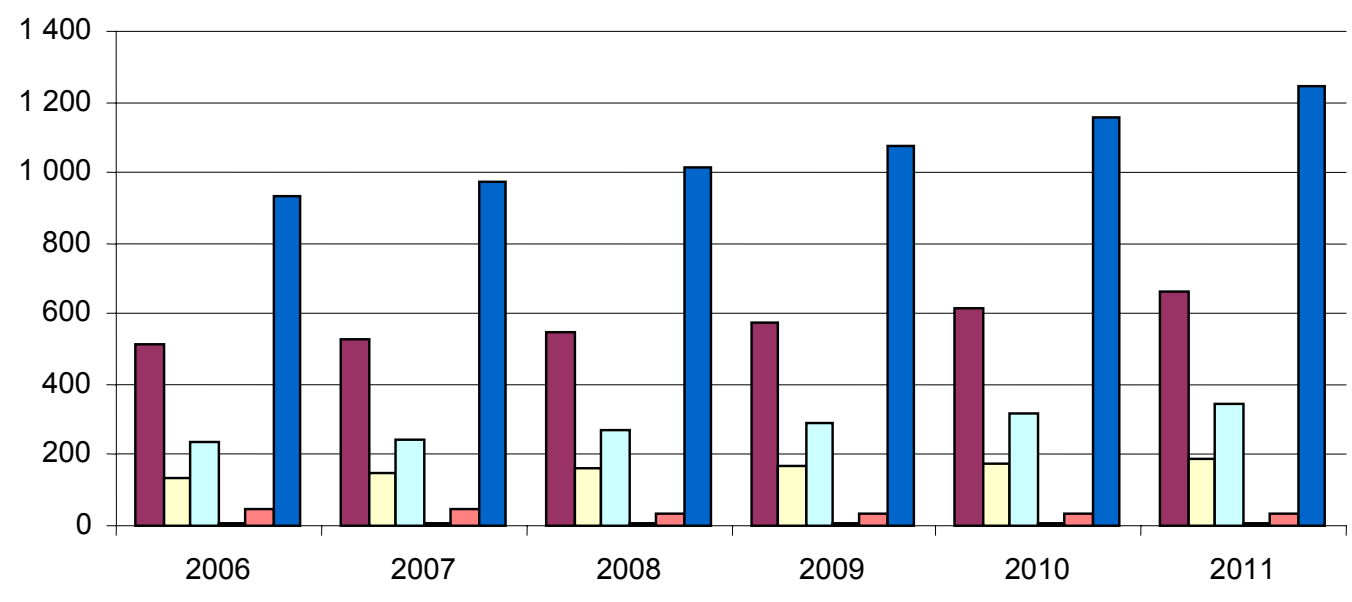

\begin{tabular}{|l|}
\hline C Current Expenditure \\
$\square$ Capital Expenditure (Internal Financing) \\
$\square$ Capital Expenditure (External Financing) \\
$\square$ Suppl. Budgets Sp. Accounts \& Funds \\
$\square$ Budget Support \\
$\square$ Total Expenditure
\end{tabular}

Table 29: Transition from DGB Presentation (Finance Law) to GFFT

\begin{tabular}{|c|c|c|c|c|c|c|}
\hline & 2006 & 2007 & 2008 & 2009 & 2010 & 2011 \\
\hline TOTAL EXPENDITURE (DGB) & 935.759 & 976.602 & $1,014.385$ & 1.075 .052 & $1,153.349$ & $1,241.745$ \\
\hline Less Repayment of external debt & -61.522 & -34.239 & -34.410 & -36.103 & -37.852 & -41.513 \\
\hline Less Clearance of liabilities (part of debt) & -15.055 & -17.080 & -10.830 & -10.732 & -10.396 & -10.253 \\
\hline Less liquidation of regular liabilities & -1.710 & -1.700 & -2.048 & -2.030 & -1.966 & -1.939 \\
\hline Less dispute costs & -1.689 & 1.350 & -2.500 & -2.500 & -2.500 & -2.500 \\
\hline Less Reimbursement VAT credit & -7.000 & 10.000 & -9.199 & -9.116 & -8.830 & -8.708 \\
\hline Less Exchange losses & -0.614 & 0.665 & -0.736 & -0.729 & -0.706 & -0.697 \\
\hline Less Reimbursement of exemptions & -15.000 & -15.000 & -15.000 & -15.000 & -15.000 & -15.000 \\
\hline Plus IMF interests & 0.500 & 0.000 & 0.000 & 0.000 & 0.000 & 0.000 \\
\hline Plus BCEAO interests & 0.500 & 0.000 & 0.000 & 0.000 & 0.000 & 0.000 \\
\hline Plus net loans & -5.576 & -5.576 & $-3,998$ & -4.417 & -4.258 & -4.042 \\
\hline Adjustment & 0.104 & -0.092 & -2.163 & -2.025 & -2.540 & -3.139 \\
\hline TOTAL BUDGET EXP. (GFFT) & 828.697 & 890.900 & 933.500 & 992.400 & 1.069 .300 & 1.153 .900 \\
\hline
\end{tabular}

Source: DNPD/DGB 
Table 30: Budgetary Expenditure 2006-2011 (GFFT Presentation)

\begin{tabular}{|c|c|c|c|c|c|c|c|}
\hline & 2006 & 2007 & 2008 & 2009 & 2010 & 2011 & $\begin{array}{l}\text { Average } \\
2007-2011\end{array}$ \\
\hline & & PRSP & PRSP & PRSP & PRSP & PRSP & \\
\hline Expenditure and net loan & 865.6 & 932.3 & 984.5 & 1048.0 & 1127.6 & 1216.7 & 1061.8 \\
\hline Budgetary expenditure & 828.7 & 890.9 & 933.5 & 992.4 & 1069.3 & 1153.9 & 1008.0 \\
\hline Current expenditure & 427.0 & 459.5 & 484.7 & 515.5 & 555.0 & 598.6 & 522.7 \\
\hline Salaries & 149.0 & 160.5 & 174.2 & 186.4 & 205.4 & 222.6 & 189.8 \\
\hline Goods and services & 161.1 & 181.8 & 189.9 & 204.8 & 221.7 & 244.3 & 208.5 \\
\hline Transfers and subsidies & 96.8 & 103.7 & 109.0 & 113.0 & 117.1 & 121.6 & 112.9 \\
\hline Interests due & 20.1 & 13.5 & 11.6 & 11.3 & 10.8 & 10.1 & 11.5 \\
\hline Internal debt & 2.6 & 1.7 & 1.6 & 1.5 & 1.4 & 1.4 & 1.5 \\
\hline External debt & 17.5 & 11.8 & 10.0 & 9.8 & 9.4 & 8.7 & 9.9 \\
\hline Capital expenditure & 401.7 & 431.4 & 448.8 & 476.9 & 514.3 & 555.3 & 485.3 \\
\hline External financing & 280.7 & 295.1 & 303.9 & 322.1 & 351.9 & 382.4 & 331.1 \\
\hline Borrowings & 152.2 & 152.9 & 166.0 & 180.2 & 197.7 & 216.0 & 182.6 \\
\hline Overall grants & 81.3 & 93.0 & 102.4 & 110.1 & 119.5 & 129.3 & 110.9 \\
\hline Sectoral budget support & 47.2 & 49.2 & 35.5 & 31.8 & 34.7 & 37.1 & 37.7 \\
\hline Internal financing 1) & 121.0 & 136.3 & 144.9 & 154.8 & 162.4 & 172.9 & 154.3 \\
\hline Sp. Fd \& Suppl. Budget expenditure & 42.5 & 47.0 & 55.0 & 60.0 & 62.6 & 66.8 & 58.3 \\
\hline Net loans & -5.6 & -5.6 & -4.0 & -4.4 & -4.3 & -4.0 & -4.5 \\
\hline
\end{tabular}

\section{Source: DNPD/DGB}

Table 31 : Breakdown of Budget Support by Programme in CFAF

\begin{tabular}{|l|l|r|r|}
\hline Programmes & Donors & Amount 2006 & \multicolumn{1}{l|}{2007} \\
\hline PISE II & Sweden & 7221122700 & 7221122700 \\
\hline & Netherlands & 14400000000 & 14400000000 \\
& S/Total & 21621122700 & 21621122700 \\
\hline PRODESS II & Sweden & 2558232300 & 2558232300 \\
\hline & Netherlands & 2600000000 & 2600000000 \\
& S/Total & 5158232300 & 5158232300 \\
\hline PARAD & European Union & & \\
\hline ANICT/FICT & & 6670749153 & 5036415373 \\
ANICT/ADERE & & 886432220 & 658180583 \\
\hline ANICT/ COM SUPPORT & & 1589433220 & 658180583 \\
\hline ANICT/FAT & 3113016271 & 1151816020 \\
PDI & & 13116139000 & 9334763041 \\
\hline & & 7329000000 & 7329000000 \\
\hline PAGAMGFT & & 5279785000 \\
\hline COTTON SECTOR REFORM & & 47224494000 & 49227495600 \\
\hline Grand Total & & & \\
\hline
\end{tabular}

\section{Source: DGB}

\subsection{Budgetary Resources and Application of Funds 2007-2011}

The stringent budget policies during the last decade helped to contain public deficit. On the medium term, the budget deficit objective is to fulfill the WAEMU convergence criterion.

The projections show that the State Budget deficit (overall balance, cash base) will reduce from CFAF 182.9 billion in 2007 to CFAF 128.4 billion in 2011.

The scenario shows that all the WAEMU convergence criteria as regards public finance would be fulfilled as from 2008 . 
Table 32: Budgetary Resources and Application of Funds (GFFT) of PRSP 2006-2011 in CFAF Billion

\begin{tabular}{|c|c|c|c|c|c|c|c|}
\hline & 2006 & 2007 & 2008 & 2009 & 2010 & 2011 & Moyenne \\
\hline & Estim. & Prév. & Prév. & Prév. & Prév. & Prév. & $2007-2011$ \\
\hline Total revenue and grants & $1,740.0$ & 749.4 & 881.4 & 935.6 & $1,008.0$ & $1,088.3$ & 932.6 \\
\hline Total revenue & 540.0 & 582.4 & 718.6 & 768.6 & 828.5 & 896.3 & 758.9 \\
\hline Budgetary revenue & 497.5 & 535.4 & 663.5 & 708.5 & 765.9 & 829.5 & 700.6 \\
\hline Tax revenue & 469.9 & 509.5 & 621.0 & 662.2 & 713.5 & 773.6 & 655.9 \\
\hline Non-tax revenue & 27.6 & 25.9 & 42.5 & 46.4 & 52.4 & 55.9 & 44.6 \\
\hline Sp. Fd \& suppl. Budgets Revenue & 42.5 & 47.0 & 55.0 & 60.0 & 62.6 & 66.8 & 58.3 \\
\hline Grants & $1,200.0$ & 167.0 & 162.9 & 167.1 & 179.5 & 191.9 & 173.7 \\
\hline Expenditure and net lendings & 865.6 & 932.3 & 984.5 & $1,048.0$ & $1,127.6$ & $1,216.7$ & $1,061.8$ \\
\hline Budgetary expenditure & 828.7 & 890.9 & 933.5 & 992.4 & $1,069.3$ & $1,153.9$ & $1,008.0$ \\
\hline Capital expenditure & 401.7 & 431.4 & 448.8 & 476.9 & 514.3 & 555.3 & 485.3 \\
\hline Sp. Fd \& Suppl. Budgets Expend. & 42.5 & 47.0 & 55.0 & 60.0 & 62.6 & 66.8 & 58.3 \\
\hline Net lendings & -5.6 & -5.6 & -4.0 & -4.4 & -4.3 & -4.0 & -4.5 \\
\hline Primary budget balance (IMF 2) & -44.9 & -54.8 & 37.9 & 42.6 & 52.8 & 62.0 & 28.1 \\
\hline Overall balance (commits, excl. grants) & -325.6 & -349.9 & -266.0 & -279.5 & -299.1 & -320.4 & -303.0 \\
\hline Overall balance (commitments) & 874.4 & -182.9 & -103.1 & -112.4 & -119.6 & -128.4 & -129.3 \\
\hline Adjustment & 0.0 & 0.0 & 0.0 & 0.0 & 0.0 & 0.0 & 0.0 \\
\hline Overall balance (cash base \& excl. grants) & -325.6 & -349.9 & -266.0 & -279.5 & -299.1 & -320.4 & -303.0 \\
\hline Overall balance (cash base) & 874.4 & -182.9 & -103.1 & -112.4 & -119.6 & -128.4 & -129.3 \\
\hline FINANCING & -874.4 & 182.9 & 103.1 & 112.4 & 119.6 & 128.4 & 129.3 \\
\hline Net external financing & -845.1 & 159.2 & 172.3 & 185.3 & 201.9 & 215.6 & 186.9 \\
\hline Borrowings & 200.7 & 182.9 & 196.0 & 210.2 & 227.7 & 246.0 & 212.6 \\
\hline Amortization & $-1,071.7$ & -34.2 & -34.4 & -36.1 & -37.9 & -41.5 & -36.8 \\
\hline Debt/HIPC settlement & 25.9 & 10.5 & 10.7 & 11.2 & 12.1 & 11.1 & 11.1 \\
\hline Net internal financing & -43.1 & 23.7 & -69.2 & -72.9 & -82.4 & -87.2 & -57.6 \\
\hline Bank (net) & -34.0 & 36.3 & -76.3 & -88.3 & -118.1 & -132.2 & -75.7 \\
\hline Privatization revenue & 8.1 & 8.1 & 4.0 & 4.0 & 4.0 & 4.0 & 4.8 \\
\hline Other financing & -17.2 & -20.7 & 3.1 & 11.4 & 31.7 & 41.0 & 13.3 \\
\hline Gov't financing gap $(+=$ deficit & 13.8 & 0.0 & 0.0 & 0.0 & 0.0 & 0.0 & 0.0 \\
\hline
\end{tabular}

1) Banking sector and private sector

2) Revenue (excluding grants) less total expenditure (incl. net loans) (excl. capital expenditure with external financing)

Source: DNPD, MME-DNPD, DGB 
Table 33: Expected Macro-budgetary Performance 2006-2011

\begin{tabular}{|c|c|c|c|c|c|c|c|c|}
\hline & & 2006 & 2007 & 2008 & 2009 & 2010 & 2011 & $\begin{array}{l}\text { Average } \\
2007-2011\end{array}$ \\
\hline \multicolumn{2}{|l|}{ Resources and Appl. of Funds for Goods \& services } & & PRSP & PRSP & PRSP & PRSP & PRSP & \\
\hline \multicolumn{2}{|l|}{ GDP at market prices (current CFAF billion) } & $3,205.8$ & $3,419.4$ & $3,653.0$ & $3,895.0$ & $4,196.9$ & $4,493.8$ & $3,931.6$ \\
\hline \multicolumn{2}{|l|}{ Real growth rate of GDP at market prices } & $3.6 \%$ & $7.0 \%$ & 6.6 & $6.5 \%$ & $7.8 \%$ & $7.1 \%$ & $7.0 \%$ \\
\hline \multicolumn{2}{|l|}{ Fixed investment rate GFCF/GDPm) } & $20.9 \%$ & $19.3 \%$ & $19.7 \%$ & $20.0 \%$ & $20.3 \%$ & $20.9 \%$ & $20.0 \%$ \\
\hline \multicolumn{2}{|l|}{-Public GFCF in \% of GDPm } & $10.0 \%$ & $8.3 \%$ & $8.7 \%$ & $9.1 \%$ & $9.5 \%$ & $9.6 \%$ & $9.0 \%$ \\
\hline \multicolumn{2}{|l|}{-Private GFCF in $\%$ of GDPm } & $11.0 \%$ & $11.0 \%$ & $11.0 \%$ & $11.0 \%$ & $10.8 \%$ & $11.2 \%$ & $11.0 \%$ \\
\hline \multicolumn{2}{|l|}{ Consumption rate (in $\%$ of GDPm) } & $84.1 \%$ & $86.1 \%$ & $85.6 \%$ & $85.0 \%$ & $85.5 \%$ & $85.9 \%$ & $85.6 \%$ \\
\hline \multirow{2}{*}{\multicolumn{2}{|c|}{$\begin{array}{l}\text {-Private consumption rate } \\
\text {-Public consumption rate }\end{array}$}} & $71.2 \%$ & $73.4 \%$ & $73.5 \%$ & $73.0 \%$ & $73.4 \%$ & $73.7 \%$ & $73.4 \%$ \\
\hline & & $12.9 \%$ & $12.7 \%$ & $12.1 \%$ & $12.0 \%$ & $12.0 \%$ & $12.2 \%$ & $12.2 \%$ \\
\hline \multicolumn{2}{|l|}{ Per capita Gross National Product in current CFAF } & 269,324 & 279,650 & 289,717 & 300,315 & 315,076 & 328,400 & 301,632 \\
\hline \multicolumn{2}{|l|}{ Per capita real growth rate of Gross National Product } & $2.5 \%$ & $3.7 \%$ & $3.4 \%$ & $3.6 \%$ & $4.9 \%$ & $4.3 \%$ & $4.0 \%$ \\
\hline \multicolumn{2}{|l|}{ Public Finance } & 2006 & 2007 & 2008 & 2009 & 2010 & 2011 & \\
\hline \multicolumn{2}{|l|}{ Tax pressure rate $(=$ Tax revenue/GDPm) } & $14.7 \%$ & $14.9 \%$ & $17.0 \%$ & $17.0 \%$ & $17.0 \%$ & $17.2 \%$ & $16.6 \%$ \\
\hline \multicolumn{2}{|l|}{ Tax rate (current revenue, excl. grants, in \% of GDP) } & $16.8 \%$ & $17.0 \%$ & $19.7 \%$ & $19.7 \%$ & $19.7 \%$ & $19.9 \%$ & $19.2 \%$ \\
\hline \multicolumn{2}{|l|}{ Tax rate (current revenue in $\%$ of GDP formal sector) } & $49.0 \%$ & $49.5 \%$ & $57.5 \%$ & $56.3 \%$ & $56.9 \%$ & $57.7 \%$ & $55.6 \%$ \\
\hline \multicolumn{2}{|c|}{ Total expenditure and net loans, in \% of GDP } & $27.0 \%$ & $27.3 \%$ & $27.0 \%$ & $26.9 \%$ & $26.9 \%$ & $27.1 \%$ & $27.0 \%$ \\
\hline \multicolumn{2}{|c|}{ Balance of current operations (national public savings) in $\%$ of GDP } & $40.5 \%$ & $8.1 \%$ & $10.6 \%$ & $10.5 \%$ & $10.6 \%$ & $10.7 \%$ & $10.1 \%$ \\
\hline \multirow{2}{*}{\multicolumn{2}{|c|}{$\begin{array}{l}\text { Balance of current operations (own savings) in } \% \text { of GDP } \\
\text { Primary balance (=own public savings excl. interests) in } \% \text { of }\end{array}$}} & $3.5 \%$ & $3.6 \%$ & $6.4 \%$ & $6.5 \%$ & $6.5 \%$ & $6.6 \%$ & $5.9 \%$ \\
\hline & & & & & & & & \\
\hline \multicolumn{2}{|l|}{ GDPm } & $4.2 \%$ & $4.0 \%$ & $6.7 \%$ & $6.8 \%$ & $6.8 \%$ & $6.9 \%$ & $6.2 \%$ \\
\hline \multicolumn{2}{|l|}{ Primary budget balance (IMF) in \% of GDP } & $0.6 \%$ & $0.2 \%$ & $2.9 \%$ & $2.9 \%$ & $3.0 \%$ & $3.1 \%$ & $2.4 \%$ \\
\hline \multicolumn{2}{|l|}{ Primary budget balance (WAEMU) in \% of GDP } & $-0.6 \%$ & $-1.3 \%$ & $1.3 \%$ & $1.4 \%$ & $1.5 \%$ & $1.6 \%$ & $0.9 \%$ \\
\hline \multicolumn{2}{|l|}{ Tot. balance (commit. base) excl. grants in \% of GDP } & $-10.2 \%$ & $-10.2 \%$ & $-7.3 \%$ & $-7.2 \%$ & $-7.1 \%$ & $-7.1 \%$ & $-7.8 \%$ \\
\hline \multicolumn{2}{|l|}{ Tot. balance (commit. base) incl. grants in \% of GDP } & $27.3 \%$ & $-5.3 \%$ & $-2.8 \%$ & $-2.9 \%$ & $-2.8 \%$ & $-2.9 \%$ & $-3.4 \%$ \\
\hline \multicolumn{2}{|l|}{ Total balance (cash base) in \% of GDP } & $27.3 \%$ & $-5.3 \%$ & $-2.8 \%$ & $-2.9 \%$ & $-2.8 \%$ & $-2.9 \%$ & $-3.4 \%$ \\
\hline \multicolumn{9}{|l|}{ External Aid } \\
\hline External aid (gross) in \% of GDP & & $46.5 \%$ & $10.5 \%$ & $10.1 \%$ & $10.0 \%$ & $10.0 \%$ & $10.0 \%$ & $10.1 \%$ \\
\hline External aid (gross) in US\$ million & & 2853.8 & 706.7 & 728.6 & 769.3 & 834.0 & 896.6 & 787.0 \\
\hline WAEMU Convergence Criteria & & 2006 & 2007 & 2008 & 2009 & 2010 & 2011 & Average \\
\hline First rank criteria & ted ratio & & & & & & & $2007-2011$ \\
\hline Base budget balance/GDPm ratio ${ }^{1 /}$ & $>=0 \%$ & $-0.6 \%$ & $-1.3 \%$ & $1.3 \%$ & $1.5 \%$ & $1.6 \%$ & $1.6 \%$ & $0.9 \%$ \\
\hline Inflation rate (IHPC Bamako) & $<=3 \%$ & $2.4 \%$ & $0.2 \%$ & $0.5 \%$ & $0.2 \%$ & $0.2 \%$ & $0.2 \%$ & $0.3 \%$ \\
\hline Outstanding internal and external debt/GDPm ratio & $<=70 \%$ & 0.0 & 0.0 & 0.0 & 0.0 & 0.0 & 0.0 & 0.0 \\
\hline Incl. outstanding external debt/GDPm & & $23.3 \%$ & $24.9 \%$ & $25.2 \%$ & $21.1 \%$ & $18.2 \%$ & $18.2 \%$ & $22.6 \%$ \\
\hline Variation of internal arrear payments (in CFAF billion) & $<=0$ & 0.0 & 0.0 & 0.0 & 0.0 & 0.0 & 0.0 & 0.0 \\
\hline Variation of external arrear payments (in CFAF billion) & $<=0$ & 0.0 & 0.0 & 0.0 & 0.0 & 0.0 & 0.0 & 0.0 \\
\hline Second rank criteria & & & & & & & & \\
\hline Wage bill/tax revenue ratio & $<=35 \%$ & $31.7 \%$ & $31.5 \%$ & $28.1 \%$ & $28.2 \%$ & $28.8 \%$ & $28.8 \%$ & $29.1 \%$ \\
\hline $\begin{array}{l}\text { Public investments financed with internal resources/tax } \mathrm{r} \\
\text { ratio }{ }^{2 /}\end{array}$ & venue & $25.8 \%$ & $22.5 \%$ & $22.5 \%$ & $22.5 \%$ & $22.5 \%$ & $22.5 \%$ & $22.5 \%$ \\
\hline Current external deficit excl. public transfers/GDPm rati & $<=5 \%$ & $-7.4 \%$ & $-7.3 \%$ & $-7.0 \%$ & $-6.7 \%$ & $-7.3 \%$ & $-7.3 \%$ & $-7.3 \%$ \\
\hline Tax pressure rate $(=$ Tax revenue/GDPm) & $>=17 \%$ & $14.7 \%$ & $14.9 \%$ & $17.0 \%$ & $17.0 \%$ & $17.0 \%$ & $17.0 \%$ & $16.6 \%$ \\
\hline
\end{tabular}

1/ Revenue (excluding grants) less total expenditure (including net loans) (excluding capital expenditure with external financing and excl. HIPC)/GDPm

2/ Here only BSI investment

Source: DNPD, MME-DNPD model. 


\section{BudgetARY AlLocations by TyPe OF EXPENDITURE 2007 - 2011}

Table 34: Budget Breakdown by Type (DGB Presentation) (in CFAF billion) 2006 - 2011

\begin{tabular}{|c|c|c|c|c|c|c|}
\hline YEAR & 2006 & 2007 & 2008 & 2009 & 2010 & 2011 \\
\hline Personnel & 149.038 & 160.479 & 174.152 & 186.353 & 205.351 & 222.610 \\
\hline Equipment-operating & 57.943 & 64.946 & 74.483 & 81.317 & 89.827 & 100.075 \\
\hline Travel - Mission & 29.856 & 33.667 & 36.612 & 38.712 & 41.624 & 41.853 \\
\hline Communication - Energy & 32.641 & 32.061 & 36.307 & 40.385 & 44.337 & 49.099 \\
\hline Other expenditure & 44.348 & 61.490 & 49.204 & 50.978 & 52.267 & 60.101 \\
\hline Scholarship grants & 5.640 & 5.460 & 5.640 & 5.640 & 5.640 & 5.640 \\
\hline Supplementary budgets & 5.387 & 5.672 & 6.091 & 6.541 & 6.785 & 6.599 \\
\hline Equipment - Capital & 135.972 & 151.270 & 159.923 & 169.787 & 177.367 & 187.945 \\
\hline Transfers and subsidies & 91.176 & 98.048 & 103.401 & 107.391 & 111.497 & 115.934 \\
\hline Restructuring of public enterprises & 5.000 & 1.000 & 5.000 & 5.000 & 5.000 & 5.000 \\
\hline Liquidation of regular liabilities + exchange losses & 2.324 & 2.365 & 2.784 & 2.759 & 2.673 & 2.636 \\
\hline Principal - interest - debt & 80.690 & 47.756 & 46.055 & 47.406 & 48.683 & 51.557 \\
\hline BSI (external financing) & 233.465 & 245.899 & 268.400 & 290.300 & 317.200 & 345.300 \\
\hline Clearance of liabilities & 15.055 & 17.080 & 10.830 & 10.732 & 10.396 & 10.253 \\
\hline Budget support & 47.224 & 49.227 & 35.503 & 31.751 & 34.702 & 37.145 \\
\hline TOTAL & 935.759 & 976.602 & $1,014.385$ & $1,075.052$ & $1,153.349$ & $1,241.745$ \\
\hline In \% of GDP & 2006 & 2007 & 2008 & 2009 & 2010 & 2011 \\
\hline Personnel & $4.6 \%$ & $4.7 \%$ & $4.8 \%$ & $4.8 \%$ & $4.9 \%$ & $5.0 \%$ \\
\hline Equipment - operating & $1.8 \%$ & $1.9 \%$ & $2.0 \%$ & $2.1 \%$ & $2.1 \%$ & $2.2 \%$ \\
\hline Travel - Mission & $0.9 \%$ & $1.05 \%$ & $1.0 \%$ & $1.0 \%$ & $1.0 \%$ & $0.9 \%$ \\
\hline Communication - Energy & $1.0 \%$ & $0.9 \%$ & $1.0 \%$ & $1.0 \%$ & $1.1 \%$ & 1.15 \\
\hline Other expenditure & $1.4 \%$ & $1.8 \%$ & $1.3 \%$ & $1.3 \%$ & $1.2 \%$ & $1.3 \%$ \\
\hline Scholarship grants & $0.2 \%$ & $0.2 \%$ & $0.2 \%$ & $0.1 \%$ & $0.1 \%$ & $0.1 \%$ \\
\hline Supplementary budgets & $0.2 \%$ & $0.2 \%$ & $0.2 \%$ & $0.2 \%$ & $0.1 \%$ & $0.1 \%$ \\
\hline Equipment - Capital & $4.2 \%$ & $4.4 \%$ & $4.4 \%$ & $4.4 \%$ & $4.2 \%$ & $4.2 \%$ \\
\hline Transfers and subsidies & $2.8 \%$ & $2.9 \%$ & $2.8 \%$ & $2.8 \%$ & $2.7 \%$ & $2.6 \%$ \\
\hline Restructuring of public enterprises & $0.2 \%$ & $0.0 \%$ & $0.1 \%$ & $0.1 \%$ & $0.1 \%$ & $0.1 \%$ \\
\hline Liquidation of regular liabilities + exchange losses & $0.1 \%$ & $0.1 \%$ & $0.1 \%$ & $0.1 \%$ & $0.1 \%$ & $0.1 \%$ \\
\hline Principal - interest - debt & $2.5 \%$ & $1.4 \%$ & $1.3 \%$ & $1.2 \%$ & $1.2 \%$ & $1.1 \%$ \\
\hline BSI (external financing) & $7.3 \%$ & $7.2 \%$ & $7.4 \%$ & $7.5 \%$ & $7.6 \%$ & $7.7 \%$ \\
\hline Clearance of liabilities & $0.5 \%$ & $0.5 \%$ & $0.3 \%$ & $0.3 \%$ & $0.2 \%$ & $0.2 \%$ \\
\hline Budget support & $1.5 \%$ & $1.4 \%$ & $1.0 \%$ & $0.8 \%$ & $0.8 \%$ & $0.8 \%$ \\
\hline TOTAL & $29.2 \%$ & $28.6 \%$ & $27.8 \%$ & 27.7 & $27.5 \%$ & $27.7 \%$ \\
\hline
\end{tabular}

Source: Projection DGB, DNPD, DGDP

\section{Staff}

36. The salary policy will remain unchanged, and will systematically be incorporated in the budget process on the basis of some key indicators (available resources, comparisons with the private sector, productivity and priority objectives).

37. It would try to solve its structural problems through the following measures, prepared by a high-level Government Commission:

- establishment of an incentives structure, which encourages promotion by merit, rather than automatically by seniority;

- streamlining of allowances and bonuses to reduce their number and improve the targeting of priority objectives and results. In particular, allowances and bonuses could further promote poverty reduction objectives, such as services in remote areas;

- relaxing the salary scales to offer appropriate incentives to qualified staff;

- inclusion of formulation of the salary policy in the budget process based on some key indicators (available resources, comparisons with the private sector, productivity and priority objectives).

- improvement of consistency of policies with the incentive structure of remunerations through a medium-term human resources strategy linked to the Millennium Goals.

38. Special attention will be paid to improvement of consistency of policies with the incentive structure of remunerations through a medium-term human resources strategy linked to the Millennium Goals. 
39. The wage bill in 2007 amounts to CFAF 160.48 billion, and will stand at CFAF 174.15 billion in 2008, CFAF 186.35 billion in 2009, CFAF 205.35 billion in 2010, and CFAF 222.61 billion in 2011, representing an increase rate of $8.5 \%$ in $2007,7.0 \%$ in 2008 , $10.2 \%$ in 2009 , and $8.4 \%$ in 2010 respectively. These increases are mainly due to coverage, each year, of:

\begin{tabular}{|l|l|}
\hline Statutory advancements and recruitment in the Public service for about & CFAF 3.5 billion \\
\hline Financial incidence on full year of recruitment of workers in the Public service for about & CFAF 1.9 billion \\
\hline Incidence of various regularizations for about & CFAF 2 billion \\
\hline $\begin{array}{l}\text { Incidence of allowances and bonuses earmarked by the Government for Basic and } \\
\text { Secondary Education Teachers for about }\end{array}$ & CFAF 1.5 billion \\
\hline Education & CFAF 354.4 million \\
\hline Health & CFAF 352.6 million \\
\hline Justice & CFAF 227.8 million \\
\hline Police & CFAF 487.2 million \\
\hline Other administrative services & CFAF 500 million \\
\hline Recruitment into the Armed Forces & CFAF 724.9 million \\
\hline Allowances and bonuses for the Armed Forces & CFAF 351 million \\
\hline
\end{tabular}

40. The objective at this level is to provide capacity building to human resources in all sectors with special emphasis on the social sectors (Education, Health).

41. Furthermore, it should be recalled that the salary projections include modification of index point value as from 2007 for a financial incidence of CFAF 3.7 billion.

\section{Equipment - Operating Expenses}

42. Equipment and operating expenses amount to CFAF 64.95 billion in 2007, and will stand at CFAF 74.48 billion in 2008, CFAF 81.32 billion in 2009, CFAF 89.83 billion in 2010, and CFAF 100.08 billion in 2011, representing an increase rate of $14.7 \%$ in $2007,9.2 \%$ in $2008,10.5 \%$ in 2009 , and $11.4 \%$ in 2010 respectively. These increases are due to:

- reinforcement of the item "purchase of technical supplies and drugs" in health;

- reinforcement of the item "purchase of teaching aids" taking into account the evolution of enrolment in the different cycles of education.

43. The main actions will concern:

- providing children and instructors with teaching aids (textbooks and guides) ;

- continuous training of the instructors;

- capacity building for the local stakeholders;

- provision of school textbooks;

- widespread establishment of documentation and information centres in institutions, their sufficient supply of books and introduction of a textbooks loan policy to pupils;

- continuous training of teachers;

- strengthening of the Secondary Education Inspectorate (IES) ;

- strengthening of supervision, with reduction of the number of students per teacher from 33 to 32 over the period;

- substantial provision of books and annual upgrading of the library funds;

- providing secondary education institutions with laboratories, computer rooms and specialized technical staff;

- establishment of exchange programmes with big foreign universities and schools in technical and administrative areas;

- intensification of scientific research;

- increase in allocations to other departments to ensure greater functionality.

44. Equipment expenditure projections take into account coverage of needs relating to furniture, office supplies and computer consumables of administrative services within a context of modernization and capacity building for State intervention. Efforts will be geared towards the deconcentrated administrative services at the regional level. 


\section{Travel and Mission}

45. Travel expenses amount to CFAF 33.67 billion in 2007, and will stand at CFAF 36.61 billion in 2008, CFAF 38.71 billion in 2009, CFAF 41.62 billion in 2010, and CFAF 41.85 billion in 2011 , representing an increase rate of $8.8 \%$ in $2007,5.7 \%$ in $2008,7.5 \%$ in 2009 , and $0.6 \%$ in 2010 respectively.

46. These increases are mainly due to higher allocations to Ministries for missions within the country and readjustment of the allocation for the transportation of pupils and students within the country and abroad during the holidays, given the increase in enrolment. The projection takes into account an increase in allocations to deconcentrated Government services.

\section{Communication and Energy}

47. Communication and energy expenditures in 2007 amount to CFAF 32.06 billion, and will stand at CFAF 36.31 billion in 2008, CFAF 40.39 billion in 2009, CFAF 44.34 billion in 2010, and CFAF 49.10 billion in 2011, representing an increase rate of $13.2 \%$ in 2007 , $11.2 \%$ in $2008,9.8 \%$ in 2009 , and $10.7 \%$ in 2010 respectively. These increases are due to:

- pursuance of alignment of budgetary allocations on the real levels of consumption at the national and regional levels;

- increase in the number of Government services;

- development of new communication technologies.

48. Furthermore, actions to control communication, water and electricity expenditures will be concurrently initiated and carried out.

\section{Other Expenditures}

49. The other expenditures in 2007 stand at CFAF 61.49 billion, and will amount to CFAF 49.20 billion in 2008, CFAF 50.98 billion in 2009, CFAF 52.27 billion in 2010, and CFAF 60.10 billion in 2011, representing a $20.0 \%$ decline in comparison to 2007, an increase rate of $3.6 \%$ in $2008,2.5 \%$ in 2009 and $15.0 \%$ in 2010 respectively. These figures are mainly due to training expenditures, election expenditures, and reimbursement of VAT credit. It should be underscored that 2007 is an election year.

\section{Supplementary Budgets and Special Accounts and Funds}

50. The supplementary budgets in 2007 amount to CFAF 5.672 billion, and will stand at CFAF 6.091 billion in 2008, CFAF 6.541 billion in 2009, CFAF 6.785 billion in 2010, and CFAF 6.599 billion in 2011. These concern:

- Malian warehouses in Senegal, Togo, Côte d'Ivoire, Guinea, Mauritania and Ghana ;

- the Road Crossing Charges Fund;

- the Mineral Resources Development Programme;

- the Equipment Security Fund ;

- the Oil Exploration Promotion Support Fund.

\section{Equipment - Investment}

51. The proposed equipment-investment expenditures in 2007 amount to CFAF 151.27 billion, and will stand at CFAF 159.92 billion in 2008, CFAF 169.79 billion in 2009, CFAF 177.37 billion in 2010, and CFAF 187.95 billion in 2011, representing an increase rate of $5.7 \%$ in $2007,6.2 \%$ in $2008,4.5 \%$ in 2009 , and $6.0 \%$ in 2010 respectively.

52. The increases are due to coverage of counterpart funds for investment projects in the Three-year Investment Programme and the financing of new projects and programmes with an impact on poverty reduction in line with the PRSP. 


\section{$\underline{\text { Transfers and Subsidies }}$}

53. Expenditures relating to transfers and subsidies, excluding grants and expenditures on the restructuring of enterprises, in 2007 amount to CFAF 98.05 billion, and will stand at CFAF 103.40 billion in 2008, CFAF 107.39 billion in 2009, CFAF 111.50 billion in 2010, and CFAF 115.93 billion in 2011, representing an increase rate of $5.5 \%$ in $2007,3.9 \%$ in $2008,3.8 \%$ in 2009 , and $4.0 \%$ in 2010 respectively. The increase shows:

- the Government's desire to control subsidies granted to personalized public establishments;

- the parametric reform measures, which will help to gradually reduce the estimated deficit of the Pension Fund of Mali.

54. However, more than half of the estimated transfers and subsidies are intended for personalized public establishments.

Table 35: Trend of Transfer Expenditures 2006-2011 (in CFAF billion)

\begin{tabular}{|l|r|r|r|r|r|r|}
\hline ITEMS & \multicolumn{2}{|c|}{$\mathbf{2 0 0 6}$} & \multicolumn{1}{c|}{$\mathbf{2 0 0 7}$} & \multicolumn{1}{c|}{$\mathbf{2 0 0 8}$} & \multicolumn{1}{c|}{$\mathbf{2 0 0 9}$} & \multicolumn{2}{|c|}{$\mathbf{2 0 1 0}$} & $\mathbf{2 0 1 1}$ \\
\hline Subsidies to EPAs & 45.4 & 52.56 & 48.32 & 49.64 & 51.14 & 52.55 \\
\hline CRM & 17.96 & 20.94 & 18 & 18 & 18 & 18 \\
\hline Others & 38.46 & 31,19 & 47.72 & 50.39 & 53 & 56.02 \\
\hline TOTAL & $\mathbf{1 0 1 . 8 2}$ & $\mathbf{1 0 4 . 6 9}$ & $\mathbf{1 1 4 . 0 4}$ & $\mathbf{1 1 8 . 0 3}$ & $\mathbf{1 2 2 . 1 4}$ & $\mathbf{1 2 6 . 5 7}$ \\
\hline
\end{tabular}

NB $=$ * The total of transfers contains grants and amount for restructuring of enterprises.

Source: DGDP, DGB

55. Expenditures on the restructuring of public enterprises amount to CFAF one billion in 2007 and CFAF 5 billion over the 2008, 2009, 2010 and 2011 period.

56. Grants will not undergo significant change; they will remain constant over the period, and stand at CFAF 5.64 billion each year.

\section{Liquidation of Regular Liabilities and Exchange Losses}

57. Expenditures relating to liquidation of the regular liabilities and exchange losses in 2007 amount to CFAF 2.37 billion, and will stand at CFAF 2.78 billion in 2008, CFAF 2.76 billion in 2009, CFAF 2.67 billion in 2010, and CFAF 2.64 billion in 2011.

58. The estimates for "liquidation of regular liabilities" will cover pending situations in enterprises whose liquidation is not yet completed.

\section{Debt- Principal - Interest}

59. The principal and interest of the debt in 2007 amount to CFAF 47.76 billion, and will stand at CFAF 46.06 billion in 2008, CFAF 47.41 billion in 2009, CFAF 48.68 billion in 2010, and CFAF 51.56 billion in 2011. This trend takes into account the foreign debt cancellation under MDRI.

\section{Expenditure using HIPC Resources}

60. Debt relief resources will be used to finance priority programmes and projects in the Poverty Reduction Strategy Paper in Education, Health, Social Development, Rural Development, Sanitation, Drinking Water and Gender Promotion.

61. These resources will also be used for current expenditure in improving basic social services, in particular the recruitment of teachers in the Education sector and Health employees. Projections for expenditure using HIPC Initiative resources from 2007 to 2009 are as follows: 
Table 36: Trend of HIPC Expenditures 2006-2011 (in CFAF billion)

\begin{tabular}{|c|c|c|c|c|c|c|}
\hline & 2006 & 2007 & 2008 & 2009 & 2010 & 2011 \\
\hline STAFF HIPC & 19.119 & 21.604 & 24.089 & 26.574 & 29.059 & 31.544 \\
\hline EQUIPMENT HIPC & 0.240 & 0.240 & 0.271 & 0.282 & 0.298 & 0.312 \\
\hline EQUIP. \& INVEST. HIPC & 1.150 & 1.722 & 1.275 & 1.414 & 1.618 & 1.814 \\
\hline TRANSFERS \& SUBSIDIES HIPC & 6.492 & 5.920 & 5.886 & 5.337 & 4.673 & 4.188 \\
\hline BSI INTERNAL FINANCING HIPC & 6.583 & 6.583 & 6.517 & 6.451 & 6.364 & 6.293 \\
\hline TOTAL EXPENDITURE HIPC & 33.584 & 36.069 & 38.038 & 40.057 & 42.013 & 44.151 \\
\hline
\end{tabular}

\section{Source: DGDP, DGB}

\section{External Financing of the Special Investment Budget}

62. Under its development policy, Mali designs and implements development projects/ programmes through the Special Investment Fund (BSI).

63. Most of these projects/programmes are financed by development partners, as well as the Government of Mali through counterpart funds.

64. Accordingly, over the past five years (2001-2005), the Government earmarked an allocation of CFAF 1,452.64 billion, with the development partners contributing CFAF 1083. 31 billion (74.6\%), and a contribution from the national budget of about CFAF 369.33 billion $(25.4 \%)$.

65. Over the same period, an average disbursement of about 727.94 billion, representing $67.2 \%$, was made through external financing, and CFAF 314.20 billion, representing $85.1 \%$, through internal financing.

66. The implementation of these development projects/programmes is often hampered by various difficulties, leading to many extensions of the completion dates of projects/programmes and additional costs with an impact on the budget deficit. This creates a deficit in the State Budget contribution to the financing of new projects. The deficit thus created increases each year.

67. The budget deficit was CFAF 46.03 billion in 2001, CFAF 61.75 billion in 2002, CFAF 80.50 billion in 2003, CFAF 87.90 billion in 2004, and CFAF 88.63 billion in 2005 . This budget deficit increased by $92.1 \%$ between 2001 and 2005 .

68. The various projects/programmes review exercises showed a slight improvement in the overall disbursement, which increased from $39.8 \%$ as at 31 December 2000 to $42.0 \%$ as at 31 December 2004.

69. For the ongoing projects, the disbursement rate increased from $42.72 \%$ as at 31 December 2000 to $49.8 \%$ as at 31 December 2004 . It should be stressed that there are disparities between these disbursement rates.

70. For example, in 2004 out of 473 projects/programmes, comprising 342 ongoing and 131 under preparation, the internal financing implementation rate was about $63.2 \%$ while that of external financing was only about $36.6 \%$.

71. The low BSI implementation rate is mainly due to difficulties in mobilizing resources for most projects/programmes with an external financing component.

72. Accordingly, out of a sample of 302 projects/programmes cofinanced by resources acquired through external financing, 140 projects/programmes required extensions of disbursement deadlines, representing $46.4 \%$. The sectoral breakdown of these projects/programmes is as follows: 
Table 37: Sectoral Breakdown of Projects and Programmes

\begin{tabular}{|l|r|r|r|}
\hline & No. of Projects & $\begin{array}{c}\text { No. of Projects with } \\
\text { Extended Deadlines }\end{array}$ & \multicolumn{1}{|c|}{ Percentage } \\
\hline & -1 & -2 & $\mathbf{3}=\mathbf{2} / \mathbf{1})$ \\
\hline $\begin{array}{l}\text { Public Authorities and General } \\
\text { Administration }\end{array}$ & 39 & 19 & $48.70 \%$ \\
\hline Education & 26 & 9 & $34.60 \%$ \\
\hline Health & 10 & 4 & $40 \%$ \\
\hline Culture, Youth, Sports & 4 & 2 & $50 \%$ \\
\hline Social Sectors & 6 & 2 & $16.60 \%$ \\
\hline Agriculture & 118 & 55 & $46.60 \%$ \\
\hline Mining, Water Resources, Industry & 53 & 19 & $35.80 \%$ \\
\hline Transport & 46 & 30 & $65.20 \%$ \\
\hline Total & $\mathbf{3 0 2}$ & $\mathbf{1 4 0}$ & $\mathbf{4 6 . 3 5 \%}$ \\
\hline
\end{tabular}

\section{Source: DNDP}

\section{NB: PRODEC and PRODESS were considered as separate projects.}

73. An analysis of the above table shows that the sectors with the highest number of extended projects concern: (i) transport: $65.2 \%$, (ii) Agriculture: 46.6\%, (iii) Health: $40.0 \%$, (iv) Mining, Water Resources, Industry: $35.8 \%$, and (v) Education: $34.6 \%$. The social sectors, excluding health and education, have projects with the least number of extended disbursement deadlines, representing $16.6 \%$.

74. The average implementation period for projects/programmes and average project duration, including extensions of disbursement and completion deadlines for projects/programmes are given in the table below:

Table 38: Average Project and Programmes Duration

\begin{tabular}{|l|c|c|}
\hline Description & $\begin{array}{c}\text { Average Project } \\
\text { Impl. Period }\end{array}$ & $\begin{array}{c}\text { Average Period } \\
\text { Incl. Extensions }\end{array}$ \\
\hline Agriculture & 5 years & 8 years \\
\hline Education & 5 years & 7 years \\
\hline Health & 5 years & 7 years \\
\hline Transport & 4 years & 6 years \\
\hline Mining - Water Resources & 4 vears & 6 vears \\
\hline
\end{tabular}

\section{Source: DNDP}

75. It should be noted that the request for extension of disbursement covers an average period of one year, and could even be two financial years. The average extension granted by the donor is one year.

76. The extension of completion dates for projects/programmes requires additional financial resources, which are often generally covered by the State Budget in accordance with the clauses of financing agreements. For example, the additional amounts incurred as a result of extensions of the completion dates of some projects/programmes are presented in the table below:

Table 39: Some Projects and Programmes following Extensions of Completion Dates (in CFAF million) 


\begin{tabular}{|l|r|r|l|}
\hline \multicolumn{1}{|c|}{ Description } & Initial Amount & \multicolumn{1}{|c|}{$\begin{array}{c}\text { Additional } \\
\text { Amount }\end{array}$} & Remarks \\
\hline $\begin{array}{l}\text { Saouné Plain Agricultural } \\
\text { Development Project }\end{array}$ & 3888.00 & 576.00 & Ongoing \\
\hline $\begin{array}{l}\text { Poultry Development Project } \\
\text { In Mali }\end{array}$ & 4039.00 & 374.00 & Ongoing \\
\hline $\begin{array}{l}\text { Mopti and Tombouctou } \\
\text { Integrated Dev Project }\end{array}$ & 2266.00 & 813.00 & Ongoing \\
\hline Gao Village Irrigation Project & 4080.00 & 38.00 & Ongoing \\
\hline $\begin{array}{l}\text { Western Sahel Livestock } \\
\text { DevelopmentProject }\end{array}$ & 7823.00 & 50.00 & Ongoing \\
\hline $\begin{array}{l}\text { Niafunké Lake Zone } \\
\text { DevelopmentProject }\end{array}$ & 12120.00 & 503.00 & Ongoing \\
Total & 34216.00 & 2354.00 & \\
\hline
\end{tabular}

\section{Source: DNDP}

77. It should be stressed that despite many extensions (see table in Annex), these projects are still ongoing. The extensions of completion and disbursement dates of projects/programmes are due mainly to:

78. Generic causes:

- delays in the ratification and effectiveness of loan or grant agreements;

- delays in fulfillment of the conditions precedent to the first disbursement. These conditions are discussed and accepted at the time of project/programme appraisal and validated during negotiation of the loan or grant. However, their fulfillment takes one and a half to two years.

79. For the fulfillment of these two pre-conditions for all the loan or grant agreements, it takes two to three years without any disbursement of external financing. During this period, the Government has already mobilized the counterpart funds;

- the long, slow and cumbersome procurement procedure (works and services) at the national level and with the donors. The average period is one and a half years for works, and one year for consultancy services. These periods may double in the case of cofinancing with several donors. The long period is due to the complexity of procedures because at each stage, the prior approval of the donor is required.

80. For example, for the works: The bidding documents should be approved by the Directorate General of Public Procurements (DGMP) and the donor(s). The invitation to bid takes 90 days. The procedure for opening bids and awarding contracts, as well as the report on the opening of bids are approved by DGMP and the donor(s). The report on the negotiations and the draft contract follow the same approval procedure. Each of these stages affects the project duration.

- Ignorance of the procedures of the technical and financial partners by the stakeholders leads to many rejections of the files during processing;

- Mobility of staff of the Project Management Units (PMU).

81. The technical causes are mainly related to inadequate final or preliminary designs of projects. These cases are frequent in projects relating to roads, dam construction, irrigation schemes and water resources.

82. The above inadequacies lead mainly to additional financing as in the case of projects for the construction of Gao Bridge (30\% additional financing), Rehabilitation of inland aerodromes, construction of the Nioro du Sahel - Mauritania border road, construction of urban roads in Bamako, agricultural development downstream Manantali dam, and agricultural development of Ké-Macina Phase II. 
83. Other causes include:

- decline of the exchange rate of the currency of project/programme financing. In 2005, this decline reached $26 \%$ in the case of the US\$ in relation to the EURO/CFAF;

- low capacity of the selected enterprises, leading to extensions of completion dates of works and even, often, cancellations; and

- addition of works.

84. To solve these problems, the following recommendations have been made:

- accelerate ratification and effectiveness procedures for loan or grant agreements;

- organize high-level missions to partners to expedite the files;

- attach project/programme implementation to public structures;

- conduct reliable studies on projects/programmes formulation and implementation;

- provide capacity building for stakeholders involved in the design and implementation of projects and programmes; and

- bring enterprises to keep strictly to their contractual commitments.

85. The financial scheduling of BSI external financing over the 2007-2011 period is as follows:

86. The external financing of BSI in 2007 amounts to CFAF 245.90 billion. The financing is estimated at CFAF 268.40 billion in 2008, CFAF 290.30 billion in 2009, CFAF 317.20 billion in 2010, and CFAF 345.30 billion in 2011. According to the three-year investment programme, BSI expenditures (external financing) could be broken down by area of intervention as follows:

Table 40: Breakdown of BSI (External Financing) by Area of Intervention 2006-2008

\begin{tabular}{|l|r|r|}
\hline \multicolumn{1}{|c|}{ AREA OF INTERVENTION } & AMT. FOR 2006-2008 & In \% \\
\hline Agriculture & 125172000 & 22.12 \\
\hline Livestock & 20936000 & 3.70 \\
\hline Fisheries & 11376000 & 2.01 \\
\hline Forestry & 11469000 & 2.03 \\
\hline Mines - Energy - Water & 75815000 & 13.40 \\
\hline Industry - Handicraft - Tourism & 12565000 & 2.22 \\
\hline Equipment-Transport -Town Planning-Comm & 169788000 & 30.01 \\
\hline Education & 45435000 & 8.03 \\
\hline Sports- Art - Culture & 431000 & 0.08 \\
\hline Health - Social Development & 70492000 & 12.46 \\
\hline General Administration - Decentralization & 22339000 & 3.95 \\
\hline Grand Total & $\mathbf{5 6 5 8 1 8 0 0 0}$ & $\mathbf{1 0 0 . 0 0}$ \\
\hline
\end{tabular}

Source: Three-year Investment Programme (DNPD)

87. It can be noted that the Equipment-Transport-Town Planning-Communication sector accounts for $30.0 \%$ of the total BSI amount (external financing), while the SPORT- ARTCULTURE sector accounts for the lowest rate of $0.1 \%$.

\section{Clearance of Liabilities}

88. The clearance of liabilities amounts to CFAF 17.10 billion in 2007 , and will stand at CFAF 10.83 billion in 2008, CFAF 10.73 billion in 2009, CFAF 10.40 billion in 2010, and CFAF 10.25 billion in 2011. This projection will cover some telephone bills and liabilities of some restructured corporations. It should be pointed out that it will cover the amount of CFAF 2.70 billion as payment of the Public Treasury guarantees and securities over the period. 


\section{Sectoral Budgetary Allocations 2007-2011}

\subsection{Overview}

89. The sectoral allocation of budgetary expenditures over the 2007-2011 period took into account the impetus that will be given to the productive sectors without worsening the recurrent cost ratios of social sectors. According to projections, the productive sector will have an average of $32.2 \%$ of overall ratios as against $27.8 \%$ for the social sector. The overall ratios of the productive sector are driven substantially by the portion of BSI allocated; in other words, investments will be increasingly geared towards this sector to stimulate growth.

Table 41: Sectoral Breakdown of Expenditures (DGB Presentation) 2006-2011 in CFAF billion

\begin{tabular}{|c|c|c|c|c|c|c|}
\hline SECTORS OF ACTIVITY & 2006 & 2007 & 2008 & 2009 & 2010 & 2011 \\
\hline PUBLIC AUTHORITIES AND GENERAL ADMINISTRA & 115.695 & 117.318 & 128.993 & 133.177 & 142.494 & 153.243 \\
\hline DIPLOMACY AND FOREIGN AFFAIRS & 16.714 & 20.265 & 20.300 & 21.778 & 23.706 & 25.455 \\
\hline NATIONAL DEFENCE AND INTERNAL SECURITY & 68.920 & 75.633 & 77.290 & 83.323 & 93.860 & 101.587 \\
\hline BASIC EDUCATION & 119.322 & 122.629 & 135.451 & 138.575 & 145.436 & 159.035 \\
\hline SEC. HIGHER EDUCATION \& SCIENTIFIC RESEARCI & 39.169 & 41.494 & 44.171 & 47.763 & 52.004 & 56.805 \\
\hline CULTURE YOUTH AND SPORTS & 13.051 & 13.668 & 14.780 & 15.758 & 17.150 & 18.126 \\
\hline HEALTH & 72.684 & 65.307 & 70.146 & 72.299 & 79.797 & 87.417 \\
\hline SOCIAL SECTORS & 27.849 & 36.620 & 38.799 & 38.976 & 41.126 & 43.342 \\
\hline EMPLOYMENT & 7.636 & 7.876 & 7.698 & 7.045 & 7.996 & 8.785 \\
\hline AGRICULTURE & 118.283 & 131.192 & 132.908 & 145.563 & 158.222 & 170.297 \\
\hline MINING WATER RESOURCES AND INDUSTRY & 53.859 & 68.353 & 72.882 & 79.626 & 85.120 & 91.030 \\
\hline TOWN PLANNING AND PUBLIC WORKS & 99.217 & 115.376 & 119.051 & 131.830 & 140.332 & 150.908 \\
\hline TRANSPORT & 10.570 & 13.749 & 14.580 & 15.969 & 18.133 & 19.982 \\
\hline COMMUNICATION & 9.100 & 10.845 & 11.945 & 12.775 & 13.579 & 14.487 \\
\hline DOMESTIC DEBT & 1.637 & 1.748 & 1.602 & 1.520 & 1.445 & 1.372 \\
\hline FOREIGN DEBT & 61.522 & 34.239 & 34.410 & 36.103 & 37.852 & 41.513 \\
\hline INTEREST FOREIGN DEBT & 17.531 & 11.769 & 10.042 & 9.783 & 9.385 & 8.671 \\
\hline UNALLOCATED FUNDS & 83.002 & 88.522 & 79.337 & 83.189 & 85.712 & 89.688 \\
\hline $\begin{array}{r}\text { TOTAL } \\
\end{array}$ & 935.759 & 976.602 & $1,014.385$ & $1,075.052$ & $1,153.349$ & $1,241.745$ \\
\hline
\end{tabular}

Source: DGB

Table 42: Sectoral Breakdown of Expenditures 2006-2011 in \% of GDP

\begin{tabular}{|c|c|c|c|c|c|c|}
\hline SECTORS OF ACTIVITY & 2006 & 2007 & 2008 & 2009 & 2010 & 2011 \\
\hline PUBLIC AUTHORITIES AND GENERAL AI & $3.6 \%$ & $3.4 \%$ & $3.5 \%$ & $3.4 \%$ & $3.4 \%$ & $3.4 \%$ \\
\hline DIPLOMACY AND FOREIGN AFFAIRS & $0.5 \%$ & $0.6 \%$ & $0.6 \%$ & $0.6 \%$ & $0.6 \%$ & $0.6 \%$ \\
\hline NATIONAL DEFENCE AND INTERNAL SE & $2.1 \%$ & $2.2 \%$ & $2.1 \%$ & $2.1 \%$ & $2.2 \%$ & $2.3 \%$ \\
\hline BASIC EDUCATION & $3.7 \%$ & $3.6 \%$ & $3.7 \%$ & $3.6 \%$ & $3.5 \%$ & $3.5 \%$ \\
\hline SEC. HIGHER EDUCATION \& SCIENTIFIC & $1.2 \%$ & $1.2 \%$ & $1.2 \%$ & $1.2 \%$ & $1.2 \%$ & $1.3 \%$ \\
\hline CULTURE YOUTH AND SPORTS & $0.4 \%$ & $0.4 \%$ & $0.4 \%$ & $0.4 \%$ & $0.4 \%$ & $0.4 \%$ \\
\hline HEALTH & $2.3 \%$ & $1.9 \%$ & $1.9 \%$ & $1.9 \%$ & $1.9 \%$ & $1.9 \%$ \\
\hline SOCIAL SECTORS & $0.9 \%$ & $1.1 \%$ & $1.1 \%$ & $1.0 \%$ & $1.0 \%$ & $1.0 \%$ \\
\hline EMPLOYMENT & $0.2 \%$ & $0.2 \%$ & $0.2 \%$ & $0.2 \%$ & $0.2 \%$ & $0.2 \%$ \\
\hline AGRICULTURE & $3.7 \%$ & $3.8 \%$ & $3.6 \%$ & $3.7 \%$ & $3.8 \%$ & $3.8 \%$ \\
\hline MINING WATER RESOURCES AND INDUS & $1.7 \%$ & $2.0 \%$ & $2.0 \%$ & $2.0 \%$ & $2.0 \%$ & $2.0 \%$ \\
\hline TOWN PLANNING AND PUBLIC WORKS & $3.1 \%$ & $3.4 \%$ & $3.3 \%$ & $3.4 \%$ & $3.4 \%$ & $3.4 \%$ \\
\hline TRANSPORT & $0.3 \%$ & $0.4 \%$ & $0.4 \%$ & $0.4 \%$ & $0.4 \%$ & $0.4 \%$ \\
\hline COMMUNICATION & $0.3 \%$ & $0.3 \%$ & $0.3 \%$ & $0.3 \%$ & $0.3 \%$ & $0.3 \%$ \\
\hline DOMESTIC DEBT & $0.1 \%$ & $0.1 \%$ & $0.0 \%$ & $0.0 \%$ & $0.0 \%$ & $0.0 \%$ \\
\hline FOREIGN DEBT & $1.9 \%$ & $1.0 \%$ & $0.9 \%$ & $0.9 \%$ & $0.9 \%$ & $0.9 \%$ \\
\hline INTEREST FOREIGN DEBT & $0.5 \%$ & $0.3 \%$ & $0.3 \%$ & $0.3 \%$ & $0.2 \%$ & $0.2 \%$ \\
\hline UNALLOCATED FUNDS & $2.6 \%$ & $2.6 \%$ & $2.2 \%$ & $2.1 \%$ & $2.0 \%$ & $2.0 \%$ \\
\hline $\begin{array}{r}\text { TOTAL } \\
\end{array}$ & $29.2 \%$ & $28.6 \%$ & $27.8 \%$ & $27.7 \%$ & $27.5 \%$ & $27.7 \%$ \\
\hline
\end{tabular}

Source: DGB 
Table 43: Sectoral Breakdown of Expenditures 2006-2011 in \% of total

\begin{tabular}{|c|c|c|c|c|c|c|}
\hline \begin{tabular}{|c|} 
SECTORS OF ACTIVITY \\
\end{tabular} & 2006 & 2007 & 2008 & 2009 & 2010 & 2011 \\
\hline PUBLIC AUTHORITIES AND GENERAL AI & $12.4 \%$ & $12.0 \%$ & $12.7 \%$ & $12.4 \%$ & $12.4 \%$ & $12.3 \%$ \\
\hline DIPLOMACY AND FOREIGN AFFAIRS & $1.8 \%$ & $2.1 \%$ & $2.0 \%$ & $2.0 \%$ & $2.1 \%$ & $2.0 \%$ \\
\hline NATIONAL DEFENCE AND INTERNAL SE & $7.4 \%$ & $7.7 \%$ & $7.6 \%$ & $7.8 \%$ & $8.1 \%$ & $8.2 \%$ \\
\hline BASIC EDUCATION & $12.8 \%$ & $12.6 \%$ & $13.4 \%$ & $12.9 \%$ & $12.6 \%$ & $12.8 \%$ \\
\hline SEC. HIGHER EDUCATION \& SCIENTIFIC & $4.2 \%$ & $4.2 \%$ & $4.4 \%$ & $4.4 \%$ & $4.5 \%$ & $4.6 \%$ \\
\hline CULTURE YOUTH AND SPORTS & $1.4 \%$ & $1.4 \%$ & $1.5 \%$ & $1.5 \%$ & $1.5 \%$ & $1.5 \%$ \\
\hline HEALTH & $7.8 \%$ & $6.7 \%$ & $6.9 \%$ & $6.7 \%$ & $6.9 \%$ & $7.0 \%$ \\
\hline SOCIAL SECTORS & $3.0 \%$ & $3.7 \%$ & $3.8 \%$ & $3.6 \%$ & $3.6 \%$ & $3.5 \%$ \\
\hline EMPLOYMENT & $0.8 \%$ & $0.8 \%$ & $0.8 \%$ & $0.7 \%$ & $0.7 \%$ & $0.7 \%$ \\
\hline AGRICULTURE & $12.6 \%$ & $13.4 \%$ & $13.1 \%$ & $13.5 \%$ & $13.7 \%$ & $13.7 \%$ \\
\hline MINING WATER RESOURCES AND INDU\$ & $5.8 \%$ & $7.0 \%$ & $7.2 \%$ & $7.4 \%$ & $7.4 \%$ & $7.3 \%$ \\
\hline TOWN PLANNING AND PUBLIC WORKS & $10.6 \%$ & $11.8 \%$ & $11.7 \%$ & $12.3 \%$ & $12.2 \%$ & $12.2 \%$ \\
\hline TRANSPORT & $1.1 \%$ & $1.4 \%$ & $1.4 \%$ & $1.5 \%$ & $1.6 \%$ & $1.6 \%$ \\
\hline COMMUNICATION & $1.0 \%$ & $1.1 \%$ & $1.2 \%$ & $1.2 \%$ & $1.2 \%$ & $1.2 \%$ \\
\hline DOMESTIC DEBT & $0.2 \%$ & $0.2 \%$ & $0.2 \%$ & $0.1 \%$ & $0.1 \%$ & $0.1 \%$ \\
\hline FOREIGN DEBT & $6.6 \%$ & $3.5 \%$ & $3.4 \%$ & $3.4 \%$ & $3.3 \%$ & $3.3 \%$ \\
\hline INTEREST FOREIGN DEBT & $1.9 \%$ & $1.2 \%$ & $1.0 \%$ & $0.9 \%$ & $0.8 \%$ & $0.7 \%$ \\
\hline UNALLOCATED FUNDS & $8.9 \%$ & $9.1 \%$ & $7.8 \%$ & $7.7 \%$ & $7.4 \%$ & $7.2 \%$ \\
\hline $\begin{array}{r}\text { TOTAL } \\
\end{array}$ & $100.0 \%$ & $100.0 \%$ & $100.0 \%$ & $100.0 \%$ & $100.0 \%$ & $100.0 \%$ \\
\hline
\end{tabular}

Source: DGB

Table 44: Overall Ratios by Sector 2006-2011

\begin{tabular}{|l|r|r|r|r|r|r|}
\hline Sectors & $\mathbf{2 0 0 6}$ & $\mathbf{2 0 0 7}$ & $\mathbf{2 0 0 8}$ & $\mathbf{2 0 0 9}$ & $\mathbf{2 0 1 0}$ & $\mathbf{2 0 1 1}$ \\
\hline All Social Sectors & $\mathbf{2 7 . 6 8}$ & $\mathbf{2 7 . 2 4}$ & $\mathbf{2 8 . 4 5}$ & $\mathbf{2 7 . 6 8}$ & $\mathbf{2 7 . 6 0}$ & $\mathbf{2 7 . 9 1}$ \\
\hline EDUCATION & 16.94 & 16.81 & 17.71 & 17.33 & 17.12 & 17.38 \\
\hline HEALTH & 7.77 & 6.69 & 6,92 & 6.73 & 6.92 & 7.04 \\
\hline SOCIAL SECTORS & 2.98 & 3.75 & 3,82 & 3.63 & 3.57 & 3.49 \\
\hline Average & \multicolumn{7}{|c|}{$\mathbf{2 7 . 7 6}$} \\
\hline Productive Sectors & $\mathbf{2 9 . 0 0}$ & $\mathbf{3 2 . 1 4}$ & $\mathbf{3 2 . 0 2}$ & $\mathbf{3 3 . 2 1}$ & $\mathbf{3 3 . 2 7}$ & $\mathbf{3 3 . 2 0}$ \\
\hline$\quad$ AGRICULTURE & 12.64 & 13.43 & 13.10 & 13.54 & 13.72 & 13.71 \\
\hline $\begin{array}{l}\text { MINING, WATER RESOURCES AND } \\
\text { INDUSTRY }\end{array}$ & 5.76 & 7.00 & 7.18 & 7.41 & 7.38 & 7.33 \\
\hline$\quad$ TOWN PLANNING AND PUBLIC WORKS & 10.60 & 11.81 & 11.74 & 12.26 & 12.17 & 12.15 \\
\hline Average & \multicolumn{7}{|c|}{} \\
\hline Other Sectors & $\mathbf{4 3 . 3 2}$ & $\mathbf{4 0 . 5 1}$ & $\mathbf{3 9 . 5 3}$ & $\mathbf{3 9 . 1 1}$ & $\mathbf{3 9} .13$ & $\mathbf{3 8 . 8 9}$ \\
\hline Average & \multicolumn{7}{|c|}{$\mathbf{4 0 . 0 8}$} \\
\hline
\end{tabular}

Source: DGB

90. As regards recurrent cost ratios, the social sector will have an average of $47.6 \%$, as against $9.3 \%$ for the productive sector. This trend is due to the high predominance of recurrent expenditure in the social sector, comprising mainly almost incompressible expenditure such as staff, purchase of teaching aids, and subsidies to the Pension Fund of Mali and Public Hospital Institutions.

Table 45: Recurrent Cost Ratios by Sector 2006-2011

\begin{tabular}{|l|r|r|r|r|r|r|}
\hline Sectors & $\mathbf{2 0 0 6}$ & $\mathbf{2 0 0 7}$ & $\mathbf{2 0 0 8}$ & $\mathbf{2 0 0 9}$ & $\mathbf{2 0 1 0}$ & $\mathbf{2 0 1 1}$ \\
\hline Social Sectors & $\mathbf{4 6 . 6 7}$ & $\mathbf{4 7 . 2 1}$ & $\mathbf{4 7 . 6 8}$ & $\mathbf{4 8 . 0 7}$ & $\mathbf{4 8 . 1 9}$ & $\mathbf{4 7 . 8 9}$ \\
\hline Education & 30.07 & 30.12 & 30.29 & 30.29 & 30.31 & 30.41 \\
\hline HEALTH & 10.63 & 10.75 & 10.84 & 11.07 & 11.22 & 11.23 \\
\hline SOCIAL SECTORS & 5.97 & 6.34 & 6.56 & 6.70 & 6.65 & 6.25 \\
\hline Average & \multicolumn{7}{|c|}{$\mathbf{4 7 . 6 2}$} \\
\hline Productive sectors & $\mathbf{9 . 4 0}$ & $\mathbf{9 . 5 3}$ & $\mathbf{9 . 8 0}$ & $\mathbf{8 . 9 7}$ & $\mathbf{9 . 4 1}$ & $\mathbf{9 . 2 9}$ \\
\hline$\quad$ AGRICULTURE & 4.85 & 5.00 & 5.17 & 4.62 & 4.55 & 4.57 \\
\hline MINING WATER RES. AND INDUSTRY & 2.24 & 2.29 & 2.39 & 2.17 & 2.68 & 2.48 \\
\hline$\quad$ TOWN PLANNING AND PBLIC WORKS & 2.31 & 2.24 & 2.24 & 2.19 & 2.18 & 2.24 \\
\hline Average & & $\mathbf{9}$ & $\mathbf{9 . 3 4}$ \\
\hline Other sectors & $\mathbf{4 3 . 9 3}$ & $\mathbf{4 3 . 2 6}$ & $\mathbf{4 2 . 5 1}$ & $\mathbf{4 2 . 9 6}$ & $\mathbf{4 2 . 4 0}$ & $\mathbf{4 2 . 8 3}$ \\
\hline Average & \multicolumn{7}{|c|}{$\mathbf{4 2 . 9 8}$} \\
\hline
\end{tabular}

Source: DGB 


\subsection{Education}

91. Expenditures of the education sector in 2007 amount to CFAF 164.12 billion. They will increase to CFAF 179.62 billion in 2008, CFAF 186.34 billion in 2009, CFAF 197.44 billion in 2010, and CFAF 215.84 billion in 2011, representing an increase rate of $7.4 \%$ in $2007,3.7 \%$ in $2008,6.0 \%$ in 2009 , and $9.3 \%$ in 2010 respectively.

Table 46: Trend of Education Expenditure 2006-2011 (in CFAF billion)

\begin{tabular}{|l|r|r|r|r|r|r|}
\hline YEAR & $\mathbf{2 0 0 6}$ & $\mathbf{2 0 0 7}$ & $\mathbf{2 0 0 8}$ & $\mathbf{2 0 0 9}$ & $\mathbf{2 0 1 0}$ & $\mathbf{2 0 1 1}$ \\
\hline BASIC EDUCATION & 119.322 & 122.629 & 135.451 & 138.575 & 145.436 & 159.035 \\
\hline $\begin{array}{l}\text { SEC. EDUC. HIGHER } \\
\text { EDUC. \& SCIENTIFIC }\end{array}$ & 39.169 & 41.494 & 44.171 & 47.763 & 52.004 & 56.805 \\
\hline RESEARCH & $\mathbf{1 5 8 . 4 9 1}$ & $\mathbf{1 6 4 . 1 2 3}$ & $\mathbf{1 7 9 . 6 2 2}$ & $\mathbf{1 8 6 . 3 3 8}$ & $\mathbf{1 9 7 . 4 4 0}$ & $\mathbf{2 1 5 . 8 4 0}$ \\
\hline
\end{tabular}

Source: Projection DGB

92. These increases are due to the sectoral policy defined in the Ten-year Education Development Programme (PRODEC). The programme aims at universal education through basic schools and Development Education Centres (CED), and improvement of the quality of education at all levels of the education system. To that end, in the medium term, the recruitment policy each year in Education will continue:

- 847 employees for National Education under PRODEC ;

- 2000 teachers of Basic Education level;

- 360 teachers of Secondary Education level.

93. As regards equipment and investment, the following activities are expected:

- construction of the Secondary Education Inspectorate;

- providing basic and secondary schools with textbooks, library books and other teaching aids;

- finalization of the construction of the teaching block of FLASH ;

- construction of BUC ;

- construction and equipment of premises for the Faculties of Law and Economics;

- construction and equipment of an amphitheatre of 1000 seats;

- construction of hotel and tourism teaching structure of the University Institute of Management;

- construction of premises for the ETP Institute for the Training of Trainers;

- construction of a university restaurant;

- conduct of a feasibility study for a university sports and cultural space;

- construction and equipment of three (3) Residences of 1,000 places ;

- construction of the residence of the Rector;

- construction and equipment of Kalabancoro high school;

- construction and equipment of classrooms of CFPAA, Gao ;

- construction and equipment of Douentza high school.

PRODEC is centred on four components:

\subsubsection{Basic Education Component}

Pre-school Education:

- Initial training for about 120 pre-school teachers, and continuous education for about 300 instructors per year,

- Capacity building for pre-school teachers in the making of local teaching aids,

- Provision of teaching aids,

- Provision of a programme and a guide for each Children's Development Centre;

- Construction and equipment of the Pre-school Teachers' Training School (EFEP);

- Construction and equipment of 250 CDPEs. 
95. First Cycle of Basic Education

\section{Initial Training}

- construction and equipment of 2,000 classrooms on average per year for the first cycle taking into account the school map and criteria for choosing the site, including the existence of water point and the objective of reducing disparities ; and

- training of an average of 2,500 teachers per year.

Alternative Strategy for the Recruitment of Teaching Staff (SARPE)

SARPE is an intermediary strategy, which will disappear during PISE II. During implementation, the following activities will be carried out:

- training of new unqualified teachers for 6 months,

- gradual increase in the proportion of women recruited.

\section{Continuous Training}

96. Refresher Courses:

- training of 15,885 teachers, with $20 \%$ of this number each year and an average of 20 days for each teacher,

- continuous training for all teachers, irrespective of their status and the category of school (public, community, médersas).

97. Continuous training by the apprenticeship communities (CA):

- field pedagogic support for all public first cycle basic schools;

- training of employees of AEs and Pedagogic Training Centres (CAP) and providing them with operating resources, so that they effectively play their above-mentioned pedagogic supervisory and support role.

98. Continuous training through the school radio:

- widespread organization of this training in case of satisfactory results from the ongoing experimentation.

99. Curriculum Development

- $\quad$ gradual generalization of level 1 (1st and $2^{\text {nd }}$ years) ;

- trial and validation of level 2 ( $3^{\text {rd }}$ and $4^{\text {th }}$ years) ;

- $\quad$ preparation, trial and validation of level 3 ( $5^{\text {th }}$ and $6^{\text {th }}$ years of Basic Education);

- preparation, trial and validation of normal education curriculum;

- preparation and application of a relevant performance evaluation system for pupils in line with the curriculum.

100. School text books, library books, and teaching aids

- operationalize the basic options of the School text book and teaching aids policy, namely privatization of the school text books chain and decentralization of the purchase, distribution and management of text books, books, and teaching aids;

- observe transition period (2006-2007) during which the DAF will award contracts for text books, library books and teaching aids, and have them distributed by the private sector;

- encourage private national publishers to put additional text books and teaching aids on the market;

- provide all schools and all classes with teaching aids deemed indispensable;

- provide each teacher with a curriculum guide and a teacher's guide for each pupils' text book;

- provide each first year pupil of the first cycle with a national language text book and a mathematics text book;

- provide each second year pupil with 2 language text books (national and French) and a mathematics text book. 
- provide each second cycle pupil with four text books: French language, maths, physical science and natural science;

- produce and disseminate a text book management guide in all schools;

- create and equip libraries and reading corners in schools or classes;

- prepare a training module for teachers in reading, as well as the use and pedagogic management of libraries and reading corners.

101. Second Cycle of Basic Education

- Construct and equip an average of 1,000 classrooms per year taking into account the school map/eligibility criteria for the site, including the existence of a water point and the objective of reducing regional disparities;

- rehabilitate about 200 classrooms and fit out about 200 classrooms for EBES;

- equip all public and community schools with separate boys-girls latrines, far from each other;

- increase the number of school canteens on the initiative of LAs so as to improve access to schools, particularly for girls.

102. Informal Education

- $\quad$ provide CEDs with pedagogic text books and guides so that each CED teacher has 2 text books (language and maths) and about 10 guides, and each learner has two text books (language and maths);

- provide initial and continuous training to CED teachers;

- support literacy education for adults with CFAF 4.24 billion per year; and

- prepare and implement a professional training strategy for auditors of CAF, CAFÉ and CED learners in consultation with MEN and MEFP.

\subsubsection{General Secondary Education (ESG), Technical and Vocational Education (ETP), and Apprenticeship Component}

103. General Secondary Education (ESG)

- construct 3 high schools with 12 classes each;

- rehabilitate classrooms and offices in 5 high schools;

- rehabilitate/construct washroom facilities in 24 public high schools.

104. Human Resources

- recruit 400 teachers for ESG ;

- provide continuous training for an average of 500 teachers per year;

- train 200 language teachers in the teaching of French;

- train 120 laboratory assistants throughout the project;

- train 184 computer maintenance workers, comprising 100 workers for private high schools and 84 for public high schools, and

- enhance supervision through continuous training of Inspectors and administrative staff of ESG.

105. Pedagogical Environment

- revise the teaching series and programmes;

- provide the CDI of more than 50 high schools with books and introduce a loan system;

- provide school text books to more than 50 high schools and introduce a system for lending out text books to pupils; and

- construct and equip a maximum of 25 laboratories (15 for the private sector), 25 computer rooms (15 for the private sector) and 25 documentation and information centres (15 for the private sector).

106. Improvement of the Management System 
- establish School Management Committees (CGS) in high schools for participatory management; and

- develop the scheme of work in high schools through training.

107. Technical and Vocational Training (ETP)

- construct and equip eight (8) industrial and/or agro-sylvo-pastoral training centres (Kidal, Kita, Koulikoro, Niono, Kayes, Sikasso, Bamako and Yélimané) ;

- rehabilitate/extend three (3) public centres: Koutiala, Gao, Fana;

- construct 3 industrial workshops in Technical High School, Bamako, to introduce new tracks.

108. Human Resources

- create and construct an ETP Teachers' Training Institute;

- provide initial training for 35 technical education teachers per year abroad (in 2006 and 2007);

- train 42 maintenance workers;

- $\quad$ prepare and implement a plan for ETP staff (trainers, administrators, support staff) ;

- provide further training to 1,500 trainers and 500 administrators and support staff of the public and private sectors following a continuous training programme.

109. Pedagogical Environment and Content:

- reproduce 10,000 copies of pedagogical documents for public institutions and approved private institutions;

- 20 former programmes will be translated into APC ;

- organize a training programme in Information and Communication Technology (TIC) ;

- provide approved public and private institutions with computer equipment;

- transform the libraries of 36 public and private schools into Documentation and Information Centres; and

- establish an information, sensitization and orientation system on ETP and a monitoring system for the integration of graduates.

110. Improve management of the system

- transform the vocational training centre into a public institution with financial and pedagogical autonomy;

- adopt the ETFP policy upon consultation with all partners of the ETFP (within the context of decentralization) to define the main aspects of the autonomy; and

- review the legal and regulatory texts of the ETFP and their implementation.

111. Vocational Training through Apprenticeship

- Training of 22,899 failed pupils in Basic 1 for one year in various trades in partnership with the private sector; and

- Qualifying modular training of 5,500 young school drop outs from Basic 2 for 3 years in Public Apprenticeship Centres.

112. Improvement of the quality and internal efficiency of apprenticeship centres

- Train 500 handicraft instructors and 300 endogenous trainers (trainers of the productive private sector) to increase supervisory possibilities in enterprises;

- Train about 150 trainers of private and public centres and about 50 workers of the private and public sectors in training engineering;

- Prepare course and programme aids for 30 new trades;

- Reproduce training and programme aids for 30 trades;

- Prepare apprenticeship regulations, and put in place a mechanism for certification and validation of experience acquired. 


\subsubsection{Higher Education and Research Component}

- search for information on labour market demand, which will be used in defining the needs, as well as job profiles and training to be developed (work to be done in collaboration with the Employment and Training Observatory);

- prepare statutory regulations for professional teachers as required by training (consideration of professional experience acquired in productive sector enterprises, time for practicals, contacts with professional circles, monitoring of internship of students and initiation of collaboration/transfer of technology activities with enterprises) ;

- enhance the autonomy of institutions to allow for more flexible management of resources (diversified resources from the State, enterprises, service contracts or from pupils, management of expensive equipment which requires maintenance and consumption of workpieces, contractualization of professionals from enterprises, more diversified teaching methods through practicals, alternation or internships in enterprises) ;

- prepare, with the professional branches, valid certificates for the private and public sectors which facilitate recognition of the level of skills on the labour market and development of a career path by students through equivalents and platforms;

- develop 10 short vocational tracks, including feasibility studies, buildings and equipment required for the tracks; train and recruit about 35 teachers for these tracks;

- create regional university centres in accordance with the results of the feasibility study;

- rehabilitate libraries;

- construct and equip the Central University Library (BUC);

- reinforce university infrastructures (buildings and science equipment) ;

- strengthen the capacities of the teaching corps, with priority for tracks that are becoming professional and are upgraded to LMD through continuous training;

- create a competitive research fund;

- improve access to science and technical information (improvement of the university network);

- establish monitoring, management and control instruments corresponding to the autonomy granted to institutions and their capacity to manage their own resources;

- design an information, school management and accounting system for higher education institutions;

- provide equipment for communication networks;

- train administrative employees in these new networks;

- design and implement a method of financing that allocates part of the budget of higher education institutions on a contractual basis.

\subsubsection{General Administration Component}

- put in place a new institutional plan of the Ministry responsible for Education;

- define framework documents for decentralization ;

- gradually install operational planning tools;

- finalize and implement a new communication strategy.

113. Management of Reform and Consultations

- establish a management structure for institutional reform in the Office of MEN;

- ensure management at the regional level;

- revitalize consultation organs on the reform.

114. Decentralization of Education and Transfer of Powers

- transfer powers in education and related resources as from January 2007;

- provide support/advisory services to Local Authorities (LA) and School Management Committees (CGS);

- train CGS in planning, implementation, monitoring and evaluation of school projects in line with a strategy developed by the Support Unit for the Decentralization - 
Deconcentration of Education (CAD-DE), including the use of standardized training modules;

- ensure social mobilization for massive enrolment of children, particularly girls, in line with the national girls advancement policy;

- ensure maintenance of school infrastructure and furniture; and

- ensure administrative and financial management of schools.

115. Construction of classrooms by LAs (Indicator 4)

- prepare a project ownership procedures manual in CAD/DE ;

- prepare the specifications of the powers transferred;

- design and implement mechanisms and procedures for financial transfers to the councils.

116. School Performance Management System

- revise school programmes to ensure acquisition of learning;

- design an annual directive fixing the school calendar, with periods of holidays and public holidays, with AEs and CAPs held responsible for proper implementation depending on realities in the field.

117. Management of professional careers and training for teachers

- provide LAs with a manual to enable them to build on training received in the career plan of teachers.

118. Status and remuneration of community teachers

- Improve the status of all community teachers that have the minimum qualification and have undergone a refresher course or recognized initial training, becoming contractual council teachers.

119. Promotion of second cycle technology education

- construct and open science blocks in all AEs.

120. Since education is a priority sector in the PRSP, the Government has made significant efforts in budget allocations in recent years.

\subsection{Health}

121. Expenditures in the health sector in 2007 amount to CFAF 65.31 billion, and will stand at CFAF 70.15 billion in 2008, CFAF 72.30 billion in 2009, CFAF 79.80 billion in 2010 and CFAF 87.42 billion in 2011, representing an increase rate of $7.4 \%$ in 2007 , $3.1 \%$ in $2008,10.4 \%$ in 2009 , and $9.55 \%$ in 2010 respectively.

Table 47: Trend of Health Expenditures (in CFAF billion)

\begin{tabular}{|c|c|c|c|c|c|c|}
\hline Year & 200 & 200 & 200 & 200 & 201 & 201 \\
\hline Expend. & $\begin{array}{|ll|}6 & 72.684 \\
\end{array}$ & 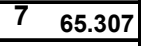 & $\begin{array}{|ll|}8 & 70.146 \\
\end{array}$ & $\begin{array}{ll}9 & 72.299 \\
\end{array}$ & $\begin{array}{|ll|}0 & 79.797 \\
\end{array}$ & $\begin{array}{lr} & 87.417 \\
\end{array}$ \\
\hline Growth rate & & $-10.15 \%$ & $7.41 \%$ & $3.07 \%$ & $10.37 \%$ & $9.55 \%$ \\
\hline
\end{tabular}

\section{Source: DGB}

122. These projections take into account the health sector policy objective, which remains that of improving the health status of the populations to enable them to participate more actively in the country's socio-economic development. It aims at extending coverage and improving the quality of health services, preventing and controlling diseases, ensuring financial accessibility to health care and participation, developing human resources and reinforcing hospitals, research institutions and specialized institutions. 
123. Consequently, the policy to recruit 305 workers under the Health and Social Development Programme will continue. Special emphasis will be laid on equipmentinvestment:

- pursue the equipment of CSCOMs and allocation of financial resources to poor areas;

- construct new CSCOMs and create new health districts;

- construct and equip regional traditional medicine centres;

- construct and equip premises for the Department of Pharmacy and Drugs, and the Health Inspectorate;

- construct the Mother and Child Centre of Nianankoro FOMBA Hospital, Ségou ;

- equip the National Health Laboratory; and

- equip the IOTA.

\subsubsection{Sub-Component 1: Geographic accessibility to health services in health} districts:

124. The proposed activities are:

- create new CSCOMs;

- develop existing CSCOMs, and revitalize non-functional CSCOMs;

- reinforce mobile teams and services at the community level;

- develop collaboration partnership with private sector service providers;

- establish appropriate technical support centres in CSREFs, including emergency surgery;

- establish and improve counter-referral and evacuation systems.

\subsubsection{Sub-Component: Availability, Quality and Management of Human Resources}

125. The proposed relevant activities are:

- increase the total production capacity of all paramedical training schools (public and private) ;

- enable the students to undergo adequate practical internships;

- make training programmes adequate for the health policy;

- revise training modules and refresher courses as necessary;

- provide health structures with adequate qualified staff;

- conduct a package of reforms based on a human resource management and development policy and a multi-year implementation plan, taking into account the reform of the administration ;

- provide MS with short and long-term technical assistance (TA) based on a rollover multi-year TA plan.

\subsubsection{Sub-Component 3: Availability of Drugs, Vaccines and Medical Consumables}

126. The proposed relevant activities are:

- ensure availability of essential drugs, vaccines and consumables, as well as laboratory tests in CSCOMs and CSREFs in all areas, particularly in poor areas and areas with difficult accessibility;

- make essential drugs financially accessible throughout the country.

\subsubsection{Sub-Component 4: Improvement of quality of health services, increase in demand and control of diseases}

The proposed relevant activities are:

- $\quad$ reinforce the integrated disease surveillance approach and response (SIMR) ;

- manage patients in line with the standards and protocols of the pathology concerned;

- improve hygiene and control of disease vectors in health institutions, work environment, schools, and food establishments);

- supervise health institutions, as well as health workers regularly;

$$
\frac{\text { MTBF PRSP 2007-2011 }}{\text { Page } 37 \text { of } 224}
$$


- ensure availability of essential drugs, including ARVs ;

- intensify intersectoral collaboration with private sector service providers and the civil society;

- initiate community activities by district health teams;

- initiate community preventive and promotional health care activities;

- meet the nutrition requirements of the populations through specific interventions in the minimum activity package (PMA).

\subsubsection{Sub-Component 5: Financial accessibility and support to demand and participation}

128 The proposed relevant activities are:

- reinforce the third-party payer mechanism so as to promote access by the poor to quality health care in health institutions;

- subsidize essential health services package for the poor and vulnerable groups;

- contribute to the implementation of alternative financing for the management of poor populations in the health care system.

\subsubsection{Sub-component 6: Reform of hospital and other research institutions}

129. The proposed relevant activities are:

- prepare the various implementing texts of the hospital law and their PHE status taking into account the economic plan of the schemes of work;

- improve the health status of the population by providing specialized institutions, including research institutions.

\subsubsection{Sub-Component 7: Institutional capacity building and decentralization}

130. The proposed relevant activities are:

- transfer part of the technical and financial powers to the local authorities so as to effectively manage health problems in councils, districts and regions;

- support health services to accomplish their mission and play their role in the implementation of PRODESS II.

\subsection{Other Social Sectors}

131. In 2007, expenditures for the other social sectors (Social Development, Employment and Vocational Training) amount to CFAF 44.50 billion. They will stand at CFAF 46.50 billion in 2008, CFAF 46.02 billion in 2009, CFAF 49.12 billion in 2010, and CFAF 52.13 billion in 2011. The increases are due to the medium-term policy of the sector, comprising:

- conduct of studies required for knowledge of the handicap phenomenon;

- develop support for self-employment initiatives for handicapped persons;

- organize sensitization, information and education campaigns on the problem of senior citizens;

- conduct studies on the phenomenon of ageing;

- conduct of studies on nicotinism, alcoholism, drug addiction and prostitution ;

- construct and equip CNAOM ;

- construct the headquarters of the National Solidarity Fund;

- implement the youth employment programme;

- implement the multi-sector rural employment investment programme (PROMIER);

- rehabilitate youth centres;

- reinforce the facilities of national youth camps;

- implement the vocational training by apprenticeship programme;

- restore the West Tribune and lighting of the Mamadou KONATE Stadium and rehabilitate Ouézin COULIBALY stadium; 
- fit out the Hunting and Shooting Museum in Yanfolila;

- construct and equip the "Maison des Arts et Cultures" (Arts and Culture Centre), Kidal; and

- provide support to grassroots PAIB extension initiatives.

In PRODESS II, the social development component has five sub-components, namely:

\subsubsection{Sub-Component 1: Strengthening of Solidarity and Fight against Exclusion}

132. Some of the proposed relevant activities are:

- conduct 2 studies required for knowledge of the specific needs of the handicapped;

- $\quad$ support the enrolment and education of 10,000 handicapped persons;

- organize a national training of trainers workshop and 9 regional senior citizens workshop for socio-health workers and the civil society; and

- support three transit centres (Bamako, Sikasso and Mopti) and 11 psychological and social supervision centres ( 3 in Bamako and 8 in the regions).

\subsubsection{Sub-component 2: Poverty Reduction}

133. Some of the proposed relevant activities are:

- organize accompanying training sessions for 1,350 social workers and social development partners in the management of cooperative societies, mutual benefit societies, SFDs and groups in the regions and Bamako District;

- finance 50 projects and AGRs for 3,000 persons in the Old Persons Assistance Programme;

- finance 250 individual and collective projects for the self-employment of handicapped persons; and

- establish a pilot project in 4 regions and Bamako District on the development and economic accessibility of traditional medicine.

\subsubsection{Sub-Component 3: Reinforcement of Social Security}

134. Some of the proposed relevant activities are:

- conduct an actuarial study on the pension scheme of CRM, as well as INPS schemes;

- conduct the financial and institutional audit of CRM and INPS;

- organize 3 consultations on coverage of natural risks in the agricultural sector;

- support the creation of 200 social and solidarity health insurance organizations (mutual benefit societies, solidarity funds); and

- organize training sessions and study trips for administrators and senior staff of social and solidarity health insurance organizations.

\subsubsection{Sub-Component 4: Institution Building}

135. Some of the proposed relevant activities are:

- construct/rehabilitate new buildings for central, attached and associated partner services;

- construct premises for regional CNPAM stations in each region and Bamako District;

- prepare a directory of stakeholders of the social and solidarity sector;

- create a National Information, Education and Communication Centre (CNIEC) in the Ministry;

- create a Website in the Ministry;

- conduct 10 annual control missions by IAS to structures and agencies under the supervisory authority of MDSSPA;

- prepare and implement a strategy and programme for fighting against some social evils (alcoholism, nicotinism, drug addiction, and prostitution);

- establish a legal and regulatory framework for the transfer of powers in development matters to local authorities. 


\subsubsection{Sub-Component 5: Human Resource Development}

136. Some of the proposed relevant activities are:

- recruit more than 60 social workers (civil servants or contract officers) per year for five years;

- train 70 INFTS teachers;

- train trainers and workers in SISo software;

- recruit 10 permanent INFTS teachers;

- train teachers of MDSSPA and partner structures in gender and development each year;

- organize further training in foreign mutual benefit groups (2 per year) ;

- organize study trips on ageing; and

- conduct a study on incentives for MDSSPA staff.

\subsection{Conditions for Budget Support (Social Sector)}

137. The tables below give us the common conditions for budget support to specific sectoral arrangements for the education, health and social development sectors. 


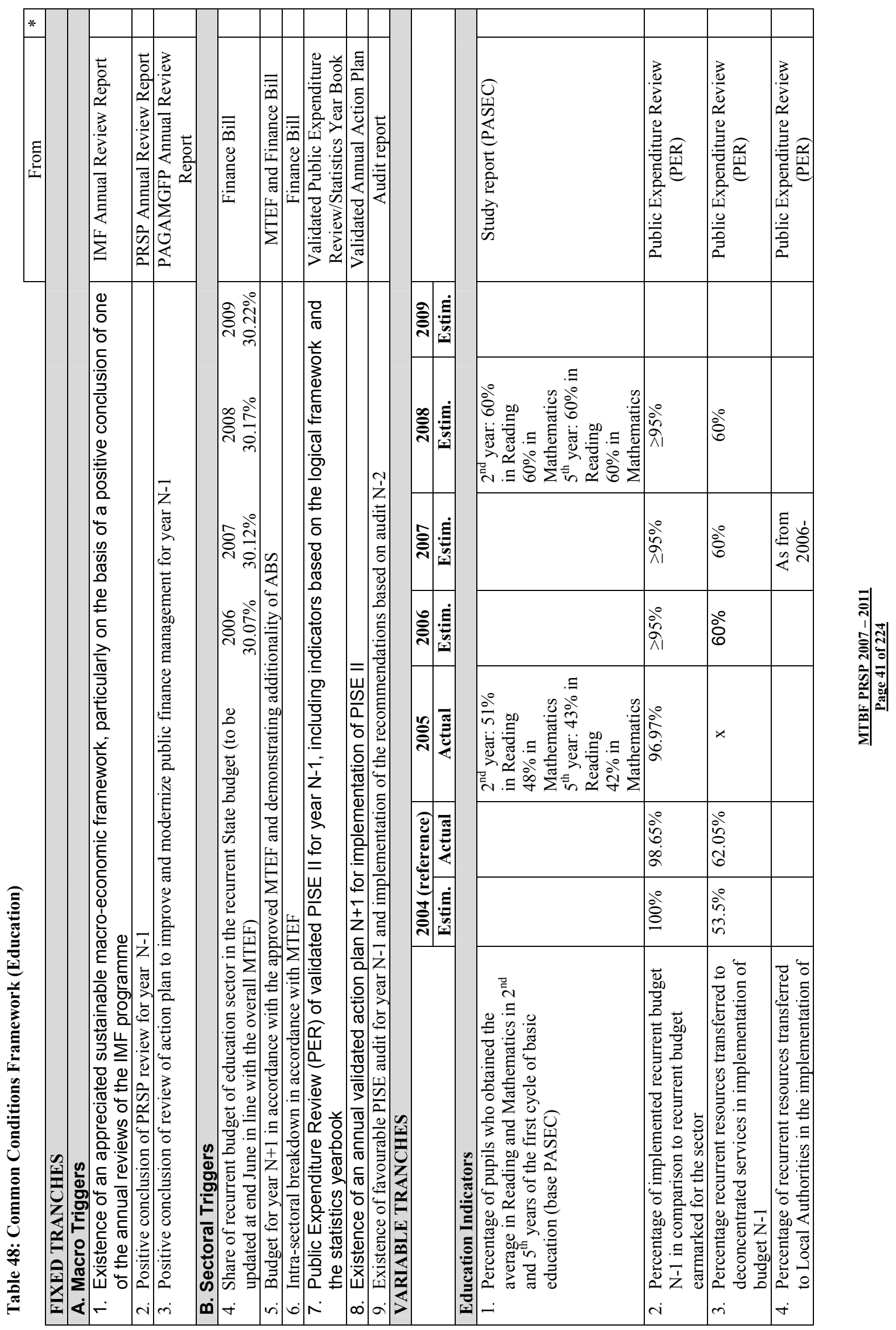




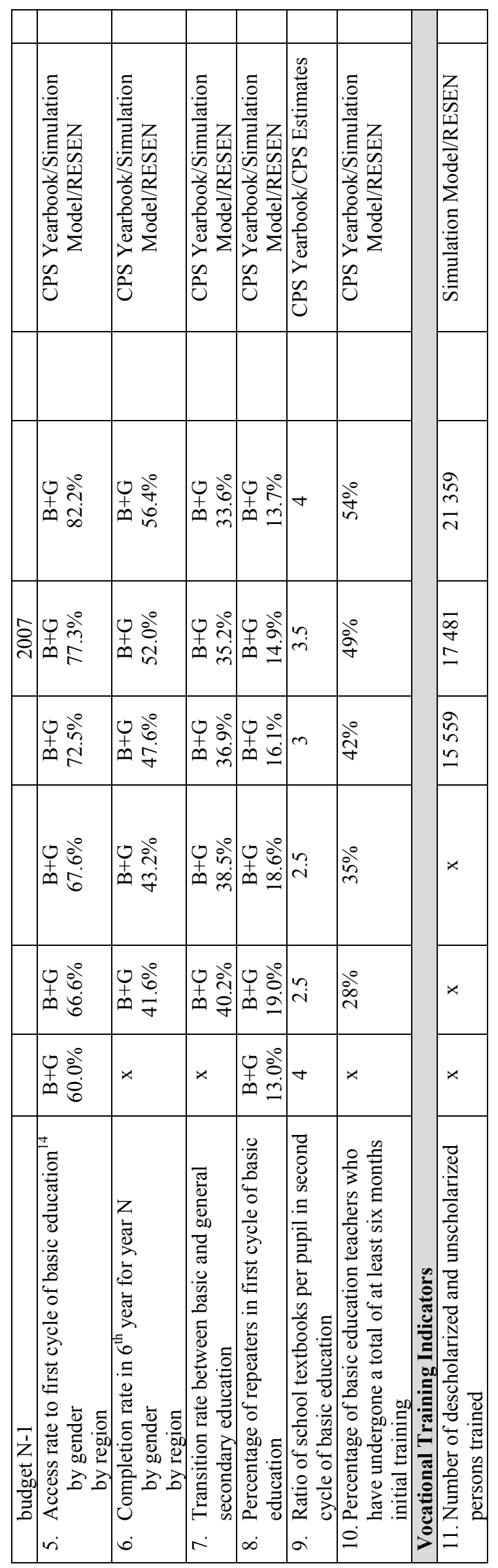

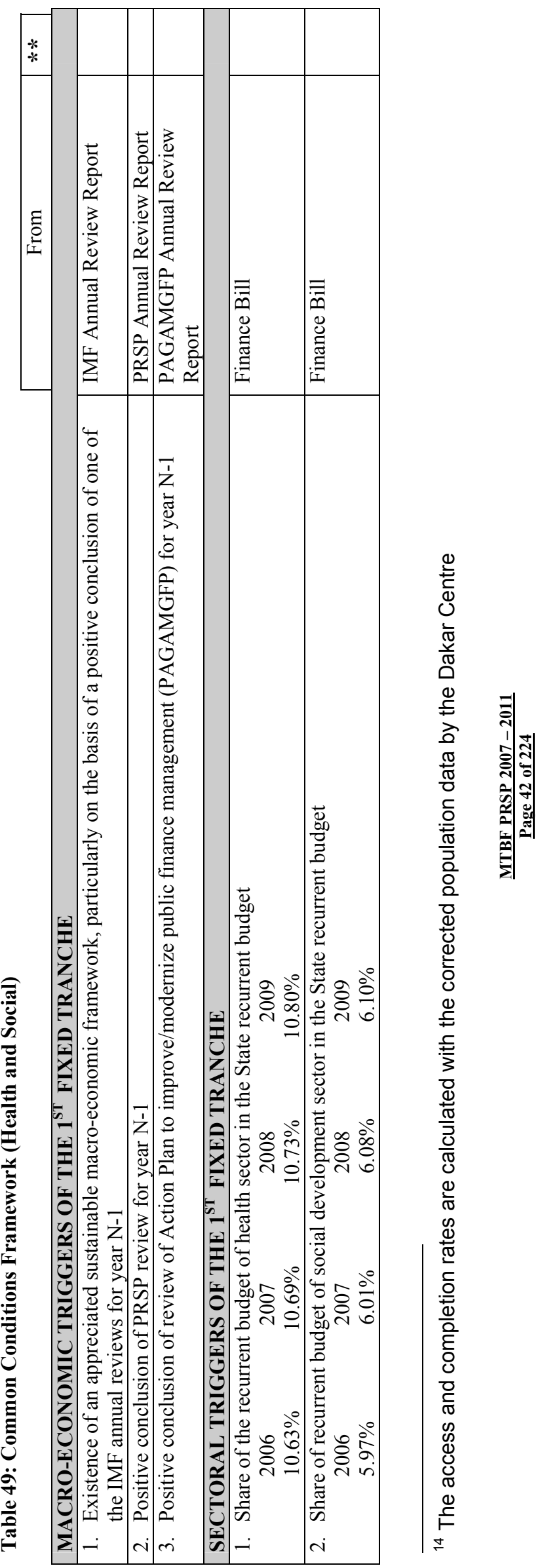



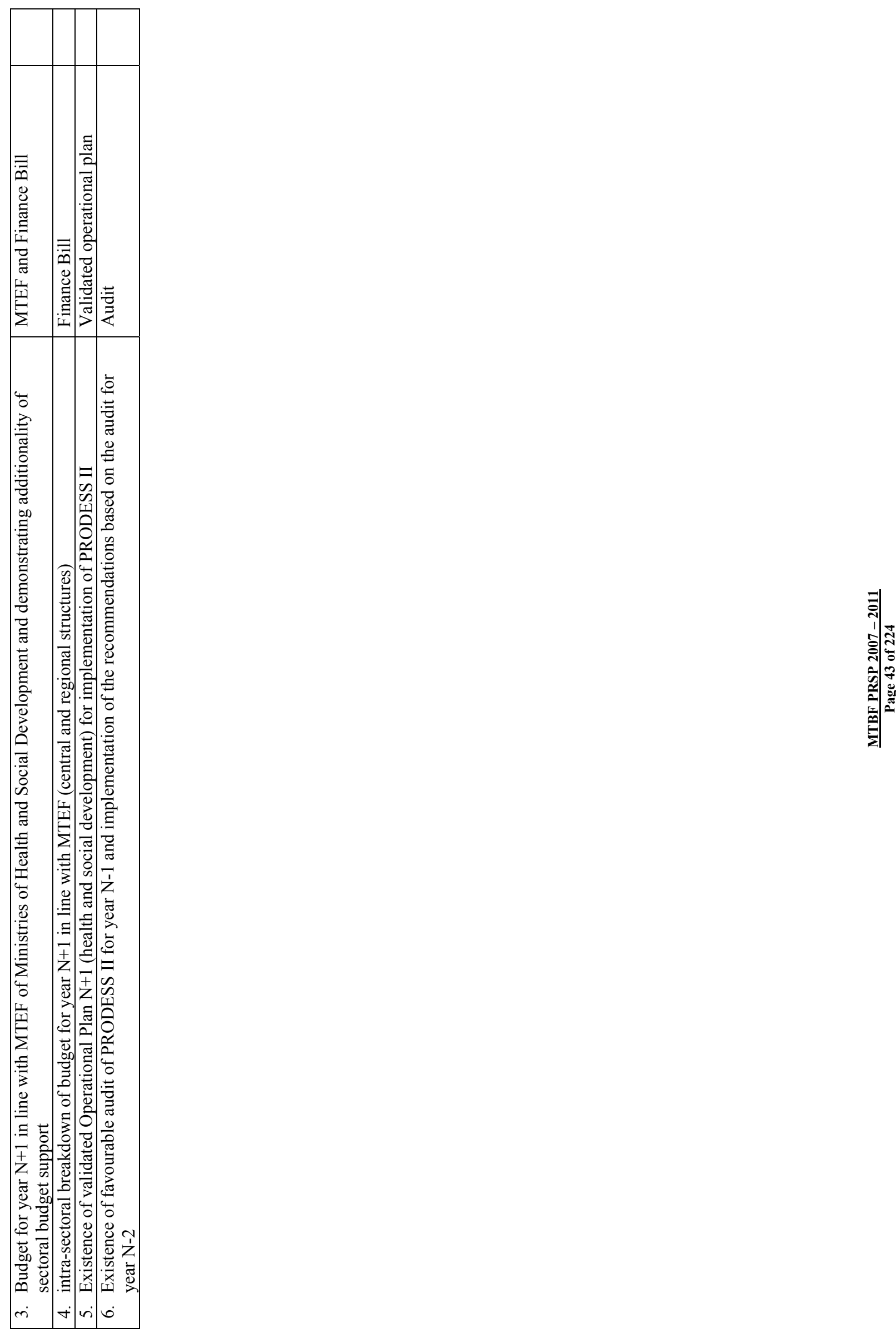


\subsection{Culture, Youth and Sports}

138. In 2007, expenditures relating to the culture, youth and sports sector amount to CFAF 13.67 billion. They will stand at CFAF 14.78 billion in 2008, CFAF15.76 billion in 2009, CFAF 17.15 billion in 2010, and CFAF 18.13 billion in 2011. The progress is due to the medium-term sector policy, particularly in the youth and sports sector. The three-year development action plan for the youths is divided into five pillars:

\subsubsection{Pillar I: Socio-education supervision of youths:}

- train at least $60 \%$ benevolent and/or voluntary youths in first degree socio-educative animation techniques;

- organize practical immersion courses for benevolent and/or voluntary youths in first degree animation techniques;

- implement programmes of extra-curricular activities for youths from 10 to 18 years old;

- train stakeholders/ youths in schools/CED;

- create extra-curricular education associations in schools/CED of rural councils;

- create a network of stakeholders/youths from schools/CED;

- define an extra-curricular minimum activities package (PMA) for youths;

- organize sports, artistic and cultural activities for youths;

- organize refresher courses for youth administration staff in sports, cultural and artistic activities;

- prepare training modules for socio-educational activities in rural areas;

- teach training modules for socio-educational activities in rural areas in the National Youth and Sports Institute; and

- promote youth activities in institutions in rural and urban areas.

\subsubsection{Pillar II: Youths and Social Vulnerability:}

- prepare a programme for the education of youths in social life as regards social development, health and justice services;

- implement the programme for education in social life in homes, meetings, as well as youth centres and associations;

- prepare a programme for education in social life in line with the needs of rural youths;

- train peers educators for youths in social life in rural areas;

- implement the programme for education of youths in rural areas;

- inform and sensitize youths on environmental protection;

- organize reforestation and sanitation worksites;

- create youth programmes in at least one radio station for all rural and urban councils, and councils with a radio station;

- provide socio-educational youth facilities with cybercafés;

- develop a local campaign by using education peers and youth centres;

- include a STI/HIVIAIDS sub-component in youth supervision programmes;

- train peer educators in communication skills for change in behaviour in youth circles;

- develop a multimedia education campaign on reproductive health;

- develop reproductive health activities for girls in rural schools; and

- inform girls on the risks of intentional abortion.

\subsubsection{Pillar III: Youths and Socio-economic Integration:}

- disseminate the youth promotion advisory assistance guide in regions and youth associations;

- $\quad$ prepare a youth promotion advisory assistance guide; 
- train and sensitize elected municipal officers on the importance of youth promotion in the country's social, economic and cultural development.

\subsubsection{Pillar IV: Capacity building for youth associations in mobilization, citizenship and participation in public life}

- Train youth associations in assistance and advisory services, as well as animation techniques;

- Organize youths in the design and implementation of the life education programme.

- Train association officials in management, programming, search for financing and administration.

\subsubsection{Pillar V: Institution Building}

- Prepare texts for the establishment and functioning of youth centres;

- Construct and equip youth centres in two regional capitals;

- Construct and equip two youth centres in districts and councils;

- Enroll 70 pupils and students per year in the socio-education track;

- Refresher courses for 20 middle youth staff in animation sciences and techniques (STA).

\subsection{Rural Development and Environment}

139. In 2007, expenditures of the "rural development and environment" sector amount to CFAF 131.20 billion. They will stand at CFAF 132.91 billion in 2008, CFAF 145.56 billion in 2009, CFAF 158.22 billion in 2010, and CFAF 170.30 billion in 2011, representing an increase rate of $1.3 \%$ in $2007,9.5 \%$ in $2008,8.7 \%$ in 2009 and $7.6 \%$ in 2010 respectively. The increases are due to the implementation of the Rural Development Sector Master Plan, which has the following objectives:

- increase the contribution of the rural development sector to the country's economic growth;

- strengthen food security and self-sufficiency;

- improve the incomes and living conditions of the rural populations;

- protect the environment and ensure better management of natural resources;

- These objectives will be achieved through the following programmes or actions:

- support to agricultural services and farmer organizations;

- enhancement of food security;

- development of agricultural sub-sectors and improvement of their competitiveness;

- revitalization of agricultural, forestry, livestock and fishery exports;

- intensification and diversification of agricultural products;

- strengthening of food security;

- promotion of loans and financing for the rural sector;

- rational management of natural resources to ensure sustainable rural development; and

- finalization and implementation of local development plans.

\section{$5.8 \quad$ Transport}

140. Expenditures of this sector in 2007 amount to CFAF 13.75 billion. They will stand at CFAF 14.58 billion in 2008, CFAF 15.97 billion in 2009, CFAF 18.13 billion in 2010, and CFAF 19.98 billion in 2011, representing an increase rate of $6.0 \%$ in $2007,9.5 \%$ in $2008,13.6 \%$ in 2009 and $10.2 \%$ in 2010 respectively. The medium-term policy of the sector is as follows: 


\subsubsection{Pillar 1: Internal accessibility of Mali - Rural Transport (roads - river ways)}

For this pillar, the actions concern studies and rehabilitation of infrastructures and equipment

Rehabilitation of infrastructures and equipment

141. The following feeder roads will be improved:

- Douentza -Bandiagara - $155 \mathrm{~km}$

- Douentza -Koro- $100 \mathrm{~km}$

- Banamba - Mourdiah - $110 \mathrm{~km}$

- Gossi - Rharouss - 147 km

- Gao - Bourem - $95 \mathrm{~km}$

Rehabilitation of boats

- The entire river fleet will be maintained. 
The following studies will be conducted:

- Study on efficient trucking

- Study on river transport

- Study on the dry ports of Kayes and Sikasso

- Interurban/urban roads

- Study on internal accessibility

- Study on a River Code.

\subsubsection{Pillar 2: Internal Accessibility of Mali - urban and interurban transport (Roads, Rail, Air)}

142. The actions concern the construction and equipment of infrastructures, tarring of roads, and improvement of modern earth roads.

Construction of infrastructures and equipment

- Construction of dry ports in Kayes and Sikasso

- Construction of motor parks

Tarred roads (interurban)

- Markala - Niono -70 km

- Kayes - Diamou -Bafoulabé - 130 km

- Fana - Dioila - $40 \mathrm{~km}$

- Koulikoro - Banamba - $90 \mathrm{~km}$

- Banankoro - Dioro - $35 \mathrm{~km}$

Modern earth roads

- Tonka -Goundam - Tombouctou

Tarred roads (urban)

- Urban roads phase II $-4.5 \mathrm{~km}$

- Urban roads Gao, Tombouctou, Bandiagara

- Koutiala, Bougouni, Kita - 30 km

Rehabilitation of Infrastructures

- Purchase of equipment for TRANSRAIL

Procurement and operation of equipment

- Purchase of 4X4 vehicles

- Purchase of 6 axle scales

- Procurement of 4 flat-bottom boats

- Purchase of service vehicles

- Purchase of ferries

\subsubsection{Pillar 3: External Accessibility of Mali (Roads-Rail-Air)}

143. Here, actions concern feasibility studies, development of the storage capacity of some Malian warehouses in coastal countries, construction of infrastructures and equipment in some airports, and tarring of sections of national roads.

- Extension of Malian warehouses in Guinea

- Extension of Malian warehouses in Togo

- Extension of Malian warehouses in Mauritania

- Construction of 3 store rooms and offices, and fitting out of existing offices in Conakry

- Construction of a store room and administrative offices in Téma, Ghana

- Construction of a store room and administrative offices in Lomé, Togo

- Construction of a store room and administrative offices in Cotonou, Benin

- Extension of the existing office and construction of a store room in Nouakchott, Mauritania (EMAMAU)

- Infrastructures of an ILS and a fuel depot at Tombouctou airport

- Equipment of the ILS and fuel depot of Tombouctou airport 
- Fencing of the security zone of Kayes airport

- Fencing of the security zone of Sikasso airport

- Construction of DNAC building

- Equipment of DNAC Building

- Infrastructures - Rehabilitation of Gao airport

- Rehabilitation - Buildings and VRD of Gao airport

- Rehabilitation of Gao airport

Tarring of national roads

- Bko-Kati-Kolokani-Didiéni - 165 km

- Kayes-Sandaré-Dièma - 270 km

- Dièma - Didiéni - 180 km

- Gao-Ansonga-Labbézanga -209 km

- Bamako -Kourémalé - $123 \mathrm{~km}$

- Nioro - Gogui - 62 km

- Sikasso - Koloko - Fre Burkina -44 km

- Kayes - Diboli - Fre Sénégal - 97.545 km

- Kati - Kita - 175 km

- Kita - Saraya - Fre Sénégal - 310 km

- Gao Bridge and access $-14 \mathrm{~km}$

- Bamako - Bougouni $-160 \mathrm{~km}$

- Bougouni- Sikasso- $210 \mathrm{~km}$

- Sevaré- Gao - 558 km

Improvement of rural roads

- Tiendaga and Kankéla bridges - $125 \mathrm{~m}$

Studies

- Study on supply and installation of an ILS and a fuel depot at Tombouctou airport

- Feasibility studies on rehabilitation of Gao airport

- Study on rehabilitation of Gao airport

- Study on fencing the security zone of Kayes airport

- Study on fencing the security zone of Sikasso airport

- Study on supervision and control of works on the DNAC Building

\subsubsection{Pillar 4: Maintain and preserve infrastructure and equipment of the rural network (roads - river ways)}

144. It will consist in reinforcing infrastructures and equipment affected by weather or wear and tear and conduct maintenance feasibility studies.

Reinforcement and Periodic Maintenance Improved feeder roads

- Dioila - Sorokoro - $38 \mathrm{~km}$

- Dioila - Massigui -Koualé $137 \mathrm{~km}$

- Didiéni - Goumbou - Nara 209 km

- Kita - kourounikoto-Diangounté $178 \mathrm{~km}$

- Tambaga - Manantali $89 \mathrm{~km}$

- CMDT roads

Studies

- Improved roads

- Periodic maintenance

- Tambaga - Manantali - 89 km 


\subsubsection{Pillar 5: Maintain and preserve infrastructures and equipment of the urban network}

145. This pillar provides for studies and maintenance of some urban roads.

Routine Maintenance

Tarred roads

- Avenue Nelson Mandéla - $5 \mathrm{~km}$

- RR14 - Nelson Mandéla - 2 km

- RR15 Square - Dalot woyo - $1 \mathrm{~km}$

- San market crossing $-1 \mathrm{~km}$

Studies

- Various urban road sections:153; 187.5; 187.5; 187.5 and $202.5 \mathrm{~km}$

\subsubsection{Pillar 6: Maintain and preserve infrastructures and equipment of the interurban network}

146. This pillar provides for studies and routine maintenance of some sections of the interurban network.

Tarred roads

- Faladiè - Ségou - $240 \mathrm{~km}$

- Sikasso - Zégoua -9 $0 \mathrm{~km}$

- Bla - San - Sienso - $115 \mathrm{~km}$

- Access to Djenné - $29 \mathrm{~km}$

- Kimparana - Kouri - $82 \mathrm{~km}$

- Bamako - koulikoro - $54 \mathrm{~km}$

- Koulouba - Kati - $11 \mathrm{~km}$

- Modern earth roads

- Mahina -Manantali - $87 \mathrm{~km}$

- Kayes - Sadiola - 74 km

- Ansongo -Kismane -Ménaka - 222 km

Improved feeder roads

- Douentza - Tombouctou - 200 km

Studies

- Inter-urban roads

- Tarred roads

- Various road sections: 2902 ; 3459 ; 3678 ; 3902 and 4193 km

- Modern earth roads

- Various road sections: $1234 ; 1234 ; 1517 ; 1598$ and 1674 km

\subsubsection{Pillar 7: Capacity building for the institution and human resources}

147. Pillar 7 has the following objectives: conduct of studies, restoration and construction of infrastructures, purchase of equipment, and training of employees.

Restructuring, establishment of new structures and constructions

Technical Assistance

- DNR

- $A R$

- PME/BET

Studies and Training

- Study on the restructuring of the National Transport Directorate

- Training in ILS maintenance in Tombouctou airport

- Study AGEROUTE 
- Formation DNR/PME/BET

Purchase of equipment

Computerization of Regional Transport Directorates and their connection to the National Directorate of Transport:

- 80 computers

- 80 UPS machines

- $28 \mathrm{CITOH}$ printers

- 60 Laser printers

- 05 CD PLAYER AND EXTERNAL BURNER

- 02 MS Office XP

IGM

- Purchase of IGM equipment

- Repatriation of map records

DNM

- Logistic support for irrigation and meteorological activities.

INFET

- Equipment of the Documentation Centre

COMANAV

- Purchase of equipment

\subsubsection{Pillar 8: Improve levels of services, safety and security of transport and performance of BET/PME}

The proposed actions are:

Construction and security equipment

- Construction of control post

- Fence along the railway in Bamako built-up area

- Improvement of services.

Revitalization of the National Road Security Committee

- Data collection

- Road control

- Study and road safety

- Casualty management

Sensitization Activities

- Sensitization campaigns;

- Road Safety Week.

\subsection{Town Planning and Public Works}

149. Expenditures of this sector in 2007 amount to CFAF 115.38 billion. It will stand at CFAF 119.05 billion in 2008, CFAF 131.83 billion in 2009, CFAF 140.33 billion in 2010 , and CFAF 150.91 billion in 2011, representing an increase rate of $3.2 \%$ in 2007, $10.7 \%$ in $2008,6.5 \%$ in 2009 , and $7.5 \%$ in 2010 respectively. The medium-term policy of the sector is as follows:

- preparation of town planning master plans in 12 towns;

- construction of 1.975 low-cost housing units in the medium term in Bamako and regional capitals;

- preparation of nine (9) sector town planning plans;

- development of the Natural Collector "Le Diafaranokô" ;

- support for the collection and dissemination of average prices and indices of building products and materials. 


\subsection{Communication}

149. Expenditures of this sector in 2007 amount to CFAF 10.85 billion. They will stand at CFAF 11.95 billion in 2008, 12.78 billion in 2009, CFAF 13.58 billion in 2010, and CFAF 14.49 billion in 2011 , representing an increase rate of $10.1 \%$ in $2007,7.0 \%$ in $2008,6.3 \%$ in 2009 , and $6.7 \%$ in 2010 respectively. The medium-term policy of the sector is as follows:

- preparation of the sector policy document of the Communication department;

- production and broadcast of news, news magazines, debates and investigative programmes for at least $25 \%$ of the air time;

- extension of TV/FM coverage to areas not covered or poorly served;

- modernization of the mail processing system at the international level (IPS).

\subsection{Armed Forces and Security}

150. Expenditures of the Armed Forces and Security in 2007 amount to CFAF 75.63 billion. They will stand at CFAF 77.29 billion in 2008, CFAF 83.32 billion in 2009, CFAF 93.86 billion in 2010, and CFAF 101.59 billion in 2011, representing an increase rate of $2.2 \%$ in $2007,7.8 \%$ in $2008,12.7 \%$ in 2009 and $8.2 \%$ in 2011 respectively. These increases are due to:

\subsubsection{Armed Forces}

- recruitment into the army;

- providing the Armed Forces with various modern communication equipment, major equipment and musical equipment;

- construction of a military hospital;

- continuation of patrols throughout the country; and

- continuous military training and further training.

\subsubsection{Internal Security and Civil Protection}

- recruitment of 520 student Gendarmes, 750 Police Officers, 250 Civil Protection Officers each year;

- construction of Police Stations and houses for Commissioners of Police;

- sensitization of the population on risks;

- training of Security Forces and Civil Protection officers;

- construction of Police Stations and houses for Commissioners of Police;

- procurement of technical supplies (special equipment and materials); and

- maintenance and renovation of buildings.

\subsection{Debt - Principal and Interest}

151. Expenditures relating to the payment of the principal and interest on debt for the 2007 financial year amount to CFAF 47.76 billion. They will stand at CFAF 46.05 billion in 2008, CFAF 47.41 billion in 2009, CFAF 48.68 billion in 2010, and CFAF 51.56 billion in 2011, representing an increase rate of $-3.6 \%$ in $2007,2.9 \%$ in $2008,2.7 \%$ in 2009 , and $5.9 \%$ in 2010 respectively. The debt policy aims at non-accumulation of payment arrears.

\subsection{Mining - Water Resources and Industry}

152. In 2007, the expenditures of the Mining, Water Resources and Industry sector amount to CFAF 68.35 billion. They will stand at CFAF 72.88 billion in 2008, CFAF 79.63 billion in 2009, CFAF 85.12 billion in 2010, and CFAF 91.03 billion in 2011, 
representing an increase rate of $6.6 \%$ in $2007,9.3 \%$ in $2008,6.9 \%$ in 2009 , and $6.9 \%$ in 2010 respectively. The medium-term policy for the sector by area of intervention is as follows:

\subsubsection{Mining}

153. Specific Objectives:

- Improve the regulatory and institutional environment of the mining and petroleum sectors;

- intensify, develop and diversify mining resources;

- put in place a mechanism for monitoring, controlling and evaluating mining and petroleum activities and projects;

- promote mines handicraft and small-scale mining;

- put in place a financing mechanism for the mining sector; and

- improve the management of mining activities.

154. Priority Actions

- Updating of the legal framework;

- Institutional reform based on redefinition and refocusing of the missions of structures operating in the mining sector;

- Promotion of the mining sector through acquisition of geological data, incentives for national mining promoters, creation and development of a local mining industry, and organization of handicraft activities;

- Training, through the establishment of a programme of academic and pluridisciplinary training and courses to upgrade the level of staff involved in the mining sector, as well as by adapting school and university education to the needs of the mining industry, and providing incentives for mining companies and their subcontractors in Mali to develop the skills of their staff.

\subsubsection{Energy}

\section{Specific Objectives}

- Satisfy the energy needs of the country in terms of quality, quantity and least cost;

- Protect people, property and the environment against risks relating to energy services;

- Provide capacity building in orientation, management, control and strategic management of the energy sector;

- Strengthen the benefits of international cooperation for the country in the area of energy.

\section{Priority Actions}

- Strengthening of institutional and regulatory framework of the emery sector;

- Creation and implementation of an efficient energy planning system;

- Development of domestic energy and rural electrification;

- Streamlining of production and use of energy;

- Promotion of alternative energy sources and traditional fuels;

- Creation of a national buffer stock of hydrocarbons;

- Improvement of control and monitoring of operators;

- Development of the interconnected national workshop;

- Development of electricity services to isolated areas;

- Electricity interconnection with countries in the sub-region;

- Development of renewable sources of energy;

- Reinforcement of national radioprotection infrastructure; 
- Promotion of exploration of hydrocarbons and solid and gaseous fuels;

- Establishment of an institutional, legal and regulatory framework adapted to the development needs of the national energy sector;

- Promotion of measures for capacity building in human, material and financial resources for public, parapublic and private stakeholders of the energy sector;

- Promotion of communication and consultation between the various stakeholders of the energy sector; and

- Support and participation in sub-regional, regional and international energy projects and programmes.

\subsubsection{Water}

\section{Objectives}

Reduce, by 2015 and by at least $50 \%$, the current water resources infrastructure deficit so as to cover $75 \%$ of the basic drinking water requirements of the entire population of Mali through the following actions:

- creation of 4841 new water points;

- rehabilitation of 6278 old pumps;

- replacement of 1675 old boreholes;

- rehabilitation of 1755 old wells;

- creation of 170 basic water supply systems;

- optimization of 149 boreholes;

- institutional support;

- study and planning programme;

- infrastructure programme;

- capacity building programme;

- communication for change of behaviour programme;

- applied research programme

\subsection{Public Authorities and Administration}

158. Expenditures of the public authorities and administration sector in 2007 amount to CFAF 117.32 billion CFAF. They will stand at CFAF 128.99 billion in 2008, CFAF 133.18 billion in 2009, CFAF 142.49 billion in 2010, and CFAF 153.24 billion in 2011 , representing an increase rate of $10.0 \%$ in $2007,3.2 \%$ in $2008,7.0 \%$ in 2009 , and $7.5 \%$ in 2010 .

159. In the medium term, the sector policy shows the implementation of key programmes on governance. The Institutional Development Programme (PDI) is implemented as reform of the entire Administration to enhance the institutional framework of governance within a perspective of sustainable development. It centres on six strategic areas of focus, namely:

- reorganization of the central Government and strengthening of public management through the following activities: (i) conduct organizational audit of all central, regional, and sub-regional structures; (ii) conduct a study on social dialogue; (iii) define and implement a training programme for central and decentralized administrative employees in their new functions; (iv) prepare and implement an Administrative Code which should reinforce legality and define the rights of users of administrative services;

- modernization of public service methods and procedures to adapt them to the new context of administrative reform: (i) evaluate the methods and procedures of central and decentralized Administrations; (ii) prepare administrative and financial procedures manuals for the administrations of regional assemblies and district councils; (iii) 
conduct a study on the technical criteria required for redistribution of budget allocations between the central and deconcentrated administrations;

- consolidation of decentralization: (i) prepare a law defining principles of administrative organization of the territory and its implementing decree; (ii) prepare and implement for each Ministry, a plan for the transfer of powers; (iii) develop the operations of the Regional Orientation Committees so as to define, coordinate, orientate, monitor and evaluate the technical support required for implementation of development plans and territorial development projects.

160. The objective or overall impact sought by decentralization is the same as that sought by the PRSP. The specific objectives concern all the impacts expected from the decentralization policy on the direct beneficiaries. They are divided into two categories corresponding to two levels:

- the intermediate impacts of level 1 are: (i) improvement of distribution of basic services and public utilities on the territory; (ii) efficient management of local authorities; (iii) improvement of partnership between development actors; (iv) full participation of citizens in the management of local affairs; $(v)$ increased participation in local elections; (vi) liberalization of local initiatives; and (vii) qualitative development of supply of local services;

- the intermediate impacts of level 2 are: (i) improved access by the populations to basic services and public utilities; (ii) strengthening of local democracy; and (iii) creation and preservation of local jobs;

161. To achieve these objectives, the following challenges will be addressed:

- the challenges of decentralization today are clear: the transfer of powers, the link between decentralization and national sectoral programmes, local taxation and resource mobilization, conditions for exercising supervisory powers, relations between councils, territorial development, communication and training;

- ownership of technical support functions by the local authorities and Government technical services;

- strategic management of decentralization at various levels to promote consistency and rationality in interventions, particularly with respect to initiatives of local authorities without undermining the results obtained in mobilization of funds made available and the emergence of local initiatives;

- the Government should specify and implement the new sharing of roles between it and the local authorities, ensure strategic management of decentralization through its representatives, and create conditions for greater involvement of the deconcentrated services in the implementation of decentralization;

- increase in resources of local authorities, consolidation of their financial support as well as the monitoring/control of financial transfers to the local authorities;

- mobilization of financial resources should be a key concern for sustainable success of decentralization.

- Development of the role of local authorities in the promotion of development:

- revise the Local Authorities Code to better specify their areas of competence;

- prepare and adopt regulations on the sharing of resources between the central Government and the local authorities;

- put in place instruments for shared governance at the local level;

- communication and relations with users;

- carry out an information and sensitization campaign on the respective roles and missions of the institutions ;

- carry out an information and sensitization campaign on the legal and regulatory framework governing the administration's relations with users;

- establishment of reception and guidance services for users; and 
- carry out activities on communication between the administrations and their users.

162. With respect to decentralization, budget allocations amount to CFAF 7.07 billion in 2007. They will stand at CFAF 7.36 billion in 2008, CFAF 7.66 billion in 2009, CFAF 7.98 billion in 2010, and CFAF 8.32 billion in 2011, representing an average increase of $4.2 \%$.

Table 50: Trend of Budgetary Expenditure on Decentralization (in CFAF thousand)

\begin{tabular}{|c|c|c|c|c|c|}
\hline ITEMS & 2007 & 2008 & 2009 & 2010 & 2011 \\
\hline Subsidies to Local Authorities & 1507539 & 1530152 & 1553104 & 1576401 & 1600047 \\
\hline $\begin{array}{l}\text { Support to supervisory structures of } \\
\text { Local Authorities }\end{array}$ & 1050781 & 1103320 & 1158486 & 1216410 & 1277231 \\
\hline National Directorate of Local Authorities & 79711 & 84510 & 89599 & 94975 & 100673 \\
\hline FICT/ANICT (EPA subsidy) & 75075 & 78829 & 82770 & 86909 & 91254 \\
\hline Missions to Support Civil Status Consolidation & 513240 & 513240 & 513240 & 518372 & 523556 \\
\hline Mission to Support Deconc/Decentralization (50\%) & 7282 & 8010 & 8811 & 9692 & 10661 \\
\hline $\begin{array}{l}\text { BSI related to Decentralization (incl. Support } \\
\text { for Local Authorities from ANICT) }\end{array}$ & 3834795 & 4037795 & 4251542 & 4476874 & 4714148 \\
\hline TOTAL & 7068423 & 7355856 & 7657552 & 7979633 & 8317570 \\
\hline
\end{tabular}

Source: DGB

163. Mention should also be made of the implementation of the Programme for the Improvement and Modernization of Public Finance Management in the PDI, through actions relating to budget decentralization, deconcentration of the public procurement procedure, and operational establishment of organization charts and deconcentrated organic frameworks. It is structured around the following pillars:

- adaptation and modernization of the general public finance framework: the proposed actions are:

- ensure conformity of laws and regulations with WAEMU directives, and institutionalize management for results;

- adapt the organization and organic framework of the Ministry of the Economy and Finance;

- strengthen governance and increase transparency through the following activities:

- make the control system coherent and effective, apply international audit standards;

- strengthen the Accounts Section of the Supreme Court;

- give the National Assembly the resources to accomplish its missions;

- build the operational capacities of the General Control of Public Services;

- build the operational capacities of the Inspectorate of Finance;

- build the capacities of the National Directorate of the Financial Control, and improve the quality of conformity control by broadening the scope, and adapting it to new technologies;

- develop the efficiency of taxation and financial administrations (DNTCP, DGI, DGD, DGABE) :

- improve transparency and simplification of financial and accounting operations;

- strengthen the accounting management of Local Authorities and Public Institutions;

- reinforce infrastructures and equipment;

- increase the relative proportion of internal tax revenue in the State budget by contributing to achievement of the objectives of overall tax pressure;

- offer quality professional services that meet the needs of taxpayers;

- modernize the tax administration through resource mobilization and professionalism;

- improve and secure customs revenue;

- enhance the quality of budget preparation and implementation: 
- adapt the Directorate General of the Budget to all its missions ;

- change the budget system to a system based on performance and results;

- improve the budget management system to meet international standards;

- include external financing in national budgetary procedures:

- ensure widespread use of budget support;

- produce exhaustive and quality financial and accounting information;

- have a budget consistent with the principle of management for results;

- increase the effectiveness and productivity of services for budget preparation and implementation;

- interconnect the National Expenditure Management Computer System:

- interconnect the expenditure chain of central and regional services;

- provide Regional Directorates with computer equipment;

- train users;

- prepare a MEF computer master plan;

- enhance the performance of DAF and related services:

- stabilize and professionalize the Directors of DAF and related services;

- enhance strict application of procedures;

- improve the quality of service to users and increase resources;

- enhance the efficiency of public procurements:

- adapt the Public Procurement Code to current administrative and economic requirements;

- refocus the institutional framework on deconcentration and decentralization efforts;

- build the capacities of structures ;

- improve access by SMEs to public contracts;

- strengthen governance and transparency in public procurements;

- implement an appropriate training programme for Finance employees by creating a continuous training structure for them.

164. Furthermore, increase in expenditures in the public authorities and administration sector is also due to:

- capacity building for the Administrations ;

- the democratic process/Institutions;

- the Institutional Support Project for all Ministries and Institutions;

- the Support Project for Preparation of Territorial Development Plans;

- the fourth general population and housing census;

- the Support Project for the Labour Intensive Unit (HIMO) ;

- preparation of regional development plans for some regions;

- recruitment of 225 employees in Justice under PRODEJ ;

- construction of 12 court houses and 10 modern prisons with separate areas for men, women and minors;

- construction of official residences for magistrates in preparation for the replacement of broad jurisdiction courts with small-claims courts (20 houses from 2006 to 2007) ; and

- rehabilitation of 15 court houses and 15 prisons.

\subsection{Diplomacy and Foreign Affairs}

165. Expenditures of the Diplomacy and Foreign Affairs Sector in 2007 amount to CFAF 20.27 billion. They will stand at CFAF 20.30 billion in 2008, CFAF 21.78 billion in 2009, CFAF 23.71 billion in 2010, and CFAF 25.46 billion in 2011, representing an increase rate of $0.2 \%$ in $2007,7.3 \%$ in $2008,8.9 \%$ in 2009 , and $7.4 \%$ in 2010 . The increases are due to: 
- participation in international meetings (United Nations General Assembly, and meetings of OIC, African Union, Movement of the Non-Aligned) ;

- extension of the central building of the Ministry of Foreign Affairs and International Cooperation, and equipment of the central services;

- inspection missions within the country and abroad;

- contact visits to Malian communities abroad;

- adequate supply of consular and civil status documents to Diplomatic and Consular Missions. 


\section{ANNEXES}

\subsection{Annex 1: Presentation of the Operationalization and Internalization Logical Framework of the MTBF Process}

Table 51: Budget Timetable

\begin{tabular}{|c|c|c|}
\hline TIMETABLE & BUDGET PROCESS STAGES & $\begin{array}{l}\text { ACTORS } \\
\text { INVOLVED }\end{array}$ \\
\hline Jan.- Feb.- March & $\begin{array}{l}\text { Annual report on implementation of } \\
\text { programme budgets } \\
\text { Preparation of macro-economic framework }\end{array}$ & $\begin{array}{l}\text { MEF (DGB) } \\
\text { DNSI-DNPD-DGB }\end{array}$ \\
\hline March - April & Update of MTBF & DGB \\
\hline April - May & Update of sectoral MTBF & Sectoral Ministries \\
\hline April - May & $\begin{array}{l}\text { National Workshop to launch the budget } \\
\text { process }\end{array}$ & MEF (DGB) \\
\hline May & $\begin{array}{l}\text { Preparation of the Circular Letter } \\
\text { incorporating the conclusions of the National } \\
\text { Workshop and concerns of sectoral MTBF }\end{array}$ & MEF (DGB) \\
\hline June & $\begin{array}{l}\text { Review of sectoral programmes in each } \\
\text { Ministry or Institution }\end{array}$ & Ministries/Institutions \\
\hline June & PRSP implementation report & PRSP Unit \\
\hline June - July & Preparation of sectoral programme budgets & Ministries/Institutions \\
\hline July & $\begin{array}{l}\text { Preparation of preliminary draft accounting } \\
\text { budget }\end{array}$ & Ministries/Institutions \\
\hline July & $\begin{array}{l}\text { Submission to DGB of draft accounting } \\
\text { budget and programme budgets }\end{array}$ & Ministries/Institutions \\
\hline July & $\begin{array}{l}\text { Pooling and consideration of draft budgets by } \\
\text { the DGB technical commissions to verify the } \\
\text { quality and accuracy of information }\end{array}$ & DGB \\
\hline July & $\begin{array}{l}\text { Technical arbitration in DGB and DNPD to } \\
\text { determine budget allocations on the basis of } \\
\text { MTBFs validated by MEF }\end{array}$ & DGB/DNPD \\
\hline August & Political arbitration of the Ministry of Finance & MEF \\
\hline August-September & $\begin{array}{l}\text { Finalization of the Finance Bill and its } \\
\text { supplementary budgets }\end{array}$ & DGB \\
\hline September & Adoption by Cabinet Meeting & Government \\
\hline & $\begin{array}{l}\text { Tabling and adoption by the National } \\
\text { Assembly }\end{array}$ & National Assembly \\
\hline
\end{tabular}

Source: DGB 


\subsection{Annex 2: Some Projects illustrating Extension of Projects/Programmes}

Table 52: Some Projects illustrating Extensions of Projects/Programmes

\begin{tabular}{|c|c|c|c|}
\hline Description & $\begin{array}{l}\text { Initial } \\
\text { Duration }\end{array}$ & $\begin{array}{l}\text { Actual } \\
\text { Duration }\end{array}$ & Remarks \\
\hline Water points project in Liptako-Gourma & 4 years & 20 years & $\begin{array}{l}\text { Project completed in } \\
2003\end{array}$ \\
\hline 200 water points Tenenkou & 4 years & 11 years & $\begin{array}{l}\text { Project completed in } \\
2005\end{array}$ \\
\hline DWS Kidal & 4 years & 9 years & $\begin{array}{l}\text { Project completed in } \\
2005\end{array}$ \\
\hline 100 water points Kayes Koulikoro region & 5 years & 8 years & $\begin{array}{l}\text { Project completed in } \\
2004\end{array}$ \\
\hline Village water supply Dogon Highlands & 5 years & 8 years & $\begin{array}{l}\text { Project completed in } \\
2004\end{array}$ \\
\hline CEAO II & 5 years & 13 years & $\begin{array}{l}\text { Project completed in } \\
2005\end{array}$ \\
\hline PDRI Mopti/Tombouctou & 4 years & 9 years & $\begin{array}{l}\text { Project completed in } \\
2005\end{array}$ \\
\hline PRODESO & 6 years & 12 years & $\begin{array}{l}\text { Project completed in } \\
2005\end{array}$ \\
\hline PSARK & 6 years & 15 years & $\begin{array}{l}\text { Project completed in } \\
2005\end{array}$ \\
\hline Lake Zone & 5years & 10 years & $\begin{array}{l}\text { Project completed in } \\
2003\end{array}$ \\
\hline Agriculture Goumbo & 3 years & 15 years & $\begin{array}{l}\text { Project completed in } \\
2000\end{array}$ \\
\hline Poultry development in Mali & 4 years & 10 years & $\begin{array}{l}\text { Project completed in } \\
2005\end{array}$ \\
\hline Saouné agricultural project & 4 years & 10 years & $\begin{array}{l}\text { Ongoing and will be } \\
\text { completed in } 2006\end{array}$ \\
\hline PIV Gao & 5 years & 14 years & $\begin{array}{l}\text { Project completed } \\
\text { in } 2005\end{array}$ \\
\hline Moyen Bani project & 5 years & 9 years & $\begin{array}{l}\text { Ongoing and will be } \\
\text { completed in } 2007\end{array}$ \\
\hline Non-Cotton zone development & 5 years & 11 years & $\begin{array}{l}\text { Project completed in } \\
2005\end{array}$ \\
\hline PDIA Manantali & 6 years & 8 years & Ongoing \\
\hline PDRI Kita & 5 years & 7 years & Ongoing \\
\hline 45 primary schools & 4 years & 11 years & Completed in 2003 \\
\hline $\begin{array}{l}\text { Construction of health centres } \\
\text { Mopti/Tombouctou }\end{array}$ & 5 years & 13 years & Completed in 2005 \\
\hline
\end{tabular}




\subsection{ANNEX 3: Contribution of Malian Mining Companies to Budgetary Revenue 2002-2006}

166. The main sources of the tax systems applicable to enterprises carrying out mining activities, including sub-contracting of the said activities, are the Mining Code and Establishment Agreements. For practical reasons and transparency in public management, the establishment Agreement summarizes the respective rights and obligations of the Government and the mining enterprises, and supplements the Mining Code. The tax system defined by the 1991 Code (established by Ordinance No. 91-065/P-CTSP of 19 September 1991) varies according to the different operation phases, namely:

Exploration, prospecting, development and first three financial years of exploitation:

167. During this period, the mining company and its sub-contractors are exempted from all taxes, internal dues and taxes (including company tax and value added tax) with the exception of some charges and taxes mainly on remunerations to employees and assets (vehicles).

168. The charges mainly consist of: fixed tax for the issue or renewal of exploration license (CFAF 300,000) irrespective of the surface area allotted, fixed tax for the issue of prospecting permit (CFAF 300,000), fixed tax for the issue of an exploitation permit (CFAF 700,000), fixed tax for the issue of an exploitation licence (CFAF 1,000,000) and charges calculated on the basis of the surface area of the mining licence.

169. The area-based charges range from CFAF 50,000 to CFAF 100,000 per square kilometer and per year depending on the size of the company. Currently, it is calculated by the National Directorate of Geology and Mining (DNGM). However, Article 32 of the Land Code of 22 March 2000 stipulates that: "The Government, like any owner, has its developed private immovable property. However, subject to the provisions of this Code, the appurtenances of forest, mining or pastoral lands are governed by specific texts, but the proceeds from these lands are collected by the lands services for the public treasury."

170. The fixed contribution (7\%) by the employer, the housing tax of $1 \%$ of the gross remuneration granted to employees of the company, and the employee remuneration tax calculated on the basis of a progressive scale and taking into account the salary and social status of each employee. In addition, the following taxes are also paid:

- tax on vehicles ("vignettes") with the exception of heavy worksite machinery,

- stamp duty,

- ad valorem tax at $3 \%$ the value of the extracted substances,

- contribution for services rendered (CPS) at the rate of $3 \%$.

Period after the first three accounting years:

171. During this period, the company, in addition to the above charges, pays the following:

- business profits tax (I/BIC),

- professional business licence charges in accordance with the provisions of the General Tax Code,

- stockholders' tax (IRVM) at $18 \%$, the tax base being the amount of profits distributed,

- value added tax (VAT) at $18 \%$ and in accordance with the rules defined by the General Tax Code, 
- tax on insurance contracts with companies in Mali. It is paid in accordance with the terms and conditions defined in the General Tax Code.

172. The Mining Code was amended in 1999 and 2000 by Ordinances No. 99-032/P-RM of 19 August 1999 and No. 00-013/P-RM of 10 February 2000 respectively. The amendments by these two Ordinances are as follows:

- abolition of the 5-year temporary exemption granted for company tax; consequently, the profits are immediately taxed without any tax vacation;

- abolition of the temporary exemption from stockholders' tax;

- introduction of a $10 \%$ tax on capital gain on mining exploration and/or exploitation licence

- abolition of the ad valorem tax.

173. Mining companies, with the exception of those exempted from all taxes, are subject to a number of deductions from the tax services.

Table 53: Share of mining companies in revenue of Directorate General of Taxes from 1 January 2002 to 31 March 2006 (in CFAF billion)

\begin{tabular}{|c|c|c|c|c|c|c|}
\hline TAXES AND DUTIES & 2002 & 2003 & 2004 & 2005 & 2006 & TOTAL \\
\hline Company tax & 0.068 & 5.37 & 6.325 & 6.679 & 0 & 18.442 \\
\hline $\begin{array}{l}\text { Deduction at source of business profits and } \\
\text { company taxes }\end{array}$ & 0.529 & 0.786 & 0.972 & 2.131 & 0.033 & 4.451 \\
\hline Tax on compensation & 4.22 & 4.694 & 5.753 & 6.44 & 0.823 & 21.93 \\
\hline Housing tax & 0.108 & 0.129 & 0.253 & 0.336 & 0.035 & 0.861 \\
\hline Vocational training tax & 0.089 & 0.104 & 0.128 & 0.154 & 0.023 & 0.498 \\
\hline $\begin{array}{l}\text { Service tax/special tax on some CPS/ISCP } \\
\text { products }\end{array}$ & 11.478 & 9.077 & 7.466 & 10.49 & 3.454 & 41.965 \\
\hline Stockholders' tax & 1.949 & 2.622 & 2.325 & 0.005 & 0 & 6.901 \\
\hline TOTAL & 22.05 & 25.778 & 29.609 & 34.232 & 4.788 & 116.457 \\
\hline
\end{tabular}

Source: CPS/DGI

174. It should be pointed out that these new provisions are not retroactive.

175. Only Morila, Yatela, Sadiola and Loulou companies pay the ad valorem tax, because they are subject to the 1991 Code. Determination of the tax base poses serious difficulties, since it is based on the value of extracted substances. However, it was only in 2006 that the mining companies started to submit refining certificates, following adjustment operations initiated by the services of the National Directorate of Lands and Survey (DNDC). These certificates provide some information such as:

- the weight of the exported quantity in $\mathrm{kg}$,

- the weight of refined gold in ounces,

- the weight of silver in the exported quantity in ounces,

- the selling price of gold and silver per once,

- the cost of refining.

176. It should also be pointed out that the price of gold and conversion rates vary (the rate of the dollar and once $/ \mathrm{kg}$ ).

177. As regards the dividends, the State owns $20 \%$ of the shares in mining companies; its dividends, if any, correspond to $18 \%$ of the net profits recorded by each company. Consequently, it is important to know if the charges calculated at the time of determining the base of the Ad Valorem Tax are not considered when determining the net profit. 
Table 54: Situation of Gold Production, Payment of Dividends and Ad Valorem Tax to DNDC

\begin{tabular}{|c|c|c|c|c|c|c|}
\hline & YEAR & 2002 & 2003 & 2004 & 2005 & 2006 \\
\hline \multirow{3}{*}{ SEMOS } & $\begin{array}{l}\text { Gold Prod. } \\
\text { in kg }\end{array}$ & 16192.84 & 15726.32 & 15569.62 & 15100.32 & \\
\hline & $\begin{array}{l}\text { Ad Valorem } \\
\text { Tax }\end{array}$ & 3.085 & 2.781 & 2. 865 & 3.119 & 0.909 \\
\hline & Dividends & 2.256 & 4.234 & 4.105 & 2.675 & 0.845 \\
\hline \multirow{3}{*}{ MORILA } & $\begin{array}{l}\text { Gold Prod. } \\
\text { in kg } \\
\end{array}$ & 38914.41 & 28638.36 & 17634.03 & 23832.07 & \\
\hline & $\begin{array}{l}\text { Ad Valorem } \\
\text { Tax } \\
\end{array}$ & 6.678 & 4.940 & 2.753 & 4.723 & 1.176 \\
\hline & Dividends & 17.519 & 18.244 & 0.659 & 6.597 & \\
\hline \multirow{3}{*}{ YATELA } & $\begin{array}{l}\text { Gold Prod. } \\
\text { in kg }\end{array}$ & 8586.53 & 7233.08 & 8109.14 & 8012.63 & \\
\hline & $\begin{array}{l}\text { Ad Valorem } \\
\text { Tax } \\
\end{array}$ & 1.695 & 1.486 & 1.388 & 1.730 & 0.668 \\
\hline & Dividends & & & & & \\
\hline \multicolumn{2}{|c|}{ Gold Production SOMIKA } & & & 272.725 & 540.499 & \\
\hline \multicolumn{2}{|c|}{ Gold Production SOMILO } & & & & 1636.04 & \\
\hline \multicolumn{2}{|c|}{ Ad valorem Tax SOMILO } & & & & 0.522 & 0.377 \\
\hline
\end{tabular}

\section{Sources: BCEAO/DNDC/ SEMOS/DNGM}

The OHADA Treaty signed in Port Louis on 17 October 1993 was ratified on 31 December 2000, and it entered into force in 1995. It stipulates in Article 146 as follows: "the terms and conditions of payment are defined by the General Meeting, which can delegate this right, as the case may be, to the Manager, Chairman and Managing Director, General Manager, or Executive Director. However, the dividends should be paid within nine months following the end of the financial year. Extension of this period may be granted by the President of the competent court." However, the reports of Boards of Directors of mining companies are submitted late to DNDC.

Table 55: Contribution of the mining sector to the revenue of DNDC from 1 January 2002 to 31 March 2006 (in CFAF billion)

\begin{tabular}{|l|r|r|r|r|r|r|}
\hline Companies & \multicolumn{1}{|c|}{$\mathbf{2 0 0 2}$} & \multicolumn{1}{c|}{$\mathbf{2 0 0 3}$} & \multicolumn{1}{c|}{$\mathbf{2 0 0 4}$} & \multicolumn{1}{c|}{$\mathbf{2 0 0 5}$} & \multicolumn{1}{c|}{$\mathbf{2 0 0 6}$} & \multicolumn{1}{c|}{ Total } \\
\hline Semos & 5.34 & 7.014 & 6.97 & 5.794 & 1.754 & $\mathbf{2 6 . 8 7 2}$ \\
\hline Morila & 24.195 & 23.182 & 3.412 & 11.319 & 1.176 & $\mathbf{6 3 . 2 8 4}$ \\
\hline Yatela & 1.694 & 1.486 & 1.388 & 1.729 & 0.667 & $\mathbf{6 . 9 6 4}$ \\
\hline Somika & 0 & 0 & 0 & 0 & 0 & $\mathbf{0}$ \\
\hline Loulo & 0 & 0 & 0 & 0.521 & 0.376 & $\mathbf{0 . 8 9 7}$ \\
\hline Total & $\mathbf{3 1 . 2 2 9}$ & $\mathbf{3 1 . 6 8 2}$ & $\mathbf{1 1 . 7 7}$ & $\mathbf{1 9 . 3 6 3}$ & $\mathbf{3 . 9 7 3}$ & $\mathbf{9 8 , 0 1 7}$ \\
\hline
\end{tabular}

\section{Sources: BCEAO/DNDC/ SEMOS/DNGM}

It should also be noted that these companies often sign agreements with the Ministry of the Economy and Finance, authorizing them to stagger, and even defer payments of dividends for several months. The gold produced in Yatela and Sadiola is exported from Kayes, and that of Morila and other private exporters from Bamako Sénou airport; consequently, some quantities may elude control. All things being equal, these companies enjoy many other benefits such as tax exemptions and reimbursement of VAT credits. Accordingly, 
from 2002 to date, the status of payments relating to reimbursement of VAT credits is as follows:

- CFAF $14,988,299,013$ in 2002, including CFAF $13,748,241,516$ for the miners, representing $92 \%$ of the total amount paid;

- CFAF $7,735,057,478$ in 2003, including CFAF $5,458,281,871$ for the miners, representing $71 \%$ of the total amount paid;

- CFAF 3,889,504,320 in 2004, including CFAF 2,306,087,453 for the miners, representing $59 \%$ of the total amount paid;

- CFAF $3,275,277,451$ in 2005, including CFAF $1,350,211,279$ for the miners, representing $41 \%$ of the total amount paid;

- as at 24 May 2006, reimbursements of VAT credit stood at CFAF 5,375,795,368, including CFAF 5,147,441,894 for the miners as compensation, representing $96 \%$ of the total amount paid. Under the same item, CFAF 1,624,205,000 are available for pending payments of CFAF 15,345,167,279 as of 24 May 2006.

The status of tax exemptions granted to mining companies is as follows:

Table 56: Exemptions granted to mining companies from 2002 to 2005 (in CFAF billion)

\begin{tabular}{|l|r|r|r|r|}
\hline & $\mathbf{2 0 0 2}$ & $\mathbf{2 0 0 3}$ & $\mathbf{2 0 0 4}$ & $\mathbf{2 0 0 5}$ \\
\hline Amounts & 8.655 & 14.548 & 15.755 & 10.498 \\
\hline
\end{tabular}

\section{Source: DGB}

A single Mining Code should be adopted. This would facilitate assessment of the tax base and the rate of the Ad Valorem Tax, and also help to clearly define the conditions of payment of dividends. The harmonization of Establishment Agreements will ensure some homogeneity in the companies. It is important to note that DNDC is a department that is not under the Ministry of the Economy and Finance; however, it should be consulted before any decision is taken on some provisions concerning mining companies.

Increase in DNDC revenues requires closer monitoring of the State portfolio, review of texts to clearly define land revenues, the determination of an ad valorem tax rate for all mining companies, the timely communication of conclusions of Boards of Directors of the various companies and resolutions of the General Meetings, and compliance with Community texts (such as OHADA texts) in force. It is necessary to identify all the mining developers and sub-contractors on the national territory.

Table 57: Contribution of mining sector to State budgetary revenue from 1 January 2002 to 31 March 2006 (in CFAF billion)

\begin{tabular}{|c|c|c|c|c|c|r|}
\hline Services & 2002 & 2003 & 2004 & 2005 & 2006 & TOTAL \\
\hline DGI & 22.05 & 25.779 & 29.609 & 34.232 & 4.788 & 116.46 \\
\hline DNDC & 31.229 & 31.682 & 11.77 & 19.363 & 3.973 & 98.02 \\
\hline TOTAL & 53.279 & 57.461 & 41.379 & 53.595 & 8.761 & 214.48 \\
\hline
\end{tabular}

Source: DGI and DNDC 


\section{$2^{\text {nd }}$ Generation PRSP $2007-2011$}

\section{Annex III \\ Actions Matrix for GPRSP \\ 2007 - 2009}

20 December 2006 
Table of Contents

1 ENHANCEMENT OF DEVELOPMENT MANAGEMENT 66

1.1 STRENGTHENING AND COORDINATION OF POVERTY REDUCTION STRATEGY

1.2 DEVELOPMENT OF MACRO-SECTORAL ANALYSIS TOOLS 66

2 INFRASTRUCTURE AND PRODUCTIVE SECTORS

$\begin{array}{llr}2.1 & \text { FOOD SECURITY } & 66\end{array}$

2.2 RURAL DEVELOPMENT 266

2.2.1 Agriculture Sub-sector $\quad 66$

$\begin{array}{lr}\text { 2.2.2 Cotton Sub-sector } & 67\end{array}$

$\begin{array}{lr}\text { 2.2.3 Livestock and Fisheries Sub-sector } & 67\end{array}$

2.2.4 Support to rural areas $\quad 68$

2.3 MINNING AND EXTRACTIVE INDUSTRIES 29

$\begin{array}{llr}2.4 & \text { SME-SMI DEVELOPMENT } & 70\end{array}$

$\begin{array}{llr}2.5 & \text { TOURISM AND HANDICRAFT } & 70\end{array}$

$\begin{array}{lll}2.6 & \text { CULTURE } & 71\end{array}$

2.7 ENVIRONMENTAL PROTECTION AND MANAGEMENT OF NATURAL RESOURCES

$\begin{array}{llr}2.8 & \text { INFRASTRUCTURE DEVELOPMENT }\end{array}$

2.8.1. Transport $r$

2.8.2. Telecommunications and ICT $\quad 72$

2.8.3. Energy 273

3 PURSUANCE AND CONSOLIDATION OF STRUCTURAL REFORMS

3.1 CONSOLIDATION OF PUBLIC ADMINISTRATION REFORMS $\quad 74$

3.1.1 Decentralization and Deoncentration $\quad 74$

3.1.2 Improvement and Modernization of Public Finance Management 74

3.2 PURSUANCE OF REFORM OF THE BUSINESS ENVIRONMENT $\quad 75$

3.3 FINANCIAL SECTOR DEVELOPMENT

3.4 PROMOTION OF DEMOCRATIC GOVERNANCE AND PUBLIC FREEDOMS $\quad 76$

$\begin{array}{ll}3.5 & \text { CAPACITY BUILDING FOR THE CIVIL SOCIETY } \\ 3.67\end{array}$

3.6 STRENGTHENING OF REGIONAL AND SUB-REGIONAL INTEGRATION INITIATIVES

4 DEVELOPMENT OF ACCESS TO BASIC SOCIAL SERVICES

$\begin{array}{llr}4.1 & \text { EDUCATION } & 78\end{array}$

$\begin{array}{llr}4.2 & \text { HEALTH } & 78\end{array}$

$\begin{array}{llr}4.3 & \text { SOCAL DEVELOPMENT } & 79\end{array}$

4.4 DRINKING WATER AND SANITATION $\quad 79$

$\begin{array}{llr}4.5 & \text { CREATION AND PROMOTION OF SUSTAINABLE JOBS } & 80\end{array}$

$\begin{array}{llr}4.6 & \text { HIV/AIDS CONTROL } & 80\end{array}$

5 CROSS-CUTTING ISSUES $\quad 81$

$\begin{array}{llr}5.1 & \text { GENDER } & 81\end{array}$

$\begin{array}{llr}5.2 & \text { PEACE AND SECURITY } & 81\end{array}$

$\begin{array}{lll}5.3 & \text { TERRITORIAL DEVELOPMENT } & 81\end{array}$

6 STRENGTHENING OF STATISTICS MECHANISM AND PRSP MONITORING 1

$\begin{array}{llr}6.1 & \text { STRENGTHENING OF STATISTICS MACHINERY } & 81\end{array}$

$\begin{array}{llr}6.2 & \text { STRENGTHENING OF PRSP MONITORING } & 82\end{array}$ 


\section{Enhancement of DeVelopment Management}

\subsection{Strengthening and Coordination of Poverty Reduction Strategy}

\begin{tabular}{|l|l|l|}
\hline Ensure linkage between PRSP, State Budget and MTEF & Budget consistent with PRSP priorities \\
\hline Ensure synergy of sector policies & Synergy between PRSP and sector policies \\
\cline { 2 - 3 } $\begin{array}{l}\text { Strengthen the participatory process and capacities of } \\
\text { institutional stakeholders (civil society, regional and local } \\
\text { committees) }\end{array}$ & $\begin{array}{l}\text { Better internalization of PRSP by the institutional } \\
\text { stakeholders. Ensure consistency of regional } \\
\text { development plans }\end{array}$ \\
\cline { 2 - 3 } Analyze poverty & $\begin{array}{l}\text { Series of thematic studies on poverty: health, } \\
\text { vulnerability and education }\end{array}$ \\
\hline
\end{tabular}

Incorporation of PRSP priorities in State budget and MTEF

Sectoral and overall review of PRSP

Regional consultations on PRSP

Ownership of PRSP by the civil society through presentation workshops

Workshops on dissemination of PRSP process and reflection on consistency with regional and local development plans

Studies on poverty and consumption based on the results of ELIM 2003 and 2006.

\subsection{Development of Macro-sectoral Analysis Tools}

Capacity building in macro-economic modelling and analysis

\section{The PRSP Unit has tools for analyzing the impact} of economic and social policy measures

Economic situation performance chart

Simple national accounting model

Macro-sectoral forecasts model, as tool for analysis of growth-oriented sectors.

Senior staff trained
Preparation of micro-simulation model (MEGC) for analysis of impacts of exogenous shocks and policy measures on poverty and income distribution (World Bank financing)

Preparation of an economic situation performance chart.

National accounts and macro-economic analysis Coordination of macro-economic modelling activitie of DNSI, Macro-economic Unit and DNPD.

Training in macro-economic modelling and analysis

\section{Infrastructure and Productive Sectors}

\subsection{Food Security}

\begin{tabular}{|c|c|c|}
\hline Reduce the impact of major food crises & & \\
\hline $\begin{array}{l}\text { Strengthen and broaden the crisis prevention and management } \\
\text { system }\end{array}$ & Complete and available buffer stock & $\begin{array}{l}\text { - Supplement SNS to } 35000 \text { tonnes } \\
\text { - Create a Food Stock Intervention Fund } \\
\text { - Create the seeds stock } \\
\text { - Finance transport } \\
\text { - Finance SNA structures: OPAM, SAP, ONA }\end{array}$ \\
\hline Implement the National Food Security Programme (PNSA) & Coverage of food requirements better ensured & $\begin{array}{l}\text {-Development of natural resources } \\
\text { - Intensification of crops } \\
\text { - Diversification of production systems } \\
\text { - Marketing and processing of agricultural products } \\
\text { - Strengthen the cereal sub-sectors } \\
\text { - Strengthen the fishery sub-sector and imprc } \\
\text { nutrition and health status } \\
\text { - Strengthen the surveillance and alert mechani } \\
\text { particularly under the 10th EDF }\end{array}$ \\
\hline Implement PIDRN & Reduction of vulnerability of North region & \\
\hline Implement PIDRK & Reduction of vulnerability of KIDAL region & \\
\hline
\end{tabular}

\subsection{Rural Development}

\subsubsection{Agriculture Sub-Sector}

\begin{tabular}{|l|l|}
\hline Implementation of the LOA & $\begin{array}{l}\text { - Texts adopted and signed } \\
\text { - Structures put in place and operational } \\
\text { - Evaluation reports produced }\end{array}$ \\
\hline Development of irrigation schemes & $\begin{array}{l}\text { The new master plan of the Niger Authority is } \\
\text { implemented }\end{array}$ \\
\hline
\end{tabular}

- Design of texts

- Establishment of structures

- Evaluation of implementation

Implement the master plan of the Niger Autho taking into account new programmes, particularly MCA programme and $10^{\text {th }} \mathrm{EDF}$ 


\begin{tabular}{|c|c|c|}
\hline & 64000 ha scheme carried out and well managed & Carry out work on 64000 ha \\
\hline Inventory of developable resources potential & $\begin{array}{l}\text { The potential to be developed is known and geo- } \\
\text { referenced. }\end{array}$ & Identify the sites to be developed with SIG \\
\hline Development of mechanized agriculture & $\begin{array}{l}\text { The programme is designed and implemented } \\
\text { with a standards frame of reference }\end{array}$ & $\begin{array}{l}\text { Design and implement a national agricultu } \\
\text { equipment programme }\end{array}$ \\
\hline Capacity building for stakeholders & & $\begin{array}{l}\text { Prepare and implement training } \\
\text { particularly under the MCA programme }\end{array}$ \\
\hline \multirow[t]{4}{*}{$\begin{array}{l}\text { Ensure sustainable development and improvement of living } \\
\text { conditions of the rural populations }\end{array}$} & $\begin{array}{l}\text { Development and irrigated agriculture } 12000 \mathrm{~h} \\
\text { Development of } 16000 \mathrm{~h} \text { of lowlands } \\
\text { Development of controlled submersion of } 20000 \\
\mathrm{~h} \text {. }\end{array}$ & \\
\hline & & $\begin{array}{l}\text { Strengthen the management, programming, design, } \\
\text { implementation, exploitation and maintenance capacities c } \\
\text { rural infrastructure }\end{array}$ \\
\hline & & $\begin{array}{l}\text { Reinforce rural infrastructure: rural, council and inter-counı } \\
\text { roads, development and rehabilitation of irrigation areas, } \\
\text { construction of water points }\end{array}$ \\
\hline & Studies and action plans conducted & $\begin{array}{l}\text { Develop the studies portfolio to ensure good planning of } \\
\text { irrigation programmes. }\end{array}$ \\
\hline $\begin{array}{l}\text { Improve the technical and economic performance of } \\
\text { agricultural production and processing systems }\end{array}$ & $\begin{array}{l}\text { - Demonstration, dissemination and service } \\
\text { centres, parcels and sites established } \\
\text { - Producers and processing actors trained } \\
\text { - Craftsmen installed }\end{array}$ & $\begin{array}{l}\text { - Demonstrate and promote technological innovation } \\
\text { - Train producers and service providers } \\
\text { - Support the dissemination of technologi } \\
\text { innovations by creating an investment and innovat } \\
\text { fund }\end{array}$ \\
\hline $\begin{array}{l}\text { Improve the economic performance of the agricultural, } \\
\text { livestock, fisheries and harvested products sectors }\end{array}$ & $\begin{array}{l}\text { - } 8 \text { well-performing sub-sectors supported and } 8 \\
\text { interprofessional structures created } \\
-10 \% \text { increase in export volumes and values } \\
-4 \text { important private investment projects } \\
\text { generated }\end{array}$ & $\begin{array}{l}\text { - Know the markets and sub-sectors } \\
\text { - Professional consultation } \\
\text { - Promotion of private investment } \\
\text { - Improvement of quality of products and th } \\
\text { marketing }\end{array}$ \\
\hline Facilitate access to financing & $\begin{array}{l}\text { - Guarantee fund created and operational } \\
\text { - CFAF } 500 \text { million of credit granted and CFAF } \\
250 \text { million guarantee granted } \\
\text { - } 90 \% \text { repayment rate obtained }\end{array}$ & $\begin{array}{l}\text { - Establish a guarantee fund } \\
\text { - Strengthen the capacities of financial institutions } \\
\text { - Promote innovative financial instruments } \\
\text { - Improve the conditions for granting agricultu } \\
\text { loans, particularly under the MCA programme }\end{array}$ \\
\hline Construct marketing and communication infrastructures & $\begin{array}{l}\text { - } 2 \text { agricultural products centralization poles, } 1 \\
\text { analysis laboratory, } 3 \text { multifunctional processing } \\
\text { platforms, and } 2 \text { markets established } \\
\text { - } 1111 \mathrm{~km} \text { of roads rehabilitated }\end{array}$ & - Rehabilitate rural roads \\
\hline
\end{tabular}

\subsubsection{Cotton Sub-Sector}

Strengthen the capacities of producers

Improve management of the sub-sector

Improve productivity and competitiveness of the sub-sector
The capacities of producers are strengthened

Concerted management of the sub-sector is improved

Productivity, competitiveness and sustainability of the sub-sector are improved
- Support establishment of cooperative societies cotton producers

- Train farmer leaders and officials

- Provide literacy education to producers

- Establish cotton interprofessions

- Create the cotton observatory

- Create CMDT subsidiaries

- Finance research activities on cotton

- Create the cotton classification authority

- Improve the rural council

- Ensure production, certification and use of seeds

- Ensure maintenance, opening and rehabilitation roads

Secure and diversify incomes

Increase the internal cotton processing rate
- Establish the cotton exchange market

- Replenish the support fund

- Create a calamity fund

- Reinforce CERFITEX

- Create new textile units

\subsubsection{Livestock and Fisheries Sub-sector}

Increase and diversify livestock production through sustainable practices

Contribute to development of the livestock sub-sector
The volume of milk, meat, hides and skins is increased

A summary sheet is prepared for each livestock sub-sector
- Implement the development plan of milk, hides : skins, and poultry sub-sectors

- Pursue implementation of development plan of beef sub-sector

Implementation of the bee-keeping support programı Pursue creation of consultation frameworks betwe 


\begin{tabular}{|c|c|c|}
\hline & & $\begin{array}{l}\text { the various stakeholders of the beef and poultry si } \\
\text { sectors }\end{array}$ \\
\hline $\begin{array}{l}\text { Deign and see to the implementation of the fisheries } \\
\text { development policy }\end{array}$ & Fish production is increased & $\begin{array}{l}\text {-Pursue implementation of the fisheries developm } \\
\text { master plan } \\
\text { Implement rural credit system adapted to the fisher } \\
\text { sector } \\
\text {-Prepare fisheries plans by region } \\
\text {-Revitalization of piscicultural and young fish cent } \\
\text { (MCA) }\end{array}$ \\
\hline $\begin{array}{l}\text { Facilitate access to rural credit for the financing of animal } \\
\text { production sub-sectors }\end{array}$ & The stakeholders are trained in rural credit & $\begin{array}{l}\text { - Pursue information, sensitization and training } \\
\text { producers in micro-finance } \\
\text { - Implement rural credit system adapted to the fisher } \\
\text { and livestock sector } \\
\text { - Pursue support and advisory services to you } \\
\text { promoters interested in livestock activities }\end{array}$ \\
\hline $\begin{array}{l}\text { Prepare national programme for control of animal diseases, } \\
\text { including zoonotic diseases }\end{array}$ & $\begin{array}{l}\text { The vaccination campaigns for } 2006 \text { to } 2009 \text { are } \\
\text { organized and officially launched }\end{array}$ & $\begin{array}{l}\text { Organize and launch vaccinatic } \\
\text { campaigns from } 2006 \text { to } 2009\end{array}$ \\
\hline & $\begin{array}{l}\text { The vaccination coverage rate increases from } \\
55 \% \text { to } 80 \% \text { for contagious cattle peri- } \\
\text { pneumonia. }\end{array}$ & $\begin{array}{l}\text { - Ensure production of vaccines } \\
\text { - Vaccinate animals against the major diseases. }\end{array}$ \\
\hline & $\begin{array}{l}\text { - } 60 \text { vaccination centres are constructed. } \\
\text { - Control of tsetse fly and animal } \\
\text { trypanosomiases in infested areas is effective }\end{array}$ & $\begin{array}{l}\text { - Construct } 60 \text { vaccination centres from } 2007 \text { to } 200 \text { ( } \\
\text { - Organize control of tsetse flies and anir } \\
\text { trypanosomiases in infested areas }\end{array}$ \\
\hline & Outbreaks of diseases are controlled & Control outbreaks of diseases \\
\hline & Control of transhumance animals is ensured & Control transhumance animals \\
\hline & $\begin{array}{l}\text { Passive surveillance of priority diseases and } \\
\text { active surveillance of avian influenza are ensured. } \\
\text { Products and foodstuffs of animal origin are } \\
\text { regularly inspected }\end{array}$ & $\begin{array}{l}\text { - Conduct passive surveillance of priority diseases } c \\
\text { active surveillance of avian influenza } \\
\text { - Inspect products and foodstuffs of animal origin }\end{array}$ \\
\hline
\end{tabular}

\subsubsection{Support to Rural Areas}

\begin{tabular}{|c|c|c|}
\hline Increase agricultural yields and production & $\begin{array}{l}\text { Seed cooperatives established in districts. } \\
\text { Producers have access to improved seeds: } \\
1,900,000 \text { ha sown with cereal crops in } \\
\text { R2/year. 200,000 tonnes produced each } \\
\text { year. Increased use of fertilizers and } \\
\text { increase in production }\end{array}$ & $\begin{array}{l}\text { - Organize production and marketing of } \mathrm{R} 2 \text { seeds in } \\
\text { regions. } \\
\text { - Facilitate purchase of inorganic fertilizers by producers }\end{array}$ \\
\hline Build the capacities of producers & $\begin{array}{l}\text { Producers master anti-erosion farming } \\
\text { methods }\end{array}$ & Train producers in anti-erosion farming methods \\
\hline Restore soil fertility & $\begin{array}{l}750,000 \mathrm{t} \text { of manure produced } \\
\begin{array}{l}1,200 \text { ha protected, } 800 \text { micro-dams } \\
\text { constructed }\end{array}\end{array}$ & $\begin{array}{l}\text { - Produce manure } \\
\text { - Support producers in constructing anti-erosion structures }\end{array}$ \\
\hline Promote job creation for the youths. & 500 youths installed as farmers & $\begin{array}{l}\text { Facilitate access by youths to developed lands and prov } \\
\text { them with training. }\end{array}$ \\
\hline Increase the incomes of producers & The created frameworks are reinforced & $\begin{array}{l}\text { Promote growth-oriented agricultural sub-sectors (rice, grt } \\
\text { onion, onion, maize, potatoes) particularly under the MCA c } \\
\text { the } 10 \text { th }^{\mathrm{EDF}} \text {. }\end{array}$ \\
\hline Build the capacities of CAAs & 3 CAAs are rehabilitated & Rehabilitate CAAs \\
\hline $\begin{array}{l}\text { Improve the technical and economic performance of } \\
\text { agricultural production and processing systems }\end{array}$ & $\begin{array}{l}\text { - Demonstration, dissemination and service } \\
\text { centres, as well as parcels and sites are } \\
\text { established } \\
\text { - Producers and processing actors trained } \\
\text { - Craftsmen installed }\end{array}$ & $\begin{array}{l}\text { - Demonstrate and promote technological innovations } \\
\text { - Train producers and service providers } \\
\text { - Support dissemination of technological innovations } \\
\text { creating an investment and innovation fund }\end{array}$ \\
\hline $\begin{array}{l}\text { Improve economic performance of agricultural, livestock, } \\
\text { fisheries and harvested products sub-sectors }\end{array}$ & $\begin{array}{l}\text { - } 8 \text { well-performing sub-sectors supported } \\
\text { and } 8 \text { inter-professional structures created } \\
-10 \% \text { increase in export volumes and } \\
\text { values } \\
-4 \text { important private investment projects } \\
\text { generated }\end{array}$ & $\begin{array}{l}\text { - Know the markets and sub-sectors } \\
\text { - Professional consultation } \\
\text { - Promotion of private investment } \\
\text { - Improvement of quality of products and their marketing }\end{array}$ \\
\hline Facilitate access to financing & $\begin{array}{l}\text { - Guarantee fund created and operational } \\
\text { - CFAF } 500 \text { million of loans granted and } \\
\text { CFAF } 250 \text { million guarantee granted } \\
\text { - 90\% repayment rate obtained }\end{array}$ & $\begin{array}{l}\text { - Establish a guarantee fund } \\
\text { - Strengthen the capacities of financial institutions } \\
\text { - Promote innovative financial instruments }\end{array}$ \\
\hline
\end{tabular}




\begin{tabular}{|c|c|c|}
\hline Construct marketing and communication infrastructures & $\begin{array}{l}\text { - } 2 \text { agricultural products centralization } \\
\text { poles, } 1 \text { analysis laboratory, } 3 \text { multi- } \\
\text { functional processing platforms and } 2 \\
\text { markets are established } \\
-1111 \mathrm{~km} \text { of roads rehabilitated }\end{array}$ & $\begin{array}{l}\text { - Construct trade infrastructures } \\
\text { - Rehabilitate rural roads } \\
\end{array}$ \\
\hline Agricultural advisory services & & Pursue contracting of extension services \\
\hline Agricultural research & & Pursue research and training \\
\hline Support to chambers and farmer organizations & & $\begin{array}{l}\text { - Strengthen the capacities of producers } \\
\text { - Establish apex organizations for growth-oriented sub-sector }\end{array}$ \\
\hline Streamline services in the Ministry & & Implement the LOA \\
\hline $\begin{array}{l}\text { Permanent monitoring-evaluation of policies, strategies, } \\
\text { projects and programmes in the agriculture, livestock and } \\
\text { fisheries sub-sectors }\end{array}$ & $\begin{array}{l}\text {-Project and programme management is } \\
\text { improved. } \\
\text { - Policies and strategies are better prepared. }\end{array}$ & $\begin{array}{l}\text { Prepare and implement permanent monitoring system } \\
\text { projects and programmes of the agriculture, livestock } \\
\text { fisheries sub-sectors. }\end{array}$ \\
\hline Establishment of a Permanent Agricultural Statistics System & $\begin{array}{l}\text { - Information on results of seasons is } \\
\text { provided. } \\
\text { - A food report is prepared. } \\
\text { - A platform for the regular collection and } \\
\text { integration of all information is created. }\end{array}$ & $\begin{array}{l}\text { - Provide information on the results of farming seasons. } \\
\text { - Gather information for preparation of food balance-sheets } \\
\text { - Ensure production of statistical series on a consistent basis }\end{array}$ \\
\hline $\begin{array}{l}\text { Implementation of the information system for agricultural } \\
\text { sub-sectors (SIFA) }\end{array}$ & $\begin{array}{l}\text { An information pool exists and is } \\
\text { operational. } \\
\text { A data validation committee is established. } \\
\text { Decision-making support models are } \\
\text { designed for each sub-sector. } \\
\text { Strategic information is processed and } \\
\text { disseminated }\end{array}$ & $\begin{array}{l}\text {-.Archive information } \\
\text { - Create consultation frameworks } \\
\text { - Provide information by sub-sector } \\
\text { - Process strategic information and disseminate it. }\end{array}$ \\
\hline
\end{tabular}

\subsection{Mining and Extractive Industries}

Development of the gold sector on a sustainable basis

\begin{tabular}{|l|} 
\\
\hline Improve geological and mining knowledge \\
\hline $\begin{array}{l}\text { Improve the regulatory and institutional environment of the } \\
\text { mining and oil sectors. }\end{array}$
\end{tabular}

Intensify, develop and diversify mining resources.

Review of the laws and regulations. Institutional reform, and technical and human capacity building.

Intensify, develop and diversify mining resources.

Promotion and development of indices.

Improvement of the legal, regulatory and institutional framework, particularly in gold taxation

Geological cartography

and mining inventory. and oil activities and projects.

Promote small-scale mining.

Improve monitoring of the financing of the mining sector.

Develop communities located near mining zones.

Control anomalies discovered on the soil.

Collect, disseminate and process geo-scientific information

Make an inventory of and promote building materials and industrial minerals.

mining and oil activities and projects.

Support for small-scale mining.

Establishment of a financing mechanism for the mining sector.

Establishment of a development strategy for communities located near mining zones. cartography.

Compilation of data, analyses of samples

Identification and drawing of maps for zones potentially rich in building materials
- Study on reform of gold taxation to introduce grad reduction of tax benefits.

- More rational and sustainable exploitation of gold min resources.

Geological, geochemical and indices maps are drawn.

Laws and regulations revised.

Institutions reformed, capacities strengthened and staff traine

Technical, economic and financial feasibility studies:

on metal mineral ores,

to boost exploitation of marble quarries,

. to revitalize quarries providing materials to the cem factory,

. on phosphate quarries,

. on peat and coal.

Establishment of a mechanism for Monitoring, control and evaluation of mining and oil activit monitoring, control and evaluation of and projects is improved.

Small-scale mining is supported.

The development strategy for communities located near min zones is prepared and implemented.

Geological prospection and detailed Geological anomalies are confirmed.

Data are compiled and samples are analyzed. and industrial minerals.
Zones potentially rich in building materials and industs minerals are identified and studied. 


\subsection{SME-SMI Development}

\begin{tabular}{|c|c|c|}
\hline Develop SME-SMIs & $\begin{array}{l}\text { The competitiveness of targeted industrial } \\
\text { enterprises is improved. }\end{array}$ & Implementation of PRMN \\
\hline Reform tax laws to include more incentives & The tax load of enterprise is reduced. & $\begin{array}{l}\text { - Organization of conventions on tax issues } \\
\text { - Revision of laws and regulations }\end{array}$ \\
\hline Improve the business environment & Improved business environment & $\begin{array}{l}\text { - Intensification of measures to combat fraud and unfair } \\
\text { competition } \\
\text { - Assistance to support project for retail traders }\end{array}$ \\
\hline $\begin{array}{l}\text { Strengthen the institutional and regulatory operation of } \\
\text { procurements. }\end{array}$ & $\begin{array}{l}\text { Anti-competition practices (fraud, } \\
\text { counterfeiting, and smuggling) are reduced } \\
\text { significantly. }\end{array}$ & $\begin{array}{l}\text { - Implement plan to fight against fraudulent imports. } \\
\text { - Preparation and implementation of a plan to combat } \\
\text { corruption in the Public Service: award of public contracts, } \\
\text { mobilization of Government revenues, management of } \\
\text { Government human resources. }\end{array}$ \\
\hline Capacity building for existing financial institutions. & $\begin{array}{l}\text { The financial situation of credit institutions } \\
\text { and insurance companies in difficulty is } \\
\text { stabilized. }\end{array}$ & $\begin{array}{l}\text { Prepare and support the implementation of a financial } \\
\text { stabilization plan and strengthening of institutional capacities } \\
\text { financial institutions in difficulty }\end{array}$ \\
\hline $\begin{array}{l}\text { Identify the real infrastructure requirements for private } \\
\text { sector development. }\end{array}$ & $\begin{array}{l}\text { The real infrastructure requirements for } \\
\text { private sector development are identified. }\end{array}$ & $\begin{array}{l}\text { Conduct studies to determine private sector infrastructure } \\
\text { requirements (transport, water, electricity, industrial zones, } \\
\text { telephone, Internet). }\end{array}$ \\
\hline $\begin{array}{l}\text { Identify the real requirements for modernizing or replacing } \\
\text { equipment needed to strengthen competitiveness of } \\
\text { enterprises. }\end{array}$ & $\begin{array}{l}\text { The real equipment requirements for private } \\
\text { sector development are identified }\end{array}$ & $\begin{array}{l}\text { Conduct studies to identify requirements for replacing or } \\
\text { modernizing equipment, particularly in transport (road, railw } \\
\text { river, etc.), data processing, information technologies, etc. }\end{array}$ \\
\hline
\end{tabular}

\subsection{Tourism and Handicraft}

\begin{tabular}{|c|c|c|}
\hline Promotion of tourism & & Preparation of PDDT \\
\hline & 800 private sector operators are trained & Training of professionals \\
\hline & 10 national events are supported each year & Support for cultural events. \\
\hline & 5 tourism towns are supported each year. & Support for sanitation of tourism towns. \\
\hline & The National Administration is managed. & Ordinary management of the National Tourism Administratic \\
\hline \multirow[t]{4}{*}{ Promotion of handicraft } & $\begin{array}{l}100 \text { craftsmen are trained. } \\
25 \text { elected officers are trained. } \\
1000 \text { apprentices are trained. }\end{array}$ & Training of craftsmen, elected officers and apprentices. \\
\hline & A census is conducted for craftsmen in Mali & Census of craftsmen \\
\hline & \begin{tabular}{lr}
\multicolumn{1}{c}{ The CRPAs } & of \\
BKO/KOUL/TOMB/GAO/KIDAL & are \\
installed. & \\
- 3 CMs are installed each year. & \\
- All the CMs are renewed. & \\
\end{tabular} & Installation of CMs and CRPAs \\
\hline & $\begin{array}{l}\text { The budgets for recurrent and capital } \\
\text { expenditure and promotion of handicraft are } \\
\text { provided. }\end{array}$ & Ordinary management of the National Handicraft Directorate \\
\hline
\end{tabular}




\subsection{Culture}

Improve the quality of human resources.

Protect and promote the cultural heritage

Generate cultural products
Professional industries are created and culture economy structured

The quality and quantity of national production are improved.

Restoration and rehabilitation of heritage sites, and enriching of tourism circuits.

The cultural heritage is better known.

Cultural identity and national unity are preserved.

Cultural events for the promotion of diversity of cultural expressions, peace and stability are organized.

The history of Mali is better Production of films of Malian epics known.

National production increases

National production increases
Creation of an Cultural Industries Promoti Agency

Opening of a cinematographic studio-school

Creation of a National Cultural Heritage Agency

Production of works on cultural heritage

Organization of artistic and cultural events.

Promotion of cultural exchange

Production of TV series

Production of Sitcom.

\subsection{Environmental Protection and Management of Natural Resources}

Contribute to improvement of the living environment

Implement the PSAs of towns

Protect the banks against erosion and silting.

Ensure integrated management of the ecosystems of the river Niger basin.
The conditions of natural habitat and ecotourism visits are improved following involvement of the populations in sanitation

Individual and collective structures are constructed.

Jobs are created

The living environment is improved. Consultations on the preliminary drafts of texts on transfer of natural resource management are organized. The banks of River Niger are developed in built-up areas

An adequate geographic information system to be used by NRBA is put in place. The territorial information on sub-basin resources (DIN, Niger Loop) is accessible

Ensure sustainable management of forest and wildlife resources.

ongoing programmes

-The CIGQE organs are functional.
The development and management plans for protected forests and areas of 5 Humid Zones, 2 Biodiversity Zones, 2 Hunting Zones, 1 Pastureland Zone, and 4 FCs are prepared

The capacities of senior officials are strengthened.

The institutional capacities of RNBA and users are strengthened.

A status report on the environment is prepared and disseminated
-Formulate the National Sanitation Policy and its strategies -Organize a sanitation forum

Construct 300 improved latrines, $500 \mathrm{~km}$ of cross drains, 250

$\mathrm{km}$ of main drains, 100 transit depots, 5 final disposal sites, 600 washing drain tanks, $50000 \mathrm{ml}$ of sewerage systems

Organization of consultations on the preliminary drafts of te on transfer of natural resource management

Development and protection of the river corridor on the Nige

- Management and structuring of territorial information on th sub-basins of River Niger

- Evaluation of river basin resources

Preparation of development and management plans protected forests and areas of 5 Humid Zones, 2 Biodivers Zones, 2 Hunting Zones, 1 Pastureland Zone and 4 FCs.

-Organization of meeting of STP/ CIGQE organs

- Strengthen the capacities of senior officials (negotiati project formulation, preparation of tools and methodologi guides, etc.)

Strengthening and development of RNBA institutional capacities

Prepare and disseminate the annual status report on environment 


\subsection{Infrastructure Development}

\subsubsection{Transport}

\section{Policy - Transport Infrastructure}

Improvement of the national transport policy, financing of road maintenance, and privatization of infrastructures concessioned, facilitation of transit and implementation of regulations

Internal and external accessibility of the country
Update of the master plan for the development of transport infrastructure network: better mobilization of internal resources, better management of railway and air transport, and reinforcement of road safety.

The state of roads is improved. Improvement of the state of the network and accessibility to various areas.

Bridges are constructed and ferries are available

Maintenance of the railway

Reduction of travel time and costs.

Passenger and freight airport and meteorology infrastructures constructed and rehabilitated, particularly under the MCA programme

Wharfs and ports are constructed

Transport administration is operational.

The number of accidents is reduced
Review of the National Transport Policy Letter, support for Road Authority, pursuance of airport concessioning facilitation of transport

Routine maintenance of the priority network (32 $281 \mathrm{Km})$

Periodic maintenance of roads $(1894 \mathrm{~km})$

- Rehabilitation (5 $450 \mathrm{~km}$ of roads)

Construction of $16959 \mathrm{~km}$ of roads

Construction bridges and ferries

( 6 bridges and 10 ferries)

Urban road network $(640 \mathrm{~km})$

Maintenance and rehabilitation of Bamako-Kayes-Dik railway line $(347 \mathrm{~km})$

Extension, rehabilitation and maintenance of passenger : freight airport and meteorology infrastructures under the Mi programme

River transport (Construction of wharfs and banks, river port

Facilitation of transport

Road safety, HIV/AIDS, and environmental protecti

particularly under $10^{\text {th }} \mathrm{EDF}$

\subsubsection{Telecommunications and ICT}

Adapt the legal and institutional framework to the promotion and development of ICTs

\section{Develop TELECOM infrastructures}

Include information and communication technologies in the formal and informal education programmes, school administration, and scientific research. Promote medical information technology to ensure widespread access to telemedicine activities and development of specific computer applications in health

Use ICTs to ensure transparency, free flow of information within the administration itself, and equal access to public information for all citizens

Gradually connect the councils of Mali to the digital network

Texts are adopted, and information is available online

Projects are implemented, and councils are served

Institutions are connected each year, and appropriate teaching aids and curricula are available

The ministries are gradually connected through the Internet

The councils are connected, services are provided, and e-mail is available and used by the councils. The workers are trained, and the ICTs are effectively used
Implement infrastructure projects

Provide ICT equipment and connect all schools and universi in the country.

Training programme for workers in the maintenance and use

this equipment

Install the Internet network of the administration gradually linking the ministries, public services and their subsidi services in the regions and councils

Schedule the connection of the councils of Mali in success phases 


\subsubsection{Energy}

Satisfy the energy needs of the country in terms of quality, quantity and least cost.

\begin{tabular}{l}
\hline Development of the energy potential \\
\hline $\begin{array}{l}\text { Diversification of sources of supply of petroleum products and } \\
\text { increase in storage capacities. }\end{array}$
\end{tabular}

increase in storage capacities.

Control of supply and demand
The portion of ENR in the national production of electricity increases by $8 \%$

Electricity coverage of the country increases to $50 \%$

The rural electrification rate increases to $15 \%$

The storage capacities of the country increase to $120000 \mathrm{~m}^{3}$

Land area transferred to community management increases to 2.75 million hectares

Overall energy consumption of the country as regards firewood moves to $65 \%$

The peaceful applications of technologies based on ionizing radiation are controlled;

$\mathrm{X}$-ray safety and security of radioactive sources and related equipment on the national territory are controlled

Protect people, property and the environment against risks inherent in energy services

Strengten the orientaion, management, control and stategic

Strengthen the orientation, management, control and strategic management capacities of the energy sector

Assessment and mitigation of

The performance of energy services is optimized environmental impacts are automatically taken into account.

The sector is provided with an institutional, legal and regulatory framework.

The sector is strengthened in terms of human, material and financial resources

The existence of a good communication system

The sector is closely involved in foreign energy programmes.
Promotion and development of ENRs

\begin{tabular}{|l|l}
\hline & \\
\hline & \\
\hline & \\
\hline
\end{tabular}

Planning, implementation and monitoring-evaluation projects and programmes in technical cooperation with AIEA

Professionalization of supply energy services to optimize th performance and minimize the risks of breaks in services c accidents.

Automatic assessment and mitigation of environmental aspe in the design, construction and utilization of enes infrastructure and equipment.

Establishment of an institutional, legal and regulat framework adapted to the development requirements of national energy sector

Promotion of capacity building measures for human, mates and financial resources of public, parapublic and priv stakeholders of the energy sector

Promotion of communication and consultation between various stakeholders of the energy sector.

Support for and participation in sub-regional, regional : international energy projects and programmes. 


\section{Pursuance and Consolidation of Structural Reforms}

\subsection{Consolidation of Public Administration Reform}

\subsubsection{Decentralization and Deconcentration}

\begin{tabular}{|c|c|c|}
\hline $\begin{array}{l}\text { Capacity building for Local Authorities and decentralization } \\
\text { stakeholders }\end{array}$ & & \\
\hline & $\begin{array}{l}\text { Institutional framework adapted to the } \\
\text { challenges of decentralization }\end{array}$ & $\begin{array}{l}\text { Strengthening of the decentralization institutional framework } \\
\text { particularly under the } 10^{\text {th }} \text { EDF. }\end{array}$ \\
\hline & $\begin{array}{l}\text { Local Authorities strengthened and } \\
\text { effectively exercising their powers }\end{array}$ & Pursuance of process to transfer powers \\
\hline & $\begin{array}{l}\text { Capacities of decentralization } \\
\text { stakeholders strengthened }\end{array}$ & $\begin{array}{l}\text { Capacity building for stakeholders of decentralization, } \\
\text { particularly under the } 10^{\text {th }} \text { EDF. }\end{array}$ \\
\hline & $\begin{array}{l}\text { Local and regional development } \\
\text { revitalized }\end{array}$ & Support for local and regional development efforts \\
\hline & $\begin{array}{l}\text { Decentralization process better managed } \\
\text { and coordinated }\end{array}$ & Management and coordination of the decentralization proces \\
\hline & $\begin{array}{l}\text { Better information on issues relating to } \\
\text { decentralization }\end{array}$ & $\begin{array}{l}\text { Implementation of an efficient communication system on } \\
\text { decentralization. }\end{array}$ \\
\hline $\begin{array}{l}\text { Improvement of equipment levels of LAs, particularly in } \\
\text { education, water resources and health sectors }\end{array}$ & & \\
\hline & Local Authorities better equipped & $\begin{array}{l}\text { Financing of the investment requirement Local Authorities } \\
\text { through the FICT managed by ANICT. }\end{array}$ \\
\hline & $\begin{array}{l}\text { Investments of Local Authorities } \\
\text { functional and maintained. }\end{array}$ & $\begin{array}{l}\text { Financing of the operating requirements of Local Authorities } \\
\text { including EPA subsidies through the FICT managed by ANIC }\end{array}$ \\
\hline
\end{tabular}

Deconcentration

Transfer the centre of power of the State Administration from the central level to as close as possible to the elected officers and population
- The deconcentrated administrations have new organization charts and organic frameworks, as well as adequate human and financial resources

- Relations between the deconcentrated authorities and decentralized authorities are institutionalized

- A territorial development policy with planning tools is defined.
- Organizational audit and presentation of the new organizati chart of the deconcentrated administrations.

- Implementation, by each Ministry, of its plan for the transfe of resources and provision of appropriate resources - Development of the operations of the Regional Orientation and Support Committee for these committees to carry out a territorial diagnosis.

- Preparation of action plans that will translate the strategy in regional development programme and identify the priorities.

\subsubsection{Improvement and Modernization of Public Finance Management}

\begin{tabular}{|c|c|c|}
\hline $\begin{array}{l}\text { Improvement of quality of budget preparation and } \\
\text { implementation }\end{array}$ & $\begin{array}{l}\text { - Capacities of DGB and DRG } \\
\text { strengthened } \\
\text { - Quality of preparation of programme } \\
\text { budgets by the Departments improved } \\
\text { - Budgetary procedures standardized and } \\
\text { can be certified. } \\
\text { - Budget implementation monitored in } \\
\text { real time and productivity and reliability } \\
\text { of operations increased. } \\
\text { - Better efficiency of DAFs and related } \\
\text { services } \\
\text { - Stores accounting effective } \\
\end{array}$ & $\begin{array}{l}\text { - Establishment of an organization chart for DGB, and capaci } \\
\text { building for DGB and DRB. } \\
\text { - Harmonize the PRSP, sectoral programmes and programme } \\
\text { budgets. } \\
\text { - Improve the budget management system } \\
\text { - Establishment of training programme } \\
\text { - Interconnect the SIG of public expenditure and secure it. } \\
\text { - Increase the performance of DAFs and related services, } \\
\text { - Strengthen stores accounting. }\end{array}$ \\
\hline \multirow[t]{3}{*}{$\begin{array}{l}\text { Development of efficiency of the tax and financial } \\
\text { administrations } \\
\text { Computerization } \\
\text { Tax pressure } \\
\text { Tax collection }\end{array}$} & $\begin{array}{l}\text { - Reliability of accounting documents } \\
\text { and production within time limits. } \\
\text { Coverage of all State operations in the } \\
\text { Treasury balance, GFFT in line with } \\
\text { WAEMU directives, treasury } \\
\text { management strengthened } \\
\text { - Install TABOR and DEPENSE } \\
\text { software in the regions } \\
\text { - Accounting management of LAs and } \\
\text { EPAs computerized, proximity services } \\
\text { delivered } \\
\text { - Installation of ASYCUDA++ in all } \\
\text { custom posts } \\
\text { - Interconnection of custom post } \\
\text { computer systems }\end{array}$ & $\begin{array}{l}\text { - Make financial and accounting operations of the Treasury } \\
\text { more transparent, and simplify them. }\end{array}$ \\
\hline & \multirow[t]{2}{*}{ Broadening and control of tax base } & $\begin{array}{l}\text { Study on measures required to attain target of } 17 \% \text { tax press } \\
\text { in } 2008 \text { in accordance with WAEMU directives } \\
\text { Implementation of adequate measures to attain target of } 17 \% \\
\text { tax pressure in } 2008\end{array}$ \\
\hline & & - Proper identification of taxpayers and information of \\
\hline
\end{tabular}




\begin{tabular}{|c|c|c|}
\hline & & $\begin{array}{l}\text { taxpayers in order to control tax evasion } \\
\text { - Capacity building for tax collection services }\end{array}$ \\
\hline Incorporate external financing in national budget procedures & $\begin{array}{l}\text { - Gather information required for } \\
\text { improving predictability of budgetary aid } \\
\text { resources } \\
\text { - Government control of all Budget } \\
\text { resources } \\
\text { - Enhanced decentralization of } \\
\text { investments }\end{array}$ & $\begin{array}{l}\text { - Adapt budget procedures to ensure widespread use of budg, } \\
\text { support. } \\
\text { - Make accounting information exhaustive, of high quality ar } \\
\text { available } \\
\text { - Investments under the supervision of Local Authorities }\end{array}$ \\
\hline $\begin{array}{l}\text { Improve the efficiency and transparency of public } \\
\text { procurements procedures }\end{array}$ & $\begin{array}{l}\text { - Scope of the Code redefined, award } \\
\text { threshold increased, purchases outside } \\
\text { contracts regulated. } \\
\text { - Organization of deconcentrated DGMP } \\
\text { - Procurement regulations adapted to } \\
\text { decentralization } \\
\text { - More effective and independent } \\
\text { controls, contracting authority given } \\
\text { more powers, public procurement } \\
\text { procedures followed. } \\
\text { - Access by SMEs and national } \\
\text { enterprises to public contracts } \\
\text { encouraged } \\
\text { - Fair prices obtained for all Government } \\
\text { purchases. }\end{array}$ & $\begin{array}{l}\text { - Renovation of the regulatory framework for public } \\
\text { procurement } \\
\text { - Reinforcement of control structures } \\
\text { - Capacity building for DGMP } \\
\text { - Improvement of access by SMEs and national enterprises tc } \\
\text { public contracts } \\
\text { - Enhancement of governance and transparency in public } \\
\text { procurements. } \\
\text { - Revision of market prices }\end{array}$ \\
\hline $\begin{array}{l}\text { Strengthen governance and enhance Transparency (cross- } \\
\text { cutting activities) }\end{array}$ & $\begin{array}{l}\text { - Texts consistent with Directives } 5 / 9 \\
\text { and } 6 / 97 \text { of WAEMU } \\
\text { - Organization, procedures and } \\
\text { competence of MEF adapted } \\
\text { - Increased efficiency of controls } \\
\text { - Control and evaluation roles of the } \\
\text { Accounts Section of the Supreme Court, } \\
\text { National Assembly, General Control of } \\
\text { Public Services and the Inspectorate of } \\
\text { Finance reinforced } \\
\text { - Upgrade the skills of employees }\end{array}$ & $\begin{array}{l}\text { - Make legal texts consistent with WAEMU Directives. } \\
\text { - Adaptation of organization charts and organic frameworks c } \\
\text { MEF services to their missions } \\
\text { - Make the control system consistent } \\
\text { - Reliability of court and administrative controls } \\
\text { - Capacity building for the Accounts Section of the Supreme } \\
\text { Court, the National Assembly, General Control of Public } \\
\text { Services and Inspectorate of Finance } \\
\text { - Adapt the conformity control } \\
\text { - Improve the quality of } a \text { priori control, and reinforce it } \\
\text { - Create a continuous training structure for Finance employe } \\
\text { - Prepare a Computer Master Plan for MEF }\end{array}$ \\
\hline
\end{tabular}

\subsection{Pursuance of Reform of the Business Environment}

\begin{tabular}{|c|c|c|}
\hline \multirow[t]{3}{*}{ Improvement of the business environment } & $\begin{array}{l}\text { Implementation of the Law establishing a } \\
\text { single identity }\end{array}$ & \\
\hline & Computerization of the trade register. & $\begin{array}{l}\text { Measures to fight against corruption particularly under } 1 \\
\text { EDF }\end{array}$ \\
\hline & $\begin{array}{l}\text { Computerization of the property loan } \\
\text { register. }\end{array}$ & Simplification of procedures for starting a business \\
\hline & $\begin{array}{l}\text { Creation of a single window for starting } \\
\text { a business. }\end{array}$ & \\
\hline & $\begin{array}{l}\text { Comparative study on } r \text { the } \\
\text { competitiveness of business tax with } \\
\text { those of WAEMU countries }\end{array}$ & $\begin{array}{l}\text { Simplification of corporate taxes, particularly under the } 1 \\
\text { EDF }\end{array}$ \\
\hline & $\begin{array}{l}\text { Ensure consistency of the regulatory } \\
\text { framework with the judicial system in } \\
\text { the business environment. }\end{array}$ & Improvement of the judicial system \\
\hline & $\begin{array}{l}\text { Study on reduction of registration duty } \\
\text { on property. }\end{array}$ & Improvement of access to land \\
\hline & $\begin{array}{l}\text { Review of the Labour Code to improve } \\
\text { flexibility of the labour market. }\end{array}$ & Improvement of labour market regulations \\
\hline & $\begin{array}{l}\text { Formalities of credit files simplified and } \\
\text { lightened. }\end{array}$ & Development of access to bank financing \\
\hline & $\begin{array}{l}\text { Reduction of water and electricity } \\
\text { charges } \\
\text { Significant } \\
\text { telecommunication charges. }\end{array}$ & $\begin{array}{l}\text { Reduction of factor costs (investments development } \\
\text { competition) }\end{array}$ \\
\hline & Study on formulation of measures to & Promotion of exports \\
\hline
\end{tabular}




\begin{tabular}{|c|c|c|}
\hline & promote exports. & \\
\hline Promote exports & $\begin{array}{l}\text { Increase in export volume } \\
\text { Increase in the incomes of producers }\end{array}$ & $\begin{array}{l}\text { Implementation of priority actions in the Integrated Mat } \\
\text { Framework }\end{array}$ \\
\hline Promote trade facilitation & Transparency of trade flows & $\begin{array}{l}\text { Support for the Interconnection Project of } \mathrm{DNCC} \\
\text { ASYCUDA }++\end{array}$ \\
\hline Draw benefit from APE and WTO agreements & The negotiations are closely monitored & $\begin{array}{l}\text { - Capacity building for thematic negotiation groups } \\
\text { - Monitoring of negotiations }\end{array}$ \\
\hline
\end{tabular}

\subsection{Financial Sector Development}

\begin{tabular}{|c|c|c|}
\hline $\begin{array}{l}\text { Improve the viability, competitiveness and performance of the } \\
\text { financial sector }\end{array}$ & & \\
\hline Strengthen the banking sector & & \\
\hline & $\begin{array}{l}\text { Effective implementation of the strategy } \\
\text { for clearing outstanding credits of } \\
\text { commercial banks. }\end{array}$ & Clearance of outstanding credits. \\
\hline & Privatization of BIM & Pursuance of privatization of banks \\
\hline & Creation of leasing. & Development of new financial products, in particular leasing. \\
\hline & $\begin{array}{l}\text { - Creation of an Investment Fund } \\
\text { - Development of credit cards and } \\
\text { electronic transfers }\end{array}$ & Establishment of an Investment Fund \\
\hline & $\begin{array}{l}\text { Improvement of access by SMEs to } \\
\text { credit. }\end{array}$ & Measures to facilitate access by SMEs to credit \\
\hline & Reduction of Social Security deficit & Restructuring of social security \\
\hline $\begin{array}{l}\text { Implementation of an action plan 2005-2008 relating to micro- } \\
\text { finance }\end{array}$ & Financial sector performing better & $\begin{array}{l}\text { Strengthen, improve and generalize control and surveillance } \\
\text { the sector }\end{array}$ \\
\hline & & Restructure and consolidate micro-finance institutions \\
\hline & & $\begin{array}{l}\text { Work for the adoption of a dynamic promotion policy for } \\
\text { extensive, but quality, development. }\end{array}$ \\
\hline
\end{tabular}

\subsection{Promotion of Democratic Governance and Public Freedoms}

- Improve performance and credibility of the public service of Justice

- Reinforce the independence of Justice

- Improve accessibility by the population to Justice

General Administration, Coordination and Control management of the career of Magistrates
- Better coordination and better control

- Capacities of structures strengthened

- Mechanism for combating corruption

functional

- National Human Rights Commission

functional

- Staff trained, particularly in human

rights

- Access to justice facilitated.

- Training programmes identified, prepared and implemented as necessary.

- Advancement for magistrates

conducted normally

- Use of statistical data and monthly

reports ensured

- Centralization of statistics introduced, and used

- Adaptation of the status of legal and

judicial professions

- Court activities are better controlled

Preparation and monitoring of laws for civil , commercial and penal matters

\section{- Proper monitoring of application of}

texts ensured

- Civil, commercial and penal matters

texts reviewed and applied.

- Opinions given on preliminary drafts of

the Uniform Act

- Laws in conformity with community

and international law

- Conditions of detention in compliance

with international standards

- Health coverage of prisoners increased

- Food ration for prisoners improved
- Inspection missions to structures

- Construction and rehabilitation of infrastructures, and

provision of equipment

- Staff recruitment and training

- Continued modernization and computerization of courts an

attached central services

- Support for revitalization of the National Human Rights

Commission

- Opening of new Reception and Guidance Offices

- Organization of press conferences

- Study on taxation of legal and judicial professions

- Pursuance of review of the rules and regulations governing

legal and judicial professions, and improvement of the said

rules and regulations

- Installation of computer network between DNAJ and Court

in Bamako

- Training of justice stakeholders

- Pursuance of centralization of statistical data and use of the

data

- Normal advancement of magistrates

- Control and moralization of the fees and emoluments of

bailiffs and other judicial experts

- Monitoring and control of the activities of courts

- Organization of courts monitoring missions

- Review of submitted national texts to adapt them to

international law, in particular

- Review of police record

- Studies on seals and nationality

- OHADA-related activities

- Utilization of the National Commercial and Property Loan

Register database

- Construction and restoration of prisons

- Achievement of better food ration

- Purchase of equipment

- Organization of school, vocational and literacy training 


\begin{tabular}{|c|c|c|}
\hline & $\begin{array}{l}\text { - Modern database of prisoners created } \\
\text { - School and vocational training of } \\
\text { prisoners undertaken }\end{array}$ & $\begin{array}{l}\text { - Procurement and equipment of workshops } \\
\text { - Operationalization of Regional Directorates } \\
\text { - Implementation of the national reeducation and social } \\
\text { reintegration policy. } \\
\text { - Strengthening of agricultural penitentiary structures }\end{array}$ \\
\hline Training of judicial staff and dissemination of law & $\begin{array}{l}\text { - Justice stakeholders better equipped to } \\
\text { accomplish their missions more } \\
\text { efficiently. } \\
\text { - Access to legal information ensured } \\
\text { - Appropriate work environment created. }\end{array}$ & $\begin{array}{l}\text { - Training of judges, trainee registrars, registry and prosecutc } \\
\text { office secretaries and prison guards } \\
\text { - Development of a computer network and access to legal } \\
\text { information } \\
\text { - Development of the work environment } \\
\text { - Update, improvement and extension of training programme } \\
\text { - Strengthening of infrastructures and reform of INFJ }\end{array}$ \\
\hline \multicolumn{3}{|l|}{$\begin{array}{l}\text { Strengthening the capacities and capabilities of the Government } \\
\text { and civil society organizations in detecting and preventing } \\
\text { corruption }\end{array}$} \\
\hline \multicolumn{3}{|l|}{$\begin{array}{l}\text { Enhancement of transparency in the management of public } \\
\text { contracts } \\
\text { (See Pillar 4: Improvement and modernization of the } \\
\text { management of public finance) }\end{array}$} \\
\hline Reinforcement of peace and security & Tranquility of the population ensured & $\begin{array}{l}\text { - Installation of new security forces, new security posts, } \\
\text { gendarmerie units, and police units } \\
\text { - Organization of patrols along the borders and urban } \\
\text { centres. } \\
\text { - Security coverage of presidential and legislative elections } \\
\text { in } 2007\end{array}$ \\
\hline Fight against financial delinquency. & $\begin{array}{l}\text { Increase effectiveness of the fight against } \\
\text { financial delinquency. }\end{array}$ & $\begin{array}{l}\text { Implementation of the GAF recommendations and GIABA } \\
\text { actions, in particular the creation of a National Financial } \\
\text { Information Processing Unit (CENTIF). }\end{array}$ \\
\hline \multicolumn{3}{|c|}{ 3.5 Capacity Building for the Civil Society } \\
\hline \multicolumn{3}{|c|}{\begin{tabular}{l|l|l} 
Enhance participation of civil society in the management of & \\
public affairs.
\end{tabular}} \\
\hline & & $\begin{array}{l}\text { Support to establishment of regional CNSC organs, } \\
\text { particularly under the } 10^{\text {th }} \text { EDF }\end{array}$ \\
\hline & & Reinforcement of Governance within the civil society \\
\hline & & Preparation of a strategic plan and its implementation \\
\hline & & Support for harmonization of OSC interventions \\
\hline & & $\begin{array}{l}\text { Conduct of a study on actual contribution by OSCs to the } \\
\text { socio-economic development of Mali. }\end{array}$ \\
\hline & & $\begin{array}{l}\text { Capacity building for youth associations in the formulation, } \\
\text { preparation, implementation and monitoring of projects. }\end{array}$ \\
\hline & & $\begin{array}{l}\text { Capacity building for stakeholders of the civil society in the } \\
\text { design, implementation, and evaluation of development } \\
\text { policies. }\end{array}$ \\
\hline & & Creation of a database in apex organizations. \\
\hline & $\bullet$ & $\begin{array}{l}\text { - Implementation of a civil } \\
\text { society programme on peace } \\
\text { and security. }\end{array}$ \\
\hline \multicolumn{3}{|c|}{ 3.6 Strengthening of Regional and Sub-regional Integration Initiatives } \\
\hline $\begin{array}{l}\text { See to the implementation of agreements and treaties relating to } \\
\text { establishment and movement of goods }\end{array}$ & $\begin{array}{l}\text { The populations and stakeholders of } \\
\text { integration are informed and sensitized } \\
\text { on integration programmes. }\end{array}$ & $\begin{array}{l}\text { - Monitoring of activities of phase II of the co-development } \\
\text { programme. } \\
\text { - Creation of an emergency and assistance fund for } \\
\text { repatriated persons. }\end{array}$ \\
\hline $\begin{array}{l}\text { Effective implementation of sectoral agreements } \text { under } \\
\text { WAEMU, ECOWAS and NEPAD }\end{array}$ & $\begin{array}{l}\text { - Free movement of people and goods, } \\
\text { the right of establishment and right of } \\
\text { residence are ensured. } \\
\text { - The population and stakeholders of } \\
\text { integration are informed and sensitized } \\
\text { on integration programmes. }\end{array}$ & $\begin{array}{l}\text { - Harmonization of WAEMU, ECOWAS, CEN-SAD and } \\
\text { AU programmes. }\end{array}$ \\
\hline
\end{tabular}




\section{Development of Access to Basic Social Services}

\subsection{Education}

\begin{tabular}{|c|c|c|c|c|c|}
\hline $\begin{array}{l}\text { By } 2015 \text {, all Malian children will } \\
\text { complete quality basic education, and } \\
\text { the education sector provides the } \\
\text { country with human resources required } \\
\text { for its development. }\end{array}$ & $\begin{array}{l}\text { The quality and } \\
\text { management of basic } \\
\text { education, as well as } \\
\text { access to it are improved. }\end{array}$ & $\begin{array}{l}\text { Improvement of quality and } \\
\text { management of basic education, and } \\
\text { improvement of access to it. }\end{array}$ & 334998 & $\begin{array}{l}2007- \\
2009\end{array}$ & MEN \\
\hline \multirow[t]{2}{*}{ Develop general secondary education. } & $\begin{array}{l}\text { The enrolment capacities } \\
\text { are increased in general } \\
\text { secondary education. }\end{array}$ & $\begin{array}{l}\text { Increase enrolment capacities in } \\
\text { general secondary education }\end{array}$ & \multirow[b]{2}{*}{32281} & \multirow[b]{2}{*}{$\begin{array}{l}2007- \\
2009\end{array}$} & \multirow[b]{2}{*}{ MEN } \\
\hline & $\begin{array}{l}\text { The quality and } \\
\text { management of general } \\
\text { secondary education are } \\
\text { improved. }\end{array}$ & $\begin{array}{l}\text { Improvement of quality and } \\
\text { management of general secondary } \\
\text { education. }\end{array}$ & & & \\
\hline $\begin{array}{l}\text { Consolidate and diversify technical and } \\
\text { vocational education }\end{array}$ & $\begin{array}{l}\text { The initial and } \\
\text { continuous training of } \\
\text { trainers of technical and } \\
\text { vocational education is } \\
\text { ensured. } \\
\text { Training is better adapted } \\
\text { to labour market } \\
\text { requirements. }\end{array}$ & $\begin{array}{l}\text { Initial and continuous training of } \\
\text { trainers of technical and vocational } \\
\text { education. } \\
\text { Adaptation of training to labour } \\
\text { market requirements. }\end{array}$ & 14208 & $\begin{array}{l}2007- \\
2009\end{array}$ & MEN \\
\hline $\begin{array}{l}\text { Provide quality higher education } \\
\text { adapted to priority needs and controlled } \\
\text { costs. }\end{array}$ & $\begin{array}{l}\text { The enrolment capacity } \\
\text { of higher training } \\
\text { institutions is increased } \\
\text { and improved. The } \\
\text { management and quality } \\
\text { of higher education are } \\
\text { improved. }\end{array}$ & $\begin{array}{l}\text { Increase and improvement of the } \\
\text { enrolment capacity of higher training } \\
\text { institutions and improvement of the } \\
\text { management and quality of higher } \\
\text { education. }\end{array}$ & 56734 & $\begin{array}{l}2007- \\
2009\end{array}$ & MEN \\
\hline $\begin{array}{l}\text { Undertake any type of scientific and } \\
\text { technological works for sustainable } \\
\text { human development. }\end{array}$ & $\begin{array}{l}\text { The results of scientific } \\
\text { production are increased } \\
\text { and disseminated. The } \\
\text { research coordination } \\
\text { organs are dynamic. }\end{array}$ & $\begin{array}{l}\text { Increase the level of scientific } \\
\text { production, and revitalization of } \\
\text { research coordination organs. }\end{array}$ & 2517 & $\begin{array}{l}2007- \\
2009\end{array}$ & $\begin{array}{l}\text { MEN, } \\
\text { Research } \\
\text { Institutes }\end{array}$ \\
\hline \multirow[t]{2}{*}{$\begin{array}{l}\text { Ensure human resources management, } \\
\text { as well as coordination, animation and } \\
\text { supervision of activities of the } \\
\text { department. }\end{array}$} & $\begin{array}{l}\text { The capacities of the } \\
\text { ministry are strengthened } \\
\text { at all levels. }\end{array}$ & $\begin{array}{l}\text { Capacity building for departments in } \\
\text { the coordination, planning and } \\
\text { management of human resources at all } \\
\text { levels. }\end{array}$ & 65322 & $\begin{array}{l}2007- \\
2009\end{array}$ & $\begin{array}{l}\text { Ministry } \\
\text { of } \\
\text { Education }\end{array}$ \\
\hline & & Total & 440738 & & \\
\hline
\end{tabular}

\subsection{Health}

Make services available and accessible in public, community and private structures with emphasis on poor zones, disinherited zones and/or zones with difficult access.

(Sub-component 1)

Improve the availability of staff in health services, laying emphasis on peripheral services.

(Sub-component 2)

Make available essential drugs,

vaccines, and consumables, as well as

laboratory tests in CSCOMs and

CSREFs in all areas, particularly in poor

areas and areas with difficult access.

(Sub-component 3)

Improve the quality of health services,

increase demand and control of priority

diseases.

(Sub-component 4)
Health centres coverage at the $1^{\text {st }}$ level is ensured: $70 \%$ of the new areas defined, $80 \%$ of which are covered by the community sector and $20 \%$ by the private

sector.

Qualified, motivated and adequate staff is available in health structures at all levels.

Quality essential drugs are more available and accessible at all levels of the health pyramid.

The population benefit from quality services in health institutions of health districts, as well as specific programmes for control of priority

\begin{tabular}{|l|l|l|l|}
\hline $\begin{array}{l}\text { Improvement of accessibility of the } \\
\text { population to quality Minimum } \\
\text { Activities Package (PMA). }\end{array}$ & 120909 & $\begin{array}{c}2007- \\
2009\end{array}$ & MS \\
& 45431 & $\begin{array}{c}2007- \\
2009\end{array}$ & MS \\
\hline $\begin{array}{l}\text { Reform of human resource } \\
\text { management }\end{array}$ & 64002 & $2007-$ & MS \\
& & 2009 & \\
- Availability of financially accessible & & & \\
essential drugs & 39242 & $2007-$ & MS \\
\hline $\begin{array}{l}\text { Improvement of quality of health } \\
\text { services, increase in demand and } \\
\text { control of priority diseases. }\end{array}$ & & & \\
\hline
\end{tabular}




\begin{tabular}{|c|c|c|c|c|c|}
\hline & diseases. & & & & \\
\hline $\begin{array}{l}\text { Improve financial accessibility and } \\
\text { sustain demand and participation. } \\
\text { (Sub-component 5). }\end{array}$ & $\begin{array}{l}\text { Financial accessibility to } \\
\text { health care is improved, } \\
\text { particularly in poor areas. }\end{array}$ & $\begin{array}{l}\text { Improvement of access by the poor to } \\
\text { quality health care in health } \\
\text { institutions through third party payer } \\
\text { mechanism. }\end{array}$ & 7595 & $\begin{array}{c}2007- \\
2009\end{array}$ & MDSSPA \\
\hline $\begin{array}{l}\text { Improve the quality of health services in } \\
\text { hospital institutions and other research } \\
\text { institutions. } \\
\text { (Sub-component 6). }\end{array}$ & $\begin{array}{l}\text { Specialized institutions, } \\
\text { including research } \\
\text { institutions contribute to } \\
\text { improving the health } \\
\text { status of the population, } \\
\text { particularly the poor. }\end{array}$ & $\begin{array}{l}\text { Improvement of health status of the } \\
\text { population, particularly the poor, } \\
\text { through the implementation of action } \\
\text { plans of specialized institutions, } \\
\text { including research institutions. }\end{array}$ & 29774 & $\begin{array}{c}2007- \\
2009\end{array}$ & MS \\
\hline \multirow[t]{2}{*}{$\begin{array}{l}\text { Reinforce decentralization and } \\
\text { institutional capacities. } \\
\text { (Sub-component } 7 \text { ). }\end{array}$} & $\begin{array}{l}\text { Local authorities are } \\
\text { capable of more } \\
\text { effectively handling } \\
\text { health problems in } \\
\text { councils, districts and } \\
\text { regions. }\end{array}$ & $\begin{array}{l}\text { Improvement of management } \\
\text { capacities of councils, districts and } \\
\text { regions in the transfer of powers in } \\
\text { health matters. }\end{array}$ & 39384 & $\begin{array}{c}2007- \\
2009\end{array}$ & $\begin{array}{l}\text { MS, } \\
\text { Research } \\
\text { Institutes, } \\
\text { MATCL, } \\
\text { MDSSPA }\end{array}$ \\
\hline & & Total & 346337 & & \\
\hline
\end{tabular}

\subsection{Social Development}

\begin{tabular}{|c|c|c|}
\hline $\begin{array}{l}\text { Ensure the protection and promotion of social categories and } \\
\text { communities in particularly difficult situation through } \\
\text { prevention, compensation and reintegration measures (Sub- } \\
\text { component). }\end{array}$ & $\begin{array}{l}\text { The protection and promotion of } \\
\text { handicapped persons are improved } \\
\text { through prevention, compensation and } \\
\text { reintegration measures. }\end{array}$ & $\begin{array}{l}\text { Promote the socio-economic integration of handicapped } \\
\text { persons. }\end{array}$ \\
\hline $\begin{array}{l}\text { Strengthen the self-promotion capacities of communities. } \\
\text { Improve incomes and access to basic services for the poorest. } \\
\text { (Sub-component). }\end{array}$ & $\begin{array}{l}\text { The living conditions of targeted most } \\
\text { underprivileged rural communities are } \\
\text { improved. }\end{array}$ & $\begin{array}{l}\text { Improvement of living conditions of targeted most } \\
\text { underprivileged rural communities. }\end{array}$ \\
\hline $\begin{array}{l}\text { Gradually extend coverage of social risks to the entire } \\
\text { population through various mechanisms and improve financial } \\
\text { accessibility to health care. (Sub-component) }\end{array}$ & $\begin{array}{l}\text { The coverage of social risks is gradually } \\
\text { extended to the entire population, and } \\
\text { financial accessibility to health care is } \\
\text { improved. }\end{array}$ & Extension of scope of social security \\
\hline \multirow{2}{*}{$\begin{array}{l}\text { Institutional capacity building for MDSSPA, partner } \\
\text { institutions and social and solidarity economy organizations. } \\
\text { Develop the institutional framework and implementation } \\
\text { process of social interventions at the decentralized level (Sub- } \\
\text { component 4). }\end{array}$} & $\begin{array}{l}\text { A legal and institutional framework } \\
\text { adapted to the missions of the ministry is } \\
\text { defined. }\end{array}$ & $\begin{array}{l}\text { Definition of a legal and institutional framework adapted to } \\
\text { the missions of the ministry. }\end{array}$ \\
\hline & $\begin{array}{l}\text { The structures and resources of the } \\
\text { ministry are managed and planned more } \\
\text { efficiently. }\end{array}$ & $\begin{array}{l}\text { Planning and efficient management of the structures and } \\
\text { resources of the ministry. }\end{array}$ \\
\hline \multirow[t]{2}{*}{$\begin{array}{l}\text { Improve human resources in terms of quantity and quality, } \\
\text { leading to professionalization of the social sector (Sub- } \\
\text { component 5) }\end{array}$} & $\begin{array}{l}\text { The capacities and quality of education } \\
\text { in INFTS and CAMASC are improved. }\end{array}$ & $\begin{array}{l}\text { Improve the capacities and quality of education in INFTS } \\
\text { and CAMASC. }\end{array}$ \\
\hline & & Total \\
\hline
\end{tabular}

\subsection{Drinking Water and Sanitation}

Satisfy the water needs, in terms of quality and quantity, of a growing population, as well as various sectors of the developing national economy, while respecting aquatic ecosystems and preserving the needs of future generations.
50 DWS and 3000 modern water points are constructed

100 DWS and 1700 modern water points rehabilitated

The project and programme monitoring and evaluation mechanism is established and functional
Construction and rehabilitation of modern water points as part of PNAEP implementation using a sectoral approach (PROSEA)

Establishment of a project and programme monitoring and evaluation mechanism (Government/TFP investments) 


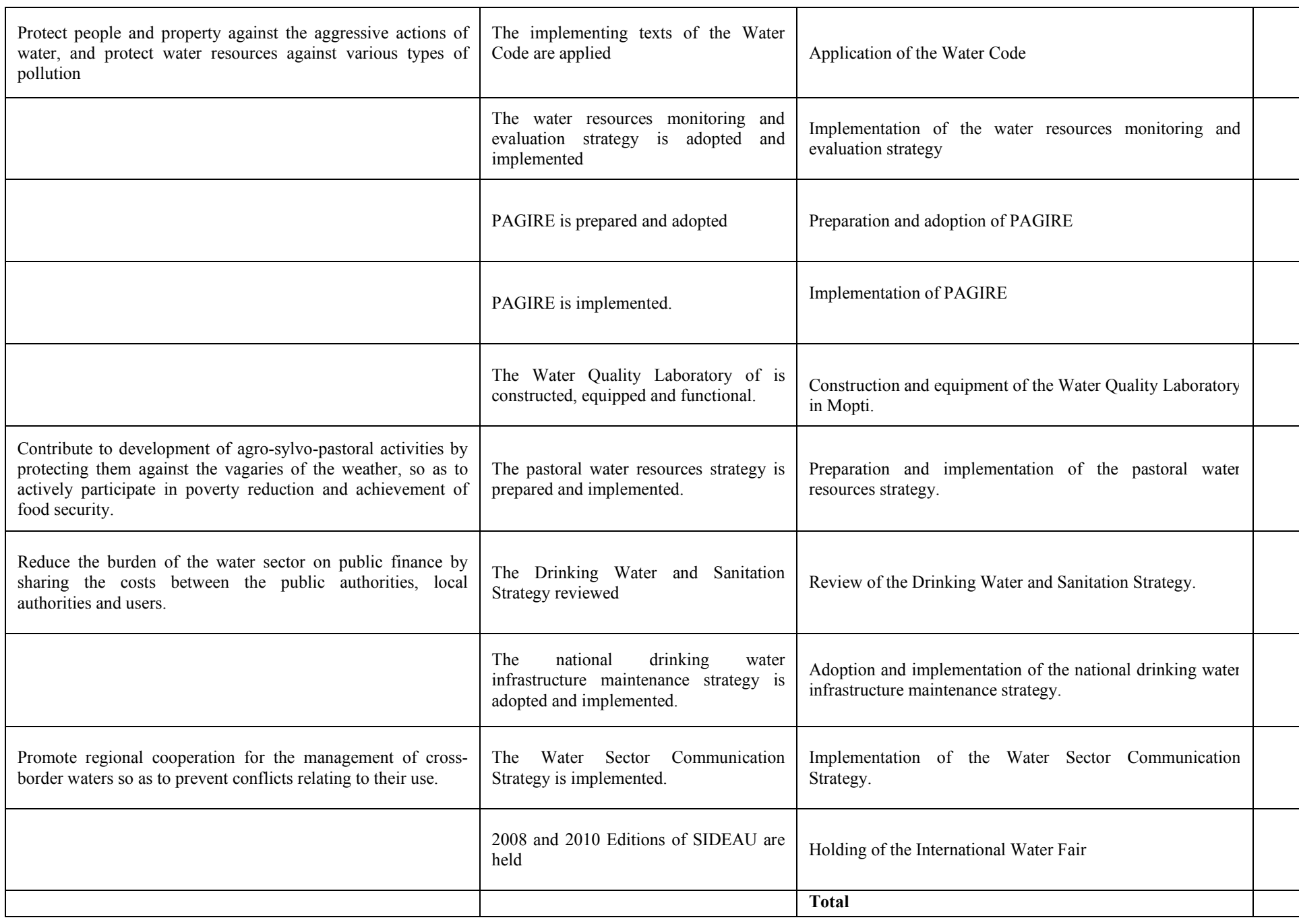

\subsection{Creation and Promotion of Sustainable Jobs}

Improve the legal framework and promote employment.

Adopt a coherent qualifying and apprenticeship continuous vocational training policy.

Ensure human resources management, as well as coordination, animation and supervision of activities relating to qualifying and apprenticeship continuous vocational training.
- Labour-intensive projects are implemented throughout the national territory.

- Jobs are created and/or consolidated in the associations or cooperatives sector. Qualifying and apprenticeship continuous vocational training is gradually extended to cover the entire country.

Synergy in coordination activities is achieved.
Consolidation of the national employment policy Coordination of activities of structures operating in the employment sector

Improvement of access to, and quality of, qualifying and apprenticeship continuous vocational training.

Establishment of a programme coordination mechanism in the implementation of the national employment policy.

\subsection{HIVIAIDS Control}

Control HIV/AIDS

HIV/AIDS prevention is ensured. Infected and affected persons are treated.
Prevention and treatment of persons infected and affected by HIV/AIDS 


\section{CROSS-Cutting Issues}

\subsection{Gender}

Guide, coordinate, evaluate and control the activities of the ministry, manage the resources and information.

Improve the social status of women.

Ensure the well-being of children and the family.
The intervention and operating capacities are strengthened.

The well-being of women is improved.

The environment is conducive for the implementation of children's and family rights.
Intervention and operating capacities are strengthened for incorporation of gender aspects in development projects/programmes

Improvement of the well-being of women through education, training, as well as economic, social and cultural promotion.

Promotion of an environment conducive to the implementation of children's and family rights.

Total

\subsection{Peace and Security}

Preserve social peace in Mali

Ensure personal security for the citizens
Take into account peace-security dimension in all projects and programmes ;

Include peace-security cross-cutting theme in civil society interventions

Strengthen the capacities of internal security and civil protection forces;

Strengthen road and river safety;

Lay the bases for a proximity police force;

Strengthen prevention and management of community conflicts;

Strengthen the disaster management mechanism;

Establish proper governance of internal security and civil protection.

\subsection{Territorial Development}

Balanced distribution of populations and activities throughout the national territory

Consistency of public and private activities, which contribute to the country's economic development

Reduction of inter-regional and intra-regional disparities in development

\section{Emergence of economic regions based on development poles}

Better coordination of the development actions of stakeholders

at the various territorial levels

Promotion of peaceful and traditional land management

Consistency between national, community and African sector

policies

Enhancement of integration within WAEMU space
Establish a geographical information system

Prepare development plans for the various territorial levels

Review sector and/or regional and local plans and programmes prior to adoption of the national territorial development policy

Train and sensitize stakeholders in territorial development

Establish partnership relations with sub-regional organizations/institutions engaged in the promotion of territorial development (WAEMU, CILSS)

\section{StRengthening OF Statistics Mechanism AND PRSP Monitoring}

\subsection{Strengthening of Statistics Mechanism}

Key surveys available on CD-ROM

Statistics available in electronic version

Initial results of ELIM 2006 available. Launching of the next ELIM survey in 2008

The production of basic statistics is

improved
Electronic archiving and dissemination of statistical information

Launching and dissemination of Malikunnafoni database

Sustainability of ELIM survey (every 2 years and increase in sampling rate to obtain significant results in decentralized authorities)

Census of craftsmen

Broadening of scope of indicators to the environment, 


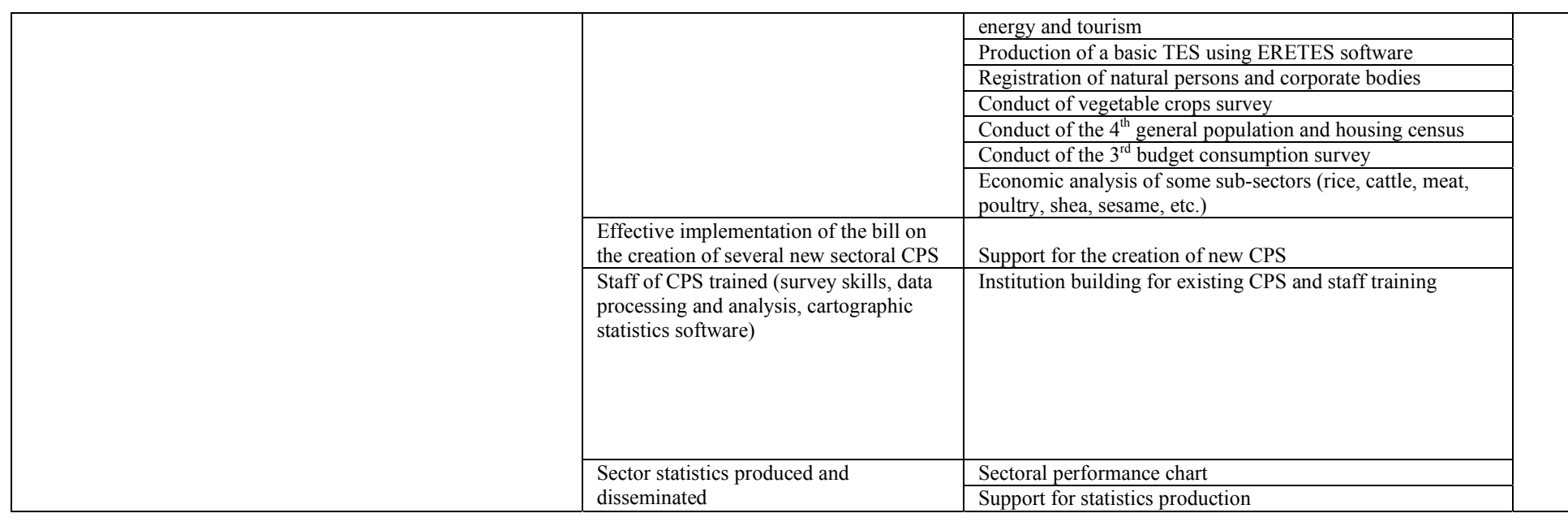

\subsection{Strengthening of PRSP Monitoring}

Improve the coordination, monitoring-evaluation of policies, programmes, as well as social, economic, cultural, sectoral and spatial development strategies
Development projects and programmes are managed

national territory

Population variables are integrated into

development programmes
Support for preparation of projects and programmes of local authorities

Extension of GEPRIMA to CPS

Preparation of report of the $7^{\text {th }}$ Review of projects and programmes in Mali

Training workshop for DRPSIAP, CPS and regional assemblies in the evaluation of development policies and strategies

Study on the technical assistance strategy

Establishment of a geographical information system (SIG) and training

Evaluation of sectoral and spatial plans and programmes Training workshops for regional committees on territorial development

Prospective study on human resources

Preparation of a programme for studies and research in

population and development

Prospective study on training and employment 
MINISTRY OF THE ECONOMY AND FINANCE

GENERAL SECRETARIAT
REPUBLIC OF MALI

One People - One Goal - One Faith

\section{SUMMARY OF THE $2^{\text {ND }}$ GENERATION PRSP}

1. The first Poverty Reduction Strategy Paper of Mali (PRSP I), which covered the 20022006 period, was adopted in May 2002. It is the single medium-term frame of reference for the economic and social development policy of Mali, and the main reference document used by Technical and Financial Partners in their support operations, in particular budget support, for the country. The PRSP has helped to implement several programmes in each of the proposed priority areas, namely: institutional development, improvement of governance and participation, human development, reinforcement of access to social services, development of infrastructures, and support to key productive sectors.

2. The reports on PRSP implementation and review conducted in June 2006 underscored the achievements and weaknesses in PRSP I preparation and implementation. Justifications for the preparation of a new generation PRSP therefore lie in the weaknesses of PRSP I, in particular:

- Inadequacy of results obtained in relation to the set overall goals;

- Lack of link between the PRSP and the State budget;

- Operational weakness of the institutional monitoring-evaluation mechanism; and

- Weakness of the various analysis instruments, indicators, and statistics.

3. It is within this context that the draft NG (new generation) PRSP or PRSP II was prepared. On 8 and 9 June 2006, the first review of the Poverty Reduction Strategy Paper (PRSP) took place. The review made it possible to:

- assess, through the various PRSP pillars and sector programmes, the trend of poverty since 2002 ;

- conduct a critical analysis of the PRSP process and the results obtained at the macro-economic and sectoral levels;

- exchange views on the constraints and difficulties which hampered implementation of the PRSP, and specifically sector projects and programmes;

- exchange views on the problem of PRSP financing; and

- make operational recommendations for preparation of the $2^{\text {nd }}$ generation PRSP.

4. These recommendations, adopted in the Cabinet Meeting of 26 July 2006, are as follows:

- give priority to productive sectors to ensure sustained growth that would reduce poverty;

- review the impact of policies and programmes, while laying emphasis on quality through better analysis ;

- improve statistics by implementing the Statistics Master Plan; 
- extend taxation to the agricultural sector (semi-urban farms) and housing (survey) ;

- implement all the PDI components;

- ensure consolidation of decentralization by accelerating transfer of resources, adopting new laws on inter-council relations, and giving impetus to efforts towards coherent and sustainable local and regional development;

- harmonize donor procedures and alignment on national procedures through budget support;

- ensure harmonization of timetables for sectoral reviews, as well as PRSP and budget process review;

- ensure PRSP-MDG integration;

- review monitoring and evaluation indicators and institutional mechanism;

- provide capacity building for monitoring-evaluation stakeholders; and

- broaden the PRSP participatory process.

5. The preparation of a new generation PRSP is justified for the following reasons:

- inadequacy of the results obtained in relation to the overall objectives defined in PRSP I;

- weaknesses noted in PRSP implementation, in particular the weak PRSP- State Budget link, the low operationalization of the institutional monitoring-evaluation mechanism, the low institutional capacity in terms of the methods, tools, instruments and indicators used, as well as the poor quality of basic statistics;

- limited consideration of some areas in the current version of the PRSP, in particular the environment, food security, the cotton sub-sector, HIVIAIDS control, handicraft and tourism, trade, the fight against corruption, the gender approach, and microfinance;

- consolidation of PRSP I outputs and consideration of the MDGs; and

- continuity of the PRSP process over time.

6. The $2^{\text {nd }}$ generation PRSP preparation process took place as follows:

- formulation and adoption, by the PRSP institutional mechanisms (Steering Committee, Mali-Development partners Joint Committee, Policy Committee), of terms of reference and detailed road map for the preparatory meetings: September to December 2005 ;

- organization and holding of a workshop to launch PRSP II preparation: 16-17 January 2006 ;

- formation of six ad hoc working groups: (1) Macro-economic Framework; (2) Budgetary framework; (3) Sector Policies Analysis; (4) PRSP I Evaluation; (5) Formulation of accelerated growth strategy; and (6) Decentralization and spatialization.

- conduct of ad hoc group meetings: February to June 2006 ;

- organization and conduct of first 2002-2005 PRSP review: 8-9 June 2006 ;

- preparation of PRSP II document: July-September 2006 ;

- national workshop on PRSP II preparation and monitoring/evaluation: 11-13 September 2006;

- incorporation of stakeholders' remarks: October 2006; 
- $22^{\text {nd }}$ meeting of Mali-TFP Joint Commission: 20 November 2006; and

- finalization of PRSP II and submission to Cabinet Meeting: November 2006.

7. The preparation of PRSP II is based on:

- the 2002-2006 PRSP;

- the reports of ad hoc groups;

- the conclusions of $1^{\text {st }}$ PRSP review; and

- sector policy documents.

8. The current version of PRSP II, which incorporates remarks from the national workshop held from 11 to 13 September 2006, is the focus of this written statement. This version also takes into account suggestions for improvement made by the civil society (meeting with PRSP Unit on 9 November 2006) and by the $22^{\text {nd }}$ meeting of the Mali-TFP Joint Commission on 20 November 2006.

\section{POVERTY IN MALI}

9. Implementation of the PRSP helped to reduce the level of poverty from $68.3 \%$ in 2001 (income base) to $59.2 \%$ in 2005 , on the basis of an updated poverty line of CFAF 153,310 . The goal of reducing poverty by one-quarter over the 2001-2006 period and bringing down the level to $47.5 \%$ in 2006 was therefore not achieved. The analysis shows a wide gap between rural areas (73.04\%) and urban areas (20.12\%). Furthermore, poverty in urban areas was reduced, since the incidence of poverty in these areas declined from $26.2 \%$ in 2001 to $20.12 \%$ in 2006 , representing a decline of more than 6 points. On the other hand, in rural areas, the incidence of poverty has remained stable, from $73.8 \%$ in 2001 to $73.04 \%$ in 2005 . The preceding analyses therefore show that in Mali poverty is essentially a rural phenomenon; the degree of poverty stood at $24.1 \%$ in 2005 as against $31.4 \%$ in 2001 , which indicates some progress. This shows that the gap between the incomes of the poor and the poverty line is reducing. In the same connection, the severity of poverty has reduced from $17.6 \%$ in 2001 to $12.6 \%$ in 2005 , representing a decline by 5 points.

10. In conclusion, it should be noted that the low level of poverty reduction during PRSP I could be due mainly to poor control of population growth, inadequate growth rate of the Malian economy, and unequal distribution of the fruits of growth.

\section{PRSP II}

11. The new generation Poverty Reduction Strategy Paper (PRSP II), which could be defined as the Growth and Poverty Reduction Strategy Paper, describes the policies and programmes which the country intends to implement at the macro-economic, structural and social levels, so as to promote growth and reduce poverty over the 20072011 period. It also presents the financing plan and related external financing requirements for the entire period.

12. The guiding principles of PRSP II preparation are as follows:

- consolidation of the achievements of PRSP I;

- acceleration of growth by eliminating major constraints and implementing new sources of growth; and 
- integration of MDGs.

13. PRSP II is based on conclusions/recommendations of the first PRSP 2002-2006 review and specific meetings of six ad hoc groups set up in the first quarter of 2006 :

- "Macro-economic Framework",

- "Budgetary framework",

- "Sector Policies Analysis",

- "PRSP I Evaluation",

- "Formulation of accelerated growth strategy",

- "Decentralization and spatialization".

14. These six ad hoc working groups discussed the themes of the 13 thematic groups that had prepared PRSP 2002-2006. Following preparations at end of 2005, the discussions started in January 2006 and the initial documents were presented in July 2006. Consultations were held with all the stakeholders throughout the preparation process, and a national workshop in September put together the views of all stakeholders in PRSP II.

15. This new strategy underscores the major expectations, as drawn from the evaluation of PRSP implementation and which can affect the achievement of PRSP II objectives; the expectations concern mainly the following points:

- continued stability of the macro-economic environment and consistency between macro-economic and budgetary forecasts, as well as external financing ;

- better adaptation of the strategies, priorities and budget programming of the Medium Term Budgetary framework (MTBF) to those of the sectoral Medium Term Expenditure Frameworks (MTEF), particularly in action plans and detailed sectoral financing plans ;

- significant reduction of poverty and hunger, especially in rural areas, as a result of real development of food security;

- improvement of the health status of the populations, especially the poorest;

- significant improvement of the quantity and quality of education ;

- creation of a conducive environment for private sector development and pursuance of structural reforms, such as privatizations (CMDT, SOTELMA);

- pursuance and acceleration of Government reform in terms of decentralization, deconcentration, and public finance.

\section{Economic and Budgetary framework}

16. The main objective of the macro-budgetary framework is to maintain macro-economic and budgetary balances, taking into account the real potential of the Malian economy, as well as the overall and sector goals of the PRSP.

17. Following consideration of several variants based on diverse public investments and tax pressure assumptions, a voluntarist scenario of strong growth was adopted, showing the political will to accelerate overall growth driven by rapid private sector development. The average estimated GDP growth rate for the 2007-2011 period will be $+7 \%$. In public finance, efforts will be made towards mobilization of internal resources, with a tax pressure of $17 \%$ as from 2008, in accordance with Mali's commitments concerning the WAEMU convergence criteria. 
18. The Government's budget and financial policy will be supported by activities proposed in the Government's Action Plan for the Improvement and Modernization of Public Finance Management (PAGAMGFP). During PRSP II, total revenue and expenditure estimates (including net loans) are consistent with the macro-economic framework and Medium Term Budgetary framework. The total revenue (excluding grants) will stand at CFAF 884 billion in 2011 as against CFAF 540 billion in 2007. Tax revenue will increase at an average annual rate of $10.3 \%$. Total expenditure and net loans would increase at an average annual rate of $7.1 \%$ to CFAF 1,217 billion in 2011. These estimates include the financing programmes, as well as evaluations of internal and external financing requirements for the period.

\section{PRSP Objectives and Actions}

19. PRSP II has two major objectives:

- promote strong annual growth of $7.0 \%$, by generating wealth and creating jobs in growth-oriented sectors of the national economy, such as rural production (agriculture, livestock, fisheries, agro-forestry, fruits and vegetables), the mining and energy sector, and the goods and services sector (tourism, culture and NICT). These growth-oriented sectors require explicit energy strategies that consider alternative forms of energy other than electricity alone (motive force, pumping). Real control of population growth and better redistribution of the created wealth will help to reduce inequalities and distortions of access to basic social services, which are the main causes of poverty;

- improve the functioning of public services by pursuing, consolidating and deepening reforms initiated at the institutional level (decentralization and deconcentration), democratic governance (democracy, fight against corruption, and establishment of the rule of law), the economic level (micro- finance and the private sector) and improvement of the social sector (education, health and, above all, HIVIAIDS control).

20. During PRSP I, priority was given to the allocation of budgetary resources to social sectors in general. In PRSP II, while continuing with these sectors, emphasis will be laid on the implementation of structural reforms and on the Special Investment Budget (BSI) to support growth-oriented sectors, such as rural production, mining and infrastructure.

21. To ensure sustained growth and sustainable poverty reduction, development should be anchored on the decentralization of government action to the local level, and on territorial development which will help to tap the existing economic, human and environmental potential, mitigate constraints and territorial imbalances, and revitalize local economies.

22. Ensuring consistency between national (Government) strategies and local (Local Authorities) priorities and improving production conditions in rural areas will create attractive development poles to reduce rural exodus of youths, particularly to urban centres. Poverty reduction also requires real control of population growth and special attention to the redistribution of wealth by social and spatial category.

\section{Strategic Orientations}

23. PRSP II is based on three strategic orientations:

I. Development of infrastructures and the productive sector;

II. Pursuance and consolidation of structural reforms; and

III. Strengthening of the social sector. 


\section{Priority Areas of Intervention}

24. The priority areas of intervention of PRSP II are as follows:

1. Food security and rural development;

2. Development of small and medium size enterprises;

3. Protection and sustainable management of natural resources;

4. Consolidation of public administration reform;

5. Pursuance of reform of the business environment;

6. Development of the financial sector;

7. Development of infrastructures;

8. Promotion of democratic governance and public freedoms;

9. Capacity building for the civil society;

10. Strengthening of regional and sub-regional integration initiatives;

11. Creation and promotion of long-term jobs;

12. Development of access to basic social services;

13. HIVIAIDS control; and

14. Integration into the Multilateral Trade System.

\section{PRSP II Accelerated Growth Strategy}

Major Constraints: climate change and volatility of world commodity prices.

Objective: sustainable growth that would improve the country's socio-economic situation and facilitate achievement of the Millennium Development Goals (MDG).

Major Challenges to the Malian Economy:

- ensure competitiveness of the economy;

- diversify its sources of growth so as to broaden its supply capacity; and

- make the private sector the principal engine of growth.

\section{Growth-oriented Sectors in Mali}

\section{Traditional Sectors}

Rural Sector

Growth of the rural sector will be achieved through maximum development of the country's agro-ecological potential and pastoral skills. Cotton will continue to be an important sector during the PRSP II period. The National Development Strategy Paper for the cotton sector will help to increase productivity of the sector.

Mining

- Gold

- Oil exploration.

\section{New Possibilities}

- industries

- trade

- tourism

- fruits, vegetables and oil plants

- handicraft

- culture

- youth and sports. 


\section{Growth-oriented infrastructures}

Growth will also be boosted through: (i) development of viable industrial zones; (ii) availability of water and electricity at better prices, (iii) construction of transport infrastructure, (iv) development of Telecommunications/ICT, and (v) access to more substantial financing. It is therefore necessary to improve the business climate.

\section{Cross-cutting Issues}

- gender

- territorial development

- population issues

- peace and security issues.

\section{Institutional Monitoring-Evaluation Mechanism}

25. Analyses have shown low operationalization of the institutional monitoring-evaluation mechanism, low capacity of the PRSP Unit, and low institutional capacity in terms of methods, tools, instruments and indicators used. Consequently, the information system remains incapable of accurately measuring the performance indicators. The reliability and consistency of information and statistics obtained from various sources remain a serious problem. Mention should also be made of the poor quality of basic statistics. Strengthening the national statistics system is included in PRSP II activities.

26. It is necessary to clarify and simplify the institutional mechanism. The PRSP institutional mechanisms will comprise: (i) a Policy Committee, (ii) a Mali Development Partners Joint Commission, (iii) a National Steering Committee, and (iv) a PRSP Technical Unit, which will be strengthened. The PRSP process will be conducted and coordinated by the Ministry responsible for the Economy.

27. As regards methods, the PRSP evaluation calls for harmonization with the three-year programme, the Special Investment Budget, and programme budgets. It also calls for a review of the number and nature of the proposed indicators by component or thematic area for better legibility and greater relevance.

\section{Next Stages of PRSP II}

- finalization and ensuring of consistency of MDG action plan with PRSP II;

- preparation of a financing plan for PRSP II;

- incorporation of the results of ongoing surveys in poverty analyses;

- finalization of the institutional mechanism and the list of monitoring-evaluation indicators;

- preparation of PRSP II communication plan; and

- preparation of PRSP II logical framework. 